



\section{CALIDAD DE VIDA}

EN LA ZONA METROPOLITANA DEL VALLE DE MÉXICO. HACIA LA JUSTICIA SOCIOESPACIAL 
UNIVERSIDAD NACIONAL AUTÓNOMA DE MÉXICO

Dr. Enrique Graue Wiechers

Rector

Dr. Leonardo Lomelí Vanegas

Secretario General

Ing. Leopoldo Silva Gutiérrez

Secretario Administrativo

Dr. Domingo Alberto Vital Díaz

Coordinador de Humanidades

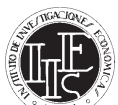

INSTITUTO DE INVESTIGACIONES ECONÓMICAS

Dr. Armando Sánchez Vargas

Director

Dra. Isalia Nava Bolaños

Secretaria Académica

Dra. Delia Margarita Vergara Reyes

Secretaria Técnica

Marisol Simón Pinero

Jefa del Departamento de Ediciones

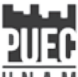

UNAM

PROGRAMA UNIVERSITARIO DE ESTUDIOS SOBRE LA CIUDAD

Dr. Javier Delgado Campos

Director

Mtra. Jessica Bautista Vergara

Secretaria Técnica Académica

Mtra. Mariana Sánchez Vieyra

Secretaria Técnica de Proyectos

Mat. Manuel Hernández Rosales

Secretario Técnico

Lic. Graciela Chávez Olvera

Jefa del Departamento de Publicaciones 


\section{CALIDAD DE VIDA}

EN LA ZONA METROPOLITANA DEL VALLE DE MÉXICO. HACIA LAJUSTICIA SOCIOESPACIAL

Adolfo Sánchez Almanza

(Coordinador)
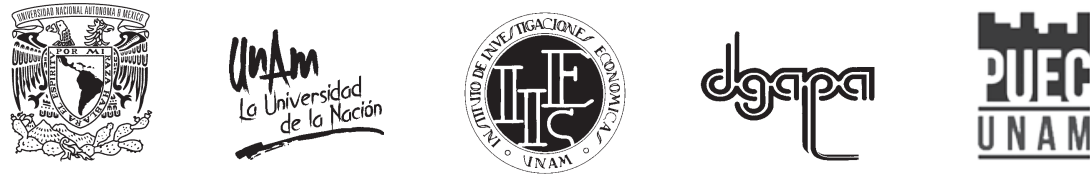
Calidad de vida en la Zona Metropolitana del Valle de México: hacia la justicia socioespacial / coordinador Adolfo Sánchez Almanza. — Primera edición. — Ciudad de México: Universidad Nacional Autónoma de México, Instituto de Investigaciones Económicas, 2018. 354 páginas: mapas, gráficos; $26 \mathrm{~cm}$.

Incluye bibliografías

ISBN 968-607-30-0313-1

1. Calidad de vida - Zona Metropolitana del Valle de México. 2. Calidad de vida — Zona Metropolitana del Valle de México - Evaluación. 3. Estratificación social — Zona Metropolitana del Valle de México. I. Sánchez Almanza, Adolfo, coordinador. II. Universidad Nacional Autónoma de México. Instituto de Investigaciones Económicas.

306.09725-scdd21

Biblioteca Nacional de México

Primera edición, 2018

D. R. ( ) Universidad Nacional Autónoma de México

Ciudad Universitaria, Coyoacán, 04510, Ciudad de México

InSTITUTO DE INVESTIGACIONES ECONÓMICAS

Circuito Mario de la Cueva s/n

Ciudad de la Investigación en Humanidades, 04510, Ciudad de México

CoOrdinación de Humanidades

Circuito Mario de la Cueva s/n, Ciudad Universitaria,

Delegación Coyoacán, C.P. 04510, Ciudad de México.

www.coord-hum.unam.mx

Programa Universitario de Estudios sobre la Ciudad

República de Cuba núm. 79, Centro Histórico,

Delegación Cuauhtémoc, C.P. 06010, Ciudad de México. www.puec.unam.mx

Proyecto de Investigación e Innovación Tecnológica-IN302014-2 "Calidad de vida en la Zona Metropolitana del Valle de México"

ISBN 978-607-30-0313-1

Cuidado de la edición: Marisol Simón

Fotografía de portada: Esteban Sánchez Ceballos

Diseño de portada: Juan Carlos Burgoa

Prohibida la reproducción total o parcial por cualquier medio sin autorización escrita del titular de los derechos patrimoniales.

Impreso y hecho en México. 
PRÓLOGO

Roberto Eibenschutz Hartman

INTRODUCCIÓN

Adolfo Sánchez Almanza

PRIMERA SECCIÓN

CAPÍTULO 1

TEORÍAS SOBRE CALIDAD DE VIDA Y JUSTICIA SOCIOESPACIAL

Adolfo Sánchez Almanza

CAPÍTULO 2

MARCO JURÍDICO PARA LA JUSTICIA SOCIOESPACIAL

EN LA ZONA METROPOLITANA DEL VALLE DE MÉXICO

Adolfo Sánchez Almanza

CAPÍTULO 3

PROSPECTIVA DE LA ZONA METROPOLITANA DEL VALLE DE MÉXICO

Roberto Ramírez Hernández

SEGUNDA SECCIÓN

CAPÍTULO 4

LA CALIDAD DE VIDA OBJETIVA Y SU MEDICIÓN

EN LA ZONA METROPOLITANA DEL VALLE DE MÉXICO

Isalia Nava Bolaños, Flor Araceli Ruiz Peña, Sergio de la Vega Estrada

Edgar Buenrostro Salazar y Adolfo Sánchez Almanza

CAPÍTULO 5

ÍNDICE DE CALIDAD DE VIDA OBJETIVO DE LAS COLONIAS

DE LA ZONA METROPOLITANA DEL VALLE DE MÉXICO

Sergio de la Vega Estrada y Flor Araceli Ruiz Peña 
CAPÍTULO 6

PERCEPCIÓN SOBRE LA CALIDAD DE VIDA DE LA POBLACIÓN

DEL DISTRITO FEDERAL

Manuel Canto Chac y Adolfo Sánchez Almanza

CAPÍTULO 7

VALORACIÓN SUBJETIVA DE LA CALIDAD DE VIDA

Andrea Colores Ramos y Erica Alejandra Hernández Montes de Oca

TERCERA SECCIÓN

CAPÍTULO 8

CALIDAD DE VIDA DE LA POBLACIÓN EN EDADES AVANZADAS

EN LA ZONA METROPOLITANA DEL VALLE DE MÉXICO: UN ANÁLISIS

A NIVEL "MANZANA"

Isalia Nava Bolaños

CAPÍTULO 9

VIVIENDA, VALOR DEL SUELO Y CALIDAD DE VIDA

EN LA ZONA METROPOLITANA DEL VALLE DE MÉXICO

Domingo Flores Miranda

CAPÍTULO 10

GRANDES CENTROS COMERCIALES, ESTRUCTURA SOCIORRESIDENCIAL

Y CALIDAD DE VIDA EN LA ZONA METROPOLITANA DEL VALLE DE MÉXICO

José Gasca Zamora

CAPÍTULO 11

EL COMERCIO INFORMAL Y SUS EFECTOS EN LA CALIDAD DE VIDA

DE LOS HABITANTES DE LA CIUDAD DE MÉXICO

Carlos Bustamante Lemus

CAPÍTULO 12

CALIDAD DE VIDA Y DESASTRES NATURALES

EN LA ZONA METROPOLITANA DEL VALLE DE MÉXICO

Abraham Granados Martínez

CAPÍTULO 13

LAS FINANZAS PÚBLICAS Y LA CALIDAD DE VIDA

EN LA ZONA METROPOLITANA DEL VALLE DE MÉXICO

Marcela Astudillo Moya

CONCLUSIONES GENERALES

Adolfo Sánchez Almanza

SOBRE LOS AUTORES 
PRÓLOGO

Roberto Eibenschutz Hartman

Bienestar, felicidad, confort, seguridad, tranquilidad, cohesión social, inclusión, dignidad, respeto, comprensión, colaboración, comunidad, igualdad, equidad, justicia, satisfacción, habitabilidad, gobernanza, identidad, pertenencia, sustentabilidad, educación, salud, conocimiento, paz son solo algunos de los conceptos que nos vinculan con la calidad de vida. Un grupo distinguido de investigadores, coordinados por Adolfo Sánchez Almanza, elaboraron este libro que nos aproxima a la complejidad del tema y ofrece un amplio panorama de la evolución de las ideas en torno a este objetivo fundamental de la humanidad a lo largo de toda su historia.

El análisis riguroso de las reflexiones teóricas aportadas por filósofos, científicos y estadistas de mediados del siglo pasado hasta hoy día presenta la diversidad de enfoques y la evolución del concepto a lo largo del tiempo y permite construir una interpretación propia de la que se desprende la metodología necesaria para intentar una medición de variables seleccionadas, hasta llegar a la definición de un índice de calidad de vida aplicable a la Zona Metropolitana del Valle de México.

La ponderación de la importancia de distintas variables (que interactúan en la definición de calidad de vida adoptada) permite comparar los datos sumamente precisos ya que parten de mediciones obtenidas por "manzana" y que se agregan por colonia o barrio, y por delegación o municipio de la metrópoli. Así, el acceso a la muy extensa base de datos generada promete el aprovechamiento de su gran potencial para estudios futuros. Sin embargo, quedan abiertas las grandes preguntas que surgen de la revisión de los textos:

- ¿Es posible adoptar un concepto único de calidad de vida para un país, una región o incluso una ciudad? 
- ¿Cómo comparar la importancia de factores objetivos como la disponibilidad de bienes y servicios en las viviendas, frente a la importancia de los factores subjetivos relacionados con la percepción de los pobladores en relación a su entorno?

- ¿Para la calidad de vida, cómo medir la importancia del goce de una puesta de sol, el murmullo de un arroyo, el ruido de las olas, el canto de los pájaros, el correr de la brisa entre los árboles o el silencio profundo que invita a la meditación?

- ¿Cómo relacionar la calidad de vida con la diversidad cultural y las manifestaciones de tradiciones y festividades?

- ¿Qué influye más en la calidad de vida?: ¿la satisfacción de comer un mole poblano bien sazonado o la que se desprende de la abstinencia para evitar daños en el sistema cardiovascular?

Éstas y otras preguntas pueden parecer simplistas o hasta divertidas, pero conducen a la reflexión sobre el paradigma de la calidad de vida que está detrás de los datos estadísticos reconocidos como datos duros cuantificables, y que se asumen como válidos y que corresponden a las características de una sociedad permeada por el consumismo, la competencia y el logro personal como definitorios de los valores supremos a alcanzar.

¿Es cierto que una losa de concreto es mejor que un techo de palma en todos los poblados y en todos los climas? ¿Poseer un refrigerador garantiza una alimentación sana? ¿Contar con un televisor o una computadora implica mejorar la cultura? ¿Ser beneficiario de programas sociales o tener escuelas evita la violencia y la corrupción? ¿Qué correspondencia hay entre lo objetivo y lo subjetivo?

Aventurarse en el bosque de la diversidad del bienestar, requiere rigor y disciplina para no perderse en la espesura, lo cual hacen los autores de esta obra aportadora de conceptos e información enriquecedores de una discusión que esperamos se mantenga abierta y nos permita avanzar en la toma de decisiones para construir un modelo de país que mejore la calidad de vida y supere las limitaciones del actual, al luchar por la igualdad social y territorial. 
Este libro se refiere al estudio de la calidad de vida de las personas que residen en el territorio de la Zona Metropolitana del Valle de México (ZMVM). El concepto de "calidad de vida" se define como la condición de bienestar general de las personas, susceptible de medirse según diferentes grados de las condiciones de vida y la satisfacción de las necesidades en varias escalas territoriales, y en determinados momentos en el tiempo. Este concepto es de tipo polisémico, sujeto a dos grandes características esenciales: a) expresarse en el eje de coordenadas de espacio y tiempo, lo cual implica rasgos geográficos e históricos, dinámicos, multifactoriales y multidimensionales, y b) incluir necesidades y satisfactores de tipo objetivo y subjetivo de bienestar individual en un contexto social determinado.

La medición integral de la calidad de vida debe considerar varios indicadores representativos de las dimensiones social, política, cultural, económica, ambiental o geográfica, así como de variables de salud, educación, empleo, ingreso, bienes materiales, condiciones de la vivienda, servicios públicos, transporte, entorno físico y arquitectónico, recreación y pertenencia a grupos sociales, entre otros.

\footnotetext{
* La investigación se realizó gracias al programa de la Universidad Nacional Autónoma de México-Dirección General de Asuntos del Personal Académico-Programa de Apoyo a Proyectos de Investigación e Innovación Tecnológica-IN302014-2 "Calidad de vida en la Zona Metropolitana del Valle de México". Agradecemos a las autoridades del programa por el apoyo recibido, en particular, a la doctora Claudia Mendoza Rosales. Los autores agradecen también el apoyo de la doctora Natalia Volkow Fernández por las facilidades para el acceso oportuno y efectivo al Servicio de Laboratorio de Microdatos del Instituto Nacional de Estadística y Geografía (INEGI). Asimismo agradecemos a las autoridades del Instituto Nacional Electoral (INE) su apoyo para la realización de esta investigación. Las conclusiones y las opiniones expresadas en esta investigación son responsabilidad exclusiva de los autores y no forman parte de las estadísticas oficiales del Sistema Nacional de Información Estadística y Geográfica, ni del INEGI ni del INE.
} 
Esta investigación destaca los aspectos objetivos de la calidad de vida con mediciones cuantitativas a partir de datos con la mayor desagregación posible, y se complementa con una valoración sobre la percepción de las personas con una encuesta representativa para el Distrito Federal, así como con entrevistas a profundidad en hogares representativos de diferentes grados de bienestar.

Los estudios orientados a medir la calidad de vida o el bienestar más utilizados en escala internacional se pueden clasificar en enfoques de tipo filosófico, de derechos, mercantiles, multilaterales, alternativos y de ciudades específicas, entre otros. Los resultados derivados de la medición se utilizan en varios ámbitos; en este caso, se orientan principalmente a apoyar el diseño y la implementación de políticas públicas para avanzar a la justicia socioespacial de acuerdo con la garantía de los derechos de la población en un espacio metropolitano.

En México, se han realizado varios estudios y mediciones que han permitido comparar el nivel de vida de las entidades federativas, los municipios o las ciudades, aunque existen pocos que consideren la escala territorial de "manzana" y "colonia-barrio" como en este libro. Este trabajo contribuye a lograr una visión integral de la calidad de vida de la metrópoli que posibilite las comparaciones válidas para el conjunto de este gran espacio, al considerar la necesidad de un diagnóstico unificado para apoyar una gestión más eficiente y eficaz.

De manera física y funcional, la ZMVM se integra con territorios de por lo menos tres entidades federativas: Distrito Federal, Estado de México y Estado de Hidalgo, con unidades politico-administrativas, es decir, municipios y delegaciones, conformados de modo físico o funcional, o que presentan tendencias de integración susceptibles de planeación prospectiva a mediano y largo plazos. En la metrópoli, operan los tres órdenes de gobierno y diferentes instituciones políticas. En este territorio, se necesitan cada vez más las políticas públicas con coordinación, cooperación, concurrencia y complementariedad, así como objetivos claros de articulación, integración y cohesión socioespacial, con una visión centrada en las personas, en el marco de los derechos humanos y sociales.

En el contexto anterior, es fundamental conocer la calidad de vida en diferentes aspectos y unidades territoriales, aunque la medición de la misma está condicionada por la disponibilidad de información estadística confiable, homogénea y desagregada en escalas menores. La principal fuente de información de este estudio es el "Censo de población y vivienda del año 2010" del Instituto Nacional de Estadística y Geografía (INEGI), cuyas cifras se complementan en varios análisis sobre temas específicos y con trabajo de campo. 
El libro contiene tres secciones. La primera sección se refiere a aspectos teóricos, conceptuales, jurídicos y de prospectiva sobre la ZMVM. Inicia con dos capítulos elaborados por Adolfo Sánchez, el primero, con una revisión de los principales enfoques sobre la calidad de vida que permiten adoptar una definición conceptual para fines operativos en la investigación. En el segundo, se sistematiza el marco jurídico relacionado con la justicia socioespacial y la calidad de vida con referencias a las instancias internacionales, nacionales y de las que rigen en las tres entidades federativas involucradas en la metrópoli, con atención especial a las leyes y decretos en materia social. En el capítulo 3, elaborado por Roberto Ramírez, se analiza la delimitación de la zona metropolitana con ejercicios de prospectiva hacia el año 2040 para establecer sus tendencias de crecimiento. La delimitación ampliada de la ZMVM ofrece el espacio para la verificación de las hipótesis que consideran la satisfacción de las necesidades básicas y una mayor calidad de vida relacionadas con un patrón de expansión por contornos tipo centro-periferia y la emergencia de un modelo con subcentros intrametropolitanos que prefiguran otro más policéntrico.

La segunda sección incluye la medición de la calidad de vida objetiva y los resultados sobre la percepción de la población acerca de la misma. En el capítulo 4, realizado de forma colectiva por Isalia Nava, Araceli Ruiz, Edgar Buenrostro, Sergio de la Vega y Adolfo Sánchez, se analizan las hipótesis generales, para lo cual se estima un índice de calidad de vida objetivo (ICVO) con tres dimensiones (personas, viviendas y entorno urbano), ocho subdimensiones y 33 indicadores, procesados a partir de los microdatos de hogar captados en el "Censo de población y vivienda del año 2010" del INEGI. Por razones de confidencialidad, el cálculo se llevó a cabo con el apoyo del personal del Laboratorio de Microdatos del INEGI, con una sintaxis en Statistical Package for the Social Sciences (SPSS) diseñada por nuestro equipo de trabajo. Los resultados de la medición incluyen el índice de calidad de vida objetivo (ICVO) para la ZMVM, con un total de 186124 "manzanas", de las cuales 126936 cuentan con el índice completo y 59188 con datos parciales por falta de información censal, y 93.23\% del total tiene cartografía asociada. A partir de los datos de "manzana", se elaboraron los Icvo de colonias y de municipios o delegaciones, así como mapas temáticos en dos escalas. En el capítulo 5, realizado por Sergio de la Vega y Araceli Ruiz, se efectúa el análisis de la calidad de vida en la escala de colonia o barrio, con consideración de su importancia como espacio de identidad ciudadana y en la instrumentación de políticas públicas, en particular, en el diseño de programas sociales vinculados con la mejoría de la calidad de vida y el cumplimiento de los derechos y la justicia socioespacial. El análisis subjetivo de la calidad de vida se aborda con los resultados sobre las percepciones en el Distrito Federal, las cuales 
describen Manuel Canto y Adolfo Sánchez en el capítulo 6, a partir de una encuesta con representatividad estadística para tres programas sociales y grado de desarrollo social territorial. En el capítulo 7, Andrea Colores y Érica Hernández valoran la calidad de vida, con base en entrevistas minuciosas para contrastar la percepción de las personas respecto de los resultados cuantitativos objetivos del ICVO.

En la tercera sección, se incluyen varios estudios de caso con temas relacionados con la calidad de vida de la población de la metrópoli. El capítulo 8 de Isalia Nava se refiere al análisis de la calidad de vida y las condiciones demográficas con atención especial a la tercera edad en la ZMVM, así como un examen asociado con el patrón espacial que se manifiesta. En el capítulo 9 de Domingo Flores, se estudia la vivienda y el bienestar con un análisis más detallado de municipios metropolitanos, donde se ha desarrollado de forma intensiva la vivienda social y autoconstruida, con datos de precio del suelo y tipo de vivienda vinculados con su localización. José Gasca realizó el capítulo 10 sobre la localización espacial de los grandes centros comerciales, en que considera la expansión de este modelo y su relación con la calidad de vida en el territorio. En el capítulo 11, Carlos Bustamante presenta un análisis sobre el comercio informal con atención especial a los mercados públicos y centros de transferencia modal (Cetram) seleccionados, y su relación con aspectos del bienestar. Abraham Granados realizó el capítulo 12 sobre desastres naturales, recursos presupuestales específicos y calidad de vida, los cuales correlacionó en el territorio metropolitano y aplicó un modelo de econometría espacial. Asimismo, en el capítulo 13. Marcela Astudillo desglosa las finanzas públicas en la ZMVM con atención a las necesidades sociales básicas que expresan la calidad de vida, en especial ingresos y gastos de los gobiernos. Por último, se presentan algunas reflexiones finales.

La base de datos del ICVO por "manzana", colonia o barrio y delegación con los indicadores correspondientes se encuentra disponible en: http://ru.iiec.unam. $\mathrm{mx} / 4122 /$

Los autores agradecen a las autoridades del Instituto de Investigaciones Económicas y de la Dirección de General de Personal Académico de la Universidad Nacional Autónoma de México (UNAM) su apoyo para la realización de esta obra. Asimismo, a las autoridades del INEGI, en particular a los responsables de su Laboratorio de Microdatos.

La gran Zona Metropolitana del Valle de México requiere de estudios útiles para conocer y enfrentar sus complejos problemas, en particular, los relacionados con la calidad de vida de sus habitantes. Esperamos que este libro contribuya a tal propósito. 
PRIMERA SECCIÓN 



\section{Teorías sobre calidad de vida y justicia socioespacial}

Adolfo Sánchez Almanza

\section{INTRODUCCIÓN}

La calidad de vida se ha estudiado desde hace varias décadas y en distintas disciplinas. Los orígenes del concepto se relacionan con los indicadores sociales que se remontan a la década de 1940, en particular después de la segunda guerra mundial, cuando las investigaciones desde las ciencias médicas y de la salud se orientaron al análisis de los aspectos sociales y psicológicos que mejoraban las condiciones de salud y bienestar de la población. A finales de los años sesenta, existía un interés generalizado por los indicadores sociales, sobre todo los de tipo objetivo. A mediados del decenio de 1970 surgió el interés, principalmente desde la psicología, por la medición de indicadores subjetivos del bienestar como medida de calidad de vida. En los años ochenta, se generó un gran número de estudios que se centraron en la revisión del concepto y su medición amplia. Durante la década de 1990 y los primeros años de siglo XXI, emergió una nueva era en la construcción de índices de calidad de vida que sintetizaron el avance obtenido en distintas dimensiones (Land et al., 2012).

En el estudio de calidad de vida, no existe una definición aceptada de modo universal del concepto, el cual es polisémico, de carácter multidimensional y multifactorial, relacional y dinámico, que alberga diferentes campos temáticos donde intervienen condiciones objetivas y subjetivas; asimismo, se relaciona con los conceptos de bienestar (well-being), bienestar total (wellness), condiciones de vida (living conditions) y nivel de vida (standard of living), aunque son diferentes. A continuación, se revisan algunas teorías y enfoques sobre la calidad de vida. 


\section{ENFOQUES DE CALIDAD DE VIDA Y BIENESTAR}

Estos se pueden clasificar de manera convencional de la manera siguiente:

a) Filosóficos: incluyen las teorías de la justicia y el bienestar, así como las de necesidades humanas y básicas con una amplia variedad de corrientes de pensamiento.

b) De derechos: propuestos por instituciones como la Organización de las Naciones Unidas (ONU), el Programa de las Naciones Unidas para el Desarrollo (PNUD) y la Organización Mundial de la Salud (OMS).

C) Europeos: entre los cuales destacan el escandinavo, el sueco y el de los Países Bajos.

d) Multilaterales: como los propuestos por la Organization for Economic Cooperation and Development (OECD), el Banco Interamericano de Desarrollo (BID), el Fondo Monetario Internacional (FMI) y el Banco Mundial.

e) Mercantiles: elaborados por Mercer, Economist Intelligence Unit y Bimsa, entre otros.

f) Alternativos: como el desarrollo local y el desarrollo en escala humana.

g) Gobiernos locales: realizados para ciudades como las de México, Monterrey y Guadalajara, así como para Madrid, Quilmes, Santiago, Medellín o Vancouver, entre otras.

h) Estudios y encuestas orientados a captar la percepción de las personas sobre su propia calidad de vida, es decir, de tipo subjetivo.

Entre este amplio grupo de enfoques, se revisan algunos de los más representativos y se destacan las dimensiones o los dominios que se consideran para medir la calidad de vida o el bienestar.

\section{ENFOQUES FILOSÓFICOS}

\section{Las necesidades humanas en la filosofía política}

El estudio de las necesidades humanas, su clasificación, bienes y servicios que se requieren para satisfacerlas y parámetros de satisfacción aplicados en cada sociedad constituye una referencia básica para determinar la calidad de vida. El análisis de este tema se ubica en el marco de varias corrientes teóricas y filosóficas, algunas de las cuales parten desde concepciones ontológicas. 
En la filosofía política, se pueden mencionar varias líneas de pensamiento que abordan las necesidades humanas o el bienestar, con autores que se consideran representativos de ellas. En la economía del bienestar o neoclásica, se encuentran autores como John S. Mill, Adam Smith, Alfred Marshall, Vilfredo Pareto o Paul Samuelson, entre otros; el liberalismo radical o libertario cuenta con autores, como Ludwig von Misses, Robert Nozick, Friedrich Hayek y James M. Buchanan; la visión del materialismo histórico clásico y analítico incluye a Carlos Marx, Federico Engels, Jürgen Habermas, Claus Offe, Ronald Dworkin, John Roemer, Jon Elster, Gerald Cohen, Giörgy Markus y Manfred Max Neef, aunque también con posiciones debatibles entre ellos; en el enfoque comunitarista, se ubican Amitai Etzioni, Charles Taylor, Robert Bellah, Michael Sandel y Michael Walzer; otros teóricos analizan las necesidades humanas o el bienestar desde la psicología humanista, como Erich Fromm, Michael Maccoby y Abraham Maslow; en el liberalismo igualitario o la Teoría de la justicia, destaca John Rawls; asimismo, en la Teoría de las titularidades y de capacidades, sobresalen Amartya Sen y Martha Nussbaum, y cercanos a estos se encuentran Len Doyal e lan Gough, con visiones esencialistas o universales del bienestar, con raíces aristotélicas, y que amplían esta noción, de sus condiciones objetivas a las percepciones de las personas (Sánchez, 2012).

En este contexto tan diverso, la calidad de vida es un concepto multifactorial que se utiliza, en general, para evaluar el grado de satisfacción de las necesidades humanas o el bienestar social de las personas, en las sociedades o en los territorios. Mientras el concepto de "nivel de vida" considera la satisfacción de las necesidades básicas de los seres humanos en calidad y cantidad (las cuales se relacionan principalmente con el ingreso), la calidad de vida se refiere a la capacidad que posee un grupo social de satisfacer sus necesidades objetivas y subjetivas con los recursos disponibles en un espacio y tiempo determinados, para alcanzar una vida humana digna o decente (Gildenberger, 2008).

Al respecto, se revisan algunas teorías sobre las necesidades humanas básicas, con atención especial a aquellas que eligen dimensiones, variables o indicadores para su medición operativa, que posibilitan la comparación de la calidad de vida y que sirven de marco de referencia al presente estudio.

\section{Las necesidades humanas según Abraham Maslow}

En esta propuesta, desde la psicología humanista, las necesidades humanas atañen a todo individuo y se jerarquizan de manera estructural como una pirámide, de acuerdo con una determinación biológica originada en la constitución genética 
del mismo. En la parte inferior de la estructura, se encuentran las necesidades más prioritarias y, en la superior, las de menor prioridad. Maslow define las necesidades humanas como demandas frente a desequilibrios que requieren compensación y, en la medida en que esta se satisface, aquellos se tornan más complejos. Al Ilenar las necesidades más básicas o subordinadas, la persona continúa con las del siguiente nivel como una nueva meta de satisfacción, lo cual da lugar a la generación sucesiva de requerimientos mayores. Las necesidades básicas que dicho autor identifica son las siguientes:

- Necesidades fisiológicas: constituyen la primera prioridad del individuo, se refieren a la supervivencia y consisten en mantener un estado normal y constante de riego sanguineo, respirar, beber agua, alimentarse, descansar o dormir, eliminar los desechos corporales, evitar el dolor, tener relaciones sexuales y conservar una temperatura corporal adecuada en un ambiente cálido.

- Necesidades de salud y seguridad: corresponden a la creación y el mantenimiento de un estado de orden y seguridad física (un refugio que proteja del clima); de salud (asegurar la alimentación futura); seguridad de recursos (disponer de educación, transporte e higiene necesarios para vivir con dignidad); protección de los bienes y los activos (casa, dinero, automóvil, etc.), y vivienda (protección).

- Necesidades sociales: una vez satisfechas las necesidades fisiológicas y de seguridad, la motivación del individuo se orienta a las necesidades sociales, como necesidad de afiliación o compañía de otros seres humanos, afecto y participación social. En este grupo, se encuentra el requerimiento de relacionarse con otras personas para expresar y recibir afecto (amistad y amor), vivir en comunidad, tener participación (inclusión grupal), y sentir aceptación social.

- Necesidades de reconocimiento: pertenecen al ego, o autoestima, y abarcan sentir aprecio, tener prestigio y destacar dentro de su grupo social, y autovaloración. La estima "alta" concierne a la necesidad del respeto a uno mismo, con sentimientos, como confianza, competencia, conocimiento de las propias habilidades y logros, independencia y libertad. La estima "baja" se vincula con el respeto de las demás personas: necesidad de atención, aprecio y reconocimiento, preocupación por la reputación, el estatus, la dignidad, la fama, la gloria e incluso el dominio.

- Necesidades de autorrealización o metanecesidades: incluyen la motivación del crecimiento del ser humano como el ideal de cada individuo. Las personas 
desean trascender con su propia obra y desarrollar al máximo su talento. Con la satisfacción de esta necesidad, se encuentra un sentido válido de la vida al desarrollar una actividad cuando los niveles previos se han alcanzado, al menos, hasta cierto punto.

Los primeros tres grupos de necesidades son de déficit, mientras que las últimas dos se refieren al ser (Maslow, 1943). Se reconoce mucho a este enfoque de necesidades, pero también se ha criticado, en particular, porque confunde las necesidades con los deseos; porque legitima la jerarquización, la polarización o la piramidalidad social, o porque la evidencia indica la carencia de una secuencia temporal o lineal entre las necesidades y que su manifestación es de tipo complejo (figura 1-1).

\section{La propuesta de Len Doyal e Ian Gough}

Estos autores elaboran una teoría de las necesidades humanas para medir el bienestar entre las naciones con indicadores adecuados y comparables. Para ello proponen un concepto universal de necesidad y dejan espacio a la existencia de satisfactores diná-

Figura 1-1

Pirámide de la jerarquía de necesidades humanas según Abraham Maslow

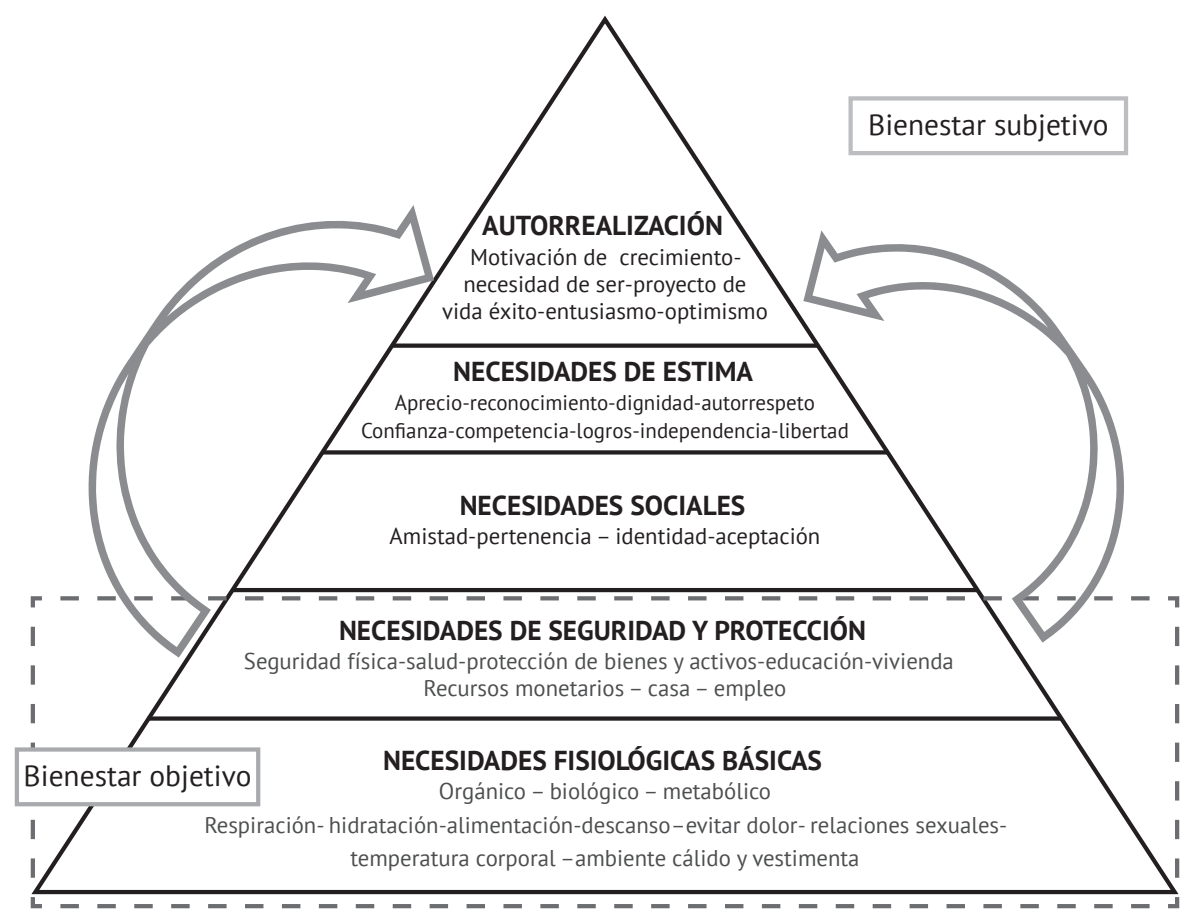


micos y abiertos; debido a que su objetivo consiste en la medición, su teoría intenta ser sustantiva y procedimental. La teoría que elaboran distingue entre necesidades como impulsos (visión conformista) y necesidades como propósitos o metas (visión progresista); parten de objetivos universales (participación social plena o prevención de grave daño), de los que se derivan necesidades básicas (salud física y autonomía), las cuales se realizan a través de necesidades intermedias.

Las "necesidades básicas universales" para ellos son dos: salud física y autonomía. La primera la definen en términos biomédicos, para asegurar una base universal, dada la estructura común que tienen todos los seres humanos. La autonomía se alcanza y recibe influencia en un sentido triple, de acuerdo con el nivel de: a) comprensión que una persona tiene respecto de sí misma, su cultura y lo que se espera de ella, lo cual supone una mínima interacción social y habilidades lingüísticas; b) capacidad psicológica (cognitiva y emotiva) para formular opciones por sí misma. y c) oportunidades objetivas que permiten actuar, como libertad de agencia o de elección personal, libertad política y habilidad para aceptar o cambiar las reglas de la cultura. La salud física y la autonomía son condiciones para alcanzar el estado último de la teoría que es evitar el daño grave, definido como: a) incapacidad para perseguir la propia visión de bien, o b) el impedimento a una participación social exitosa.

A partir de estos planteamientos, identifican satisfactores que contribuyen a cubrir las necesidades básicas en distintos contextos culturales, pero con características universales, es decir, como aquellas propiedades de bienes, servicios, actividades y relaciones que potencian la salud física y la autonomía humana en todas las culturas. El puente entre las necesidades universales básicas y los satisfactores socialmente relativos son las necesidades intermedias siguientes: agua limpia y comida nutritiva, vivienda protectora, ambiente laboral carente de riesgos, medio ambiente sin riesgos, cuidado adecuado de la salud, seguridad en la infancia, relaciones primarias significativas, seguridades física y económica, educación apropiada, parto seguro y cuidado neonatal. La satisfacción de las necesidades básicas e intermedias se mide con normas que tienen un óptimo de satisfacción universal, no un mínimo absoluto, ni uno relativo desde el punto de vista cultural; dicho óptimo puede tener un umbral menor como meta a cumplir en el mediano plazo. La propuesta teórica limita la variabilidad de los indicadores entre países y culturas, aunque acepta las diferencias temporales (Doyal y Gough, 1994).

\section{La versión de Martha Nussbaum}

En esta versión del bienestar, existen ciertas características del sentido de humanidad común susceptibles de entender como una lista de capacidades centrales, al seguir 
de cerca las esferas mencionadas por Aristóteles y al desarrollar su análisis con los siguientes funcionamientos:

- Mortalidad: garantizar una extensión normal de la vida y tener la posibilidad de evitar una muerte prematura.

- Cuerpo: mantener la eficacia biológica con salud corporal, salud reproductiva y alimentación adecuada.

- Placer y dolor: tener la oportunidad de evitar el dolor y experimentar placer, con integridad corporal, libertad de movimiento y seguridad frente a todo tipo de agresiones, así como oportunidades para la satisfacción sexual y para la elección en materia de reproducción.

- Capacidad cognoscitiva: percibir de forma sensorial, imaginar, pensar y razonar, con educación, alfabetización, entrenamiento científico y matemático básico, producción artística y acción.

- Razón práctica: poder formarse una concepción del bien y planear la vida propia, con capacidad de plasmar una idea del bien y de comprometerse de modo crítico en la planificación de la propia vida (libertad de conciencia).

- Afiliación: tener la oportunidad de vivir por y para otros. Ser capaz de tener empatía y de comprometerse en distintas maneras de interacción social, lo cual supone la libertad de reunión y de expresión de las ideas políticas, con bases sociales de autorrespeto, trato digno y con igual valor que los demás, así como ausencia de discriminación y poseer la habilidad de llevar a cabo trabajo humano.

- Humor: contar con la posibilidad de disfrutar actividades recreativas y el juego.

- Relación con la naturaleza o la dimensión ecológica de la vida humana.

- Vivir la vida propia en un entorno distintivo en dos dimensiones: el político con participación, y el material como oportunidad real de ejercer la propiedad (de la tierra y de bienes muebles) en condiciones de igualdad de derechos; con derecho al empleo sobre bases iguales a las de otros, y no ser objeto de registro o incautación injustificada (Nussbaum, 1993).

En esta visión esencialista, la dignidad humana se instrumenta con el cumplimiento de los umbrales básicos de cada capacidad, los cuales representan derechos exigibles a cada gobierno. 


\section{ENFOQUES DE DERECHOS}

Existen varios enfoques de derechos como los promovidos por la Organización de las Naciones Unidas (ONU), en particular, los expresados en la "Declaración de los Derechos Humanos", en la Definición y medición internacional del nivel de vida. Guía provisional (Organización de la Naciones Unidas, 1961), en el "Pacto internacional de los derechos económicos, sociales y culturales", y en los Objetivos de desarrollo del milenio (Organización de las Naciones Unidas, 1976).

A partir de las críticas a la visión que suponía al crecimiento económico como sinónimo del desarrollo o el bienestar social y del producto interno bruto (PIB) como su principal indicador, surgieron algunos trabajos en organismos internacionales. En la "Conferencia Mundial del Empleo", en 1976, la Organización Internacional del Trabajo adoptó la Declaración de principios y un programa de acción, donde estableció lineamientos sobre necesidades esenciales y diversos temas de mano de obra y empleo. La "Cumbre Mundial sobre el Desarrollo Social" en Copenhague (1995), y los Objetivos de desarrollo del milenio (2000) enfatizaron la medición de la pobreza por ingresos y de indicadores sociales sobre mortalidad y acceso a servicios básicos en coincidencia con las iniciativas promovidas desde 1978 por el Banco Mundial.

Entre los 17 objetivos de desarrollo sustentable destaca, para los propósitos de este capítulo, el número 11, orientado a conseguir que las ciudades y los asentamientos humanos sean inclusivos, seguros, resilientes y sostenibles. La Iniciativa de ciudades prósperas de ONU-Hábitat se deriva de este objetivo como una forma de medición y un instrumento de diálogo político para que las ciudades generen indicadores espaciales comparables con validación internacional, que permitan definir objetivos y metas para el diseño de políticas de las autoridades municipales y metropolitanas e identificar oportunidades y áreas de intervención.

El concepto de prosperidad urbana cuenta con 10 metas: a) vivienda adecuada, segura y asequible; $b$ ) sistemas de transporte accesibles y sostenibles para todos; c) urbanización incluyente y sostenible; $d$ ) salvaguarda del patrimonio cultural y natural mundial; e) reducción del número de personas afectadas por desastres; f) disminución del efecto ambiental en las ciudades; g) acceso universal a los espacios públicos seguros; $h$ ) enlaces de apoyo entre zonas urbanas, periurbanas y rurales; i) incremento de políticas y planes integrados hacia la mitigación y la adaptación al cambio climático, y j) construcción de edificios sostenibles y resistentes que utilicen materiales locales. Esta iniciativa se instrumenta en el Índice de prosperidad urbana que incluye las seis dimensiones siguientes: 
- Productividad: una ciudad próspera contribuye al crecimiento económico y el desarrollo, a la generación de ingresos, al empleo y a la igualdad de oportunidades que proporcionan mejores niveles de vida para la población.

- Equidad e inclusión social: una ciudad solo es próspera en la medida en que la pobreza y las desigualdades son mínimas. Ninguna ciudad puede presumir de ser próspera cuando grandes segmentos de la población viven en abyecta pobreza o privación. Esto implica reducir la incidencia de tugurios y nuevas formas de pobreza y marginación.

- Infraestructura: una ciudad próspera despliega la infraestructura, los bienes físicos y los servicios (agua adecuada, saneamiento, suministro de energía, red de carreteras, tecnologías de información y comunicación, y otros) necesarios para sostener a la población, la economía y mejorar la calidad de vida.

- Calidad de vida: una ciudad próspera ofrece servicios, como los sociales, de educación, salud, recreación, seguridad y protección indispensables para el incremento de los niveles de vida, lo cual permite a la población maximizar el potencial individual y llevar una vida plena.

- Sustentabilidad ambiental: el crecimiento y el desarrollo económicos no deben destruir ni degradar el medio ambiente; los recursos naturales han de conservarse por el bien de la urbanización sostenible. Las ciudades bien planificadas promueven la sostenibilidad ambiental.

- Gobernanza y legislación: las ciudades son más capaces de combinar la sostenibilidad y la prosperidad compartida a través de una gobernanza urbana eficaz y un liderazgo transformador, al implementar políticas, leyes y reglamentos adecuados y eficaces, con creación de marcos institucionales e instituciones locales fuertes, así como arreglos institucionales sólidos. Estas dimensiones cuentan con 26 indicadores para estimar el índice (cuadro 1-1).

En este enfoque, también se encuentran el "Índice de calidad de vida" de la ONU, así como las contribuciones de Amartya Sen sobre capacidades y funcionamientos que condujeron a la elaboración del Informe de desarrollo humano elaborado desde 1990 por el "Programa de las Naciones Unidas para el Desarrollo" (PNUD, 1990), y los sucesivos informes anuales y de países, al adoptar un enfoque de derechos.

En el caso de la Comisión Económica para América Latina (CEPAL), en la "Conferencia Regional sobre Población y Desarrollo" que organizó, se acordó: "[...]avanzar en la consolidación de sistemas de planificación que coadyuven a la construcción de 
Cuadro 1-1

Índice de prosperidad urbana de la Organización de Naciones Unidas-Hábitat (ONU-Hábitat)

\begin{tabular}{|c|c|}
\hline Dimensiones & Indicadores \\
\hline Productividad & $\begin{array}{l}\text { Producto per cápita de la ciudad } \\
\text { Tasa de crecimiento del empleo } \\
\text { Tasa de empleo informal } \\
\text { Tasa de desempleo } \\
\text { Tasa de empleo en la industria manufacturera }\end{array}$ \\
\hline Infraestructura & $\begin{array}{l}\text { Muertes por accidente de tránsito } \\
\text { Acceso a agua mejorada } \\
\text { Acceso a mejores servicios de saneamiento } \\
\text { Acceso a electricidad } \\
\text { Cobertura de redes móviles } \\
\text { Acceso a internet }\end{array}$ \\
\hline Calidad de vida & $\begin{array}{l}\text { Bosque o zonas verdes como porcentaje de la superficie total } \\
\text { Tasa de homicidios } \\
\text { Población sometida a la violencia }\end{array}$ \\
\hline Equidad e inclusión social & $\begin{array}{l}\text { Tasa de pobreza } \\
\text { Mujeres en la administración local } \\
\text { Brecha de género en los salarios } \\
\text { Desempleo juvenil } \\
\text { Tasa de crecimiento de } 40 \% \text { más bajo }\end{array}$ \\
\hline $\begin{array}{l}\text { Sustentabilidad } \\
\text { ambiental }\end{array}$ & $\begin{array}{l}\text { Población expuesta a la contaminación ambiental exterior } \\
\text { Tratamiento de aguas residuales } \\
\text { Cuota de recursos de energías renovables } \\
\text { Cuota de reciclaje de residuos sólidos }\end{array}$ \\
\hline $\begin{array}{l}\text { Gobernanza y } \\
\text { legislación }\end{array}$ & $\begin{array}{l}\text { Capacidad de inversión } \\
\text { Eficiencia del gasto local } \\
\text { Asociaciones públicas-privadas }\end{array}$ \\
\hline
\end{tabular}

Fuente: ONU-Hábitat, 2016.

sociedades equitativas y sin exclusión social mediante el desarrollo de políticas públicas dirigidas a reducir las brechas existentes en la calidad de vida y en el ejercicio de derechos de todas las personas, con énfasis en las condiciones de vida de los seres humanos y su relación con el territorio que ocupan" (CEPAL, 2013:14). Asimismo, el trabajo realizado por esta Comisión ha sido relevante con sus diferentes informes, entre los cuales destaca el Panorama social de América Latina (CEPAL, 2000).

Como se puede observar, los objetivos de desarrollo definidos en escala internacional constituyen agendas para la acción o los mandatos para los países miembros de esas organizaciones, los cuales se combinan con los propósitos nacionales. 


\section{MODELOS EUROPEOS}

Entre los enfoques aplicados en países europeos, se encuentran los "Indicadores de Laeken" de la Unión Europea (UE, 2001 y Council of Europe, 2005). Asimismo, sobresalen tres modelos que definen las necesidades básicas de: tener, amar y ser, con dominios e indicadores maximalistas, es decir, correspondientes a niveles de alto desarrollo social con "estados de bienestar" maduros. En estos modelos, se consideran dimensiones, variables e indicadores amplios con normas de cumplimiento más alto, que relacionan el bienestar con aspectos no tradicionales, como recursos políticos o seguridad de la vida y de la propiedad (cuadro 1-2).

\section{Cuadro 1-2}

Enfoques europeos de bienestar desarrollado

\begin{tabular}{l|l|l|l}
\hline \multirow{2}{*}{$\begin{array}{l}\text { Necesidad } \\
\text { básica }\end{array}$} & Escandinavo & Sueco & \multicolumn{2}{l}{ Países Bajos } \\
\hline \multirow{4}{*}{ Tener } & Recursos económicos & Recursos económicos & Poder de compra \\
\cline { 2 - 4 } & Condiciones de la vivienda & Vivienda & Vivienda \\
\cline { 2 - 4 } & Empleo & Empleo & \\
\cline { 2 - 4 } & Condiciones de trabajo & Condiciones de trabajo & Movilidad \\
\cline { 2 - 4 } & Salud & Salud y acceso al cuidado de la salud & Salud \\
\cline { 2 - 4 } & Educación & Educación y capacitación & \\
\hline \multirow{2}{*}{ Amar } & & Familia e integración social & Participación social \\
\hline \multirow{3}{*}{ Ser } & & Recursos políticos & Actividades recreativas \\
\hline & & & Vacaciones \\
\hline & & & Actividades deportivas \\
\hline
\end{tabular}

Fuente: Elaboración propia con base en datos tomados de Allardt, 1998; Erikson, 1998, y Hagerty, 2001.

\section{PROPUESTAS MULTILATERALES}

Entre los modelos de bienestar multilaterales, se encuentra la propuesta de la OECD, con el "Índice para una vida mejor", bajo una reflexión inicial que lo acerca al bienestar objetivo: "Aunque el dinero quizá no compre la felicidad, es un medio importante para alcanzar estándares de vida más elevados y, por consiguiente, un mayor bienestar. Contar con recursos económicos más altos también puede mejorar el acceso a la educación, los servicios de salud y la vivienda de calidad" (OECD, 2016). 
El índice incluye 24 indicadores y 11 dimensiones esenciales para medir las condiciones de vida materiales y la calidad de vida: hogar-vivienda, ingreso, trabajo, comunidad, educación, medioambiente, compromiso cívico, salud, satisfacción ante la vida, seguridad y conciliación de la vida laboral (cuadro 1-3).

\section{ESTUDIOS MERCANTILES}

Estos incluyen el enfoque de Mercer que evalúa las condiciones de vida locales en más de 450 ciudades abarcadas en su Encuesta de calidad de vida de las ciudades mundiales (Mercer, 2016). El ranking ayuda a las compañías multinacionales a compensar a sus empleados cuando se les envía a misiones internacionales. Las

\section{Cuadro 1-3}

Indicadores del Î́ndice para una vida mejor de la Organización para la Cooperación y el Desarrollo Económicos

\begin{tabular}{ll}
\hline Hogar-vivienda & Viviendas sin servicios básicos \\
& Gastos del hogar \\
& Habitaciones por persona \\
\hline Ingreso & Ingreso disponible neto ajustado de los hogares \\
& Riqueza financiera neta de los hogares \\
\hline Trabajo & Inseguridad del mercado laboral \\
& Tasa de empleo \\
& Tasa de desempleo de larga duración \\
& Ingresos personales \\
\hline Comunidad & Calidad de la red de apoyo \\
\hline Educación & Nivel de instrucción \\
& Habilidades aprendidas \\
& Años de educación \\
\hline Medio ambiente & Contaminación del aire \\
& Calidad del agua \\
\hline Compromiso cívico & Participación de interesados en el desarrollo de normas \\
& Participación electoral \\
\hline Salud & Esperanza de vida \\
& Autoinforme de salud \\
\hline Satisfacción con la vida & Satisfacción con la vida \\
\hline Seguridad & Sentimiento de seguridad al caminar solo por la noche \\
\hline Balance de la vida laboral & Tasa de homicidios \\
\hline Fuente:0ECD 2016. & Empleados que trabajan muchas horas \\
& Tiempo dedicado al ocio y el cuidado personal \\
\hline
\end{tabular}

Fuente: OECD, 2016. 


\section{Cuadro 1-4}

Índice de calidad de vida de las ciudades mundiales

\begin{tabular}{ll}
\hline Categoría & Factores \\
\hline Entorno sociopolítico & Estabilidad política, delincuencia y cumplimiento de la ley \\
\hline Entorno económico & Regulaciones del tipo de cambio y servicios bancarios \\
\hline Entorno sociocultural & Disponibilidad de medios y censura, y restricciones a las libertades individuales \\
\hline Consideraciones & Suministros y servicios médicos, enfermedades infecciosas, desagües, elimi- \\
médicas y de salud & nación de deshechos, contaminación atmosférica, etc. \\
\hline Escuelas y educación & Nivel y disponibilidad de escuelas internacionales \\
\hline Servicios públicos y & Electricidad, agua, transporte público, congestión vial, etc. \\
transporte & \\
\hline Entretenimiento & Restaurantes, teatros, cines, deportes y esparcimiento, etc. \\
\hline Bienes de consumo & Disponibilidad de alimentos, artículos de consumo diario, automóviles, etc. \\
\hline Vivienda & Vivienda, electrodomésticos, muebles, servicios de mantenimiento. \\
\hline Medio ambiente & Clima, antecedentes de catástrofes naturales \\
\hline
\end{tabular}

Fuente: Mercer, 2016.

condiciones de vida se analizan según 39 factores, agrupados en 10 categorías (cuadro 1-4).

Otro ejemplo es el "Índice de calidad de vida" de la Economist Intelligence Unit (EIU), realizado con una metodología que vincula factores objetivos y subjetivos, con indicadores y fuentes de información que permiten la comparación entre países. Se refieren elementos que propician una vida digna, cómoda, agradable y satisfactoria, los cuales pueden ser tanto emocionales, como materiales o culturales. En este sentido, la calidad de vida de una persona la definen, en primer término, por la posibilidad de vivir de manera agradable con sus pares, principalmente con el grupo que forma su familia y que le da identidad. Otros aspectos que contribuyen a la calidad de vida (materiales) pueden ser por ejemplo el acceso a una vivienda digna, a servicios como agua potable, alimentos e incluso electricidad (Economist Intelligence Unit, 2012) (cuadro 1-5).

\section{MODELOS ALTERNATIVOS}

Entre las visiones críticas se han formulado propuestas para mejorar la calidad de vida con enfoques, necesidades y satisfactores alternativos, como la noción de "DesarroIlo a escala humana". En este enfoque, se propone una matriz con nueve necesidades con categorías axiológicas: subsistencia, protección, afecto, entendimiento, partici- 
Cuadro 1-5

Índice de calidad de vida de la Economist Intelligence Unit (EIU)

\begin{tabular}{|c|c|c|}
\hline Factores & Indicadores y fuentes de información & Fuentes \\
\hline Salud & Esperanza de vida al nacer (en años) & $\begin{array}{l}\text { Oficina del Censo de Estados } \\
\text { Unidos }\end{array}$ \\
\hline Vida familiar & $\begin{array}{l}\text { Tasa de divorcio por } 1000 \text { habitantes, } \\
\text { convertida en índice de } 1 \text { (menor tasa } \\
\text { de divorcios) a } 5 \text { (más alta) }\end{array}$ & $\begin{array}{l}\text { "Naciones Unidas y } \\
\text { Euromonitor" }\end{array}$ \\
\hline Vida comunitaria & $\begin{array}{l}\text { Valor } 1 \text { si el país tiene tasa alta de } \\
\text { asistencia a la iglesia o pertenencia a } \\
\text { sindicatos y } 0 \text { en caso contrario. }\end{array}$ & Encuesta mundial de valores \\
\hline Bienestar material & PIB por persona, en PPA & Economist Intelligence Unit \\
\hline $\begin{array}{l}\text { Estabilidad política y } \\
\text { seguridad }\end{array}$ & $\begin{array}{l}\text { Estabilidad política y clasificaciones } \\
\text { de seguridad }\end{array}$ & Economist Intelligence Unit \\
\hline Clima y geografía & $\begin{array}{l}\text { Latitud, para distinguir entre los cli- } \\
\text { mas más cálidos y más fríos }\end{array}$ & CIA World Factbook \\
\hline Seguridad del empleo & Tasa de desempleo (\%) & Economist Intelligence Unit \\
\hline Libertad política & $\begin{array}{l}\text { Promedio de índices de las libertades } \\
\text { políticas y civiles. Escala de } 1 \text { (libre } \\
\text { por completo) a } 7 \text { (sin libertad) }\end{array}$ & Freedom House \\
\hline Igualdad de género & $\begin{array}{l}\text { Proporción de la media en los ingresos } \\
\text { masculinos y femeninos }\end{array}$ & IDH, PNUD \\
\hline
\end{tabular}

IDH, Índice de Desarrollo Humano; PIB, producto interno bruto; PNUD, Programa de las Naciones Unidas para el Desarrollo; PPA, paridad de poder de compra.

Fuente: EIU, 2012.

pación, ocio, creación, identidad y libertad, las cuales se combinan con cuatro categorías existenciales: ser, tener, hacer y estar. Cada necesidad se considera un derecho humano que requiere satisfactores susceptibles de funcionar con efectos sinérgicos y relacionales. En este sentido, la construcción de una nueva ciudadanía incluye la lucha por la satisfacción de los nuevos derechos de tercera o cuarta generación, por lo cual emergen formas de democracia participativa o reactiva para la gestión de recursos y servicios en el territorio (Max-Neef et al., 2003).

Ante procesos metropolitanos donde se produce gran número de estímulos relacionales en un territorio expandido, pero también se reducen los vínculos de reciprocidad y se generan fenómenos de exclusión, segregación, marginalidad y soledad, entre otros, se ofrece este enfoque con una perspectiva centrada en las posibilidades de realización de ser humano. Esta idea se expresa en diversas variables e indicadores cruzados, los cuales tienen un ámbito general, pero también uno espacial que permite hablar de la ciudad en escala humana, entendida como el lugar 
Cuadro 1-6

Matriz de necesidades para el desarrollo en escala humana

\begin{tabular}{|c|c|c|c|c|c|}
\hline \multirow{2}{*}{\multicolumn{2}{|c|}{ Categorías }} & \multicolumn{4}{|c|}{ Necesidades según categorías existenciales } \\
\hline & & Ser (sujetos de derechos) & Tener & Hacer & Relaciones \\
\hline & \multirow{4}{*}{ Subsistencia } & Derecho a la vida & Alojamiento & Descansar & \multirow{2}{*}{ Entorno vital } \\
\hline & & \multirow{2}{*}{ Derecho a la salud } & Alimentos & \multirow{3}{*}{$\begin{array}{l}\text { Buena } \\
\text { alimentación }\end{array}$} & \\
\hline & & & Salud & & \\
\hline & & Derechos ambientales & Trabajo & & Minedio social \\
\hline \multirow{7}{*}{\multicolumn{2}{|c|}{ 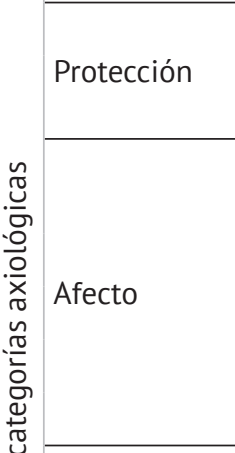 }} & \multirow{2}{*}{$\begin{array}{l}\text { Derechos sociales } \\
\text { y económicos }\end{array}$} & Seguridad & \multirow[b]{2}{*}{ Cooperación } & \multirow{2}{*}{$\begin{array}{l}\text { Entorno social } \\
\text { integrador }\end{array}$} \\
\hline & & & Solidaridad & & \\
\hline & & \multirow{5}{*}{ Derechos relacionales } & $\begin{array}{l}\text { Relaciones fami- } \\
\text { liares }\end{array}$ & $\begin{array}{l}\text { Expresar } \\
\text { emociones }\end{array}$ & Vida privada \\
\hline & & & \multirow{2}{*}{ Redes sociales } & \multirow{4}{*}{ Compartir } & Intimidad \\
\hline & & & & & Amistad \\
\hline & & & \multirow{2}{*}{ Generosidad } & & Vecindad \\
\hline & & & & & Familiar \\
\hline . & \multirow{4}{*}{ Participación } & $\begin{array}{l}\text { Derechos de } \\
\text { ciudadanía }\end{array}$ & Responsabilidad & Compartir & De reciprocidad \\
\hline$\frac{n}{\tilde{0}}$ & & $\begin{array}{l}\text { Derecho al buen } \\
\text { gobierno }\end{array}$ & $\begin{array}{l}\text { Capacidad de } \\
\text { decisión }\end{array}$ & Decidir & Consenso \\
\hline 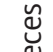 & & \multirow{2}{*}{$\begin{array}{l}\text { Derecho a la producción } \\
\text { del espacio }\end{array}$} & \multirow{2}{*}{$\begin{array}{l}\text { Capacidad de } \\
\text { gestión }\end{array}$} & \multirow[b]{2}{*}{ Asociarse } & Negociación \\
\hline z & & & & & $\begin{array}{l}\text { Responsabilidad } \\
\text { compartida }\end{array}$ \\
\hline & \multirow{5}{*}{ Creación } & \multirow{3}{*}{ Derecho al trabajo } & Formación & Estudiar & De intercambio \\
\hline & & & Información & Analizar & \multirow[t]{2}{*}{ De colaboración } \\
\hline & & & Soportes & Diseñar & \\
\hline & & \multirow[b]{2}{*}{$\begin{array}{l}\text { Derecho a la } \\
\text { información }\end{array}$} & Recursos & Planificar & \multirow[b]{2}{*}{ De cooperación } \\
\hline & & & $\begin{array}{l}\text { Equipamientos } \\
\text { polivalentes }\end{array}$ & Innovar & \\
\hline
\end{tabular}

construido y apropiado por el sujeto que desarrolla derechos y deberes, para lograr la satisfacción de sus necesidades (cuadro 1-6).

\section{ESTUDIOS DE CIUDADES ESPECÍFICAS}

En la lógica de la acción pública y de la planeación del desarrollo hay esfuerzos por medir y diseñar políticas, y formular metas de desarrollo en algunas ciudades. Entre estas se encuentran algunos estudios, como el realizado para la ciudad de Santiago 
Continuación Cuadro 1-6

\begin{tabular}{|c|c|c|c|c|c|}
\hline \multirow{2}{*}{\multicolumn{2}{|c|}{ Categorías }} & \multicolumn{4}{|c|}{ Necesidades según categorías existenciales } \\
\hline & & Ser (sujetos de derechos) & Tener & Hacer & Relaciones \\
\hline \multirow{4}{*}{ 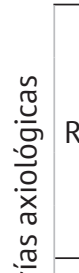 } & \multirow{4}{*}{ Recreo } & Derecho al tiempo libre & Espacios libres & \multirow[b]{2}{*}{ Imaginar } & De proximidad \\
\hline & & $\begin{array}{l}\text { Derecho a la libre circu- } \\
\text { lación }\end{array}$ & Tiempo liberado & & De amistad \\
\hline & & \multirow{2}{*}{$\begin{array}{l}\text { Derecho al espacio } \\
\text { público }\end{array}$} & \multirow{2}{*}{ Equipamientos } & \multirow{2}{*}{ Crear } & De vecindad \\
\hline & & & & & De familia \\
\hline \multirow{7}{*}{ 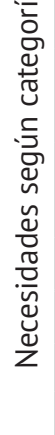 } & \multirow{4}{*}{ Identidad } & \multirow{4}{*}{ Derechos culturales } & Autoestima & Afirmarse & \multirow{2}{*}{$\begin{array}{l}\text { Múltiples con los } \\
\text { otros }\end{array}$} \\
\hline & & & $\begin{array}{l}\text { Ámbitos de per- } \\
\text { tenencia }\end{array}$ & Participar & \\
\hline & & & $\begin{array}{l}\text { Espacios simbó- } \\
\text { licos }\end{array}$ & Tolerarse & \multirow[t]{2}{*}{ Interculturalidad } \\
\hline & & & Apropiados & Apropiarse & \\
\hline & \multirow{3}{*}{ Libertad } & \multirow{3}{*}{$\begin{array}{l}\text { Derechos políticos } \\
\text { y jurídicos }\end{array}$} & Autonomía & \multirow{3}{*}{ Convivencia } & Democráticas \\
\hline & & & Capacidad de & & Tolerantes \\
\hline & & & elección & & Abiertas \\
\hline
\end{tabular}

Fuente: Elaborado con datos tomados de Max-Neef, et al., (1986) y Alguacil (2008).

de Chile, en el cual se elabora el "Índice de calidad de vida urbana", donde se aplican ponderadores a las dimensiones de bienestar de la manera siguiente: condición laboral (9.4\%), conectividad y movilidad (9.1\%), ambiente de negocios $(16.5 \%)$, condiciones socioculturales (17.4\%), vivienda y entorno $(29.0 \%)$, y salud y medio ambiente (18.6\%) (Orellana, 2014).

En el caso de la ciudad de Quilmes de Argentina, se consideran cuatro dimensiones: hábitat, social, económica y subjetiva; asimismo, se encuentran 32 indicadores considerados confiables con los cuales se elabora su índice de calidad de vida (cuadro 1-7).

\section{ENFOQUES SUBJETIVOS}

Los estudios sobre calidad de vida subjetiva se impulsan en el ámbito internacional, sobre todo, a partir del informe elaborado por la Comisión Stiglitz, Sen y Fitoussi del año 2009, en el cual se afirma que la medición con indicadores objetivos es insuficiente para comprender el bienestar, el desarrollo o la felicidad. Señalan que, si bien el PIB por habitante es el mejor agregado macroeconómico para medir el nivel de actividad de los países, resulta inadecuado como indicador de bienestar ya que 


\section{Cuadro 1-7}

Indicadores confiables encontrados para la ciudad de Quilmes

\begin{tabular}{|c|c|}
\hline Dimensión & Indicador \\
\hline \multirow{7}{*}{ Hábitat } & Cobertura red de cloacas (\%) \\
\hline & Cobertura red de agua (\%) \\
\hline & Cobertura red de electricidad (\%) \\
\hline & Cobertura red de gas (\%) \\
\hline & Obstáculos promedio al peatón \\
\hline & Reclamos ingresados en ETOSS \\
\hline & Indice de privación material de hogares \\
\hline \multirow{8}{*}{ Social } & Población NBI (\%) \\
\hline & Población con cobertura social (\%) \\
\hline & Población de 18 a 29 años en nivel superior de educación (\%) \\
\hline & Tasa de analfabetismo \\
\hline & Tasa de mortalidad infantil cada 1000 habitantes \\
\hline & Hogares deficitarios (\%) \\
\hline & Población victimizada (\%) \\
\hline & Crímenes de zona sur (\%) \\
\hline \multirow{5}{*}{ Económica } & PIB regional bienes y servicios (\%) \\
\hline & Tasa de variación del precio del metro cuadrado construido \\
\hline & Importancia de la industria manufacturera (\%) \\
\hline & Transferencias de provincia (\%) \\
\hline & Cantidad de locales productores de bienes y servicios \\
\hline \multirow{12}{*}{ Subjetiva } & Percepción sobre el medio ambiente \\
\hline & Percepción sobre ABL \\
\hline & Percepción sobre la participación ciudadana \\
\hline & Percepción sobre el estado de los espacios públicos \\
\hline & Percepción sobre la asistencia social \\
\hline & Percepción sobre la eficiencia del transporte público \\
\hline & Percepción sobre las soluciones al barrio \\
\hline & Percepción sobre la política cultural \\
\hline & Percepción sobre la salud pública \\
\hline & Percepción sobre la obra pública \\
\hline & Percepción sobre la movilidad urbana \\
\hline & Percepción sobre la seguridad urbana \\
\hline
\end{tabular}

ABL,???; ETOSS, Ente Tripartito de Obras y Servicios Sanitarios; NBI, Necesidades Básicas Insatisfechas.

Fuente: Leva, Germán (2005), Indicadores de calidad de vida urbana. Teoría y metodología. Hábitat Metrópolis, Buenos Aires, Universidad Nacional de Quilmes. 
refiere solo al valor de cambio, esconde la distribución de los activos y no expresa la relación de las necesidades con los satisfactores. La propuesta es la Medición del progreso de las sociedades con tres grandes dimensiones: a) progreso material, b) sostenibilidad y c) calidad de vida que incluye las vertientes de capacidades y de bienestar subjetivo.

El progreso material sigue considerando indicadores macroeconómicos, como los recursos de las personas y los hogares para atender sus necesidades, pero también la forma de su distribución entre la población. La sostenibilidad se refiere a las acciones, realizadas u omitidas, para no comprometer los derechos de las generaciones futuras en materia ambiental, en recursos naturales económicos o bióticos; se trata de preservar el capital natural, pero también los capitales social, humano y físico.

A su vez, la dimensión de calidad de vida considera dos aspectos. Primero, las capacidades, relacionadas con la medición de las condiciones objetivas en que viven las personas para determinar si están en un contexto propicio o no para desarrollar su potencial y para ejercer funcionamientos en libertad. Este enfoque se instrumentó en el índice de desarrollo humano (IDH) del PNUD y en los Objetivos de desarrollo del milenio, los cuales permiten hacer comparaciones internacionales entre países y establecer metas de cumplimiento en varios indicadores. En segundo lugar, se incluye el bienestar subjetivo, el cual atiende a un enfoque psicológico de satisfacción o de felicidad, de la forma en que experimentan las personas sus vidas, al considerar sus antecedentes, su entorno y su proyección a futuro.

A partir de este impulso, se desarrollaron varios estudios sobre calidad de vida que consideran la felicidad y proponen cuentas nacionales de bienestar subjetivo por grupos y territorios para apoyar el diseño de políticas. Entre estos se mencionan como factores causales: a) personalidad y genética; $b$ ) aspectos sociales, como el desarrollo económico (relacionado con la satisfacción de las necesidades básicas); c) relaciones sociales solidarias; d) capital social, baja corrupción, y sentirse respetado y digno de confianza, y e) un medio ambiente sano y sin contaminación, que incluya amplios espacios verdes, agua y aire limpio. Se reconoce que la felicidad de las personas y las sociedades tiene ventajas, pero esto no significa que prevendrá todos los problemas o que es útil pero no suficiente para lograr una calidad de vida alta (Diener, 2013). Asimismo, el goce subjetivo de la vida entendida como felicidad personal, bienestar subjetivo o satisfacción de vida, en la visión de Jeremy Bentham, se alinea con la satisfacción de necesidades universales (Veenhoven, 2013).

Entre los diferentes estudios con el enfoque de bienestar subjetivo y con índices comparativos en el ámbito internacional, se encuentran: a) la "Encuesta mundial 
de valores"; b) la "Encuesta mundial Gallup"; c) los informes de "Latinobarómetro"; d) el índice de bienestar económico; e) el índice de progreso genuino; f) el índice de prosperidad, o g) el índice del planeta feliz, entre otros.

Los análisis internacionales incluyen en especial las aportaciones de Angus Deaton que, con los datos de la "Encuesta mundial Gallup" del año 2006 para 123 países, establecen una asociación importante entre la duplicación del PIB por habitante y el incremento constante en la satisfacción de la vida, aunque las diferencias entre ambas tienden a ser mayores en los países más ricos que entre los más pobres. No obstante, otros trabajos cuestionan esta afirmación, y con series de tiempo de 37 naciones desarrolladas, en desarrollo y en transición, demuestran que no existe una relación importante entre ambas; y que la mejoría del bienestar depende más de las políticas de empleo pleno y asistencia social (Easterlin, 2013).

En México, es posible mencionar algunos trabajos, como el realizado por el Instituto Nacional de Estadística y Geografía (INEGI), el cual aplicó el módulo de bienestar subjetivo autoinformado (Biare) en el año 2012, con un cuestionario de autollenado en el marco de la "Encuesta nacional de gastos de los hogares". La medición del bienestar subjetivo considera cuatro componentes: satisfacción con la vida, eudaimonia (felicidad o plenitud), equilibrio afectivo y dominios de satisfacción o qué tan felices se consideran a sí mismas las personas. Algunos temas específicos que se consideran son: tiempo libre, logros personales, perspectivas a futuro, situación económica, trabajo, vivienda, vecindario o colonia, estado de salud, educación o instrucción, vida familiar, vida social, apariencia y país en el que vive (INEGI, 2015). Algunos resultados de investigación parecen comprobar una correlación notable entre la medición del bienestar subjetivo del Biare con el bienestar objetivo estimado con el método de medición integrada de la pobreza en México, donde los estratos más altos de ambas mediciones se asocian entre sí y lo mismo se observa entre los estratos más bajos (Jaramillo, 2016).

El equipo de Imagina México, A. C., realizó el "Ranking de felicidad en MéxiCo, 2012", a partir del concepto de satisfacción de vida o felicidad definida, como "el grado hasta el cual un individuo juzga la calidad de su propia vida en general de manera favorable. Es decir, cuánto le gusta a una persona la vida que lleva" (Universidad Popular Autónoma del Estado de Puebla, 2013: 119). El cuestionario incluye nueve indicadores compuestos: felicidad, satisfacción en dominio de vida, evaluación de vida, índice de equilibrio afectivo, índice de afectos positivos, índice de afectos negativos, disponibilidad de tiempo, relaciones de apoyo y satisfacción con servicios municipales; así como 62 reactivos aplicados con 26409 encuestas 
en 100 municipios del país, con hallazgos que revelan un nivel alto de felicidad en comparación con el resto del mundo, lo cual permite ofrecer propuestas para mejorar la calidad de vida (Universidad Popular Autónoma del Estado de Puebla, 2013).

A su vez, en el seminario "Satisfacción subjetiva con la vida y la sociedad", del Instituto de Investigaciones Sociales de la Universidad Nacional Autónoma de México (UNAM), se analizó el bienestar subjetivo, entendido como "el bienestar experimentado y autoinformado por los individuos y las sociedades a partir de su propia experiencia cotidiana y de la evaluación de su vida, sus condiciones y oportunidades percibidas". Los dominios vitales de satisfacción considerados fueron: situación económica propia, vida familiar, casa en que vive, trabajo, vida afectiva o emocional, salud, vida social, tiempo libre disponible, barrio o colonia donde vive, relaciones con sus amigos, ciudad y localidad donde vive, y país y educación que tiene. A partir de ello, en el año 2014, se levantó la "Encuesta nacional sobre satisfacción con la vida y la sociedad", aplicada a personas de 18 años y más, con 1200 entrevistas en cuatro regiones de México.

Entre los principales resultados de este estudio, se obtuvo que $35.6 \%$ de los mexicanos está muy satisfechos con su vida en general y $46.7 \%$ satisfecho; en contraste, $14.1 \%$ contestó que está insatisfecho y $3.4 \%$ nada satisfecho. Los varones informaron una calificación de 8.6 (escala de 1 a 10) para el nivel de satisfacción de sus vidas y, las mujeres, 8.45. El ámbito que mayor satisfacción le proporciona a los mexicanos es la vida familiar y le siguen la casa en que vive, su trabajo, su vida afectiva y su salud. En general, a mayor satisfacción con las oportunidades que ofrece la ciudad, mayor el promedio de satisfacción vital.

El dominio que menor satisfacción reporta es la situación económica personal, junto con la educación que se tiene y la relación con amigos. Cincuenta por ciento de los encuestados informó dificultades para sobreponerse emocionalmente a situaciones difíciles; $27 \%$ no está satisfecho con su vida social, $42 \%$ no tiene empatía por las personas de su ambiente, 29\% mantiene relaciones de amistad insatisfactorias, y $35 \%$ cree que sus amigos no son recíprocos. En general, los mexicanos no consideran que las políticas públicas repercutan en su bienestar personal. Las brechas de satisfacción vital más amplias corresponden a los nada y muy satisfechos con las oportunidades de integración social, de trabajo y de un mejor ingreso (Millán, 2014).

Los diferentes enfoques aceptan que el estudio de la calidad de vida debe ser integral, es decir, combinar métodos cuantitativos y cualitativos, o bien, objetivos y subjetivos. No obstante, las dimensiones, variables e indicadores son distintos por país o región y se depende de la disponibilidad de bases de datos que cumplan cri- 
terios de confiabilidad y comparabilidad. El levantamiento de encuestas es muy costoso; por ello, cuando es posible, se recurre, por ejemplo, a información secundaria o bases de microdatos de tipo censal.

\section{FENÓMENOS LIMITANTES PARA UNA MEJOR CALIDAD DE VIDA}

Los avances en la calidad de vida suponen la reducción de fenómenos, como la desigualdad y la pobreza, e implican la superación de rezagos sociales en marginación, exclusión, segregación, segmentación, vulnerabilidad, inseguridad o discriminación. En general, se acepta que los parámetros de calidad de vida se deben adecuar a las condiciones socioeconómicas específicas de cada país, pero también existen algunos umbrales internacionales considerados "metas sociales deseables", como los objetivos de desarrollo del milenio (ODM) y los objetivos de desarrollo sostenible (ODS). En este sentido, el papel del Estado resulta fundamental para lograr esas mejorías, en el marco de un contrato que incluye la participación de los actores sociales (públicos y privados) bajo un Estado Social de Derechos. En el contexto anterior, algunos fenómenos son expresiones de la violación de derechos humanos socioeconómicos y culturales, o factores que limitan avances en la calidad de vida; entre ellos, se pueden mencionar algunos con sus dimensiones y métodos de medición correspondientes (cuadro 1-8).

\section{DERECHO A LA CIUDAD Y JUSTICIA SOCIOESPACIAL}

Los diferentes enfoques que analizan la calidad de vida y la desigualdad en el territorio o en el espacio se relacionan de forma esencial con los postulados de justicia. Los principios de la justicia social que consideran juicios éticos y morales se aplicaron a principios de la geografía, con superación de la visión de objetividad y neutralidad positivista de esta ciencia, al ofrecer propuestas para la planificación urbana y regional, y lograr la trascendencia hacia un diálogo multidisciplinario. A partir de la justicia social, se propone la justicia distributiva territorial para atender demandas conflictivas y asignar ingresos y beneficios de manera justa en diferentes escalas espaciales.

En el marco del capitalismo, existen mecanismos que generan diferentes modalidades de desigualdad, distribuciones territoriales injustas como en la concentración de la riqueza, la escasez, la explotación de algunos territorios por otros o un sistema de intercambio desigual en precios. En las visiones marxistas ortodoxas, se 
Cuadro 1-8

Limitantes para la mejoría de la calidad de vida

\begin{tabular}{|c|c|c|}
\hline Fenómeno & Dimensión & Método de medición \\
\hline \multirow{3}{*}{ Desigualdad } & Dotación de recursos & $\begin{array}{l}\text { Distribución del ingreso entre personas, } \\
\text { hogares y territorios }\end{array}$ \\
\hline & Desigualdad & Índices tipo Gini, Theil, Atkinson, FGT, etc. \\
\hline & Desigualdad & Métodos subjetivos \\
\hline \multirow{4}{*}{ Pobreza } & Biológica & Nutrición \\
\hline & Ingreso & Método indirecto-Línea de pobreza \\
\hline & Necesidades básicas & $\begin{array}{l}\text { Necesidades básicas insatisfechas } \\
\text { (salud, educación, vivienda y entorno) }\end{array}$ \\
\hline & Multidimensional & Multidimensional integrado \\
\hline \multirow{3}{*}{ Marginación } & Ámbito ecológico y geográfico & $\begin{array}{l}\text { Provisión de infraestructura } \\
\text { y servicios públicos }\end{array}$ \\
\hline & $\begin{array}{l}\text { Marginalidad económica, laboral y } \\
\text { educativa }\end{array}$ & Inserción al mercado laboral \\
\hline & Reserva de mano de obra & Empleo y desempleo \\
\hline \multirow{3}{*}{ Exclusión } & $\begin{array}{l}\text { Quiebre de vínculos individuales, } \\
\text { comunitarios y sociales }\end{array}$ & $\begin{array}{l}\text { Indicadores de redes sociales, funcionales } \\
\text { y culturales }\end{array}$ \\
\hline & Procesos de causalidad múltiple & Derechos de ciudadanía \\
\hline & Institucionalidad & Derechos económicos, sociales y culturales \\
\hline \multirow{3}{*}{ Segmentación } & $\begin{array}{l}\text { Dualismo laboral } \\
\text { y sectorial }\end{array}$ & Estructura económica y mercado laboral \\
\hline & Escaso capital humano & Eficiencia y eficacia educativas \\
\hline & Desigualdad socioespacial & Segregación residencial \\
\hline \multirow{3}{*}{ Inseguridad } & Espacios públicos & Incidencia delictiva \\
\hline & Barrios pobres & Marginación \\
\hline & Movilidad intraurbana & Flujos origen y destino \\
\hline \multirow{3}{*}{ Discriminación } & $\begin{array}{l}\text { Mecanismos implícitos o explícitos } \\
\text { de discriminación por género, etnia, } \\
\text { discapacidad o edad }\end{array}$ & Factores de diferenciación de las personas \\
\hline & $\begin{array}{l}\text { Construcción cultural de la desigual- } \\
\text { dad discriminación }\end{array}$ & Ciclo de vida y acceso a los recursos \\
\hline & $\begin{array}{l}\text { División discriminatoria del trabajo } \\
\text { doméstico, comunitario y social }\end{array}$ & Uso del tiempo y oportunidades \\
\hline \multirow{3}{*}{ Vulnerabilidad } & $\begin{array}{l}\text { Inseguridad y riesgos de personas, } \\
\text { familias o grupos ante las crisis }\end{array}$ & Disponibilidad y tipo de activos \\
\hline & Incapacidad de respuesta & Estrategias de uso de activos \\
\hline & Dificultad de adaptación & Aprovechamiento de oportunidades \\
\hline
\end{tabular}

FGT, Foster-Greer-Thorbecke.

Fuente: Elaboración propia. 
afirmaba que primero debían derrumbarse las condiciones estructurales del capitalismo, por lo que la lucha por la justicia era secundaria, no obstante, han avanzado otras nociones que no esperan al cambio del sistema, como las formuladas desde la filosofía política donde destacan el derecho a la ciudad propuesto por Lefevre, la justicia social territorial por Harvey, la justicia ambiental desarrollada desde la ecología política, o bien, los modelos de eficacia espacial y de asignación de recursos elaborados desde la geografía cuantitativa con el apoyo de sistemas de información geográfica para apoyar la planeación orientada a mejorar la calidad de vida de la población.

En una primera formulación de corte marxista interesada en la injusticia generada por el proceso de urbanización, se propone la justicia social territorial en la cual se considera que: "la distribución del ingreso debería ser tal que: a) sean cubiertas todas las necesidades de la población dentro de cada territorio; $b$ ) sean asignados recursos a fin de minimizar los efectos multiplicadores regionales (reforzamiento de las externalidades positivas), y c) sean invertidos recursos suplementarios para contribuir a superar dificultades especiales provenientes del medio físico y social"; asimismo que "[...] los mecanismos (institucionales, organizativos, políticos y económicos) deben ser tales que las perspectivas de los territorios menos aventajados sean las más favorables posible" (Harvey, 1977).

En la geografía moral, inspirada en la justicia liberal de Rawls, se afirma que los conflictos sociales por la distribución del valor son las causas que explican las estructuras espaciales del bienestar humano en diferentes escalas geográficas; por ello, en términos metodológicos es necesario estimar índices, como el de acceso a los servicios públicos para la satisfacción de las necesidades sociales, con el objeto de formular alternativas a la redistribución de los recursos (Smith, 1994).

En la geografía cuantitativa útil para fines de planeación, se consideran tres conceptos de justicia que orientan la toma de decisiones sobre la localización y la asignación de la infraestructura y el equipamiento para mejorar la calidad de vida de la población: a) la eficacia espacial, entendida como la minimización de las distancias entre la oferta de un servicio y su demanda; $b$ ) la justicia espacial, que se refiere a la distribución espacial óptima de las infraestructuras deseables; c) la justicia ambiental que remite a la localización adecuada de las infraestructuras indeseables al aumentar la distancia (Buzai y Baxendale, 2006).

Otra línea destaca la posición que pugna por la justicia socioespacial al considerar, en particular, la multidimensionalidad del espacio y la potencialidad de la ciudad como lugar de disfrute con una sociedad justa, en el marco de las normas básicas de 
la democracia, la igualdad, la ciudadanía y de un bloque jurídico que asegure los derechos humanos, cívicos, sociales, económicos, culturales y ambientales de la población, o el derecho a la ciudad (Lefevre, 1978).

En una visión posmodernista, la justicia en su sentido amplio se entiende también como la existencia de libertad, igualdad, democracia y derechos civiles, ya que es un fenómeno social, pero también un hecho espacial. La justicia y la injusticia están incrustadas en la espacialidad y se manifiestan en formas de distribución de los recursos, la estructura y la dinámica económica, los bienes y los servicios en las geografías multiescalares, donde se valoran y utilizan de modo social. La justicia socioespacial es una categoría de análisis para las ciencias sociales y constituye la manifestación territorial de las modalidades económicas y sociales de la justicia que no pueden separarse (Soja, 2010).

En este enfoque, hay injusticias espaciales sin consecuencias y con consecuencias, que se derivan de geografías exógenas de orden global, y endógenas, las cuales se expresan de manera multiescalar y que explican el surgimiento de movimientos sociales antisistémicos. Ante la injusticia socioespacial, se requiere explicar sus procesos causales como, por ejemplo, los efectos de los modelos económicos en la distribución de la riqueza, el empleo y el ingreso, o los efectos de las inversiones públicas y privadas, las políticas y los programas con efecto territorial, como los de urbanización y vivienda en la conformación de estructuras espaciales tipo centro-periferia con sesgos antipopulares, lo cual se expresa en fenómenos negativos, como marginalidad, segmentación, segregación, discriminación o vulnerabilidad, entre otros.

En resumen, la lucha por la justicia es un objetivo elemental en toda sociedad, pero adquiere mayor relevancia ante el aumento de la desigualdad socioeconómica derivada del modelo de globalización capitalista neoliberal y de sus consecuencias en los territorios subnacionales. La injusticia socioespacial tiene varias expresiones, entre las cuales destacan la segregación residencial (como confinamiento involuntario de algún grupo social) y la desigual (no absoluta) distribución de recursos y servicios para atender de manera racional y digna las necesidades sociales. La justicia socioespacial, a su vez, debe ser el objetivo último de la mayoría de las políticas de desarrollo. En este sentido, el marco jurídico de derechos y la planeación urbana deben considerar la justicia distributiva como una dimensión necesaria, aunque insuficiente, para promover formas de igualdad para enfrentar las causas económicas, sociales y políticas que originan la injusticia en el territorio (Marcuse, 2008). 


\section{EL CONCEPTO OPERATIVO DE CALIDAD DE VIDA}

En el contexto anterior, la calidad de vida se define en este capítulo como la condición de bienestar general de las personas y las sociedades expresada en la satisfacción de necesidades objetivas y subjetivas en un espacio y tiempo determinados. Dicha condición es multidimensional y multifactorial, susceptible de medirse según diferentes niveles de vida ascendentes y de satisfacción de necesidades óptimas, en varias escalas territoriales, sociedades y momentos en el tiempo.

La calidad de vida se expresa en tres ámbitos: a) el humano, que incluye factores psicológico, social, demográfico, económico, político, cultural, tecnológico y ambiental; b) el espacial, que considera diferentes escalas territoriales, la movilidad y la conectividad, y c) el temporal, el cual puede ser estático o dinámico.

Al respecto, las necesidades a satisfacer se dividen en dos grandes grupos: a) necesidades objetivas que incluyen el nivel de vida referido al ingreso o el consumo, así como las necesidades básicas, con atención especial a la alimentación, la salud, la educación, la vivienda y su entorno y b) necesidades subjetivas, es decir, las percepciones sobre el grado de satisfacción, felicidad y aspiraciones de las personas. Si bien hay umbrales mínimos y universales de bienestar, también es cierto que por arriba de ellos hay diferencias relativas en cada sociedad y en momentos determinados. En ese sentido, en este libro se aportan varios elementos sobre la calidad de vida objetiva y su contraste con la subjetiva.

\section{BIBLIOGRAFÍA}

Alguacil, Julio (2008), "Espacio público y espacio político. La ciudad como el lugar para las estrategias de participación", Revista Polis, vol. 7, núm. 20, pp. 199-223.

Allardt, Erick (1998), "Tener, amar, ser: una alternativa al modelo sueco de investigación sobre el bienestar", en Martha Nussbaum y Amartya Sen (comps.), La calidad de vida, México, Fondo de Cultura Económica, pp. 126-143.

Buzai, Gustavo y Baxendale, Claudia (2006), Análisis socioespacial con sistemas de información geográfica, Buenos Aires, Lugar Editorial.

Comisión Económica para la América Latina (2000), “Panorama social de América Latina, 19992000", Santiago de Chile, CEPAL. (2013), "Consenso de Montevideo sobre población y desarrollo", Primera reunión de la Conferencia Regional sobre Población y Desarrollo en América Latina y el Caribe, Montevideo, CEPAL. 
Council of Europe (2005), "Concerted development of social cohesion indicators. Methodological", guide. http://book.coe.int.

Diener, Edward (2013), “¿Por qué las sociedades necesitan la felicidad y cuentas nacionales de bienestar?" en Universidad Popular Autónoma del Estado de Puebla, Ranking de la felicidad en México, 2012, México, UPAEP, pp. 13-31.

Doyal, Len y Gough, Ian (1994), Teoría de las necesidades humanas, Madrid, Icaria-FUHEM.

Easterlin, Richard A. (2013), "Bienestar subjetivo y políticas públicas" en Universidad Popular Autónoma del Estado de Puebla, Ranking de la felicidad en México, 2012, México, UPAEP, pp. 55-97.

Economist Intelligence Unit (2012), "Quality of life", http://www.economist.com/media/pdf/ QUALITY_OF_LIFE.pdf

Erikson, Robert (1998), "Descripciones de la desigualdad: el enfoque sueco de la investigación sobre el bienestar" en Martha Nussbaum y Amartya Sen (comps.), La calidad de vida, México, Fondo de Cultura Económica, pp. 101-120.

Gildenberger, Carlos (2008), "Desarrollo y calidad de vida", mundolatino.org/i/política/descalvi.htm.

Hagerty, Michael, et al (2001), "Quality of life indexes for national policy: Review and agenda for research", Social Indicators Resarch, núm. 55, pp.:1-96.

Harvey, David (1977), Urbanismo y desigualdad social, Madrid, Siglo XXI España.

INEGI (2015), "Módulo de bienestar autorreportado 2015, BIARE, documento metodológico", http://internet.contenidos.inegi.org.mx/contenidos/Productos/prod_serv/contenidos/espanol/bvinegi/productos/nueva_estruc/702825075415.pdf

Jaramillo, Máximo (2016), "Mediciones de bienestar subjetivo y objetivo: ¿complemento o sustituto?", Acta Sociológica, mayo-agosto, núm. 70, pp. 49-71.

Land, Kenneth, et al (2012), "The development and evolution of research on social indicators and quality of life (QOL)", en Kenneth Land, et al (eds.), Handbook of social indicators and quality of life research, New York, Springer, pp. 1-22.

Lefèvre, Henry (1978), El derecho a la ciudad, Barcelona, Ediciones Península.

Leva, Germán (2005), Indicadores de calidad de vida urbana. Teoría y metodología, Quilmes, Universidad Nacional de Quilmes.

Marcuse, Peter (2008), "La justice spatiale: à la fois résultante et cause de l'injustice sociale", Justice spatiale, www.jssj.org.

Maslow, Abraham (1943), "A theory of human motivation", Psychological Review, núm. 50, pp. 370-396.

Max-Neef, Manfred, et al (1998), Desarrollo a escala humana, Conceptos, aplicaciones y algunas reflexiones, $2^{\text {a }}$ ed., Barcelona, Editorial Nordan-Comunidad, Icaria Editorial. 
(2003), "Desarrollo a escala humana", http://www.ecoportal.net/Temas-Especiales/Desarrollo-Sustentable/Desarrollo_a_Escala_Humana.

Mercer (2016), "Quality of living worldwide city rankings, 2016", https://www.imercer.com/ content/mobility/quality-of-living-city-rankings.html.

Millán, René (2014), "El bienestar como el nuevo "objeto" del progreso. Cinco reflexiones" en Mariano Rojas (coord.), La medición del progreso y del bienestar, propuestas desde América Latina, Foro Consultivo Científico y Tecnológico, A. C., México, pp. 19-28.

Nussbaum, Martha (1993), "Virtudes no relativas: un enfoque aristotélico", en Martha Nussbaum y Amartya Sen, La calidad de vida, México, Fondo de Cultura Económica.

Orellana, Arturo (2014), Indicador calidad de vida urbana, Santiago de Chile, Núcleo de Estudios Metropolitanos, Instituto de Estudios Urbanos, Universidad de Chile y Cámara Chilena de la Construcción.

Organización de la Naciones Unidas (1961), Definición y medición internacional del nivel de vida, Guía provisional, Nueva York, ONU.

(1976), "Pacto internacional de derechos económicos, sociales y culturales", A/RES/2200 A (XXI), 16 de diciembre. http://www.cinu.org.mx/onu/documentos/pidesc.htm.

(2016), "Los objetivos de desarrollo sostenible y la iniciativa de ciudades prósperas", http:// unhabitat.org/los-objetivos-de-desarrollo-sostenible-y-la-iniciativa-de-ciudades-prosperas.

Organization for Economic Co-operation and Development (2016), "Better life index. Country reports", http://stats.oecd.org/Index.aspx?DataSetCode=BLI.

Programa de Naciones Unidas para el Desarrollo (1990), Desarrollo humano, Informe 1990, Bogotá, Tercer Mundo Editores.

Sánchez, Adolfo (2012), "Las teorías de la justicia distributiva" en Francisco Hernández (coord.), Geografía y pobreza, México, Centro Regional de Investigaciones Multidisciplinarias-Universidad Nacional Autónoma de México, pp. 25-50.

Smith, David (1994), Geography and social justice, Oxford, Blackwell.

Soja, Edward W. (2010), Seeking spatial justice, Minneapolis, University of Minnesota Press.

Unión Europea (2001), "Conclusiones de la Presidencia, Consejo Europeo de Laeken", Gotemburgo 15 y 16 de junio, Unión Europea.

Universidad Popular Autónoma del Estado de Puebla (2013), Ranking de la felicidad en México, 2012, México, UPAEP.

Veenhoven, Ruut (2013), "Mayor felicidad para más personas. ¿Es esto posible en México?" en Universidad Popular Autónoma del Estado de Puebla, Ranking de la felicidad en México, 2012, México, UPAEP, pp. 33-53. 



\section{Marco jurídico para la justicia socioespacial en la zona metropolitana del Valle de México}

Adolfo Sánchez Almanza

\section{INTRODUCCIÓN}

El estudio de la calidad de vida se ubica en un contexto jurídico que obliga a su mejoría con el cumplimiento de los derechos sociales por los estados. Al respecto, existen varios lineamientos internacionales y nacionales que conforman un amplio bloque legal, entre los cuales se mencionan a continuación los más relevantes.

\section{LAS DECLARACIONES UNIVERSALES DE DERECHOS}

La Organización de las Naciones Unidas (ONU) y otros organismos afines asumen que el objetivo principal del proceso de desarrollo es la búsqueda de sociedades más equitativas y democráticas; por ello es prioritaria la vigencia de los derechos, tanto los de primera generación o civiles y políticos, como los de segunda generación o económicos, sociales y culturales, o los de tercera generación relacionados con aspectos ambientales, de sustentabilidad y de género. Estos derechos tienen como soporte valores fundamentales, como la libertad, la igualdad, la solidaridad y la ausencia de discriminación; asimismo, en la "Declaración del milenio" se agregan la tolerancia, el respeto de la naturaleza y la responsabilidad común.

La ONU, en el artículo 22 de la Declaración Universal de los Derechos Humanos, establece que: "Toda persona, como miembro de la sociedad, tiene derecho a la seguridad social y a obtener, mediante el esfuerzo nacional y la cooperación internacional, habida cuenta de la organización y los recursos de cada Estado, la satisfacción de los derechos económicos, sociales y culturales, indispensables a su 
dignidad y al libre desarrollo de su personalidad" (Organización de la Naciones Unidas, 1948).

Los derechos económicos, sociales y culturales, por su parte, constituyen normas aceptadas por la mayoría de los gobiernos del mundo con legitimidad en el sistema internacional y en sus respectivas Constituciones. ${ }^{1}$

En el "Pacto internacional de derechos económicos, sociales y culturales" (PIDESC) en su artículo $2^{\circ}$, fracción 1; se señala que:" [...] cada uno de los Estados Partes en el presente Pacto se compromete a adoptar medidas, tanto por separado como mediante la asistencia y la cooperación internacionales, especialmente económicas y técnicas, hasta el máximo de los recursos de que disponga, para lograr progresivamente, por todos los medios apropiados, inclusive en particular la adopción de medidas legislativas, la plena efectividad de los derechos aquí reconocidos" (Organización de la Naciones Unidas, 1976).

En el artículo 11, fracción 1, se establece que "Ios Estados Partes [...] reconocen el derecho de toda persona a un nivel de vida adecuado para sí y su familia, incluso alimentación, vestido y vivienda adecuados, y a una mejora continua de las condiciones de existencia. Los Estados Partes tomarán medidas apropiadas para asegurar la efectividad de este derecho, reconociendo a este efecto la importancia esencial de la cooperación internacional fundada en el libre consentimiento" (ibid.).

En el marco del PIDESC, se recomienda garantizar los derechos por parte de los Estados, su exigibilidad con un marco jurídico que determine su contenido y obligaciones. En este enfoque, se transita de metas políticas a derechos de las personas y se superan los argumentos sobre la escasez de fondos fiscales; además, se señala que no todos los derechos requieren un presupuesto adicional. El Pacto establece la progresividad del gasto social, con mejorías efectivas en el bienestar, con redistribución y reducción de brechas socioeconómicas que conduzcan hacia un umbral deseable, de manera independiente de las condiciones iniciales.

En América Latina y el Caribe, en el "Protocolo de San Salvador" (1998), se agregaron: el derecho a un ambiente sano, los derechos de la niñez, los derechos de protección a los ancianos y a los minusválidos. Ante la falta de cumplimiento de los derechos económicos, sociales y culturales, los derechos civiles y políticos perderán sentido para los sectores con menores recursos y más bajos niveles de educación e información. En otras palabras, la democracia carece de sentido cuando no hay mejoría en la calidad de vida de los ciudadanos (Diario Oficial de la Federación, 1998).

\footnotetext{
${ }^{1}$ Firmaron 133 países el PIDESC y México lo ratificó en 1981.
} 
El camino hacia la equidad atraviesa por el establecimiento de ciertos mínimos factibles para la realización de los derechos económicos, sociales y culturales (DESC), y requiere de la combinación de voluntades para construir una política de desarroIlo sustentada en derechos con base en un sistema económico, social y político que ofrezca gobernabilidad. No obstante, en las diferentes definiciones de derechos subsiste el problema de establecer los mínimos necesarios a satisfacer por los miembros de una sociedad, así como los mecanismos y la parte que le corresponde a las esferas responsables de otorgarlos, es decir, el Estado, el mercado, la familia y las organizaciones civiles. Este dilema se resuelve en el contrato social que caracteriza a cada sociedad, sin embargo, los estados nacionales están comprometidos a cumplir con lo establecido en los pactos internacionales y en su marco constitucional, así como a informar sobre sus avances o retrocesos.

Los derechos humanos se violan cuando no se cumple con la protección de los habitantes, por acción u omisión, y es el Estado el responsable de garantizarlos. El incumplimiento de los derechos a alimentación, salud, educación, vivienda, seguridad social, trabajo, etc., significa perder el derecho a la vida porque la consecuencia es hambre, desnutrición, morbilidad, mortalidad, pobreza, exclusión social y violencia, lo cual significa un enorme costo socioeconómico que, en la lógica económica, también reduce la competitividad de países y regiones.

En la "Declaración Universal de los Derechos Humanos", se reconocía el "Derecho al techo" en condiciones de salubridad en el marco del derecho a la salud. Con el tiempo esa concepción se superó y dio paso al "Derecho a la vivienda digna" con asentamientos humanos sustentables que se consolidó en los foros mundiales urbanos deVancouver en 1976 y de Estambul en 1996, en el marco de los "Derechos Económicos, Sociales y Culturales"; asimismo, se agregaron la "Carta Europea de Salvaguarda de los Derechos Humanos en la Ciudad" del año 2000 y el "Estatuto de la Ciudad" de Brasil en el año 2001. En las cumbres mundiales de ciudades de onu-Hábitat, se instituyó el "Derecho a la ciudad"; en el 2005, se adoptó la "Carta mundial por el derecho a la ciudad" $y$, en el 2006, la "Carta de Derechos y Responsabilidades" de Montreal. A su vez, en el "Foro Urbano Mundial de Río de Janeiro" del año 2010, se expidió "El derecho a la ciudad. Reduciendo la brecha urbana", con un enfoque que incluye el usufructo equitativo de la ciudad bajo principios de sustentabilidad y justicia social. Asimismo, los "Objetivos de desarrollo sostenible" hacia el año 2030 establecen, en su objetivo 11, que las ciudades deben ser inclusivas, seguras, resilientes y sostenibles, y se formula la idea de prosperidad urbana (Organización de las Naciones Unidas-Hábitat, 2015 y 2016). 
Los lineamientos internacionales han superado la idea de vivienda digna en su versión intradoméstica y establecen una ruta hacia el derecho a un entorno próximo y remoto adecuado, al desarrollo y la realización efectiva de los derechos vinculados con la participación en la toma de decisiones colectivas asociada con la ciudadanía. Además, se consideran las dimensiones físicas, económicas, sociales, ambientales, políticas y culturales, en general, el espacio social e imaginario que habita el ser humano, con reivindicaciones de identidad y creación del espacio físico y cultural.

El derecho a la ciudad es interdependiente entre la población, los recursos, el medio ambiente, las relaciones económicas y la calidad de vida; busca soluciones a los efectos negativos de la globalización, la privatización, la escasez de recursos naturales, el aumento de la pobreza y la fragilidad ambiental, y significa el ejercicio pleno de la ciudadanía en tanto el resultado es la dignidad y el bienestar colectivo. Los derechos a la vivienda, al agua, la movilidad, el transporte, la energía, entre otros, crean condiciones de desarrollo colectivo y de solidaridad para hacer un usufructo pleno de la ciudad. Los principios del derecho a esta última son la preservación de la identidad cultural, el reconocimiento de formas de convivencia pacífica, la realización de producción social del hábitat y la organización para la acción; todo ello para la construcción de una gestión democrática donde los diversos actores se fortalezcan en su autonomía, en que prevalezca el interés común sobre el derecho individual de propiedad, lo cual implica el uso socialmente justo y sustentable desde el punto de vista ambiental.

En esta línea, se aprobó la "Carta de la Ciudad de México por el derecho a la ciudad". Este último constituye un derecho humano colectivo que se define como el usufructo equitativo de las ciudades dentro de los principios de sustentabilidad y justicia socioespacial. En general, la ciudad es un espacio de realización de todos los derechos humanos civiles, políticos, económicos, sociales, culturales y ambientales, y los sujetos de los derechos son todos los habitantes de la misma. Se trata de alcanzar una ciudad democrática, incluyente, sostenible, productiva, educadora, habitable, innovadora, segura, saludable, convivencial, con diversidad y justicia culturales, entre otros fines (Comité Promotor, 2010).

Esta visión adquiere una enorme relevancia en el marco de la "Constitución Política de la Ciudad de México", así como por la compleja realidad metropolitana con una expansión física y funcional sujeta a una delimitación politicoadministrativa que aplica derechos diferenciados a poblaciones semejantes, con lo cual se generan formas de discriminación y, en general, se merma el ejercicio de los derechos más avanzados, tal como se observa en la ZMVM. 
El derecho a la ciudad implica poner por adelante el bien público sobre los intereses privados y, aunque es un aspecto central, no se limita solo a la vivienda, el suelo y el entorno próximo, sino que incluye el equipamiento social, el espacio público y la movilidad para todos los residentes en cualquier lugar de la ciudad; asimismo, considera el aumento de la productividad y la innovación científica-tecnológica, el crecimiento y la calidad del empleo, la sustentabilidad ambiental, la cultura y la participación ciudadana en la gestión de la ciudad. Las mejorías en la calidad de vida pasan por el cumplimiento de estos derechos.

\section{LOS DERECHOS SOCIOESPACIALES EN LA LEGISLACIÓN NACIONAL}

La "Constitución Política de los Estados Unidos Mexicanos" establece los grandes principios y derechos sociales que deben regir a la sociedad. El título primero, capítulo I de los Derechos Humanos y sus Garantías, en el artículo $1^{\circ}$ de la Constitución establece que:

[...] todas las personas gozarán de los derechos humanos reconocidos en esta Constitución y en los tratados internacionales de los que el Estado Mexicano sea parte, así como de las garantías para su protección, cuyo ejercicio no podrá restringirse ni suspenderse, salvo en los casos y bajo las condiciones que esta Constitución establece. Las normas relativas a los derechos humanos se interpretarán de conformidad con esta Constitución y con los tratados internacionales de la materia favoreciendo en todo tiempo a las personas la protección más amplia. Todas las autoridades, en el ámbito de sus competencias, tienen la obligación de promover, respetar, proteger y garantizar los derechos humanos de conformidad con los principios de universalidad, interdependencia, indivisibilidad y progresividad. En consecuencia, el Estado deberá prevenir, investigar, sancionar y reparar las violaciones a los derechos humanos, en los términos que establezca la ley (Cámara de Diputados, 2016).

En otros artículos constitucionales, se destaca el compromiso social del Estado. Entre estos sobresalen, el artículo $3^{\circ}$, que establece el carácter laico y gratuito de la educación, su orientación científica, democrática, nacionalista, con respeto a la cultura, la dignidad de la persona y la integridad de la familia; el artículo $4^{\circ}$ que consigna la igualdad de género, la libertad de procreación, la protección de la salud, el derecho a la vivienda digna y decorosa, la satisfacción de necesidades y la salud física, y el 
artículo 123, sobre los derechos de los trabajadores y el empleo socialmente útil. La Constitución establece los grandes derechos de la sociedad que se orientan a alcanzar un nivel digno de calidad de vida.

La "Ley general de desarrollo social" de México establece, en su artículo 3, varios principios importantes para la mejoría de la calidad de vida y la justicia socioespacial, entre ellos:

[...] II. Justicia distributiva: garantiza que toda persona reciba de manera equitativa los beneficios del desarrollo conforme a sus méritos, sus necesidades, sus posibilidades y las de las demás personas; III. Solidaridad: colaboración entre personas, grupos sociales y órdenes de gobierno, de manera corresponsable para el mejoramiento de la calidad de vida de la sociedad; IV. Integralidad: articulación y complementariedad de programas y acciones que conjunten los diferentes beneficios sociales, en el marco de la Política Nacional de Desarrollo Social; V. Participación social: derecho de las personas y organizaciones a intervenir e integrarse, individual o colectivamente en la formulación, ejecución y evaluación de las políticas, programas y acciones del desarrollo social; VI. Sustentabilidad: preservación del equilibrio ecológico, protección del ambiente y aprovechamiento de recursos naturales, para mejorar la calidad de vida y la productividad de las personas, sin comprometer la satisfacción de las necesidades de las generaciones futuras (Cámara de Diputados, 2004).

En su título segundo de los "Derechos y las obligaciones de los sujetos del desarrollo social", en su artículo $6^{\circ}$, se señala que "[...] son derechos para el desarrollo social la educación, la salud, la alimentación, la vivienda, el disfrute de un medio ambiente sano, el trabajo y la seguridad social y los relativos a la no discriminación en los términos de la Constitución Política de los Estados Unidos Mexicanos" (ibid.).

En el título tercero referido a la "Política nacional de desarrollo social", capítulo I De los Objetivos, artículo $11^{\circ}$, se define la Política nacional de desarrollo social que tiene los siguientes objetivos:

I. Propiciar las condiciones que aseguren el disfrute de los derechos sociales, individuales o colectivos, garantizando el acceso a los programas de desarrollo social y la igualdad de oportunidades, así como la superación de la discriminación y la exclusión social; II. Promover un desarrollo económico con sentido social que propicie y conserve el empleo, eleve el nivel de ingreso y mejore su 
distribución; III. Fortalecer el desarrollo regional equilibrado, y IV. Garantizar formas de participación social en la formulación, ejecución, instrumentación, evaluación y control de los programas de desarrollo social" (ibid.).

En el caso de la "Ley General de Asentamientos Humanos" del año 1993, se establecía en su artículo $3^{\circ}$ "[...] el ordenamiento territorial de los asentamientos humanos y el desarrollo urbano de los centros de población tenderán a mejorar el nivel y la calidad de vida de la población urbana y rural" (Diario Oficial de la Federación, 2014). Asimismo, se mencionaban varios aspectos con implicaciones socioespaciales que eran pertinentes para este trabajo (con consideración de los datos del 2010 sobre calidad de vida aquí analizados), en los incisos siguientes:

I. La vinculación del desarrollo regional y urbano con el bienestar social de la población; II. El desarrollo socioeconómico sustentable del país, armonizando la interrelación de las ciudades y el campo y distribuyendo equitativamente los beneficios y cargas del proceso de urbanización; [...] IV. La adecuada interrelación socioeconómica de los centros de población; [...] VII. La descongestión de las zonas metropolitanas; VIII. La protección del patrón de asentamiento humano rural y de las comunidades indígenas; IX. La eficiente interacción entre los sistemas de convivencia y de servicios en los centros de población; X. La creación y el mejoramiento de condiciones favorables para la relación adecuada entre zonas de trabajo, vivienda y recreación; XI. La estructuración interna de los centros de población y la dotación suficiente y oportuna de infraestructura, equipamiento y servicios urbanos; XII. La prevención, control y atención de riesgos y contingencias ambientales y urbanos en los centros de población; [...] XV. El ordenado aprovechamiento de la propiedad inmobiliaria en los centros de población; XVI. La regulación del mercado de los terrenos y el de la vivienda de interés social y popular; [...] XVIII. La participación social en la solución de los problemas que genera la convivencia en los asentamientos humanos; XIX. El desarrollo y adecuación en los centros de población de la infraestructura, el equipamiento y los servicios urbanos que garanticen la seguridad, libre tránsito y accesibilidad que requieren las personas con discapacidad (ibid.).

Este marco jurídico establecía principios, derechos y compromisos básicos internacionales y nacionales en materia socioespacial que conformaban un escenario con objetivos claros de justicia y mejoría del bienestar de sus habitantes, los cuales, 
además de ser derechos humanos, son acciones preventivas que evitan fenómenos antisociales, como la violencia o la delincuencia.

A su vez, en la nueva "Ley General de Asentamientos Humanos, Ordenamiento Territorial y Desarrollo Urbano", en su artículo 4², sobre planeación, regulación y gestión de los asentamientos humanos, los centros de población y la ordenación territorial, se establece que estos deben conducirse en apego a varios principios de política pública, entre los cuales destacan:

I. Derecho a la ciudad. Garantizar a todos los habitantes de un Asentamiento Humano o Centros de Población el acceso a la vivienda, infraestructura, equipamiento y servicios básicos, a partir de los derechos reconocidos por la Constitución Política de los Estados Unidos Mexicanos y los tratados internacionales suscritos por México en la materia;

II. Equidad e inclusión. Garantizar el ejercicio pleno de derechos en condiciones de igualdad, promoviendo la cohesión social a través de medidas que impidan la discriminación, segregación o marginación de individuos o grupos. Promover el respeto de los derechos de los grupos vulnerables, la perspectiva de género y que todos los habitantes puedan decidir entre una oferta diversa de suelo, viviendas, servicios, equipamientos, infraestructura y actividades económicas de acuerdo a sus preferencias, necesidades y capacidades" (Diario Oficial de la Federación, 2016).

Asimismo, se consideran los principios de: derechos a propiedad urbana, Coherencia y racionalidad, participación democrática y transparencia, productividad y eficiencia, protección y progresividad del espacio público, resiliencia, seguridad urbana y riesgos, sustentabilidad ambiental y accesibilidad universal y movilidad.

Esta obligatoriedad jurídica aplica a los tres órdenes de gobierno que coexisten en la ZMVM, pero también hay leyes y programas estatales complementarios como los que se mencionan más adelante.

\section{LA DELIMITACIÓN DE LA ZONA METROPOLITANA DEL VALLE DE MÉXICO}

La Ciudad de México se ha desarrollado con procesos de expansión física y funcional que han conformado una gran zona metropolitana en un espacio megalopolitano, para crear un sistema complejo con diferentes problemáticas y ordenamientos jurídicos. En la evolución de la capital del país, se han rebasado las fronteras políticas-ad- 
ministrativas estatales y municipales o delegacionales, entendidas como ejercicios hegemónicos de poder que delimitan el espacio y que generan diferencias o formas de exclusión social, cultural, económica o jurídica. No obstante, hay varias modalidades de integración con flujos de personas, bienes o servicios entre el centro y los intersticios periurbanos que superan las fronteras jurídicas formales y plantean retos para la igualdad de la población.

La ZMVM se define con tres delimitaciones recientes, las cuales se revisaron para adoptar la utilizada en esta investigación. La primera delimitación se define como el ámbito inmediato de influencia socioeconómica y física-espacial de la Zona Urbana del Valle de México, en el "Programa de Ordenación de la Zona Metropolitana de la Ciudad de México" del año 1991. En este documento, se consideran las 16 delegaciones del Distrito Federal, 58 municipios del Estado de México y uno (Tizayuca) del Estado de Hidalgo; se incluyeron unidades políticas-administrativas completas que podían tener una tasa baja de urbanización, pero valor ambiental alto a preservar, así como criterios de prospectiva que permiten pronosticar y planificar el desarrollo urbano en el mediano y largo plazos (Sedesol, Gobierno del Distrito Federal, Gobierno de Estado de México, 1991).

El Grupo Interinstitucional para la Delimitación de Zonas Metropolitanas estableció la segunda definición, la cual determina como zona metropolitana:

[...] al conjunto de dos o más municipios donde se localiza una ciudad de 50000 o más habitantes, cuya área urbana, funciones y actividades rebasan el límite del municipio que originalmente la contenía, incorporando como parte de sí misma o de su área de influencia directa a municipios vecinos, predominantemente urbanos, con los que mantiene un alto grado de integración socioeconómica. También se incluyen a aquellos municipios que por sus características particulares son relevantes para la planeación y política urbanas de las zonas metropolitanas en cuestión. Adicionalmente, se define como zonas metropolitanas a todos aquellos municipios que contienen una ciudad de 1 millón o más habitantes, así como aquellos con ciudades de 250000 o más habitantes que comparten procesos de conurbación con ciudades de Estados Unidos de América (Sedesol, Conapo e INEGI, 2012: 28).

Este grupo, con base en estas definiciones y criterios, identificó, para el año 2010, un total de 76 municipios en la ZMVM: 16 delegaciones del Distrito Federal, 59 municipios del Estado de México y un municipio del estado de Hidalgo, es decir, 
confirmó la delimitación previa. La clasificación indica que 52 delegaciones y municipios centrales están conurbados de forma física, y 24 municipios son exteriores, de los cuales, siete presentan integración funcional y 17 se consideran metropolitanos por el criterio de política y planeación urbana.

La tercera delimitación se encuentra en el "Programa de Ordenación de la Zona Metropolitana del Valle de México", elaborado por el "Programa Universitario de Estudios sobre la Ciudad" de la Universidad Nacional Autónoma de México (UNAM) (Programa Universitario de Estudios sobre la Ciudad, 2011). En este documento que aprobaron de manera oficial los gobiernos de las tres entidades federativas, se señala que la ZMVM "[...] comprende las 16 delegaciones políticas-administrativas del Distrito Federal, 59 municipios conurbados del Estado de México y 21 del Estado de Hidalgo" (Sedesol, Gobierno del Distrito Federal, Gobierno de Estado de Hidalgo y Gobierno del Estado de México, 2012). Esta definición amplía la metrópoli a un total de 96 unidades politicoadministrativas, la cual coincide en general con el escenario prospectivo hacia el año 2030 y ofrece circunstancias adecuadas para la comprobación de las hipótesis de investigación del autor (capítulo. 3).

La Ciudad de México ha evolucionado hacia una gran metrópoli en el marco del proceso de urbanización nacional. La población de la ciudad pasó de 345 mil habitantes en el año 1900, a 1049000 habitantes en 1930, con un área urbanizada de $63 \mathrm{~km}^{2}$ y una densidad de 16757 habitantes por kilómetro cuadrado; hacia el año 1970 ya en su proceso de metropolización, alcanzó 8657000 ha-

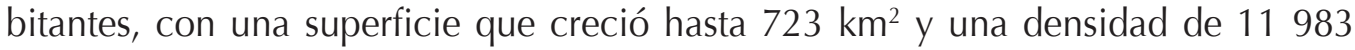
habitantes por kilómetro cuadrado. En el 2010, la ZMVM contaba con una población de 20865000 habitantes y una superficie urbanizada de $1460 \mathrm{~km}^{2}$, y una densidad promedio de 14288 por kilómetro cuadrado. La población de la Ciudad de México aumentó de manera constante su participación relativa en la población nacional hasta 1980 (20.55\% del total), para estabilizarse en los años siguientes (18.57\% en 2010); mientras que creció en la población urbana del país hasta 1950 y luego disminuyó, pero manteniéndose en un nivel alto de cerca de $30 \%$ del total, lo cual expresa su gran fuerza de concentración aun en el marco del modelo de apertura comercial (cuadro 2-1).

\section{MARCOS JURÍDICOS SOCIALES}

\section{La Ciudad de México}

En la Ciudad de México (antes Distrito Federal), se han aplicado varias políticas socioculturales, económicas y ambientales consideradas de vanguardia en el país 
Cuadro 2-1

México y Zona Metropolitana del Valle de México (ZMVM). Población, superficie y densidad, 1900 a 2010

\begin{tabular}{|c|c|c|c|c|c|c|c|c|}
\hline \multirow{3}{*}{ Año } & \multicolumn{3}{|c|}{ Población nacional } & \multicolumn{2}{|c|}{$\begin{array}{c}\text { Población de Ciudad } \\
\text { de México-ZMVM/po- } \\
\text { blación nacional }\end{array}$} & \multicolumn{3}{|c|}{ Ciudad de México-ZMVM } \\
\hline & Censal & Urbana & $\begin{array}{c}\text { Urbanal } \\
\text { Censal }\end{array}$ & Censal & Urbana & Población & $\begin{array}{c}\text { Área } \\
\text { urbana }\end{array}$ & Densidad \\
\hline & $\begin{array}{c}\text { Miles de } \\
\text { habitantes }\end{array}$ & $\begin{array}{c}\text { Más de } 15 \\
\text { mil habi- } \\
\text { tantes }\end{array}$ & Porcentaje & Porcentaje & Porcentaje & $\begin{array}{c}\text { Miles de } \\
\text { habitantes }\end{array}$ & $K m^{2}$ & $\begin{array}{l}\text { Habitan- } \\
\text { tes } / \mathrm{Km}^{2}\end{array}$ \\
\hline 1900 & 13607 & 1437 & 10.56 & 2.54 & 24.01 & 345 & 12 & 28727 \\
\hline 1910 & 15160 & 1783 & 11.76 & 3.11 & 26.42 & 471 & 14 & 34384 \\
\hline 1921 & 14335 & 2100 & 14.65 & 4.62 & 31.52 & 662 & 46 & 14269 \\
\hline 1930 & 16553 & 2891 & 17.47 & 6.34 & 36.29 & 1049 & 63 & 16757 \\
\hline 1940 & 19649 & 3928 & 19.99 & 7.94 & 39.71 & 1560 & 118 & 13275 \\
\hline 1950 & 25779 & 7210 & 27.97 & 11.57 & 41.36 & 2982 & 263 & 11349 \\
\hline 1960 & 34923 & 13512 & 38.69 & 14.76 & 38.15 & 5155 & 417 & 12366 \\
\hline 1970 & 48225 & 22731 & 47.14 & 17.95 & 38.08 & 8657 & 723 & 11983 \\
\hline 1980 & 66847 & 36740 & 54.96 & 20.55 & 37.38 & 13735 & 891 & 15413 \\
\hline 1990 & 81250 & 51491 & 63.37 & 18.52 & 29.22 & 15048 & 1295 & 11620 \\
\hline 2000 & 97483 & 65653 & 67.35 & 18.87 & 28.02 & 18397 & 1400 & 13140 \\
\hline 2010 & 112337 & 70179 & 62.47 & 18.57 & 29.73 & 20865 & 1460 & 14287 \\
\hline
\end{tabular}

Fuente: Elaboración propia con base en: INEGI, 2010 y Sánchez, 2004.

Nota: En el año 2010 se consideran 96 municipios y delegaciones.

y en el exterior, entre otras razones por: la fuerte presencia histórica de diferentes fuerzas políticas; ser sede de los poderes federales; poseer gran importancia económica, un alto nivel educativo que favorece el debate de ideas, y un amplio número de medios y redes de comunicación; así como por la participación de los ciudadanos ante la toma de decisiones.

En el caso del marco jurídico que rige la política social en la Ciudad de México, éste cuenta con algunos rasgos específicos y mantiene algunas diferencias importantes en relación con la establecida e implementada por el gobierno federal, como los que se citan a continuación. Al respecto, destaca la "Ley de Desarrollo Social del Distrito Federal" que consigna varios principios rectores: universalidad, igualdad, equidad de género, equidad social, justicia distributiva, diversidad, integralidad, territorialidad, exigibilidad, participación, transparencia y efectividad. En su artículo $3^{\circ}$, fracción $\mathrm{VI}$, se define el desarrollo social como "[...] el proceso de realización 
de los derechos de la población mediante el cual se fomenta el mejoramiento integral de las condiciones y calidad de vida" (Asamblea Legislativa del Distrito Federal, 2000).

En esta Ley, cabe señalar el principio de justicia distributiva que se define como: "la obligación de la autoridad a aplicar de manera equitativa los programas sociales, priorizando las necesidades de los grupos en condiciones de pobreza, exclusión y desigualdad social" (ibid.).

En el artículo $1^{\circ}$, se definen objetivos en materia socioespacial:

II. Promover, proteger y garantizar el cumplimiento de los derechos sociales universales de los habitantes del Distrito Federal en particular en materia de alimentación, salud, educación, vivienda, trabajo e infraestructura social; III. Disminuir la desigualdad social en sus diversas formas, derivada de la desigual distribución de la riqueza, los bienes y los servicios, entre los individuos, grupos sociales y ámbitos territoriales; Iv. Integrar las políticas y programas contra la pobreza en el marco de las políticas contra la desigualdad social; [...] VI. Revertir los procesos de exclusión y de segregación socio-territorial en la ciudad; [...] IX. Contribuir a construir una sociedad con pleno goce de sus derechos económicos, sociales y culturales; [...] XII. Articular el desarrollo social, el urbano y el rural; XIII. Coadyuvar al reconocimiento y ejercicio del derecho a la ciudad (ibid.).

En el mismo sentido, en el artículo $3^{\circ}$, fracción XIV de la Ley, se define la política de desarrollo social como:

[...] la que realiza el Gobierno del Distrito Federal y está destinada al conjunto de los habitantes del Distrito Federal con el propósito de construir una ciudad con igualdad, equidad, justicia social, reconocimiento de la diversidad, alta cohesión e integración social, pleno goce de los derechos, creciente elevación de la calidad de vida y acceso universal al conjunto de bienes y servicios públicos urbanos; mediante la cual se erradican la desigualdad y la exclusión e inequidad social entre individuos, grupos y ámbitos territoriales con el fin de lograr su incorporación plena a la vida económica, social y cultural y construirse como ciudadanos con plenos derechos (ibid.).

Este posicionamiento ofrece el marco para el diseño, la operación, la instrumentación y la evaluación de resultados de las políticas y los programas. A su vez, en la 
Ley se destaca el concepto de pobreza definida en la fracción XV como: "[...] la incapacidad de un individuo o un hogar de satisfacer de manera digna y suficiente sus necesidades básicas en materia de alimentación, salud, educación, vivienda, transporte, recreación, servicios y tiempo libre" (ibid.).

En general, existe la intención de contribuir a la construcción de una sociedad con pleno goce de sus derechos económicos, sociales y culturales, en línea con el PIDESC, así como disminuir la desigualdad social en sus diversas formas, derivada de la distribución inequitativa de la riqueza, los bienes y los servicios, entre individuos, grupos sociales y, en particular, en los ámbitos territoriales.

Para lograr estos objetivos resulta importante la medición y la localización espacial del bienestar social, al considerar que, si bien aplica el principio de universalidad que implica derechos para todos los habitantes de la ciudad cuando, por razones presupuestales, un programa no pueda lograr en sus primeras fases la plena universalidad, se optará por la focalización territorial para delimitar un ámbito socioespacial en el cual se aplicará a todos los habitantes de dicho territorio que reúnan las características del programa específico. Es decir, la "focalización" se entiende como un proceso gradual de cumplimiento de derechos, y no como la aplicación restrictiva de la política social hacia los grupos en pobreza extrema.

En este contexto, hay unidades territoriales prioritarias debido a que su población tiene una calidad de vida menor y debe atenderse para alcanzar los principios de justicia distributiva e igualdad. Este marco jurídico para la planeación ofrece un modelo en el diseño y la implementación de las políticas públicas en la Ciudad de México que sirve de contraste respecto de los estados de Hidalgo y de México.

A su vez, la Constitución Política de la Ciudad de México considera una gama amplia de derechos de la población y reitera el derecho a la ciudad. En su artículo $4^{\circ}$, en relación con la protección de los derechos humanos, establece que: "Las autoridades adoptarán medidas para la disponibilidad, accesibilidad, diseño universal, aceptabilidad, adaptabilidad y calidad de los bienes, servicios e infraestructura públicos necesarios para que las personas que habitan en la Ciudad puedan ejercer sus derechos y elevar los niveles de bienestar, mediante la distribución más justa del ingreso y la erradicación de la desigualdad" (Gaceta Oficial de la Ciudad de MéxiCo, 2017).

En el artículo 9०, "Ciudad solidaria, derecho a la vida digna", se afirma que "las autoridades adoptarán las medidas necesarias para que progresivamente, se erradiquen las desigualdades estructurales y la pobreza, y se promueva el desarrollo sustentable, que permita alcanzar una justa distribución de la riqueza y del ingreso entre 
personas, familias, grupos sociales y ámbitos territoriales". A su vez, en el "Derecho a la vivienda", se establece que "las autoridades tomarán medidas para que las viviendas reúnan condiciones de accesibilidad, asequibilidad, habitabilidad, adaptación cultural, tamaño suficiente, diseño y ubicación seguros que cuenten con infraestructura y servicios básicos de agua potable, saneamiento, energía y servicios de protección civil". En relación con el "Derecho al agua y a su saneamiento", se dice que "toda persona tiene derecho al acceso, a la disposición y saneamiento de agua potable suficiente, salubre, segura, asequible, accesible y de calidad para el uso personal y doméstico de una forma adecuada a la dignidad, la vida y la salud; así como a solicitar, recibir y difundir información sobre las cuestiones del agua".

En el artículo 12, sobre el "Derecho a la Ciudad", se incluyen dos grandes temas:

1. La Ciudad de México garantiza el derecho a la ciudad que consiste en el uso y el usufructo pleno y equitativo de la ciudad, fundado en principios de justicia social, democracia, participación, igualdad, sustentabilidad, de respeto a la diversidad cultural, a la naturaleza y al medio ambiente. 2 . El derecho a la ciudad es un derecho colectivo que garantiza el ejercicio pleno de los derechos humanos, la función social de la ciudad, su gestión democrática y asegura la justicia territorial, la inclusión social y la distribución equitativa de bienes públicos con la participación de la ciudadanía (ibid.).

\section{El Estado de Hidalgo}

En la Ley de Desarrollo social del Estado de Hidalgo, destacan algunos aspectos socioespaciales. En su artículo $2^{\circ}$, la Ley tiene por objeto: "I. Fomentar el desarroIlo social y humano, garantizar el pleno ejercicio de los derechos sociales y crear los mecanismos necesarios para lograr la cabal realización y concreción de los mismos" (Congreso del Estado de Hidalgo, 2006). En el artículo $3^{\circ}$, se define el desarroIlo social como: "el proceso de mecanismos y políticas públicas permanentes que generen condiciones para la incorporación plena de individuos, grupos y sectores de la sociedad, comunidades y regiones al mejoramiento integral y sustentable de sus capacidades productivas y que su calidad de vida garantice el disfrute de los derechos constitucionales, a fin de erradicar la desigualdad social" (ibid.).

En esta Ley, se menciona el principio de justicia distributiva pero entendida no como una obligación de gobierno, como en la Ciudad de México, sino como la que: "establece y garantiza que los beneficiarios reciban de manera equitativa los beneficios del desarrollo social conforme a sus necesidades" (ibid.). 
En el Estado de Hidalgo y en el Estado de México, no se menciona la universalización de los derechos como en la Ciudad de México, sino que se definen procesos de focalización en "zonas de atención prioritaria" constituidas por grupos vulnerables que se encuentren en condiciones de pobreza, a los cuales deberá beneficiarse por medio de alguna de las tres vertientes de la política social: compensatoria, de desarrollo regional y de fomento. Los grupos beneficiados por estas serán:

[...] madres solteras y jefas de familia con el objeto de generar condiciones de equidad de género; personas con discapacidad; migrantes; indígenas; jornaleros agrícolas; trabajadores de zonas urbanas y campesinos en condiciones de pobreza alimentaria y patrimonial; niñas y niños de hasta cinco años de edad, en condición de pobreza alimentaria; adultos mayores, de 70 años y más, que habiten en localidades de alta y muy alta marginación de zonas urbanas y rurales en condiciones de pobreza alimentaria o patrimonial (ibid.).

\section{El Estado de México}

La Ley de Desarrollo Social del Estado de México establece que el desarrollo social es el: "proceso de mecanismos y políticas públicas permanente que genera las condiciones para la integración plena de individuos, grupos y sectores de la sociedad, comunidades y regiones al mejoramiento integral y sustentable de sus capacidades productivas y su calidad de vida que garantice el disfrute de los derechos constitucionales, a fin de erradicar la desigualdad social"; asimismo, la política de desarrollo social la define como el "conjunto de estrategias, programas y acciones de gobierno y de la sociedad que, de manera subsidiaria e integral, articulan procesos que potencien y garanticen el desarrollo sostenible y con equidad que se transforme en bienestar y calidad de vida para la sociedad" (Poder Legislativo del Estado de México, 2004).

En esta Ley se define la justicia distributiva como la que "garantiza que toda persona reciba de manera equitativa los beneficios del desarrollo conforme a sus méritos, sus necesidades, sus posibilidades y las de las demás personas" (ibid.). Esta es una definición condicional y no obligatoria para el gobierno.

A su vez, la calidad de vida se define como el "conjunto de condiciones sociales que permiten que todos los habitantes tengan acceso a una vida más justa, equitativa y equilibrada, favoreciendo el desarrollo integral de todos y cada uno de los miembros de la comunidad" (ibid.). Y por su connotación espacial, es importante la definición de la marginación como "la condición social en la cual las personas en 
hogares pueden presentar carencias sociales y bajo ingreso, y se encuentran geográficamente fuera del acceso y disponibilidad de bienes y servicios necesarios para su desarrollo integral" (ibid.).

En general, existen disposiciones y definiciones, más o menos avanzadas, en las legislaciones de las tres entidades federativas que forman parte de la ZMVM, respecto de la obligación de los gobiernos de procurar, de manera obligatoria o no, mayor calidad de vida a la población, con consideración de su localización geográfica y enfrentando la desigualdad socioespacial bajo el principio de la justicia distributiva.

En este contexto, cabe enfatizar la necesidad de aplicar el enfoque de derechos como el más avanzado y progresista en todos los espacios de integración física y funcional del territorio, de forma independiente de los límites politicoadministrativos en la metrópoli. Asimismo, es importante mencionar algunos de los grandes problemas que enfrenta la ZMVM relacionados con la calidad de vida, los cuales constituyen un marco de referencia adecuada para la medición de ésta última.

\section{GRANDES PROBLEMAS SOCIOESPACIALES DE LA ZONA METROPOLITANA DEL VALLE DE MÉXICO}

Los objetivos sobre la calidad de vida y la justicia socioespacial metropolitana se enfrentan a una realidad heterogénea con varios problemas que constituyen limitantes y retos para las relaciones intergubernamentales, entre los cuales se pueden destacar los siguientes fenómenos.

La expansión urbana física y funcional de la ZMVM ha sido de tipo centro-periferia y ha significado rebasar los límites politicoadministrativos, lo cual ha generado una inadecuación formal y de planeación entre ambos tipos de espacio. El proceso de reestructuración urbana produjo nuevos subcentros o nodos intraurbanos, así como la ampliación de los contornos intrametropolitanos que van conformando un espacio más policéntrico, pero con graves desigualdades y rezagos sociales por la falta de atención y regulación adecuadas para el ordenamiento del territorio.

El análisis de la división social del espacio y la diferenciación intraurbana de la Zona Metropolitana de la Ciudad de México con la construcción de índices comparables y estimados mediante análisis factorial del área geoestadística básica (AGEB), entre los años 1990 y 2000, presenta varios datos que confirman un proceso de consolidación urbana y un patrón de segregación espacial con mayor centralidad de los estratos altos y donde los estratos más pobres tienden a localizarse en zonas cada vez 
más alejadas de las áreas centrales de consumo e intercambio de bienes, servicios o empleo (Rubalcava y Schteingart, 2012).

La construcción de la vivienda avanzó bajo el predominio del mercado, con procesos de privatización y especulación del espacio urbano que benefician a las desarrolladoras y las instituciones financieras, y que relegan la función social del suelo y la vivienda, y su valor de uso. La localización de las nuevas áreas de poblamiento está condicionada por el aumento de los precios en las zonas centrales con más servicios públicos y revalorizadas ("gentrificación"), y costos más bajos en las periferias rurales; esto genera, entre otros problemas, asentamientos precarios con inseguridad, ampliación de la distancia entre los lugares de residencia masivos y los destinos cotidianos por motivos de trabajo, educación, salud, ocio o por razones familiares, entre otros. Este proceso también se generó de la política de vivienda y financiamiento que favoreció las decisiones de los vendedores sobre los compradores, sin la regulación adecuada para hacer ciudad.

La desigualdad socioespacial, en general, ha aumentado y tiene en su extremo inferior a los pobres con viviendas autoproducidas o informales (de manera asociada con la informalidad laboral) localizadas en el suelo más barato, pero en lugares distantes de los núcleos urbanos, en condiciones de precariedad y hacinamiento, con falta de equipamientos y servicios públicos, en asentamientos irregulares periféricos o en zonas de riesgo, es decir, con menor calidad de vida o injusticia socioespacial, con consecuencias e incumplimiento de derechos jurídicos.

En el caso del trabajo, la ubicación de la oferta y la demanda indicaba, ya desde el año 1999, el avance de un modelo más multinodal, con un proceso de terciarización económica y de concentración del empleo en 35 subcentros definidos por AGEB, que atraían a la cuarta parte del empleo de la zona urbana de la Zona Metropolitana de la Ciudad de México, la mayoría en el Centro Histórico, en los corredores de Paseo de la Reforma, Polanco, Insurgentes centro y sur, así como el aeropuerto internacional; mientras, el resto se localizaba de manera dispersa y gradual en nodos ubicados en los sucesivos contornos intrametropolitanos, como la Central de Abasto o los que se encontraban a lo largo de la carretera a Querétaro. Hacia la periferia, se observaba un patrón disperso del empleo, aunque diferenciado según las actividades económicas de manufactura, comercio o servicios. Este patrón espacial del trabajo se combinó con la urbanización de la periferia metropolitana y la existencia de "ciudades dormitorio" lejanas de los nodos de demanda de empleo que motivan desplazamientos a mayores distancias (Aguilar y Alvarado, 2004). 
En la movilidad, se observa la inadecuación de los flujos de origen y destino que produce un incremento en los costos de transportación y la saturación de las vialidades debido a las necesidades de mayor movilidad a mayor distancia, con un modelo de transportación privado ineficaz y con carencias en el transporte público, donde los hogares terminan internalizando los costos del desorden.

En el entorno, los equipamientos y los servicios públicos, a su vez, se han rezagado ante el crecimiento de la población que aumenta la demanda por el abasto de agua, luz, drenaje, alcantarillado, escuelas, mercados, servicio de recolección de basura, transporte, seguridad pública, etc., los cuales no se satisfacen de manera eficaz ni suficiente, al ritmo necesario y de forma equitativa en el territorio.

La ZMVM enfrenta problemas ambientales, como el manejo ineficiente del agua en una cuenca cerrada con transvase del líquido desde Lerma-Cutzamala, desalojo y desperdicio de aguas limpias y sucias sin reciclar, con un uso irracional del recurso, con sobrexplotación o contaminación de sus mantos acuíferos y áreas de reserva ambiental que se deterioran, lo cual causa condiciones críticas de sustentabilidad.

Las finanzas públicas enfrentan una fuerte presión en los tres órdenes de gobierno de la ZMVM, pero existe la obligatoriedad de cumplir con los derechos de la población a mejorar su calidad de vida, con reserva del presupuesto necesario mediante un enfoque de justicia distributiva para superar las fallas de coordinación fiscal intergubernamental, sin violar los marcos jurídicos (capítulo 13).

La planeación urbana y metropolitana ha sido inútil e ineficaz en la conducción del crecimiento de la ZMVM, pero los grandes problemas acumulados obligan a revisar los aciertos y las fallas para adelantarse al futuro previsto. El Estado tiene un papel fundamental en materia de regulación del mercado, como en el caso del control y la redistribución de las plusvalías, con instrumentos de financiamiento y apoyo técnico para la construcción de la vivienda social y para intervenir el hábitat, donde el suelo urbano sea un bien social cuyo disfrute esté al alcance de toda la población. Hacer ciudades sustentables y resilientes implica que la vivienda sea el acto de habitar y no una mercancía final, donde la calidad de vida sea semejante en el territorio (Ortiz, 2012).

Entre los estudios que analizan los diferentes problemas metropolitanos están algunos que miden la desigualdad o el bienestar socioespacial de manera objetiva, con un conjunto de variables e indicadores, en escala nacional y en sentido negativo, como los siguientes: el "Índice de marginación por entidad federativa y municipio" de la Coordinación General del Plan Nacional de Zonas Deprimidas y Grupos Marginados (Coplamar) para el año de 1970 (Coplamar, 1982); los “Índices de marginación 
por entidad federativa, municipio, localidad y AGEB" de Conapo (Conapo, 2012); las estimaciones de "Pobreza por ingresos e índice de rezago social por entidad federativa y municipio del Consejo Nacional de Evaluación de la Política de Desarrollo Social (Coneval)" (Coneval, 2012); el "Índice de masa carencial" estimado para asignar el Fondo de Aportaciones de Infraestructura Social en el artículo $34^{\circ}$ de la "Ley de Coordinación Fiscal" por entidad federativa (Diario Oficial de la Federación, 2016). En sentido positivo, se encuentran los "Índices de desarrollo humano por entidad federativa y municipio" realizados por el Programa de las Naciones Unidas para el Desarrollo (PNUD) (Programa de las Naciones Unidas para el Desarrollo-México, 2014).

La Ciudad de México, a su vez, cuenta con varios estudios, como el Atlas socioeconómico y de marginación por "manzana" realizado por el Gobierno del Distrito Federal (Gobierno del Distrito Federal, Coordinación de Planeación del Desarrollo Territorial, 2003); los "Índices de desarrollo social de las unidades territoriales (delegaciones-colonias-manzanas) del Distrito Federal, 2005, 2010 y 2015", elaborados por el Consejo de Evaluación del Desarrollo Social del Distrito Federal-EvalúaDF (2011, 2012 y 2016).

Entre los trabajos que analizan el bienestar subjetivo, se encuentran: la "Encuesta de calidad de vida", del Centro de Estudios sobre el Bienestar de la Universidad de Monterrey (CEBUM) y el Centro de Estudios Sociales y de Opinión Pública (CESOP) de la Cámara de Diputados de México (2008), y el "Reporte de indicadores sobre calidad de vida, Así vamos en Jalisco", del Observatorio Ciudadano (2011 y 2012). Asimismo, el periódico El Universal patrocinó los trabajos de “Cómo vamos, Ciudad de México?", en los cuales clasificó indicadores objetivos por municipio y delegación, y aplicó la "Encuesta de percepción ciudadana de calidad de vida en la Ciudad de México", que incluyó 121 preguntas agrupadas en 13 categorías, con 3 000 entrevistas a personas de 15 años de edad y mayores, residentes en el Distrito Federal y 36 municipios del Estado de México, y presentó varios ensayos sobre el tema. Este tipo de trabajos se han realizado en varias ciudades de América Latina y se creó la "Red Latinoamericana por Ciudades Justas, Democráticas y Sustentables".

Como se puede observar, existe una amplia gama de investigaciones orientadas a conocer el bienestar de la población y cada uno aporta diferentes elementos para su comprensión. La diferencia principal con los contenidos de este libro radica en que aquí se estima un índice de calidad de vida comparable y desagregado para tres escalas metropolitanas, a partir de las bases censales de microdatos, lo cual permite verificar hipótesis causales con énfasis en su manifestación socioespacial. 


\section{BIBLIOGRAFÍA}

Aguilar, Guillermo y Alvarado, Concepción (2004), "La reestructuración del espacio urbano de la Ciudad de México. ¿Hacia una metrópoli multinodal?" en Guillermo Aguilar (coord.), Procesos metropolitanos y grandes ciudades. Dinámicas recientes en México y otros países, México, UNAM, Cámara de Diputados, Miguel Ángel Porrúa.

Asamblea Legislativa del Distrito Federal (2000), "Ley de Desarrollo Social para el Distrito Federal", Gaceta Oficial del Distrito Federal, 23 de mayo, México.

Cámara de Diputados (2004), "Ley general de desarrollo social", Diario Oficial de la Federación, 20 de enero, México.

_ (2011), "Ley de Coordinación Fiscal", Diario Oficial de la Federación, 27 de octubre, México.

_ (2016), "Constitución Política de los Estados Unidos Mexicanos", Diario Oficial de la Federación, 27 de enero, México.

Centro de Estudios sobre el Bienestar de la Universidad de Monterrey (CEBUM) y el Centro de Estudios Sociales y de Opinión Pública (CESOP) de la Cámara de Diputados de México (2008), "Encuesta de calidad de vida", México, CEBUM-CESOP.

Comité Promotor (2010), "Carta de la Ciudad de México por el derecho a la ciudad", file:///C:/ Users/Adolfo/AppData/Local/Microsoft/Windows/INetCache/IE/RPDPLKJN/CartadelaCiudaddeMexico.pdf.

Congreso del Estado de Hidalgo (2006), "Ley de desarrollo social del Estado de Hidalgo", Periódico Oficial, 29 de diciembre, Pachuca de Soto.

Consejo de Evaluación del Desarrollo Social del Distrito Federal-EvalúaDF (2011), "Índice de desarrollo social de las unidades territoriales (delegaciones-colonias-manzanas) del Distrito Federal, 2005", México.

_ (2012), Índice de desarrollo social de las unidades territoriales (delegaciones-colonias-manzanas) del Distrito Federal, 2010, México. (2016), "Índice de desarrollo social de las delegaciones del Distrito Federal, 2015", México.

Consejo Nacional de Evaluación (2012), "Evolución de la pobreza por ingresos, 1990-2010", México, http://www.coneval.gob.mx.

Consejo Nacional de Población (2012), "Índices de marginación 2010", México http://www. conapo.gob.mx.

Jefatura de Gobierno de la Ciudad de México "Constitución Política de la Ciudad de México" (2017), Gaceta Oficial de la Ciudad de México, 5 de febrero, México.

Coordinación General del Plan Nacional de Zonas Deprimidas y Grupos Marginados (1982), Geografía de la marginación, Necesidades esenciales de México, México, Siglo XXI. 
Diario Oficial de la Federación (1998), "Protocolo adicional a la convención americana sobre derechos humanos en materia de derechos económicos, sociales y culturales 'Protocolo de San Salvador'", $1^{\circ}$ de septiembre, México, Diario Oficial de la Federación. (2014), "Ley general de asentamientos humanos", 24 de enero, México.

(2016), "Ley general de asentamientos humanos, ordenamiento territorial y desarrollo urbano", 28 de noviembre, México. (2016), "Ley de coordinación fiscal", 18 de julio, México.

Gobierno del Distrito Federal, Coordinación de Planeación del Desarrollo Territorial (2003), Distrito Federal, Atlas socioeconómico y de marginación por manzana, México, GDF.

INEGI (2010), Manual de cartografía geoestadística, México, INEGI.

Observatorio Ciudadano (2011), ¿Cómo nos vemos los tapatíos?, Encuesta de percepción ciudadana de calidad de vida en el Área Metropolitana de Guadalajara, 2011 en Jalisco. Cómo vamos. Observatorio Ciudadano, Jalisco.

Observatorio Ciudadano (2012), "Así vamos en Jalisco, Reporte de indicadores sobre calidad de vida, 2012", en David Gómez Álvarez (ed.), Jalisco. Cómo vamos, Jalisco, Observatorio Ciudadano .

Organización de la Naciones Unidas (1948), Declaración universal de los derechos humanos, 10 de diciembre, Nueva York, ONU.

(1976), "Pacto internacional de derechos económicos, sociales y culturales", Doc. A/6316 (1966), 993 U.N.T.S. 3, Nueva York, ONU.

Organización de la Naciones Unidas-Hábitat (2015), "Diálogo sobre el tema especial del 25º periodo de sesiones del Consejo de Administración", HSP/GC/25/4, 2 de febrero.

_ (2016), "Hábitat III. New Urban Agenda, Draft outcome document for adoption in Quito", en United Nation Conference on Housing and Sustainable Urban Department, octubre, Quito, ONU-Hábitat.

Ortiz, Enrique (2012), Producción social de la vivienda y el hábitat. Bases conceptuales y correlación con los procesos habitacionales, México, HIC-AL.

Poder Legislativo del Estado de México (2004), "Ley de desarrollo social del Estado de México", Periódico Oficial Gaceta de Gobierno, 31 de diciembre.

Programa de la Naciones Unidas para el Desarrollo en México (2014), Índice de Desarrollo Humano Municipal en México: nueva metodología, México, PNUD.

Programa Universitario de Estudios sobre la Ciudad (2011), Programa de ordenación de la Zona Metropolitana del Valle de México, México, PUEC- UNAM y Fondo Metropolitano del Valle de México, 423 pp.

Rubalcava, Rosa María y Schteingart, Martha (2012), Ciudades divididas. Desigualdad y segregación social en México, México, El Colegio de México. 
Sánchez, Adolfo (2004), Panorama histórico de la Ciudad de México, México, Instituto de Investigaciones Económicas, UNAM, Gobierno del Distrito Federal, Miguel Ángel Porrúa.

Sedesol, Conapo e INEGI (2012), Delimitación de las zonas metropolitanas de México 2010, México, Grupo Interinstitucional para la Delimitación de Zonas Metropolitanas, p. 28.

Sedesol, Gobierno del Distrito Federal, Gobierno del Estado de Hidalgo y Gobierno del Estado de México (2012), "Programa de ordenación de la Zona Metropolitana del Valle de México, Actualización 2012", Síntesis Ejecutiva, México, Sedesol-GDF-GEH-GEM.

Sedesol, Gobierno del Distrito Federal, Gobierno del Estado de México (1991), Programa de ordenación de la Zona Metropolitana del Valle de México, México, Sedesol-GDF-GEM. 


\section{Prospectiva de la Zona Metropolitana del Valle de México}

Roberto Ramírez Hernández

\section{INTRODUCCIÓN}

El estatus jurídico del territorio específico que hasta hace poco se llamaba "Distrito Federal" cambio a "Ciudad de México", pero este nombre resulta incomprensible desde cualquier enfoque si no se consideran las otras partes integrantes del territorio urbano metropolitano, donde los municipios conurbados desempeñan un papel clave en su desarrollo económico, social y político. Ante ello, surgen algunas preguntas: ¿qué sucederá a partir de la expansión de la Ciudad de México y su zona metropolitana en el futuro?, ¿qué implicaciones de orden político y jurídico tendrían para su funcionamiento algunos procesos inevitables, como sus crecimientos económico y demográfico, y su expansión física?

En este capítulo se analizan las tendencias en la conformación de la Zona Metropolitana de la Ciudad de México (ZMVM) hacia el 2040, mediante el uso de un modelo formal prospectivo que se vale de técnicas de simulación espacio-temporal. El modelo coadyuvará a identificar los posibles requerimientos de política de desarrollo urbano a partir de conocer una probable zona metropolitana en el año 2040.

\section{ELEMENTOS METODOLÓGICOS PARA LA CONSTRUCCIÓN DEL MODELO PROSPECTIVO TERRITORIAL PARA LA ZONA METROPOLITANA DEL VALLE DE MÉXICO}

\section{Prospectiva y prospectiva territorial}

La prospectiva territorial, análisis poco desarrollado aun, permite establecer (mediante modelos ya sea de corte cuantitativo o cualitativo, o bien simplemente con el uso de información detallada y ordenada) escenarios futuros sobre un territorio, esto es, 
plantear los posibles cambios en el tiempo en términos físicos, económicos, políticos, sociales o de cualquier naturaleza. El ejercicio de observar los futuros probables no se concibe únicamente como pronósticos; en realidad implica la construcción de un escenario, esto es, de una descripción completa de atributos asociados e interrelacionados con el objeto de estudio, que en términos espaciales se denomina prospectiva territorial.

Para la realización de un ejercicio de prospectiva territorial es posible usar una amplia gama de métodos y técnicas: desde enfoques cualitativos donde la experiencia personal del que construye los escenarios es indispensable (y en la medida que más se conozca sobre el tema de interés, mejor calidad tendrá el ejercicio prospectivo), hasta enfoques cuantitativos donde las herramientas matemáticas (en especial las de corte estadístico) permiten la construcción de escenarios futuros en que la proyección de datos se basa en parámetros probabilísticos y, desde luego, en valores medidos en periodos anteriores, con lo cual es posible tener control sobre la precisión de cada dato estimado.

Por otro lado, para realizar un ejercicio de prospectiva en el ámbito territorial es necesario involucrar otros recursos metodológicos en los que el territorio físico quede representado de forma adecuada. De allí que la prospectiva territorial implique esfuerzos metodológicos adicionales a la prospectiva en general, esto es, se incorpora una dimensión adicional a la temporal, es decir, la dimensión espacial.

Las técnicas de simulación constituyen una de las principales herramientas para la realización de un ejercicio de prospectiva territorial, de allí que se revisen a continuación algunos conceptos importantes, asociados con la simulación de sistemas.

\section{Simulación, concepto de sistema y autómatas celulares}

Para la investigación, se diseñó un método cuantitativo con base en herramientas de simulación; asimismo, se empleó la técnica de "autómatas celulares" (AC) con el fin de darle a la simulación una dimensión territorial.

"La simulación es una técnica numérica para conducir experimentos en una computadora digital mediante gráficos, animación y otros dispositivos tecnológicos, la cual involucra ciertos tipos de modelos matemáticos y lógicos que describen el comportamiento de un sistema (o algún componente de este) durante un cierto periodo de tiempo" (González Videgaray, 1996).

Otra definición dice: "La simulación de un sistema o un organismo es la operación de un modelo, el cual es una representación del sistema u organismo. El modelo puede ser manipulado de formas que serían imposibles, demasiado costosas o imprácticas en la entidad real. La operación del modelo puede estudiarse para inferir propiedades concernientes al sistema real" (Shubik, 1960). 
La simulación es una herramienta de análisis cada vez más utilizada. En la medida que se comprende de forma cabal su utilidad, esta se incorpora en nuevos campos de conocimiento. Hoy día, no solo la física, la química y la ingeniería emplean este enfoque metodológico, también disciplinas como la biología, la sociología, la demografía y la economía han recurrido a sus bondades.

De manera específica, para el crecimiento de ciudades hay poca literatura pues su uso es incipiente; no obstante, es posible encontrar algunos casos de aplicación. Entender cómo implementar la simulación y, más importante aun, cuándo hacerlo, es una cuestión de comprender los elementos en torno al diseño de estos modelos. A continuación se enuncian algunos de ellos.

\section{Concepto de sistemas y elementos que lo constituyen}

Simular un fenómeno implica necesariamente conocer las partes integrantes e interrelacionarlas para analizar su comportamiento general. Por este motivo, todo fenómeno debe verse como un sistema y conocer sus elementos integrantes.

Un "sistema" es un conjunto de elementos interrelacionados entre sí y que funcionan con un objetivo común (González Videgaray, 1996). Para comprender de modo cabal un sistema, es indispensable conocer los parámetros de un sistema:

1. Componente: cualquier parte importante del sistema (un sistema puede tener varios componentes).

2. Atributo: se refiere a las propiedades de cualquier componente del sistema (un componente puede tener varios atributos).

3. Actividad: cualquier proceso que causa cambios en el sistema.

4. Estado del sistema: descripción de componentes, atributos y actividades de un sistema, en un determinado periodo de tiempo (Prawda W., 1988).

Todo sistema se encuentra enmarcado dentro de otro mayor que le sirve como marco de referencia. A este macrosistema se le conoce como "marco ambiental" o "medio amniótico". Un buen sistema debe contar con un modo de retroalimentación, esto es, una manera de vigilancia del comportamiento con respecto a ciertos estándares de medición. Así, será factible tomar medidas para controlar el sistema si este incurre en alguna desviación.

\section{Simulación y pasos generales}

Un "modelo de simulación" es en esencia un diseño representativo del sistema en 
observación, que en condiciones controladas reproduce su comportamiento para observar la interacción de sus partes. Se basa casi siempre en un modelo matemático para describir comportamientos del sistema y las relaciones entre sus componentes. Un modelo matemático establece relaciones y comportamiento mediante ecuaciones, identidades, variables y funciones matemáticas. Los pasos generales en la ejecución de un modelo de simulación son:

- Formulación del problema

- Conceptualización del modelo

- Obtención y procesamiento de los datos

- Elaboración del modelo matemático

- Estimación de los parámetros del modelo

- Implementación del modelo

- Evaluación del modelo

- Validación de resultados y calibración de parámetros

- Diseño de experimentos de simulación

- Análisis de resultados y conclusiones

- Recomendaciones

Los pasos no necesariamente son secuenciales, pero deben ser iterativos, de manera que sea posible calibrar el modelo (ajuste de parámetros) tantas veces como se requiera (González Videgaray, 1996).

\section{Simulación con la técnica de Montecarlo}

Los modelos de simulación reproducen el comportamiento de un sistema de acuerdo con diversas relaciones entre variables que a su vez conforman los atributos de dicho sistema. El conjunto de relaciones se expresa en un modelo matemático diseñado para tales efectos. No obstante, muchos sistemas requieren de componentes aleatorios, esto es, que muchos de sus comportamientos y atributos son azarosos o es imposible expresarlos mediante una relación matemática de tipo analítico o determinístico.

Para delinear de forma adecuada los comportamientos al azar, es necesario usar números aleatorios que alimenten ciertas partes del modelo. Al generar tales números e integrarlos al modelo de simulación, se emplea la técnica de Monte Carlo. ${ }^{1}$ De

${ }^{1}$ El término "análisis o técnica de Monte Carlo" se utilizó por primera vez de manera científica en una publicación sobre procesos estocásticos de Nicholas Metropolis y S. Ulam en 1949. El término "Monte Carlo" fue un nombre en código usado en la segunda guerra mundial para cálculos ul- 
ahí que siempre deba tenerse en cuenta un método para la generación de números aleatorios, los cuales a su vez deben asociarse con una variable aleatoria, misma que por definición obedece a una función de distribución probabilística. La manera de generar los números aleatorios debe involucrar esta función de distribución y desde luego una variable aleatoria.

\section{Autómatas celulares: concepción y aplicación}

La metodología de los $\mathrm{AC}^{2}$ consiste en calcular el estado de un píxel o celda en función de un estado inicial, considerar las condiciones en los pixeles circundantes (interacción o influencia de la vecindad espacial), así como un conjunto de reglas de transición. El algoritmo puede ser simple, pero quizá se produzca un comportamiento mucho más complejo y variado (Wolfram, 1986).

Los AC son de uso cada vez más común dada su facilidad para tomar en cuenta las interacciones espaciales entre unidades territoriales. Se han utilizado en estudios de desarrollo urbano por (Clarke y Gaydos, 1998; White et al., 1997; Wu y Webster, 1998; Li y Yeh, 2000), pero además se han aplicado en modelos de uso del suelo capaces de simular varios tipos de este último (White y Engelen, 2000).

\section{Aplicación de autómatas celulares en modelos de simulación urbana}

Los modelos tradicionales de crecimiento urbano, basados en el cambio de uso de suelo por medio de Ac, consideran como variables clave en la simulación más o menos los mismos elementos:

trasecretos que se realizaban con el fin de predecir el flujo de neutrones en una bomba atómica. El flujo de millones de electrones con caminos aleatorios a través de una masa de moléculas de uranio sólo puede modelarse en una computadora y es imposible pronosticarlo de manera teórica. Como los caminos de los neutrones varían al azar y dado que la construcción de la bomba atómica era una gigantesca apuesta, se dio a los cálculos el nombre en código de "Monte Carlo", porque esta es la capital del principado de Mónaco, el centro mundial de las apuestas (ganar la guerra era la gran apuesta) (González Videgaray, 1996).

${ }^{2}$ Los "autómatas celulares" surgen en los años cincuenta con John von Neumann. En primera instancia, se interpretaron como conjuntos de células que crecían, se reproducían y morían a medida que pasaba el tiempo. A esto se debe su nombre, a la similitud con el crecimiento de las células. Los "autómatas celulares" son un tipo de simulación que se compone de elementos muy simples: una cuadrícula con cuadrados que pueden adoptar distintos colores y pasos discretos de tiempo. En cada lapso que pasa, el AC evoluciona con base en reglas muy simples. El nuevo valor (color) de una celda se calcula a partir de la actual y sus vecinas. Esto se lleva a cabo para todas las celdas al mismo tiempo (Gómez, s.f.). 
- Los niveles de accesibilidad dada la red de transporte

- El uso de suelo previamente establecido

- Las características físicas del territorio, como la pendiente del terreno, el tipo de suelo, los cuerpos de agua existentes y las restricciones politico-administrativas a la urbanización en ciertas áreas, entre otras.

Tal es el caso de modelos muy consolidados, como el Sleuth (Slope, Land use, Exclusion, Urban extent, Transportation, Hillshade), que Keith C. Clarke desarrolló en la Universidad de California. Los requisitos de este modelo clásico son el uso de suelo en cuatro periodos, la red de transporte, el suelo restringido por políticas, el porcentaje de pendiente del terreno urbanizable y la especificación de barreras naturales, como colinas, montañas y cerros. La mayoría de los modelos creados en todo el mundo mediante AC utilizan estos mismos parámetros.

Un estudio muy interesante en torno a la aplicación de AC para modelos de crecimiento urbano es el de Roger White, quien combinó las bondades de la metodología AC, los requerimientos tradicionales de información de entrada al modelo, con la inclusión de la influencia que la estructura policéntrica de una ciudad tiene en la expansión; asimismo, se estiman las cantidades de población y empleo en industria, comercio y servicios en las celdas territoriales.

Por otro lado, Liu y Phinn (2004) plantearon el uso de una función matemática que permitiera "regular" el ritmo de crecimiento global de una ciudad en tanto, de manera simultánea, se determina el uso de suelo por celda territorial. Con este planteamiento, ponderan las etapas de crecimiento de una ciudad, de forma específica a través de funciones logísticas, de manera que, si se simulan las etapas iniciales de una ciudad, el ritmo de crecimiento es lento, en la segunda etapa se acelera y, en la tercera y última, de nuevo se alenta.

\section{Modelos de simulación urbana y uso de autómatas celulares en ciudades mexicanas}

En México, no se ha desarrollado una tradición de modelos de crecimiento urbano y mucho menos basados en AC. Algunos trabajos de modelos de expansión urbana se realizan a través de otros enfoques. Suárez y Delgado (2007), por ejemplo, pronostican la probable expansión de la Ciudad de México al 2020 a través de un modelo sustentado en regresión logística binomial y asistencia de sistemas de información geográfica con el área geoestadística básica (AGEB), donde señalan las zonas de mayor probabilidad de urbanización, esto es, "urbanización sí" o "urbanización no" únicamente, por lo cual no es un modelo de cambio de uso de suelo en el sentido general 
del término. No obstante, sí es un precedente en modelos de expansión urbana para la Ciudad de México. Las variables empleadas son:

- Distancia a vías primarias de transporte

- Distancia a la localidad urbana más cercana

- Población

- Porcentaje de inclinación del territorio

- Número de empleos de industria en el municipio

- Número de empleos de servicios en el municipio

- Ingreso mediano municipal

- Proporción de hectáreas con riego dedicadas a la agricultura

A su vez, el gobierno de la ciudad de Monterrey posee un modelo cuya función es pronosticar el crecimiento y la expansión de la ciudad y prevé requerimientos de servicios urbanos. Pérez-Miranda et al, 2011. aplican AC al área de Texcoco para predecir el cambio de uso de suelo al 2014, no solo urbano sino los distintos usos naturales, como pastizal, bosque, áreas mineras, y otros. Tal vez el único antecedente directo de un modelo de expansión urbana basado en AC para una ciudad mexicana sea el de Márquez L. (2008), quien propone el uso del conocido modelo Sleuth para Ciudad Juárez en Chihuahua, y que pronostica su expansión hacia el año 2030. En este modelo, se emplean las variables típicas que requiere Sleuth para su operación correcta: uso de suelo en este caso en seis periodos (1973, 1986, 1992, 1999, 2003 y 2007), la red de transporte, el suelo restringido por políticas, el porcentaje de pendiente del terreno urbanizable y la especificación de barreras naturales, como colinas, montañas y cerros.

\section{Construcción del modelo para la Ciudad de México y su zona metropolitana}

El modelo a construir debe contar con un recorrido en cada unidad espacial o territorial, donde se determinen primero las nuevas áreas urbanas y luego se calcule si dicha unidad cambiará de uso de suelo y cuál sería el nuevo. Para la definición de los usos de suelo del modelo, se utilizó el análisis contenido en la publicación de Ramírez H. (2016b).

Por último, se estimarán las nuevas cantidades de población, vivienda y empleo a través de técnicas de interpolación. Cada cantidad calculada y el uso de suelo determinado estarán en función de las características asociadas con la unidad espacial en específico. Dichas características se expresarán en variables previamente construidas. Por 
este motivo, los atributos mencionados han de explicar qué nuevas áreas se urbanizan, cómo quedan definidos los usos de suelo y las cifras de población, vivienda y empleo que existirán en cada recorrido, mismo que se entiende como un ciclo o un periodo.

La unidad espacial o territorial corresponde a la "celda territorial", misma que se explica a continuación. Dado que el modelo será para el cambio de uso de suelo mediante la metodología de AC, deben considerarse las unidades como elementos de una matriz de renglón "i" y una columna "j". Para este efecto, cada unidad territorial de observación se denomina "celda territorial" (CT). De ahí que el conjunto de celdas territoriales represente todo el territorio de estudio (en este caso, el Valle de México) en una cuadrícula o malla (gráfica 3-1).

El uso de celdas territoriales iguales para observar el crecimiento de la Ciudad, en lugar de utilizar las unidades politicoadministrativas típicas (municipios, delegaciones, AGEB o "manzanas" urbanas) tiene la gran ventaja de analizar el proceso de crecimiento y expansión en unidades iguales y con suficiente desagregación espacial; por ello, la observación se facilita de modo enorme. ${ }^{3}$

Por otra parte, las celdas permiten analizar con mayor detenimiento la influencia espacial de cada una, en particular si tiene información relevante en cuanto a posible expansión. Para el caso específico del modelo para la Ciudad de México y su zona metropolitana y mediante el uso en ArcGIS los datos bajo la vertiente "ráster", se definieron celdas territoriales cuyo tamaño físico es equivalente a un cuadrado perfecto de 250000 metros cuadrados (500 metros x 500 metros). Dado que el modelo utiliza un sistema de información geográfica (SIG) visual, las CT se representan en un sistema de modelo "ráster" en ArcView 10. En total se cuenta con 52459 Cт que cubren la ZMVM mediante una rejilla de 251 renglones por 209 columnas.

El diseño, construcción y resultados completos del modelo pueden consultarse en (Ramírez H., 2016a). Se presentan a continuación algunos de sus principales hallazgos.

\footnotetext{
${ }^{3}$ Es importante recordar que unidades politico-administrativas, como los municipios o las delegaciones políticas, son estables en el tiempo, es decir, con pocas posibilidades de que se redefinan como área y, por tanto, de que alteren de forma sensible la información estadística asociada. No obstante, tienen la gran desventaja de poseer una gran agregación espacial; por ende, son poco útiles en un análisis detallado. Las AGEB y las manzanas urbanas son más eficaces para un análisis desagregado, pero presentan el gran inconveniente de su inestabilidad en el tiempo, pues el marco geoestadístico a nivel de la AGEB o la "manzana" urbana, o ambas, cambia de manera importante cada periodo censal. De ahí que surjan nuevas AGEB o manzanas urbanas y que desaparezcan otras tantas en cantidades notablemente altas, lo cual genera obstáculos en el análisis de la información en el tiempo.
} 


\section{Gráfica 3-1}

Representación de la malla o conjunto de celdas territoriales construidas para la Zona Metropolitana del Valle de México

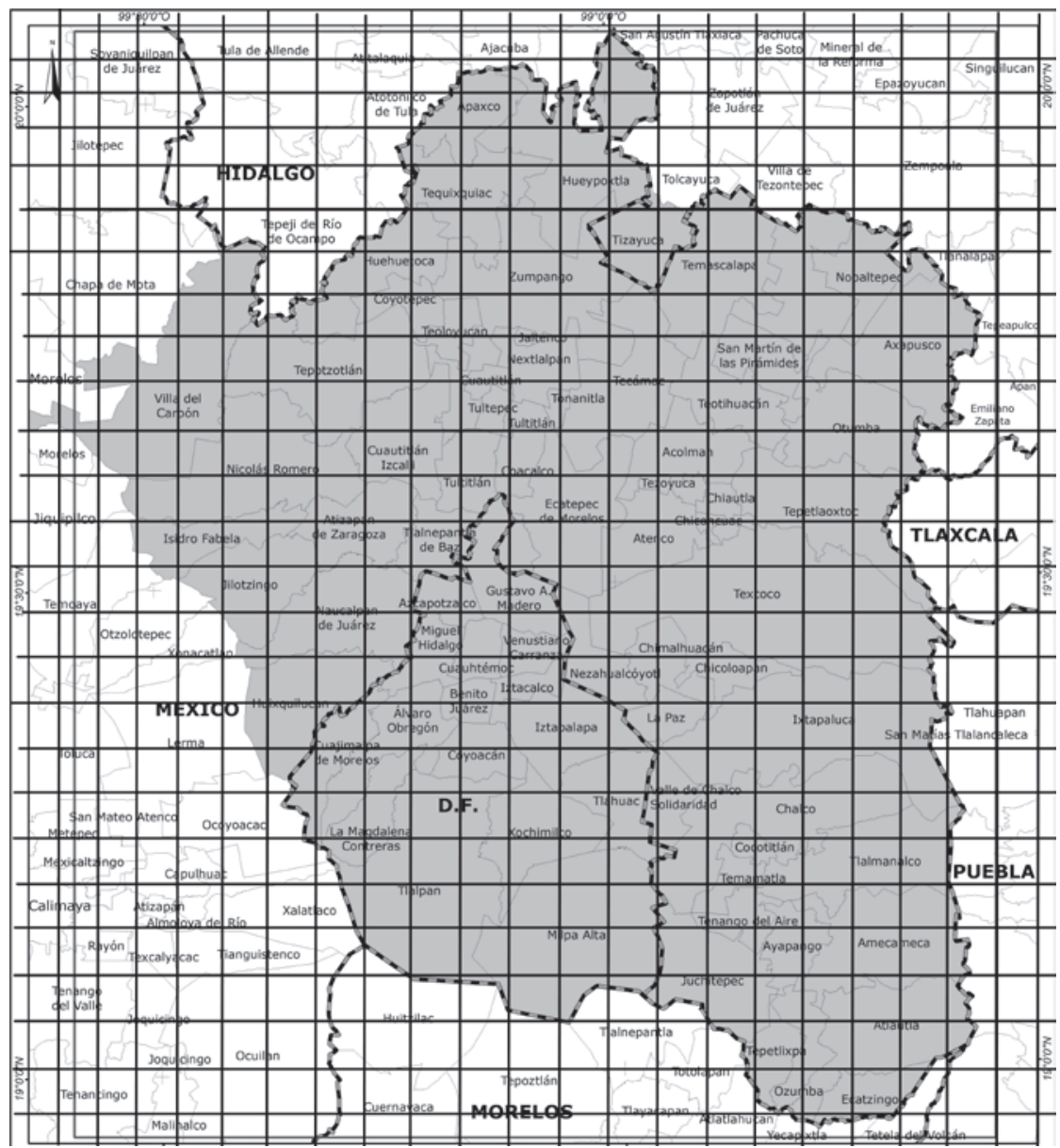

Fuente: Elaboración propia.

\section{HALLAZGOS A PARTIR DEL MODELO DE PROSPECTIVA TERRITORIAL PARA LA ZONA METROPOLITANA DEL VALLE DE MÉXICO}

\section{Expansión física generada en kilómetros cuadrados en nuevas áreas urbanas por zona}

Los resultados para el modelo informan crecimiento y expansión en todos los puntos cardinales de la zona de estudio; sin embargo, es claro que dicha expansión es diferenciada en función de los atributos específicos de cada punto del territorio (cuadro 3-1).

De esta manera, las áreas donde se da la mayor expansión urbana de acuerdo con los resultados del modelo es el norte del Valle de México y de manera muy específica en el nororiente. De ahí que municipios del Estado de México, como 
Cuadro 3-1

Expansión generada en kilómetros cuadrados por periodo y ubicación geográfica en el Valle de México

\begin{tabular}{lrrrr}
\hline "Municipios ubicados al" & & & & "Expansión Total \\
2020 a 2040"
\end{tabular}

Fuente: Ramírez H., 2016a, pp. 173-174.

Axapusco, Temascalapa, Otumba, Teotihuacán, San Martín de las Pirámides, Texcoco, y Tizayuca, Villa de Tezontepec, Zempoala y Tolcayuca como municipios de Hidalgo sean los principales receptores de la urbanización metropolitana entre 2020 y 2040. Si se agregan los municipios Apaxco, Hueypoxtla, Tequixquiac, Zumpango, Huehuetoca, Tecámac y Ecatepec del Estado de México más los de Hidalgo, como San Agustín Tlaxiaca y Atotonilco de Tula, todos ubicados al norte, con claridad se puede concluir que la mayor parte del proceso de expansión urbana para la Ciudad de México y su Zona Metropolitana, se dirige al norte y nororiente del Valle de México (cuadro 3-1).

En contraste, si bien asimismo hay expansión urbana al sur del Valle de México, esta corresponde a una proporción sensiblemente menor. Las delegaciones al sur del Valle de México ${ }^{4}$ y según los resultados del modelo, se notifica una expansión probable de menos de 70 kilómetros cuadrados, lo cual es congruente con la existencia de una barrera natural al sur del Valle de México entre la parte sur de Milpa Alta y Tlalpan dada por la Sierra Ajusco-Chichinautzin, que no permite la expansión hacia el estado de Morelos. Tiene importancia que la mayoría de la expansión se ubica al oriente del Valle de México, nororiente en primer lugar y luego suroriente y oriente (cuadro 3-1).

En el cuadro 3-2, se agrupan los ocho puntos cardinales en sólo cuatro de ellos con el propósito de comprender mejor las tendencias de expansión en el Valle de México.

Los resultados del modelo indican que, de acuerdo con las nuevas áreas ocu-

\footnotetext{
${ }^{4}$ De hecho, no se reportó expansión en los municipios al sur del Valle de México, sino sólo en las delegaciones Xochimilco y Tlalpan de la Ciudad de México.
} 


\section{Cuadro 3-2}

Expansión generada en kilómetros cuadrados por periodo y ubicación geográfica (cuatro puntos cardinales) en el Valle de México

\begin{tabular}{lcccc}
\hline & & & "Expansión total \\
"Municipios ubicados al" & 2020 & 2030 & 2040 & 2020 a 2040" \\
\hline Norte & 391.5 & 319.5 & 423.8 & 1134.8 \\
Sur & 127.8 & 86.5 & 101.3 & 315.5 \\
Oriente & 54.0 & 34.3 & 48.0 & 136.3 \\
Poniente & 19.8 & 15.0 & 12.0 & 46.8 \\
Total & 593.0 & 455.3 & 585.0 & 1633.3 \\
\hline
\end{tabular}

Fuente: Ramírez H., 2016a, pp. 173-174.

padas en el año 2020, se integrarían los municipios de Cocotitlán o Temascalapa del Estado de México. Asimismo, municipios como Atotonilco, Tula, Tezontepec, Tolcayuca y Zempoala del Estado de Hidalgo, y Tlahuapan de Puebla deberían formar parte de la ZMCM, con un total de 78 municipios de cuatro entidades.

Para el año 2030, se unirían municipios como Atitalaquia (Hidalgo), Tianguistenco (México) y San Nicolás de los Ranchos (Puebla), entre otros, con lo cual se alcanzarían un total de 84 municipios (Ramírez H., 2016a: 179-181).

Hacia el año 2040, se tendría un total de 90 municipios, en los que además de las cuatro entidades mencionadas, se agregarían Morelos y Tlaxcala, con los municipios de Totolapan y Calpulalpan, respectivamente. En términos funcionales, Calpulalpan también pertenecería a la zona metropolitana de Tlaxcala, misma situación que puede enfrentar el municipio de Lerma en el Estado de México, el cual pertenece a la zona metropolitana de Toluca (mapa 3-1).

Los posibles municipios y delegaciones que integrarían la ZMCM en los años 2020, 2030 y 2040 se enumeran en los cuadros 3-3 a 3-5.

\section{Población por delegación y municipio de 2020 a 2040}

En función de los resultados del modelo, además del crecimiento poblacional natural de municipios y delegaciones ya integrados a la ZMCM en el año 2010, la incorporación de los nuevos municipios, en especial los de Hidalgo y Estado de México, Ilevarían a la Ciudad de México y su zona metropolitana a un crecimiento sin precedentes, pero asimismo a una cantidad de retos en materia de desarrollo urbano e integración metropolitana a considerar. De acuerdo con estos resultados, la ciudad llegaría a 21 millones de habitantes en 2020. Para 2030, la ciudad tendría casi 23 millones y en 2040 por lo menos 24.3 millones de habitantes (cuadros 3-6 y 3-7). 
Mapa 3-1

Delegaciones y municipios pertenecientes a la Zona Metropolitana del Valle de México (1990 a 2040)
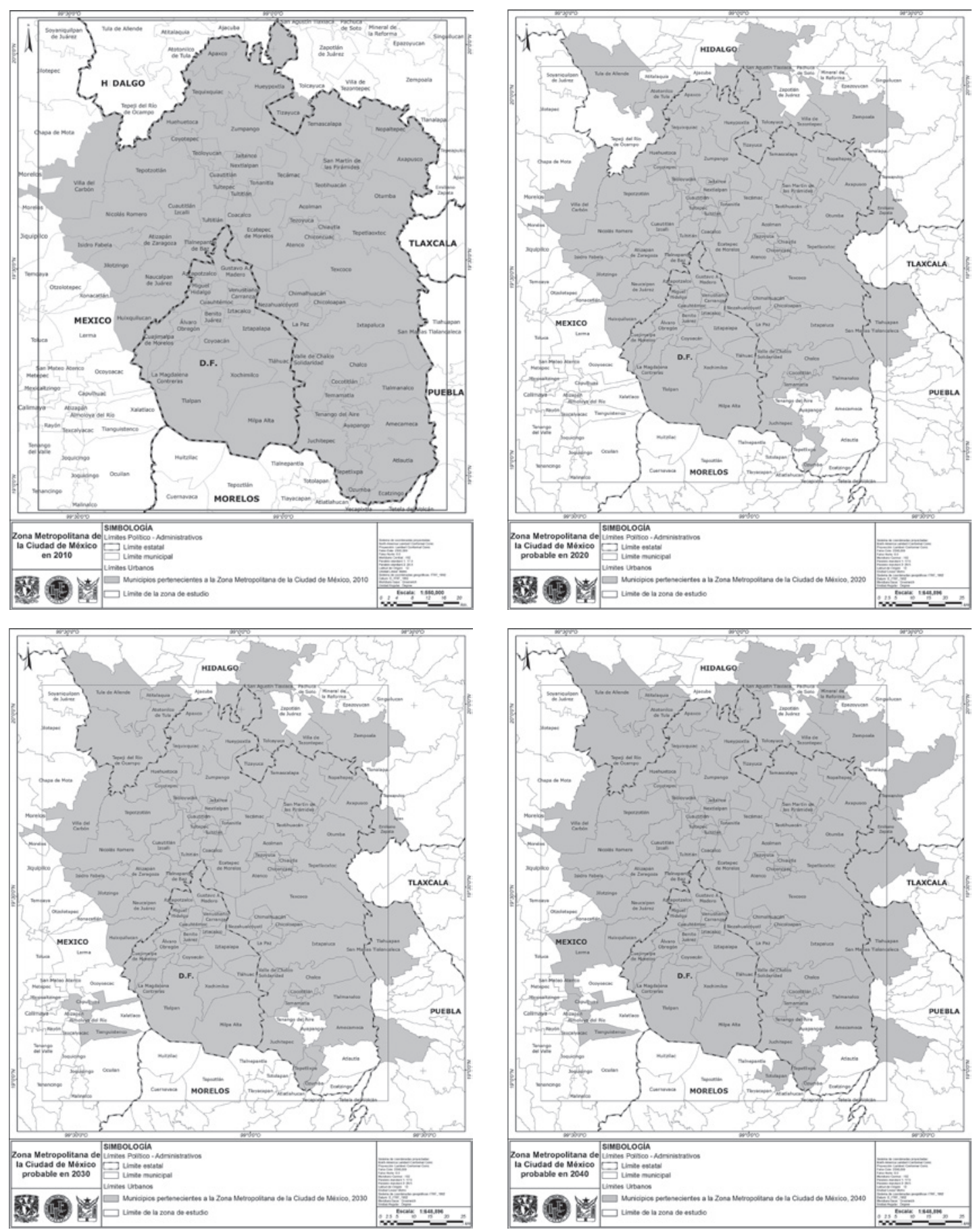

Fuente: Ramírez H., 2016a: 179-181. 


\section{Cuadro 3-3}

Municipios integrantes probables de la Zona Metropolitana de la Ciudad de México (ZMCM) en el año 2020

\begin{tabular}{|c|c|c|c|c|c|}
\hline & $\begin{array}{l}\text { Entidad } \\
\text { federativa }\end{array}$ & Municipio-delegación & & $\begin{array}{l}\text { Entidad } \\
\text { federativa }\end{array}$ & Municipio-delegación \\
\hline 1 & Distrito Federal & Álvaro Obregón & 40 & México & Ecatepec de Morelos \\
\hline 2 & Distrito Federal & Azcapotzalco & 41 & México & Huehuetoca \\
\hline 3 & Distrito Federal & Benito Juárez & 42 & México & Hueypoxtla \\
\hline 4 & Distrito Federal & Coyoacán & 43 & México & Huixquilucan \\
\hline 5 & Distrito Federal & Cuajimalpa de Morelos & 44 & México & Isidro Fabela \\
\hline 6 & Distrito Federal & Cuauhtémoc & 45 & México & Ixtapaluca \\
\hline 7 & Distrito Federal & Gustavo A. Madero & 46 & México & Jaltenco \\
\hline 8 & Distrito Federal & Iztacalco & 47 & México & Jilotzingo \\
\hline 9 & Distrito Federal & Iztapalapa & 48 & México & Juchitepec \\
\hline 10 & Distrito Federal & La Magdalena Contreras & 49 & México & La Paz \\
\hline 11 & Distrito Federal & Miguel Hidalgo & 50 & México & Melchor Ocampo \\
\hline 12 & Distrito Federal & Milpa Alta & 51 & México & Naucalpan de Juárez \\
\hline 13 & Distrito Federal & Tláhuac & 52 & México & Nextlalpan \\
\hline 14 & Distrito Federal & Tlalpan & 53 & México & Nezahualcóyotl \\
\hline 15 & Distrito Federal & Venustiano Carranza & 54 & México & Nicolás Romero \\
\hline 16 & Distrito Federal & Xochimilco & 55 & México & Nopaltepec \\
\hline 17 & Hidalgo & Atotonilco de Tula & 56 & México & Otumba \\
\hline 18 & Hidalgo & Emiliano Zapata & 57 & México & Ozumba \\
\hline 19 & Hidalgo & San Agustín Tlaxiaca & 58 & México & Papalotla \\
\hline 20 & Hidalgo & Tizayuca & 59 & México & San Martín de las Pirámides \\
\hline 21 & Hidalgo & Tolcayuca & 60 & México & Tecámac \\
\hline 22 & Hidalgo & Tula de Allende & 61 & México & Temamatla \\
\hline 23 & Hidalgo & Villa de Tezontepec & 62 & México & Temascalapa \\
\hline 24 & Hidalgo & Zempoala & 63 & México & Teoloyucan \\
\hline 25 & México & Acolman & 64 & México & Teotihuacán \\
\hline 26 & México & Apaxco & 65 & México & Tepetlaoxtoc \\
\hline 27 & México & Atenco & 66 & México & Tepotzotlán \\
\hline 28 & México & Atizapán de Zaragoza & 67 & México & Tequixquiac \\
\hline 29 & México & Axapusco & 68 & México & Texcoco \\
\hline 30 & México & Chalco & 69 & México & Tezoyuca \\
\hline 31 & México & Chiautla & 70 & México & Tlalmanalco \\
\hline 32 & México & Chicoloapan & 71 & México & Tlalnepantla de Baz \\
\hline 33 & México & Chiconcuac & 72 & México & Tonanitla \\
\hline 34 & México & Chimalhuacán & 73 & México & Tultepec \\
\hline 35 & México & Coacalco de Berriozábal & 74 & México & Tultitlán \\
\hline 36 & México & Cocotitlán & 75 & México & Valle de Chalco Solidaridad \\
\hline 37 & México & Coyotepec & 76 & México & Villa del Carbón \\
\hline 38 & México & Cuautitlán & 77 & México & Zumpango \\
\hline 39 & México & Cuautitlán Izcalli & 78 & Puebla & Tlahuapan \\
\hline
\end{tabular}

Fuente: (Ramírez H., 2016a: 194).. 


\section{Cuadro 3-4}

Municipios integrantes probables de la Zona Metropolitana de la Ciudad de México (ZMCM) en el año 2030

\begin{tabular}{|c|c|c|c|c|c|}
\hline & $\begin{array}{l}\text { Entidad } \\
\text { federativa }\end{array}$ & Municipio-delegación & & $\begin{array}{l}\text { Entidad } \\
\text { federativa }\end{array}$ & Municipio-delegación \\
\hline 1 & Distrito Federal & Álvaro Obregón & 43 & México & Ecatepec de Morelos \\
\hline 2 & Distrito Federal & Azcapotzalco & 44 & México & Huehuetoca \\
\hline 3 & Distrito Federal & Benito Juárez & 45 & México & Hueypoxtla \\
\hline 4 & Distrito Federal & Coyoacán & 46 & México & Huixquilucan \\
\hline 5 & Distrito Federal & Cuajimalpa de Morelos & 47 & México & Isidro Fabela \\
\hline 6 & Distrito Federal & Cuauhtémoc & 48 & México & Ixtapaluca \\
\hline 7 & Distrito Federal & Gustavo A. Madero & 49 & México & Jaltenco \\
\hline 8 & Distrito Federal & Iztacalco & 50 & México & Jilotzingo \\
\hline 9 & Distrito Federal & Iztapalapa & 51 & México & Juchitepec \\
\hline 10 & Distrito Federal & La Magdalena Contreras & 52 & México & La Paz \\
\hline 11 & Distrito Federal & Miguel Hidalgo & 53 & México & Melchor Ocampo \\
\hline 12 & Distrito Federal & Milpa Alta & 54 & México & Naucalpan de Juárez \\
\hline 13 & Distrito Federal & Tláhuac & 55 & México & Nextlalpan \\
\hline 14 & Distrito Federal & Tlalpan & 56 & México & Nezahualcóyotl \\
\hline 15 & Distrito Federal & Venustiano Carranza & 57 & México & Nicolás Romero \\
\hline 16 & Distrito Federal & Xochimilco & 58 & México & Nopaltepec \\
\hline 17 & Hidalgo & Atitalaquia & 59 & México & Otumba \\
\hline 18 & Hidalgo & Atotonilco de Tula & 60 & México & Ozumba \\
\hline 19 & Hidalgo & Emiliano Zapata & 61 & México & Papalotla \\
\hline 20 & Hidalgo & San Agustín Tlaxiaca & 62 & México & San Martín de las Pirámides \\
\hline 21 & Hidalgo & Tepeji del Río de Ocampo & 63 & México & Tecámac \\
\hline 22 & Hidalgo & Tizayuca & 64 & México & Temamatla \\
\hline 23 & Hidalgo & Tolcayuca & 65 & México & Temascalapa \\
\hline 24 & Hidalgo & Tula de Allende & 66 & México & Teoloyucan \\
\hline 25 & Hidalgo & Villa de Tezontepec & 67 & México & Teotihuacán \\
\hline 26 & Hidalgo & Zempoala & 68 & México & Tepetlaoxtoc \\
\hline 27 & México & Acolman & 69 & México & Tepetlixpa \\
\hline 28 & México & Amecameca & 70 & México & Tepotzotlán \\
\hline 29 & México & Apaxco & 71 & México & Tequixquiac \\
\hline 30 & México & Atenco & 72 & México & Texcoco \\
\hline 31 & México & Atizapán de Zaragoza & 73 & México & Tezoyuca \\
\hline 32 & México & Axapusco & 74 & México & Tianguistenco \\
\hline 33 & México & Chalco & 75 & México & Tlalmanalco \\
\hline 34 & México & Chiautla & 76 & México & Tlalnepantla de Baz \\
\hline 35 & México & Chicoloapan & 77 & México & Tonanitla \\
\hline 36 & México & Chiconcuac & 78 & México & Tultepec \\
\hline 37 & México & Chimalhuacán & 79 & México & Tultitlán \\
\hline 38 & México & Coacalco de Berriozábal & 80 & México & Valle de Chalco Solidaridad \\
\hline 39 & México & Cocotitlán & 81 & México & Villa del Carbón \\
\hline 40 & México & Coyotepec & 82 & México & Zumpango \\
\hline 41 & México & Cuautitlán & 83 & Puebla & San Nicolás de los Ranchos \\
\hline 42 & México & Cuautitlán Izcalli & 84 & Puebla & Tlahuapan \\
\hline
\end{tabular}

Fuente: (Ramírez H., 2016a: 194).. 
Cuadro 3-5

Municipios integrantes probables de la Zona Metropolitana de la Ciudad de México (ZMCM) en el año 2040

\begin{tabular}{|c|c|c|c|c|c|}
\hline & $\begin{array}{l}\text { Entidad } \\
\text { federativa }\end{array}$ & Municipio-delegación & & $\begin{array}{l}\text { Entidad } \\
\text { federativa }\end{array}$ & Municipio-delegación \\
\hline 1 & Distrito Federal & Álvaro Obregón & 46 & México & Huehuetoca \\
\hline 2 & Distrito Federal & Azcapotzalco & 47 & México & Hueypoxtla \\
\hline 3 & Distrito Federal & Benito Juárez & 48 & México & Huixquilucan \\
\hline 4 & Distrito Federal & Coyoacán & 49 & México & Isidro Fabela \\
\hline 5 & Distrito Federal & Cuajimalpa de Morelos & 50 & México & Ixtapaluca \\
\hline 6 & Distrito Federal & Cuauhtémoc & 51 & México & Jaltenco \\
\hline 7 & Distrito Federal & Gustavo A. Madero & 52 & México & Jilotzingo \\
\hline 8 & Distrito Federal & Iztacalco & 53 & México & Juchitepec \\
\hline 9 & Distrito Federal & Iztapalapa & 54 & México & La Paz \\
\hline 10 & Distrito Federal & La Magdalena Contreras & 55 & México & Lerma \\
\hline 11 & Distrito Federal & Miguel Hidalgo & 56 & México & Melchor Ocampo \\
\hline 12 & Distrito Federal & Milpa Alta & 57 & México & Naucalpan de Juárez \\
\hline 13 & Distrito Federal & Tláhuac & 58 & México & Nextlalpan \\
\hline 14 & Distrito Federal & Tlalpan & 59 & México & Nezahualcóyotl \\
\hline 15 & Distrito Federal & Venustiano Carranza & 60 & México & Nicolás Romero \\
\hline 16 & Distrito Federal & Xochimilco & 61 & México & Nopaltepec \\
\hline 17 & Hidalgo & Atitalaquia & 62 & México & Otumba \\
\hline 18 & Hidalgo & Atotonilco de Tula & 63 & México & Ozumba \\
\hline 19 & Hidalgo & Emiliano Zapata & 64 & México & Papalotla \\
\hline 20 & Hidalgo & Mineral de la Reforma & 65 & México & San Martín de las Pirámides \\
\hline 21 & Hidalgo & San Agustín Tlaxiaca & 66 & México & Tecámac \\
\hline 22 & Hidalgo & Tepeapulco & 67 & México & Temamatla \\
\hline 23 & Hidalgo & Tepeji del Río de Ocampo & 68 & México & Temascalapa \\
\hline 24 & Hidalgo & Tizayuca & 69 & México & Tenango del Aire \\
\hline 25 & Hidalgo & Tolcayuca & 70 & México & Teoloyucan \\
\hline 26 & Hidalgo & Tula de Allende & 71 & México & Teotihuacán \\
\hline 27 & Hidalgo & Villa de Tezontepec & 72 & México & Tepetlaoxtoc \\
\hline 28 & Hidalgo & Zempoala & 73 & México & Tepetlixpa \\
\hline 29 & México & Acolman & 74 & México & Tepotzotlán \\
\hline 30 & México & Amecameca & 75 & México & Tequixquiac \\
\hline 31 & México & Apaxco & 76 & México & Texcoco \\
\hline 32 & México & Atenco & 77 & México & Tezoyuca \\
\hline 33 & México & Atizapán de Zaragoza & 78 & México & Tianguistenco \\
\hline 34 & México & Axapusco & 79 & México & Tlalmanalco \\
\hline 35 & México & Chalco & 80 & México & Tlalnepantla de Baz \\
\hline 36 & México & Chiautla & 81 & México & Tonanitla \\
\hline 37 & México & Chicoloapan & 82 & México & Tultepec \\
\hline 38 & México & Chiconcuac & 83 & México & Tultitlán \\
\hline 39 & México & Chimalhuacán & 84 & México & Valle de Chalco Solidaridad \\
\hline 40 & México & Coacalco de Berriozábal & 85 & México & Villa del Carbón \\
\hline 41 & México & Cocotitlán & 86 & México & Zumpango \\
\hline 42 & México & Coyotepec & 87 & Morelos & Totolapan \\
\hline 43 & México & Cuautitlán & 88 & Puebla & San Nicolás de los Ranchos \\
\hline 44 & México & Cuautitlán Izcalli & 89 & Puebla & Tlahuapan \\
\hline 45 & México & Ecatepec de Morelos & 90 & Tlaxcala & Calpulalpan \\
\hline
\end{tabular}




\begin{tabular}{|c|c|c|c|c|c|c|c|c|c|c|c|c|c|c|c|c|c|}
\hline$\stackrel{\pi}{-}$ & $\begin{array}{l}\text { ㄱ. } \\
\text { }\end{array}$ & 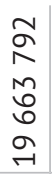 & 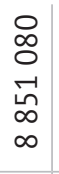 & 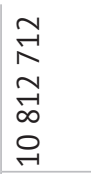 & 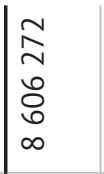 & $\begin{array}{l}\hat{M} \\
\stackrel{-}{-} \\
\vec{N} \\
\stackrel{-}{-}\end{array}$ & 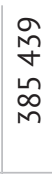 & $\begin{array}{l}\vec{n} \\
\infty \\
\vec{n} \\
n\end{array}$ & $\begin{array}{l}a \\
\infty \\
\infty \\
\mathbb{N} \\
m\end{array}$ & \begin{tabular}{l}
$\infty$ \\
$\stackrel{0}{\alpha}$ \\
$\circ$ \\
\multirow{y}{*}{}
\end{tabular} & $\begin{array}{l}\text { N } \\
\stackrel{+}{\circ} \\
\stackrel{N}{N}\end{array}$ & $\begin{array}{l}\overrightarrow{-} \\
\vec{N} \\
\vec{\forall}\end{array}$ & $\begin{array}{l}0 \\
\dot{+} \\
\text { ○ } \\
\text { }\end{array}$ & $\begin{array}{l}\text { N } \\
\text { L } \\
\infty \\
\rightarrow \\
-1\end{array}$ & 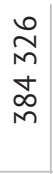 & $\begin{array}{l}\infty \\
\infty \\
\stackrel{2}{n} \\
\stackrel{-1}{\infty} \\
-1\end{array}$ & $\begin{array}{l}\infty \\
\infty \\
\circ \\
o \\
N \\
\sim\end{array}$ \\
\hline 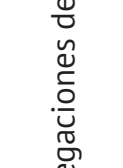 & ஜิ & $\begin{array}{l}\text { M } \\
\stackrel{1}{-1} \\
\sim \\
N \\
\infty \\
\infty \\
\sim\end{array}$ & 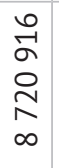 & 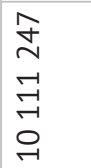 & $\begin{array}{l}\hat{N} \\
\hat{n} \\
\infty \\
\infty \\
\infty \\
\infty\end{array}$ & 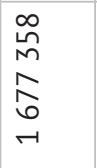 & $\begin{array}{l}\hat{-} \\
\text { o } \\
\text { ผn } \\
m\end{array}$ & $\begin{array}{l}\infty \\
\stackrel{+}{m} \\
\stackrel{H}{N}\end{array}$ & $\begin{array}{l}\stackrel{+}{\omega} \\
\omega \\
m \\
\omega \\
m\end{array}$ & \begin{tabular}{l} 
装 \\
\multirow{f}{f}{}
\end{tabular} & $\begin{array}{l}\hat{0} \\
\stackrel{n}{n} \\
\stackrel{0}{ }\end{array}$ & \begin{tabular}{l}
$\stackrel{\infty}{\sim}$ \\
$\stackrel{\sim}{\sim}$ \\
\multirow{\gamma}{*}{}
\end{tabular} & 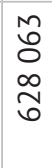 & $\begin{array}{l}\vec{b} \\
\overrightarrow{1} \\
M \\
\sigma \\
\overrightarrow{-} \\
-1\end{array}$ & $\begin{array}{l}\stackrel{\text { ㅇ }}{0} \\
\text { ผू } \\
\text { ஸn }\end{array}$ & $\begin{array}{l}\infty \\
\infty \\
\infty \\
\circ \\
\infty \\
\infty \\
-1\end{array}$ & 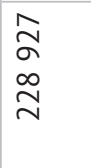 \\
\hline $\begin{array}{l}\frac{5}{0} \\
\frac{0}{0} \\
\frac{0}{n} \\
\frac{0}{v}\end{array}$ & $\begin{array}{l}8 \\
\searrow \\
\sim\end{array}$ & $\begin{array}{l}\hat{N} \\
\infty \\
0 \\
-1 \\
0 \\
\infty \\
+1\end{array}$ & 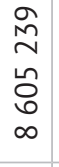 & $\begin{array}{l}\infty \\
N \\
i \\
น n \\
o \\
a\end{array}$ & $\begin{array}{l}\text { I } \\
0 \\
M \\
\infty \\
0 \\
\infty\end{array}$ & \begin{tabular}{l}
$a$ \\
\multirow{2}{-}{} \\
2 \\
$\sigma$ \\
$\sigma$ \\
-1
\end{tabular} & \begin{tabular}{l}
$\infty$ \\
\multirow{+}{*}{} \\
0 \\
M
\end{tabular} & 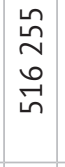 & $\begin{array}{l}\text { O } \\
6 \\
\text { N } \\
\text { m }\end{array}$ & 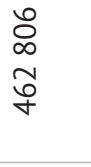 & $\begin{array}{l}\text { O } \\
0 \\
1 \\
\infty \\
0\end{array}$ & $\begin{array}{l}\infty \\
8 \\
\stackrel{+}{\forall}\end{array}$ & 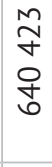 & 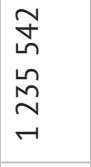 & $\begin{array}{l}\vec{\sim} \\
m \\
\vec{\forall} \\
\vec{\forall}\end{array}$ & $\begin{array}{l}\text { M } \\
\stackrel{N}{M} \\
N \\
N \\
N\end{array}$ & $\begin{array}{l}\text { 융 } \\
\text { N } \\
\text { N }\end{array}$ \\
\hline 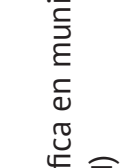 & $\begin{array}{l}\text { ñ } \\
\text { } \\
-1\end{array}$ & $\begin{array}{l}0 \\
\dot{1} \\
\infty \\
\infty \\
\infty \\
0 \\
\sim\end{array}$ & $\begin{array}{l}\hat{8} \\
8 \\
\circ \\
\infty \\
+ \\
\infty\end{array}$ & 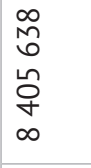 & $\begin{array}{l}\hat{N} \\
\overrightarrow{1} \\
N \\
\infty \\
0 \\
\infty\end{array}$ & 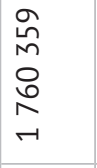 & 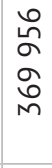 & $\begin{array}{l}\text { I } \\
\text { m } \\
0 \\
+ \\
\text { L }\end{array}$ & $\begin{array}{l}\infty \\
o \\
m \\
\vdots \\
b \\
m\end{array}$ & 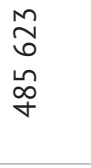 & 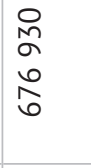 & $\begin{array}{l}\vec{m} \\
\stackrel{-1}{\omega} \\
\stackrel{\leftrightarrow}{+}\end{array}$ & 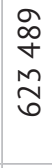 & 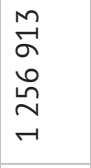 & $\begin{array}{l}\text { N } \\
\alpha \\
\infty \\
\stackrel{+}{+}\end{array}$ & 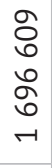 & $\begin{array}{l}\infty \\
\infty \\
\infty \\
\stackrel{-}{\sim} \\
\stackrel{1}{1}\end{array}$ \\
\hline 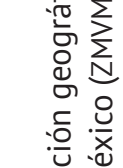 & $\begin{array}{l}\text { Дे } \\
\text { নे }\end{array}$ & 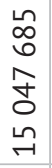 & $\begin{array}{l}\underset{J}{J} \\
\stackrel{2}{N} \\
\stackrel{1}{N} \\
\infty\end{array}$ & $\begin{array}{l}\vec{q} \\
\sigma \\
\vec{z} \\
\overrightarrow{1} \\
0\end{array}$ & $\begin{array}{l}\text { \% } \\
0 \\
o \\
\hat{\omega} \\
\infty\end{array}$ & $\begin{array}{l}\hat{D} \\
\stackrel{1}{0} \\
o \\
N \\
\sigma \\
r\end{array}$ & $\begin{array}{l}\overrightarrow{1} \\
\infty \\
\hat{\sigma} \\
\hat{\sigma}\end{array}$ & $\begin{array}{l}\text { 유 } \\
\text { ผू } \\
\text { ஸ் }\end{array}$ & $\begin{array}{l}\infty \\
0 \\
\infty \\
\varnothing \\
o \\
q\end{array}$ & 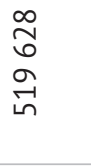 & 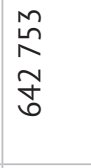 & 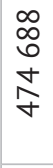 & $\begin{array}{l}0 \\
0 \\
\circ \\
\text { 웅 }\end{array}$ & \begin{tabular}{l}
$\infty$ \\
0 \\
0 \\
$\infty$ \\
0 \\
\multirow{2}{r}{} \\
-1
\end{tabular} & \begin{tabular}{l} 
N \\
$N$ \\
$\infty$ \\
\multirow{+}{*}{}
\end{tabular} & $\begin{array}{l}\text { જ } \\
\text { } \\
\text { \& } \\
+ \\
+1\end{array}$ & 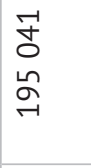 \\
\hline 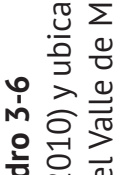 & $\begin{array}{l}\infty \\
2 \\
\sim 1\end{array}$ & 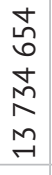 & 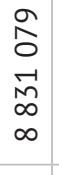 & 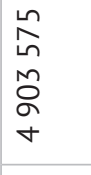 & 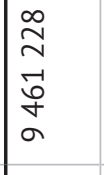 & 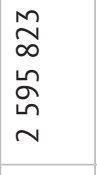 & \begin{tabular}{l} 
D \\
$\infty$ \\
\multirow{2}{*}{} \\
மn
\end{tabular} & $\begin{array}{l}M \\
\infty \\
\sigma \\
\dot{J} \\
\infty\end{array}$ & 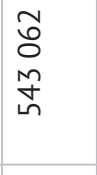 & 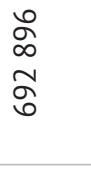 & $\begin{array}{l}\stackrel{M}{\sim} \\
\stackrel{N}{N} \\
\text { }\end{array}$ & $\begin{array}{l}\stackrel{+}{\sim} \\
\text { ஸ் } \\
\stackrel{-}{0}\end{array}$ & 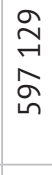 & 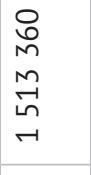 & $\begin{array}{l}\hat{N} \\
m \\
0 \\
\text { Ln }\end{array}$ & 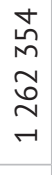 & 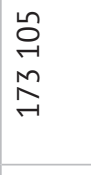 \\
\hline 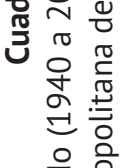 & $\begin{array}{l}R \\
\text { On } \\
-1\end{array}$ & 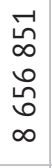 & \begin{tabular}{l}
$\hat{a}$ \\
$\dot{y}$ \\
\multirow{1}{*}{} \\
o \\
0
\end{tabular} & $\begin{array}{l}0 \\
\infty \\
0 \\
\sim \\
\infty \\
D \\
-1\end{array}$ & 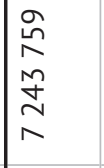 & 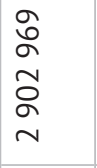 & & & & & $\begin{array}{l}\text { مे } \\
\text { ๖o } \\
\stackrel{2}{q}\end{array}$ & $\begin{array}{l}\stackrel{+}{\mathrm{n}} \\
\stackrel{\sim}{\mathrm{m}} \\
\stackrel{\mathrm{n}}{n}\end{array}$ & $\begin{array}{l}\stackrel{o}{7} \\
\text { ' } \\
\text { m }\end{array}$ & $\begin{array}{l}\hat{0} \\
\text {-1 } \\
0 \\
\infty \\
-1 \\
-1\end{array}$ & \begin{tabular}{l}
$\vec{N}$ \\
$M$ \\
$\hat{N}$ \\
\multirow{f}{*}{}
\end{tabular} & 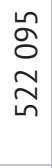 & 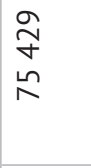 \\
\hline 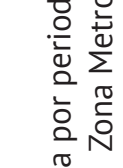 & $\begin{array}{l}8 \\
2 \\
-1\end{array}$ & 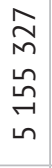 & 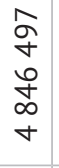 & $\begin{array}{l}\text { ㅇ } \\
\infty \\
\infty \\
\infty \\
M\end{array}$ & $\begin{array}{l}\text { ને } \\
\stackrel{-}{ન} \\
\hat{n} \\
\infty \\
\forall \\
\forall\end{array}$ & $\begin{array}{l}M \\
M \\
\stackrel{2}{N} \\
N \\
\infty \\
\sim\end{array}$ & & & & & $\begin{array}{l}\text { 겸 } \\
\circ \\
\stackrel{ }{N}\end{array}$ & $\begin{array}{l}\stackrel{+}{N} \\
\stackrel{0}{N}\end{array}$ & $\begin{array}{l}\vec{ન} \\
- \\
0 \\
\sigma \\
\vec{\sigma}\end{array}$ & $\begin{array}{l}\infty \\
\infty \\
\stackrel{-1}{o} \\
\text { in }\end{array}$ & 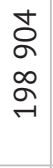 & 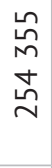 & 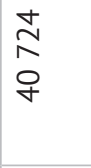 \\
\hline $\begin{array}{l}\frac{0}{0} \\
\cdot \frac{0}{2} \\
\cdot \frac{1}{2} \\
\frac{0}{0}\end{array}$ & \begin{tabular}{l}
0 \\
2 \\
\multirow{2}{*}{}
\end{tabular} & \begin{tabular}{l}
$n$ \\
\multirow{2}{0}{} \\
$\sim$ \\
$\infty$ \\
$\curvearrowright$ \\
$\sim$
\end{tabular} & 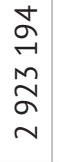 & $\begin{array}{l}-1 \\
\infty \\
\infty \\
\infty \\
\infty\end{array}$ & 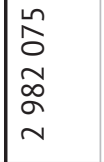 & $\begin{array}{l}\stackrel{n}{\alpha} \\
N \\
N \\
N \\
\sim\end{array}$ & & & & & $\begin{array}{l}\frac{0}{\sim} \\
\stackrel{-}{N} \\
\sigma\end{array}$ & 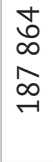 & $\begin{array}{l}\text { 옹 } \\
\text { 웅 }\end{array}$ & $\begin{array}{l}M \\
\text { D } \\
\text { D } \\
\text { N }\end{array}$ & $\begin{array}{l}\text { ^n } \\
\text { } \\
\text { M } \\
m\end{array}$ & $\begin{array}{l}\stackrel{-}{\widetilde{\sigma}} \\
\stackrel{0}{N}\end{array}$ & $\begin{array}{l}\text { nㅡㅁ } \\
\alpha \\
\stackrel{\sim}{N}\end{array}$ \\
\hline $\begin{array}{l}\bar{\pi} \\
\frac{\pi}{0} \\
\frac{0}{U} \\
\frac{\pi}{0} \\
0 \\
0\end{array}$ & $\begin{array}{l}\text { g } \\
2 \\
-1\end{array}$ & $\begin{array}{l}n \\
\vec{m} \\
0 \\
0 \\
\sigma \\
-1\end{array}$ & 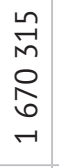 & & $\begin{array}{l}n \\
\stackrel{n}{M} \\
0 \\
0 \\
o \\
-1\end{array}$ & \begin{tabular}{l}
$\stackrel{M}{Y}$ \\
$\mathcal{Y}$ \\
$\infty$ \\
\multirow{J}{*}{} \\
-1
\end{tabular} & & & & & $\begin{array}{l}M \\
\stackrel{M}{M} \\
\stackrel{N}{m}\end{array}$ & $\begin{array}{l}8 \\
8 \\
\text { ஸू }\end{array}$ & $\begin{array}{l}\stackrel{\infty}{\sim} \\
\stackrel{\sim}{N} \\
M\end{array}$ & $\begin{array}{l}\hat{0} \\
\stackrel{1}{n} \\
\vec{\gamma}\end{array}$ & 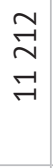 & $\begin{array}{l}m \\
\stackrel{m}{N} \\
\stackrel{n}{N}\end{array}$ & $\begin{array}{l}\sigma \\
\stackrel{n}{n} \\
\stackrel{n}{m} \\
\sim\end{array}$ \\
\hline 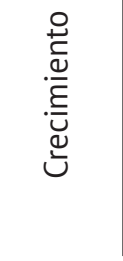 & $\begin{array}{l}\frac{9}{0} \\
\text { w. }\end{array}$ & $\sum_{N}^{\sum}$ & 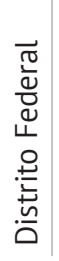 & 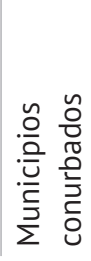 & 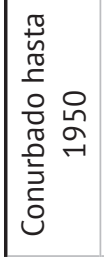 & 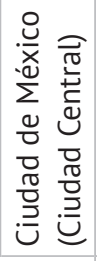 & 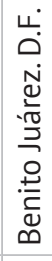 & 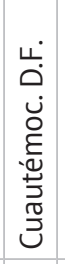 & 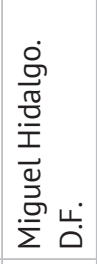 & 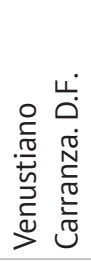 & 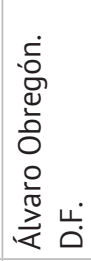 & 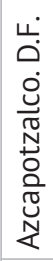 & 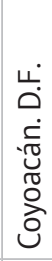 & 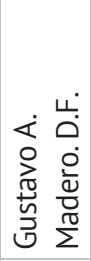 & 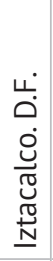 & 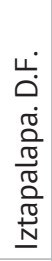 & 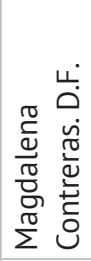 \\
\hline & & & & & & & -1 & $N$ & $M$ & $\nabla$ & in & 0 & $\lambda$ & $\infty$ & $\sigma$ & $\stackrel{ }{\ominus}$ & $\exists$ \\
\hline
\end{tabular}




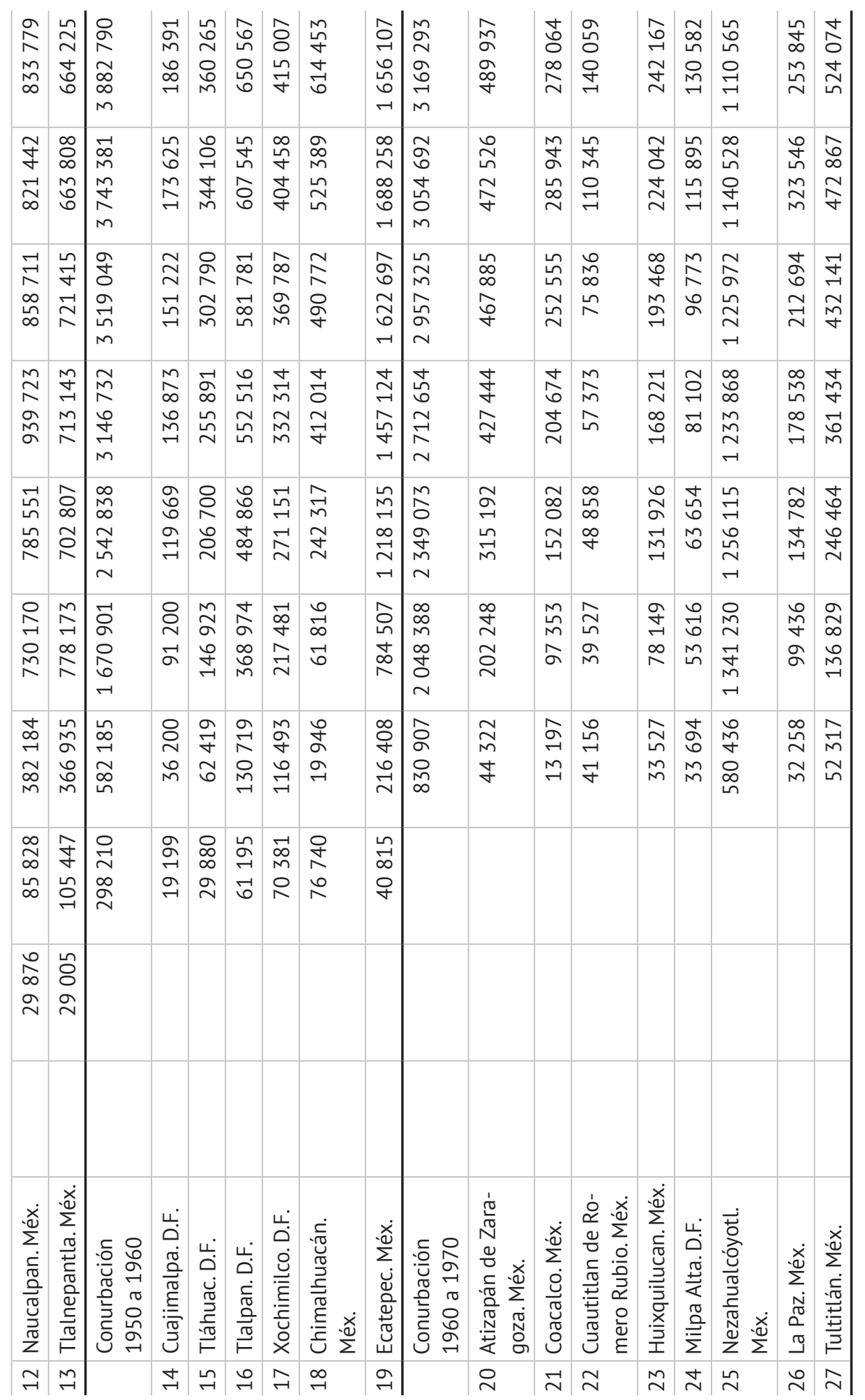




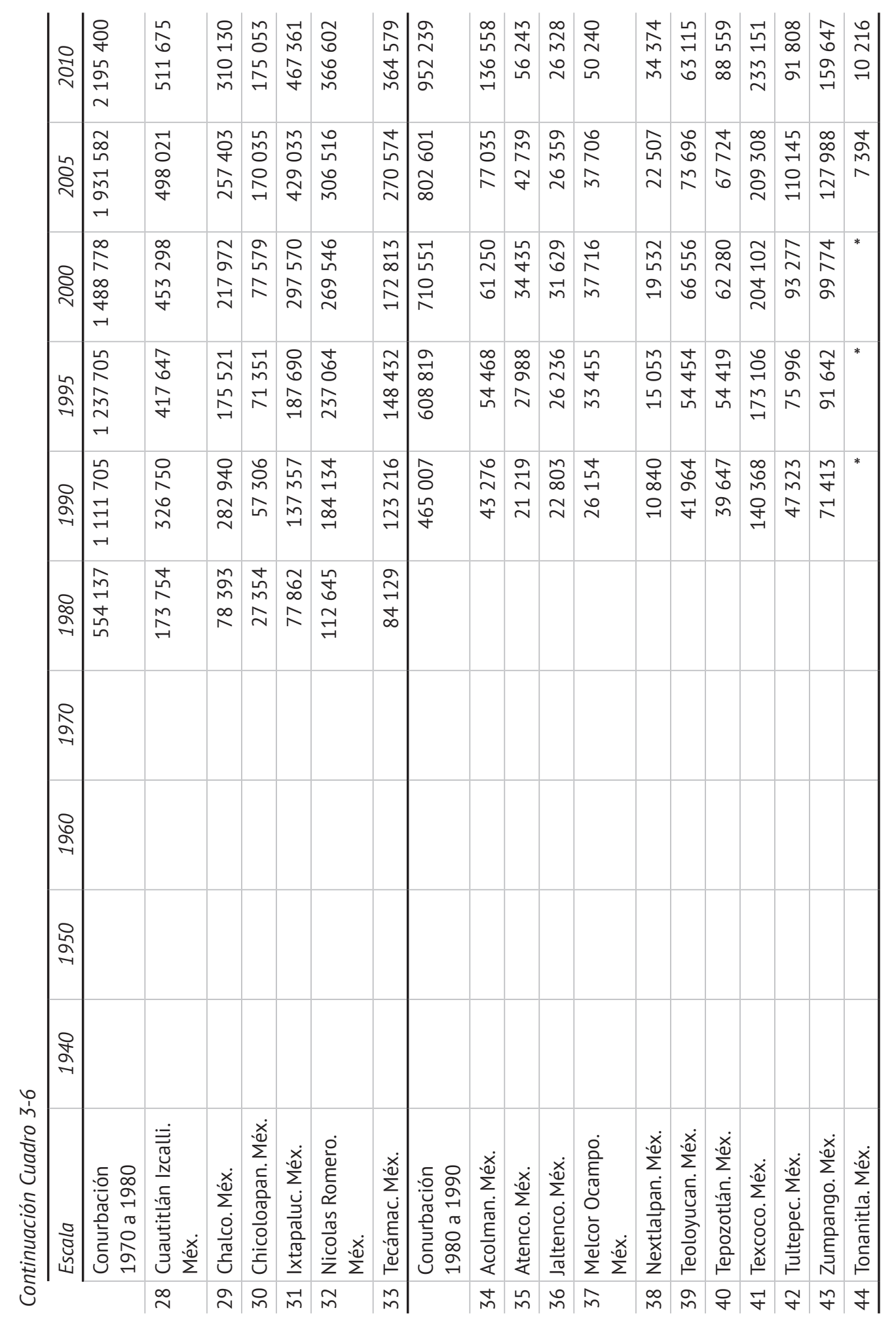




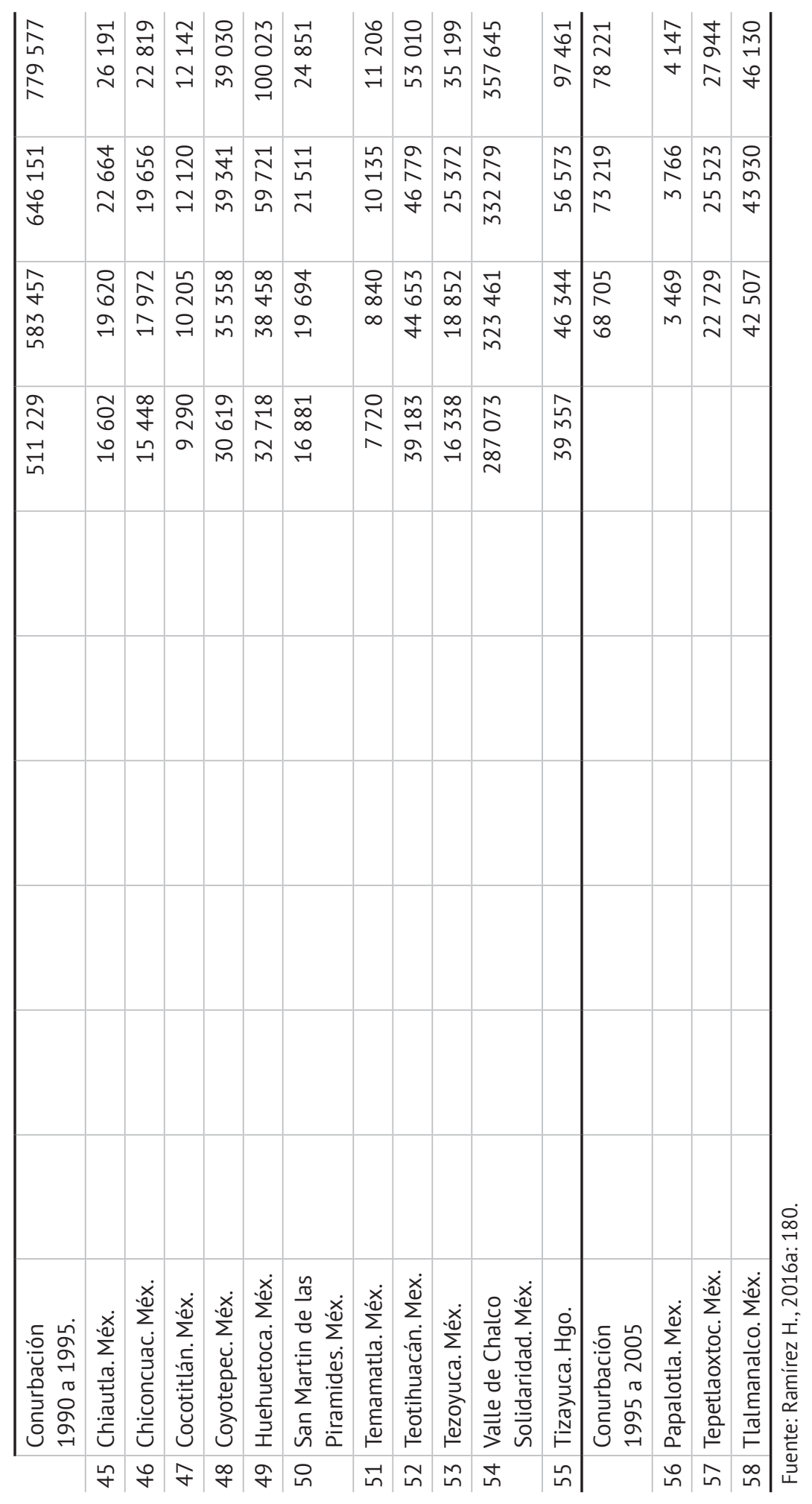




\section{Cuadro 3-7}

Crecimiento poblacional y de vivienda por periodo (2020 a 2040) y ubicación geográfica en municipios y delegaciones de la Zona Metropolitana del Valle de México (ZMVM)

\begin{tabular}{|c|c|c|c|c|}
\hline & Escala & 2020 & 2030 & 2040 \\
\hline & ZMCM & 21453145 & 22658457 & 24327809 \\
\hline & Distrito Federal & 9851300 & 10288196 & 10997630 \\
\hline & Municipios conurbados & 11601844 & 12370261 & 13330180 \\
\hline & Conurbación 2010 a 2020 & 603630 & 634502 & 666950 \\
\hline 59 & Atotonilco de Tula, Hgo. & 32667 & 34338 & 36094 \\
\hline 60 & Emiliano Zapata, Hgo. & 14040 & 14758 & 15513 \\
\hline 61 & Tolcayuca, Hgo. & 33696 & 35420 & 37231 \\
\hline 62 & San Agustín Tlaxiaca, Hgo. & 13904 & 14616 & 15363 \\
\hline 63 & Tula de Allende, Hgo. & 109233 & 114822 & 120692 \\
\hline 64 & Villa de Tezontepec, Hgo. & 12250 & 12876 & 13535 \\
\hline 65 & Zempoala, Hgo. & 41145 & 43249 & 45461 \\
\hline 66 & Apaxco, Méx. & 28928 & 30408 & 31963 \\
\hline 67 & Axapusco, Méx. & 26866 & 28240 & 29684 \\
\hline 68 & Hueypoxtla, Méx. & 41903 & 44046 & 46298 \\
\hline 69 & Isidro Fabela, Méx. & 10835 & 11389 & 11972 \\
\hline 70 & Jilotzingo, Méx. & 18889 & 19855 & 20870 \\
\hline 71 & Juchitepec, Méx. & 24669 & 25962 & 27289 \\
\hline 72 & Nopaltepec, Méx. & 9350 & 9828 & 10331 \\
\hline 73 & Otumba, Méx. & 35983 & 37823 & 39757 \\
\hline 74 & Ozumba, Méx. & 28598 & 30061 & 31598 \\
\hline 75 & Temascalapa, Méx. & 37827 & 39762 & 41795 \\
\hline 76 & Tequixquiac, Méx. & 35641 & 37464 & 39380 \\
\hline \multirow[t]{2}{*}{77} & Villa del Carbón, Méx. & 47176 & 49589 & 52125 \\
\hline & Conurbación 2020 a 2030 & & 270640 & 284480 \\
\hline 79 & Atilalaquia, Hgo. & & 29726 & 31246 \\
\hline 80 & Tepeji del Rio de Ocampo, Hgo. & & 89068 & 93623 \\
\hline 81 & Amecameca, Méx. & & 53500 & 56236 \\
\hline 82 & Tepetlixpa, Méx. & & 20249 & 21285 \\
\hline \multirow[t]{2}{*}{83} & Tianguistenco, Méx. & & 78096 & 82090 \\
\hline & Conurbación 2030 a 2040 & & & 72288 \\
\hline 86 & Tepeapulco, Hgo. & & & 60003 \\
\hline 88 & Tenango del Aire, Méx. & & & 12285 \\
\hline
\end{tabular}

Fuente: Ramírez H., 2016a: 181. 
En general, los resultados prospectivos coinciden con la delimitación del "Programa de Ordenación de la Zona Metropolitana del Valle de México" del año 2012, aunque existen algunas diferencias en el caso de otras entidades federativas, como Puebla, Tlaxcala y Morelos, con municipios que también tienden a integrarse a la ZMCM.

\section{CONCLUSIONES}

En este capítulo se ha hecho patente la importancia que reviste la Ciudad de México y su zona metropolitana para el país. El modelo de prospectiva territorial planteado y desarrollado en la publicación de Ramírez H. (2016a) deja muy clara su utilidad para procesos de planeación urbana pues permite adelantarse a situaciones futuras que quizá representen graves conflictos para los tomadores de decisiones y, además, da lugar a corregir tendencias de crecimiento y expansión de la ciudad, una vez que se operan las variables de política y gestión, en especial la restricción al uso de suelo.

El modelo hace posible conocer las tendencias de crecimiento y expansión urbanas para entender la urbanización de la ciudad que, si bien presentará crecimientos en todos los puntos cardinales, su tendencia principal será hacia el norte y el nororiente. Por ello los municipios involucrados deberían prepararse en conjunto con los gobiernos de la Ciudad de México, y de los estados de México y de Hidalgo, así como trazar estrategias de control y manejo del crecimiento urbano a fin de preservar la funcionalidad y la calidad de vida de todos sus habitantes de aquí al 2040.

El modelo ayuda a entender mejor los factores que influyen de manera decisiva en el crecimiento y la expansión de la ciudad, así como la observancia de las consecuencias del nulo o casi nulo control del uso de suelo en los espacios urbanos, esto es, cómo el crecimiento horizontal de la Ciudad de México será cada vez más un problema para los gobiernos involucrados y cómo los niveles de inversión deberán ser cada vez mayores. De ahí que las economías de aglomeración, las fuerzas de concentración y dispersión (que a su vez operan en condiciones de rentabilidad territorial), y la formación de áreas urbanas de mercado al interior de la ciudad sean factores insoslayables, los cuales no se toman en cuenta en los planes y las políticas de desarrollo urbano de ciudades como la capital mexicana.

Más allá de parecer una curiosidad técnica o computacional, los modelos de simulación constituyen una herramienta muy útil en diversos fenómenos. En el caso de los procesos de expansión urbana y crecimiento económico de las ciudades, con claridad pueden desempeñar un papel central en la toma de decisiones, pues más allá de parecer una bola de cristal, marcan con objetividad los riesgos de un crecimien- 
to excesivo o de la desatención a una problemática urbana compleja. Las ciudades en el mundo son entes de gran importancia debido a su concentración económica y poblacional. Por este hecho, los esfuerzos en planear el crecimiento de las ciudades deben incrementarse antes de sufrir crisis sin precedentes.

En el caso específico de las ciudades mexicanas, no se tienen instrumentos suficientes para un análisis prospectivo. Los procesos de planeación en México, y sobre todo los referidos al crecimiento de las ciudades, tienden a parecer simples ejercicios académicos de nivel medio o básico. Se cree que la aplicación de promedios móviles o el cálculo de tendencias lineales es suficiente para conocer el futuro del crecimiento demográfico y socioeconómico.

Baste recordar, por ejemplo, el Plan de Ordenación de la Zona Metropolitana del Valle de México (POZMVM) (1998) (considerado el ejercicio más serio en materia de planeación urbana para la Ciudad de México), el cual es un estudio valioso en muchos aspectos, pero insuficiente porque contempla supuestos para sus pronósticos que no se cumplirán. Tampoco se explica la localización de las actividades económicas ni poblacionales, ni se señalan las posibles zonas de crecimiento en el futuro ni sus causas.

El modelo presentado, como cualquier modelo, tiene limitaciones naturales igual que todo ejercicio prospectivo, sin embargo, permite reajustar las tendencias en función de contar con nueva información. Asimismo, es posible conocer las nuevas áreas con mayor probabilidad de urbanización y realizar análisis de diferentes decisiones de política (a través de la restricción del uso de suelo). Por ello, los ejercicios de simulación urbana que consideran la perspectiva territorial tienen amplias posibilidades de que los tomadores de decisiones y los planeadores urbanos los utilicen de manera seria.

En relación con la Ciudad de México, a partir del modelo prospectivo se obtienen conclusiones muy interesantes e incluso señala los principales peligros del crecimiento horizontal ilimitado que la ciudad ha experimentado desde su fundación, esto es, costos urbanos crecientes (como contaminación vehicular e industrial, sobrepoblación, incremento en niveles de inseguridad, accidentes y alargamiento de los tiempos de traslado) que conlleva a la demanda de nuevas soluciones y nuevos servicios urbanos, los cuales a su vez demandan más presupuestos.

Hacia el año 2040, la ZMCM contaría con casi 96 municipios y delegaciones; por ello habría que preguntarse si hay preparación para afrontar los costos urbanos que hoy no se contemplan en los planes. Desde el 2012, se propuso que el Estado de Hidalgo incorpore 20 municipios a la ZMCM, lo cual es aceptable desde el punto de vista de la planeación preventiva. No obstante, de acuerdo con los resultados del modelo 
prospectivo, no todos estos municipios hidalguenses contendrían el área urbana de la metrópoli en el mediano plazo; a su vez, deben considerarse otros pertenecientes a entidades como Puebla, Tlaxcala y Morelos. Por esta razón, los esfuerzos actuales para que sólo algunos de estos municipios se incorporen a esta área de planeación no tienen sentido, pero sí deberían invertirse recursos presupuestales en territorios con gran probabilidad de incorporarse a la ZMCM. Además, estos otros estados deben incorporar nuevos ordenamientos jurídicos y esfuerzos de coordinación metropolitana en conjunto con la Ciudad de México, y los Estados de Hidalgo y de México. Asimismo, de acuerdo con los resultados del modelo prospectivo, las nuevas áreas urbanizadas requerirán nuevos servicios urbanos (como transporte público, vialidades, energía eléctrica, agua potable, drenaje, mercados, escuelas, parques, y otros); tal es el caso de municipios, como Axapusco, Apaxco, Tequixquiac o Hueypoxtla, lejanos desde un punto de vista geográfico del centro histórico de la Ciudad de México. Hoy día no se cuenta con una estimación de los costos de esta nueva urbanización.

Por último, el modelo prospectivo es útil para comprender lo pernicioso de no actuar contra la tendencia al crecimiento horizontal de las ciudades, en particular la expansión desde el centro de la Ciudad de México. Es necesario fomentar el interés por el crecimiento vertical y por el auténtico control del uso de suelo, e incorporarlo en los planes de desarrollo urbano, y en toda política estatal y federal de financiamiento a la vivienda. Es fundamental involucrar a los gobiernos locales en estas políticas para contemplar juntos los nuevos requerimientos y las necesidades de la metrópoli.

En el presente, las reflexiones se hacen en torno a los resultados del modelo prospectivo con datos de la ZMCM y debe extenderse a las demás ciudades mexicanas, pues muchas de ellas también crecen con descuido en su desarrollo urbano, por lo cual es urgente adquirir conciencia del mismo antes de carecer de soluciones viables.

\section{BIBLIOGRAFÍA}

Clarke, K.C., y L. Gaydos. "Loose-coupling a cellular automaton model and GIS: long-term urban growth prediction for San Francisco and Washington/Baltimore», International Journal of Geographic Information Science, vol. 12, pp. 699-714.

Gómez, R. A. (s.f.) «Autómatas Celulares», obtenido en: http://www.monografias.com/traba jos-pdf/automatas-celulares/automatas-celulares.pdf

González Videgaray, Ma. del Carmen. Modelos y Simulación. Naucalpan, Edo. de México: FES Acatlán UNAM, 1996. 
Li, X., y A. Yeh. "Modelling sustainable urban development by the integration of constrained cellular automata and GIS.» International Journal of Geographical Information Science vol. 14 (2000): 131-152.

Liu, Y., Phinn, S.R.: Developing a Cellular Automaton Model of Urban Growth Incorporating Fuzzy Set Approaches. Proceedings of the 6th International Conference on GeoComputation, University of Queensland, Brisbane, Australia (2001).

Márquez L., Bogart Yail. Análisis y Simulación del crecimiento urbano utilizando sistemas de información geográficos: Ciudad Juárez, Chihuahua. Tesis de Maestría. Tijuana, B.C., México: El Colegio de la Frontera Norte AC, 2008.

Pérez-Miranda et. al., R. «Predicción espacial de cambios del uso de suelo en Texcoco, Estado de México.» Revista mexicana de ciencias forestales vol. 2, nº No. 5 (2011).

Prawda W., Juan. Métodos y Modelos de Investigación de Operaciones. Vol. 2. 2 vols. Ciudad de México: Limusa, 1988.

Ramírez H., Roberto. Crecimiento urbano policéntrico y expansión de la Zona Metropolitana de la Ciudad de México y sus impactos en el desarrollo urbano 1990-2040. Aplicación de un modelo de simulación para prospectiva territorial. Tesis doctoral. Ciudad de México: UNAM, 2016a.

_ La expansión metropolitana de la Ciudad de México y la dinámica de su estructura policéntrica: Un análisis de las fuerzas de dispersión y concentración económicas como factores de crecimiento urbano entre 1993 y 2008. Ciudad de México: IIEc UNAM, 2016b.

Shubik, Martin. «Simulation of the Industry and the Firm.» American Economic Review, vol. 50, No. 5 (1960): 908-909.

Suárez L., Manuel, y Javier Delgado. "La expansión urbana probable de la Ciudad de México. Un escenario pesimista y dos alternativos para el año 2020.» Editado por El Colegio de México. Estudios Demográficos y Urbanos vol. 22 no. 1 (2007).

White, R., G. Engelen, y I. Uljee. «The use of constrained cellular automata for high-resolution modelling of urban land-use dynamics.» Environment and Planning B vol. 24 (1997): 323343.

White, R., y G. Engelen. «High resolution integrated modelling of the spatial dynamics of urban and regional systems.» Computers, Environment and Urban Systems 24 (2000): 383-400.

Wolfram, S. «Cellular Automaton Fluids 1: Basic Theory.» Journal of Statistical Physics vol. 45 (November 1986): 56 pp.

Wu, F., y C. Webster. «Simulation of land development through the integration of cellular automata and multicriteria evaluation.» Environment and planning B, 1998: 103-126. 
SEGUNDA SECCIÓN 



\section{La calidad de vida objetiva y su medición en la Zona Metropolitana del Valle de México}

Isalia Nava Bolaños, Flor Araceli Ruiz Peña, Sergio de la Vega Estrada, Edgar Buenrostro Salazar y Adolfo Sánchez Almanza

\section{INTRODUCCIÓN}

En este capítulo, la calidad de vida se define como la condición de bienestar general de las personas y las sociedades expresada en la satisfacción de necesidades objetivas y subjetivas en un espacio y tiempo determinados. Es un concepto multidimensional y multifactorial susceptible de medición según la satisfacción de dos grandes grupos de necesidades: a) las objetivas que incluyen el nivel de vida referido al ingreso o el consumo, y las necesidades básicas (como alimentación, salud, educación, vivienda y entorno), y b) las subjetivas, es decir, las percepciones que se refieren a la satisfacción, los valores, la felicidad y la aspiración de las personas.

La hipótesis general de los autores es que en la Zona Metropolitana del Valle de México (ZMVM) existen condiciones de desigualdad socioespacial objetiva que impiden una calidad de vida más igualitaria y justa de acuerdo con el grado de satisfacción de las necesidades básicas de las personas y la cohesión social, con fuertes contrastes entre las áreas centrales y las periféricas en el contexto de un modelo metropolitano tipo centro-periferia, con nodos internos que prefiguran una estructura policéntrica.

Las hipótesis específicas son dos: a) la calidad de vida objetiva es más satisfactoria y homogénea en territorios metropolitanos centrales y se reduce de acuerdo con su alejamiento hacia los contornos periféricos, y b) en "manzanas" más alejadas del centro y de subcentros intrametropolitanos, la calidad de vida disminuye de manera gradual generando un patrón de desigualdad e injusticia socioespacial.

La respuesta a las hipótesis implicó la elaboración de varios cálculos, entre los 
cuales destaca la medición de la calidad de vida para la ZMvм y su georreferenciación, lo cual es el propósito de este capítulo.

\section{LA ZONA METROPOLITANA DEL VALLE DE MÉXICO}

El análisis de la calidad de vida se realiza para 96 unidades politico-administrativas localizadas en el Estado de México, el Estado de Hidalgo y la Ciudad de México, lo cual permite una mejor valoración del bienestar de la población en un contexto de alto crecimiento demográfico, continuas expansiones físicas y funcionales de la metrópoli, y de la prospectiva de largo plazo en el entorno regional (capítulo. 3). Esta delimitación ofrece un universo de estudio adecuado para contrastar las condiciones sociales desde espacios centrales con niveles muy altos hasta espacios periféricos atrasados con muy baja calidad de vida. Asimismo, se toma en cuenta la localización de las delegaciones y los municipios de acuerdo con la etapa en que se incorporaron o que lo harán a la ZMVM' (mapa 4-1).

\section{ESTIMACIÓN DEL ÍNDICE DE CALIDAD DE VIDA OBJETIVO}

El índice de calidad de vida objetivo (ICvo) se refiere al bienestar objetivo, sustentado en los valores de uso que satisfacen las necesidades de las personas, mismo que se construye al considerar dimensiones, variables e indicadores ponderados y comparables. La medición de la calidad de vida de la población se realiza a partir de la base de microdatos obtenida en los hogares y viviendas censales, con las respuestas a las preguntas aplicadas en los cuestionarios del "Censo de población y vivienda del año 2010" en la ZMVM. El ıCVO se calcula al inicio por "manzana" (la unidad de medida territorial más pequeña) y después para las escalas de colonia o barrio (capítulo. 5) y de delegación o municipio. En este sentido, se enfatiza el carácter espacial del bienestar con una clasificación para todas las escalas metropolitanas. El alcance del índice de calidad de vida objetivo está condicionado a la disponibilidad de los datos más desagregados y es de tipo estático ya que utiliza sólo las bases de microdatos del año 2010.

El ICVO minimiza los errores de medición porque no es de tipo dicotómico, sino que se estima con los valores de los indicadores de satisfacción de necesidades, los

${ }^{1}$ Las delegaciones y los municipios considerados en la ZMVM se definen con base en los resultados del capítulo 3 de este libro y la delimitación del "Programa de ordenación de la ZMVM" (2012); asimismo, se clasifican por contorno metropolitano a partir de datos de Suárez y Delgado (2007). 


\section{Mapa 4-1}

Zona Metropolitana del Valle de México. Delimitación por contorno según la etapa de incorporación.

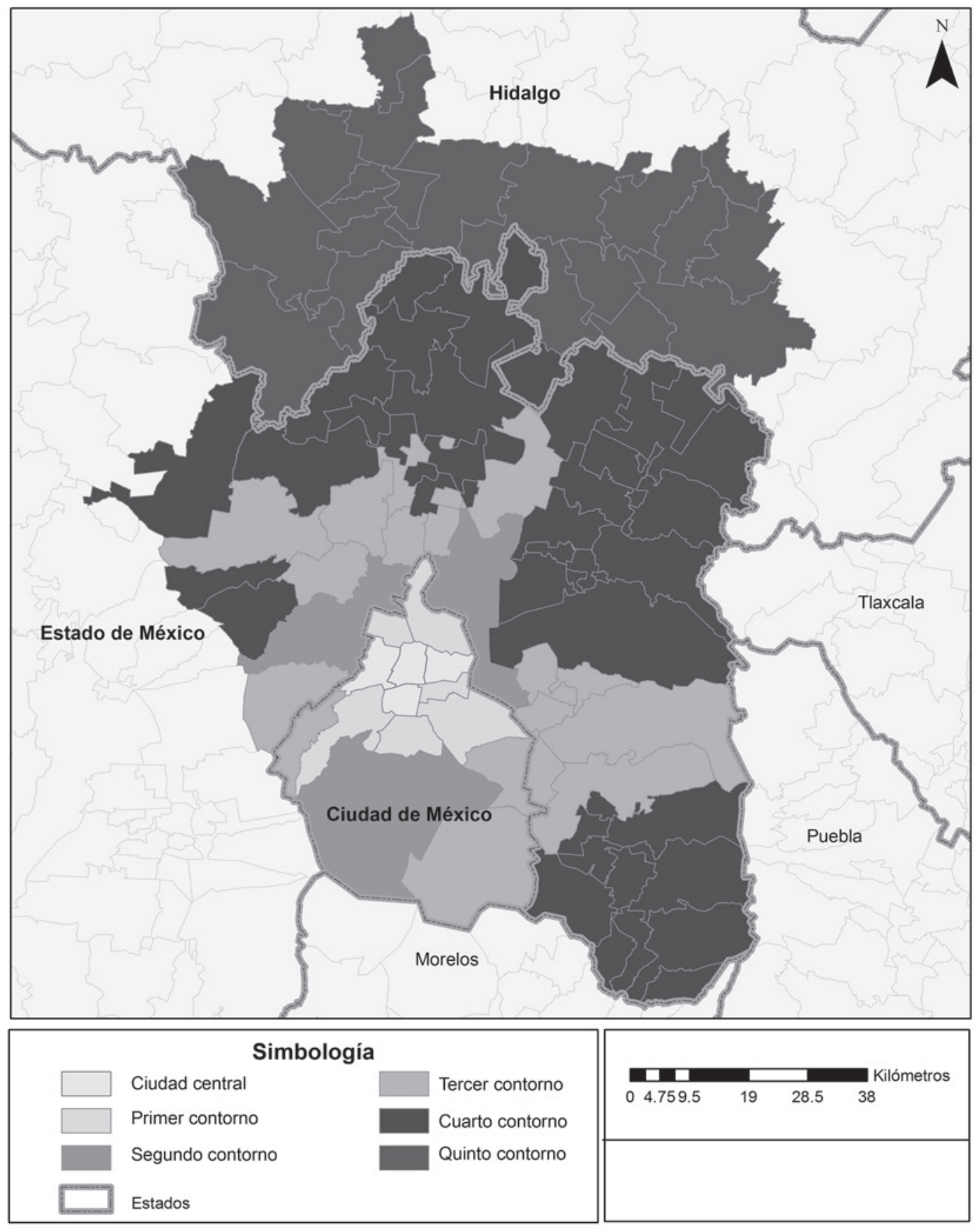

Fuente: elaboración propia con datos de Ramírez, 2016, y Suárez y Delgado, 2007. 
cuales se ponderan de acuerdo con su mayor o menor grado de calidad de vida y, con ello, se conserva la riqueza de la información censal, la única existente con este nivel de desagregación y de cobertura universal. No se definen umbrales normativos por indicador, pero si se valoran de manera gradual sus máximos y mínimos en la ZMVM, sin adoptar juicios de valor respecto a las condiciones de la calidad de vida en la metrópoli. En el cálculo del índice, no se incluyen otras dimensiones, como el ingreso o el tiempo (para los cuales no hay información en microdatos censales), por lo cual refleja sólo una parte del bienestar integral objetivo de las personas.

Es importante señalar que la principal contribución de la estimación y la estratificación del ICVO es de tipo espacial y permite comparar la calidad de vida ubicada de la manera más desagregada en el territorio. Con esto se ofrece un diagnóstico basal que apoya el diseño de las políticas públicas orientadas al logro de la justicia socioespacial. Esta noción remite al mínimo vital de subsistencia digna que garantiza el marco jurídico vigente, aunque diferenciado en la zona metropolitana. Asimismo, se desarrollan varios análisis específicos que toman como referencia la misma base de datos del índice.

La medición resulta heterogénea y compleja porque el concepto de calidad de vida se nutre de contenido a partir de los distintos componentes considerados. En este capítulo, la medición de la calidad de vida en la zмvм se realiza a partir de:

a) Los elementos teóricos y conceptuales explicados en el capítulo 1 .

b) Las restricciones derivadas de la disponibilidad de información estadística.

c) Las bases de georreferenciación para las unidades territoriales, según los datos d) el INEGI en el "Censo de población y vivienda del año 2010" y de otras fuentes, como las generadas por el Instituto Nacional Electoral (INE) o la Secretaría de Desarrollo Urbano y Vivienda (Seduvi) para el caso de la Ciudad de México.

\section{VARIABLES E INDICADORES DEL ÍNDICE DE CALIDAD DE VIDA OBJETIVO}

La medición de la calidad de vida objetivo se realiza con base en el "Censo de población y vivienda del año 2010" que levanta el INEGI, a partir de los datos captados en dos instrumentos. El primero, es el cuestionario básico que proporciona información sobre las variables de las personas (salud y educación), así como de las viviendas (clase, material, espacio, servicios e instalaciones) y bienes y acceso a tecnologías de información y comunicación (TIC). El segundo, es el cuestionario de entorno urbano que contiene información por "manzana" sobre infraestructura vial, mobilia- 
rio y servicios urbanos; éste abre el panorama hacia las condiciones de los espacios exteriores públicos donde la población transita y realiza parte de su vida social. Las cifras informadas se refieren a las condiciones que presentan las localidades de 5 000 habitantes y más. A partir de las variables e indicadores seleccionados de ambos cuestionarios, se estimó el ICVO con tres dimensiones y ocho subdimensiones. Para cumplir con los criterios de confiabilidad, comparabilidad y confidencialidad indispensables para las estimaciones del ICVO, la única fuente existente es el censo referido. Asimismo, esta medición se orienta de modo fundamental al análisis espacial y no existe más información estadística desagregada sobre la calidad de vida en la escala "manzana" para el año 2010, con la cual elaborar una estimación más amplia.

A partir de la revisión bibliográfica y de la información disponible en la base de microdatos, se seleccionaron las variables que integran el ICVO que incluyen:

a) Personas: derechohabiencia a servicios de salud (primera institución), discapacidad (no tiene), asistencia a la escuela, escolaridad (grado y nivel académico), escolaridad acumulada (años aprobados acumulados) y alfabetismo.

b) Viviendas: clase de vivienda particular, pisos, cuartos dormitorio, total de cuartos, electricidad, agua entubada, excusado, admisión de agua, drenaje, bienes y tecnologías de información y comunicación (TIC) (radio, televisor, refrigerador, lavadora, automóvil o camioneta, computadora, línea telefónica fija, teléfono celular e internet).

c) Entorno: disponibilidad de pavimento, banquetas, plantas de ornato, rampa para sillas de ruedas, alumbrado público, drenaje pluvial y transporte colectivo; acceso para peatones y automóviles; presencia de comercios semifijo y ambulante (figura 4-1).

\section{Variables del cuestionario básico: personas y viviendas}

Las variables y los indicadores de las dimensiones de personas y viviendas se obtienen a partir de la información estadística del cuestionario básico que se aplica a toda la población.

Dimensión personas. Se integra con las subdimensiones de salud y educación:

a) Salud. La presencia de servicios de salud facilita diversos aspectos de la vida de las personas y contribuye al diagnóstico y la atención del deterioro en el estado de salud. Se trata de un mecanismo que otorga protección contra contingencias derivadas de enfermedades y discapacidades. Por otro lado, la ausencia de discapacidad incrementa las oportunidades de la población, al tener mayor movilidad, menor 
Figura 4-1

Dimensiones, subdimensiones y variables del índice de calidad de vida objetivo

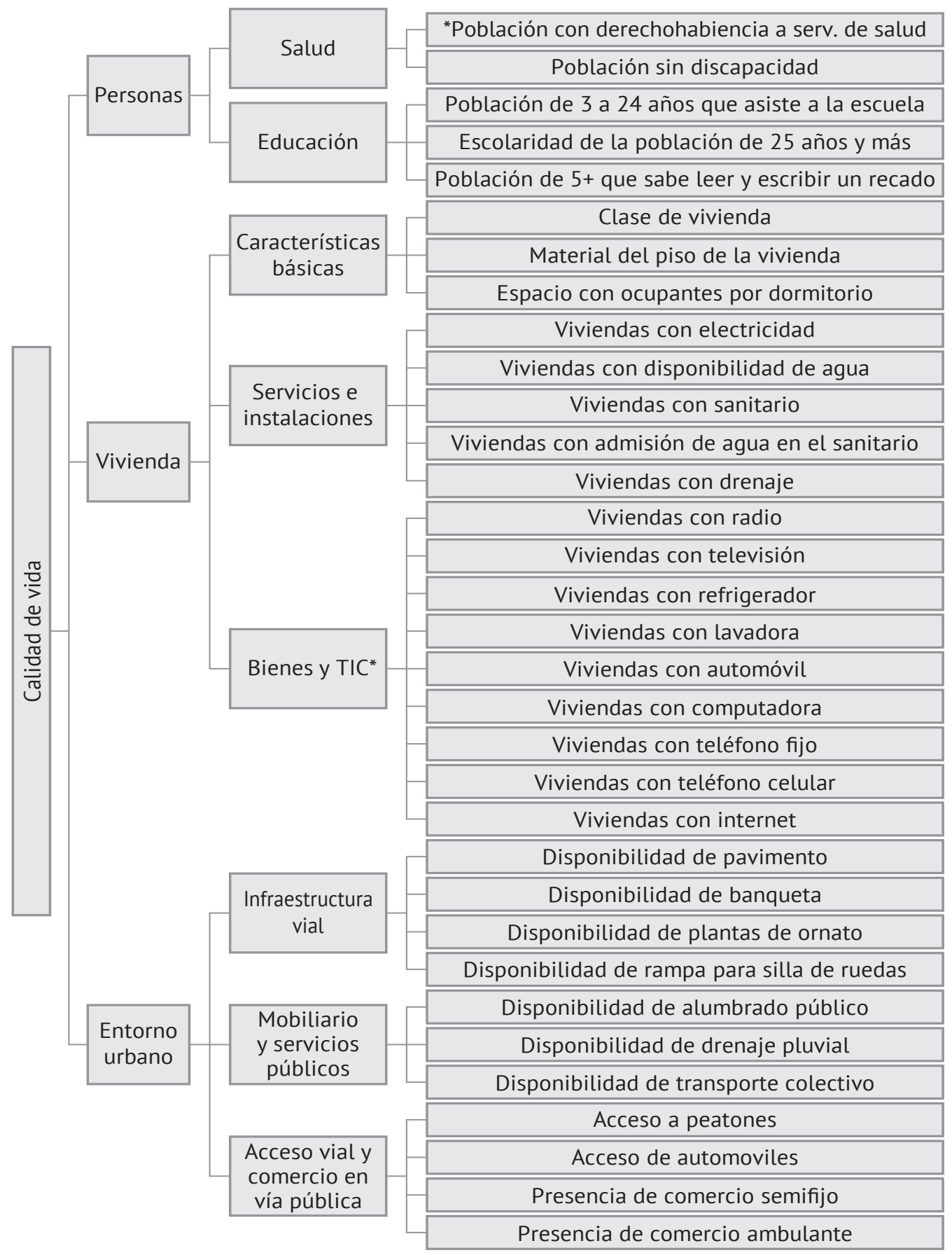

*TIC, tecnologías de información y comunicación.

Fuente: Elaboración propia con datos del Instituto Nacional de Estadística y Geografía (INEGI), 2010. 
dependencia para realizar las actividades cotidianas y enfrentar menor discriminación en diversas áreas de inclusión social, como la escuela o el mercado laboral. La subdimensión salud se construye con base en dos variables: 1) Derechohabiencia a servicios de salud, que identifica a las personas con derecho a los servicios médicos en instituciones públicas o privadas, y 2) ausencia de discapacidad, la cual ubica a la población que en su vida diaria no presenta dificultades para llevar a cabo las tareas básicas como caminar, moverse, subir o bajar, ver (aun con anteojos), hablar, comunicarse o conversar, oír (aun con aparato auditivo), vestirse, bañarse o comer, poner atención o aprender cosas sencillas; o presentar alguna limitación mental.

b) Educación. La formación escolar es un factor primordial para el desarrollo personal y social de la población. Con mayor educación se puede acceder a empleos con mejores prestaciones y remuneraciones; además, determina mucho el nivel de salud y socioeconómico. La calidad de vida de las personas mejora cuando cuentan con alfabetismo, escolaridad y mejor preparación. La subdimensión educación se integra con tres variables: 1) asistencia escolar, la cual se refiere a las personas de tres años cumplidos o más que al momento del censo asistían a un centro de enseñanza del sistema educativo nacional, de forma independiente de su modalidad (pública, privada, escolarizada, abierta, a distancia, etc.); 2) escolaridad, que da cuenta del último grado y el nivel que aprobaron las personas de tres años cumplidos de edad o más, y 3) aptitud para leer y escribir y alfabetismo, lo cual identifica si las personas de cinco años cumplidos o más saben leer y escribir un recado. A partir del censo de 1990 se considera la aptitud para leer y escribir para la población menor de 15 años de edad, mientras que para la población de 15 años y más se toma en cuenta la condición de alfabetismo.

Dimensión vivienda. Se integra con las tres subdimensiones siguientes:

a) Características básicas: contar con una vivienda adecuada es un factor que favorece la calidad de vida de las personas. Se considera que la vivienda vista como estructura es un espacio que otorga protección ambiental frente a las condiciones y los fenómenos que se presentan en el exterior y, a medida que la estructura externa se integre de materiales resistentes y durables, brindará mayor protección. Para influir en la calidad de vida de las personas, las viviendas deben ofrecer espacios habitables y funcionales, de otro modo pueden tener lugar problemas, como el hacinamiento, con repercusiones en el desarrollo de las personas (Celade, 2006). La subdimensión característica básica de la vivienda considera las siguientes variables:

- Clase de vivienda: permite clasificar a las viviendas particulares con base en el tipo de construcción, independencia y propósito de la edificación. 
- Material del piso de la vivienda: da cuenta del material que predomina en los pisos de las viviendas particulares.

- Espacio con ocupantes por dormitorio: se refiere a los cuartos de la vivienda que se utilizan para dormir, sin tomar en cuenta los pasillos e independientemente de que se realicen otras actividades.

b) Servicios e instalaciones. El saneamiento en la vivienda es otro de los elementos que contribuye a la calidad de vida. En la medida en que las viviendas cuentan con servicios de salubridad adecuados, las personas pueden disponer de condiciones domésticas más seguras y saludables. Además, las instalaciones proporcionan comodidad y aseguran mayores facilidades al conjunto de residentes. La subdimensión servicios e instalaciones se compone de las variables siguientes:

- Viviendas con electricidad: cuando hay luz eléctrica en la vivienda.

- Viviendas con disponibilidad de agua: da cuenta de los mecanismos a través de los cuales las personas se abastecen de agua, ya sea para consumo personal o doméstico.

- Viviendas con sanitario: cuando existe una instalación sanitaria que se utilice para la eliminación de los desechos humanos.

- Viviendas con admisión de agua en el sanitario: permite clasificar el servicio sanitario con base en el uso de agua para el desalojo de los desechos humanos. - Viviendas con drenaje: hace posible identificar el tipo de sistema de tuberías a través de las cuales se desaloja el agua que se utiliza en el inodoro, el fregadero, la regadera, etcétera.

c) Bienes y tecnologías de información y comunicación. Los bienes en la vivienda se refieren a los aparatos que reducen las tareas domésticas y que brindan comodidad en los traslados. En este conjunto, se encuentran las siguientes: refrigerador, lavadora y automóvil.

La disponibilidad de tecnologías de información y comunicación (TIC) se refiere a los aparatos y los servicios a través de los cuales es posible recibir y reproducir señales, procesar datos y comunicar a las personas. En esta categoría, se incluyen: radio, televisión, computadora, teléfono fijo, teléfono celular e internet.

\section{Variables del cuestionario de entorno urbano}

La dimensión de entorno urbano se expresa en tres subdimensiones: a) infraestructura vial; b) mobiliario y servicios públicos, y c) accesibilidad vial y comercio en vía 
pública. Las tres se observan en las localidades de 5000 habitantes y más, y estas a su vez, se construyen a partir de 11 variables. Cada una de estas hace referencia a las características de las "manzanas", por lo cual contienen información categórica que especifica su presencia o ausencia. Cada "manzana" se clasifica con tres criterios: 1) presencia en todas las vialidades; 2) presencia en alguna vialidad, o 3) ausencia en cualquier vialidad. Se descartaron las "manzanas" no especificadas y los conjuntos habitacionales ya que no proporcionaban información suficiente para medir sus condiciones de entorno urbano. A continuación, se describen de forma breve los indicadores y las variables del entorno urbano.

a) Infraestructura vial. La infraestructura vial se refiere a las obras y demás elementos físicos dispuestos en la red vial, que tienen como propósito posibilitar y facilitar el tránsito de las personas, tanto a pie como en vehículo. Este indicador considera cuatro variables:

- Disponibilidad de pavimento. El recubrimiento en las vialidades es un elemento constructivo que constituye un signo de bienestar y una meta de cobertura deseable, ya que contribuye a la reducción de enfermedades respiratorias, digestivas y dermatológicas; favorece el desplazamiento de vehículos y, con ello, el transporte de personas, bienes y servicios; además, mejora la imagen de los centros de población. El recubrimiento se considera como cualquier tipo de revestimiento que presente la calle, ya sea asfalto o pavimento, concreto, adoquines o piedras.

- Disponibilidad de banqueta. Las banquetas que se construyen en las aceras de las vialidades están destinadas para el desplazamiento de personas a pie y deben tener una altura mayor que el arroyo vehicular para asegurar la integridad física y la comodidad al peatón.

- Disponibilidad de plantas de ornato. La existencia de vegetación en el ámbito urbano tiene cualidades funcionales y estéticas. Los árboles y las plantas reducen la fuerza del viento, controlan la erosión del suelo que puede provocar la Iluvia, protegen del polvo y del asoleamiento a las edificaciones, proporcionan un paisaje estético agradable, delimitan fronteras entre inmuebles e imprimen un toque diferencial a las edificaciones, sin importar la cantidad o el predominio en las aceras de las vialidades que rodean las "manzanas".

- Disponibilidad de rampa para sillas de ruedas. Su inclusión en la temática del entorno urbano tiene el propósito de conocer si en las vialidades con banqueta 
existen rampas, por lo general en las esquinas, que faciliten el desplazamiento de personas en silla de ruedas.

b) Mobiliario y servicios públicos. Esta subdimensión refleja beneficios directos para la población y, en combinación con las características de las viviendas, permite conocer la cobertura de servicios básicos. Las variables son las siguientes.

- Disponibilidad de alumbrado público. El alumbrado público brinda condiciones mínimas de iluminación para el tránsito de peatones o vehículos y es de primer orden con respecto a otra clase de mobiliario por razones de seguridad para la población, al brindar una visión confortable en la noche y en lugares oscuros, facilitar el tránsito peatonal y vehicular, evitar accidentes nocturnos, contribuir a la prevención de delitos y apoyar en la protección policiaca, además de que propicia el funcionamiento de establecimientos económicos, entre otros aspectos positivos. Con esta variable, se identifican las "manzanas" que cuentan con al menos una luminaria en cada vialidad que la circunda.

- Disponibilidad de drenaje pluvial. La planeación y la construcción de un sistema de drenaje pluvial en los centros urbanos es necesaria para evitar inundaciones de las vialidades y edificaciones, pues la misma construcción y la concentración de casas, edificios, calles y estacionamientos modifican los cauces de escurrimiento natural y propician la creación de superficies poco permeables. La disponibilidad de drenaje pluvial se identifica por la existencia de al menos una alcantarilla o coladera en la vialidad, sin importar su ubicación o forma, y puede hallarse en la misma vialidad, pero en la acera de enfrente; su existencia controla los escurrimientos de agua y evita inundaciones, y hace posible el tratamiento o reaprovechamiento de agua.

- Disponibilidad de transporte colectivo. Este es un servicio básico que permite el desplazamiento de personas de un lugar a otro, ahorra tiempo y esfuerzo y significa un impulso en las actividades económicas; su carencia es un factor que limita el desarrollo de las actividades y las oportunidades de la población y reduce la calidad de vida.

c) Acceso vial y comercio en vía pública. Esta subdimensión considera situaciones que limitan u obstaculizan el tránsito en las vías públicas de peatones o automóviles. Dichas restricciones se pueden explicar por cuestiones de seguridad, privacidad o exclusividad, o por la presencia de puestos de comercio sobre las ban- 
quetas y los arroyos vehiculares que afectan el desplazamiento de la población. Su construcción parte de cuatro variables:

- 1. Accesos de peatones y 2. de automóviles. En ciertas zonas de las ciudades, los colonos instalan algún tipo de obstáculo físico para restringir o impedir el tránsito por las calles, tanto a personas no residentes como a vehículos, práctica que puede considerarse justificable, pero que le quita el carácter público a la vialidad y contraviene el derecho de desplazamiento al apropiarse de los espacios públicos y coartar la circulación de transeúntes.

- 1. Presencia de comercio semifijo y 2. de comercio ambulante. El comercio informal constituye una alternativa de ocupación y una forma de obtener ingresos para muchas personas que no tienen oportunidades de empleo formal. En las ciudades, este fenómeno ha adquirido relevancia y puede observarse en los espacios públicos: calles, banquetas y plazas, muchas de ellas no diseñadas para dar cabida a este tipo de instalaciones ya sea de manera temporal o indefinida. Al respecto, la Ley General de Asentamientos Humanos establece que las autoridades son responsables del ordenamiento territorial y señala la importancia de "crear y mejorar las condiciones favorables para la relación adecuada entre zonas de trabajo, vivienda y recreación", lo cual implica habilitar mercados y establecimientos para reubicar los comercios ambulante y semifijo. El fenómeno es difícil de controlar, aunque los reglamentos de tránsito y vialidad contemplan la instalación de casetas de comercio semifijo (puestos de periódicos, flores, confites y juegos de azar para la asistencia pública), hay lugares donde se ha extendido afectando la funcionalidad de las vías públicas y el bienestar social.

\section{CÁLCULO DEL ÍNDICE DE CALIDAD DE VIDA OBJETIVO}

El procedimiento metodológico para el cálculo del Icvo consistió en tres etapas: normalización de datos, agregación y ponderación.

\section{Normalización de datos}

Variables del cuestionario básico

La sintaxis que el equipo de investigación de los autores elaboró para solicitar la base procesada al Instituto Nacional de Estadística y Geografía (INEGI) estableció lo siguiente: primero, el "rango válido" definido por el INEGı para cada respuesta se ordenó de mayor a menor valor, es decir, la categoría que corresponde a una mejor 
calidad de vida siempre tiene el valor de 1 y en la calificación de los autores se le otorga el valor más alto. Por ejemplo, en la variable clase de vivienda, la mejor condición en términos de calidad de vida corresponde a "casa independiente" que originalmente aparece con valor 1; por tanto, se recodificó con el valor más alto, que en este caso es 7 (cuadro 4-1).

Cuadro 4-1

Dimensión vivienda. Recodificación de rangos de mayor a menor valor

\begin{tabular}{lcc}
\hline Pregunta y categoría & $\begin{array}{c}\text { Rango } \\
\text { válido }\end{array}$ & $\begin{array}{c}\text { Nueva definición } \\
\text { de rango válido }\end{array}$ \\
\hline Clase de vivienda particular & $\begin{array}{c}\{1 . .7,9, \mathrm{~b}\} \\
\text { Casa independiente }\end{array}$ & 7 \\
Departamento en edificio & 2 & 6 \\
Vivienda en vecindad & 3 & 5 \\
Vivienda en cuarto de azotea & 4 & 4 \\
Local no construido para habitación & 5 & 3 \\
Vivienda móvil & 6 & 2 \\
Refugio & 7 & 1 \\
No especificado & 9 & \\
Blanco por pase & $\mathrm{b}$ & \\
\hline
\end{tabular}

Fuente: Elaboración propia con datos del Instituto Nacional de Estadística y Geografía (INEGI), 2010.

\section{Cuadro 4-2}

Dimensión personas. Recodificación de rangos de mayor a menor valor en servicios médicos

\begin{tabular}{lcc}
\hline Pregunta y categoría & $\begin{array}{c}\text { Rango } \\
\text { válido }\end{array}$ & $\begin{array}{c}\text { Nueva definición } \\
\text { de rango válido }\end{array}$ \\
\hline Tiene derecho a servicios médicos (primera institución): & $\{1 . .9\}$ & 3 \\
Seguro Social (IMSS) & 1 & 3 \\
ISSSTE & 2 & 3 \\
ISSSTE estatal & 3 & 3 \\
Pemex, Defensa o Marina & 4 & 2 \\
"Seguro popular" o para una “Nueva generación" & 5 & 3 \\
Seguro privado & 6 & 2 \\
Otra institución & 7 & 1 \\
No tiene derecho a servicios médicos & 8 & $\mathrm{NE}$ \\
No especificado & 9 & 2 \\
\hline
\end{tabular}

IMSS, Instituto Mexicano del Seguro Social; ISSSTE, Instituto de Seguridad y Servicios Sociales de los Trabajadores del Estado.

Fuente: Elaboración propia con datos del Instituto Nacional de Estadística y Geografía (INEGI), 2010. 


\section{Cuadro 4-3}

Dimensión personas. Recodificación de rangos de mayor a menor valor en escolaridad

\begin{tabular}{|c|c|c|}
\hline Pregunta y categoría & $\begin{array}{l}\text { Rango } \\
\text { válido }\end{array}$ & $\begin{array}{l}\text { Nueva definición } \\
\text { de rango válido }\end{array}$ \\
\hline ¿Cuál es el último año o grado que aprobó en la escuela? (nivel) & $\{00 . .12,99, \mathrm{~b}\}$ & \\
\hline Ninguno & 0 & 1 \\
\hline Preescolar & 1 & 2 \\
\hline Primaria & 2 & 3 \\
\hline Secundaria & 3 & 4 \\
\hline Preparatoria o bachillerato & 4 & 5 \\
\hline Normal básica & 5 & 6 \\
\hline Estudios técnicos o comerciales con primaria terminada & 6 & 7 \\
\hline Estudios técnicos o comerciales con secundaria terminada & 7 & 8 \\
\hline Estudios técnicos o comerciales con preparatoria terminada & 8 & 9 \\
\hline Normal de licenciatura & 9 & 10 \\
\hline Licenciatura o profesional & 10 & 10 \\
\hline Maestría & 11 & 11 \\
\hline Doctorado & 12 & 12 \\
\hline No especificado & 99 & NE \\
\hline Blanco por pase & $b$ & NE \\
\hline
\end{tabular}

Fuente: Elaboración propia con datos del Instituto Nacional de Estadística y Geografía (INEGI), 2010.

Segundo, las variables de derechohabiencia a servicios de salud y escolaridad se ponderaron por medio de las características del servicio. Por ejemplo, en términos de la calidad de vida de una persona, el derecho a servicios médicos es una variable relevante. Sin embargo, la calidad es mayor cuando la persona tiene acceso a los servicios que proporciona el Instituto Mexicano del Seguro Social (IMSS) o el Instituto de Seguridad y Servicios Sociales de los Trabajadores del Estado (ISSSTE), en comparación con la protección que otorga el Seguro Popular; ${ }^{2}$ por esta razón, se asigna un menor valor a este último (cuadros 4-2 y 4-3).

Tercero, con el objetivo de evitar los sesgos producidos por la escala de medida, antes de agregar las variables seleccionadas, se procedió a la normalización de los datos, a partir de la técnica de "reescalamiento", la cual "consiste en transformar los niveles de las variables para llevarlos al intervalo, al emplear la distancia entre los valores

${ }^{2}$ El total de intervenciones de salud del "Catálogo universal de servicios de salud del 2010" fue de 275 e incluyó 1407 enfermedades. Sin embargo, no abarcó el total de las enfermedades, y quedaron fuera varias, como tumores malignos de pulmón o de páncreas. 
máximos y mínimos que la variable adquiere cuando se consideran todos los datos de la variable de manera conjunta. La unidad de análisis de mayor desempeño tendrá un valor de 1 y, la de menor, 0" (Schuschny y Soto, 2009: 58) (cuadros 4-4 y 4-5).

$$
y_{t}^{i}=\frac{x_{t}^{i}-\min _{\forall p}\left(x_{t}^{i}\right)}{\max _{\forall p}\left(x_{t}^{i}\right)-\min _{\forall p}\left(x_{t}^{i}\right)} \in[0,1]
$$

\section{Cuadro 4-4}

Dimensión personas. Reescalamiento de variables de servicios médicos

\begin{tabular}{|c|c|c|c|}
\hline Pregunta y categoría & $\begin{array}{l}\text { Rango } \\
\text { válido }\end{array}$ & $\begin{array}{l}\text { Nueva definición } \\
\text { de rango válido }\end{array}$ & $\begin{array}{c}\text { Reescala- } \\
\text { miento }\end{array}$ \\
\hline Clase de Servicio médico & $\{1 . .7,9, \mathrm{~b}\}$ & & \\
\hline IMSS & 1 & 3 & 1 \\
\hline ISSSTE & 2 & 3 & 1 \\
\hline ISSSTE estatal & 3 & 3 & 1 \\
\hline Pemex, Defensa o Marina & 4 & 3 & 1 \\
\hline "Seguro Popular" o para una "Nueva generación" & 5 & 2 & 0.5 \\
\hline Seguro privado & 6 & 3 & 1 \\
\hline Otra institución & 7 & 2 & 0.5 \\
\hline No tiene derecho a servicios médicos & 8 & 1 & 0 \\
\hline No especificado & 9 & NE & NE \\
\hline
\end{tabular}

IMSS, Instituto Mexicano del Seguro Social; ISSSTE, Instituto de Seguridad y Servicios Sociales de los Trabajadores del Estado.

Fuente: Elaboración propia con datos del Instituto Nacional de Estadística y Geografía (INEGI), 2010.

Cuadro 4-5

Dimensión vivienda. Reescalamiento de variables de vivienda particular

\begin{tabular}{|c|c|c|c|}
\hline Pregunta y categoría & $\begin{array}{l}\text { Rango } \\
\text { válido }\end{array}$ & $\begin{array}{c}\text { Nueva definición } \\
\text { de rango válido }\end{array}$ & $\begin{array}{c}\text { Reescala } \\
\text { miento }\end{array}$ \\
\hline Clase de vivienda particular & $\{1 . .7,9, b\}$ & & \\
\hline Casa independiente & 1 & 7 & 1 \\
\hline Departamento en edificio & 2 & 6 & 0.83 \\
\hline Vivienda en vecindad & 3 & 5 & 0.67 \\
\hline Vivienda en cuarto de azotea & 4 & 4 & 0.5 \\
\hline Local no construido para habitación & 5 & 3 & 0.33 \\
\hline Vivienda móvil & 6 & 2 & 0.17 \\
\hline Refugio & 7 & 1 & 0 \\
\hline No especificado & 9 & $\mathrm{NE}$ & NE \\
\hline Blanco por pase & b & NE & NE \\
\hline
\end{tabular}

Fuente: Elaboración propia con datos del Instituto Nacional de Estadística y Geografía (INEGI), 2010. 
En las variables del cuestionario de entorno urbano, para mantener la misma escala de medida de las dimensiones anteriores, se normalizaron los datos; se definió si la presencia de la condición del entorno urbano a la que se refiere la variable se considera positiva o negativa y, a partir de ello, se reescaló a 0-1. Los valores cercanos a 1 presentan las mejores condiciones y, los cercanos a 0 , las peores. Por ejemplo, en disponibilidad de pavimento, una mejor condición es que cuenten con él todas las vialidades de la "manzana", es decir, un valor de 1 a esa categoría, y la peor condición sería que no se disponga de pavimento en ninguna de sus calles, por lo cual se le aplica un valor de 0 a esa categoría (cuadro 4-6).

En la variable de comercio semifijo, una mejor condición se da cuando no se encuentra en ninguna vialidad de la "manzana", otorgándole un valor de 1 a esa categoría; mientras que la peor condición se produce cuando existe en todas las vialidades, otorgándole un valor de 0 (cuadro 4-7).

\section{Ponderación}

\section{Cuadro 4-6}

Dimensión entorno urbano. Reescalamiento de variables en pavimento

\begin{tabular}{lcc}
\hline Pregunta y categoría & Rango válido & Reescalamiento \\
\hline Categoría de la manzana según la disponibilidad de pavimento & $\{1,2,3,4$ y 5$\}$ & 1 \\
en sus vialidades & & 1 \\
Todas las vialidades & 1 & 0.5 \\
Alguna vialidad & 2 & 0 \\
Ninguna vialidad & 3 & $\mathrm{NE}$ \\
No especificado & 4 & $\mathrm{NE}$ \\
Conjunto habitacional & 5 & \\
\hline
\end{tabular}

Fuente: Elaboración propia con datos del Instituto Nacional de Estadística y Geografía (INEGI), 2010.

\section{Cuadro 4-7}

Dimensión entorno urbano. Reescalamiento de comercio semifijo

\begin{tabular}{lcc}
\hline Pregunta y categoría & Rango válido & Reescalamiento \\
\hline Categoría de la manzana según la presencia de comercio & $\{1,2,3,4$ y 5$\}$ & 1 \\
semifijo en sus vialidades & & \\
Todas las vialidades & 1 & 0 \\
Alguna vialidad & 2 & 0.5 \\
Ninguna vialidad & 3 & NE \\
No especificado & 4 & NE \\
Conjunto habitacional & 5 & \\
\hline
\end{tabular}

Fuente: Elaboración propia con datos del Instituto Nacional de Estadística y Geografía (INEGI), 2010. 
El cálculo del ıcvo integrado por "manzana" se estimó al aplicar ponderadores equiproporcionales para cada una de las dimensiones de personas, viviendas y entorno, y lo mismo se hizo en cada una de las subdimensiones, de acuerdo con la fórmula siguiente (cuadro 4-8).

$$
I C V=\frac{1}{3} \text { Personas }+\frac{1}{3} \text { viviendas }+\frac{1}{3} \text { entorno }
$$

\section{Agregación}

Las dimensiones de personas y viviendas del ıcvo se calcularon por "manzana" con el promedio ponderado de las características asociadas con la calidad de vida, y a partir de dichos datos se estimaron los valores para las colonias o los barrios y para los municipios o delegaciones. En la dimensión del entorno urbano, se obtuvo el valor de las "manzanas" de acuerdo con el promedio del valor de los casos que informaron dato y después se calcularon los valores en la escala municipal o delegacional. El IIVO es el resultado de la suma ponderada de las tres dimensiones anteriores: personas, viviendas y entorno urbano, donde cada una constituye la tercera parte del total. ${ }^{3}$

\section{Procesamiento}

El procesamiento de la información con los criterios metodológicos mencionados consideró dos etapas. En la primera, el Laboratorio de Microdatos del INEGI dio facilidades para aplicar la sintaxis elaborada por este equipo de investigación a los datos del cuestionario básico del censo de población y vivienda, lo cual requirió trabajar con los microdatos, es decir, con 20.6 millones de personas y 5.4 millones de viviendas que conforman la ZMVM. ${ }^{4}$ El INEGI llevó a cabo un proceso de revisión de las nuevas bases de datos generadas que corresponden a la información estadística necesaria para el cálculo del ıcvo por "manzana", en el cual se verificó que se cumpliera con los requisitos de confidencialidad. ${ }^{5}$

\footnotetext{
${ }^{3}$ La base de datos con el ICvo correspondiente a municipios y delegaciones, colonias o barrios y manzanas de la zмvм se encuentra disponible en la sección de Repositorio del Instituto de Investigaciones Económicas de su página de internet (http://ru.iiec.unam.mx/4122/).

${ }^{4}$ Esta información no está disponible para su descarga en la página de internet del INEGI, ya que de acuerdo con el artículo 37 de la Ley del Sistema Nacional de Información Estadística y Geográfica, los datos que proporcione el INEGI "serán estrictamente confidenciales" (INEGI, 2008). ${ }^{5}$ De acuerdo con el INEGI, se aplican criterios de confidencialidad en el ámbito municipal cuando cualquier indicador incluye menos de tres unidades, a excepción de las variables de "población total", "total de viviendas" y "total de viviendas habitadas". A nivel "manzana", cuando
} 


\section{Cuadro 4-8}

Ponderadores del índice de calidad de vida objetivo

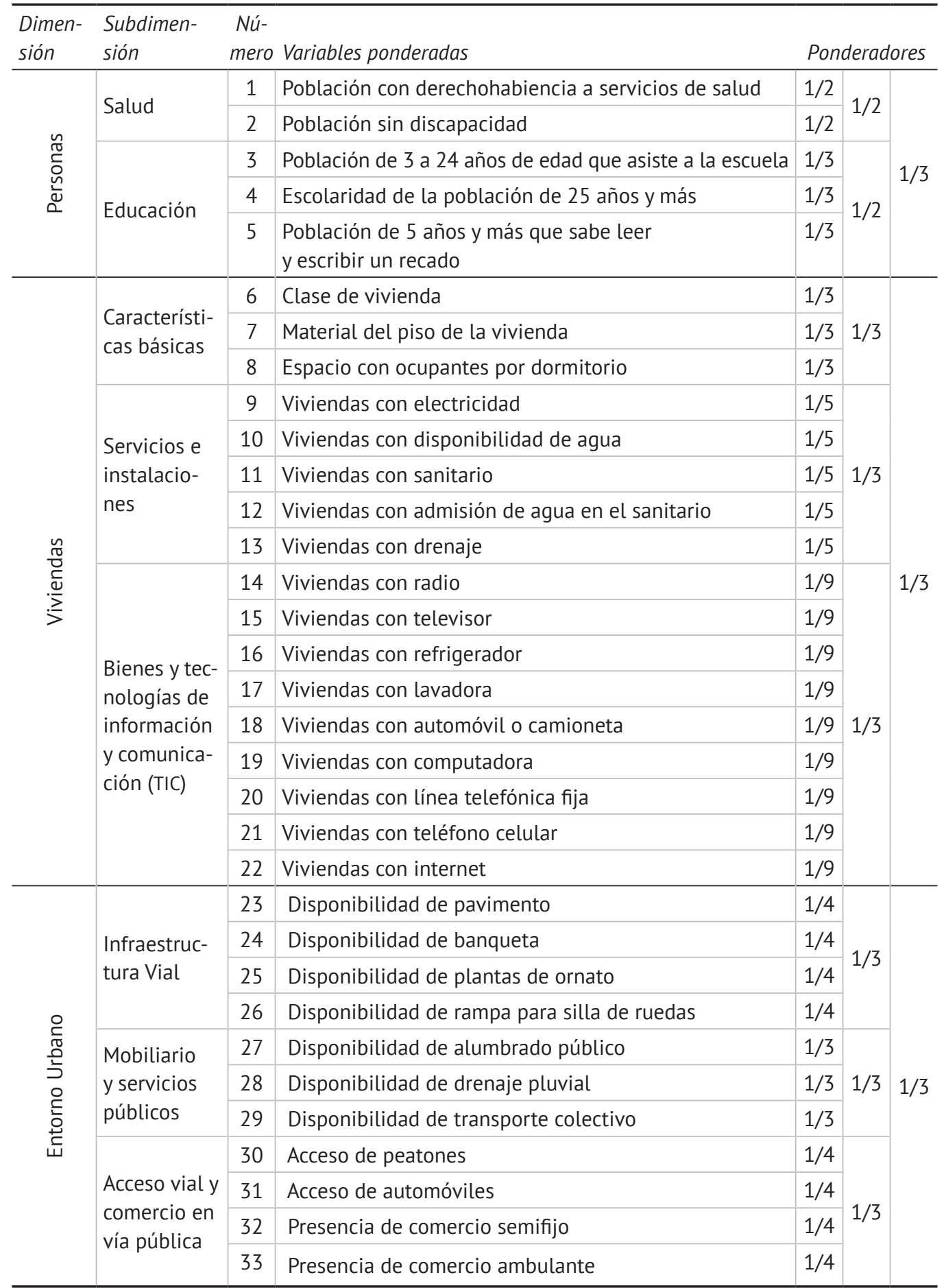

Fuente: Elaboración propia. 
En algunos casos, la información entregada por el INEGI en la escala de "manzana" no presentó información y en su lugar aparecieron asteriscos. Esto indica que la "manzana" no cumplió con los criterios de confidencialidad y aparece como no especificado.

\section{ESCALAS Y GEORREFERENCIACIÓN}

La elección de la escala espacial más adecuada para el estudio de un fenómeno determina su relevancia, efecto, evolución y trascendencia (Valenzuela, 2004). Existen cuatro concepciones básicas de escala: tamaño, nivel, red y relación. La primera corresponde a la escala cartográfica y establece la magnitud y el grado de detalle; la segunda alude al nivel jerárquico (mundial, nacional, local); la escala como red se refiere a los agentes que operan a distintos niveles y la influencia que ejercen; $y$, por último, la escala como relación. Los elementos que se contemplan son los mismos, pero al cambiar de escala, las relaciones entre ellos son distintas y se logra distinguir su importancia.

En este estudio, la escala mínima de análisis territorial es la "manzana", la cual se ha usado poco en índices como el de calidad de vida aquí estimado, con las características de la población, la vivienda y su entorno, que aporta información detallada para el diagnóstico del bienestar objetivo y, de manera indirecta, para la instrumentación y la evaluación socioespacial de las políticas públicas. La escala de colonia o barrio, donde se autorreconoce la población y se manifiesta la identidad ciudadana, se presenta en el capítulo 5.

El ICVO se muestra en mapas a partir de la cartografía generada por el INEGI, según el "Marco geoestadístico nacional 2010 versión 5.00 A", ${ }^{6}$ en particular con las capas geográficas en formato shape de entidades federativas y municipios. Asimismo, para la representación del índice por "manzana" se utilizó la "Cartografía geoestadística urbana"7 generada por el INEGI, para cada uno de los municipios que integran la ZMVM.

\footnotetext{
además del anterior, sólo hay una y dos viviendas habitadas, excepto las variables "población total" $\mathrm{y}$ "total de viviendas".

${ }^{6}$ El "Marco geoestadístico básico" se encuentra disponible en http://www.inegi.org.mx/geo/conteni dos/geoestadistica/m_geoestadistico.aspx

${ }^{7}$ La "Cartografía geoestadística urbana" se puede consultar en: http://www.inegi.org.mx/geo/conte nidos/urbana/default.aspx
} 


\section{ANÁLISIS DE RESULTADOS DEL ÍNDICE DE CALIDAD DE VIDA OBJETIVO}

\section{Análisis por contornos metropolitanos}

La hipótesis principal de este trabajo es que la calidad de vida objetiva es más satisfactoria y homogénea en unidades territoriales metropolitanas centrales y viceversa, de acuerdo con su alejamiento hacia los contornos periféricos. El análisis de los datos del ıcvo y su georreferenciación confirman este patrón general.

La ZMVM notificó un ICVO agregado total de 0.720 (en una escala general de 0 a 1), mientras que las delegaciones y los municipios de la ciudad central alcanzaron un valor de 0.823; en el primer contorno fue de 0.763 , en el segundo llegó a 0.725 , en el tercero se redujo a 0.689 y en el cuarto disminuyó hasta 0.661 ; a su vez, el quinto contorno resultó un poco mayor con 0.697 , en gran medida por la localización de municipios cercanos a la ciudad de Pachuca.

La estructura espacial en las dimensiones de persona y vivienda es semejante al patrón general, aunque cambia en el caso de la dimensión de entorno urbano, donde la periferia más lejana también reporta mala calidad de vida. La dimensión que presenta las mejores condiciones de bienestar objetivo es la vivienda (0.793), le sigue la dimensión de personas (0.723), en un nivel semejante al promedio metropolitano (0.720) y al final está la dimensión de entorno urbano (0.644), la cual informa una mayor capacidad estadística discriminante, por lo que se analiza adelante con más detalle.

Si bien ningún indicador consigue cobertura, disponibilidad o accesibilidad totales, destacan algunos casos extremos. Los valores más altos corresponden a: viviendas con electricidad, sanitario y televisión, así como población de cinco años de edad y más que sabe leer y escribir un recado, con subíndices mayores a 0.970.

Los indicadores específicos de calidad de vida también presentan un modelo centro-periferia con condiciones más favorables en delegaciones y municipios céntricos, y su disminución constante hacia los lugares más lejanos. En el otro extremo, los indicadores que manifiestan mayores rezagos que reducen la calidad de vida incluyen: viviendas con computadora y con internet, disponibilidad de transporte colectivo y de rampas para silla de ruedas con valores menores de 0.400 (cuadro 4-9).

\section{Análisis de la dimensión personas}

En la revisión de los indicadores de salud por contorno metropolitano, se observa que el valor promedio de la población sin discapacidad se mantiene constante y cercano a 1, tanto en la ciudad interior, como en los cinco contornos de estudio. Sin 


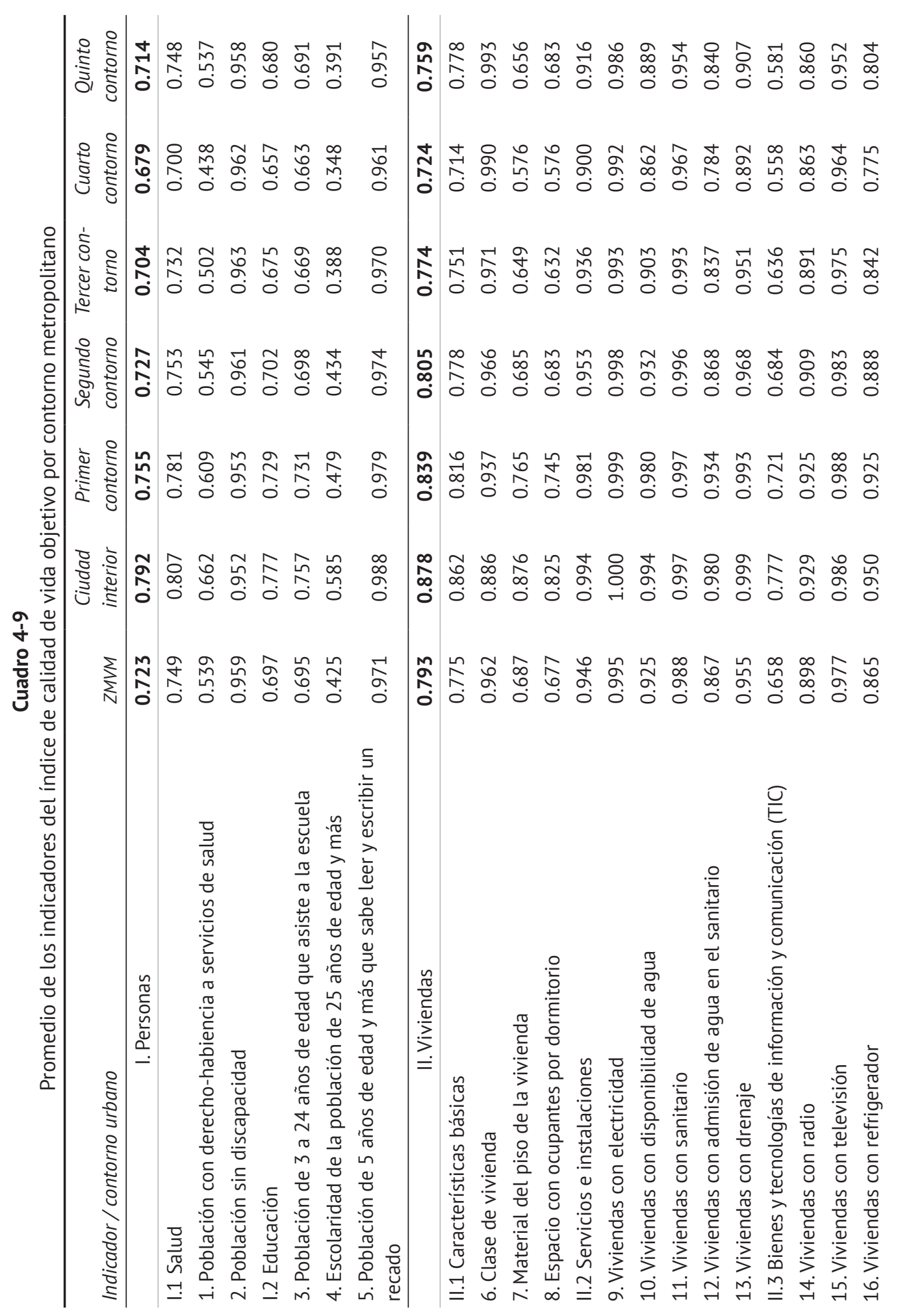




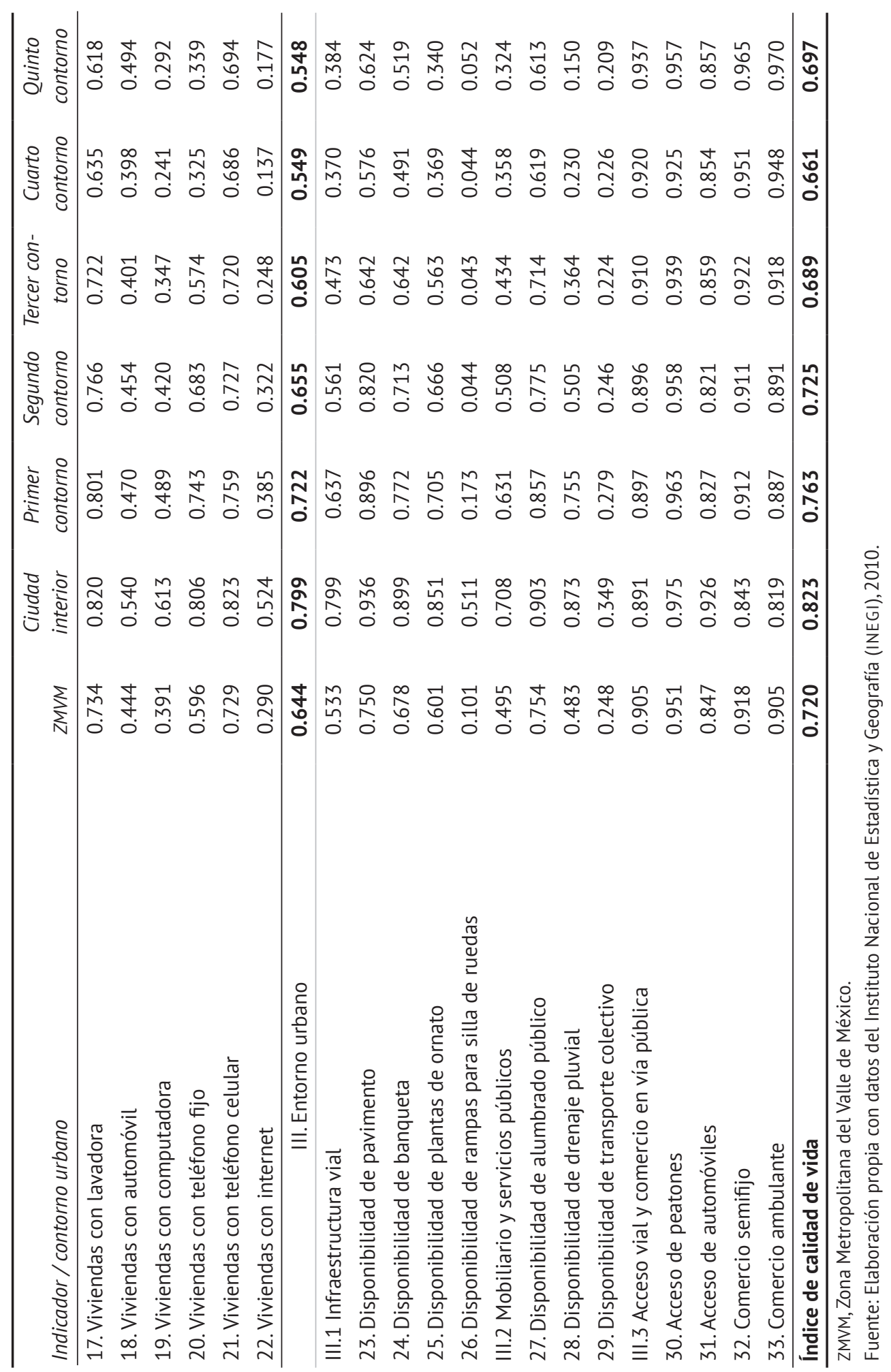


Gráfica 4-1

Indicadores de salud por contorno metropolitano

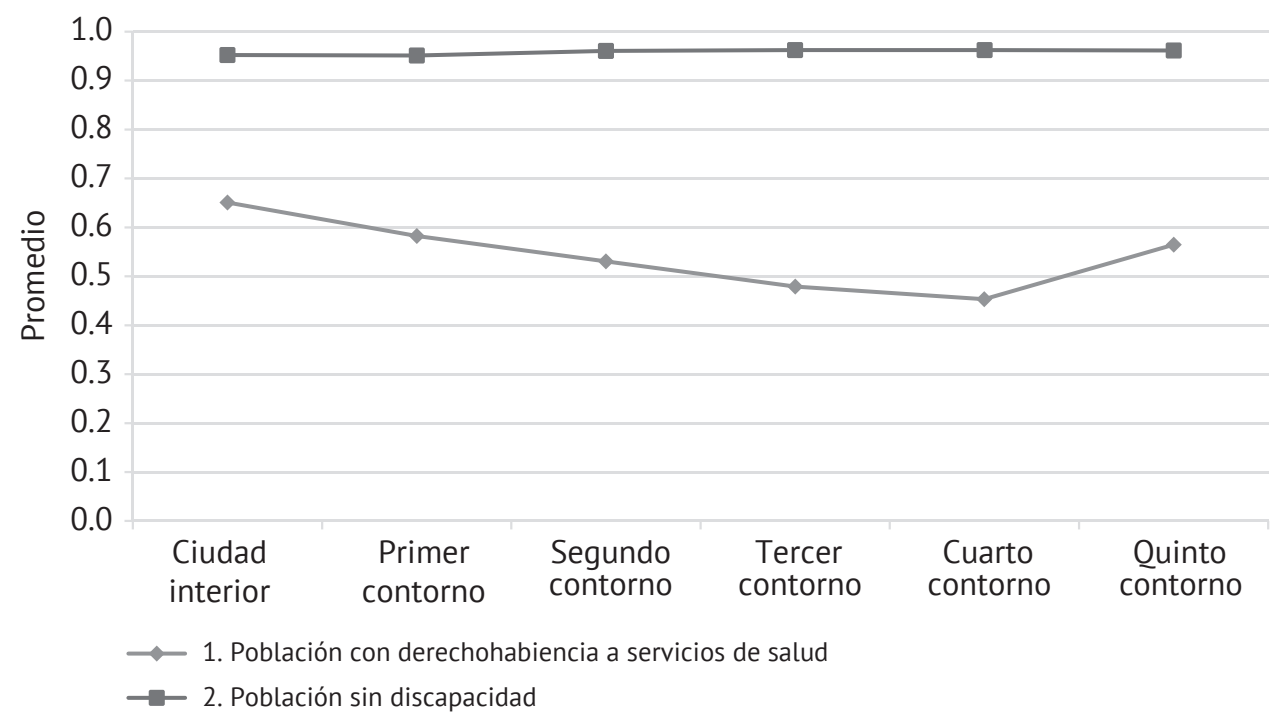

Fuente: Elaboración propia con datos del Instituto Nacional de Estadística y Geografía (INEGI), 2010.

embargo, la población con derechohabiencia a servicios de salud describe un patrón centro-periferia que se caracteriza por valores más altos en la ciudad interior y una disminución conforme se avanza en los contornos; particular atención requiere el cuarto contorno donde el valor medio es 0.453 . El quinto contorno rompe con el patrón anterior y muestra un valor similar al primer contorno, en gran medida por la inclusión de la ciudad de Pachuca (gráfica 4-1).

En relación con los indicadores que integran la subdimensión educación, se encuentra que la población de cinco años y más que sabe leer y escribir un recado registra valores muy similares y cercanos a 1 , a lo largo de los contornos metropolitanos. Mientras que la población de 3 a 24 años de edad que asiste a la escuela tiene valores más bajos, en la ciudad interior el valor es de 0.752 . Un caso que se considera relevante en términos de la generación de medidas de acción y políticas públicas es el de la escolaridad de la población de 25 años y más, ya que es el indicador con cifras medias más reducidas, en la ciudad interior, es de 0.581 , pero se reduce 0.367 en el cuarto contorno, mientras que el quinto manifiesta una mejora (0.429) (gráfica 4-2).

\section{Análisis de la dimensión vivienda}

Entre los indicadores de la subdimensión de características básicas de la vivienda, la clase de la vivienda tiende a registrar promedios altos; esta es la única variable que 
Gráfica 4-2

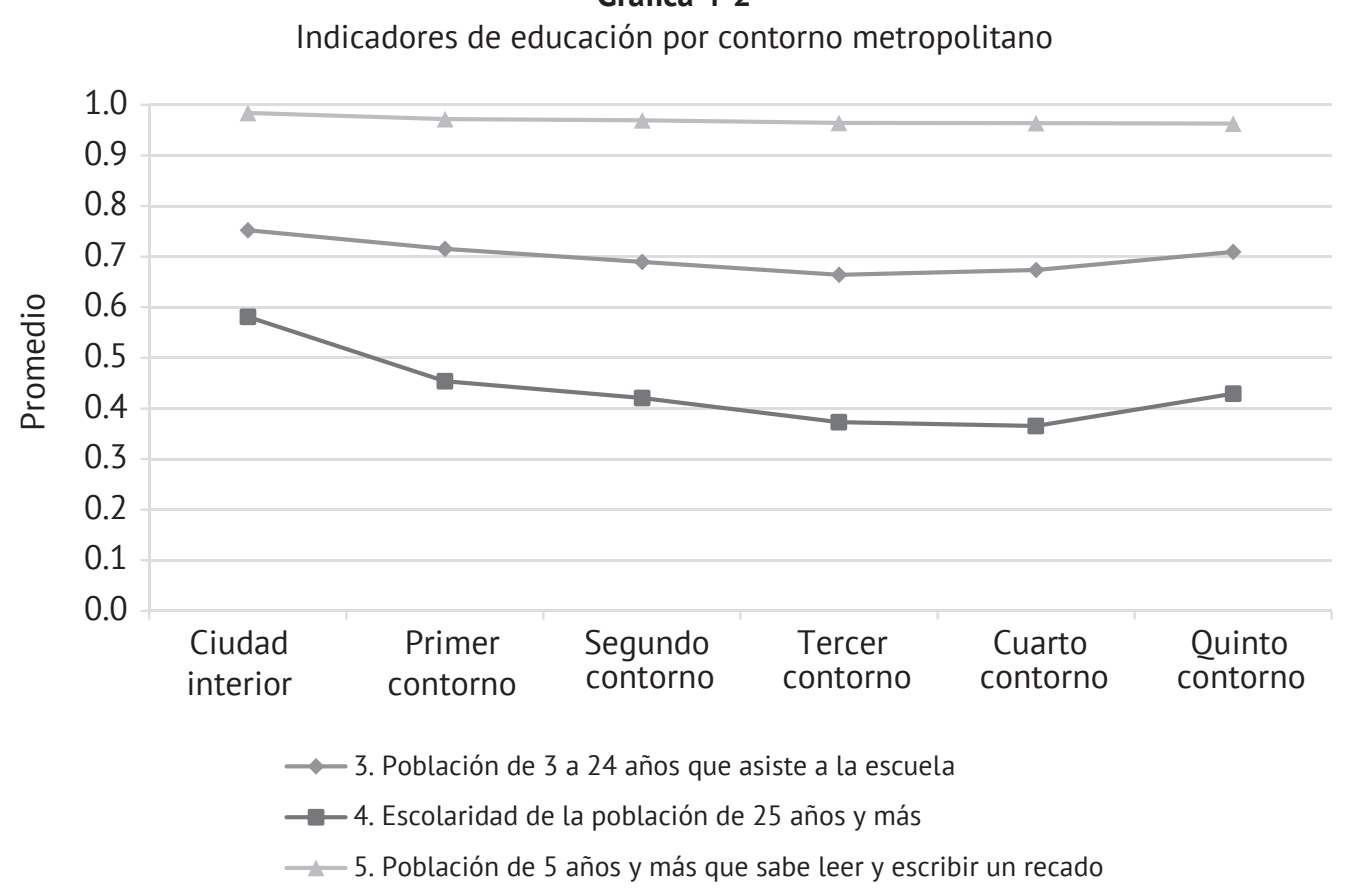

Fuente: Elaboración propia con datos del Instituto Nacional de Estadística y Geografía (INEGI), 2010.

presenta un valor más bajo en la ciudad interior (0.894) en comparación con el resto de los contornos. El material del piso de la vivienda y el espacio con ocupantes por dormitorio registran un comportamiento y valores muy similares; en la ciudad interior el promedio es de 0.870 y 0.818 , respectivamente. A medida que se avanza en los contornos, el indicador empeora hasta llegar al cuarto contorno; el quinto contorno se caracteriza por una mejoría de ambos indicadores (gráfica 4-3).

En la subdimensión de servicios e instalaciones, las viviendas con electricidad presentan los valores más altos, incluso en la ciudad interior, donde el primer contorno y segundo contorno son de 1. Algo similar ocurre con las viviendas con sanitario, en términos de registrar altos promedios. Las viviendas con drenaje presentan valores más altos en el centro y luego disminuyen hasta llegar al cuarto contorno (0.924); enseguida, en el quinto contorno, se reporta una mejoría. Las viviendas con disponibilidad de agua siguen el mismo comportamiento, aunque en general muestran valoresmás bajos; en el cuarto contorno, la media es de 0.877 . El indicador con promedios más bajos, aunque con el mismo perfil corresponde a las viviendas con admisión de agua en el sanitario, y en el cuarto contorno es de 0.811 (gráfica 4-4).

En los indicadores de la subdimensión de "Bienes y TIC", se encuentra que los 
Gráfica 4-3

Indicadores de características básicas por contorno metropolitano

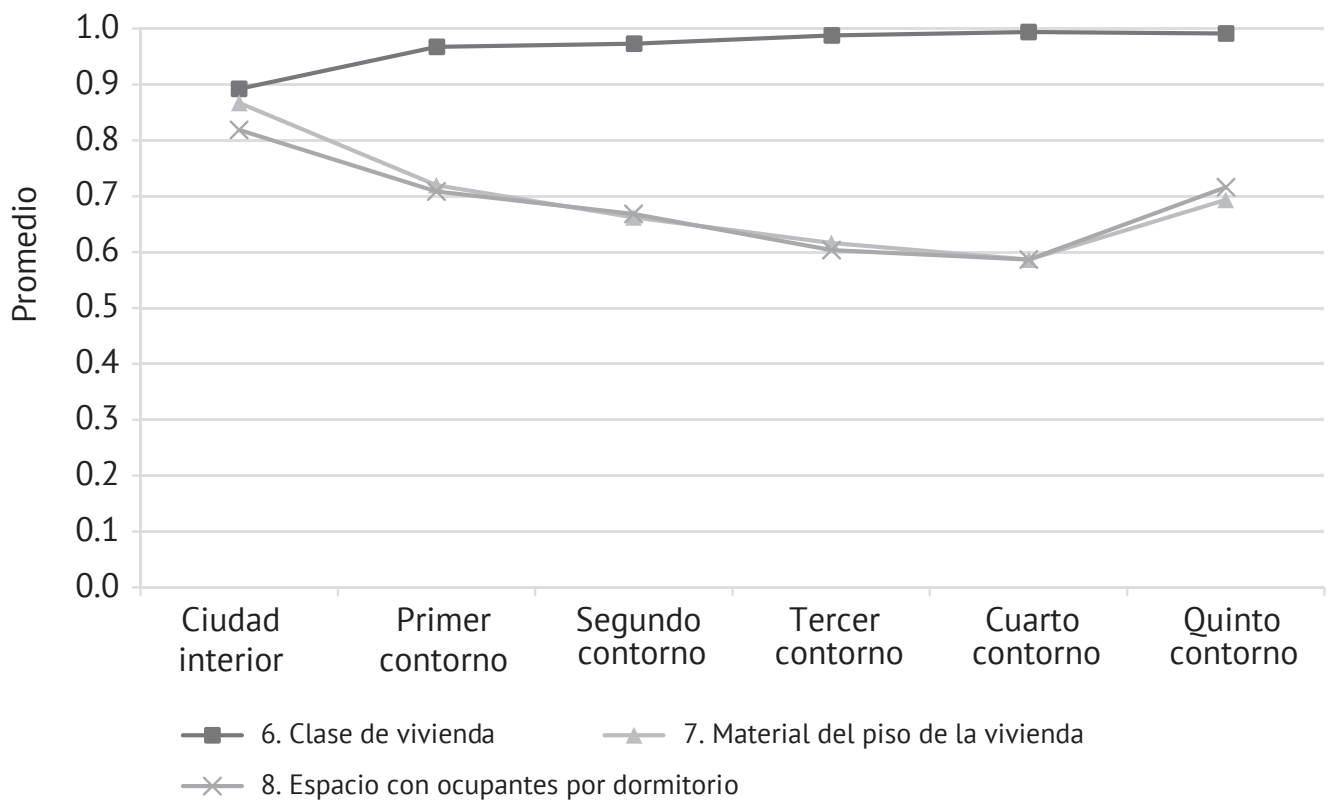

Fuente: Elaboración propia con datos del Instituto Nacional de Estadística y Geografía (INEGI), 2010.

Gráfica 4-4

Indicadores de servicios e instalaciones por contorno metropolitano

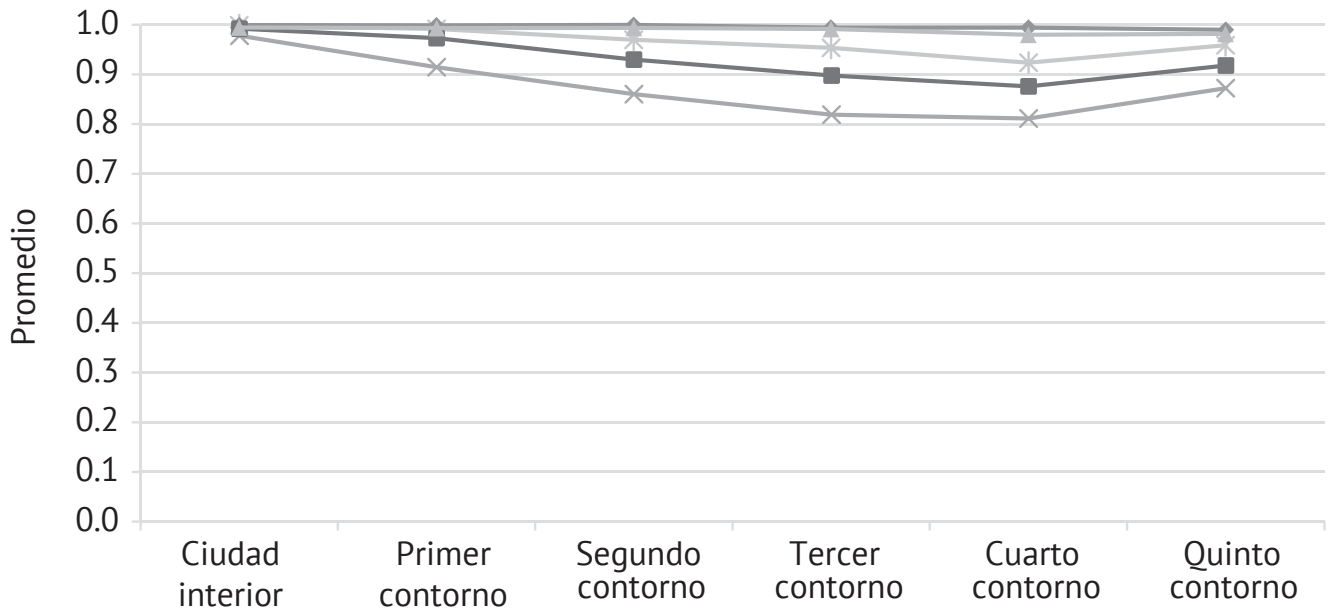

$\longrightarrow$ 9. Viviendas con electricidad

- 11. Viviendas con sanitario

* 13. Viviendas con drenaje
10. Viviendas con disponibilidad de agua

$\leftarrow$ 12. Viviendas con admisión de agua en el sanitario

Fuente: Elaboración propia con datos del Instituto Nacional de Estadística y Geografía (INEGI), 2010. 
valores más altos y homogéneos entre contornos corresponden a las viviendas con televisión. Enseguida aparecen las viviendas con radio y las viviendas con refrigerador. En el otro extremo, los promedios más bajos corresponden a las viviendas con internet, mientras que en la ciudad interior es de 0.522 , en el cuarto contorno se reduce hasta 0.159 y el quinto contorno describe una mejoría (0.237). Un caso que resulta particular es el de las viviendas con teléfono fijo ya que es el indicador que muestra mayor reducción a medida que hay un alejamiento de la ciudad interior, donde el promedio es de 0.798 y disminuye a 0.358 en el cuarto contorno (gráfica 4-5).

\section{Gráfica 4-5}

Indicadores de bienes y tecnologías de información y comunicación por contorno metropolitano

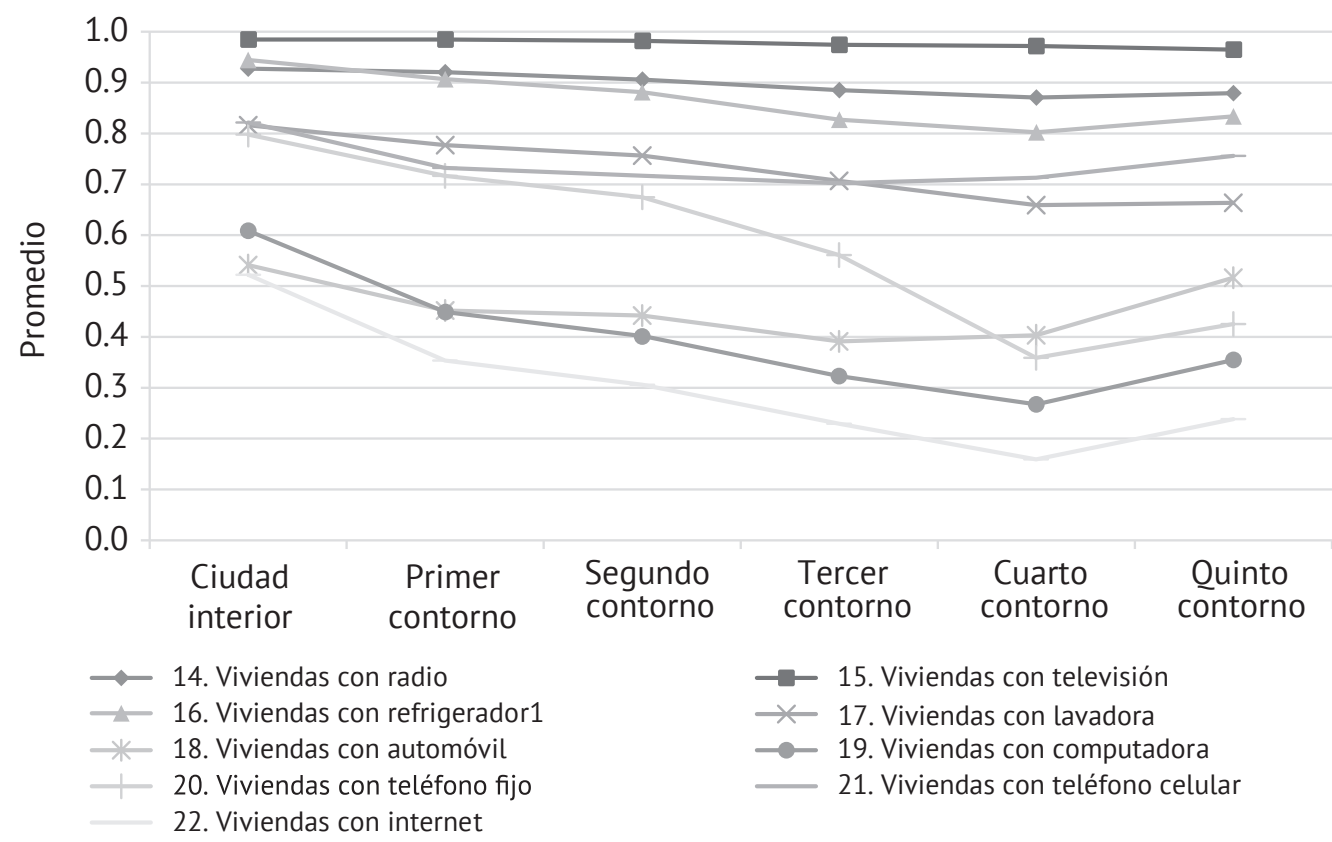

Fuente: Elaboración propia con datos del Instituto Nacional de Estadística y Geografía (INEGI), 2010.

\section{Análisis de la dimensión entorno urbano}

La dimensión del entorno urbano informa el valor más bajo del ICv (0.644), lo cual confirma en general mayores carencias en servicios e infraestructura en la ZMVM. En el caso de la subdimensión de infraestructura vial, el valor fue menor (0.533), con datos menores en los contornos de la periferia, en particular, por la falta de rampas para sillas de ruedas. Los indicadores de disponibilidad de pavimento, banquetas y 
plantas de ornato fueron muy parecidos en la ciudad interior y menores en los últimos dos contornos más alejados del centro.

En rampas para sillas de ruedas, la ciudad interior presentó una mayor cobertura (0.511), seguida del primer contorno metropolitano (0.173), mientras que los otros espacios tuvieron valores más bajos. Esta situación limita la movilidad de las personas con alguna discapacidad física y condiciona su interacción con el medio urbano (gráfica 4-6).

\section{Gráfica 4-6}

Indicadores de infraestructura vial por contorno metropolitano

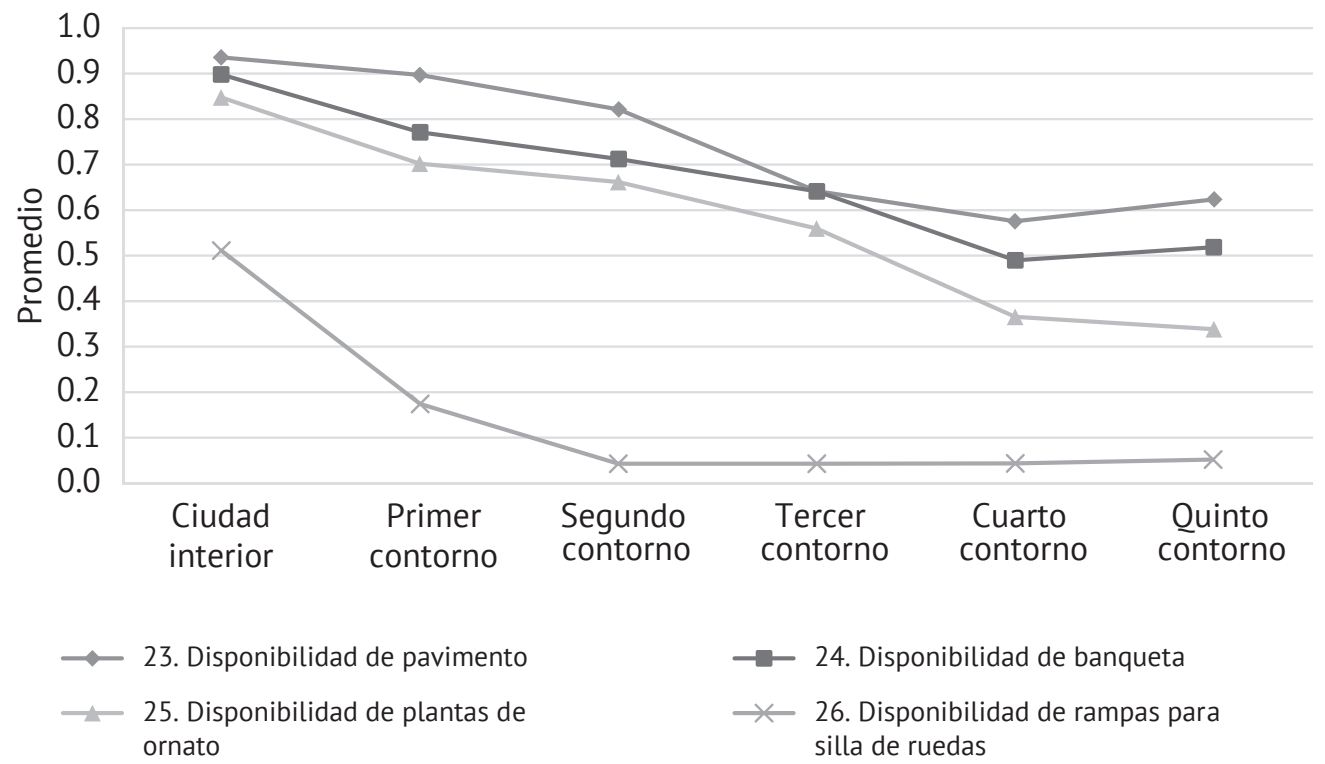

Fuente: Elaboración propia con datos del Instituto Nacional de Estadística y Geografía (INEGI), 2010.

El mobiliario y los servicios públicos presentaron las peores condiciones al obtener un valor de 0.495, como resultado principal de las carencias en el drenaje pluvial y servicios de transporte colectivo. Este último es insuficiente en todos los espacios metropolitanos, pero es peor en función de la distancia (gráfica 4-7).

El acceso vial y el comercio en vía pública tuvieron el valor más alto del entorno urbano (0.905), pero notifican valores más altos en los contornos de la periferia, es decir, presentaron mejores condiciones de calidad de vida por la ausencia de comercio que restrinja el libre tránsito de los peatones por las banquetas.

Por su parte, el acceso a peatones y vehículos fue mejor en la ciudad central y se reduce hacia la periferia; sin embargo, el acceso a vehículos fue mejor en los últimos tres contornos metropolitanos que en el primer y segundo contornos, lo cual se 
Gráfica 4-7

Indicadores de mobiliario y servicios públicos por contorno metropolitano

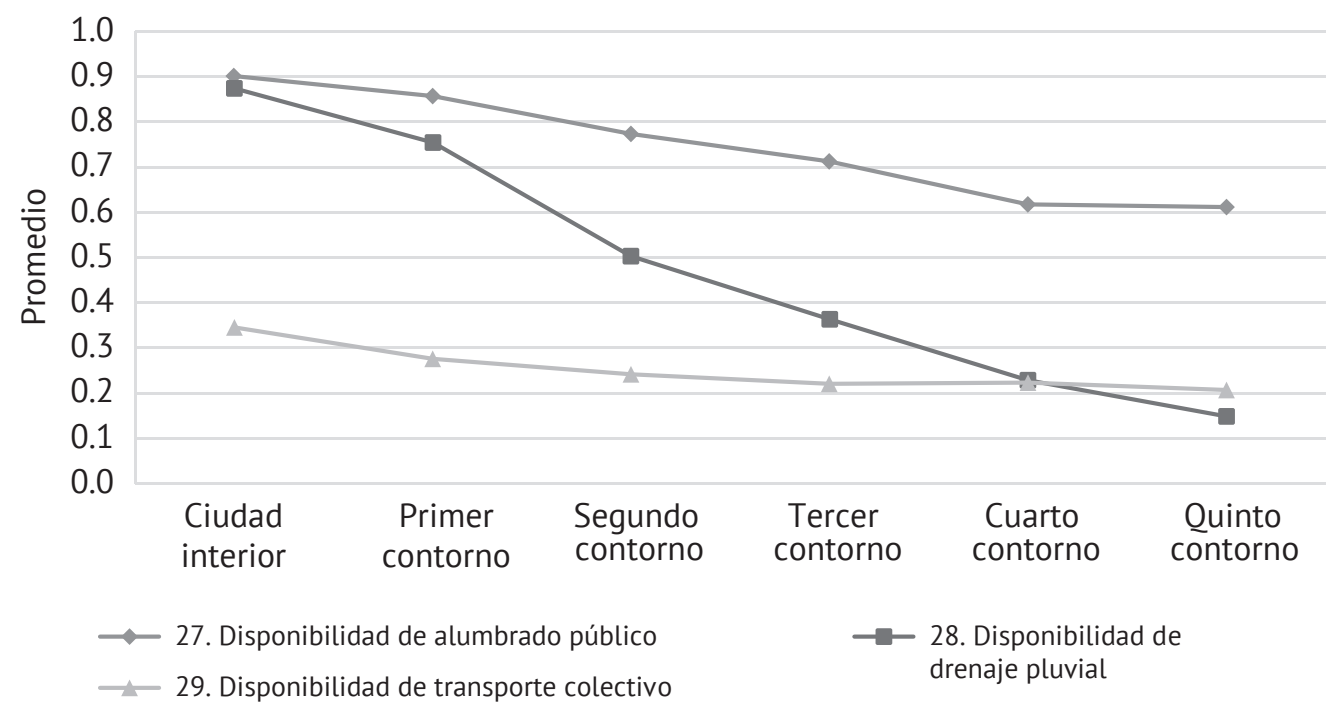

Fuente: Elaboración propia con datos del Instituto Nacional de Estadística y Geografía (INEGI), 2010.

relaciona con la existencia de zonas residenciales donde se han colocado elementos como casetas y plumas para restringir el acceso a cualquier persona e incrementar la seguridad de sus hogares, limitando con ello el libre tránsito de las personas por sus calles (gráfica 4-8).

\section{Gráfica 4-8}

Indicadores de acceso vial y comercio en vía pública por contorno metropolitano

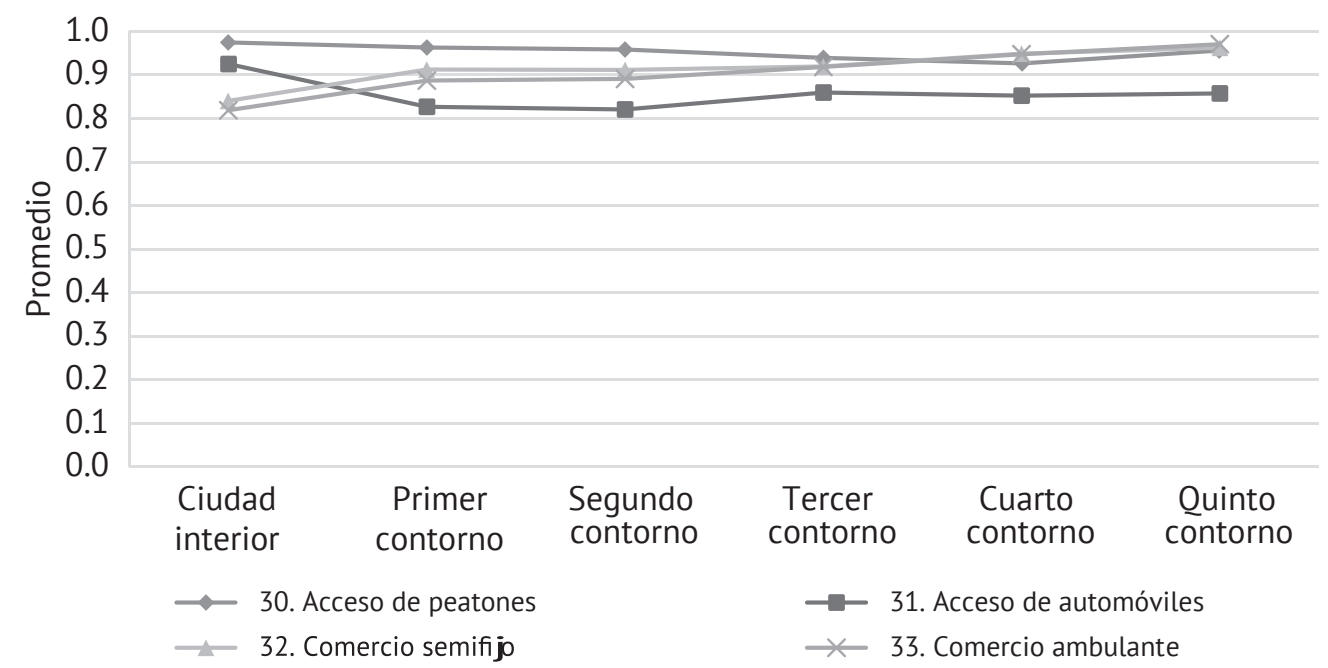

Fuente: Elaboración propia con datos del Instituto Nacional de Estadística y Geografía (INEGI), 2010. 
Los resultados para las dimensiones de personas, viviendas y entorno urbano ofrecen elementos de juicio para el diseño de políticas públicas orientadas a alcanzar condiciones más igualitarias que incrementen la calidad de vida de la población.

\section{REPRESENTACIÓN CARTOGRÁFICA}

La representación del ICVO de la ZMVM considera tres escalas geográficas. La primera se refiere a los grados de calidad de vida total por municipio o delegación, y por las dimensiones de personas, viviendas y entorno urbano, con la cartografía del Estado de Hidalgo (21 municipios), el Estado de México (59 municipios) y el Distrito Federal (16 delegaciones), elaborada por el INEG en su versión 2015, 5.0a. La segunda escala es la unidad territorial de colonia (capítulo 5). La escala más desagregada es la "manzana" con una representación cartográfica con los resultados del ICVO total y las tres dimensiones que lo integran. Al respecto, se utilizó la cartografía "Geoestadística urbana 2010", la cual incluye las "manzanas" de las cabeceras municipales y de las localidades con más de 2500 habitantes. ${ }^{8}$

El utilizar la información estadística y cartográfica de una sola fuente permite tener mayor certeza en cuanto a la coincidencia numérica tanto de datos estadísticos como de "manzanas"; sin embargo, debido a distintas causas, esto no es así. Las diferencias en el número de datos estadísticos por "manzana" pueden obedecer a varias razones, pero en especial se deben a la confidencialidad de los datos y la actualización del levantamiento cartográfico (ya que se dan de baja o de alta algunas "manzanas" en el tiempo). En este estudio, se tiene la información estadística de todas las localidades que conforman los 96 municipios o las delegaciones de la ZMVM, pero como no todas son localidades urbanas, en cartografía sólo están aquellas que pertenecen a localidades de más de 2500 habitantes. $^{9}$

Existen diferencias entre el número de "manzanas" de la cartografía geoestadística urbana con polígono y el número de "manzanas" para las cuales se estimó el

\footnotetext{
${ }^{8}$ La cartografía geoestadística urbana corresponde al cierre del "Censo de población y vivienda 2010" y contiene nombre de calles, ubicación de los principales servicios, los límites de las áreas geoestadísticas básicas (AGEB) urbanas, así como sus respectivas claves de identificación (INEGI, 2010).

${ }^{9}$ El INEGI cuenta con la cartografía urbana y rural amanzanada para el año 2015; sin embargo, para este estudio solo se consideraron los datos censales de 2010 y su respectiva georreferenciación cartográfica al mismo año.
} 
ICVO. La base de datos contiene 186124 "manzanas" para las cuales se estimó el índice total o parcial para alguna dimensión, pero sólo se identificaron en la cartografía geoestadística urbana un total de 173517 "manzanas", es decir, 93.2\% del total.

El Distrito Federal presenta la menor diferencia entre un dato y el otro ya que hay una mayor coincidencia de uno a uno, sobre todo en las delegaciones centrales; mientras que en las delegaciones periféricas o semirurales (como Milpa Alta, Tlalpan y Xochimilco) aumentan las discrepancias. En el Estado de México, las diferencias son más marcadas debido a la mayor presencia de localidades rurales, como en los municipios de "Villa del Carbón", "Jilotzingo", "Isidro Fabela", "San Martín de las Pirámides", "Tultepec" y "Tenango del Aire", donde más de la mitad de los datos no posee georreferencia porque no se cuenta con un polígono cartográfico. La mayor diferencia entre los datos georreferenciados se observó en el Estado de Hidalgo, ya que cerca de 25\% de las "manzanas" con ICV carece de polígono. También se registraron algunos casos donde había polígono de la "manzana", pero no se tenía dato estadístico, como se presentó en el municipio de Tultitlán (mapas 4-2 a 4-5) (cuadro 4-10).

\section{CONCLUSIONES}

El ıcvo ofrece elementos para valorar el bienestar objetivo de la población residente en la ZMVM. Los datos desagregados desde la unidad de medición espacial más básica, es decir, la "manzana", permitieron verificar las hipótesis de investigación, tanto en esta escala como en los municipios y las delegaciones.

Una primera verificación de la hipótesis general es que se confirma de manera agregada el patrón centro-periferia metropolitano de calidad de vida, donde al aumentar la distancia respecto del centro y los subcentros intrametropolitanos, se reduce el bienestar de la población. Asimismo, existe evidencia de que a menor distancia de otro nodo urbano, mejora la calidad de vida como se observa en los municipios periféricos más próximos a la ciudad de Pachuca. Esta última ciudad y los municipios del Estado de Hidalgo se incluyen en la delimitación de la ZMVM, lo cual se justifica con los resultados del modelo prospectivo y funciona como contraste en relación con los espacios más próximos al núcleo metropolitano.

En el piso social básico con los indicadores que miden la calidad de vida, la medición de las brechas territoriales indica serios retos para el cumplimiento de los derechos sociales, aunque como ya se analizó (capítulo 2), hay diferencias en los marcos jurídicos de las tres entidades federativas de la ZMVM. 


\section{Mapa 4-2}

Zona Metropolitana del Valle de México: índice de calidad de vida objetivo por delegación o municipio, 2010

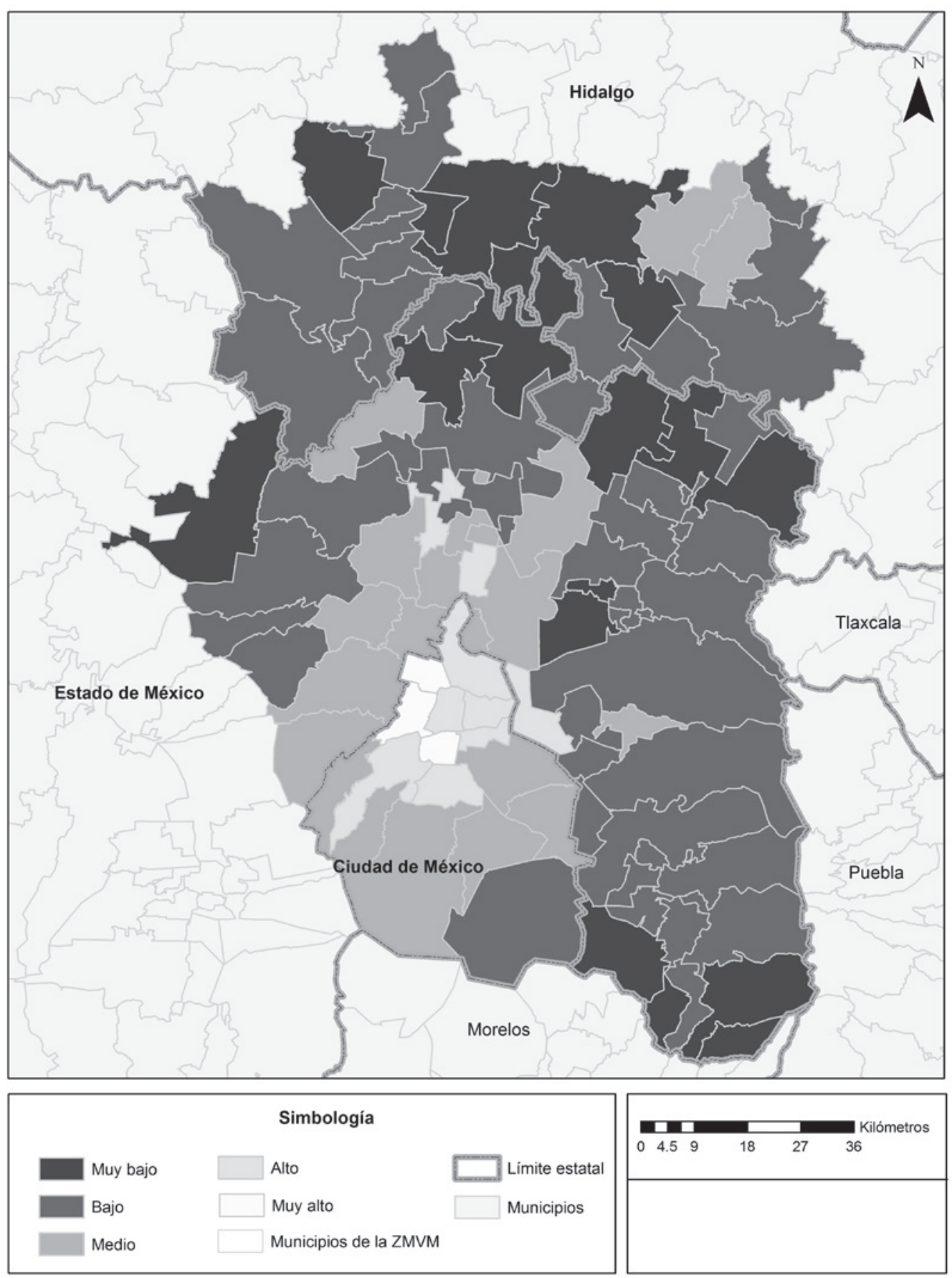

Fuente: Elaboración propia con datos del Instituto Nacional de Estadística y Geografía (INEGI), 2010. 


\section{Mapa 4-3}

Zona Metropolitana del Valle de México: índice de calidad de vida objetivo por manzana, 2010

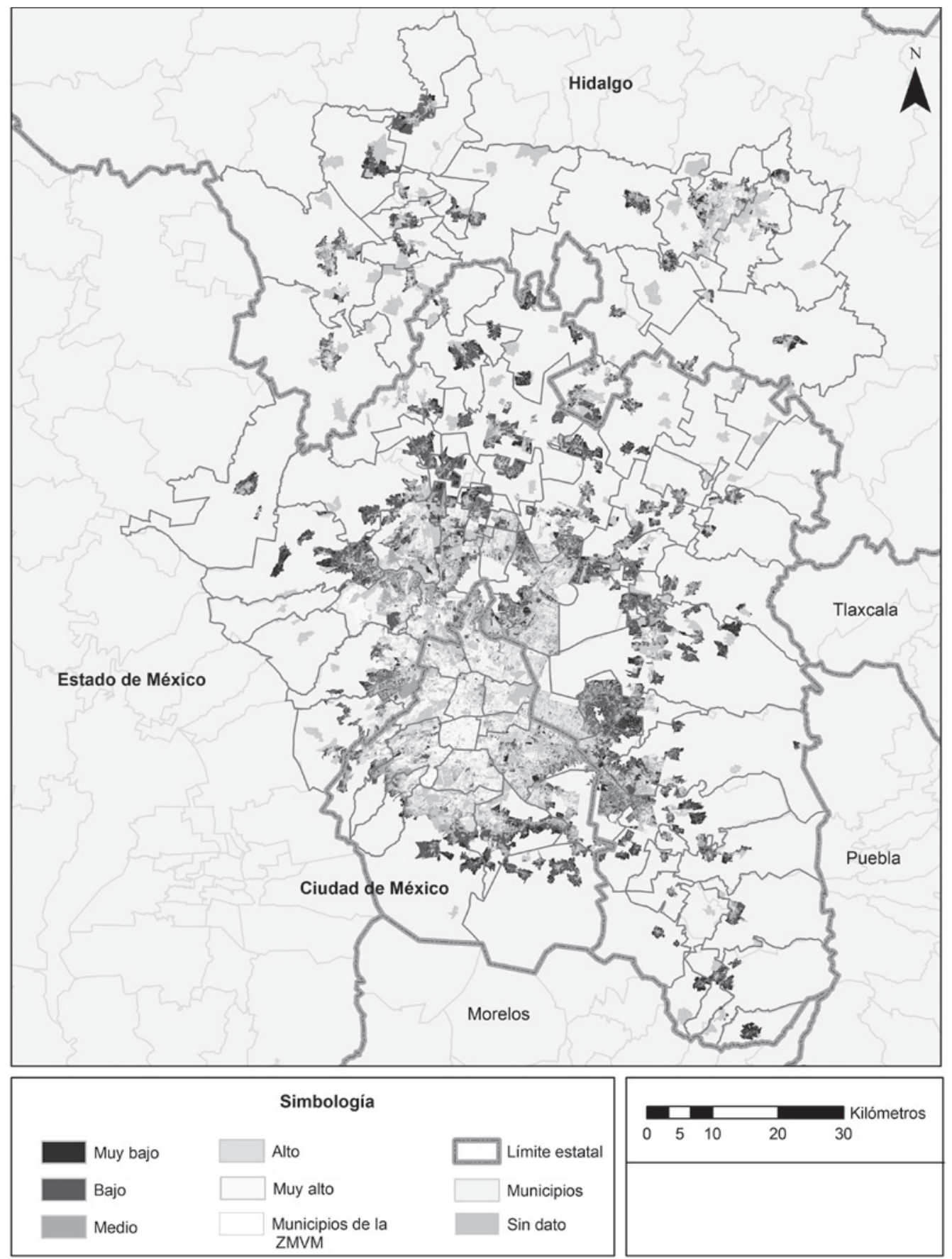

Fuente: Elaboración propia con datos del Instituto Nacional de Estadística y Geografía (INEGI), 2010. 


\section{Mapa 4-4}

Zona Metropolitana del Valle de México: índice de calidad de vida objetivo en la dimensión de personas, 2010

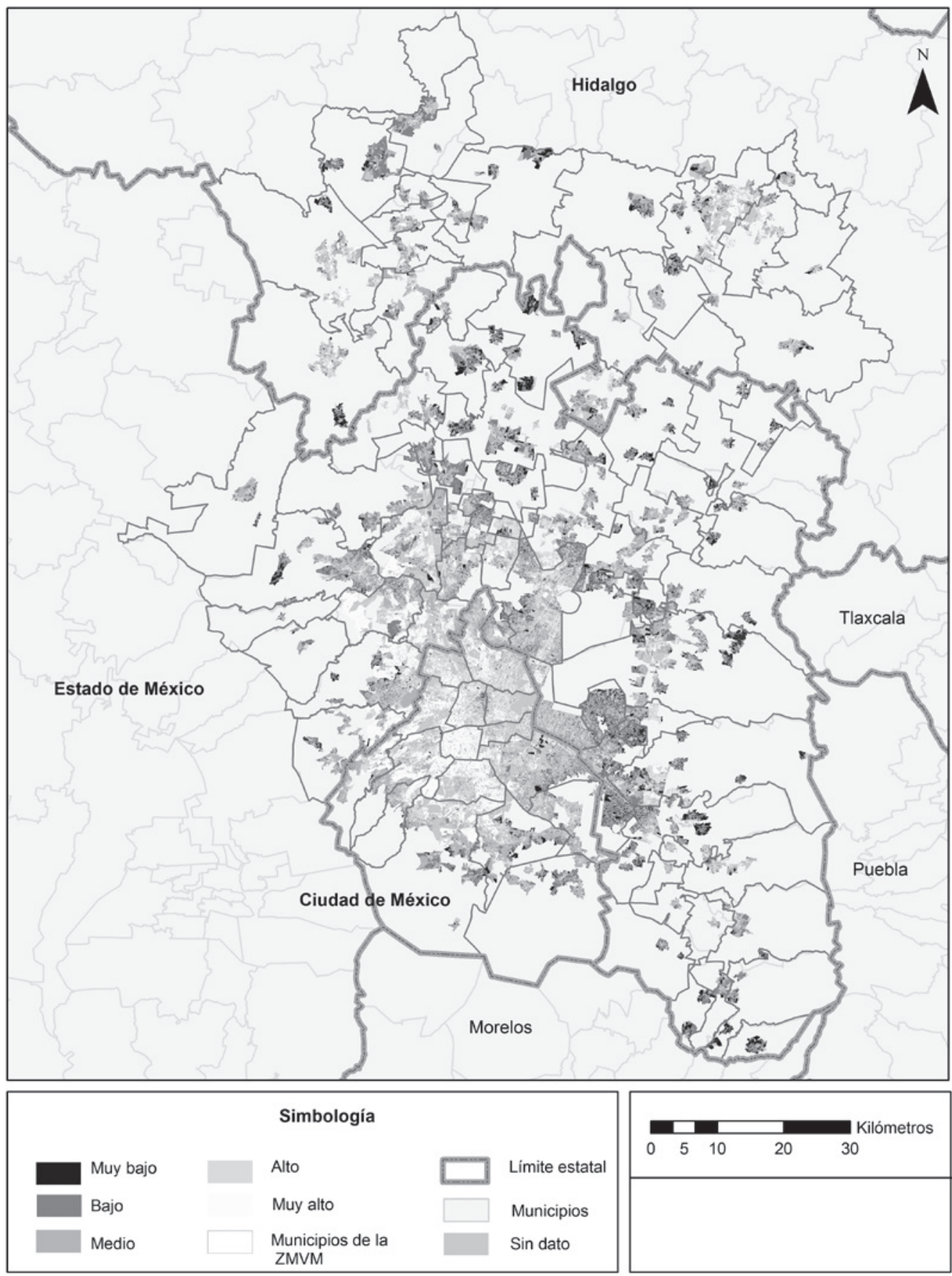

Fuente: Elaboración propia con datos del Instituto Nacional de Estadística y Geografía (INEGI), 2010. 


\section{Mapa 4-5}

Zona Metropolitana del Valle de México: índice de calidad de vida objetivo en la dimensión de viviendas, 2010

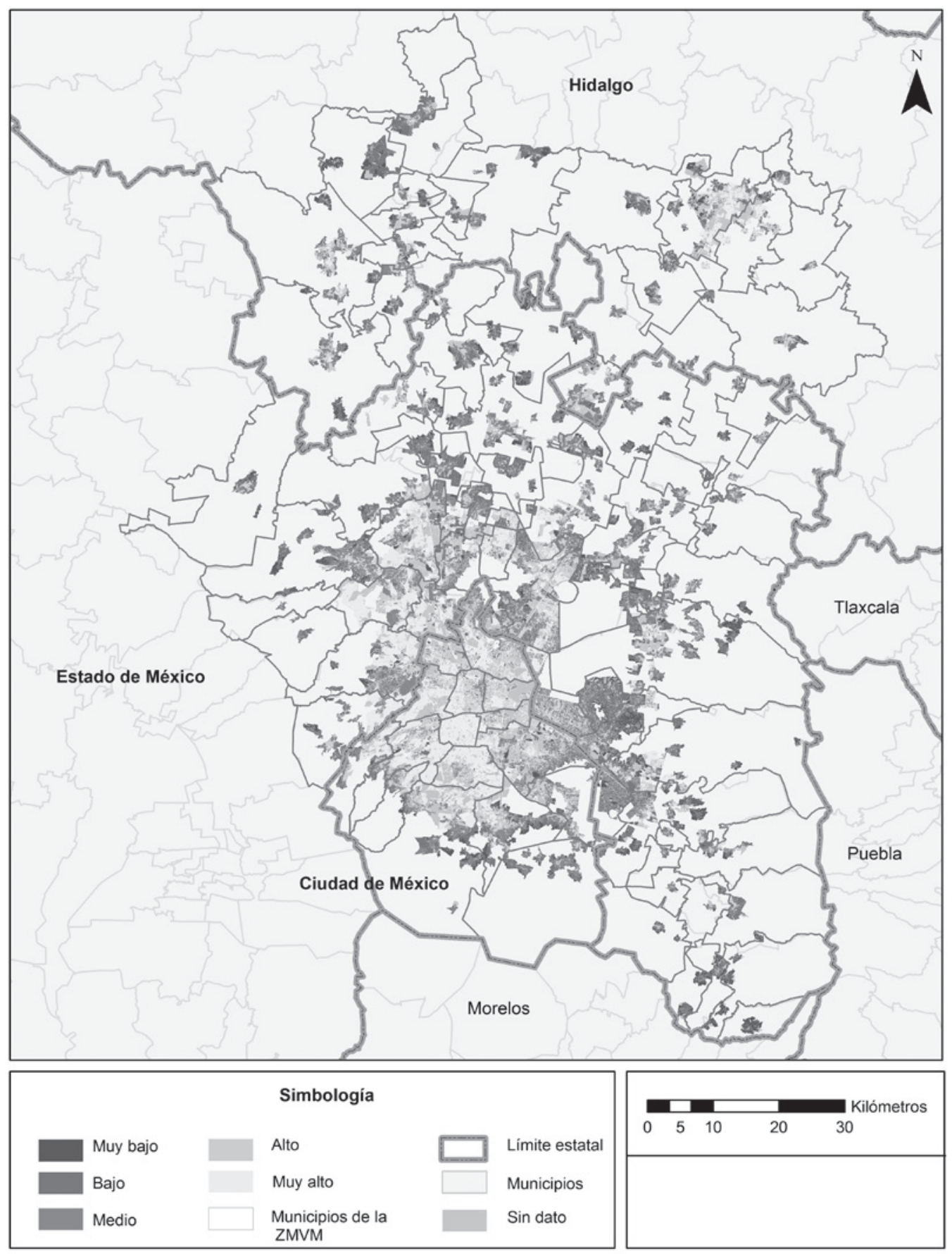

Fuente: Elaboración propia con datos del Instituto Nacional de Estadística y Geografía (INEGI), 2010. 


\section{Mapa 4-6}

Zona Metropolitana del Valle de México índice de calidad de vida en la dimensión de entorno urbano, 2010

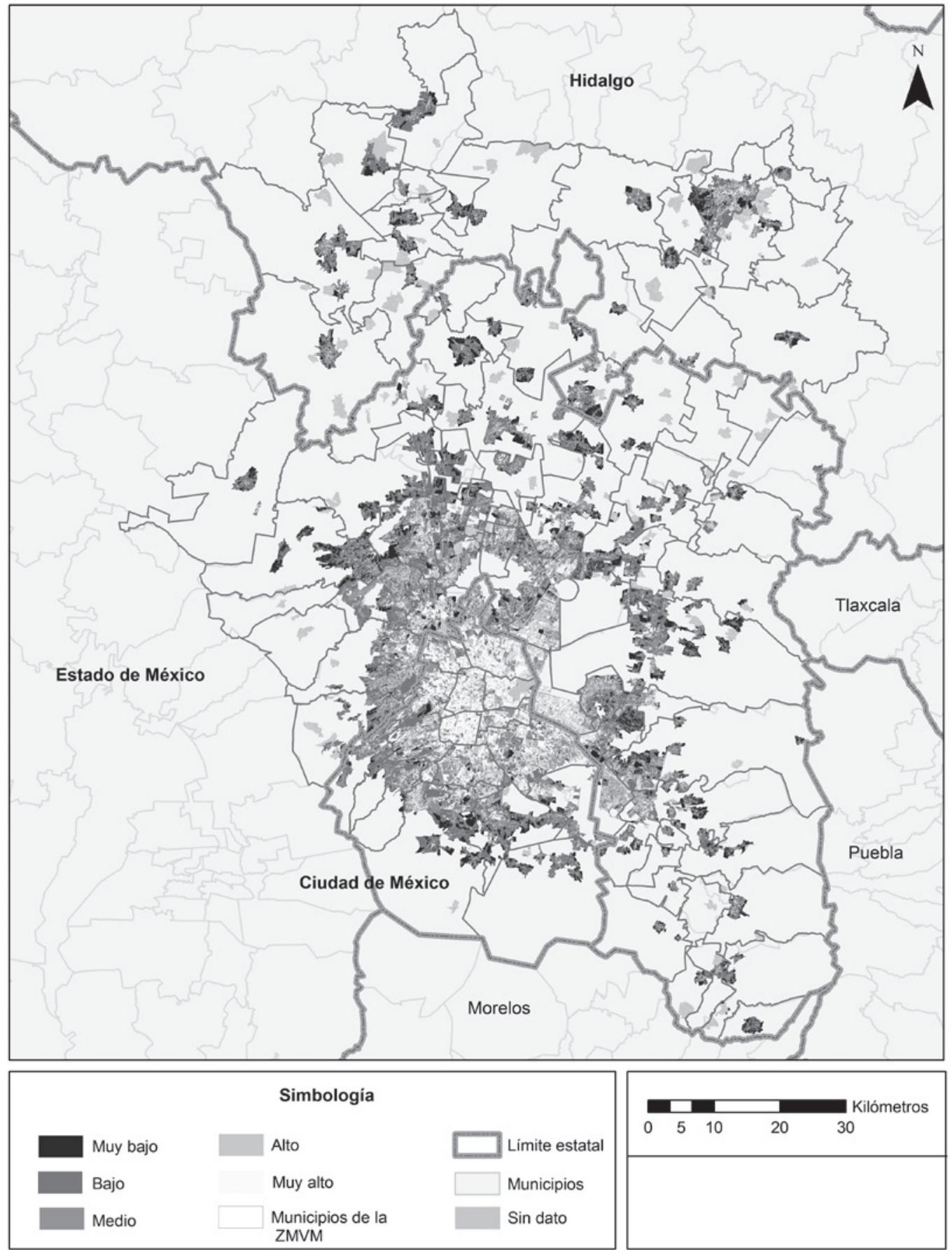

Fuente: Elaboración propia con datos del Instituto Nacional de Estadística y Geografía (INEGI), 2010. 


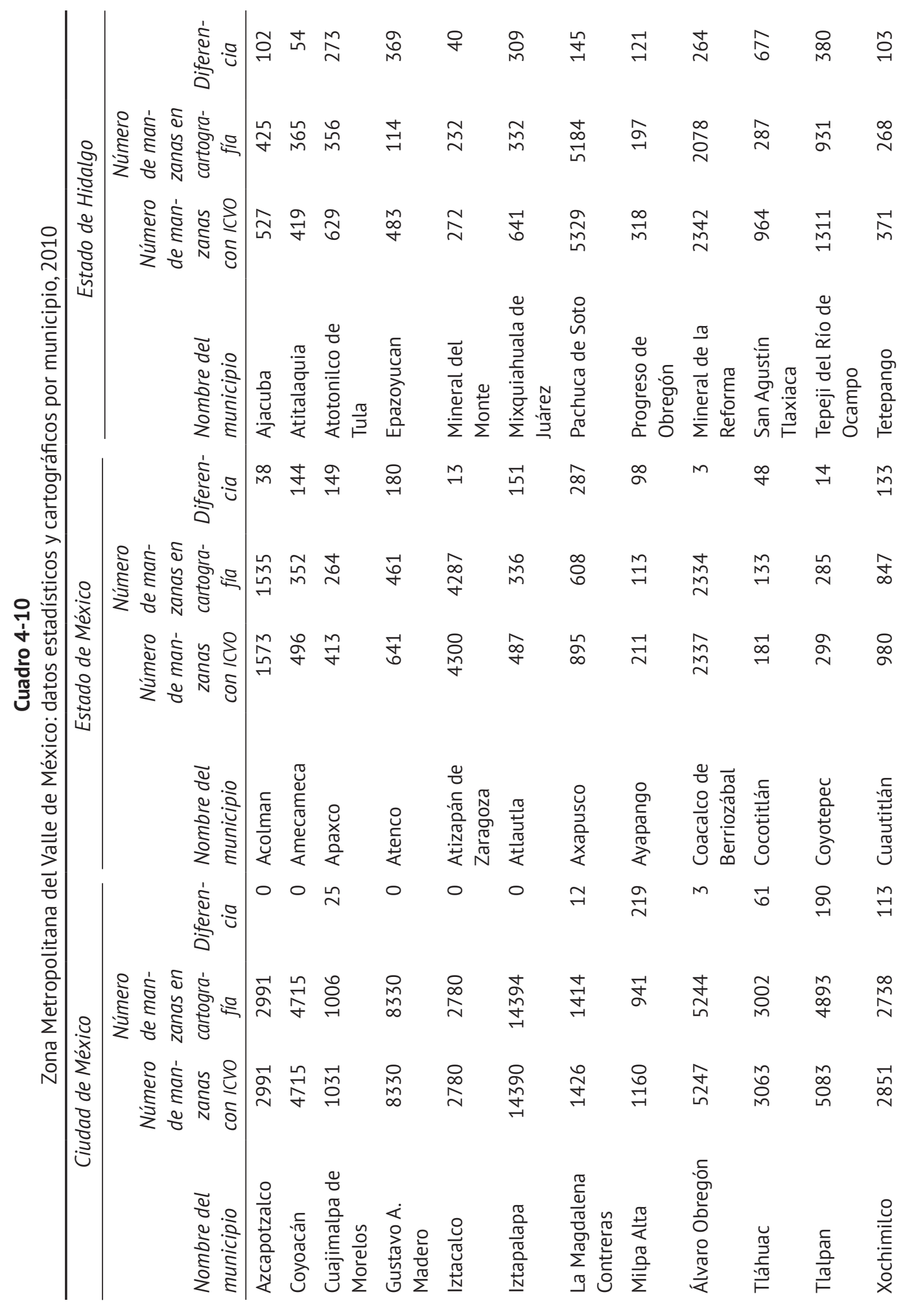




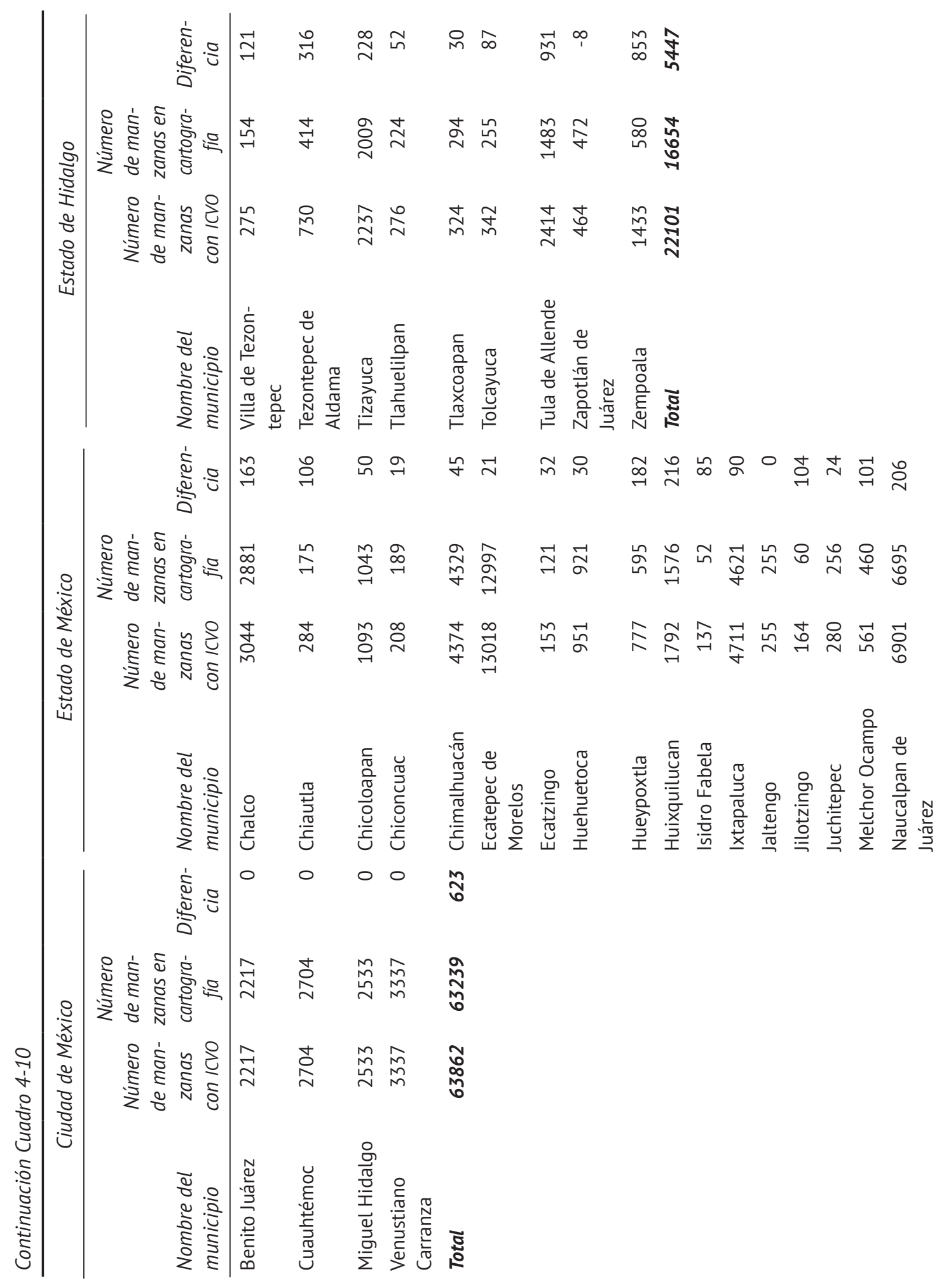




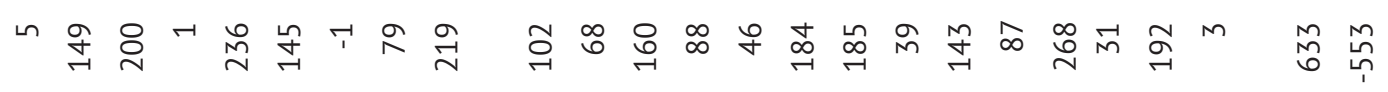

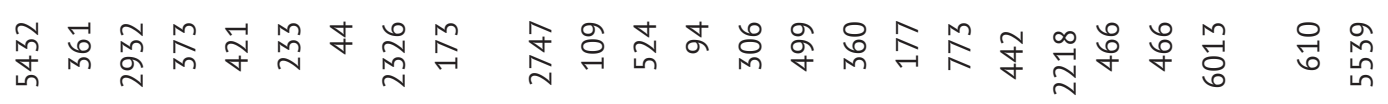

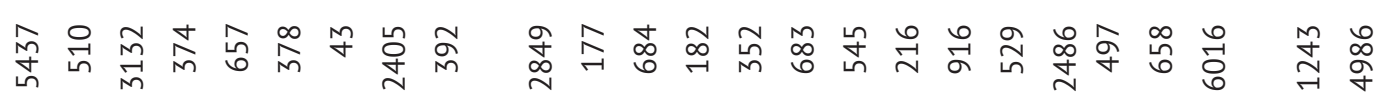

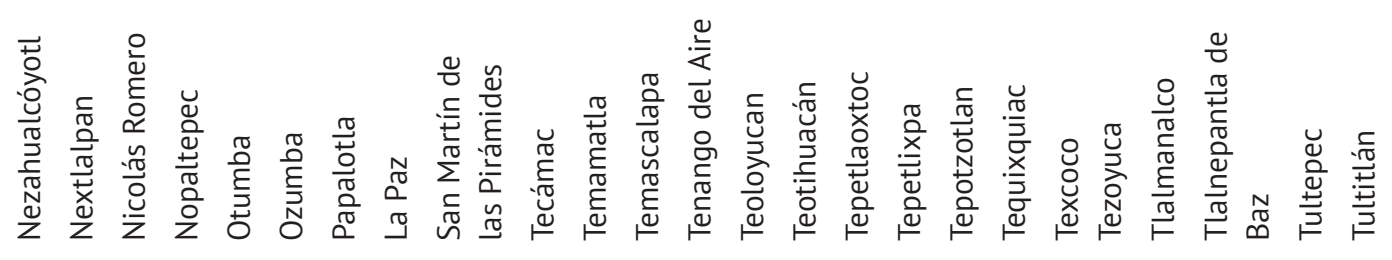




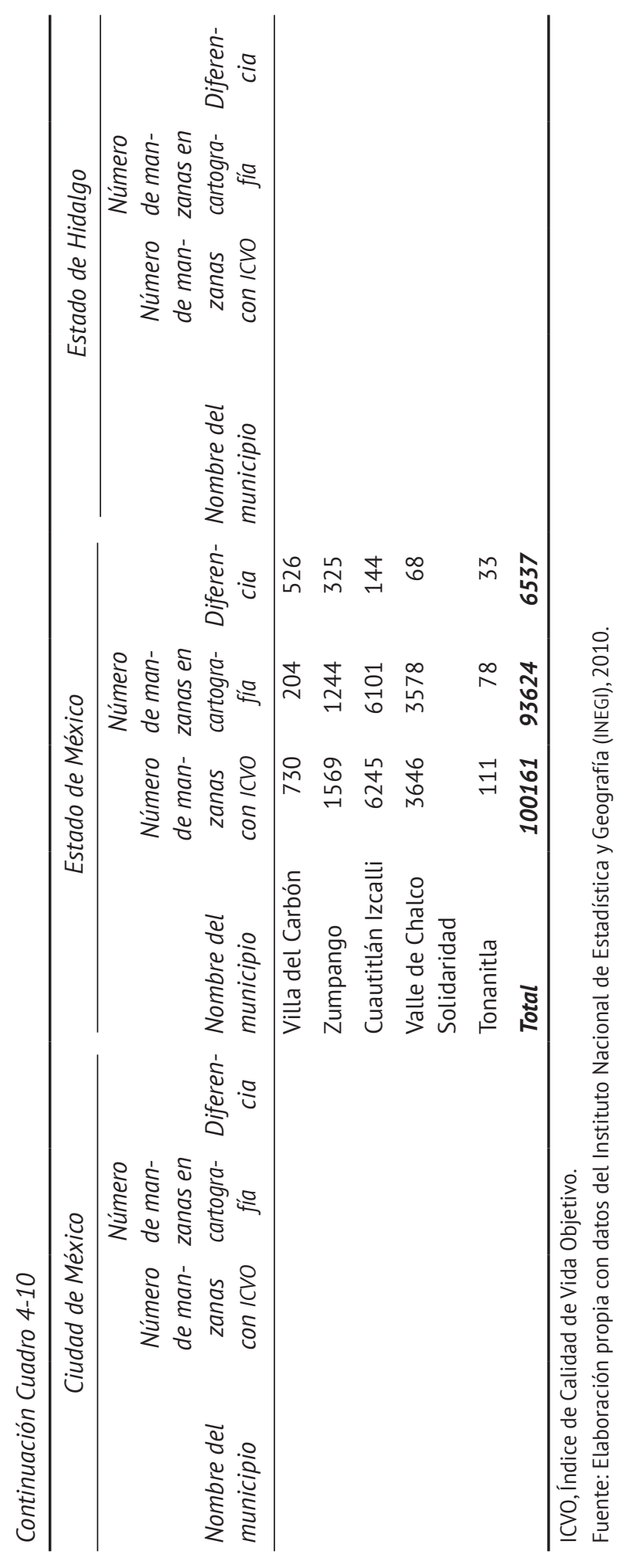


Las peores condiciones se ubican en los espacios de las interfaces semiurbanas con menores niveles de satisfacción en las dimensiones de educación y salud, y en la menor disponibilidad de bienes y servicios en la vivienda, sobre todo en los rezagos o carencias de servicios públicos en el entorno urbano. Estas conclusiones generales constituyen el marco para algunos análisis temáticos más específicos que se presentan en los capítulos siguientes.

\section{BIBLIOGRAFÍA}

Centro Latinoamericano y Caribeño de Demografía (2006), Manual sobre indicadores de calidad de vida en la vejez, Santiago de Chile, CEPAL, pp. 1-203.

Instituto Nacional de Estadística y Geografía (2008), "Ley del Sistema Nacional de Información Estadística y Geográfica", México, Instituto Nacional de Estadística y Geografía. (2010), “Censo de población y vivienda, 2010", http://www.censo2010.org.mx.

Schuschny, Andrés y Soto, Humberto (2009), Guía metodológica. Diseño de indicadores compuestos de desarrollo sostenible, Santiago de Chile, CEPAL, p. 58.

Suárez, Manuel y Delgado, Javier (2007), "La expansión urbana probable de la Ciudad de México. Un escenario pesimista y dos alternativos para el año 2020", Estudios demográficos y urbanos, vol. 22, núm. 1(64), pp. 101-142. 



\section{Índice de calidad de vida objetivo de las colonias de la Zona Metropolitana del Valle de México}

Sergio de la Vega Estrada y Flor Araceli Ruiz Peña

\section{INTRODUCCIÓN}

Este capítulo describe la construcción del índice de calidad de vida objetivo (ICVO) para colonias o barrios de la Zona Metropolitana del Valle de México (ZMVM), el cual se estima con base en el índice de "manzanas" (capítulo 4), lo cual permite aumentar el número de casos con dato. Por un lado, se incrementan las "manzanas" con ICVO y, por el otro, se cuenta con índices por colonia que permiten otra lectura novedosa y propositiva del territorio que se define con esta clasificación espacial administrativa. Los resultados y los mapas que se elaboran muestran las bondades de esta metodología.

\section{LA COLONIA COMO UNIDAD TERRITORIAL CON IDENTIDAD}

La colonia, el barrio o los pueblos son categorías de análisis espacial que se han utilizado poco para el estudio de los distintos fenómenos y problemáticas que afectan a la población. Algunas de las razones por las que no se utiliza con mayor regularidad esta escala de análisis geográfico incluyen la inexistencia de una institución oficial que las delimite en todo el país y se carece de información estadística referida a ella. Hasta el momento, la delimitación de colonias (de carácter más urbano) la realizan las secretarías encargadas del desarrollo urbano en los estados y hay algunas instituciones, como Correos de México o el Instituto Nacional Electoral (INE), que efectúan levantamientos para sus operativos de campo o para fines específicos de acuerdo con sus funciones. 
La colonia es la unidad territorial más inmediata a la vivienda y al entorno; por ello, los habitantes se identifican más con este espacio; es el ámbito donde satisfacen sus necesidades básicas y donde conviven con las personas que comparten ese espacio; es el lugar donde se generan diversos procesos sociales, culturales y económicos que permiten caracterizar e identificar con ciertas particularidades a cada colonia que forma parte del entramado urbano. Por esta razón, se considera que es una unidad espacial susceptible de aportar información relevante acerca de la calidad de vida de las personas.

Para la georreferenciación del ICVO a nivel colonia, ya que el Instituto Nacional de Estadística y Geografía (INEGI) no genera cartografía a esta escala, se utilizaron dos fuentes de información: el INE y la Secretaría de Desarrollo Urbano y Vivienda (Seduvi) de la Ciudad de México. Esta última es la institución encargada de elaborar cartografía en la escala de colonia ${ }^{1}$ y la información cartográfica está referida al año 2010. La información cartográfica utilizada para los Estados de Hidalgo y de México corresponde al año 2014 y el INE la proporcionó. La diferencia en fuentes y años de la información cartográfica se debe principalmente a que la cartografía por colonia de la Seduvi es una fuente oficial, por lo cual no presenta incongruencias en cuanto a los límites delegacionales o de "manzanas" y el año de levantamiento cartográfico coincide con los datos estadísticos del "Censo de población y vivienda" del INEGı. En los Estados de Hidalgo y de México, no se encontró un símil cartográfico al de la Seduvi, por lo que se consultaron otras fuentes, y fue a través del INE ${ }^{2}$ que se obtuvo la cobertura de colonias; sin embargo, por cuestiones de logística, solo se obtuvo la del año 2014. No hay una diferencia importante entre el número de colonias entre los años 2010 y 2014.

Con la cartografía de ambas fuentes, el siguiente paso fue la revisión de los límites de colonia para asignarles las "manzanas" del INEGI y estimar el índice por colonia. La cartografía de Seduvi no presentó irregularidades a diferencia de la del INE, la cual tenía algunas incongruencias en el trazado y el cierre de polígonos, o superposición de estos, pero estas condiciones no afectaron la ubicación de las "manzanas". La asignación de una misma proyección a la información cartográfica fue importante, ya que era necesario que la información de la Seduvi y del INE tuvieran los mismos

\footnotetext{
${ }^{1}$ En el portal de la Seduvi, se encuentra el Sistema de Información Geográfica de la Ciudad de México donde se puede hacer una serie de consultas a distinta escala geográfica, entre las que se encuentra la colonia (http://ciudadmx.df.gob.mx:8080/seduvi/)

${ }^{2}$ Una de las funciones del INE es generar cartografía para los procesos electorales, por lo cual dicha cartografía está en constante actualización.
} 
parámetros cartográficos que la del INEGI. El siguiente paso fue asignar al listado de colonias de la Ciudad de México, el Estado de México y el Estado de Hidalgo una clave única para identificarlas. En este caso, se retomó la nomenclatura del INEGı y se construyeron claves de tres dígitos y la asignación de estas se hizo por orden alfabético y para cada municipio que forma parte de la ZMVM.

Con las claves asignadas a cada colonia de la ZMVM, se realizó una superposición de capas, "manzanas" de INEGI y colonias de la Seduvi y del INE. A cada una de las "manzanas", se asignó la clave de colonia a la cual pertenecían. Durante este procesamiento, tuvieron lugar algunos problemas, como el desajuste de polígonos por la diferencia de límites de las colonias, polígonos dobles, líneas mal trazadas o polígonos abiertos, o ambas situaciones a la vez, que se resolvieron.

En el análisis de la información cartográfica, se identificó que la Ciudad de México registró el mayor número de colonias a las cuales se les asignaron "manzanas" y, por tanto, se estimó su ICVO. El Estado de Hidalgo registró el menor número de colonias con índice de calidad de vida objetivo y por ello el menor número de "manzanas". El Estado de México, por su mayor número de municipios y habitantes, registró una cantidad más alta de colonias, pero no todas obtuvieron una categoría en el índice ya que no había "manzanas" asignadas. En la asignación de "manzanas" a colonias, se presentaron dos casos de excepción: en el primero había "manzanas" INEGI, pero no existía un polígono de colonia (Seduvi o INE) para agruparlas y, en el segundo, existía un polígono de colonias, pero no de "manzanas" para agrupar, por lo que no se contaba con un valor de ICvo (cuadro 5-1).

\section{CÁLCULO DEL ÍNDICE POR COLONIA}

En la creación de información, es común iniciar con el manejo de municipios al mismo tiempo que de entidades federativas, pero de manera independiente, un espacio territorial contenido en el otro. Después aparecen unidades territoriales menores que van desde las localidades, pasando por las áreas geoestadísticas básicas (AGEB) y terminando con las "manzanas" cuando existen observaciones construidas para estas escalas, todo ello en el marco de acción del INEGI. En general, los niveles naturales de observación por criterios operativos son: estados, municipios, localidades, AGEB y "manzanas", no es común trabajar datos por colonia. En este capítulo, se desea difundir una propuesta metodológica que contribuya a la obtención del índice por colonias, al mostrar las bondades al obtenerlo; asimismo, este permite reconstruir índices de "manzanas" que, por falta de alguna de las tres dimensiones que lo integran, no tuvieron dato de inicio. 
Cuadro 5-1

Zona Metropolitana del Valle de México (ZMVM). Número de colonias por delegación y municipio. Número de colonias por delegación y municipio

\begin{tabular}{|c|c|c|c|c|c|c|c|}
\hline \multicolumn{2}{|c|}{ Ciudad de México } & \multicolumn{2}{|c|}{ Estado de Hidalgo } & \multicolumn{4}{|c|}{ Estado de México } \\
\hline $\begin{array}{c}\text { clave } \\
\text { municipal }\end{array}$ & $\begin{array}{l}\text { colo- } \\
\text { nias }\end{array}$ & $\begin{array}{c}\text { clave } \\
\text { municipal }\end{array}$ & $\begin{array}{l}\text { colo- } \\
\text { nias }\end{array}$ & $\begin{array}{c}\text { clave } \\
\text { munici- } \\
\text { pal }\end{array}$ & $\begin{array}{l}\text { colo- } \\
\text { nias }\end{array}$ & $\begin{array}{c}\text { clave } \\
\text { municipal }\end{array}$ & $\begin{array}{l}\text { colo- } \\
\text { nias }\end{array}$ \\
\hline 9002 & 87 & 13005 & 21 & 15002 & 41 & 15059 & 14 \\
\hline 9003 & 95 & 13010 & 19 & 15009 & 24 & 15060 & 105 \\
\hline 9004 & 45 & 13013 & 14 & 15010 & 17 & 15061 & 6 \\
\hline 9005 & 177 & 13022 & 11 & 15011 & 34 & 15065 & 24 \\
\hline 9006 & 38 & 13039 & 40 & 15013 & 214 & 15068 & 19 \\
\hline 9007 & 198 & 13041 & 13 & 15015 & 38 & 15069 & 6 \\
\hline 9008 & 39 & 13048 & 257 & 15016 & 20 & 15070 & 78 \\
\hline 9009 & 34 & 13050 & 9 & 15017 & 7 & 15075 & 12 \\
\hline 9010 & 221 & 13051 & 101 & 15020 & 134 & 15081 & 107 \\
\hline 9011 & 71 & 13052 & 12 & 15022 & 7 & 15083 & 8 \\
\hline 9012 & 143 & 13063 & 26 & 15023 & 14 & 15084 & 18 \\
\hline 9013 & 104 & 13065 & 10 & 15024 & 75 & 15089 & 9 \\
\hline 9014 & 53 & 13066 & 11 & 15025 & 119 & 15091 & 26 \\
\hline 9015 & 33 & 13067 & 19 & 15028 & 27 & 15092 & 26 \\
\hline 9016 & 81 & 13069 & 54 & 15029 & 44 & 15093 & 15 \\
\hline \multirow[t]{15}{*}{9017} & 66 & 13070 & 10 & 15030 & 14 & 15094 & 12 \\
\hline & & 13074 & 26 & 15031 & 110 & 15095 & 28 \\
\hline & & 13075 & 11 & 15033 & 514 & 15096 & 14 \\
\hline & & 13076 & 107 & 15034 & 8 & 15099 & 257 \\
\hline & & 13082 & 22 & 15035 & 42 & 15100 & 13 \\
\hline & & 13083 & 19 & 15036 & 23 & 15103 & 50 \\
\hline & & & & 15037 & 130 & 15104 & 229 \\
\hline & & & & 15038 & 13 & 15108 & 63 \\
\hline & & & & 15039 & 116 & 15109 & 193 \\
\hline & & & & 15044 & 6 & 15112 & 22 \\
\hline & & & & 15046 & 13 & 15120 & 67 \\
\hline & & & & 15050 & 5 & 15121 & 204 \\
\hline & & & & 15053 & 23 & 15122 & 34 \\
\hline & & & & 15057 & 367 & 15125 & 7 \\
\hline & & & & 15058 & 76 & & \\
\hline
\end{tabular}

cve_mun, clave de municipio.

Fuente: Elaboración propia con datos de la Secretaría de Desarrollo Urbano y Vivienda (SEDUVI), 2010 y del Instituto Nacional Electoral (INE), 2014. 
En la metodología propuesta es factible utilizar el dato de población y darle un peso determinado en la elaboración de unidades de observación superiores. En este caso se trata de construir un índice para las colonias de la ZMVM, con base en la información de las "manzanas" y el índice obtenido para ellas.

El ICVO por "manzana" tiene datos de 33 indicadores agrupados en tres dimensiones: población, vivienda y entorno urbano. Por la fuente de información y la unidad observada, hay 186124 "manzanas" que tienen datos estadísticos (el respectivo código de "manzana" y al menos una de las 33 variables que generan las tres dimensiones); de ellas, 173352 "manzanas" tienen dato cartográfico (código de "manzana" y polígono cartográfico), y 164998 manifiestan dato de población (código y monto). Con estas combinaciones, se construyó el Icvo de 126936 "manzanas" donde habitan 18 millones de personas.

En la base de microdatos, no todas las "manzanas" ni todas las colonias tienen los valores de las tres dimensiones. La metodología aplicada permite abarcar ese tipo de faltantes y además estimar datos no recopilados para las colonias. El punto de partida son las cerca de 127000 "manzanas" para que las colonias representadas adquieran un índice; la técnica incluye la utilización del monto de población de las "manzanas" como ponderador para obtener el índice de las colonias. Para cada colonia, se agrupan sus "manzanas" conservando su índice y su población particulares; el monto de población multiplica al índice que le corresponde y a la suma de estos productos se le divide por el total de población en la colonia. Con este proceso, se obtuvo el índice para 4641 colonias con 17415613 habitantes. Además de estas últimas, hay otros 67 conglomerados de "manzanas" con 426935 habitantes, lo cual hace posible abarcar mayor superficie para completar las colonias de la ZMVM (cuadro 5-2).

Para las colonias obtenidas con la ponderación de "manzanas", la Ciudad de México tiene como promedio 30 "manzanas" por colonia, el Estado de Hidalgo 19 y el Estado de México, 26. En el caso del promedio de habitantes por colonia, la Ciudad

\section{Cuadro 5-2}

Colonias, "manzanas" y población por entidad federativa

\begin{tabular}{lrcr}
\hline Entidad federativa & Colonias & “Manzanas” & \multicolumn{1}{c}{ Población } \\
\hline Ciudad de México & 1465 & 43665 & 7234921 \\
Hidalgo & 467 & 8849 & 595526 \\
México & 2709 & 71629 & 9585166 \\
Total & 4641 & 124143 & 17415613 \\
\hline
\end{tabular}

Fuente: Elaboración propia con datos de la Secretaría de Desarrollo Urbano y Vivienda (SEDUVI), 2010 y del Instituto Nacional Electoral (INE), 2014. 
Cuadro 5-3

Colonias, "manzanas" y población por grado del índice de calidad de vida objetivo (ICVO)

\begin{tabular}{lccr}
\hline Grado ICVO & Colonias & “Manzanas” & Población \\
\hline Muy bajo & 464 & 8370 & 710428 \\
Bajo & 937 & 28202 & 3464807 \\
Medio & 1233 & 32240 & 4517174 \\
Alto & 1115 & 31693 & 5455001 \\
Muy alto & 892 & 23638 & 3268203 \\
Total & 4641 & 124143 & 17415613 \\
\hline
\end{tabular}

Fuente: Elaboración propia con datos de la Secretaría de Desarrollo Urbano y Vivienda (SEDUVI), 2010 y del Instituto Nacional Electoral (INE), 2014.

de México tiene 4 900; Hidalgo, 1300 y el Estado de México, 3500 personas. Los 4641 casos se clasifican, de acuerdo con el método de estratificación de Dalenius modificado (De la Vega, 1994, pp. 20-22), en una de las cinco categorías del ıcvo: muy bajo, bajo, medio, alto y muy alto. El índice de colonias tiene su mínimo en 0.4203 y su máximo en 0.9275 y se establecen los cortes en: $0.6200,0.6752,0.7279$ y 0.7874 ; con estos cortes se clasifican las colonias con distribuciones interesantes de "manzanas" y población correspondientes (cuadros 5-3 y 5-4).

La distribución de los 17 millones de habitantes en este análisis tiene su punto de mayor valor en la categoría de grado alto de ICVO, y la menor cantidad de pobladores está en la categoría de índice muy bajo. Para una segunda observación de los datos, la misma población donde se involucran los estados de residencia, las cifras y las posiciones son importantes para los objetivos de este libro. Uno de estos consiste en rescatar la colonia como espacio de observación analítica, lo cual permite dilucidar de manera diferente los espacios de identidad socioespacial.

Cuadro 5-4

Población por grado del índice de calidad de vida objetivo (ICVO) según entidad federativa

\begin{tabular}{lcccc}
\hline Grado de ICVO & Ciudad de México & Estado de Hidalgo & Estado de México & \multicolumn{1}{c}{ Total } \\
\hline Muy bajo & 15741 & 43060 & 651627 & 710428 \\
Bajo & 483239 & 180388 & 2801180 & 3464807 \\
Medio & 1718540 & 179954 & 2618680 & 4517174 \\
Alto & 2584594 & 142975 & 2727432 & 5455001 \\
Muy alto & 2432807 & 49149 & 786247 & 3268203 \\
Total & 7234921 & 595526 & 9585166 & 17415613 \\
\hline
\end{tabular}

Fuente: Elaboración propia con datos de la Secretaría de Desarrollo Urbano y Vivienda (SEDUVI), 2010 y del Instituto Nacional Electoral (INE), 2014. 
En este sentido, los espacios con la categoría de ICVO muy bajo constituyen el mayor reto para el cumplimiento de derechos sociales y para la justicia territorial en la metrópoli. En este grado, se ubican un poco más de 710000 personas, sobre todo las colonias del Estado de México, las cuales concentran 92\% de este subtotal metropolitano. Las colonias con muy bajo índice tienen en promedio 18 "manzanas" y 1500 habitantes y difieren de los promedios del conjunto de las colonias de la ZMVM analizadas que son 27 y 3 800, respectivamente.

La localización espacial del ICvO por "manzana" (capítulo 4) se confirma por colonias, como una escala con una identidad social dibujada con propósitos de innovación, tanto metodológica como analítica. La manifestación espacial revela un patrón centro-periferia ampliado con mayores rezagos dispersos, sobre todo en el oriente y el norte de la ZMVM, mientras que la mejor calidad de vida se localiza en el centro y el poniente, y donde la zona metropolitana de Pachuca es testigo de este tipo de expansión (mapa 5-1).

El manejo de datos por colonia permite su identificación y, entre otras cosas, focalizar programas sociales, aunque éstos sean de carácter universal como en la Ciudad de México. Por su tamaño, sobresalen aquellas colonias que equivalen a una ciudad (la cifra de 15000 habitantes o más determina que una localidad se considere ciudad) y hay varias colonias que rebasan este tamaño. Entre los casos a destacar del primer grupo de muy bajo ICVO sobresale la colonia "Luis Donaldo Colosio" en el municipio de Ecatepec de Morelos con 240 "manzanas" y 22422 habitantes. En el grupo de ICVO bajo, se encuentran colonias de la Ciudad de México: las de "Buenavista" y "Lomas de la Estancia", ambas en la delegación Iztapalapa, con 190 "manzanas" y 35476 habitantes, y 165 "manzanas" y 27925 habitantes, respectivamente y, en la delegación Tlalpan, se encuentra la colonia "Pueblo San Miguel Topilejo" con 118 "manzanas" y 23005 habitantes. En el Estado de México, sobresalen para el ICVO bajo: "Ciudad Cuauhtémoc" en Ecatepec con 538 "manzanas" y 82419 personas, "Dr. Jorge Jiménez Cantú" en Tlalnepantla con 291 "manzanas" y 35967 habitantes, y "San Lorenzo" en Chimalhuacán con 156 colonias y 32844 habitantes.

En el otro extremo, donde el ICvO es muy alto, las colonias que sobresalen en la Ciudad de México por su cantidad de habitantes son: "Agrícola" en Pantitlán, Iztacalco, con 312 "manzanas" y 69333 habitantes; "Simón Bolívar" en la delegación "Venustiano Carranza" con 188 "manzanas" y 41043 personas y "Doctores", en la delegación "Cuauhtémoc" con 124 "manzanas" para 40716 habitantes. Estas colonias no necesariamente requieren asistencia social por su índice promedio, pero cuentan con mucha población y, en la escala de "manzana", también son heterogéneas. En ocasiones, las 


\section{Mapa 5-1}

Índice de calidad de vida objetivo (ICVO) por colonia en la Zona Metropolitana del Valle de México (ZMVM).

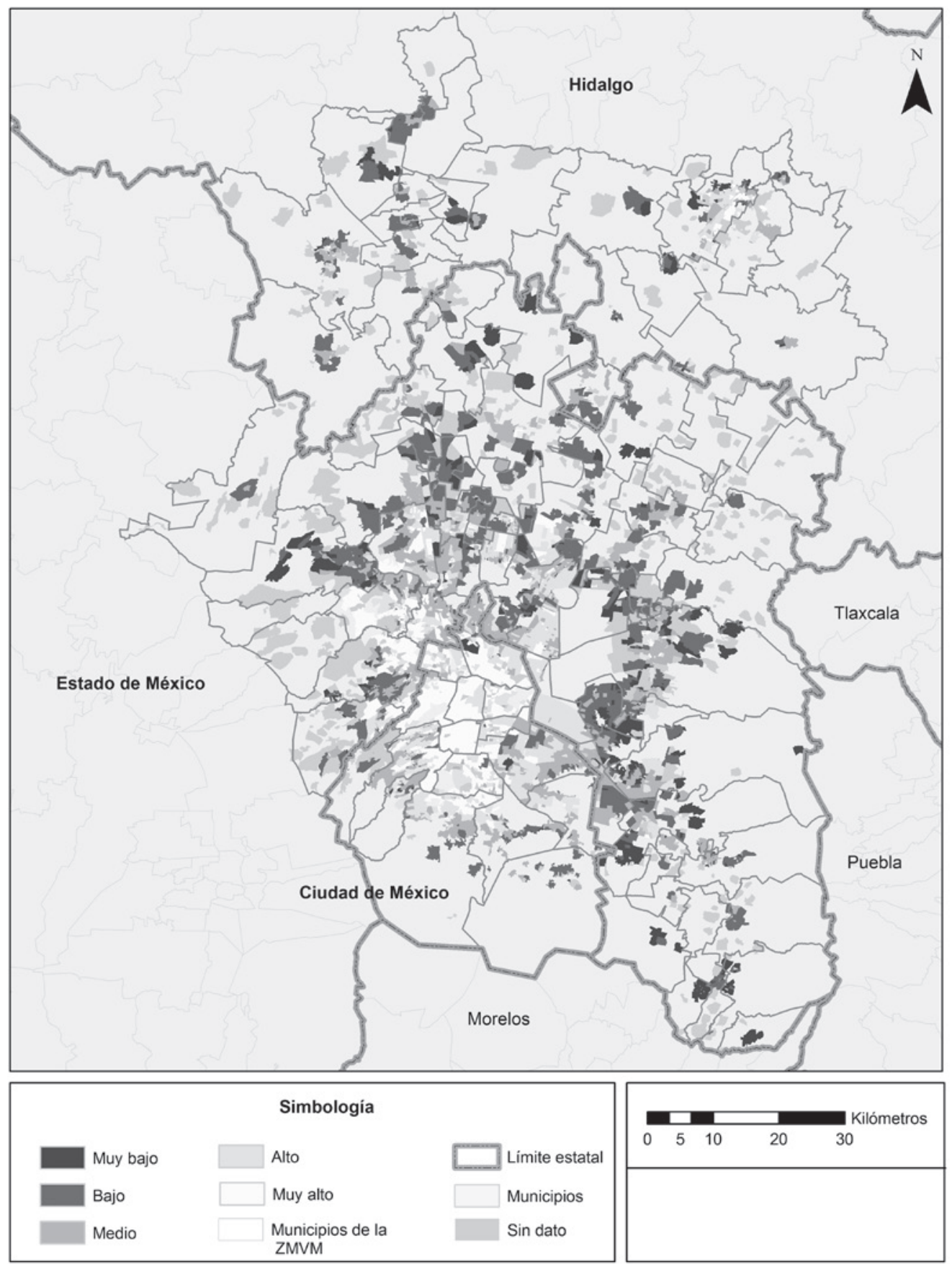

Fuente: Elaboración propia con datos de la Secretaría de Desarrollo Urbano y Vivienda (SEDUVI), 2010 y del Instituto Nacional de Estadística y Geografía (INEGI), 2014. 
concentraciones urbanas contienen carencias particulares (como ha llegado a ser el caso de pobreza patrimonial en municipios urbanos). Así, también hay que subrayar la existencia de colonias en el Estado de México, con un grado de ICVO muy alto y gran concentración de habitantes, como "Villa de las Flores", Coacalco con 274 "manzanas" y 43093 habitantes; "Valle de Aragón" 3ra. Sección, Ecatepec, con 357 "manzanas" y 30026 personas, y "Valle de Aragón" 1ra. Sección, Nezahualcóyotl, con 271 "manzanas" y 27509 habitantes.

\section{DIMENSIONES DE LAS COLONIAS}

Para sustentar la propuesta del manejo de colonias es útil observar la exposición de los mapas de dimensiones; del mapa 5-2 al 5-4, están las tres utilizadas en el estudio donde se observa el comportamiento de cada una, lo cual facilita su comparación. La propuesta es dar seguimiento a lo visual para que surjan algunas tareas en posteriores análisis.

Los mapas de este capítulo son exclusivos de colonias obtenidas con la metodología mencionada, al considerar que la suma de totales en las "manzanas" genera el valor de los totales en las colonias, y que al calcular los datos relativos de población por la suma resulta igual que obtenerlos por el promedio ponderado. El índice y las tres dimensiones se ponderan mediante el monto de población ya que esto se considera el criterio adecuado que jerarquiza a las personas que habitan los lugares. Medir por población es el método adecuado para resaltar la importancia de los pobladores. Así, el índice y las dimensiones quedan "sensibilizadas" por la presencia de los habitantes.

En el mapa 5-1, se muestra una distribución de colores que describe un patrón centro-periferia ampliado; se observa el gran centro en la originaria Ciudad de México y otros subcentros periféricos, pero menores, dada la superficie que abarcan. A partir de las colonias, los territorios muestran un perfil más definido. Por ejemplo, las colonias del municipio de Pachuca describen uno de estos subcentros menores; lo mismo sucede en áreas de Tecámac, Coacalco, Cuautitlán, Tlalnepantla, Atizapán, Naucalpan y Huixquilucan, todos del Estado de México. No se observa un centro único a partir del cual se dispersen los demás territorios, pero hay una gran concentración en la originaria Ciudad de México y, hacia la periferia, se forman otros nodos menores.

Las tres dimensiones manifiestan los subcentros, el de la ciudad central y los menores, pero con distinto grado de integración próxima. La dimensión de personas (mapa 5-2) describe con su grupo de muy bajo índice (el de color más oscuro) una franja que va desde el norte con Tezontepec, Hidalgo, hasta Valle de Chalco. En la dimensión de viviendas (mapa 5-3), el color oscuro describe una dispersión que llega 
a las periferias. En la dimensión de entorno (mapa 5-4), el color oscuro expresa un rodeo a la Ciudad de México.

Las tres dimensiones muestran patrones complementarios. El que primero llama la atención es el de entorno urbano: el color claro de grado muy alto describe un núcleo dominante en seis delegaciones de la Ciudad de México. A partir de este centro tan amplio, los colores de esparcen hacia la periferia con una definición de aumento de color y grupo de índice.

El mapa de la dimensión vivienda tiene también un gran centro en la misma posición, pero aparecen más espacios de color tenue hacia el exterior. Los colores oscuros se esparcen, pero se combinan con pequeños espacios tenues. En el mapa de dimensión de personas, los colores claros están más esparcidos y los colores oscuros tienen concentraciones definidas hacia el oriente de la ZMVM. La combinación de las tres dimensiones del ICVO describe un patrón no tan policéntrico como se esperaba, sino que predomina un modelo centro-periferia metropolitano ampliado y disperso.

\section{"MANZANAS"AÑADIDAS}

En el código utilizado para identificar las "manzanas", además de tener una cifra específica para "manzana", se indica la pertenencia al estado, municipio, la localidad y el AGEB; y las colonias se numeran dentro del municipio al que corresponden. Por el procesamiento de la información, no todas las "manzanas" reúnen sus tres dimensiones de población, vivienda y entorno urbano; de las 186124 "manzanas" iniciales, 126936 tienen datos completos con los que se calcula el ICVO correspondiente y son la base para estimar el índice de las colonias. En el caso de las "manzanas" con datos incompletos que están dentro de una colonia que sí reunió elementos para calcular su índice, fue posible completarlos a partir de los datos de la colonia a la que pertenecen. Esta técnica implica que hay un cálculo de los valores faltantes de la "manzana" mediante el valor de la colonia respectiva. Por supuesto que esto debe seguir un criterio donde el número de valores estimados no sea mayor al número de valores reales.

En el caso de las "manzanas", por situaciones de captura original, la dimensión que presenta más ausencias es la de entorno urbano, ya que los criterios de recolección de datos no contemplan la totalidad de los espacios. Si en aquellos donde faltan se logra incorporar por métodos estadísticos una medición equivalente apropiada, estos espacios se incorporan al análisis para abarcar así mayor superficie. Dada la conveniencia de esta variable, se propone utilizar los datos de las colonias con el propósito de asignar valores a las "manzanas" vecinas y faltantes de esta dimensión 


\section{Mapa 5-2}

Índice de calidad de vida objetivo (ICVO) de colonias en la dimensión de personas de la Zona Metropolitana del Valle de México (ZMVM)

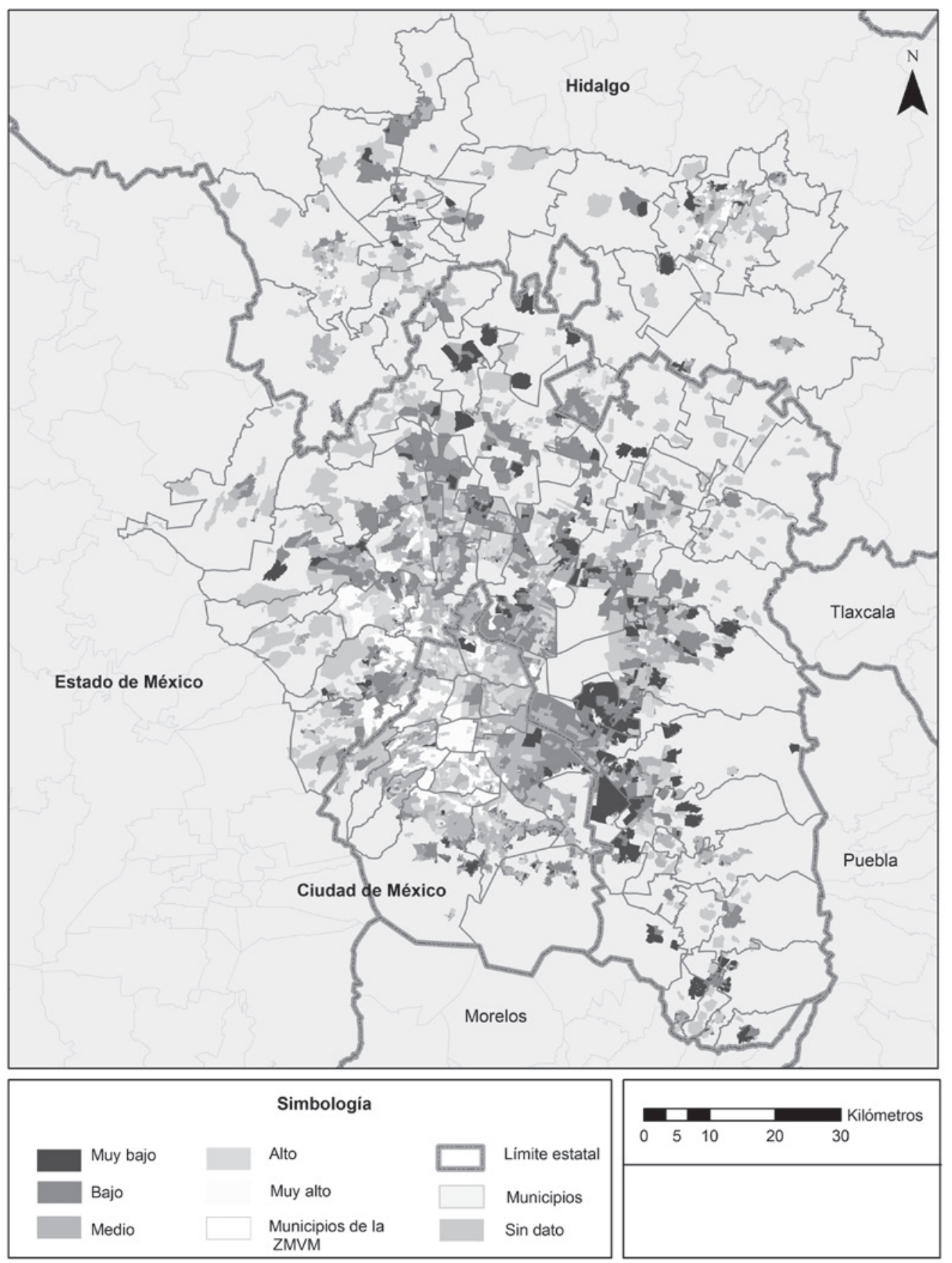

Fuente: Elaboración propia con datos de la Secretaría de Desarrollo Urbano y Vivienda (SEDUVI), 2010 y del Instituto Nacional de Estadística y Geografía (INEGI), 2014. 
Mapa 5-3

Índice de calidad de vida objetivo (ICVO) de colonias en la dimensión vivienda de la Zona Metropolitana del Valle de México (ZMVM).

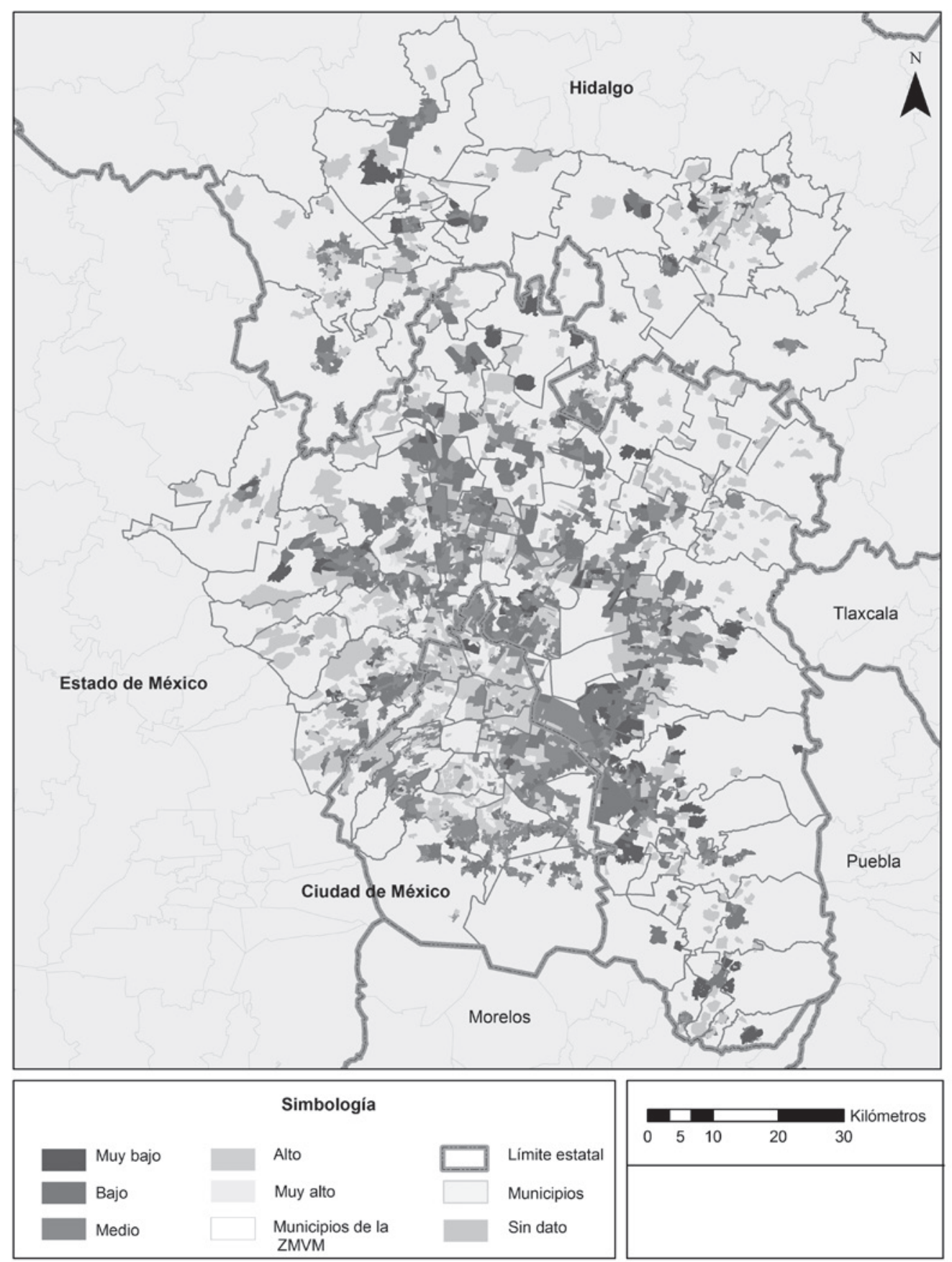

Fuente: Elaboración propia con datos de la Secretaría de Desarrollo Urbano y Vivienda (SEDUVI), 2010 y del Instituto Nacional de Estadística y Geografía (INEGI), 2014. 
Mapa 5-4

Índice de calidad de vida objetivo (ICVO) de colonias en la dimensión de entorno de la Zona Metropolitana del Valle de México (ZMVM)

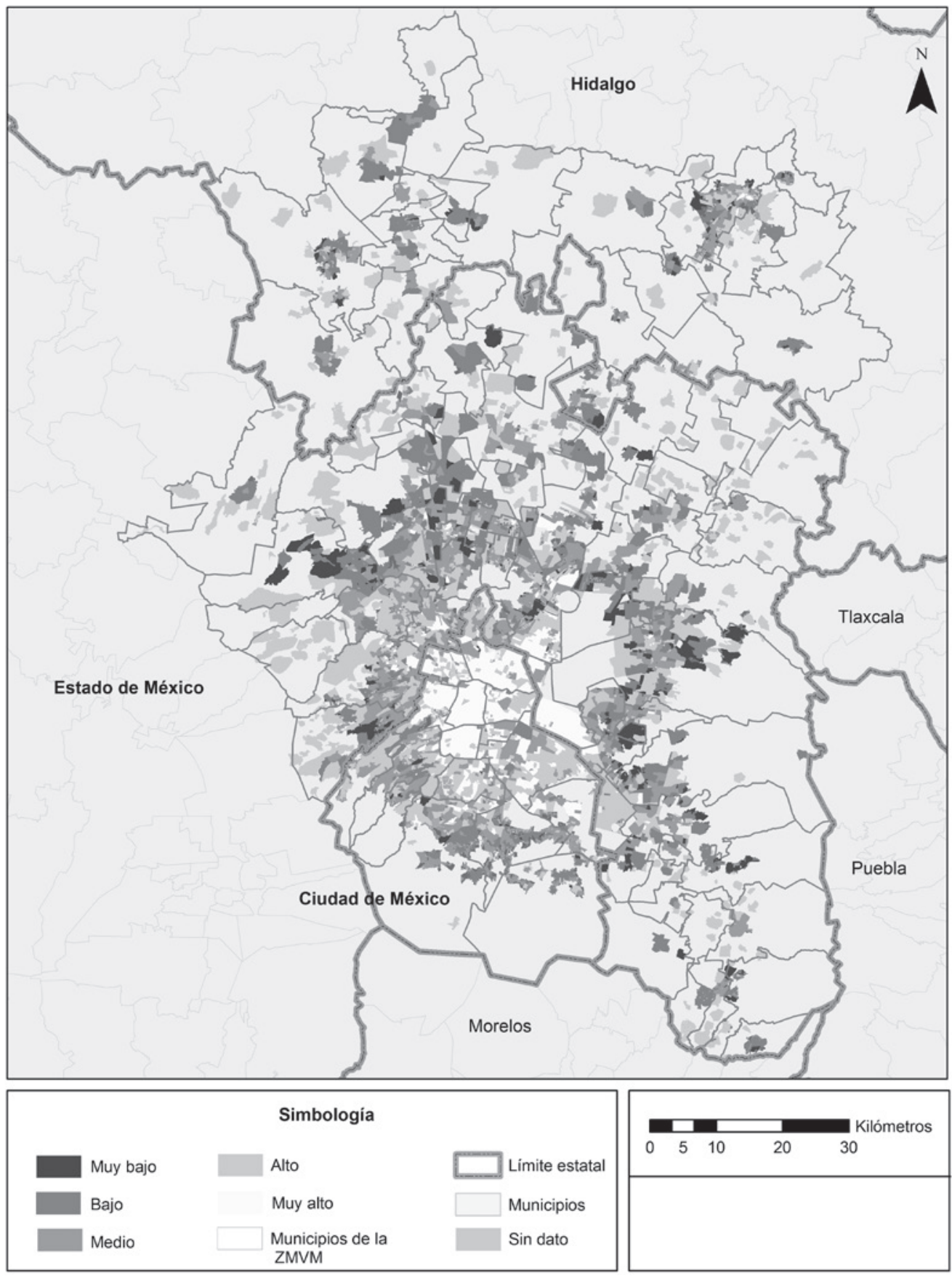

Fuente: Elaboración propia con datos de la Secretaría de Desarrollo Urbano y Vivienda (SEDUVI), 2010 y del Instituto Nacional de Estadística y Geografía (INEGI), 2014. 
de entorno. Todo esto es una ventaja más para mostrar la importancia del cálculo del ICVO y propiciar su uso (cuadro 5-5).

La dimensión de entorno urbano se estima para las "manzanas" que la requieren a partir del valor de la colonia y, cuando la "manzana" incompleta no tiene valor de colonia, se tomará del AGEB; si es imposible la estimación mediante estos dos caminos, se usa el valor de la localidad. Los valores del espacio inmediato pueden heredar un valor coherente con la ubicación.

Las 37898 "manzanas" que carecen del dato "entorno urbano" se promueven para adquirir su valor propio; de esas, por medio del valor de entorno de la colonia respectiva, se consigue recuperar 19793 casos; por los valores de AGEB, se logran 1737 más y, por último, gracias a los valores de localidad, se añaden otros 1 642, y con ello se recupera un total de 23172 "manzanas". En cada proceso de recuperación, el valor asignado representa el promedio del índice ponderado por la población de la "manzana". La vecindad cartográfica ofrece el punto de confianza para utilizar el promedio ponderado (cuadro 5-6).

La ventaja aparte de aumentar "manzanas", es que se agrega población observada. Las 23000 "manzanas" contienen 1654994 habitantes, los cuales se añaden al total. Cada una de estas "manzanas" tiene adjudicado el valor faltante de entorno urbano y, por tanto, al completar con los datos de las dimensiones de personas y vivienda, es posible construir su ICVO para elaborar un nuevo total (cuadro 5-7).

La contabilidad que más se beneficia es la de la Ciudad de México, tanto por el número de "manzanas" como por la cifra de población y aumenta 13338 "manzanas" con una población de 997755 habitantes. La categoría que más absorbe datos es la del ICVO alto. De las 23172 incorporadas, 9623 "manzanas" quedan clasificadas en ICVO alto con un aporte de 716992 habitantes. Mediante este procedimiento, la población asignada se incrementa a casi 19.5 millones de personas (cuadro 5-8).

La nueva cantidad de "manzanas" y población en la ZMVM permite elaborar ma-

Cuadro 5-6

"Manzanas" y población añadidas por entidad federativa

\begin{tabular}{lrr}
\hline Entidad & "Manzanas" & \multicolumn{1}{c}{ Población } \\
\hline Ciudad de México & 13338 & 997755 \\
Hidalgo & 618 & 39700 \\
México & 9216 & 617539 \\
Total & 23172 & 1654994 \\
\hline
\end{tabular}

Fuente: Elaboración propia con datos de la Secretaría de Desarrollo Urbano y Vivienda (SEDUVI), 2010 y del Instituto Nacional Electoral (INE), 2014. 
Cuadro 5-7

“Manzanas" por categoría de índice de calidad de vida (ICVO) según entidad federativa

\begin{tabular}{lcccc}
\hline Grado ICV & Ciudad de México & Estado de Hidalgo & Estado de México & Total \\
\hline Muy bajo & 1443 & 1277 & 8922 & 11642 \\
Bajo & 4608 & 2428 & 19109 & 26145 \\
Medio & 10445 & 2627 & 24824 & 37896 \\
Alto & 20019 & 2465 & 20790 & 43274 \\
Muy alto & 22104 & 979 & 8068 & 31151 \\
Total & 58619 & 9776 & 81713 & 150108 \\
\hline
\end{tabular}

Fuente: Elaboración propia con datos de la Secretaría de Desarrollo Urbano y Vivienda (SEDUVI), 2010 y del Instituto Nacional Electoral (INE), 2014.

pas más completos, ya que se añaden casi 895000 habitantes en la Ciudad de México en las categorías alto y muy alto; y 482000 habitantes en Hidalgo y el Estado de México en categorías de ICVO medio y alto. También es posible visualizar los patrones socioespaciales con las subdimensiones de personas, viviendas y entorno urbano.

\section{CONCLUSIONES}

En este capítulo se describió un análisis de la calidad de vida objetiva en la escala de colonia, barrio o comunidad para la gran ZMVM, el cual ha estado ausente de los análisis del territorio a pesar de que en dicha zona se encuentran procesos comunes de identidad ciudadana y de participación social por cercanía o proximidad física; asimismo, tales procesos constituyen unidades espaciales para la planeación del desarrollo, en particular, para el diseño y la instrumentación de los programas sociales, con los cuales se hacen realidad los derechos de la población y es posible la aplicación de estrategias que permitan alcanzar la justicia socioespacial.

\section{BIBLIOGRAFÍA}

De la Vega, Sergio (1994), Construcción de un índice de marginación. Condiciones de población y vivienda de los municipios de la República Mexicana, 1990. Tesis de Maestría en Estadística e Investigación de Operaciones, Colegio de Ciencias y Humanidades, UNAM, México.

Instituto Nacional Electoral (2014), "Cartografía electoral", http://cartografia.ife.org.mx/

Secretaría de Desarrollo Urbano y Vivienda (Seduvi) (2019), "Sistema de Información Geográfica de la Ciudad de México", http://ciudadmx.df.gob.mx:8080/seduvi/ 



\section{Percepción sobre la calidad de vida de la población del Distrito Federal}

Manuel Canto Chac y Adolfo Sánchez Almanza

\section{INTRODUCCIÓN}

Los estudios sobre calidad de vida, en general, establecen el grado de correspondencia entre las condiciones objetivas y las subjetivas de la población. En este capítulo, se realiza un análisis de este tipo para el Distrito Federal, ahora Ciudad de México, como parte de la Zona Metropolitana del Valle de México (ZMVM), para lo cual se utilizó la "Encuesta sobre calidad de vida" (Encavi)ำ (EvalúaDF, 2012a). Esta última ofrece información sobre la percepción de la calidad de vida de la población, al considerar como referencia aspectos objetivos socioespaciales. Los resultados permiten establecer el grado de cumplimiento de los derechos sociales según el marco jurídico vigente y, con ello, la posibilidad de valorar la acción del Estado; asimismo, pueden elaborarse propuestas correctivas a la política social y a políticas para el bienestar de la población.

Los objetivos generales de este estudio consisten en: a) analizar los resultados de percepción obtenidos en la Encavi aplicada en el Distrito Federal y complementar con grupos focales; $b$ ) realizar un análisis comparativo de esos resultados con factores objetivos, como las condiciones de desarrollo social en el territorio y los programas sociales universales más importantes aplicados por el Gobierno del Distrito Federal (GDF) relacionados con la calidad de vida de la población, y c) proponer algunas

${ }^{1}$ La Encavi fue una encuesta que EvalúaDF levantó en el Distrito Federal en el mes de enero de 2012, con representatividad por el grado de desarrollo social y los beneficiarios de los tres principales programas sociales aplicados por el GDF. La base de datos de la encuesta está disponible en la página de internet de EvalúaDF: http://www2.df.gob.mx/virtual/evaluadf/encuestas.php. 
recomendaciones correctivas para el mejoramiento de la política social. El análisis de la percepción ciudadana considera tres programas de desarrollo social: "Pensión para adultos mayores", "Prepa Sí" y "Atención médica y medicamentos gratuitos", elegidos por su carácter universal y por representar alrededor del $70 \%$ del gasto total en programas sociales del GDF.

\section{CALIDAD DE VIDA OBJETIVA EN EL DISTRITO FEDERAL}

La calidad de vida objetiva se midió para el Distrito Federal con el índice de desarrollo social (IDS) de 2010, el cual se estima con el enfoque de "necesidades básicas insatisfechas" aplicado a los datos intradomésticos de las bases de microdatos del "Censo de población y vivienda" del año 2010 del Instituto Nacional de Estadística y Geografía (INEGI), y con el total de las preguntas incluidas en el cuestionario básico. El índice se calculó primero para la escala territorial de "manzana" y, a partir de los datos, se estimaron de manera aditiva los correspondientes a colonia o barrio y delegación del Distrito Federal. La información definitiva cuenta con indicadores estadísticos georreferenciados, para las dimensiones que integran el índice y las tres escalas territoriales (EvalúaDFb). Los resultados miden la desigualdad socioespacial y el grado de cumplimiento de los derechos sociales en la medida en que se incluyen variables relacionadas con los derechos económicos, sociales y culturales que forman parte del marco legal que rige al Distrito Federal (capítulo 2).

Los datos del IDs fueron la referencia territorial objetiva para contrastar las percepciones de la sociedad, ya que esta es un criterio fundamental en el diseño de la muestra de la Encavi. Los resultados agregados del IDs para el año 2010 colocaron a la delegación "Benito Juárez" en el primer lugar con un grado alto de desarrollo social; siete delegaciones se ubicaron en un grado medio y otras siete en uno bajo, mientras que la delegación "Milpa Alta" ocupó el último lugar en un grado muy bajo. El índice general se asocia con los componentes que lo integran, de manera que en adecuación energética y educación, las condiciones son muy semejantes en la ciudad con valores altos de 4; en cambio, los componentes que presentan un mayor rezago y aportan variabilidad estadística son los de salud y seguridad social, vivienda, adecuación sanitaria y bienes durables (cuadro 6-1).La clasificación de delegaciones, colonia o barrio y "manzana" según el IDs debe considerarse de acuerdo con la "Ley de desarrollo social para el Distrito Federal", en el diseño y la instrumentación de programas y servicios en la materia a cargo del gobierno local, los cuales otorgan las dependencias de la administración pública central y delegacional (Asamblea Legisla- 


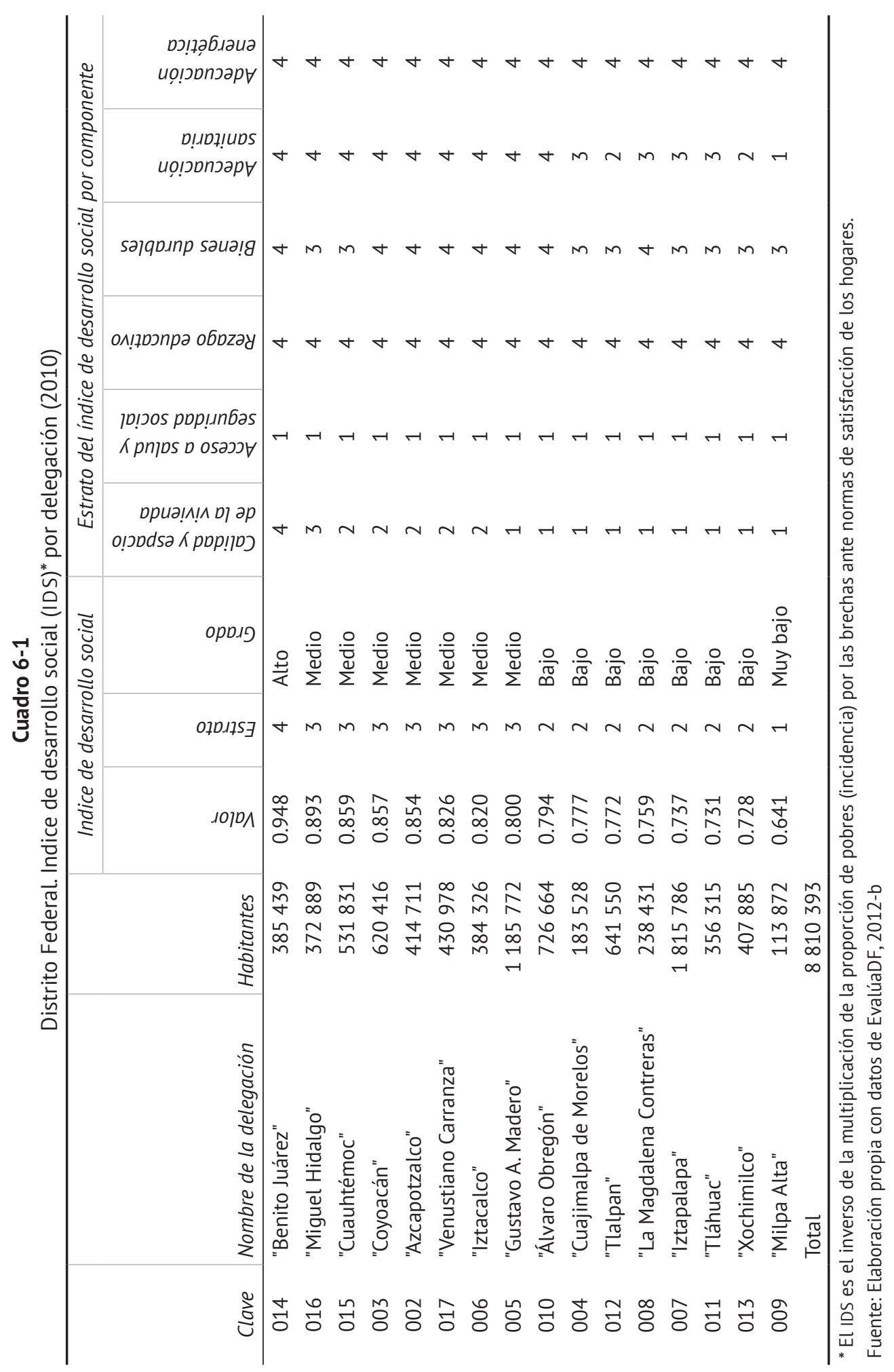


tiva del Distrito Federal, 2000). Por ello, es relevante comparar los aspectos objetivos y subjetivos ya que tienen incidencia legal y operativa en las políticas públicas de la ciudad en el marco de los derechos de la ciudadanía.

\section{PERCEPCIÓN SOBRE LA CALIDAD DE VIDA EN EL DISTRITO FEDERAL}

Los datos reportados en la Encavi, acerca de las percepciones de los ciudadanos sobre su calidad de vida, se contrastan de acuerdo con: a) el nivel socioeconómico, el ingreso, la educación y la edad; $b$ ) la pertenencia a alguno de tres programas de tipo universal, con mayor cobertura y presupuesto analizados ("Pensión para adultos mayores", "Prepa Sí" y "Atención médica y medicamentos gratuitos") frente a las opiniones de un grupo de "control", conformado por personas no participantes en esos programas, y c) el grado de desarrollo social del territorio en el que se ubican los entrevistados, de acuerdo con la clasificación del IDS del año 2010. Con base en lo anterior, se analizaron las respuestas a las preguntas de la encuesta y, para enriquecer el análisis, se aplicaron grupos focales e historias de vida. ${ }^{2}$

\section{Percepción sobre los problemas públicos}

De forma agregada, los tres principales problemas que percibe la sociedad al aplicar una pregunta abierta son: inseguridad (28\% del total de respuestas), pobreza (27\%) y falta de empleo (18.1\%), lo cual acumula $73.1 \%$ del total. Los demás problemas mencionados se distribuyen en porcentajes menores de 8\%. Si bien la inseguridad está en el primer nivel, seguida muy de cerca por la pobreza, al sumar esta con desempleo, por ser ambos de naturaleza socioeconómica, se llega a 45.1\%. Cuando se pregunta sobre el problema considerado en segundo lugar, se obtienen frecuencias de 24.6, 14.2 y 19.6\%, respectivamente. El único desplazamiento notable es que "trabajo" aparece en segundo lugar y "pobreza" en tercer lugar. Esto indica que en estos tres temas, se agrupa de manera consistente la respuesta de la población encuestada. Ante la pregunta ¿a quién se responsabiliza para la solución de los pro-

\footnotetext{
${ }^{2}$ La información emanada en este ejercicio, se ordenó y analizó mediante la recuperación de nueve historias de vida y entrevistas a profundidad, y tres grupos focales, con usuarios de los tres programas sociales seleccionados. En los grupos focales, se obtuvo información para dar cuenta de los efectos que han vivido los participantes de programas sociales. En las historias de vida y entrevistas a profundidad, se identificaron tanto las razones que los llevaron a acercarse a dichos programas como los mecanismos (redes formales e informales) que aplicaron para acceder y ser beneficiarios, además de ubicar la percepción que tienen sobre ellos.
} 
Cuadro 6-2

Porcentajes de respuestas a algunos problemas sociales

\begin{tabular}{lcccccc}
\hline Problema & Gobierno & Empresa & Uno mismo & Todos & Otros & Total \\
\hline Inseguridad & 72.7 & 0.9 & 3.0 & 20.0 & 3.4 & 100.0 \\
Pobreza & 60.4 & 2.7 & 12.3 & 21.4 & 3.2 & 100.0 \\
Falta de empleo & 65.4 & 10.5 & 7.1 & 14.4 & 2.6 & 100.0 \\
\hline
\end{tabular}

Fuente: Elaboración propia con datos de la "Encuesta sobre calidad de vida" (ENCAVI), 2012, levantada por EvalúaDF, 2012.

blemas expresados?, la población contesta que el principal responsable de resolver todos los problemas es el gobierno con variaciones, pertinentes, acerca de los otros responsables (cuadro 6-2).

\section{Percepción sobre los programas de desarrollo social}

En general, los resultados sobre la percepción de la población respecto de los programas sociales del GDF indican lo siguiente. Al sumar las opiniones que pueden considerarse positivas ("bien planteados, pero con fallas en su práctica" y "son adecuados") resulta que la mayoría de las personas interrogadas (63.4\%), si se suman las negativas ("ganar votos", "mal diseñados" y "no son adecuados") es de 32.6\%, con lo cual se concluye que la mayor parte de la población acepta los programas; no obstante, hay diferencias importantes al momento de desagregar las opiniones, con base en los elementos de contrastación referidos.

La primera diferencia se da entre la población que no participa en alguno de los tres programas y la que sí participa. Se observan diferencias notables de 57.4 y $70.6 \%$, respectivamente, de opinión favorable, con lo cual quienes reciben los beneficios tienen una opinión más positiva. Al ubicar otras variables, se encuentra que la respuesta: "son adecuados" tiende a incrementarse con la edad y las opiniones negativas tienden a aumentar con la escolaridad (cuadro 6-3).

Por otra parte, la opinión sobre los programas sociales según las características económicas indica que estas no son las que marcan tendencias importantes en los cambios de percepción. La opinión que presenta una tendencia notable al aumentar la escolaridad es "están mal diseñados y mal ejecutados" (cuadro 6-4).

En general, la opinión sobre los programas está en función de su uso y su conocimiento. Las tendencias generales hablan de una aceptación importante de los programas, que puede mejorar (sin que ello fuera un desafío fundamental para la política social) si se difundiera mayor información acerca de sus características, entre la población en general y no solo entre los usuarios potenciales. 
Cuadro 6-3

Opinión sobre los programas sociales en general

\begin{tabular}{lrrr}
\hline Opinión & General & Beneficiarios & No beneficiarios \\
\hline Están bien planteados pero falla su puesta en práctica & 33.6 & 36.0 & 31.7 \\
Son adecuados & 29.8 & 34.6 & 25.7 \\
Son solo para ganar votos & 15.3 & 13.8 & 16.5 \\
Están mal diseñados y mal ejecutados & 11.3 & 8.6 & 13.6 \\
No son adecuados & 6.0 & 5.2 & 6.6 \\
No los conozco & 2.5 & 0.3 & 4.3 \\
No sé & 0.9 & 0.6 & 1.1 \\
Otro & 0.6 & 0.9 & 0.5 \\
Total & 100.0 & 100.0 & 100.0 \\
\hline
\end{tabular}

Nota: Las respuestas se ordenan de acuerdo con la frecuencia de la forma en que se respondieron, en orden descendente.

Fuente: Elaboración propia con datos de la "Encuesta sobre calidad de vida" (ENCAVI), 2012, levantada por EvalúaDF, 2012.

La falta de información sobre programas sociales, se señaló en los instrumentos cualitativos, como una de las restricciones de acceso y ocasión de su politización:

Por una parte, no todo el mundo tiene acceso a la información de los programas y los pocos que la tienen, la politizan [...] La usan de bandera para los candidatos y como la gente no sabe, pues ni lo percibe, [...] les interesa tener un pueblo mediocre al que se le puede matar el hambre por un ratito, pero va a seguir con hambre. Entonces realmente casi no se ve gente a la que le interese (Historia de vida/Usuario 39 años). Delegación Coyoacán. "Programa de medicamentos y servicios médicos gratuitos" y "Operadora de programas".

\section{Percepción sobre programas sociales específicos}

Entre las opiniones de los usuarios de los programas, predomina la satisfacción y, dentro de ésta, la mayor satisfacción. Las razones de esto pueden ser diversas, por ejemplo, en el "Programa de medicamentos", las personas que dijeron que su tiempo de espera fue de una hora o menos es de $67.5 \%$; sin embargo, de inmediato se perciben los déficit principales del programa: sólo $58.5 \%$ manifestó haber recibido los medicamentos prescritos completos; de quienes requirieron un especialista, $69.6 \%$ dijo haber sido canalizado; entre el tiempo de la consulta general y la del especialista, $68 \%$ refirió que transcurrió menos de un mes. Un porcentaje de 69.5 expresó haber recibido buen trato de médicos y enfermeras, cuyas principales razones incluyeron "buena atención" 
Cuadro 6-4

Opinión sobre los programas por edad, escolaridad e ingreso por rango*

\begin{tabular}{|c|c|c|c|c|c|c|}
\hline \multirow[b]{2}{*}{ Opinión } & \multirow[b]{2}{*}{ Variable } & \multicolumn{5}{|c|}{ Rango } \\
\hline & & I & II & III & IV & $V$ \\
\hline \multirow{3}{*}{$\begin{array}{l}\text { Están bien planteados, pero } \\
\text { falla su puesta en práctica }\end{array}$} & Edad & 31.7 & 36.1 & 33.6 & 33.0 & 31.3 \\
\hline & Escolaridad & 32.8 & 35.5 & 34.0 & 34.3 & 34.8 \\
\hline & Ingreso & 33.7 & 34.3 & 33.7 & 37.5 & 31.0 \\
\hline \multirow{3}{*}{ Son adecuados } & Edad & 27.2 & 26.7 & 28.5 & 24.6 & 34.3 \\
\hline & Escolaridad & 32.2 & 28.8 & 31.0 & 24.8 & 19.6 \\
\hline & Ingreso & 30.2 & 31.0 & 30.8 & 25.7 & 28.0 \\
\hline \multirow{3}{*}{ Son sólo para ganar votos } & Edad & 16.2 & 14.6 & 13.2 & 17.7 & 16.7 \\
\hline & Escolaridad & 17.9 & 14.8 & 12.6 & 16.4 & 10.9 \\
\hline & Ingreso & 15.2 & 13.4 & 15.6 & 17.1 & 15.4 \\
\hline \multirow{3}{*}{$\begin{array}{l}\text { Están mal diseñados y mal } \\
\text { ejecutados }\end{array}$} & Edad & 15.1 & 12.6 & 13.9 & 11.6 & 8.4 \\
\hline & Escolaridad & 10.3 & 11.8 & 11.6 & 13.7 & 19.6 \\
\hline & Ingreso & 10.7 & 12.3 & 10.5 & 11.2 & 13.9 \\
\hline \multirow{3}{*}{ No son adecuados } & Edad & 5.4 & 4.9 & 6.0 & 8.9 & 5.8 \\
\hline & Escolaridad & 4.4 & 6.1 & 6.9 & 4.2 & 6.5 \\
\hline & Ingreso & 6.5 & 5.9 & 5.7 & 4.6 & 4.8 \\
\hline Otros & Edad & 4.4 & 5.1 & 4.8 & 4.2 & 3.5 \\
\hline Otros & Escolaridad & 2.4 & 3.0 & 3.9 & 6.6 & 8.6 \\
\hline Otros & Ingreso & 3.7 & 3.1 & 3.7 & 3.9 & 6.9 \\
\hline Total & Edad & 100.0 & 100.0 & 100.0 & 100.0 & 100.0 \\
\hline Total & Escolaridad & 100.0 & 100.0 & 100.0 & 100.0 & 100.0 \\
\hline Total & Ingreso & 100.0 & 100.0 & 100.0 & 100.0 & 100.0 \\
\hline
\end{tabular}

* Edad: I = 18 a 24; II = 25 a 34; III = 35 a 44; IV = 45 a 54; V = 55 y más. Escolaridad: I = Primaria; II = Secundaria; III = Media superior; IV = Superior; V = Posgrado. Ingresos: I = 400 a 800; I I = 801 a 1 200; III = 1201 a 1 600; IV = 1601 a 2000; $V=+$ de 2000.

Fuente: Elaboración propia con datos de la "Encuesta sobre calidad de vida" (ENCAVI), 2012, levantada por EvalúaDF, 2012.

(36.6\%) y "amabilidad" (22.1\%). Entre las personas que necesitaron hospitalización, $60 \%$ dijo recibir un "trato bueno" o "muy bueno". De los participantes en el programa, 95.8\% expresó no haber contraído ninguna obligación a cambio de los servicios recibidos; el restante $4.2 \%$ que respondió haberla contraído, de entre los tipos de obligación principales referidos, los significativos son: "asistir a reuniones" (0.3\%), "asistir a reuniones políticas" (0.1\%) y "votar por un partido político (0.1\%) (cuadros 6-5 y 6-6).

La mayoría de los usuarios satisfechos no resulta tan evidente cuando se indaga en entrevistas y grupos focales donde se señalan algunas críticas y sugerencias, en 
Cuadro 6-5

Satisfacción de los usuarios del programa en que participan

\begin{tabular}{l|c|c|c|c|c|c}
\hline & $\begin{array}{c}1 . \\
\text { Muy Satis- } \\
\text { fecho }\end{array}$ & $\begin{array}{c}2 . \\
\text { Satisfecho }\end{array}$ & $\begin{array}{c}3 . \\
\text { Indiferente }\end{array}$ & $\begin{array}{c}4 . \\
\text { Insatisfe- } \\
\text { cho }\end{array}$ & $\begin{array}{c}5 . \text { Muy } \\
\text { insatisfe- } \\
\text { cho }\end{array}$ & Total \\
\hline a) "Adultos mayores" & 54.3 & 31.1 & 8.0 & 4.8 & 1.8 & 100.0 \\
\hline b) "Prepa Sín & 48.7 & 36.6 & 11.6 & 2.4 & 0.7 & 100.0 \\
\hline $\begin{array}{l}\text { c) "Atención médica" y "Medi- } \\
\text { camentos gratuitos" }\end{array}$ & 85.5 & 5.3 & 5.6 & 3.1 & 0.5 & 100.0 \\
\hline a) $1+2,3,4+5$ & 85.4 & & 8.0 & 6.6 & & 100.0 \\
\hline b) $1+2,3,4+5$ & 85.3 & & 11.6 & 3.1 & & 100.0 \\
\hline c) $1+2,3,4+5$ & 90.8 & & 5.6 & 3.6 & & 100.0 \\
\hline
\end{tabular}

Fuente: Elaboración propia con datos de la "Encuesta sobre calidad de vida" (ENCAVI), 2012, levantada por EvalúaDF, 2012.

Cuadro 6-6

Nivel de satisfacción de los usuarios de los programas

\begin{tabular}{|c|c|c|c|c|c|c|}
\hline Programa & $\begin{array}{l}\text { Satis- } \\
\text { facción }\end{array}$ & Ventaja & Problema & $\begin{array}{l}\text { Condicio- } \\
\text { namiento }\end{array}$ & $\begin{array}{l}\text { Tipo de condi- } \\
\text { cionamiento }\end{array}$ & $\begin{array}{c}\text { Universal } \\
\text { Si\% }\end{array}$ \\
\hline \multirow{2}{*}{$\begin{array}{l}\text { "Adultos } \\
\text { mayores" }\end{array}$} & \multirow[t]{2}{*}{85.4} & $\begin{array}{l}\text { Cambia situación } \\
\text { dentro de la familia }\end{array}$ & & Sí & $\begin{array}{l}\text { Asistir a } \\
\text { reuniones }\end{array}$ & \multirow[t]{2}{*}{86.6} \\
\hline & & 69.8 (a) & & 12.5 & 7.3 & \\
\hline \multirow{2}{*}{$\begin{array}{l}\text { "Medica- } \\
\text { mentos } \\
\text { gratuitos" }\end{array}$} & \multirow[t]{2}{*}{90.8} & Buen trato & $\begin{array}{l}\text { Medicamentos } \\
\text { incompletos }\end{array}$ & Sí & $\begin{array}{l}\text { Asistir a } \\
\text { reuniones }\end{array}$ & \multirow[t]{2}{*}{78.7} \\
\hline & & 69.5 & 41.5 & 4.2 & 0.3 & \\
\hline \multirow[t]{2}{*}{ "Prepa Sí" } & \multirow[t]{2}{*}{85.3} & $\begin{array}{l}\text { Cambia (a) situación } \\
\text { dentro de la familia }\end{array}$ & $\begin{array}{c}\text { Retraso o } \\
\text { incumplimiento } \\
\text { de pago }\end{array}$ & Sí & $\begin{array}{l}\text { Asistir a (b) } \\
\text { reuniones }\end{array}$ & \multirow[t]{2}{*}{82.9} \\
\hline & & 50.5 & 10.2 & 46.1 (b) & 67.5 & \\
\hline
\end{tabular}

(a) Fue pregunta explícita.

(b) Este programa de forma explícita implica obligaciones del beneficiario como contraprestación, por lo cual el sentido de la pregunta no se alcanzó a precisar.

Fuente: Elaboración propia con datos de la "Encuesta sobre calidad de vida" (ENCAVI), 2012, levantada por EvalúaDF, 2012.

particular al programa "Prepa Sí", que en la encuesta registra el mayor número de opiniones negativas, por ejemplo:

En el programa Prepa Si, te pagan cada mes, pero te depositan cada cuatro meses, cada seis, o sea, no es nada regular (Historia de vida/Usuaria de 18 años de edad). Delegación "Cuauhtémoc". "Programa Prepa Sí". 
Las actividades de 'Prepa Sí' son actividades, pero a veces no haces nada, nos hacen perder nuestro tiempo, deberían hacer algo, no sé, más productivo; solo nos llevan a 'quesque' eventos para hacer bola, o nos piden ponernos unas playeras y estar en sus actividades; yo creo que son solo cosas políticas, pero no ayudamos en nada a la comunidad (Grupo focal/Usuarios de 19 años de edad). Delegación "Benito Juárez". "Programa Prepa Sí".

Para mejorar el programa, lo primero que haría es mejorar la administración, yo creo que, desde arriba, no porque el director del fideicomiso sea el que esté en error, sino porque no hay una buena supervisión del programa, porque muchas veces hay retrasos gigantes de meses para los depósitos, también he sabido de muchos casos en donde los jóvenes no son bien tratados por parte de los funcionarios; además, creo es necesario analizar la realidad en la que viven los jóvenes que se benefician. Hacer un estudio socioeconómico más profundo y, si ya existe esa información, tenerla en cuenta y darle en la medida de lo posible seguimiento (Historia de vida/Usuaria de 18 años de edad). Delegación "Iztapalapa". "Programa Prepa Sí".

Aunque entiendo que el GDF se presente como un gobierno de izquierda con una ideología que quiere beneficiar a todos, yo creo que sería mejor si se brindaran apoyos para las personas que de verdad lo necesiten y también para actividades que amplíen los beneficios a la comunidad. ¿Qué actividades realizan que realmente beneficien a la comunidad? A veces pienso que se dan malos manejos de los recursos, tanto de los chavos como de la administración, nadie hace lo que le toca. Es necesario hacer equilibrio entre operadores, funcionarios, participantes y la comunidad (Grupo focal/Usuario de 18 años de edad). Delegación "Coyoacán". "Programa Prepa Sí".

En las entrevistas a profundidad o de grupo, se propician relaciones de confianza, lo cual permitió que se expresaran las opiniones negativas al programa, mientras que en una relación distante, como lo es el cuestionario, estas tienden a inhibirse.

\section{Cultura política}

En la aproximación a valores que son representativos de las actitudes ciudadanas ante los fenómenos de la vida pública, se utilizaron las mismas preguntas de algunas encuestas que se aplican en América Latina para tener algún punto de comparación. 
Cuadro 6-7

Opinión sobre la democracia por edad, escolaridad e ingreso según rango*

\begin{tabular}{|c|c|c|c|c|c|c|}
\hline Opinión & Variable & I & II & III & IV & $V$ \\
\hline \multirow{3}{*}{$\begin{array}{l}\text { La democracia es preferible a otra } \\
\text { forma de gobierno }\end{array}$} & Edad & 61.7 & 58.2 & 62.8 & 60.9 & 61.0 \\
\hline & Escolaridad & 56.1 & 60.6 & 61.3 & 69.1 & 73.9 \\
\hline & Ingreso & 58.4 & 59.8 & 61.3 & 66.4 & 69.3 \\
\hline \multirow{3}{*}{$\begin{array}{l}\text { Un gobierno autoritario puede ser } \\
\text { preferible que uno democrático }\end{array}$} & Edad & 16.0 & 20.3 & 15.9 & 18.6 & 17.4 \\
\hline & Escolaridad & 18.9 & 17.7 & 18.1 & 15.0 & 15.2 \\
\hline & Ingreso & 19.0 & 19.1 & 18.0 & 14.5 & 15.4 \\
\hline \multirow{3}{*}{$\begin{array}{l}\text { Da lo mismo un régimen democrático } \\
\text { que no democrático }\end{array}$} & Edad & 22.3 & 21.3 & 21.3 & 20.5 & 21.4 \\
\hline & Escolaridad & 24.7 & 21.7 & 20.6 & 15.6 & 10.9 \\
\hline & Ingreso & 22.6 & 21.1 & 20.6 & 19.1 & 15.1 \\
\hline Otra & Edad & 0.0 & 0.2 & 0.0 & 0.0 & 0.2 \\
\hline Otra & Escolaridad & 0.3 & 0.0 & 0.0 & 0.3 & 0.0 \\
\hline Otra & Ingreso & 0.0 & 0.0 & 0.1 & 0.0 & 0.2 \\
\hline Total & Edad & 100.0 & 100.0 & 100.0 & 100.0 & 100.0 \\
\hline Total & Escolaridad & 100.0 & 100.0 & 100.0 & 100.0 & 100.0 \\
\hline Total & Ingreso & 100.0 & 100.0 & 100.0 & 100.0 & 100.0 \\
\hline
\end{tabular}

*Edad: I = 18 a 24; II = 25 a 34; III = 35 a 44; IV = 45 a 54; V = 55 y más. Escolaridad: I = Primaria; II = Secundaria; III = Media superior; IV = Superior; V = Posgrado. Ingresos: I = 400 a 800; II = 801 a 1 200; III = 1201 a 1 600; IV = 1601 a 2 000; V = + de 2000.

Fuente: Elaboración propia con datos de la "Encuesta sobre calidad de vida" (ENCAVI), 2012, levantada por EvalúaDF, 2012.

En relación con la democracia, las respuestas que se obtuvieron se encuentran en el cuadro 6-7.

"Escolaridad" e "ingreso" son las variables más proclives a los valores democráticos, mientras que la edad no tiene un comportamiento tendencial; esto refuerza la idea de que la percepción de la democracia está condicionada por sus resultados en la vida del ciudadano; puesto de otra manera, la democracia también es un asunto de desarrollo. Llama la atención la ligeramente menor identificación con los valores democráticos del grupo de 25 a 34 años, lo cual se podría explicar porque acumulan mayor frustración por la falta de oportunidades. La fuerte relación entre desarrollo socioeconómico y compartir valores democráticos queda aun más claro cuando se comparan las respuestas con el nivel de desarrollo social del territorio en que habitan los informantes (cuadro 6-8).

Lo más notable es la relación entre grado de desarrollo social e indiferencia ante la democracia. La adhesión a la democracia es un asunto de cultura política, 
Cuadro 6-8

Opinión sobre la democracia según el grado de desarrollo social

\begin{tabular}{l|c|c|c|c|c}
\hline \multirow{2}{*}{ Opinión } & \multicolumn{5}{|c}{ Grado de desarrollo social } \\
\cline { 2 - 6 } & Alto & Medio & Bajo & Muy Bajo & Promedio \\
\hline $\begin{array}{l}\text { La democracia es preferible a otra forma } \\
\text { de gobierno }\end{array}$ & 64.9 & 63.5 & 56.4 & 54.8 & 59.9 \\
\hline $\begin{array}{l}\text { Un gobierno autoritario puede ser prefe- } \\
\text { rible que uno democrático }\end{array}$ & 16.7 & 19.9 & 19.2 & 17.8 & 18.4 \\
\hline $\begin{array}{l}\text { Da lo mismo un régimen democrático } \\
\text { que no democrático }\end{array}$ & 18.4 & 16.6 & 24.4 & 27.4 & 21.7 \\
\hline Total & 100.0 & 100.0 & 100.0 & 100.0 & 100.0 \\
\hline
\end{tabular}

Fuente: Elaboración propia con datos de la "Encuesta sobre calidad de vida" (ENCAVI), 2012, levantada por EvalúaDF, 2012.

pero ésta es un tema de desarrollo y, en ese sentido, también habrá que preguntarse: ¿qué puede hacer la política social para fortalecer la democracia? Responder a esta interrogante conduce a otra: ¿qué pasa cuando se compara entre beneficiarios y no beneficiarios de programas sociales? (cuadro 6-9).

Hay una ligera tendencia más favorable a la democracia entre los beneficiarios en comparación con quienes no lo son. Si bien el monto de la misma no es importante desde el punto de vista estadístico, su comportamiento, incluso cuando se controla por escolaridad e ingreso, hace pensar que existe algún elemento entre los participantes en los programas considerados que podría explicar esta mayor proclividad, y tal vez éste corresponda a las actividades que realizan en el marco de los programas que, de ser válida la hipótesis, estarían marcando un potencial de capacidad pedagógica en los mismos y que hasta ahora no se ha utilizado de forma suficiente.

\section{Cuadro 6-9}

Opinión sobre la democracia según condición de beneficiarios de programas sociales

\begin{tabular}{l|c|c|c|c}
\hline Opinión & General & Beneficiarios & $\begin{array}{c}\text { No } \\
\text { beneficiarios }\end{array}$ & Diferencia \\
\hline $\begin{array}{l}\text { La democracia es preferible a otra forma de } \\
\text { gobierno }\end{array}$ & 61.4 & 62.7 & 60.0 & 2.7 \\
\hline $\begin{array}{l}\text { Un gobierno autoritario puede ser preferible que } \\
\text { uno democrático }\end{array}$ & 17.7 & 16.9 & 18.5 & -1.6 \\
\hline $\begin{array}{l}\text { Da lo mismo un régimen democrático que no } \\
\text { democrático }\end{array}$ & 21.0 & 20.4 & 21.5 & -1.1 \\
\hline \begin{tabular}{l} 
Total \\
\hline
\end{tabular}
\end{tabular}

Fuente: Elaboración propia con datos de la "Encuesta sobre calidad de vida" (ENCAVI), 2012, levantada por EvalúaDF, 2012. 
Cuadro 6-10

Confianza ciudadana en algunas instituciones según el grado de desarrollo social

\begin{tabular}{l|c|c|c|c|c|c|c|c}
\hline \multirow{2}{*}{} & \multicolumn{2}{|c|}{ Alto } & \multicolumn{2}{c}{ Medio } & \multicolumn{2}{c}{ Bajo } & \multicolumn{2}{c}{ Muy Bajo } \\
\cline { 2 - 11 } & $\begin{array}{c}\text { Mucho+ } \\
\text { algo }\end{array}$ & $\begin{array}{c}\text { Poco+ } \\
\text { nada }\end{array}$ & $\begin{array}{c}\text { Mucho+ } \\
\text { algo }\end{array}$ & $\begin{array}{c}\text { Poco+ } \\
\text { nada }\end{array}$ & $\begin{array}{c}\text { Mucho+ } \\
\text { algo }\end{array}$ & $\begin{array}{c}\text { Poco+ } \\
\text { nada }\end{array}$ & $\begin{array}{c}\text { Mucho+ } \\
\text { algo }\end{array}$ & $\begin{array}{c}\text { Poco+ } \\
\text { nada }\end{array}$ \\
\hline Gobierno de la Ciudad & 43.3 & 56.7 & 35.4 & 64.6 & 35.0 & 65.0 & 26.6 & 73.4 \\
\hline $\begin{array}{l}\text { Gobierno de la dele- } \\
\text { gación }\end{array}$ & 39.7 & 60.3 & 33.6 & 67.4 & 32.6 & 67.4 & 21.4 & 78.7 \\
\hline $\begin{array}{l}\text { Gobierno federal } \\
\text { Promotores de progra- } \\
\text { mas sociales }\end{array}$ & 35.2 & 64.8 & 32.6 & 67.4 & 34.1 & 65.9 & 23.4 & 76.6 \\
\hline Partidos & 59.0 & 41.8 & 58.2 & 45.5 & 54.3 & 31.5 & 68.3 \\
\hline $\begin{array}{l}\text { Organizaciones ciuda- } \\
\text { danas }\end{array}$ & 43.1 & 57.0 & 36.9 & 63.1 & 43.9 & 56.1 & 27.2 & 72.7 \\
\hline
\end{tabular}

Fuente: Elaboración propia con datos de la "Encuesta sobre calidad de vida" (ENCAVI), 2012, levantada por EvalúaDF, 2012.

La pregunta siguiente corresponde a ¿cuál es el grado de confianza de la población en las instituciones de acuerdo con su grado de desarrollo social? (cuadro 6-10).

La primera reflexión es que el GDF goza de mejor opinión de manera uniforme en todos los estratos socioeconómicos, en comparación con las delegaciones y el gobierno federal. La segunda es que esta opinión favorable decrece de modo lineal en cuanto se reduce el nivel de desarrollo social; esto tiene lugar con todos los niveles, a excepción del bajo, en el cual el gobierno federal tiene un repunte respecto del nivel medio. La tercera conclusión se refiere al importante papel que cumplen los promotores de los programas sociales como mecanismo de comunicación con la sociedad; su experiencia debería incorporarse mejor en el rediseño de los programas, pero se carece de información en cuanto a algo de esto esté ocurriendo (Canto y Berrios, 2012). La cuarta reflexión indica que: a menor nivel de desarrollo social, menor confianza en las instituciones políticas, lo que es congruente con el tema de "cultura política". Si se invierte la pregunta: ¿en quiénes confía la ciudadanía?, considerada por grado de desarrollo social, aparecen otros asuntos de importancia. En el cuadro 6-11, se reordena la información, siempre teniendo en cuenta que las "preferencias de confianza" son menores de $50 \%$ en todos los casos.

La única institución política que alcanza a aparecer es el gobierno de la ciudad, pero lo curioso es que lo hace solo en el nivel alto de desarrollo social, lo cual quizá identifique la acción del gobierno de la ciudad en cuanto a dotación de servicios; 


\section{Cuadro 6-11}

Preferencia de instituciones según el grado de desarrollo social

\begin{tabular}{lll}
\hline Grado de desarrollo social & $1^{\text {a }}$ Preferencia & $2^{a}$ Preferencia \\
\hline Alto & Gobierno de la Ciudad & Organizaciones ciudadanas \\
Medio & Promotores de programas sociales & Organizaciones ciudadanas \\
Bajo & Promotores de programas sociales & Organizaciones ciudadanas \\
Muy Bajo & Promotores de programas sociales & Organizaciones ciudadanas \\
\hline
\end{tabular}

Fuente: Elaboración propia con datos de la "Encuesta sobre calidad de vida” (ENCAVI), 2012, levantada por EvalúaDF, 2012.

para el resto de los estratos, la preferencia es de promotores y, en todos los casos, la siguiente opción corresponde de manera constante a las organizaciones ciudadanas. En esta última categoría, hay también un potencial para el rediseño de los programas; para ello, se cuenta con instrumentos adecuados, como los consejos de desarrollo social, mismos que la administración pública no ha atendido de manera adecuada (Sánchez Mejorada, 2010).

La pertenencia o no a los programas, a su vez, no introduce diferencias notables desde el punto de vista estadístico, pero sí llama la atención que de modo consistente la opinión de los beneficiarios respecto de las instituciones tenga la tendencia menos favorable en comparación con la opinión de quienes no reciben beneficio, excepto la que se relaciona con los promotores de los programas sociales con 2.6 puntos porcentuales de diferencia. Es posible suponer que la cercanía de los promotores a las personas es lo que explica esa diferencia (cuadro 6-12).

Con el fin de ponderar cuál de las variables socioeconómicas podría pesar más, se analiza la relación entre ambas con la opinión sobre las instituciones. Al simplifi-

\section{Cuadro 6-12}

Opinión sobre las instituciones según la condición de beneficiarios de programas sociales

\begin{tabular}{l|c|c|c|c}
\hline \multirow{2}{*}{ Subtítulos } & \multicolumn{2}{c|}{ Beneficiarios } & \multicolumn{2}{c}{ No beneficiarios } \\
\cline { 2 - 5 } Gobierno de la Ciudad & Favorable & Desfavorable & Favorable & Desfavorable \\
Gobierno de la Delegación & 35.0 & 65.0 & 34.3 & 65.7 \\
Gobierno Federal & 30.3 & 69.7 & 32.0 & 68.0 \\
Promedio de programas sociales & 29.0 & 71.0 & 30.2 & 69.8 \\
Partidos & 40.7 & 59.3 & 38.2 & 61.8 \\
Organizaciones ciudadanas & 17.4 & 82.6 & 17.7 & 82.3 \\
\hline
\end{tabular}

Fuente: Elaboración propia con datos de la "Encuesta sobre calidad de vida" (ENCAVI), 2012, levantada por EvalúaDF, 2012. 
Cuadro 6-13

Opinión sobre las instituciones según edad, escolaridad e ingreso*

\begin{tabular}{l|l|c|c|c|c|c}
\hline Opinión/Rango & Variable & $I$ & $I I$ & $I I$ & $I V$ & $V$ \\
\hline \multirow{4}{*}{ Gobierno de la Ciudad } & Edad & 32.0 & 30.5 & 34.3 & 38.0 & 35.8 \\
\cline { 2 - 7 } & Escolaridad & 32.0 & 29.4 & 34.7 & 43.0 & 39.1 \\
\hline \multirow{3}{*}{ Gobierno de delegación } & Ingreso & 32.8 & 34.3 & 33.3 & 46.0 & 40.6 \\
\hline \multirow{3}{*}{ Gobierno federal } & Edad & 31.3 & 30.5 & 32.1 & 32.2 & 32.2 \\
\hline & Escolaridad & 28.5 & 28.8 & 30.9 & 39.3 & 26.0 \\
\hline & Ingreso & 29.9 & 30.5 & 31.5 & 38.1 & 37.0 \\
\hline \multirow{3}{*}{ Promotores de programas sociales } & Edad & 27.0 & 28.5 & 29.1 & 32.5 & 31.3 \\
\hline & Escolaridad & 28.7 & 27.3 & 29.8 & 32.7 & 34.7 \\
\hline & Ingreso & 28.8 & 29.0 & 30.2 & 35.5 & 34.0 \\
\hline \multirow{3}{*}{ Partidos } & Edad & 42.4 & 39.8 & 38.5 & 36.3 & 39.9 \\
\hline & Escolaridad & 38.0 & 39.6 & 38.0 & 42.2 & 45.7 \\
\cline { 2 - 7 } & Ingreso & 38.7 & 40.2 & 37.1 & 43.5 & 43.3 \\
\hline & Edad & 17.2 & 14.6 & 18.8 & 18.3 & 17.5 \\
\hline & Escolaridad & 14.3 & 17.2 & 18.7 & 19.8 & 15.2 \\
\hline & Ingreso & 18.0 & 17.3 & 17.1 & 16.4 & 21.1 \\
\hline \multirow{3}{*}{ Organizaciones ciudadanas } & Edad & 39.0 & 37.6 & 36.3 & 35.7 & 33.0 \\
\hline & Escolaridad & 32.2 & 33.5 & 37.7 & 42.5 & 47.9 \\
\hline & Ingreso & 33.6 & 35.3 & 37.5 & 47.3 & 44.8 \\
\hline
\end{tabular}

*Edad: I = 18 a 24; II = 25 a 34; III = 35 a 44; IV = 45 a 54; V = 55 y más. Escolaridad: I = Primaria; II = Secundaria; III = Media superior; IV = Superior; V = Posgrado. Ingresos: I = 400 a 800; II = 801 a 1 200; III = 1201 a 1 600; IV = 1601 a $2000 ; V=$ + de 2000.

Fuente: Elaboración propia con datos de la "Encuesta sobre calidad de vida” (ENCAVI), 2012, levantada por EvalúaDF, 2012.

car el cuadro, se presentan solo las opiniones favorables (cuadro 6-13).

La lectura de las preguntas acerca de las instituciones revela que quienes tienen mejor opinión del gobierno de la ciudad son las personas con un gasto familiar de 8000 pesos mensuales, seguidas por aquellas cuyos ingresos superan esa cantidad, luego las personas con educación superior, seguidas por quienes tienen posgrado y que tienen entre 45 y 54 años de edad o más, es decir, una clase media baja, ilustrada y ya madura, la cual siente mayor confianza en el GDF. Este mismo grupo manifiesta más confianza en el gobierno de la delegación y también, por su edad y su ingreso (no por su escolaridad), es el que mejor opinión relativa tiene del gobierno federal. Es decir, corresponde al grupo que más confía o, en rigor, que menos desconfía de los gobiernos; asimismo, presenta las diferencias más notables entre las diversas ca- 
tegorías, por ejemplo, entre gobierno de la ciudad y gobierno federal, con diferencias a favor del primero de 10.5 puntos en cuanto a escolaridad y 5.5 puntos con respecto a ingreso y edad; la explicación de estas diferencias rebasa los contenidos de la encuesta.

Contrario a lo anterior, el grupo de quienes menos confianza tienen en el gobierno de la ciudad y las delegaciones abarca a los adultos jóvenes, de 25 y 34 años de edad, seguidos por los más jóvenes, de 18 a 24 años, excepto el gobierno federal, en el cual confían menos los más jóvenes, seguidos por los adultos jóvenes, el nivel de escolaridad bajo (secundaria o primaria) y estar en el nivel más bajo de ingresos. Si bien, al igual que el grupo que tiene más confianza, no parece haber mayores diferencias en cuanto a la tendencia en su actitud hacia los gobiernos.

Al final, puede afirmarse que los programas sociales no han sido ocasión de mejorar de manera sustancial la imagen del GDF, la cual parece relacionarse con diversos factores; incluso la percepción de los beneficiarios es (leve pero uniforme) menos favorable hacia el gobierno; esto quizá tendría más que ver con la condición socioeconómica tendencial de los usuarios que con la "gratitud" hacia un beneficio recibido, lo cual en principio es alentador.

La participación o no en los programas en cuestión no es la variable determinante de diferencias importantes en cuanto a la opinión de la población sobre el gobierno; en apariencia, dicha opinión la determina la trayectoria educativa y de ingresos y la edad de los interrogados. Con lo anterior queda claro que la imputación que suele hacerse a los programas en cuanto a su uso clientelar no se corresponde con las opiniones de las personas que participan en ellos, al menos en el caso de los tres programas universalizados que se consideran en el estudio, lo cual, por otra parte, no niega que en su operación concreta se den casos con este tipo de manejo.

\section{La ciudadanía}

La definición asumida de "ciudadanía" se refiere a la adquisición de derechos; como consecuencia, tenderá a haber más "ciudadanía" a medida que la población vea a los programas sociales como derecho y no como ayuda del gobierno. Las respuestas de los participantes en los tres programas analizados se encuentran en el cuadro 6-14.

Si bien la mayoría relativa de la población respondió que "son ayudas", es notable la diferencia entre los participantes y quienes no lo son con la respuesta "es un derecho", como también lo es la diferencia entre quienes piensan que los programas son para ejercer un control político.

Las variables de "edad" e "ingreso" también son importantes en esta diferencia, 
Cuadro 6-14

Opinión sobre los programas sociales según la condición de beneficiario

\begin{tabular}{l|r|r|r|r}
\hline Opinión & General & Beneficiarios & $\begin{array}{l}\text { No benefi- } \\
\text { ciarios }\end{array}$ & Diferencia \\
\hline Son un derecho & 32.0 & 36.6 & 28.2 & 8.4 \\
\hline Son instrumentos contra la pobreza & 13.9 & 12.6 & 14.9 & -2.3 \\
\hline Son ayudas del gobierno & 33.4 & 37.1 & 30.3 & 6.8 \\
\hline $\begin{array}{l}\text { Son formas que utilizan los gobiernos } \\
\text { para controlar políticamente }\end{array}$ & 20.1 & 13.5 & 25.6 & -12.1 \\
\hline Otra & 0.6 & 0.2 & 1.0 & -0.8 \\
\hline Total & 100.0 & 100.0 & 100.0 & \\
\hline
\end{tabular}

Fuente: Elaboración propia con datos de la "Encuesta sobre calidad de vida" (ENCAVI), 2012, levantada por EvalúaDF, 2012.

si bien con una distancia menor que entre beneficiarios y no beneficiarios. Llama la atención que la respuesta "es un derecho" no haya tenido incrementos al aumentar el nivel de estudios, y sí, de manera paradójica, con el nivel de ingresos; quizás esta percepción surge en la práctica concreta de los programas (cuadro 6-15).

¿Qué es lo que pasa cuando se confrontan las opiniones individuales con las expresadas cuando hay mayor confianza o de forma colectiva, es decir, en historias de vida y en grupos focales? Llama la atención la percepción del uso clientelar de los programas, tanto en operadores como en usuarios de los mismos, pero a la vez hay conciencia de que esto es indebido o ineficaz porque es imposible la coacción; no obstante la buena opinión sobre los promotores, se piensa que convertirse en promotor es aceptar las pretensiones de quienes pretenden ganar clientelas políticas.

Los programas actualmente están secuestrados para determinado grupo político. Eso aunado a las disputas políticas, las disputas por el poder. Lo veo bien difícil.

Cuadro 6-15

Respuesta a: "la razón de los programas sociales es un derecho"*

\begin{tabular}{lcccccc}
\hline Categoria/Rango & $I$ & $I I$ & $I I I$ & $I V$ & $V$ & $V-I$ \\
\hline Edad & 28.6 & 29.2 & 33.2 & 31.0 & 35.1 & 6.5 \\
Escolaridad & 34.0 & 31.2 & 31.0 & 32.7 & 32.6 & -1.4 \\
Ingresos & 29.9 & 31.1 & 36.5 & 32.2 & 37.3 & 7.4 \\
\hline
\end{tabular}

*Edad: I = 18 a 24; II = 25 a 34; III = 35 a 44; IV = 45 a 54; V = 55 y más. Escolaridad: I = Primaria; II = Secundaria; III = Media superior; IV = Superior; V = Posgrado. Ingresos: I = 400 a 800; II = 801 a 1 200; III = 1201 a 1 600; IV = 1601 a 2 000; V = + de 2000.

Fuente: Elaboración propia con datos de la "Encuesta sobre calidad de vida" (ENCAVI), 2012, levantada por EvalúaDF, 2012. 
Siento que va a ser más difícil el acceso a los programas sociales, porque mucha gente ya se acostumbró a vivir del erario, le gusta el poder, se vicia con el poder. Es obvio que cada corriente del partido tiene a su gente trabajando en el gobierno y estos programas seguirán secuestrados, no podrán ser vistos ni manejados como derechos de los ciudadanos (Historia de vida/Usuaria de 52 años de edad), Delegación Azcapotzalco. "Programa de medicamentos y servicios médicos gratuitos".

No nos ponemos a pensar que los programas no deben tener tinte político, no colores. Los programas son destinados para la gente, no importa si es panista, priista o de cualquier partido, desgraciadamente se han convertido en una compra de votantes (Historia de vida/Usuario 39 años de edad), Delegación Tláhuac. "Programa de medicamentos y servicios médicos gratuitos" y "Operadora comunitaria de programas".

Pues esos programas son para ganar votos, pero también depende de cada uno si vota por ese partido o candidato o no, si en tu cabeza está, voto por tal para que el programa siga, pues así votan, pero si cambias tu voto pues el político ni se da cuenta. (Beneficiario/76 años de edad; grupo focal) Delegación Tláhuac. "Programa pensión alimentaria para adultos mayores".

Al contrastar ambos tipos de instrumentos, surge la interrogante de por qué manifiestan ausencia de condicionamientos y una percepción de que se utilizan de modo clientelar. Al respecto, hay tres posibilidades:

- Primero, ante el levantamiento a domicilio de los cuestionarios, las personas tal vez se inhibieron al pensar que quienes coordinan estos programas podrían identificar sus opiniones y tener alguna represalia, hecho improbable porque la encuesta se levantó de manera anónima y, en el Distrito Federal, recibir visitas de encuestadores es algo conocido por la población.

- Segundo, existencia de prácticas de algunos miembros de partidos, sobre todo a nivel local que, al presentarse como emisarios gubernamentales, traten de utilizar en su provecho político la existencia de estos programas, con lo cual se genera una percepción de uso clientelar sin que haya condicionamientos concretos; esta idea se puede reforzar cuando en los grupos focales no surge la referencia a hechos reales de coacción. Si esta fuera la explicación, se pone en el centro la capacidad comunicativa del gobierno de la ciudad. 
- Tercero, presencia de una dualidad en el comportamiento de los agentes gubernamentales, en las historias de vida y en los grupos focales; es claro que los casos concretos de manejo clientelar de los programas están referidos a las delegaciones, sin embargo, para la población no es evidente la diferencia entre los programas administrados por el gobierno central y por las delegaciones, de ahí entonces que cuando se les pregunta de condicionamientos específicos de los tres programas, las respuestas son negativas, pero cuando se interroga en general por los programas sociales, se refieren a lo que ocurre en las delegaciones.

\section{Percepción de diferencias}

La "cohesión social" es la relación entre los mecanismos de inclusión y exclusión, y las percepciones de los ciudadanos. Pero ¿cómo se perciben las diferencias sociales? De acuerdo con el grado de desarrollo social, casi nunca hay diferencias entre el país y el Distrito Federal; en los tres primeros niveles, la diferencia a favor de la ciudad es mínima, y en el nivel muy bajo, por lo contrario, se tiende a pensar que es más injusta la distribución en la ciudad (cuadro 6-16).

Respecto de la distribución de los recursos económicos en la ciudad, a partir de la información obtenida en las historias de vida y grupos focales, es relevante que al haber una percepción de injusticia, no se plantea una situación de ruptura con las reglas de funcionamiento del sistema; incluso se valora lo que la política social hace por el mejoramiento de las condiciones de vida. Los siguientes son comentarios de personas con escasos recursos y beneficiarios de programas sociales:

Siento que esta ciudad es como muy injusta, es desigualitaria, no les dan los mismos beneficios a los que tienen y a los que no tienen, por ejemplo, una persona tiene dinero va al hospital la atienden bien y le cobran todo, y una que no tiene

\section{Cuadro 6-16}

Opinión sobre las diferencias sociales injustas y muy injustas según el grado de desarrollo social

\begin{tabular}{lcccc}
\hline Opinión (injusta + muy injusta) & Alto & Medio & Bajo & Muy Bajo \\
\hline México & 85.7 & 86.7 & 86.4 & 84.3 \\
Distrito Federal & 85.3 & 84.7 & 85.5 & 87.7 \\
México-DF & 0.4 & 2.0 & 0.9 & -3.4 \\
\hline
\end{tabular}

Fuente: Elaboración propia con datos de la "Encuesta sobre calidad de vida" (ENCAVI), 2012, levantada por EvalúaDF, 2012. 
dinero, no le atienden igual, lo hacen que espere por horas, formado y luego no tiene las medicinas que necesita (Grupo focal/Usuaria de 18 años de edad). Delegación "Coyoacán". "Programa Prepa Sí".

Teníamos y hemos tenido pocos recursos, esta ciudad y el gobierno no da para tener algo de dinero, yo con siete hijos, pues no me alcanza, a veces pienso, ¿por qué hay personas que tienen más dinero? Pero aquí seguimos luchando (Historia de vida/Usuaria de 73 años de edad). Delegación "Azcapotzalco". "Programa pensión alimentaria para adultos mayores".

El programa está bien, somos un grupo vulnerable y nos es necesario, pero también me doy cuenta de que las cosas suben y suben de precio y total que no alcanza, no cambia (Grupo focal/Usuario de 70 años de edad). Delegación "Coyoacán". "Programa pensión alimentaria para adultos mayores".

Vendía ropa, comida y todo lo que podía. Trabajando mucho y con esfuerzos entré a la delegación, trabajé hasta comprar una casita, pero fue porque era delegada sindical por años, trabajaba todos los días de ocho a ocho, si no fuera así, no lo conseguiría, porque así se dan las cosas en el D. F. (Historia de vida/ Usuaria de 52 años de edad). Delegación "Azcapotzalco". "Programa de medicamentos y servicios médicos gratuitos".

Nací en Iztacalco, tengo un hermano, mi madre es ama de casa y eso es un trabajo doble o triple, ese trabajo no tiene paga. Mi papá trabaja en Iztapalapa en el área de limpia, comenzó como barrendero y luego fue chofer de camión de basura; las condiciones económicas siempre han sido muy duras; creo que a personas como mi papá no le pagan lo justo (Historia de vida/Usuario de 33 años de edad). Delegación "Coyoacán". "Programa de medicamentos y servicios médicos gratuitos" y "Operador de programas".

\section{Estrategias}

Entre los principales problemas detectados, la mayoría se inclina por responsabilizar al gobierno de su solución. La pregunta es ¿qué están dispuestos a hacer los ciudadanos para propiciar que el gobierno asuma el papel que se le asigna y qué están dispuestos ellos mismos a hacer para remediar estos problemas? En cuanto a la participación ciudadana (PC), tres asuntos son importantes. En tres momentos se 
preguntó sobre la participación como valor; posteriormente sobre su actitud ante la participación y, por último, acerca de su experiencia participativa. Los resultados son elocuentes (cuadro 6-17).

\section{Cuadro 6-17}

Valores, actitudes y experiencias (\%)

\begin{tabular}{lc}
\hline Valores: está de acuerdo con la participación & 86.40 \\
Actitudes: está dispuesto a participar & 71.00 \\
Experiencias: ha participado en alguna ocasión & 9.70 \\
\hline Fuente: Fuente: Elaboración propia con datos de la “Encuesta sobre cali- \\
dad de vida” (ENCAVI), 2012, levantada por EvalúaDF, 2012.
\end{tabular}

Al desagregar la información por nivel socioeconómico, se obtiene que la disposición a participar es más alta en los grupos menores y, de manera constante, la experiencia es mayor en los grupos de mayor edad. En escolaridad, a mayor nivel, más experiencia y disposición; por ingreso, quienes perciben un ingreso medio son los más dispuestos; y juventud, escolaridad alta e ingresos medios parecen ser las características de los más dispuestos, si bien la variable educación parece ser la determinante de la disposición (cuadro 6-18).

\section{Cuadro 6-18}

Disposición a participar y experiencia de haber participado (solo respuesta "Sí")*

\begin{tabular}{|c|c|c|c|c|c|c|}
\hline \multicolumn{2}{|c|}{ Opinión/Rango } & I & II & III & IV & $V$ \\
\hline \multirow{2}{*}{ Edad } & Dispuesto & 79.9 & 84.7 & 70.6 & 70.3 & 60.5 \\
\hline & Experiencia & 8.3 & 9.2 & 9.9 & 11.1 & 11.1 \\
\hline \multirow{2}{*}{ Educación } & Dispuesto & 66.6 & 75.8 & 69.9 & 71.8 & 78.3 \\
\hline & Experiencia & 8.9 & 8.6 & 10.2 & 11.1 & 21.7 \\
\hline \multirow{2}{*}{ Ingreso } & Dispuesto & 70.4 & 70.6 & 76.5 & 75.7 & 71.4 \\
\hline & Experiencia & 9.4 & 9.2 & 10.2 & 9.2 & 12.0 \\
\hline
\end{tabular}

*Edad: I = 18 a 24; II = 25 a 34; III = 35 a 44; IV = 45 a 54; V = 55 y más. Escolaridad: I = Primaria; II = Secundaria; III = Media superior; IV = Superior; V = Posgrado. Ingresos: I = 400 a 800; II = 801 a 1 200; III = 1201 a 1 600; IV = 1601 a 2 000; V = + de 2000.

Fuente: Elaboración propia con datos de la "Encuesta sobre calidad de vida" (ENCAVI), 2012, levantada por EvalúaDF, 2012.

Las diferencias son irrelevantes y la variable "escolaridad" parece ser la más influyente; entonces no resulta raro que el menor predominio de esa variable entre los beneficiarios pueda explicar la diferencia, pero leído en sentido inverso, recibir los 
Cuadro 6-19

Opinión sobre participación en colonias

\begin{tabular}{|c|c|c|c|c|c|c|c|c|}
\hline \multirow[b]{2}{*}{ Subtítulos } & \multicolumn{2}{|c|}{$\begin{array}{l}\text { Interés en } \\
\text { problemas }\end{array}$} & \multicolumn{2}{|c|}{ Exigen derechos } & \multicolumn{2}{|c|}{ Interés en política } & \multicolumn{2}{|c|}{$\begin{array}{c}\text { Participan en } \\
\text { soluciones }\end{array}$} \\
\hline & D. F. & Colonia & D. F. & Colonia & D. F. & Colonia & D. F. & Colonia \\
\hline Mucho + algo & 25.6 & 29.3 & 36.9 & 40.1 & 33.1 & 34.2 & 29.3 & 33.4 \\
\hline Poco + nada & 74.4 & 70.7 & 63.1 & 59.9 & 66.9 & 65.8 & 70.7 & 66.6 \\
\hline Total & 100.0 & 100.0 & 100.0 & 100.0 & 100.0 & 100.0 & 100.0 & 100.0 \\
\hline
\end{tabular}

Fuente: Elaboración propia con datos de la "Encuesta sobre calidad de vida” (ENCAVI), 2012, levantada por EvalúaDF, 2012.

beneficios de los tres programas sociales analizados parece no generar mayor disposición a participar.

También se observa una percepción baja, pero importante, a considerar que en el ámbito territorial más cercano de la colonia es donde la gente está más dispuesta a interesarse por sus problemas y a exigir sus derechos (cuadro 6-19).

¿Cuáles son las posibles estrategias que utilizarían los ciudadanos, dada la aceptación mayoritaria de la participación como un valor? La asociación entre participación y organización tiene una mayoría evidente; parece haber una tendencia sostenida en organizarse para participar; las relaciones vecinales constituyen un vínculo fundamental y un contenido básico es la información (cuadro 6-20).

\section{Cuadro 6-20}

Estrategias de participación social

\begin{tabular}{lc}
\hline Estrategias & Porcentaje \\
\hline Organizarnos para demandar con más fuerza & 49.0 \\
Acudir a los medios de comunicación & 11.4 \\
Pedir el apoyo de otras organizaciones sociales & 9.4 \\
Pedir el apoyo de un partido político & 2.5 \\
Poner demandas legales & 6.0 \\
Hacer manifestaciones públicas (marchas, mítines) & 7.7 \\
Votar por otro partido & 2.9 \\
Pedir apoyo a los diputados & 1.4 \\
De todas maneras no nos harán caso & 8.8 \\
Otra & 0.8 \\
No especificado & 0.1 \\
Total & 100.0 \\
\hline
\end{tabular}

Fuente: Elaboración propia con datos de la "Encuesta sobre calidad de vida" (ENCAVI), 2012, levantada por EvalúaDF, 2012. 
Las opiniones resultantes cuando se indaga con las técnicas cualitativas son: Cuando era joven vivía en "Santa María la Rivera", cerca del kiosco "Morisco"; platicábamos mucho con los vecinos, todos nos conocíamos; creo el necesitar cosas y estar compartiendo la misma delegación y problemas nos Ilevó a hablarnos y organizarnos para hacer cosas juntos, mínimo exigir los servicios (Historia de vida/Usuaria de 82 años de edad). Delegación "Coyoacán". "Programa pensión alimentaria para adultos mayores".

Se me da mucho apoyar a la gente, pero no lo hago porque una Ley así lo indique o porque tenga un interés en ver qué saco o me toca; es más nato, o sea, me nace, pues así se van dando las oportunidades; ahora me está buscando un vecino... dice que hay la oportunidad de seguro de desempleo, que reúne un grupo de personas y entreguen sus papeles, otra vecina me dice, muchas gracias por darnos información (Historia de vida/Usuaria de 42 años de edad). Delelagación "Tláhuac". "Programa de medicamentos y servicios médicos gratuitos".

Estas apreciaciones también implican una lectura de las relaciones de poder y de los agentes políticos, sin dejar de lado a aquellos que piensan que la participación puede ser un mecanismo de ascenso político:

El poder siempre va a estar dominado, la gente se va cansando, yo les decía a algunos compañeros y vecinos; ¿se dan cuenta?, los directores siguen siendo igual que hace muchos años, seguimos siendo igual y nos tratan igual; quien tiene el poder es quien los y nos maneja; algunos de nosotros queremos cambiar las cosas, pero se tienen costumbres feas, malas, corruptas de hacer las cosas (Historia de vida/Usuario de 42 años de edad). Delegación "Tláhuac". "Programa de medicamentos y servicios médicos gratuitos" y "Operador comunitario de programas".

Yo lo que busco es no formar parte de un partido, no tener ningún cargo, pero sí incidir políticamente en las decisiones; ya me han invitado a diferentes movimientos más sociales y ahora sí estoy interesado en participar, porque hay muchas cosas interesantes que hacen los partidos y muchas que no las hacen ellos, y que no se ven, a mí me gustaría hacer cosas en mi colonia (Historia de vida/ Usuario de 18 años de edad). Delegación "Iztapalapa". "Programa Prepa Sí". 
Seguido me invitaban a ver cómo se maneja una delegación, desde otros espacios, porque yo ya militaba dentro de un partido; no podía ser parte de su equipo de colaboradores, pero ya era muy activo dentro de la política, buscaba en donde acomodarme; así es esto de la política, participas, te ven los de los partidos y te invitan a colaborar con ellos, hasta que te toca algo (Historia de vida/Usuario de 42 años de edad). Delegación "Tláhuac". "Programa de medicamentos y servicios médicos gratuitos".

\section{Calidad de vida y entorno urbano}

La percepción de las personas sobre su calidad de vida en relación con algunos aspectos de su entorno físico espacial revela varios hechos, como los siguientes. Las opiniones de la población sobre su nivel de satisfacción respecto de los temas del entorno urbano presentaron un patrón similar, donde la respuesta predominante es "regular", tanto de la población beneficiaria, como de la no beneficiaria de programas sociales. Al agrupar las respuestas sobre: a) los servicios de transporte y vialidades en la colonia; $b$ ) las condiciones de la vialidad para acceso en automóvil o transporte público en la colonia; $c$ ) las condiciones en que se encuentra el recubrimiento de la calle; $d$ ) el mantenimiento de las áreas verdes próximas a su calle; e) el servicio de recolección de basura en su calle; f) seguridad de la calle en que vive, y g) la calidad del agua, se tiene el resultado que a continuación se describe.

Existe una tendencia clara donde la población que reside en lugares con grado de desarrollo social muy bajo y bajo opina que dichos servicios son "muy deficientes" y "deficientes", en una proporción mayor comparada con quienes viven en zonas de grado de desarrollo social medio o alto. Asimismo, la mayor frecuencia en la percepción de servicios "buenos" o "excelentes" corresponde a quienes habitan en lugares de desarrollo social medio y alto. Lo anterior confirma una correspondencia positiva entre la calidad de vida objetiva y la subjetiva en estas variables (cuadro 6-21).

Cuadro 6-21

Opinión promedio de siete preguntas sobre el entorno*

\begin{tabular}{l|c|c|c|c|c}
\hline \multirow{2}{*}{ Opinión } & \multicolumn{4}{|c|}{ Grado de desarrollo social } & \\
\cline { 2 - 5 } & Muy bajo & Bajo & Medio & Alto & Total \\
\hline Muy deficiente y deficiente & 26.1 & 23.9 & 17.6 & 13.3 & 20.4 \\
Regular & 48.0 & 47.3 & 47.5 & 36.4 & 44.3 \\
Bueno y excelente & 25.9 & 28.7 & 34.9 & 50.2 & 35.3 \\
Total & 100.0 & 100.0 & 100.0 & 100.0 & 100.0 \\
\hline
\end{tabular}

* Transporte y vialidades, accesibilidad, recubrimiento de la calle, áreas verdes, basura, seguridad y agua.

Fuente: Elaboración propia con datos de la "Encuesta sobre calidad de vida" (ENCAVI), 2012, levantada por EvalúaDF, 2012. 
Entre las opiniones relacionadas con el entorno urbano, destacan algunas con mayor diferencia estadística en los resultados. Entre ellas, se puede mencionar la frecuencia en el surtido de agua, que es más eficaz entre las viviendas de un grado de desarrollo social más alto que entre los más bajos (cuadro 6-22).

\section{Cuadro 6-22}

Regularidad del servicio de agua potable por grado de desarrollo social

\begin{tabular}{|c|c|c|c|c|c|}
\hline \multirow[b]{2}{*}{ Frecuencia } & \multicolumn{4}{|c|}{ Grado de desarrollo social } & \multirow[b]{2}{*}{ Total } \\
\hline & Muy bajo & Bajo & Medio & Alto & \\
\hline Siempre & 57.7 & 81.7 & 97.2 & 93.5 & 79.8 \\
\hline Horas al día & 12.0 & 6.9 & 0.8 & 1.9 & 6.0 \\
\hline Por semana & 28.4 & 10.2 & 1.8 & 4.1 & 13.1 \\
\hline Por mes & 1.7 & 1.2 & 0.2 & 0.5 & 1.0 \\
\hline Aisladas al año & 0.3 & 0.0 & 0.0 & 0.0 & 0.1 \\
\hline Total & 100.0 & 100.0 & 100.0 & 100.0 & 100.0 \\
\hline
\end{tabular}

Fuente: Elaboración propia con datos de la "Encuesta sobre calidad de vida" (ENCAVI), 2012, levantada por EvalúaDF, 2012.

En general, la percepción de la calidad de vida de los entrevistados en el Distrito Federal se encuentra entre "muy buena" y "buena", seguida de "regular". Entre ambas categorías, se tiene alrededor de más de $96 \%$ del total de las respuestas y no hay una diferencia estadística importante entre beneficiarios y no beneficiarios de

\section{Cuadro 6-23}

Percepción de la calidad de vida en general según el grado de desarrollo social y condición de beneficiario de programas sociales

\begin{tabular}{l|l|c|c|c|c}
\hline $\begin{array}{l}\text { Grado de } \\
\text { desarrollo social }\end{array}$ & $\begin{array}{l}\text { Tipo de beneficiario de pro- } \\
\text { gramas sociales }\end{array}$ & $\begin{array}{c}\text { Muy buena } \\
\text { y buena }\end{array}$ & Regular & $\begin{array}{c}\text { Mala y } \\
\text { muy mala }\end{array}$ & Total \\
\hline \multirow{2}{*}{ Alto } & Población beneficiaria & 66.2 & 31.5 & 2.3 & 100.0 \\
\cline { 2 - 6 } & Población no beneficiaria & 69.0 & 28.4 & 2.6 & 100.0 \\
\hline \multirow{2}{*}{ Medio } & Población beneficiaria & 52.3 & 45.3 & 2.4 & 100.0 \\
\cline { 2 - 6 } & Población no beneficiaria & 56.8 & 38.7 & 4.5 & 100.0 \\
\hline \multirow{2}{*}{ Bajo } & Población beneficiaria & 50.0 & 46.5 & 3.5 & 100.0 \\
\cline { 2 - 6 } & Población no beneficiaria & 46.8 & 48.5 & 4.7 & 100.0 \\
\hline \multirow{2}{*}{ Muy bajo } & Población beneficiaria & 45.8 & 50.8 & 3.4 & 100.0 \\
\cline { 2 - 6 } & Población no beneficiaria & 40.3 & 54.5 & 5.2 & 100.0 \\
\hline
\end{tabular}

Fuente: Elaboración propia con datos de la "Encuesta sobre calidad de vida” (ENCAVI), 2012, levantada por EvalúaDF, 2012. 
los programas sociales en general, lo cual puede interpretarse como que la población ya los asimiló como derechos. No obstante, es clara la tendencia de una mejor percepción de la calidad de vida entre la población que reside en lugares de estrato de desarrollo social alto, y más aún entre los no beneficiarios de programas sociales, en relación con quienes viven en zonas de muy bajo desarrollo social, donde quienes los no beneficiarios de programas sociales opinan que su calidad de vida es peor. Este último grupo que recibe un trato de injusticia o de discriminación según su localización en el territorio es la población objetivo del GDF en materia de derechos socioespaciales (cuadro 6-23).

\section{CONCLUSIONES Y SUGERENCIAS}

A partir del análisis anterior es posible formular algunas reflexiones y propuestas sobre el funcionamiento de los programas sociales y la calidad de vida en su contexto espacial.

\section{COMENTARIOS}

Los tres programas sociales analizados no tienen esquemas ni mecanismos de participación ciudadana, no cuentan con formas de diálogo ni escucha y son sólo de dotación de recursos de forma directa o a través de tarjetas, o de servicios. La comunicación entre instituciones y ciudadanos se reduce a preguntas específicas y entrega de documentos. Los responsables de la microimplementación de programas son quienes tienen cercanía con la población. No es clara la lógica de garantías o de cumplimiento de derechos sociales, y faltan los recursos y la voluntad política por parte de instituciones y ciudadanos. Las fallas de coordinación intrainstitucional e interinstitucional repercuten en la ejecución de las acciones de los programas sociales. Es oportuno generar una política social de forma integral, sustentable y reconocida por los beneficiarios.

De acuerdo con las entrevistas, los programas sociales del GDF son ocasión de manejo político, resultado de tensiones entre órdenes de gobierno, partidos y otros actores que tienen intereses sobre todo económicos y políticos. La política se ubica como un espacio únicamente de gobierno y partidos, como una arena corrupta, carente de transparencia y con múltiples obstáculos para la participación de los ciudadanos. La mayoría de los participantes señalaron que los programas sociales son derechos, sin embargo, aún no es una visión generalizada. En este sentido, la parti- 
cipación ciudadana se reconoce como un derecho importante a realizar, pero pocas personas participan o tienen interés en hacerlo.

La democracia se entiende como una forma de gobernar, pero sólo desde el gobierno. La percepción de los ciudadanos como fundamento de la democracia y la participación ciudadana como mecanismo que la facilite se reconocen en pocos casos y, en la mayoría, apenas se percibe.

Los programas son pieza clave para la generación de cohesión social en el Distrito Federal; es necesario reorientar los recursos financieros y humanos a través de la capacitación y el reconocimiento de lo ya existente, y construir de forma colectiva con la aportación de múltiples actores.

Los objetivos de justicia socioespacial, a su vez, resultan fundamentales ante las condiciones de desigualdad territorial que se observan, y sobre las cuales los ciudadanos tienen conciencia al opinar sobre su calidad de vida de acuerdo con sus satisfactores materiales intradomésticos y los de su entorno.

\section{"Prepa Sí"}

Este programa ha tenido aciertos al ser una propuesta para la juventud que ya asiste a la escuela, aunque presenta deficiencias en la operación, por ejemplo, el pago de la beca se retrasa, llegan a pasar meses sin recibir el apoyo y, en algunos casos, meses en los que simplemente no se paga. La falta de información, al acudir a las instituciones correspondientes por una aclaración, denota falta de cuidado y seguimiento en la implementación del programa. Las actividades planteadas como retribución a la comunidad carecen de sentido colectivo, no están orientadas a la construcción de ciudadanía, no se ubican como un espacio o mecanismo de participación social en la ciudad y los participantes las perciben sólo como requisito para no perder la beca.

Sin embargo, en la mayoría de entrevistas fue notorio el deseo de los jóvenes por llevar a cabo acciones que generen un efecto y beneficien a la comunidad de forma eficaz con un efecto positivo. Sería oportuno utilizar las horas de servicio del programa para dotar de cultura política democrática y perspectiva de derechos humanos a los jóvenes, facilitarles metodologías de análisis para que desarrollen prácticas democráticas y no continúen con la imagen negativa de los esquemas partidarios, populistas, corporativos o paternalistas como formas de hacer política.

La juventud no es un problema, hay que reconocerla como sujeto de derecho y parte de las propuestas y las acciones de desarrollo. 


\section{Adultos mayores}

Los apoyos otorgados a los adultos mayores han repercutido de modo favorable en su calidad de vida. Hoy, ellos aportan a los gastos de la casa y, en este sentido, se les toma más en cuenta, pero no necesariamente es un reconocimiento a su trabajo o experiencia, es su aportación a los gastos lo que ha cambiado. En varios casos, los adultos mayores mencionaron que a pesar de reconocer como un derecho el recurso que reciben por parte del GDF, no debería generalizarse o estandarizarse, y plantean que es necesario hacer una distribución que tome en cuenta las necesidades económicas diferenciadas de los adultos. Los recursos que proporciona el GDF con este programa se utilizan para pagar servicios, impuestos y alimentos, y en muchos casos constituye la única fuente de recursos que tienen los adultos mayores, lo cual les proporciona cierta autonomía e independencia de la familia.

\section{Medicamentos gratuitos}

Este programa, presenta deficiencias de calidad en el servicio, como el tiempo (3 a 4 horas en promedio) para atender a las personas usuarias, la falta de dotación en medicamentos, la carencia de instalaciones necesarias, y el cansancio por parte del grupo que atiende dado el gran número de personas que requieren el servicio, lo cual torna ineficiente la ejecución. La introducción del "Seguro Popular" dentro de la carpeta de servicios que ya se proporcionaban antes en los centros de salud, ha venido a sobrecargar a las trabajadoras y los trabajadores; los médicos tienen que cumplir una mayor cuota de consultas y el área administrativa está sometida a la elaboración de nuevos informes, reportes y otras actividades burocráticas extras.

La falta de información y coordinación entre instituciones (federales y locales) se pone de manifiesto en la confusión de los usuarios, quienes señalan desconocer los alcances del servicio y algunos operadores abonan a esta confusión, al denotar poca relación interinstitucional sobre programas sociales. En algunos casos, se mencionó maltrato por parte de los operadores; por ello, se sugiere que proporcionen un trato digno a los beneficiarios, ya que representan el enlace entre estos últimos y las instituciones responsables de la política social.

\section{Calidad de vida y territorio}

En el Distrito Federal, predomina la percepción de que la calidad de vida es "buena" o "muy buena", pero es mayor entre las personas que residen en lugares con un grado de desarrollo social alto y medio, ubicadas sobre todo en áreas centrales, mientras que, en el otro extremo, se considera "mala" o "muy mala" en zonas con un grado de 
desarrollo social "bajo" o "muy bajo" en áreas periféricas. Los resultados confirman de manera afirmativa la hipótesis general de este libro en el sentido que la desigualdad socioespacial impide una calidad de vida más justa de acuerdo con el grado de satisfacción de las necesidades básicas de las personas y de la cohesión social. A partir de una encuesta con representatividad estadística para el Distrito Federal, esta demostración indica que la población se encuentra consciente de su situación objetiva y que sus condiciones materiales se deben mejorar. En este sentido, adquieren relevancia el enfoque de derechos y la justicia socioespacial.

\section{Consideraciones finales}

La política social del GDF ha sido exitosa por su aceptación alta en la ciudadanía; sin embargo, también hay la percepción de su uso clientelar, misma que habría que modificar. A la vez, se cuenta con oportunidades aprovechadas de manera insuficiente, tanto para corregir sus defectos, como para incrementar sus rendimientos de cohesión social.

La percepción ciudadana sobre los programas sociales del GDF es positiva en su mayor parte, tanto entre sus usuarios como entre quienes no lo son. La opinión de usuarios de programas específicos (como los de "Prepa Sî", "Adultos mayores y atención médica y medicamentos gratuitos") es de aceptación por razones explícitas. Estos programas se han diseñado para la satisfacción de las necesidades sociales consideradas básicas: salud, alimentación y educación, y uno de sus resultados más apreciados por la población beneficiaria, sobre todo en el caso de las dos primeras, es que contribuyen a la autonomía de adolescentes y adultos mayores, quienes suelen carecer de ingresos.

En este capítulo, se demuestra que los valores democráticos también son un asunto de desarrollo social y que se arraigan más en aquellos sectores con acceso a satisfactores de salud, educación, vivienda e ingreso, ubicados en zonas de mayor nivel socieconómico relativo. La investigación también recolectó una tendencia, muy leve pero constante; que los participantes en los programas de desarrollo social analizados tuvieran mayor proclividad a los valores democráticos, lo cual permite formular la hipótesis que en los programas sociales hay espacio para que estos se fortalezcan a través de la interacción. La comunicación entre instituciones y ciudadanos se reduce a preguntas específicas y entrega de documentos; los programas se agotan en la dotación directa de recursos, a través de tarjetas o de entrega de servicios. No se han enfatizado las garantías de los derechos sociales.

El potencial de los programas sociales para la formación de ciudadanía queda de relieve cuando se observa que sus destinatarios tienen una ventaja importante sobre 
los no participantes en cuanto a considerar a dichos programas como un derecho y, por tanto, como una obligación del gobierno. Urge potencializar estas posibilidades con la participación de la sociedad civil y los derechohabientes de los programas, así como aprovechar los aprendizajes de los responsables de la microimplementación de programas, quienes tienen cercanía con la población, porque de lo contrario puede acentuarse la tendencia a presentar rendimientos decrecientes, no como fuente de legitimación gubernamental, sino como productores de cohesión social. Para ello existen múltiples obstáculos que remover, así como oportunidades que aprovechar.

\section{BIBLIOGRAFÍA}

Asamblea Legislativa del Distrito Federal, IV Legislatura (2000), "Ley de desarrollo social para el Distrito Federal", Gaceta Oficial del Distrito Federal, 23 de mayo.

Canto, Manuel y Berrios, Pilar (2012), "Desarrollo social, derechos humanos, ciudadanía y cohesión social", México, Evalúa DF.

EvalúaDF (Consejo de Evaluación del Desarrollo Social del Distrito Federal) (2012a), "Encuesta sobre calidad de vida, 2012 (Encavi)", http://www2.df.gob.mx/virtual/evaluadf/encuestas. php (2012b), "Índice de desarrollo social de las unidades territoriales (delegaciones-colonias-“manzanas") del Distrito Federal, 2010", México.

Sánchez Mejorada, Cristina (2010), Evaluación del diseño, instrumentación y resultados de la política de participación ciudadana en el desarrollo social del gobierno del Distrito Federal, México, Evalúa DF. 



\section{Valoración subjetiva de la calidad de vida}

Andrea Colores Ramos y Erica Alejandra Hernández Montes de Oca

\section{INTRODUCCIÓN}

El concepto de "calidad de vida" en el ámbito internacional se utiliza de dos formas: para referirse al estilo o nivel de vida objetivo de un individuo y a su grado de satisfacción; en este sentido, es difícil compararla entre países, regiones o culturas porque la medición está sujeta a parámetros exclusivos e inherentes de cada tiempo y espacio que la califica. Si a esto se le suma la definición estricta de la calidad de vida, que incluye los aspectos objetivos y cuantificables, así como una dimensión subjetiva que depende de la percepción, se enfrentan varios retos en la forma de evaluar su importancia para el desarrollo de los seres humanos.

Al respecto, el objetivo de este trabajo es conocer la valoración de los habitantes de la Zona Metropolitana del Valle de México (ZMVM) acerca de su calidad de vida, con consideración de los resultados de su medición objetiva expresada en el índice de calidad de vida objetiva (ICVO) estimado en este libro (capítulo 4), para lo cual se aplican entrevistas a profundidad de personas con hogares correspondientes a diferentes rangos de acuerdo con la estratificación de este último índice. Asimismo, se revisan otras fuentes de información que informan aspectos subjetivos para la ZMVM. Este capítulo expone las principales características y discrepancias de cuatro encuestas y se consideran sus contenidos para el diseño de las entrevistas a profundidad, con el propósito de tener una visión más amplia de la calidad de vida de un individuo en su contexto.

En la primera sección, se describen algunas encuestas que captan las percepciones sobre la calidad de vida y se describen sus características y metodología uti- 
lizada; posteriormente se presenta la comparación de resultados entre metodologías y, por último, se lleva a cabo un análisis acerca de la medición cuantitativa y la percepción de los habitantes.

\section{MEDICIÓN DE LA CALIDAD DE VIDA Y METODOLOGÍA UTILIZADA}

Existe la preocupación, tanto en el sector público como en el ámbito académico, de incluir la percepción como un rubro más a calificar dentro de la medición de la calidad de vida tradicional u objetiva. En el caso de México, esta preocupación se ha manifestado como un esfuerzo de algunas autoridades públicas, institutos de investigación y organizaciones privadas, por comparar información objetiva y subjetiva a través del diseño de encuestas de percepción. El Consejo de Evaluación del Desarrollo Social del Distrito Federal (capítulo 6), el Instituto Nacional de Estadística y Geografía (INEGI), el Instituto de Investigaciones Sociales de la Universidad Nacional Autónoma de México (IIS-UNAM) y el periódico El Universal han utilizado tal técnica con distintos propósitos y temáticas. En el cuadro 7-1, se hace una recopilación de estos esfuerzos con distinción de sus atributos, mientras que en el cuadro 7-2, se mencionan los principales ejes temáticos de cada encuesta.

Los contenidos de las encuestas enriquecieron el diseño de la entrevista a profundidad aquí aplicada y que contiene 32 preguntas divididas en los siguientes 10 ejes temáticos: infraestructura y servicios, movilidad, educación, salud, espacio público y recreación, vivienda, seguridad, relaciones sociales y participación ciudadana, gobierno y política, y calidad de vida y felicidad. Este orden se decidió con el fin de entablar una conversación en confianza, partiendo de aspectos generales hasta los temas personales. De estas preguntas, 17 son abiertas y las respuestas se transcribieron de forma fiel para su posterior análisis, mientras que las 15 preguntas restantes son cerradas y las respuestas se codificaron para su estudio ulterior.

La entrevista no cuenta con representatividad estadística y únicamente se aplicó en las delegaciones Benito Juárez, Coyoacán y Milpa Alta, y en los municipios de Ecatepec y Villa del Carbón, de acuerdo con los rangos propuestos por el ICVO. En cada caso, se entrevistó a integrantes de un hogar con el propósito de conocer la percepción que tienen de su calidad de vida y de la forma en que vaIoran cada dominio. Dada la variedad temática y la naturaleza del instrumento aplicado, el tiempo promedio para cada entrevista fue de dos horas, las cuales transcurrieron en un ambiente tranquilo, en un clima de confianza y amabilidad, percibiéndose que todos los entrevistados estuvieron dispuestos a opinar acer- 


\section{Cuadro 7-1}

Encuestas de percepción de calidad de vida en la Zona Metropolitana del Valle de México (ZMVM)

\begin{tabular}{|c|c|c|c|c|}
\hline Institución & EvalúaDF & INEGI & IIS-UNAM & El Universal \\
\hline Encuesta & $\begin{array}{l}\text { Encuesta sobre } \\
\text { la calidad de vida } \\
\text { (Encavi), } 2012\end{array}$ & $\begin{array}{l}\text { Encuesta de Bienes- } \\
\text { tar autorreportado } \\
\text { (Biare) }\end{array}$ & $\begin{array}{l}\text { Encuesta nacional } \\
\text { sobre satisfacción } \\
\text { subjetiva de la vida y } \\
\text { la sociedad (Ensaviso) }\end{array}$ & $\begin{array}{l}\text { ¿Cómo vamos, Ciu- } \\
\text { dad de México? }\end{array}$ \\
\hline \multirow{3}{*}{ Ventajas } & Enfoque global & \multirow{3}{*}{$\begin{array}{l}\text { Basada en la meto- } \\
\text { dología propuesta } \\
\text { por la Organización } \\
\text { para la Cooperación } \\
\text { y el Desarrollo Eco- } \\
\text { nómico }\end{array}$} & \multirow{2}{*}{$\begin{array}{l}\text { Representatividad } \\
\text { estadística y territorial } \\
\text { nacional }\end{array}$} & \multirow{3}{*}{$\begin{array}{l}\text { Representatividad } \\
\text { estadística para la } \\
\text { ZMVM }\end{array}$} \\
\hline & $\begin{array}{l}\text { Representatividad } \\
\text { estadística territo- } \\
\text { rial por grado de } \\
\text { desarrollo social y } \\
\text { para tres progra- } \\
\text { mas sociales }\end{array}$ & & & \\
\hline & & & $\begin{array}{l}\text { Cuestionario amplio, } \\
\text { profundo y exhausti- } \\
\text { vo de la percepción } \\
\text { subjetiva de la calidad } \\
\text { de vida }\end{array}$ & \\
\hline \multirow[b]{2}{*}{ Desventajas } & & $\begin{array}{l}\text { No posee represen- } \\
\text { tatividad estadística }\end{array}$ & & \multirow[b]{2}{*}{$\begin{array}{l}\text { Falta de represen- } \\
\text { tatividad terri- } \\
\text { torial en escalas } \\
\text { menores de la } \\
\text { ZMVM }\end{array}$} \\
\hline & $\begin{array}{l}\text { Solamente se con- } \\
\text { sidera la Ciudad } \\
\text { de México }\end{array}$ & $\begin{array}{l}\text { Sesgo territorial, sin } \\
\text { información sobre } \\
\text { la residencia de los } \\
\text { encuestados } \\
\text { Únicamente consi- } \\
\text { dera el aspecto sub- } \\
\text { jetivo de la calidad } \\
\text { de vida }\end{array}$ & $\begin{array}{l}\text { Falta de medición de } \\
\text { aspectos objetivos de } \\
\text { la calidad de vida }\end{array}$ & \\
\hline
\end{tabular}

IIS-UNAM Instituto de Investigaciones Sociales de la Universidad Nacional Autónoma de México; INEGI, Instituto Nacional de Estadística y Geografía.

Fuente: Elaboración propia con datos de las páginas de internet de: "EvalúaDF", INEGI, IIS-UNAM y El Universal.

ca de cada uno de los temas de manera amplia, consciente y de acuerdo con su perspectiva individual.

\section{VALORACIÓN SOBRE LA CALIDAD DE VIDA}

La valoración de la calidad de vida se realiza a partir de los resultados obtenidos con tres instrumentos: ICvO (objetivo), “Cómo vamos?" (subjetivo) y entrevistas de percepción a profundidad (subjetivo). La información se dividió de acuerdo con dos criterios: el tema de la entrevista y el grado del ICVO, para analizar correspondencias, 


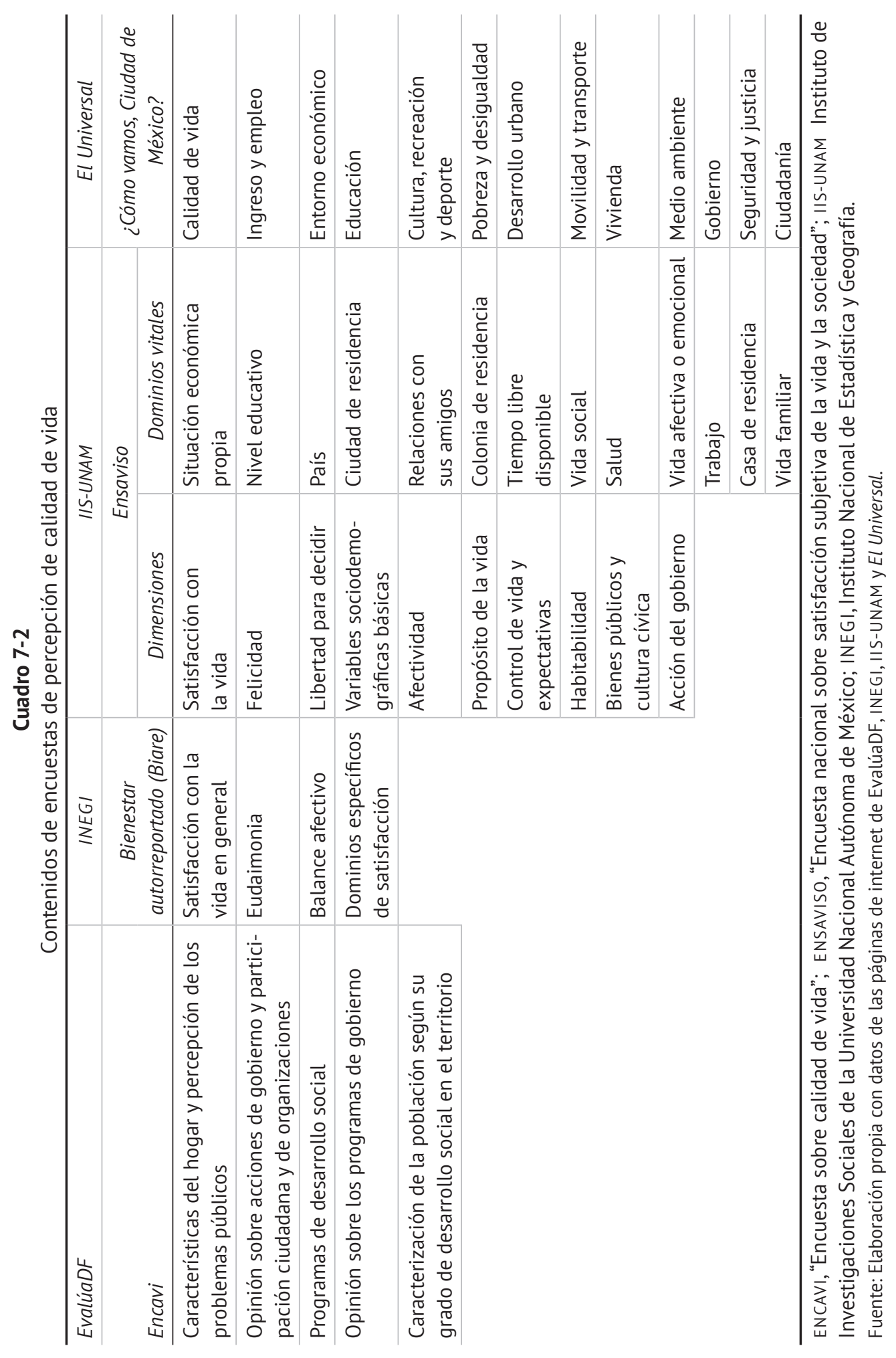


similitudes y discrepancias entre ellos, con señalamiento de los temas que tienen mayor influencia, positiva y negativa, sobre la calidad de vida. Se hace especial énfasis en aquellos dominios donde las mediciones objetivas no abarcan la complejidad del tema en comparación con las subjetivas y las perceptuales.

Los datos objetivos califican la calidad de vida en cada unidad politicoadministrativa territorial según un ranking, mientras que la percepción obtenida en cada uno de ellos no concuerda por completo con este último. Estos resultados se desagregan de modo temático con el objetivo de encontrar los dominios clave para cada rango (cuadro 7-3).

\section{Cuadro 7-3}

Comparación de resultados generales en casos

\begin{tabular}{|c|c|c|c|}
\hline $\begin{array}{l}\text { Delegación } \\
\text { o municipio }\end{array}$ & $\begin{array}{l}\text { Índice de } \\
\text { calidad de vida } \\
\text { objetivo }\end{array}$ & “Cómo vamos, Ciudad de México?” & Entrevista de percepción \\
\hline Benito Juárez & $\begin{array}{l}\text { Posición } \\
1 \text { de } 96\end{array}$ & $\begin{array}{l}\text { Posición } 9 \text { de población muy } \\
\text { satisfecha con su calidad de vida }\end{array}$ & $\begin{array}{l}\text { Su calidad de vida es muy } \\
\text { buena y es muy feliz }\end{array}$ \\
\hline Coyoacán & $\begin{array}{l}\text { Posición } \\
3 \text { de } 96\end{array}$ & $\begin{array}{l}\text { Posición } 16 \text { de población muy } \\
\text { satisfecha con su calidad de vida }\end{array}$ & $\begin{array}{l}\text { Su calidad de vida es muy } \\
\text { buena y es muy feliz }\end{array}$ \\
\hline Ecatepec & $\begin{array}{l}\text { Posición } \\
26 \text { de } 96\end{array}$ & $\begin{array}{l}\text { Posición } 34 \text { de población muy } \\
\text { satisfecha con su calidad de vida }\end{array}$ & $\begin{array}{l}\text { Su calidad de vida es } \\
\text { buena y es muy feliz }\end{array}$ \\
\hline Milpa Alta & $\begin{array}{l}\text { Posición } \\
63 \text { de } 96\end{array}$ & $\begin{array}{l}\text { Posición } 36 \text { de población muy } \\
\text { satisfecha con su calidad de vida }\end{array}$ & $\begin{array}{l}\text { Su calidad de vida es } \\
\text { buena y es algo feliz }\end{array}$ \\
\hline Villa del Carbón & $\begin{array}{l}\text { Posición } \\
93 \text { de } 96\end{array}$ & No indexada & $\begin{array}{l}\text { Su calidad de vida es } \\
\text { buena y es muy feliz }\end{array}$ \\
\hline
\end{tabular}

Fuente: Elaboración propia con datos del capítulo 4 de este libro; “¿Cómo vamos, Ciudad de México?”; y entrevistas a profundidad realizadas para este trabajo

\section{Aspectos objetivos}

\section{Educación}

La percepción de los entrevistados sobre su educación corresponde a la posición que ocupan en el ICVO, el cual es más importante para los municipios o delegaciones con mayor calidad de vida y menos notable para quienes notifican menor calidad de vida, al grado en que la entrevistada residente en el municipio de Villa del Carbón valoró su educación como algo que influyó en su vida:

Yo busqué, yo fui construyendo un proyecto de vida donde, por educación, todo me quedara cerca, donde todo estuviera a mi mano y donde fuera, pues, de buena calidad. Y mi educación, pues ayudó a eso porque mi escolaridad me da 
un mejor trabajo, un mejor salario y eso hace que yo pueda organizar este proyecto (caso Villa del Carbón).

Salud

En este tema, las relaciones no son correspondientes. Por ejemplo, en el caso del municipio de Villa del Carbón, este se encuentra en mejor posición que la delegación de Milpa Alta de acuerdo con el ICvo, debido a que posee menor porcentaje de población con discapacidad y mayor porcentaje de población con algún tipo de derechohabiencia; sin embargo, estos rubros no fueron determinantes ya que para los entrevistados lo importante es que el servicio al que acuden sea confiable y de buena calidad. La posición objetiva no corresponde con la encuesta, ya que la población de estos municipios consideró este servicio regular.

\section{Vivienda}

Con respecto a los servicios e instalaciones de las viviendas, los tres instrumentos mantienen la tendencia general marcada por el ıcvo, en que las delegaciones Benito Juárez y Coyoacán presentan las mejores condiciones, sin deficiencias y se perciben mejorías; el municipio de Ecatepec de Morelos, de acuerdo con la entrevista, carece de una dotación constante de agua potable y se determina en la encuesta "¿Cómo vamos, Ciudad de México?" (CVCM) que el servicio ha empeorado; la delegación de Milpa Alta y el municipio de Villa del Carbón, según la entrevista, también carecen de dotación constante de agua potable, y los entrevistados consideran que el servicio ha empeorado, tienen un sistema de drenaje de poca cobertura que mejora con lentitud, pero opera en detrimento de su calidad de vida. A pesar de estas deficiencias en los servicios públicos al interior de su vivienda y las calificaciones obtenidas en el ıcvo, todos los entrevistados expresaron estar contentos y cómodos dentro de sus hogares y en el ambiente interno de ellas, pero señalan todos que tienen la intención de mejorar las características constructivas o de decoración.

\section{Infraestructura vial}

Los valores relacionados con este dominio corresponden poco con el ICvO, la encuesta CVCM y las entrevistas, cuando se toman en cuenta los temas de pavimentación de las calles, estado de las banquetas y estado actual de las calles. Las entrevistas en las delegaciones Benito Juárez y Coyoacán consideran bueno el estado de las calles; sin embargo, la representatividad estadística de la encuesta CVCM difiere con estos resultados, lo cual coincide con el resto de los rangos en un sentimiento de insatisfacción 
general con respecto a la infraestructura vial como opciones para la movilidad. A nivel perceptual, la presencia de plantas de ornato en las calles adquirió mayor importancia en los rangos más bajos de calidad de vida (municipios de Ecatepec de Morelos y Villa del Carbón, así como en la delegación de Milpa Alta), mismos donde la entrevista y la encuesta coinciden en que el resto de los rubros calificados ha empeorado. A su vez, según la posición de cada municipio y delegación en el ICVO, Villa del Carbón supera a Milpa Alta, cuya posición se encuentra en un estrato más alto de calidad de vida en este tema: "Se reduce a dos cosas, para llegar a donde vivo hay dos maneras de llegar y para llegar a otros lugares que están cercanos hay dos maneras de llegar y para llegar al centro de Ecatepec hay dos maneras de llegar, ¿entienden el problema? [...] o sea si no es la Vía Morelos, es la autopista México-Pachuca y ya" (caso Ecatepec).

\section{Mobiliario y servicios}

Existe una situación de falta de correspondencia entre los resultados en este tema. Las entrevistas coinciden en la deficiencia de alumbrado público y, de forma general, nadie está satisfecho con las rutas de transporte público, aunque las delegaciones Benito Juárez y Coyoacán valoran la oferta que hay, elemento ausente en el resto de los estratos. Esta inconformidad se ha reforzado con la encuesta CVCM en el municipio de Ecatepec de Morelos y la delegación de Milpa Alta, donde se observa que el alumbrado público ha empeorado con los años. En este rubro, el municipio de Villa del Carbón coloca de manera muy alta su posición, con respecto a su ubicación en el ıcvo general, pese a que mantiene el último lugar de los municipios estudiados.

\section{Aspectos subjetivos}

Además de los temas de naturaleza objetiva que se han mencionado antes, la entrevista acota los aspectos subjetivos de la calidad de vida en cinco grandes temas: 1) espacio público; 2) movilidad; 3) seguridad y gobierno; 4) participación ciudadana y relaciones sociales, y 5) calidad de vida. Por su naturaleza subjetiva, estos temas se analizan mediante la encuesta CVCM, lo cual permite un punto de comparación entre los casos individuales de las entrevistas y la estadística representativa de la encuesta.

\section{Equipamiento y espacio público}

Las entrevistas en las delegaciones Benito Juárez y Coyoacán, así como en los municipios de Ecatepec de Morelos y Villa del Carbón coinciden en la existencia, calidad y cercanía de la mayor parte de los servicios; por otro lado, la persona entrevistada en la delegación Milpa Alta denuncia la carencia o mala calidad de 
equipamientos, como bibliotecas, centros comunitarios, parques, unidades deportivas o plazas públicas, en contraste con la postura detectada en la encuesta СvсM, donde este municipio alcanza las posiciones más altas de satisfacción, por la presencia de estos espacios, situación similar registrada en la delegación Coyoacán.

Las encuestas en la delegación Benito Juárez y el municipio de Ecatepec de Morelos registran resultados similares al evidenciar la inexistencia de bibliotecas, centros comunitarios, unidades deportivas y plazas públicas, mientras que los mercados y los parques se consideran de muy buena calidad. Más allá de esta comparación, dada la naturaleza subjetiva de las entrevistas, cada individuo detectó necesidades prioritarias para su comunidad, las cuales varían de acuerdo con el rango de calidad de vida en el que se encuentran; por ejemplo, la delegación de Milpa Alta y el municipio de Villa del Carbón coinciden en que la necesidad más urgente es la creación de espacios públicos y áreas con jardín; en el municipio de Ecatepec de Morelos, se requieren mercados públicos y, en la delegación Benito Juárez, se considera fundamental el control del ambulantaje:

A la colonia le hace falta una cosa, que pongan un hasta aquí a que se llenen las calles de comercios porque eso no va a resultar bien [...] esta colonia no debe permitir que siga creciendo el ambulantaje [...] se necesita una gente en este lugar que diga este lugar sigue siendo un buen lugar (caso de la delegación Benito Juárez).

\section{Movilidad}

Para los entrevistados en las delegaciones Benito Juárez, Coyoacán y Milpa Alta, así como en el municipio de Ecatepec de Morelos, el tema de la movilidad fue en particular polémico y las conclusiones se polarizaron, mismas que coinciden con los resultados de la encuesta. En el caso de las delegaciones Benito Juárez y Coyoacán, los tiempos de traslado se consideraron un problema que afecte la calidad de vida e, incluso, se piensa que son privilegiados por esta situación; por el contrario, para los entrevistados en el municipio de Ecatepec de Morelos y la delegación de Milpa Alta, el tiempo de traslado a sus actividades diarias constituye un problema ya que destinan dos horas o más por viaje en promedio, lo cual reduce sus posibilidades de ocuparse de otros asuntos:

A nosotros nos cambió la calidad de vida (cambiarse a la colonia Del Carmen, en Coyoacán). Porque acuérdate que vivíamos en Villa Coapa y todo, todo nos 
quedaba espantosamente lejos y aparte Coapa es un sitio de tráfico (caso de Coyoacán).

En el caso del municipio de Villa del Carbón, la entrevistada declaró un tiempo de traslado de casi cinco minutos en taxi (único medio de transporte público) a sus actividades cotidianas, lo cual indica movilidad local.

\section{Seguridad y gobierno}

Este tema incluye tres grandes dominios: percepción de delitos e inseguridad, confianza en las instituciones y las acciones de gobierno, de los cuales el primero fue el que todos los entrevistados consideraron más importante. De estos resultados, se extraen dos grandes conclusiones: hay correspondencia entre lo percibido en la entrevista y lo informado por la encuesta $\mathrm{CVCM}$, y que la importancia del tema depende de la experiencia de los individuos como víctimas de los delitos.

El descontento en relación con la amplia variedad y frecuencia de los delitos, al grado de sentirse inseguro en su colonia, lo manifiesta un entrevistado residente del municipio de Ecatepec de Morelos, lo cual concuerda con los resultados de la encuesta en que la mayoría de la población se siente muy insegura en su colonia. Esto contrasta con el resto de los entrevistados, quienes a pesar de que consideran que existen problemas de seguridad en el lugar donde viven, no se sienten inseguros ya que no han sido víctimas de algún delito:

Si decidí regresarme al Distrito Federal fue por la inseguridad, realmente en los dos años que viví ahí, en mi vida me habían asaltado, y en esos dos años me asaltaron tres veces y en una tuve lesiones (caso de Ecatepec).

La percepción en la calidad de vida presenta una polarización entre la delegación Benito Juárez y el municipio de Ecatepec de Morelos, ya que en la primera no se considera que la presencia de ciertos delitos sea grave, mientras que en el segundo la frecuencia de actos delictivos merece atención prioritaria por su gravedad. De la misma manera, las delegaciones de Milpa Alta y Coyoacán coinciden en que la situación del consumo y venta de alcohol y drogas en la vía pública es muy grave, mientras que el resto de los delitos los consideran poco o nada graves; sin embargo, los entrevistados fueron más específicos con las situaciones de riesgo, entre las que destacan el robo a casa habitación en la delegación de Coyoacán y las violaciones en Milpa Alta. En este sentido, si bien la calidad de vida objetiva mide varias necesi- 
dades materiales y la percepción indica un patrón asociado con ésta, en otros casos no se corresponden según el tipo de variable considerada, por ejemplo, la seguridad que se presenta en todo el territorio metropolitano pero que resulta más grave en algunos lugares.

En general, es posible establecer que la población de los municipios y las delegaciones estudiados no confía en las instituciones de gobierno y la seguridad pública, los medios de comunicación o la iglesia católica; la única que expresó confianza en esta última fue la persona del municipio de Villa del Carbón que es más rural.

También se registró un consenso cuando los entrevistados expresaron que las acciones gubernamentales para combatir la inseguridad son pocas e ineficientes, al buscar como propuesta general el aumento de vigilancia policial.

\section{Participación ciudadana y relaciones sociales}

Los entrevistados coinciden en que no tiene lugar dicho ejercicio en su colonia, mientras que solo en las delegaciones de Milpa Alta y Coyoacán se habló de comunidades organizadas para la solución de problemas comunes y planeación de fiestas patronales. Resalta que la mayor parte de los entrevistados tienen un alto grado de confianza en las relaciones personales que sostienen con familiares y amigos, además de participar en una relación amable pero no cercana con los vecinos.

\section{Calidad de vida y felicidad}

En el cuadro 7-3, se observan las posiciones establecidas en el ICVO y la encuesta CVCM coinciden en torno a este tema; sin embargo, las entrevistas resultan mucho más esclarecedoras: en los casos de las delegaciones Benito Juárez y Coyoacán, los entrevistados se consideran muy felices y con una muy buena calidad de vida, además, conocen los privilegios que su localización les ha brindado; por otro lado, los entrevistados en los municipios de Ecatepec de Morelos y Villa del Carbón también se consideran muy felices y creen que su calidad de vida es buena; estos aspectos en la primera demarcación se atribuyen a las dimensiones de su vivienda y de los espacios públicos, mientras que en la segunda se atribuyen al arraigo que tienen a su localidad; por último, la entrevistada en la delegación de Milpa Alta se considera algo feliz y que su calidad de vida es buena, aunque hay una percepción sobre las limitaciones en su desarrollo personal cuya causa la achaca a su entorno:

Pero es que aquí, de verdad es una protección, un privilegio, que hay en pocos lugares [...] Entonces vivir aquí es un privilegio, en serio (caso Coyoacán). 


\section{ANÁLISIS}

Las discrepancias entre el ICVO y las entrevistas a profundidad reflejan la complejidad de medir la calidad de vida, así como la variedad de metodologías existentes que responden al aspecto objetivo o subjetivo que se pretende valorar. En este estudio, el ıcvo representa una estimación objetiva sintetizada, mientras que las entrevistas ofrecen elementos para matizar y complementar este fenómeno.

Dadas las características de este estudio y las condiciones personales de los entrevistados, se puede concluir que las verdaderas diferencias en los rangos no giran tanto en torno a las dimensiones de personas y viviendas, como los define el ICVO, ya que todos los entrevistados tienen una opinión similar sobre sus variables. La mayor desigualdad radica en las problemáticas de entorno urbano, donde los territorios se diferencian, no solo por la cantidad de elementos disponibles, sino también por su calidad, lo cual genera profundas diferencias en una zona metropolitana que debe promover las mismas condiciones de vida y oportunidades para todos sus habitantes en todo el territorio.

Las desigualdades socioespaciales fueron evidentes al hablar de la localización de las viviendas y la movilidad, donde no sólo la oferta, la distancia y las rutas de transporte (naturaleza objetiva) afectan de forma directa el tiempo de traslado de la población, sino también la forma en que esta última utiliza su tiempo libre (naturaleza subjetiva); así, se resalta la dependencia funcional de las periferias a las áreas centrales de la metrópoli, así como largos recorridos que implican altos costos sociales, económicos y ambientales. Un caso diferente, como en algunos otros similares, es el municipio de Villa del Carbón, donde algunas personas realizan tiempos de traslado cortos a sus actividades cotidianas, porque no hay una relación funcional directa con el núcleo de la ZMVM.

De acuerdo con el concepto de "calidad de vida subjetiva", cada entrevistado ponderó de modo diferente los diversos temas tratados, así como los aspectos que influyen más en su percepción. Por ejemplo, para parejas de la tercera edad, como en la delegación Benito Juárez, el comercio informal perjudica su calidad de vida de forma directa pero reconocen que hay aspectos objetivos que la reducen, en especial por su edad; en el caso de la familia de la delegación Coyoacán, no hubo un tema específico que causara detrimento en su calidad de vida, sin embargo, considera que el gobierno no cumple con sus responsabilidades para mejorarla. En el caso del estudiante del municipio de Ecatepec de Morelos, su descontento con la violencia e inseguridad que vive así como con la falta de conectividad influyen de manera muy negativa en su calidad de vida; la estudiante de la delegación de Milpa Alta recalcó 
la estrecha relación que existe entre la lejanía de su vivienda, los beneficios del centro de la ciudad, la ineficiencia del transporte público y la falta de equipamientos y espacio público en su colonia. Por último, la comerciante del municipio de Villa del Carbón estableció que la falta de equipamientos y servicios públicos representan limitantes para mejorar su calidad de vida.

En correspondencia con estos resultados, se observa que las exigencias y las expectativas de su entorno por parte de los hogares incrementan su complejidad y detalle, conforme aumenta la jerarquía que poseen en el ICVO; esto se debe a que los grados más bajos tienen como prioridad la satisfacción de sus necesidades básicas (equipamientos y servicios públicos), mientras que los grados más altos se enfocan en combatir y reducir problemáticas específicas (comercio informal y acciones gubernamentales) y son más exigentes con la naturaleza de los servicios públicos ya existentes:

"Mi calidad de vida es buena, muy buena [...] No, bueno, ¿sabes qué?, te voy a decir una cosa, me falta hacer reuniones y bailar" (caso de delegación "Coyoacán").

Esta cantidad y calidad de información hubiera sido imposible de obtener utilizando solo un instrumento de medición de calidad de vida, ya que la complementariedad entre ellos no sólo es temática, sino también metodológica, lo cual amplía el panorama y profundiza en la información obtenida. Esto se suma a las limitadas fuentes confiables de información cuantificable que imposibilitan vislumbrar la totalidad de aspectos que contribuyen a la calidad de vida de un ser humano.

\section{CONCLUSIONES}

La naturaleza de los resultados al comparar las metodologías objetivas y subjetivas en la medición de la calidad de vida permite desprender dos tipos de conclusiones: una, con respecto a la metodología y los instrumentos aplicados a la medición del concepto, así como su aplicación en políticas públicas, y, la otra, en relación con la diferencia de perspectivas que tuvieron los entrevistados sobre su calidad de vida.

La comparación de resultados hace posible confirmar el carácter personal y polisémico que caracteriza al concepto de "calidad de vida" y torna evidente la complejidad de su uso para fines operativos. La cantidad de información subjetiva y su diversidad no dejan tener una representatividad estadística (por los recursos que requiere) o un registro sistemático, lo cual es el mayor reto al que se enfrentan los 
estudios de calidad de vida actuales: la creación de una metodología que conjunte diversos instrumentos y, al mismo tiempo, sintetice la información para que pueda aplicarse en las políticas públicas, donde su riqueza e innovación permita integrar los aspectos físicos del entorno (objetivos) y las relaciones del individuo con su entorno (subjetivo) para la mejora de la calidad de vida de las personas.

Asimismo, es fundamental resaltar que la aplicación de los tres instrumentos utilizados coincide en que la localización de un individuo con respecto a los centros urbanos es clave en la calidad de vida, dadas las ventajas y los atributos que estos les proveen en materia de provisión o accesibilidad a servicios, infraestructura y equipamientos. El ICVO califica con una menor calidad de vida objetiva a las demarcaciones territoriales que se encuentran más alejadas del núcleo central metropolitano, lo cual refuerza el modelo centro-periferia analizado en las teorías. El aspecto subjetivo medido en la encuesta “¿Cómo vamos, Ciudad de México?" contribuye a este planteamiento al posicionar a municipios y delegaciones en el mismo orden que el ICVO. En el enfoque perceptual, la movilidad y el transporte son los dominios que tienen mayor influencia y una relación directa y proporcional con la calidad de vida de las personas. De esta forma, el modelo centro-periferia posee implicaciones que traspasan los temas tradicionales de movilidad laboral, valor del suelo y oportunidades de desarrollo, lo cual lo vuelve un modelo que influye de modo directo en la calidad de vida.

Por último, a pesar de las desigualdades socioespaciales confirmadas con los resultados de la aplicación de mediciones objetivas, en la percepción del individuo respecto de su calidad de vida, parece predominar su satisfacción y refleja que pueden ser felices a pesar del contexto en que viven.

\section{BIBLIOGRAFÍA}

Consejo de Evaluación del Desarrollo Social del Distrito Federal (Evalua DF), (2012), Encuesta sobre la calidad de vida, México. http://evalua.cdmx/storage/app/media/uploaded-fils/fils/ Estudios/encuestas/encavi/encavi-resultados.pdf

El Universal (2014), ¿Cómo vamos Ciudad de México?, México, http://www.comovamosciuda ddemexico.com.mx.

Instituto de Investigaciones Sociales,UNAM (2015), Encuesta Nacional sobre satisfacción Subjetiva con la vida y la Sociedad (ENSAVISO), México.

Instituto Nacional de Estadística y Geografía (2012), Bienestar Subjetivo, (BIARE), México. http:// www.beta.inegi.mx/proyectos/investigacion/bienestar/piloto. 

TERCERA SECCIÓN 



\section{Calidad de vida de la población en edades avanzadas en la Zona Metropolitana del Valle de México:} un análisis a nivel "manzana"

Isalia Nava Bolaños

\section{INTRODUCCIÓN}

En el siglo xx, México transitó por una parte importante del proceso de transición demográfica, que en su versión más simplificada se refiere al paso de un esquema donde predominan altas tasas de mortalidad y fecundidad, a otro donde ambas variables registran disminuciones importantes. La evolución de los componentes de la dinámica demográfica también se refleja en la Zona Metropolitana del Valle de México (ZMVM). Tuirán (2015) identificó dos grandes etapas: la primera ocurre entre 1950 y 1970 y se caracteriza por el crecimiento de la ZMVM, producto de las altas tasas de crecimiento natural y la cuantiosa inmigración de las localidades rurales a los municipios metropolitanos; la segunda se ubica hacia fines de la década de 1960 e inicios de los años setenta y se caracteriza por una desaceleración en el crecimiento demográfico, consecuencia del decremento de la fecundidad, la mortalidad y, sobre todo, de la migración interna. Se trata de cambios demográficos que modifican la estructura por edades y que apuntan hacia el inevitable envejecimiento de la población. Una parte de los desafíos y los retos que implica el fenómeno del envejecimiento es garantizar la calidad de vida en la población.

La calidad de vida se refiere al bienestar de las personas desde una óptica multidimensional e incluye elementos objetivos, a través de los cuales los individuos desarrollan su vida, y aspectos subjetivos sobre la valoración de esas condiciones desde la perspectiva de los propios individuos (Somarriba-Arechavala y Pena-Trapero, 2009). En relación con la población en edades avanzadas, Huenchuan (2009) señala la importancia de la calidad de vida en la vejez y la necesidad de que las personas 
dispongan de bienes en general, económicos y no económicos, así como la necesidad de prestar atención a aquellos factores condicionantes en la merma de la calidad de vida, como pobreza, discapacidad y falta de vivienda.

A partir de estos antecedentes en esta investigación, se plantea analizar la calidad de vida en la población en edades de 60 años y más (P60+) en la ZMVM. La dimensión territorial de análisis son las "manzanas", ya que se trata del espacio geográfico mínimo disponible. Para ello se calcula el índice de calidad de vida objetivo (ICVO) con base en la metodología creada por Sánchez, Nava, Ruiz, Buenrostro y De la Vega (capítulo 5). A diferencia de esta propuesta, solo se consideran las dimensiones vivienda y persona, puesto que interesa obtener el índice de calidad de vida objetivo (ICVO) para el total de la P60+, y los datos sobre infraestructura y características del entorno urbano solo incluyen las localidades de 5000 habitantes y más. La fuente de información es el "Censo de población y vivienda del año 2010" que levanta el Instituto Nacional de Estadística y Geografía (INEGI).

Este capítulo se integra de tres apartados, más introducción y conclusiones. En la primera sección se presenta una revisión del proceso de envejecimiento a nivel nacional y con énfasis en las tres entidades de la ZMvм que son el Distrito Federal (D. F.), el Estado de México (EdoMéx) e Hidalgo; se reconoce la importancia de este fenómeno demográfico en la región, y se revisan las implicaciones del envejecimiento, con énfasis en la necesidad de asegurar la calidad de vida en la vejez y las variables que contribuyen a ello. En la segunda parte, se exponen los principales elementos metodológicos de la investigación, se incluye una breve explicación del "Censo de población y vivienda del año 2010", las variables que integran las dimensiones "vivienda" y "persona", y el cálculo del ıcvo. En la tercera parte, se describen los resultados de la investigación, donde se incluye un panorama sobre el ICVO en las "manzanas" de la ZMVM; también se apuntan algunas reflexiones relacionadas con la calidad de vida y el grado de envejecimiento de las "manzanas", esto último se construye a partir de la participación de la P60+ en el total de la población y abarca la siguiente tipología de "manzanas": jóvenes, en transición, envejecidas e hiperenvejecidas.

\section{ENVEJECIMIENTO Y CALIDAD DE VIDA}

Proceso de envejecimiento en México y la Zona Metropolitana del Valle de México. En el análisis del proceso de transición demográfica en México, el primer gran cambio que se registró fue el decremento de la mortalidad. Esta transformación resultó del progreso y el avance de la sociedad mexicana hacia la modernidad, lo cual se 
manifestó en acciones médicas, sanitarias, educativas y de salud encaminadas a mejorar las condiciones de vida del país (Gómez de León y Partida, 2001). Mientras que en el quinquenio 1950 a 1955 se registraban 118.7 decesos en el primer año de vida por cada 1000 nacimientos en el país, la tasa de mortalidad infantil (TMI) disminuyó a 71.2 en el periodo 1970 a 1975, y 33.0 en 1990 a 1995. La disminución de la TMı fue importante, pero se presentó con marcadas diferencias a lo largo del territorio nacional y entre las tres entidades de la ZMVM. Las cifras del cuadro 8-1 muestran que la TMı en el Distrito Federal y el Estado de México siempre registró valores inferiores a la tasa nacional, en particular las tasas en el Distrito Federal son marcadamente menores. En las próximas décadas, la TMI seguirá disminuyendo, aunque a ritmos más lentos.

Los decrementos en la mortalidad se manifiestan en mayores esperanzas de vida. En tan solo cuatro décadas, la esperanza de vida femenina en el país aumentó de 53.3 años a 75.1 y la masculina pasó de 50.2 a 70.2 años. En el cuadro 8-1, se aprecia que el aumento en la vida media presenta variaciones en las entidades analizadas. El Distrito Federal aparece con las cifras más altas, mientras que Hidalgo presenta los valores más bajos; sin embargo, es en esta entidad donde se presentan las mayores ganancias de vida en el tiempo. Asimismo, se observa que en escala nacional y en las tres entidades, el aumento en la expectativa de vida ha sido mayor entre la población femenina. Se espera que en las próximas décadas continúe el aumento en la esperanza de vida y las brechas entre entidades se cierren.

El segundo gran cambio fue la disminución de la fecundidad, lo cual se debió a los mayores niveles de escolaridad de las mujeres, la presencia de nuevas pautas reproductivas, el uso ampliado de las campañas de planificación familiar y el uso de métodos modernos de anticoncepción (Mier y Terán, y Partida, 2001; y Zavala de Cosío, 2001). Mientras en el quinquenio de 1950 a 1955 la tasa global de fecundidad (TGF) nacional fue de 6.7, en el periodo 1990 a 1995 se registraron 3.1 hijos en promedio por mujer. En el mismo cuadro, se observan las diferencias en las tres entidades de análisis; el Distrito Federal se ha caracterizado por presentar las menores tasas; por ejemplo, en 2010 registró tasas con valores menores de dos hijos por mujer, es decir, menores del nivel de reemplazo, mientras que Hidalgo aparece como la entidad con las TGF más altas. En las próximas décadas, se espera que la fecundidad se reduzca a niveles inferior a la tasa de reemplazo.

El tercer gran cambio se relaciona con los patrones migratorios, tanto internos como internacionales. En especial la migración interna ha sido un factor determinante de la distribución territorial de la población en la ZMVM. De acuerdo con Partida 
(2001), durante la segunda mitad del siglo Xx aumentó el flujo de inmigrantes y los principales destinos interestatales fueron el Distrito Federal y el Estado de México, aunque el primero comenzó a registrar reducciones a partir de 1970, como consecuencia del "acomodo poblacional" en la zona metropolitana. En relación con el flujo de emigrantes, el D. F.., muestra un incremento sostenido en el tiempo; un número importante de esta población se dirige al Estado de México. En los próximos años, se espera que la presencia de saldos netos migratorios mantenga valores negativos en el Distrito Federal (cuadro 8-1).

Los cambios en la mortalidad, la fecundidad y la migración se reflejan en las transformaciones de las estructuras por género y edad. En la pirámide poblacional de la región (D. F., EdoMéx e Hidalgo), en 1990 se percibe una población joven caracterizada por una base ancha, como resultado de la reducción de la mortalidad y las altas tasas de fecundidad. Sin embargo, en las siguientes décadas la silueta deja de ser piramidal, ya que se observa una base cada vez más angosta debido a la reducción de la fecundidad, al mismo tiempo que se vuelve más notoria la participación de la población en las edades adultas y laborables. Estos cambios, junto con el aumento en la esperanza de vida conducen hacia el envejecimiento demográfico (gráfica 8-1).

Las proyecciones más recientes del Conapo estiman que en las siguientes décadas se reducirá la participación de la población de niños y jóvenes, y se incrementará de modo importante el sector de adultos y de edades avanzadas. Así, se espera que la pirámide de población en 2030 adopte una forma regresiva o "envejecida", caracterizada por una base muy angosta y una cúspide ancha.

\section{Envejecimiento}

Las edades avanzadas constituyen una etapa donde aumentan las posibilidades de deterioro del bienestar. Por un lado, se incrementa la presencia de las enfermedades crónicas degenerativas y las incapacidades, así como la necesidad de cuidados; por otro lado, se intensifica el retiro de la actividad laboral, en especial cuando las condiciones de salud y el desempeño físico merman por vejez; como consecuencia, los ingresos también se reducen. Se trata de elementos que tienden a disminuir la calidad de vida de las personas mayores. Además, como mencionan Flores et al. (2011: 94), hay cambios sociales que influyen de forma negativa en la vejez, como "respuesta social al deterioro biológico, pérdida de la ocupación, disminución del ingreso y deterioro de la identidad social, ideología de los viejos, desvalorización social de la vejez y ausencia de un rol social para el adulto mayor". 
Cuadro 8-1

Indicadores demográficos por entidad federativa de 1950 a 2010

\begin{tabular}{|c|c|c|c|c|c|c|c|c|c|c|c|c|}
\hline $\begin{array}{l}\text { República } \\
\text { Mexicana y } \\
\text { entidades }\end{array}$ & \multicolumn{2}{|c|}{$\begin{array}{c}1950 a \\
1955\end{array}$} & \multicolumn{2}{|c|}{$\begin{array}{c}1970 a \\
1975 \\
\end{array}$} & \multicolumn{2}{|c|}{$\begin{array}{c}1990 a \\
1995\end{array}$} & \multicolumn{2}{|c|}{2010} & \multicolumn{2}{|c|}{2020} & \multicolumn{2}{|c|}{2030} \\
\hline \multicolumn{13}{|c|}{ Tasa de mortalidad infantil } \\
\hline Nacional & \multicolumn{2}{|c|}{118.7} & \multicolumn{2}{|c|}{71.2} & \multicolumn{2}{|c|}{33.0} & \multicolumn{2}{|c|}{13.0} & \multicolumn{2}{|c|}{10.0} & \multicolumn{2}{|c|}{8.5} \\
\hline D. F. & \multicolumn{2}{|c|}{59.0} & \multicolumn{2}{|c|}{39.7} & \multicolumn{2}{|c|}{20.7} & \multicolumn{2}{|c|}{11.3} & \multicolumn{2}{|c|}{9.4} & \multicolumn{2}{|c|}{8.5} \\
\hline EdoMex & \multicolumn{2}{|c|}{111.6} & \multicolumn{2}{|c|}{64.9} & \multicolumn{2}{|c|}{27.3} & \multicolumn{2}{|c|}{15.3} & \multicolumn{2}{|c|}{11.7} & \multicolumn{2}{|c|}{10} \\
\hline Hidalgo & \multicolumn{2}{|c|}{142.4} & \multicolumn{2}{|c|}{88.0} & \multicolumn{2}{|c|}{40.1} & \multicolumn{2}{|c|}{14.2} & & 16 & & 9.1 \\
\hline & & & & peranz & de vid & a al na & imien & & & & & \\
\hline & M & $\mathrm{H}$ & M & $\mathrm{H}$ & M & $\mathrm{H}$ & M & $\mathrm{H}$ & M & $\mathrm{H}$ & M & $\mathrm{H}$ \\
\hline Nacional & 53.3 & 50.2 & 65.3 & 60.9 & 75.1 & 70.2 & 77.0 & 71.1 & 78.3 & 73.3 & 79.4 & 74.6 \\
\hline D. F. & 60.6 & 57.3 & 70.0 & 65.7 & 77.6 & 72.9 & 78.0 & 73.1 & 79.0 & 74.4 & 80.0 & 75.6 \\
\hline EdoMex & 55.5 & 52.4 & 67.2 & 62.7 & 76.6 & 71.7 & 77.2 & 71.9 & 78.4 & 73.7 & 79.5 & 75.0 \\
\hline Hidalgo & 50.6 & 48.2 & 63.3 & 59.0 & 74.1 & 70.0 & 76.2 & 71.2 & 77.6 & 72.9 & 78.8 & 74.3 \\
\hline & & & & Tasa o & obal de & fecun & lidad & & & & & \\
\hline Nacional & & .7 & & 3 & & .1 & & .3 & & .1 & & 2.1 \\
\hline D. F. & & .6 & & .1 & & .2 & & $\mathrm{~m}$ & & .8 & & 1.8 \\
\hline EdoMéx & & .3 & & .9 & & .0 & & .2 & & .1 & & 2.1 \\
\hline Hidalgo & & .2 & & .9 & & .4 & & .4 & & .2 & & 2.1 \\
\hline & & & & Inmig & antes in & terest & tales & & & & & \\
\hline Nacional & 1226 & 228 & 3043 & 704 & 4000 & 950 & 864 & 092 & 905 & 123 & 929 & 204 \\
\hline D. F. & 441 & 499 & 559 & 435 & 449 & 549 & & 714 & & 328 & & 573 \\
\hline EdoMéx & & 647 & 668 & 472 & 1020 & 832 & 147 & 636 & 145 & 449 & 140 & 890 \\
\hline Hidalgo & & 327 & & 545 & & 249 & & 974 & & 839 & & 841 \\
\hline & & & & Emigi & antes in & terest & ales & & & & & \\
\hline Nacional & 1262 & 228 & 3043 & 704 & 4000 & 950 & 864 & 092 & 905 & 123 & 929 & 204 \\
\hline D. F. & & 629 & 483 & 201 & 1144 & 120 & 155 & 333 & 145 & 236 & 134 & 874 \\
\hline EdoMéx & & 889 & 197 & 664 & 488 & 280 & & 753 & 102 & 206 & 109 & 602 \\
\hline Hidalgo & & 120 & & 473 & & 490 & & 358 & & 733 & & 337 \\
\hline
\end{tabular}

EdoMéx, Estado de México; M, mujer; H, hombre.

Fuente: Elaboración con datos de Gómez de León y Partida, 2001; Mier y Terán y Partida, 2001; Partida, 2001, y Conapo, 2014.

Esta investigación parte de considerar la intensificación de los riesgos en la vejez y la necesidad de garantizar el derecho a una calidad de vida adecuada en las edades avanzadas, como quedó expresado en 1982, en el "Plan de acción internacional de Viena", donde las representaciones de los países asistentes: 
Gráfica 8-1.

Estructuras por sexo y edades quinquenales. D.F., Estado de México e Hidalgo, 1990-2030

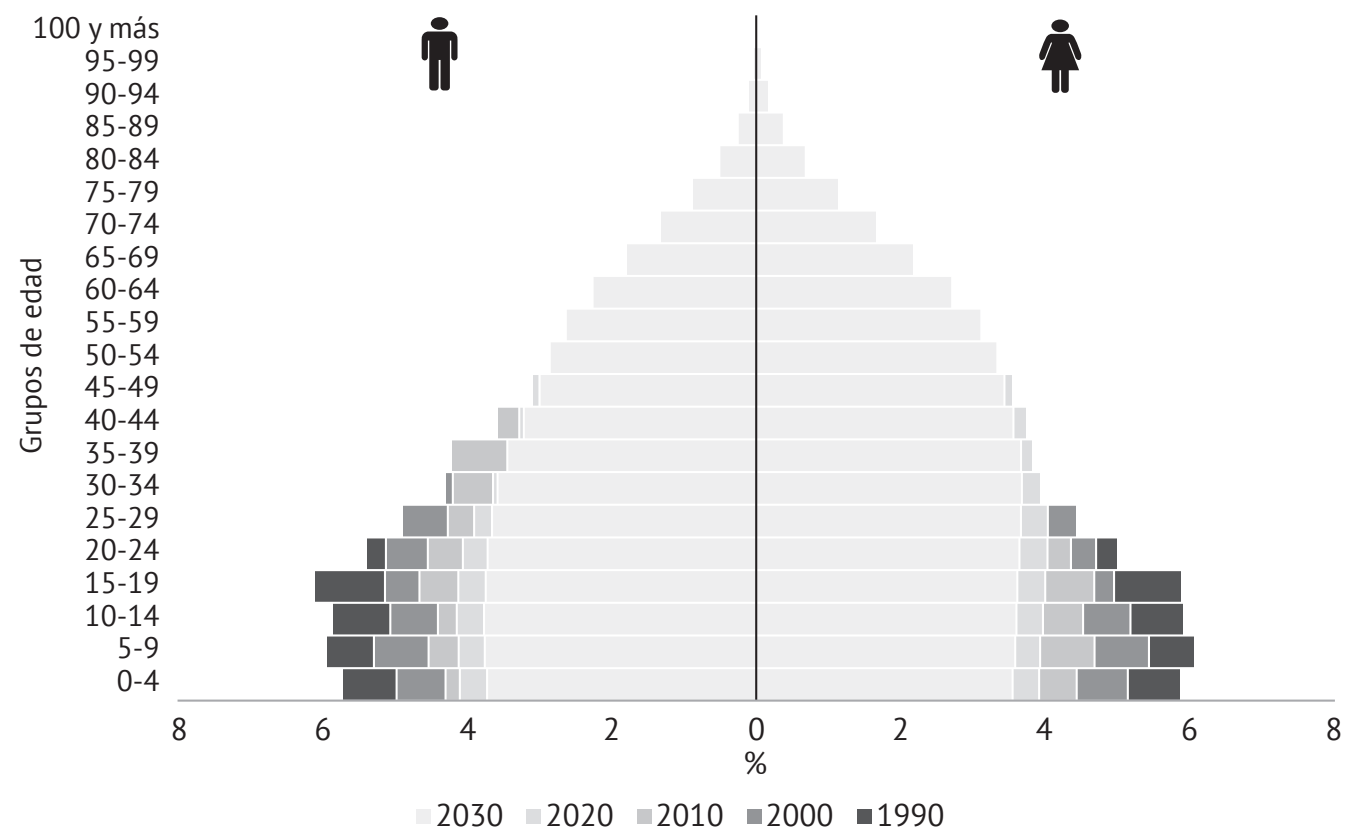

Fuente: elaboración propia con base en datos de Censos de Población y Vivienda (INEGI, 2013) y Proyecciones de la población 2010-2050 (Conapo, 2014).

reafirmaron su creencia en que los derechos fundamentales e inalienables consagrados en la "Declaración Universal de los Derechos Humanos" se aplican plenamente y sin menoscabo a las personas de edad, y reconocieron que la calidad de vida no es menos importante que la longevidad y que, por consiguiente, las personas de edad, en la medida de lo posible, deben disfrutar en el seno de sus propias familias y comunidades de una vida plena, saludable y satisfactoria y ser estimados como parte integrante de la sociedad (CEPAL, 2011: 10).

El concepto de calidad de vida es amplio, de carácter multifactorial y no se mide de forma directa. ${ }^{1}$ Fernández-Ballesteros y Maciá (1993) fueron de los primeros que enfatizaron en la necesidad de contar con un concepto operacional de la calidad de vida en la vejez. Los autores destacaron su complejidad, su condición de multidimensionalidad y la presencia de elementos subjetivos y objetivos en su medición. A ello debe agregarse que durante la vejez la calidad de vida se relaciona con las ex-

| 1 Para una revisión extensa véase el capítulo uno. 
periencias acumuladas a lo largo de la vida y que la presencia de fenómenos como la feminización de la vejez y los efectos cohorte vuelven más compleja la medición.

El estudio de la calidad de vida en la población adulta mayor incluye un conjunto amplio de variables e indicadores. ${ }^{2}$ Entre éstos, destacan los factores determinantes que Fernández-Ballesteros y Maciá (1993) han identificado: salud, aptitudes funcionales, condiciones económicas, relaciones sociales, actividad, servicios sociales y de salud, calidad en casa y en el contexto próximo, satisfacción con la vida y oportunidades culturales y de aprendizaje. Algunos otros determinantes abarcan autonomía, apoyo familiar, calidad de sueño, edad, felicidad, ocio, movilidad, paz y religión (Aguilar et al., 2011).

Otro elemento a mencionar es la carencia de consenso sobre la variable más determinante en la calidad de vida de la población en edades avanzadas. Xavier et al. (2003) identifican a la salud como el principal factor. Mientras que Fernández-BaIlesteros (1998) concluye que para la mayoría de las dimensiones de calidad de vida, la posición social, la edad y el género son más importantes en comparación con vivir en el propio domicilio o en una residencia. Por otro lado, Farquhar (1995) encuentra que las relaciones familiares, el contacto social y las actividades tienen un efecto igual de importante que la salud y el estado funcional. En la misma dirección, los hallazgos de Wilhelmson et . (2005, citado por Aguilar et al, 2011, p. 167] muestran que "las relaciones sociales, la capacidad funcional y las actividades influyen en la calidad de vida de las personas mayores tanto como el estado de salud".

La ausencia de consensos también se extiende a la dificultad para asignar pesos en la construcción del ICVO en la vejez. De acuerdo con Browne et al. (2004), cuando se pide a las personas que identifiquen los dominios o las áreas de interés en su calidad de vida, suelen seleccionar distintos dominios como los más importantes, por ello es difícil establecer una taxonomía que se adapte a todas las personas.

A pesar de las complejidades del concepto antes mencionadas, Aranibar (2003) identifica tres consensos de la calidad de vida en la vejez: 1) la especificidad del concepto en este grupo de población, es decir, en el tramo de las edades avanzadas intervienen factores que no resultan importantes en otras etapas de la vida; 2) la condición multidimensional, ya referida, y su interrelación entre las distintas variables que integran el concepto, lo cual implica que las condiciones de salud se vinculan de forma estrecha con las características socioeconómicas de las personas en edades avanzadas, y 3) la presencia de elementos objetivos y subjetivos que determinan la

\footnotetext{
${ }^{2}$ Para una revisión detallada véase Aguilar et al., 2011.
} 
calidad de vida, a fin de conocer, tanto las condiciones de vida, como la percepción y las experiencias de vida.

Si se toma en cuenta que la calidad de vida es un concepto multidimensional y la disponibilidad de información censal a nivel "manzana" en la ZMVM, este capítulo parte de considerar el estudio de la calidad de vida en la P60+, a partir de indicadores objetivos en dos dimensiones que se consideran igualmente prioritarias: viviendas y personas.

En relación con la vivienda, el Centro Latinoamericano y Caribeño de Demografía (Celade) (2006:146) identifica "múltiples influencias de la vivienda y el vecindario en la calidad de vida, ya sea en la esfera objetiva de las condiciones de vida y del patrimonio de las personas, como en la esfera subjetiva o de percepción de bienestar". Algunos de los elementos relevantes para analizar las condiciones de vivienda de la población en edades avanzadas son: 1) las condiciones de habitabilidad de las viviendas a través del régimen de propiedad, el material y la calidad de las viviendas, el acceso a servicios básicos de agua potable y saneamiento, el acceso a servicios de electricidad y el hacinamiento en la vivienda (variables relacionadas con la calidad habitacional de las personas en edades avanzadas); 2) los planes habitacionales y viviendas adecuadas y seguras en la vejez, y 3 ) la percepción de la calidad de vida que mujeres y hombres mayores tienen en relación con las viviendas que habitan.

Respecto de la dimensión "personas", la mayoría de las investigaciones sobre calidad de vida en la vejez incluyen aspectos vinculados con las situaciones individuales. La calidad de vida suele ser más alta entre quienes poseen más y mejores recursos (Aguilar et al., 2011). Entre la población adulta mayor, hay dos elementos que en esta investigación se consideran relevantes. El primero se relaciona con el nivel de instrucción formal como factor diferenciador en el bienestar socioeconómico; se debe recordar que esta es una población que tuvo acceso a la educación cuando el sistema de educativo en México aun no estaba consolidado (Ham, 2003). El segundo se vincula con la salud y la importancia de contar con servicios de salud (Aguilar et al., 2011).

\section{METODOLOGÍA}

\section{Fuente de información}

La base de datos que se utiliza en este trabajo es el "Censo de población y vivienda del año 2010". Se trata de la fuente de información estadística más completa que ofrece datos sobre las principales características demográficas y socioeconómicas de la población, así como las características básicas de las viviendas. El "Censo 2010" 
fue uno de hecho, lo cual implica el empadronamiento de toda la población presente entre el 31 de mayo y el 25 de junio de ese año. La población objetivo abarcó los residentes habituales del país, los hogares censales y las viviendas particulares y colectivas. El "Censo 2010" permite ubicar la distribución de la población en escalas nacional, por entidad federativa, por municipio o delegación, por localidad, por área geoestadística básica (AGEB) y por "manzana".

El análisis que se presenta en este capítulo se elaboró a partir del cuestionario básico y del procesamiento de la información en el Laboratorio de microdatos del INEGI. Dado que se trabajó con el "Censo", y no con la muestra censal, no existen problemas relacionados con la representatividad de la información frente a unidades con un número reducido de $\mathrm{P} 60+$.

\section{Variables}

La calidad de vida de la P60+ se estima a partir de dos dimensiones y cinco subdimensiones, $y$ las variables que la componen son: ${ }^{3}$

- Personas: incluye las subdimensiones: a) salud (derechohabiencia a servicios de salud), y b) educación (escolaridad y alfabetismo).

- Viviendas: abarca las subdimensiones: a) características básicas (clase de vivienda particular, pisos, cuartos dormitorio, total de cuartos); b) servicios e instalaciones (electricidad, agua entubada, excusado, admisión de agua y drenaje), y c) bienes y tecnologías de información y comunicación (TIC) (radio, televisor, refrigerador, lavadora, automóvil o camioneta, computadora, línea telefónica fija, teléfono celular e internet).

\section{Estimación del índice de calidad de vida}

La metodología utilizada para la estimación del ıcvo entre la P60+ es similar a la que se utilizó en el capítulo 5. En su descripción simple, primero se realizó la normalización de los datos a partir de la técnica de reescalamiento; segundo, se obtuvo el promedio ponderado de las dimensiones y subdimensiones en cada municipio o delegación, y tercero, se aplicaron pesos equiproporcionales, es decir, se considera que las dimensiones de análisis son igualmente prioritarias para la estimación de la calidad de vida:

$$
I C V_{P 60+}=\frac{1}{2} \underbrace{\left(\frac{1}{2} \text { Salud }+\frac{1}{2} \text { Educación }\right)}_{\text {Personas }}+\frac{1}{2} \underbrace{\left(\frac{1}{3} \text { Carac }+\frac{1}{3} \operatorname{Serv} \_ \text {Ins }+\frac{1}{3} \text { Bienes_TIC }\right)}_{\text {Viviendas }}
$$

\footnotetext{
${ }^{3}$ Una descripción detallada de cada variable aparece en el capítulo 5.
} 
Enseguida, el ICVO se clasifica en cinco estratos o grados: muy bajo (0.01 a 0.19); bajo (0.20 a 0.39$)$; medio (0.40 a 0.59$)$; alto (0.60 a 0.79$)$, y muy alto (0.80 a 1.00$)$.

\section{CALIDAD DE VIDA EN LA POBLACIÓN DE EDADES AVANZADAS EN LA ZONA METROPOLITANA DEL VALLE DE MÉXICO}

\section{Análisis del índice de calidad de vida}

A partir de los microdatos del "Censo de población y vivienda del año 2010" es posible analizar las características de la población en las 176400 "manzanas" de la ZMVM. En relación con la $\mathrm{P} 60+$, por criterios de confidencialidad, no se cuenta con información en 11400 "manzanas" (6.5\%) y, en 13600 "manzanas" (7.7\%), los residentes habituales se encuentran en edades menores de los 60 años. Por tanto, el análisis que enseguida se presenta es con base en las 151400 "manzanas" (85.8\%) que tienen datos disponibles y donde hay personas en edades avanzadas. Se estima que en 2010, la P60+ alcanzó 1.9 millones de personas, esto es, 9.3\% de la población total en la ZMVM. El Distrito Federal aparece como la región con el mayor volumen de población en edades avanzadas, con 993300 personas (que conforman 11.6\% del total de población en la entidad); enseguida, en el Estado de México aparecen 831200 personas en edades de 60 años y más (8\%), mientras que en Hidalgo la población envejecida llegó a 80600 personas (7.6\%).

La estimación del ICVO en la ZMVM genera resultados interesantes para considerarse en la agenda de las políticas públicas. En general, predomina una buena calidad de vida entre la población en edades avanzadas: 55.6\% de las "manzanas" presenta un grado alto, $22.6 \%$ medio, $18.9 \%$ muy alto, $2.8 \%$ bajo y solo $0.1 \%$ muy bajo. En el análisis de este resultado, se debe tomar en cuenta que el disfrute de la calidad de vida es acorde con las dimensiones y subdimensiones que se incluyeron en la estimación del índice.

En la desagregación del ICVO, se encuentra que la P60+ presenta mejores condiciones en la subdimensión "servicios e instalaciones", donde el promedio del indicador es 0.95 (en una escala general de 0 a 1). Enseguida, el valor medio de las características básicas de la vivienda fue 0.81 . Se trata de resultados relevantes, ya que como señala Celade (2006: 145), "el acceso a una vivienda adecuada constituye una exigencia imprescindible para una plena satisfacción de las necesidades humanas". A partir de los atributos considerados (electricidad, agua, sanitario, drenaje, clase de vivienda, pisos y cuartos), se puede señalar que las viviendas donde habitan las personas en edades avanzadas cumplen con los requerimientos básicos de saneamiento 
y comodidad. Después, el valor promedio de la subdimensión "salud" fue 0.73. En este caso, la derechohabiencia y el acceso a servicios de salud fortalecen la capacidad de las personas para enfrentar o retrasar las pérdidas de capacidad y autonomía derivadas de enfermedades degenerativas y padecimientos crónicos que suelen ocurrir a medida que avanza la edad. En la literatura, la salud aparece como un "componente básico de la calidad de vida en la vejez" (Celade, 2006: 77). El valor promedio que corresponde a "bienes y tecnologías de información y comunicaciones" es 0.63.

La subdimensión con media más baja corresponde a "educación" y es de 0.56. Este valor resulta de los efectos cohorte, es decir, de las menores oportunidades educativas que tuvo este grupo de población y que afectan su llegada a edades avanzadas (Ham, 2003). En este caso, los menores niveles de escolaridad se relacionan de modo negativo con el acceso a recursos económicos en la vejez y, como consecuencia, con menor calidad de vida.

Respecto de la distribución de la calidad de vida de la P60+ en las "manzanas" de la ZMVM, el mapa 8-1 ilustra cierta concentración de las "manzanas" de grados muy alto y alto en el Distrito Federal, mientras que en la periferia se identifican más "manzanas" con un grado medio de este índice.

En el norte y oriente del Distrito Federal, se concentran las "manzanas" con grado alto del ICVO. Esta tendencia prevalece para algunos municipios del Estado de México, ya que se presenta una proporción alta de "manzanas" con grado alto en el municipio de Nezahualcóyotl y, para el municipio de Ecatepec, se encuentran ya algunas "manzanas" con nivel medio del ICVO. Al alejarse del Distrito Federal, con dirección al oriente y norte de la ZMVM, hay algunas "manzanas" con grados bajos y muy bajos del ICVO, como es el caso del municipio en "Ecatzingo" en el Estado de México, ubicado muy próximo al estado de Morelos. Algo semejante ocurre al sur de la ZMVM, a los límites de esta región en el estado de Hidalgo.

Contrario a estas zonas precarias, sobresale la región noroeste de la ZMVM, por concentrar "manzanas" con Icvo muy alto en el municipio de Pachuca, en Hidalgo. Sin embargo, la mayor concentración de "manzanas" con ICVO muy alto se presenta en el sudeste del Distrito Federal, tendencia espacial que se mantiene para varias "manzanas" del Estado de México, en los municipios de Naucalpan y Tlalnepantla, y que se expande hasta los municipios de Cuautitlán Izcalli y algunas "manzanas" de Zumpango y Tecámac. 
Mapa 8-1.

"Manzanas" con índice de calidad de vida objetiva y adultos mayores en la Zona Metropolitana del Valle de México (ZMVM). Manzanas con más de 10\% de población con 60 años de edad y más.

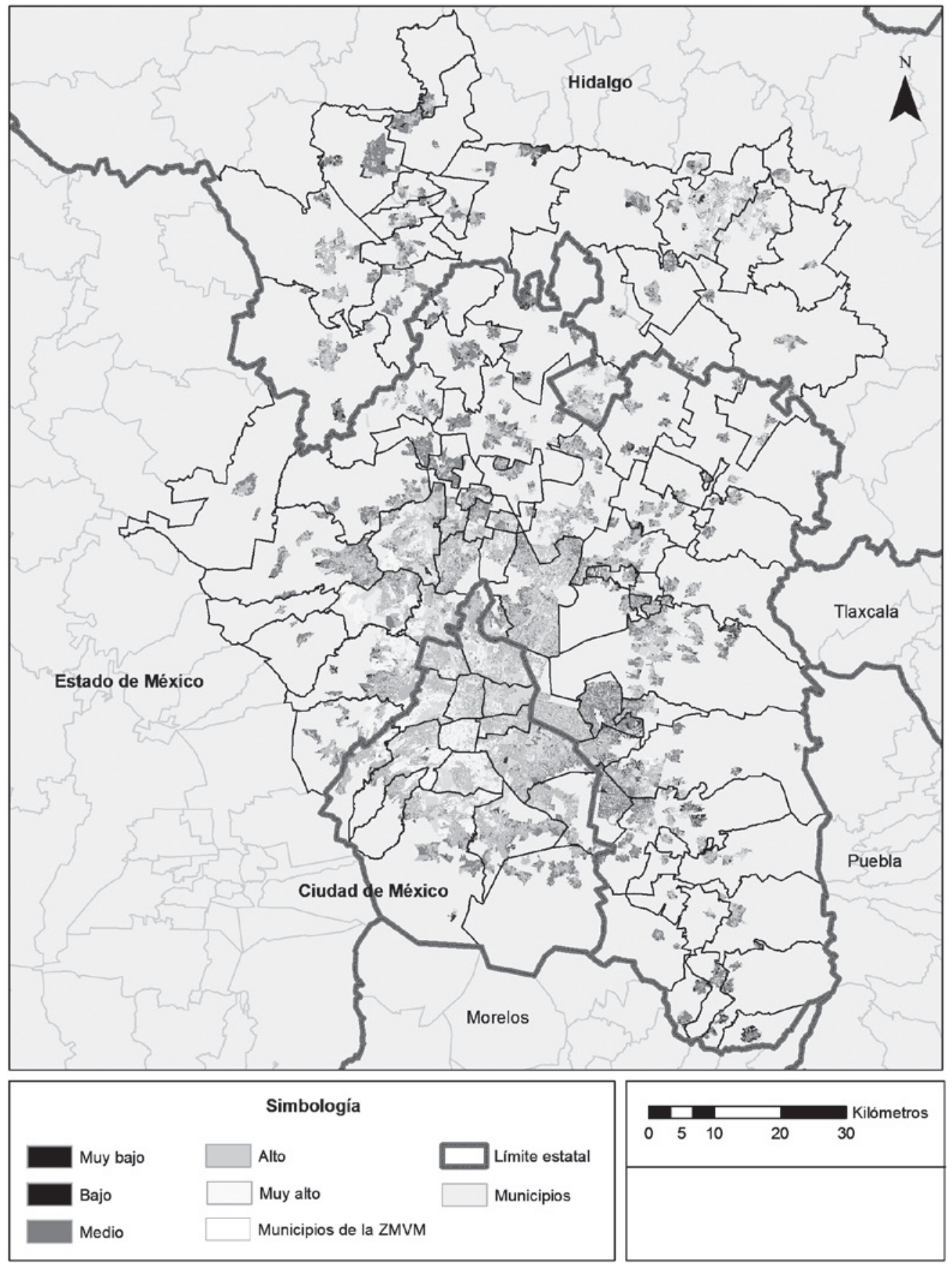

Fuente: elaboración con base en: INEGI, Censo de Población y Vivienda 2010. 


\section{CALIDAD DE VIDA Y CONCENTRACIÓN DE LA POBLACIÓN DE 60 AÑOS Y MÁS}

Con la finalidad de analizar con mayor detalle a la población en edades avanzadas en la ZMVM, se agrupan las "manzanas" en cuatro grupos a partir de la clasificación del índice global de envejecimiento (AgeWatch, 2015):

1. "Manzanas" jóvenes: menos de 10\% de la población tiene 60 años de edad y más

2. "Manzanas" en transición: entre 10 y 19\% de la población tiene 60 años de edad y más

3. "Manzanas" envejecidas: entre 20 y 29\% de la población tiene 60 años de edad y más

4. "Manzanas" hiperenvejecidas: más de 30\% de la población tiene 60 años de edad y más.

La distribución espacial de la P60+ por "manzanas" en la ZMVM, con base en la clasificación ya mencionada, se presenta en el mapa 8-2. Se evidencia mayor proporción de "manzanas" jóvenes en la ZMVM, es decir, donde menos de 10\% de la población total tiene 60 años de edad y más, distribuidas principalmente en una especie de periferia alrededor del Distrito Federal, ya que estas "manzanas" se expanden más en los municipios del Estado de México e Hidalgo. Les siguen en importancia las "manzanas" en transición, las cuales se concentran sobre todo en el Distrito Federal, con mayor preponderancia al norte y oriente. También, estas "manzanas" en transición acompañan a las "manzanas" jóvenes en diversos municipios del Estado de México e Hidalgo. Las "manzanas" envejecidas e hiperenvejecidas, en proporción, son relativamente pocas en la ZMVM. Sin embargo, son regiones de gran importancia por las necesidades sociales y económicas que implican el logro de una calidad de vida que permita envejecer con seguridad y dignidad.

El mapa 8-3 ilustra la distribución espacial del ıcvo en las "manzanas" envejecidas e hiperenvejecidas. Destaca el Distrito Federal como la entidad que reúne más "manzanas" con alta concentración de P60+ en la ZMVM. Se puede verificar una ruta de estas unidades territoriales que parte desde la delegación "Coyoacán" y se expande hasta los municipios de "Naucalpan", "Tlalnepantla" y "Atizapán" en el Estado de México. Asimismo, es posible identificar cierta concentración de "manzanas" envejecidas e hiperenvejecidas en el municipio de "Pachuca", en Hidalgo. 
Mapa 8-2

Población adulta mayor por “manzanas” en la Zona Metropolitana del Valle de México (ZMVM).

“Manzanas" con más de $10 \%$ de población con 60 años de edad y más.

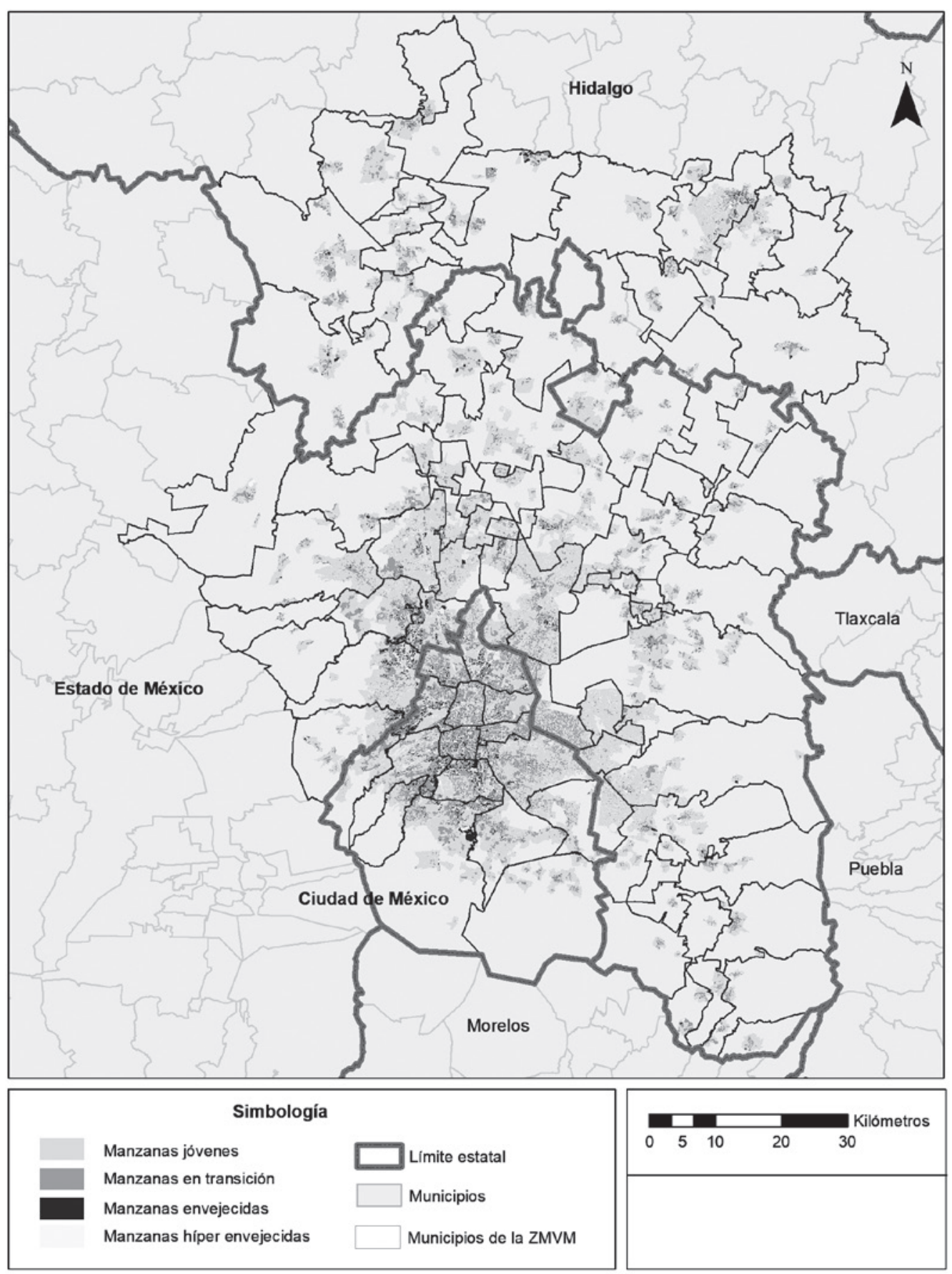

Fuente: Elaboración propia con datos del “Censo de población y vivienda del año 2010” (INEGI). 


\section{Mapa 8-3}

Índices de calidad de vida objetiva en "manzanas" con población envejecida e hiperenvejecida en la Zona Metropolitana del Valle de México (ZMVM). "Manzanas" con más de $10 \%$ de población con 60 años de edad y más.

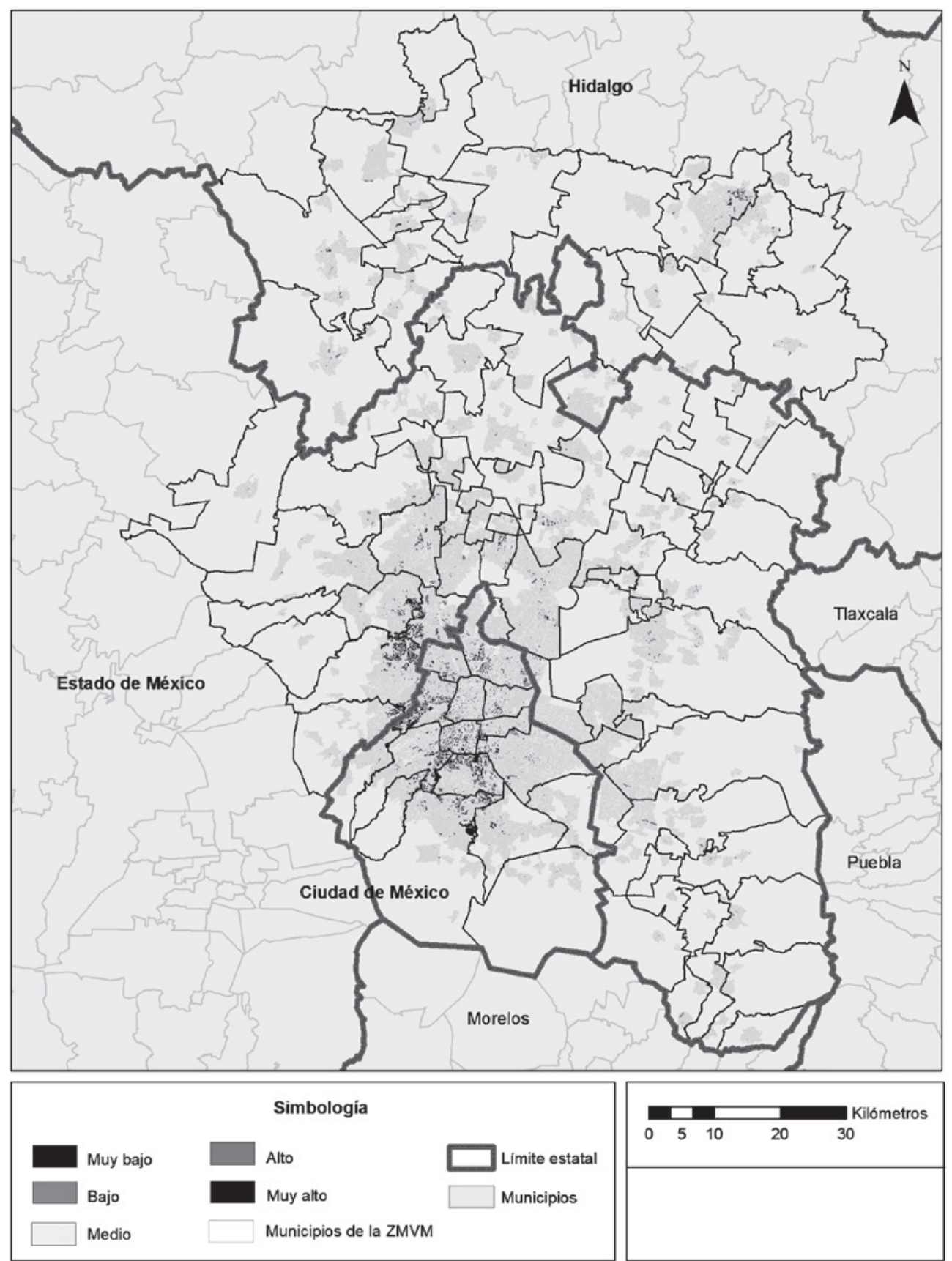

Fuente: Elaboración propia con datos del “Censo de población y vivienda del año 2010” (INEGI). 
Es sobresaliente que la mayoría de "manzanas" envejecidas e hiperenvejecidas muestre grado muy alto del ICVO, seguidas por grado alto de este mismo índice. No obstante, en el norte de la ZMVM, en los límites con el estado de Hidalgo, se ubican algunas "manzanas" con grados medio y bajo. Mientras que solo una "manzana" tiene un ICVO muy bajo, la cual se ubica en el municipio de "Atizapán", en el Estado de México.

El ICVO de las "manzanas" jóvenes que aparece en el mapa 8-4 ilustra una distribución distinta en relación con las "manzanas" envejecidas e hiperenvejecidas, ya que predomina el grado alto del índice, le sigue el grado medio y, en menor medida, se encuentran "manzanas" con ICVO muy alto; aquellas con ICVO muy bajo son mínimas.

El Distrito Federal concentra más "manzanas" con ICVO alto, sin embargo, se pueden distinguir algunas con grado medio al sur y oriente. En cambio, al poniente de este último, hay varias "manzanas" con un grado muy alto, ubicadas en especial en las delegaciones de Cuajimalpa, Álvaro Obregón y Miguel Hidalgo. Otras con grado muy alto del ICVO se localizan en Huixquilucan, Naucalpan" y Atizapán. En el mismo sentido, el municipio de Pachuca concentra "manzanas" jóvenes con grados alto y muy alto del ICVO, pero a sus alrededores es posible observar varias "manzanas" con grado medio.

Tal vez la población más envejecida considere criterios de localización más estrictos en términos de condiciones de vida en comparación con la población más joven. Además, las personas en edades avanzadas lograron instalarse en lugares con mejores niveles de vida desde años anteriores, cuando los precios eran más accesibles a los actuales. Es decir, en un periodo económico favorable, donde la ciudad era menos extensa y la periferia se encontraba más próxima al centro de la ciudad. Por su parte, la población más joven enfrenta retos distintos, ante una ciudad extensa, con costos habitacionales altos, en especial en zonas que en el pasado no lo eran. Así, al buscar independizarse, con regularidad deben elegir zonas más alejadas del centro de la ciudad y por ello tienden a informar menor calidad de vida. 


\section{Mapa 8-4}

Índices de calidad de vida objetivo en "manzanas" jóvenes en la Zona Metropolitana del Valle de México (ZMVM). "Manzanas" con más de 10\% de población con 60 años de edad y más.

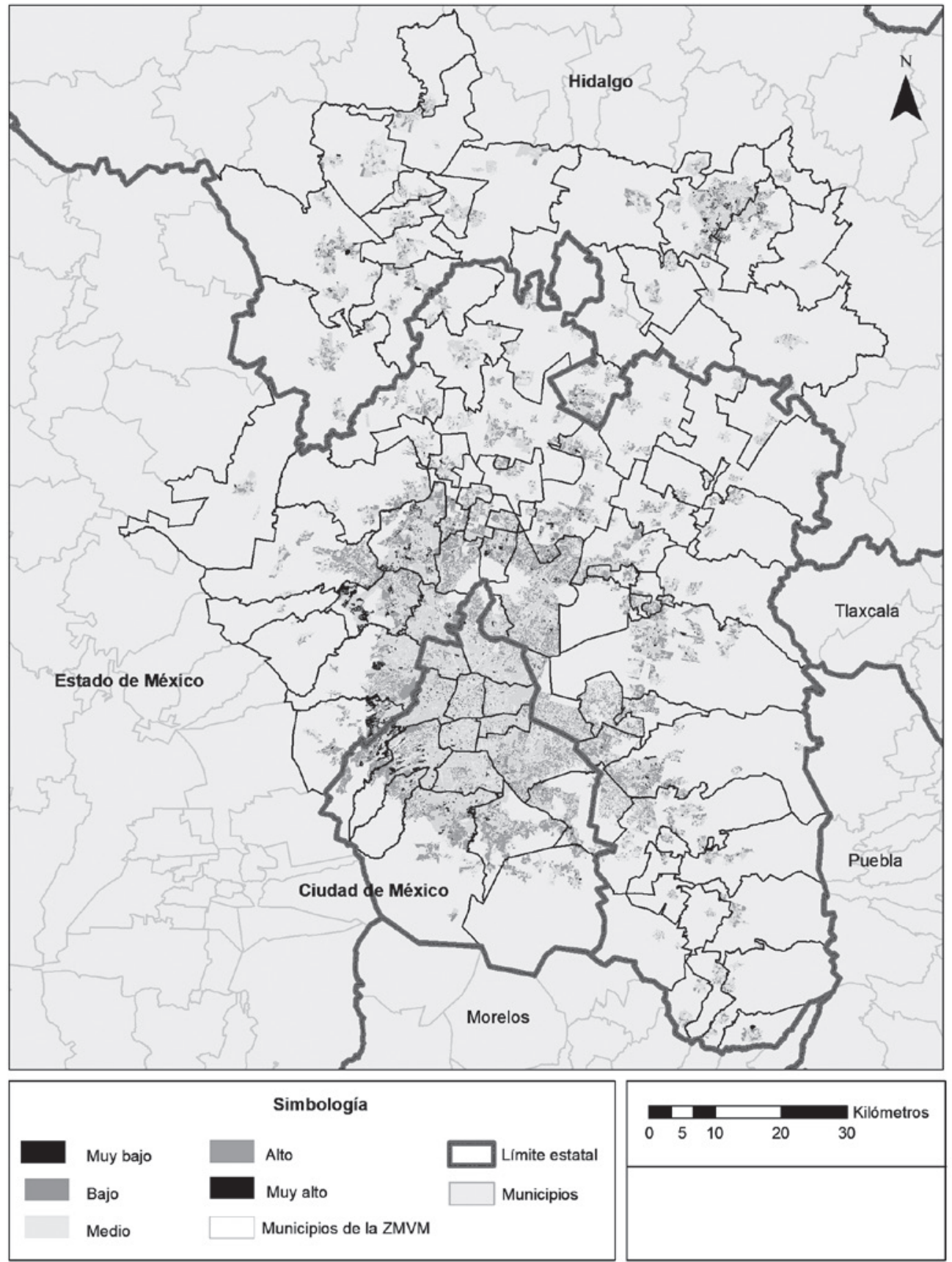

Fuente: Elaboración propia con datos del “Censo de población y vivienda del año 2010” (INEGI). 


\section{CONCLUSIONES}

A partir de la estimación previa de la calidad de vida en la P60+ en la ZMVM, hay varios elementos importantes a resaltar:

- Primero: considerar las "manzanas" como unidad de análisis porque a partir de los resultados previos es posible establecer estrategias territoriales de actuación encaminadas a mejorar la calidad de vida de las personas en edades avanzadas.

- Segundo, predomina un grado alto de calidad de vida en la P60+, pero hay "manzanas" con grados bajo y muy bajo donde se requiere de manera urgente de medidas y acciones de política pública dirigidas a las personas en edades avanzadas de estas unidades.

- Tercero, la subdimensión que presenta mejores resultados es la de servicios e instalaciones de la vivienda. En el otro extremo, aparece la subdimensión de educación con los valores promedio más bajos. Toda vez que las características educativas se relacionan con el acceso a recursos económicos en la vejez, habría que garantizar los medios de subsistencia a las personas con niveles bajos de escolaridad.

- Cuarto, las "manzanas" con muy alta calidad de vida tienden a concentrarse en el Distrito Federal, mientras que los grados medios aparecen en la periferia, por tanto, estos últimos espacios requieren mayor atención.

- Quinto, las "manzanas" envejecidas e hiperenvejecidas poseen mejor calidad de vida en comparación con las "manzanas" jóvenes. ¿Cómo van a modificarse estos resultados frente a un escenario de la ZMVM, compuesta de forma exclusiva por "manzanas" envejecidas e hiperenvejecidas? Por otra parte ¿qué debe hacerse el día de hoy para asegurar la calidad de vida de las personas en edades avanzadas, en un contexto de envejecimiento demográfico?

Este trabajo centró su objetivo en el estudio de la calidad de vida a partir de elementos objetivos, pero es importante que en futuras investigaciones se añada el componente subjetivo. Es indispensable explorar apreciaciones, percepciones y valoraciones de las personas en edades avanzadas, en cuanto a los distintos componentes de su calidad de vida, pero sin eliminar el carácter objetivo. Además, como parte de la dimensión objetiva, deben considerarse otras dimensiones y subdimensiones de análisis, ya que como menciona Aranibar (2001: 26, citado en Fernández-Ba- 
Ilesteros, 1992) "la vida es ontológicamente multidimensional y la evaluación de su calidad habrá de serlo también". Por ahora el ejercicio más cercano para seguir avanzando en el estudio de la calidad de vida a nivel "manzana" es el de agregar las características relacionadas con el entorno urbano.

Por último, el tema de la calidad de vida en la vejez resulta relevante frente a los escenarios demográficos que anticipan un incremento permanente de la población en edades avanzadas en las próximas décadas. Emprender las acciones necesarias para garantizarla no sólo beneficia a la población en edades avanzadas, sino a la sociedad en general.

\section{BIBLIOGRAFÍA}

Aguilar, J. M. et al. (2011), Factores que determinan la calidad de vida de las personas mayores, Infad: Revista de Psicología, vol. 1, núm. 4, pp. 161-168.

Aranibar, Paula (2001), Acercamiento conceptual a la situación del adulto mayor en América Latina, Santiago de Chile, CEPAL, 70 pp.

Brown, A. (2015), "Claim and contest in street trading. Dynamics of legal \& spatial empowerment", International Seminar on Street Trading in the Global South, 15 March, Londres, The Bartlett Development Planning Unit, UCL, University of London.

Comisión Económica para la América Latina (2011), Los derechos de las personas mayores: materiales de estudio y divulgación, Santiago de Chile, CEPAL, 13 pp.

Conapo (2014), "Proyecciones de población, 2010-2050", México, Conapo.

Farquhar M. (1995), "Definitions of quality of life: a taxonomy", Joumal of Advanced Nursmg, núm. 22, pp. 502-508.

Fernández-Ballesteros, R. y A. Maciá, (1993), "Calidad de vida en la vejez", Revista Intervención Social, vol. 2, núm. 5, pp. 77-94.

Flores, María E. et al. (2011), "Concepto de la calidad de vida en relación con el adulto mayor" en María E. Flores et al. (coords.), Condiciones sociales y calidad de vida en el adulto mayor, Guadalajara, Universidad de Guadalajara, pp. 87-98.

Gómez de León, José y Virgilio Partida, (2001), "Niveles, tendencias y diferencias de la mortalidad", en José Gómez de León y Cecilia Rabell, La población de México, México, Conapo-Fondo de Cultura Económica, pp. 81-108.

Ham, Roberto (2003), El envejecimiento en México: el siguiente reto de la transición demográfica, México, El Colegio de la Frontera Norte, Miguel Ángel Porrúa, p. 332.

Huenchuan, Sandra (2009), Envejecimiento, derechos humanos y políticas públicas, Santiago de Chile, CEPAL. 
Instituto Nacional de Estadística y Geografía (2010), "Censo de población y vivienda, 2010", http://www.censo2010.org.mx.

Mier y Terán, Marta y Virgilio Partida, (2001), "Niveles, tendencias y diferenciales de la fecundidad en México, 1930-1957", en José Gómez de León y Cecilia Rabell, La población de México, México, Conapo y Fondo de Cultura Económica, pp.168-203.

Partida, Virgilio (2001), "La migración interna", en José Gómez de León y Cecilia Rabell, La población de México, México, Conapo y Fondo de Cultura Económica, pp. 403-443.

Somarriba-Arechavala y Pena-Trapero (2009), "La medición de la calidad de vida en Europa, el papel de la información subjetiva", Estudios de Economía Aplicada, vol. 27, núm. 2, pp. 373-396.

Tuirán, Rodolfo (2015), Implicaciones demográficas y territoriales de la construcción de un nuevo aeropuerto en la ZMVM, México, Conapo.

Wilhelmson, K., et al (2005), "Elderly people's perspectives on quality of life", Ageing and Society, vol. 25, núm. 4, 585-600.

Xavier, F.M.F. et al. (2003), "Elderly people's definition of quality of life", Revista Brasileira de Psiquiatria, vol. 25, núm. 1, pp. 31-39.

Zavala de Cosío y María Eugenia Partida, (2001), "La transición de la fecundidad en México", en José Gómez de León y Cecilia Rabell, La población de México, México, Conapo-Fondo de Cultura Económica, pp. 47-167. 


\section{Vivienda, valor del suelo y calidad de vida en la Zona Metropolitana del Valle de México}

Domingo Flores Miranda

\section{INTRODUCCIÓN}

La localización de la población en el espacio urbano se ha considerado una condición favorable para tener oportunidades de bienestar y desarrollo; en este sentido, para las personas provenientes del ámbito rural o de escasos recursos, las ciudades representaban una posibilidad para mejorar sus condiciones de vida al tener acceso a satisfactores, como educación, trabajo remunerado, y acceso a la salud, la recreación y una vivienda digna donde desenvolverse con la familia, por mencionar solo algunos aspectos. El cambio de residencia significaba una forma de mejorar la calidad de vida de la población, al cobrar relevancia entre los distintos satisfactores, la obtención de una morada que cubriera los requerimientos en cuanto a habitabilidad y servicios públicos en ciudades o metrópolis, por lo cual estas crecieron.

Los espacios urbanos se caracterizan por ser un mosaico de asentamientos humanos, diferenciados por el poder adquisitivo y el valor del suelo para situar las actividades económicas y sociales; de esta forma, el crecimiento y los usos de suelos habitacionales responden a la competencia y a los intereses de grupos que se encargan de participar en el mercado. Un resultado es la segregación de la población de escasos recursos en áreas específicas; esto configuró un espacio urbano basado en el poder económico de los grupos poblacionales y el valor del suelo (Buzai, 2003).

En la diferenciación de la ocupación del suelo urbano, se observa un agrupamiento espacial de hogares con atributos socioeconómicos similares, que conforman áreas residenciales homogéneas en un espacio urbano heterogéneo, es decir, una ciudad diferenciada con asentamientos habitacionales homogéneos de escasos 
recursos, y otros con grado alto de riqueza y de desarrollo. Esta dinámica de ocupación del suelo genera segregación con un crecimiento urbano disperso y fragmentado.

Por lo anterior, es importante la localización de las familias al interior de la ciudad. Menciona Mills (1975), al referirse a lo expuesto por Alonso (1964), que las familias eligen su ubicación considerando el costo del suelo y la cantidad de servicios que requieren, ya que donde la familia decida vivir, esta consumirá cierta cantidad de suelo y servicios urbanos que les proporcionen la mayor satisfacción. Sin embargo, una de las principales argumentaciones que limitan la ubicación respecto de los sectores con mejor infraestructura y equipamiento es el ingreso familiar, el gasto destinado a satisfacer el costo de la vivienda y el costo de los servicios urbanos, y así, optan por ocupar el espacio donde los servicios de la vivienda, ya sean baratos o costosos, se adecuen al ingreso familiar.

Los espacios metropolitanos expresan la accesibilidad a la ciudad de acuerdo con los precios del suelo coherentes a la localización que tiene, lejos o cerca de centros urbanos, a los servicios y el empleo. Esta diferencia en la ubicación explica la aparición de áreas marginales con familias de bajos recursos donde, casi siempre, se asume un bajo valor del suelo, pero un alto costo en el acceso a los servicios urbanos cuando no los hay o para dotarlos, así como la internalización de los costos de transportación por los hogares.

Las zonas metropolitanas tendrán ventajas comparativas interurbanas e intraurbanas, es decir, ventajas sobre otras urbes o dentro de las municipalidades que conforman la metrópoli, lo cual se expresa en la concentración y el aumento del bienestar de la población en sectores con disponibilidad de servicios urbanos y centros de trabajo, así como una disminución importante de la calidad de vida en espacios carentes de infraestructura, equipamiento y servicios (Porter, 1991).

Las grandes ciudades, como las mexicanas, muestran fenómenos de segregación, dispersión y fragmentación, y comparten un modelo de crecimiento con zonas habitacionales con viviendas autoproducidas y de interés social, periféricas para la población con menores ingresos, como se observa en la Zona Metropolitana del Valle de México (ZMVM).

A partir de esa morfología urbana, la localización de la población en zonas habitacionales periféricas conlleva tener menor calidad de vida inicial, debido a la escasa conectividad con los centros de trabajo y la carencia de infraestructura urbana necesarias para el bienestar familiar, aunque estas pueden mejorar de modo gradual.

En el contexto anterior, el propósito de este capítulo es realizar un análisis de asociación entre el índice de calidad de vida objetiva (ICVO) (capítulo 5), con los cos- 
tos del suelo' obtenidos de las tablas de valores unitarios del mismo para su uso habitacional, las cuales se utilizaron para determinar los valores catastrales en el año 2015, tanto para las 16 delegaciones de la Ciudad de México, como para los 59 municipios metropolitanos del Estado de México.

Se trata entonces, de establecer la relación existente entre el ICVO y el valor promedio del suelo por metro cuadrado ( $\left.\mathrm{VPSM}^{2}\right)$ en escalas municipal y delegacional, con verificación de la equivalencia que, al ocupar una vivienda con un uso de suelo barato y tipología precaria, daría como resultado un Icvo bajo y, de manera inversa, al ocupar una vivienda con un costo de suelo alto se espera un mejor ICVO.

Si bien se contextualiza la ZMVM, ${ }^{2}$ dentro de esta asociación, se pone especial atención a los municipios periféricos del norte de la metrópoli, cuyo crecimiento habitacional ha sido exponencial en los últimos años, ya que han captado mucha población con necesidades de vivienda para mejorar su calidad de vida.

\section{EL VALOR DEL SUELO Y EL ÍNDICE DE CALIDAD DE VIDA OBJETIVO EN LA ZONA METROPOLITANA DEL VALLE DE MÉXICO}

La mejoría de la calidad de vida de la población involucra la satisfacción de tener una vivienda, acceso a servicios e infraestructura pública, con una localización adecuada. Al respecto, las instituciones gubernamentales y el sector privado han realizado varias acciones facilitadoras para producir y obtener una casa, primordialmente nueva. Un estudio del Instituto del Fondo Nacional de la Vivienda para los Trabajadores (Infonavit) (2013) indica que el Distrito Federal y el Estado de México se encontraban entre las cinco entidades con mayor necesidad de vivienda; por el rezago habitacional más la formación de nuevos hogares generaron un requerimiento de 25901 y 71981 unidades, respectivamente; asimismo, se muestra la relación de la demanda, al tomar en cuenta datos de los Organismos Nacionales de Vivienda (Onavis) y al empatarlos con la oferta del Registro Único de Vivienda (RUV). El resultado es que para el Distrito Federal faltaba producir 19631 viviendas y, para el Estado de México, 37 881; no obstante, también distingue nueve entidades que tienen excedentes de viviendas, de las cuales destacan Nuevo León, Jalisco, Guanajuato y Querétaro,

\footnotetext{
1 El término "costo", "valor" o "precio" se utiliza de manera indistinta para referirse al valor catastral del suelo, aunque los gobiernos estatales priorizan el término "valor del suelo" para significar el valor monetario utilizado para el cálculo catastral.

${ }^{2}$ En el caso del Estado de Hidalgo, no se cuenta con información para el cálculo del valor de suelo.
} 
discrepancia que refleja lo desacertado de las políticas públicas, ya que se construye donde la oferta rebasa la demanda.

Los datos de la Sociedad Hipotecaria Federal (SHF) (2014) muestran una necesidad mayor de vivienda, con una demanda de 57187 casas para el Distrito Federal y 106047 que correspondían a requerimientos del Estado de México para el año 2014. A su vez, estimaciones de la Cámara Nacional de la Industria de Desarrollo y Promoción de la Vivienda (Canadevi), Valle de México (2012) indican que para el año 2018 los requerimientos habitacionales en la ZMVM aumentarán a 937000 viviendas, un gran reto en el sector.

La satisfacción de tales niveles de demanda de vivienda a través de los años incluye dos aspectos: primero, se ha dado apertura al mercado inmobiliario a través de promover la inversión de empresas privadas tanto en la producción como en el financiamiento, con el aumento del número de créditos de organismos e instituciones públicas; estas políticas de apertura al financiamiento y producción habitacional contribuyen a reducir los requerimientos en cuanto a generar un mayor número de viviendas, enfocándose en la producción masiva de vivienda nueva; y segundo, este proceso trajo consigo problemas en relación con la edificación masiva de casas, ya que las empresas inmobiliarias buscaron reducir los costos de producción en materiales de construcción, requerimientos gubernamentales y costo del suelo donde se construirían los nuevos fraccionamientos, factor que explica la expansión urbana horizontal de la zMvм.

Con la adquisición de suelo barato para la edificación masiva de vivienda, se incorporaron áreas periféricas a la metrópoli, es decir, el crecimiento habitacional se intensificó en municipios metropolitanos alejados de los centros urbanos. Para ilustrar lo anterior, en los últimos años, el mayor número de conjuntos habitacionales de interés social autorizados por el gobierno del Estado de México han sido en los municipios periféricos de la ZMVM, entre los cuales destacan Tecámac, Zumpango y Huehuetoca (cuadro 9-1); estos vieron crecer su población por los grandes desarroIlos habitacionales, lo que a su vez ha originado una fuerte demanda por ampliar los servicios públicos, la infraestructura urbana y la creación de fuentes de empleo en lugares cercanos para satisfacer las necesidades sociales.

La expansión urbana motivada por la producción habitacional y, en particular, por la búsqueda de suelos baratos, dio como resultado zonas habitacionales dirigidas a los sectores medios-bajos con ingresos de al menos dos veces el salario mínimo en municipios periféricos, donde el costo de la tierra es más bajo. Las "Tablas de valores unitarios de suelo y construcción" para determinar los valores catastrales en 


\section{Cuadro 9-1}

Municipios metropolitanos con mayor número de conjuntos habitacionales autorizados por el gobierno del Estado de México, 2000 a 2013

\begin{tabular}{lcc}
\hline Municipio & $\begin{array}{c}\text { Número de conjuntos } \\
\text { habitacionales }\end{array}$ & Número de viviendas \\
\hline Tecámac & 52 & 134841 \\
Zumpango & 32 & 89369 \\
Huehuetoca & 24 & 68878 \\
Chalco & 14 & 43818 \\
Chicoloapan & 14 & 38883 \\
Cuautitlán & 14 & 25436 \\
Ecatepec de Morelos & 12 & 22066 \\
Cuautitlán Izcalli & 13 & 21095 \\
Nicolás Romero & 13 & 16831 \\
Coacalco de Berriozábal & 10 & 16494 \\
\hline
\end{tabular}

Fuente: Elaboración propia con datos de estadísticas de conjuntos urbanos autorizados por el gobierno del Estado de México, Secretaría de Desarrollo Urbano.

el año 2013 muestran suelos de uso habitacional con valor mínimo; por ejemplo, para Huehuetoca de 15 pesos por metro cuadrado, para Zumpango de 29 pesos y, para Tecámac, el valor del suelo mínimo es de 300 pesos; ${ }^{3}$ con este valor del suelo, muchas empresas inmobiliarias obtuvieron grandes superficies, al igual que forjaron sus reservas de tierra para construir vivienda. En este sentido, existen condiciones objetivas para predecir que el crecimiento del espacio físico construido seguirá hacia el norte de la metrópoli a partir de la construcción de más vivienda y de la consolidación de las áreas urbanas.

En este contexto, la calidad de vida cobra relevancia respecto de la localización de las zonas habitacionales, donde la población con limitados ingresos será segregada; cabe hacer entonces el ejercicio de relacionar el valor promedio del suelo de uso habitacional con el índice de calidad de vida objetivo (ICVO) y analizar esta asociación.

Para obtener el valor promedio por metro cuadrado de uso de suelo habitacional en los municipios metropolitanos del Estado de México, se consideraron los datos publicados en la Gaceta de Gobierno (2014) de las tablas de valores unitarios del suelo para determinar el catastro en 2015, y se clasificaron en áreas homogéneas

${ }^{3}$ Los valores del suelo utilizados para el catastro son muy diferentes a los valores comerciales que les puedan dar los dueños del suelo en el mercado de tierra, sean privados, ejidales o comunitarios, y estos en municipios periféricos varían entre los 200 a 350 pesos por metro cuadrado. 
habitacionales, de acuerdo con el "Reglamento del Título Quinto del Código Financiero del Estado de México y Municipios", denominado "Catastro" (2009), donde las áreas o zonas habitacionales ${ }^{4}$ se catalogan con las nomenclaturas $\mathrm{H} 1, \mathrm{H} 2, \mathrm{H} 3, \mathrm{H} 4$, $\mathrm{H} 5$ y $\mathrm{H} 6$, caracterizadas de la forma siguiente:

- Habitacional H1. Se localizan en la periferia de la ciudad o en pueblos; con frecuencia se presentan asentamientos irregulares; la vivienda es precaria, sin proyecto, construida con materiales de mala calidad o de desecho, sin acabados o mal realizados; hay autoconstrucción o autofinanciamiento por periodos largos o ambas situaciones. Respecto de los servicios públicos y la infraestructura, estos son incompletos e incipientes; se cuenta con agua potable mediante hidrantes públicos y, en ocasiones, con tomas domiciliarias; el drenaje se encuentra a cielo abierto, a veces entubado; el alumbrado público cuenta con pocas luminarias, hay luz domiciliaria y vialidades de importancia local, poco definidas, de terracería y algunos accesos de asfalto.

- Habitacional H2. Las áreas se encuentran en la periferia de las ciudades o los centros de algunos pueblos; quizás existan asentamientos espontáneos; la vivienda es económica sin proyecto o definido de modo parcial; los materiales son económicos con acabados incipientes y ejecución de poca calidad; la autoconstrucción y el autofinanciamiento tienen lugar en periodos medianos o largos. Los servicios públicos y la infraestructura son incompletos y, en algunos casos, completos; el agua potable se obtiene mediante tomas domiciliarias, con drenaje y, en ocasiones, con drenaje pluvial; alumbrado público con pocas o número regular de luminarias y luz en el domicilio; vialidades de importancia local, terciarias y algunas secundarias, definidas con cerradas o calles no continuas, de terracería y asfalto.

- Habitacional H3. Las zonas se ubican en regiones urbanas y urbanizables, por lo general fuera de zonas consolidadas; la vivienda es de interés social con proyecto típico definido; materiales económicos con ejecución de mediana calidad; construcción es en serie por empresas particulares u oficiales, con financiamiento oficial o bancario a corto o largo plazo, en conjuntos urbanos o en lotes aislados; es frecuente que sean conjuntos en condominio; el techo es de

${ }^{4}$ El área habitacional está conformada por una "manzana" o un grupo de "manzanas" con características homogéneas y un solo uso de suelo, con excepción de aquellos asentamientos que, por la naturaleza del desarrollo de la población, posean una mezcla de usos de suelo que el catastro considere permanente e indivisible; en estos casos, se asigna el uso predominante. 
concreto o concreto premezclado; muros de block, tabique, tabicón, u otros. Los servicios públicos y la infraestructura son completos, con agua potable mediante tomas domiciliarias, drenaje y alcantarillado; alumbrado público con suficiente número de luminarias, luz domiciliaria; vialidades de importancia local terciaria y algunas secundarias, definidas con asfalto, banquetas y guarniciones de concreto; hay vigilancia, servicio de limpia y con transporte público.

- Habitacional H4. Las áreas se localizan en zonas urbanas consolidadas, a veces en zonas periféricas de grandes poblaciones; la vivienda es regular con proyecto definido y funcional; los materiales son de calidad media o buena con acabados bien ejecutados, construcción bajo supervisión de un profesionista o de una empresa constructora; hay autofinanciamiento o financiamiento oficial o bancario; se localizan en zonas consolidadas de los centros de población o en conjuntos urbanos residencial medio y campestre; los materiales utilizados son de concreto y bóvedas; la techumbre, por lo general, incluye impermeabilizantes y recubrimientos de teja o ladrillo; los muros son de tabique, tabicón, block, adobe y piedra. Los servicios públicos y la infraestructura están completos, con agua potable mediante tomas domiciliarias, drenaje y alcantarillado integrados; hay alumbrado público con buen número de luminarias, luz domiciliaria, vialidades de importancia local secundarias y, en algunos casos, primarias, definidas de asfalto, ancho medio de arroyo con nueve metros o más, banquetas y guarniciones de concreto; hay servicios de vigilancia, limpia y con transporte público. - Habitacional H5. Las áreas se encuentran en zonas consolidadas de la región urbana; la vivienda es buena, con proyecto definido, funcional y de calidad; materiales de buena calidad, acabados bien ejecutados con detalles especiales; la construcción es realizada por empresas constructoras, con autofinanciamiento y se localizan en zonas exclusivas o en conjuntos urbanos residenciales altos. Los servicios públicos y la infraestructura están completos, con agua potable mediante tomas domiciliarias, drenaje y alcantarillado integrados; hay alumbrado público con buen número de luminarias, luz domiciliaria, vialidades de importancia local secundarias y, en algunos casos, primarias, con retornos, definidas de asfalto y guarniciones de concreto, vigilancia en ocasiones especial, con servicios de limpia, transporte público y gas, entre otros.

- Habitacional H6. Las áreas se localizan en zonas exclusivas normalmente fuera de regiones consolidadas; la vivienda es muy buena, con proyecto de calidad y detalles especiales, materiales de buena calidad y de lujo, de fabricación nacional e importados, acabados muy bien ejecutados con proliferación de 
detalles e instalaciones especiales; la construcción está a cargo de especialistas o empresas constructoras; la ubicación es en zonas exclusivas de lujo y en conjuntos urbanos residenciales exclusivos. Los servicios públicos y la infraestructura están completos, con agua potable mediante tomas domiciliarias, drenaje y alcantarillado por separado; el alumbrado público tiene buen número de luminarias y luz domiciliaria; las vialidades de importancia local son secundarias $y$, en algunos casos, primarias, con retornos, definidas de asfalto, banquetas y guarniciones de concreto; se cuenta con vigilancia especial, y servicios de limpia, transporte público periférico, gas, etcetera.

Para las delegaciones del Distrito Federal, la clasificación de las áreas habitacionales difiere de las establecidas en los municipios metropolitanos del Estado de México. Para los municipios, un área homogénea habitacional se compone de una manzana o un grupo de "manzanas"; en las delegaciones, se inscriben áreas de valor formadas por colonias catastrales, ${ }^{5}$ las cuales, a su vez, tienen un grupo de "manzanas" con características similares en infraestructura, equipamiento urbano, tipos de inmuebles y dinámica inmobiliaria.

De acuerdo con los valores unitarios de suelo para colonias catastrales del Distrito Federal (2014), cada área de valor se identifica mediante una serie de dígitos, de los cuales el último dígito clasifica a las colonias catastrales de la siguiente forma:

- Dígito 0. Aplica a la colonia catastral que corresponde a áreas periféricas de valor bajo con desarrollo incipiente, con usos del suelo que están iniciando su incorporación al área urbana y con equipamientos y servicios dispersos.

- Dígito 1. Es para la colonia catastral que corresponde a áreas periféricas o intermedias de valor bajo, en proceso de transición o cierta consolidación, con usos del suelo en definitiva habitacionales y con equipamientos y servicios semidispersos y de pequeña escala.

- Dígito 2. Es para la colonia catastral que corresponde a áreas intermedias de valor medio-bajo, en proceso de transición o cierta consolidación, con usos del

${ }^{5}$ La "colonia catastral" es una porción determinada de territorio continuo del Distrito Federal que comprende grupos de manzanas o lotes, que tiene asignado un valor unitario de suelo, expresado en pesos por metro cuadrado, en atención a la homogeneidad observable en cuanto a características de exclusividad y valor comercial. Existen tres tipos de colonia catastral: área de valor, enclave de valor y corredor de valor. Para fines de este apartado, sólo se consideran las zonas de valor con uso habitacional. 
suelo sobre todo habitacionales o una incipiente mezcla de usos, y con equipamientos y servicios semidispersos y de regular escala.

- Dígito 3. Corresponde a la colonia catastral con áreas intermedias de valor medio, con cierto proceso de transición o en consolidación, usos del suelo en especial habitacionales o mezcla de usos, y con equipamientos y servicios semiconcentrados y de regular escala.

- Dígito 4. Colonia catastral de áreas urbanas, servicios completos, equipamiento urbano en escala importante en la zona o las zonas cercanas, con usos de suelo habitacional o mixtos y nivel socioeconómico de medio a medio-alto.

- Dígito 5. Es para la colonia catastral de áreas urbanas, con servicios completos, equipamiento urbano en escala importante en la zona o las zonas cercanas, con usos de suelo habitacionales o mixtos y nivel socioeconómico de medio-alto a alto.

- Dígito 6. Colonia catastral de áreas urbanas, servicios completos, equipamiento urbano en escala notable en la zona o las zonas cercanas, usos de suelo habitacional o mixtos y nivel socioeconómico de alto a muy alto.

Las categorías de áreas homogéneas habitacionales son diferentes para municipios y delegaciones de la ZMVM, y cada entidad federativa tiene su propia clasificación. En los municipios metropolitanos, existen seis categorías y siete en las delegaciones, por lo que se realiza una comparación con el fin de homologar las clasificaciones de las áreas de uso habitacional, de modo que quedan sólo seis para ambas entidades. Dicha comparación se lleva a cabo por tipo de vivienda (cuadro 9-2).

En esta agrupación de categorías, los dígitos 5 y 6 de uso de suelo habitacional en las delegaciones corresponderán a la categoría habitacional H6 en los municipios, lo cual genera una sola tipología de vivienda de muy buena o de lujo; esto no es sólo para homologar las clasificaciones, sino para observar de mejor manera en donde se encuentran las zonas con uso habitacional de menor valor del suelo, con una tipología de vivienda precaria o económica y, por ende, con una calidad de vida menor.

Si se efectúa un comparativo de las condiciones habitacionales por tipología de vivienda y del precio de suelo entre las delegaciones del Distrito Federal y los municipios metropolitanos del Estado de México, se observa que mientras los municipios tienen un porcentaje mayor de "manzanas" con viviendas precarias de 19\% y económicas de 58\%; en el Distrito Federal las "manzanas" con precariedad conforman 4\% 


\section{Cuadro 9-2}

Homologación de categorías de uso de suelo habitacional para municipios y delegaciones por tipo de vivienda

\begin{tabular}{lll}
\hline $\begin{array}{l}\text { Categorías de uso de } \\
\text { suelo habitacional } \\
\text { para municipios } \\
\text { metropolitanos }\end{array}$ & $\begin{array}{l}\text { Tipos de vivienda homologadas } \\
\text { para municipios y delegaciones }\end{array}$ & $\begin{array}{l}\text { Categorías } \\
\text { de uso de suelo } \\
\text { habitacional para } \\
\text { delegaciones }\end{array}$ \\
\hline Habitacional H1 & Vivienda precaria & Dígito 0 \\
Habitacional H2 & Vivienda económica & Dígito 1 \\
Habitacional H3 & Vivienda de interés social de proyecto típico definido & Dígito 2 \\
Habitacional H4 & Vivienda regular-media de proyecto definido y funcional \\
Habitacional H5 & Vivienda de buena calidad & Dígito 3 \\
Habitacional H6 & Vivienda muy buena o de lujo & Dígito 4 \\
\hline
\end{tabular}

Fuente: Elaboración propia.

y, las económicas, 23\%. En lo que respecta a "manzanas" con viviendas catalogadas de muy buenas o de lujo (dígitos 5 y 6 y nomenclatura H6), la Ciudad de México tiene $8 \%$ con un promedio del valor del suelo de 5530 pesos por metro cuadrado (valor catastral), mientras que en los municipios del Estado de México las "manzanas" con este nivel solo constituyen 1\% con un valor promedio de 3191 pesos por metro cuadrado (cuadro 9-3).

La diferencia entre las tipologías de vivienda y valor del suelo de las entidades que conforman la zmvм es muy marcada; la Ciudad de México mantiene un nivel más equitativo en cuanto a viviendas con características económicas, de interés social de proyecto típico definido y de vivienda regular-media de proyecto definido y funcional, al tener menos "manzanas" de uso habitacional en precariedad. En este sentido, el abreviado de datos para la obtención del promedio de metro cuadrado de valor del suelo a escalas municipal y delegacional (anexo 9-1) refleja el patrón metropolitano, donde la periferia reúne las viviendas con características de menor calidad; estas zonas habitacionales tienen el valor de suelo más barato y en ellas recurre la población con menor poder adquisitivo para establecerse. Esta situación de los usos de suelo por tipo de vivienda en relación con el valor de suelo se observa con mayor precisión en el mapa 9-1.

El escenario territorial ejemplifica también la desigualdad en el acceso a servicios, fuentes de empleo, equipamiento e infraestructura urbana; asimismo, marca que en la localización de la vivienda va implícito un cierto nivel de calidad de vida, y del disfrute y goce del bienestar en la ciudad. En este sentido, se requiere una metró- 


\section{Cuadro 9-3}

Comparativo entre delegaciones de la Ciudad de México y municipios metropolitanos del Estado de México, con respecto al promedio del valor del suelo por metro cuadrado de uso habitacional, según tipo de vivienda por "manzana"

\begin{tabular}{|c|c|c|c|c|c|c|c|}
\hline \multirow{2}{*}{$\begin{array}{l}\text { Delegación/municipio } \\
\text { Dígito/habitacional }\end{array}$} & \multicolumn{6}{|c|}{ "Manzanas" de uso de suelo habitacional } & \multirow[b]{2}{*}{ Total } \\
\hline & $0=H 1$ & $1=H 2$ & $2=H 3$ & $3=\mathrm{H} 4$ & $4=H 5$ & 5 y $6=H 6$ & \\
\hline \multicolumn{8}{|l|}{ Delegaciones } \\
\hline Total de "manzanas" & 2217 & 11219 & 17983 & 9754 & 4764 & 3797 & 49734 \\
\hline Porcentaje de "manzanas" & 4 & 23 & 36 & 20 & 9 & 8 & 100 \\
\hline $\begin{array}{l}\text { Valor promedio de metro } \\
\text { cuadrado }\end{array}$ & 709 & 978 & 1761 & 2412 & 3069 & 5530 & 2410 \\
\hline \multicolumn{8}{|l|}{ Municipios } \\
\hline Total de "manzanas" & 17834 & 54695 & 12469 & 6667 & 1588 & 860 & 94113 \\
\hline Porcentaje de "manzanas" & 19 & 58 & 13 & 7 & 2 & 1 & 100 \\
\hline $\begin{array}{l}\text { Valor promedio de metro } \\
\text { cuadrado }\end{array}$ & 329 & 629 & 1139 & 1283 & 1792 & 3191 & 1394 \\
\hline \multicolumn{8}{|l|}{ Total general } \\
\hline Total de "manzanas" & 20051 & 65914 & 30452 & 16421 & 6352 & 4657 & 143847 \\
\hline $\begin{array}{l}\text { Promedio total del valor } \\
\text { por metro cuadrado }\end{array}$ & 376 & 672 & 1288 & 1678 & 2484 & 4945 & 1907 \\
\hline
\end{tabular}

Fuente: Elaboración propia con datos de las tablas de valores unitarios de suelo y construcciones actualizadas para la determinación de valores catastrales en el año 2015.

poli equilibrada, con niveles más homogéneos de accesibilidad a suelo equipado para conformar espacios de verdadero desarrollo humano en cuanto a lo habitacional.

La analogía entre el valor de suelo de uso habitacional dada la localización de la vivienda y su tipología, con respecto a la calidad de vida que tiene la población, corresponde a una lógica urbana centro-periferia, donde las delegaciones centrales (como Miguel Hidalgo, Cuauhtémoc, Benito Juárez) con valores de suelo alto y viviendas muy buenas o de lujo, cuyo índice de calidad de vida objetivo (ICVO) es el mejor, mientras que en la periferia pasa lo contrario, viviendas carentes de servicios públicos, precarias, económicas o de interés social, con un índice de calidad de vida bajo, localizadas en municipios como Axapusco, Tepetlaoxtoc, Temascalapa, entre otros, que aun muestran su vocación rural y agrícola más que urbana.

En este sentido, la correlación entre la variable del ICvO y el valor del suelo de uso habitacional ofrece los resultados que se muestran en el cuadro 9-4.

El grado de asociación entre el valor promedio del suelo por metro cuadrado (VPSM2) y el ICVO muestra un coeficiente de 0.858, es decir, una correlación alta en un 
Mapa 9-1

Promedio integrado de valor del suelo por metro cuadrado ponderado con "manzanas", por municipio y delegación

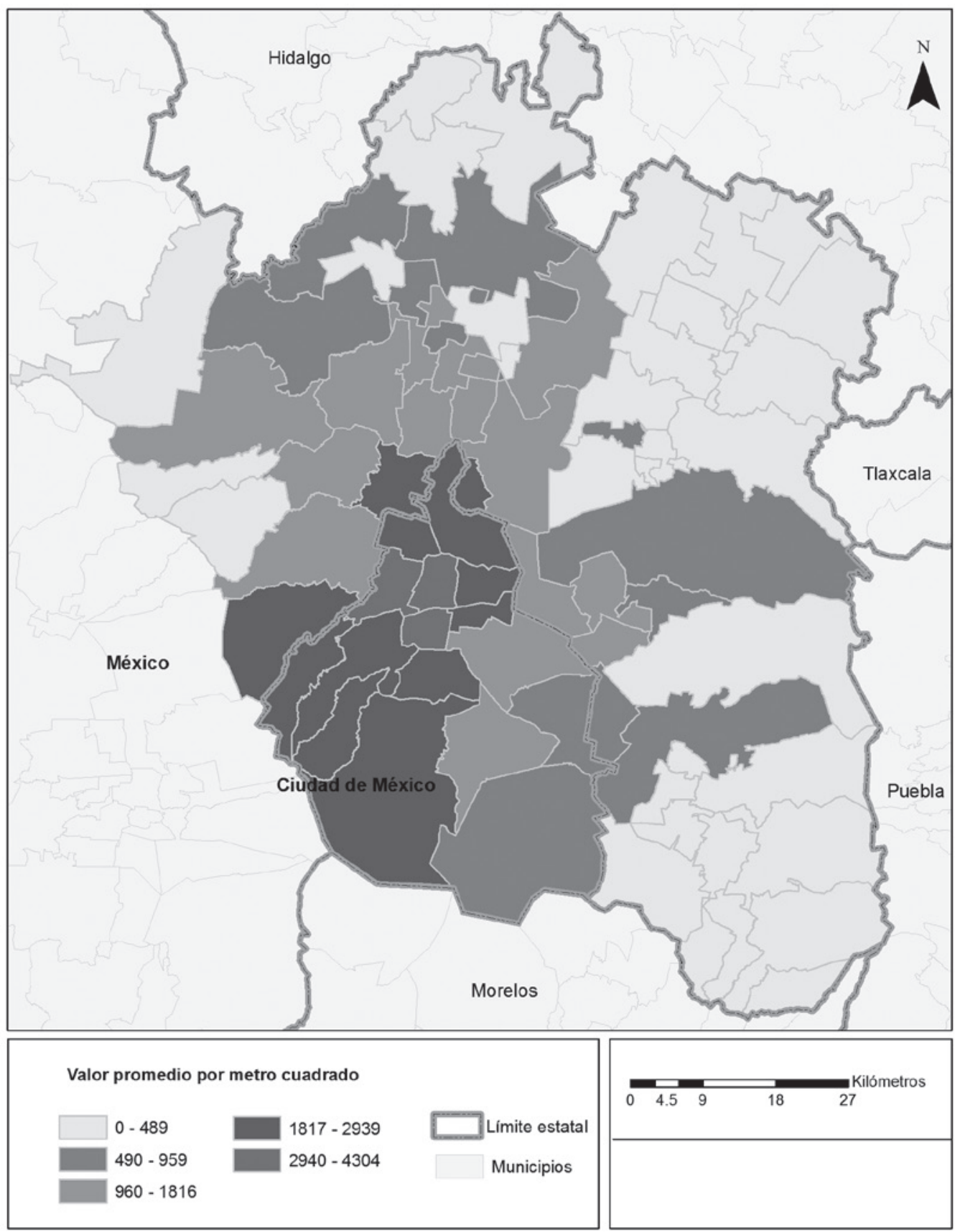

Fuente: Elaboración propia con datos de las tablas de valores unitarios de suelo y construcciones actualizadas para la determinación de valores catastrales en el año 2015. 


\section{Cuadro 9-4}

Correlación entre datos del Índice de calidad de vida objetivo (ICVO) y el valor promedio del suelo metro cuadrado de uso habitacional por municipio y delegación (VPSM2)

\begin{tabular}{|c|c|c|c|}
\hline Concepto & & $I C V$ & VPSM2 \\
\hline \multirow[t]{3}{*}{ ICVO } & Pearson Correlation & 1.000 & $.858^{* *}$ \\
\hline & Sig. (2-tailed) & & 0.000 \\
\hline & $\mathrm{N}$ & 75 & 75 \\
\hline \multirow{3}{*}{$\begin{array}{l}\text { Valor Promedio del Suelo por Metro } \\
\text { Cuadrado (VPSM2) }\end{array}$} & Pearson Correlation & $.858^{* *}$ & 1.000 \\
\hline & Sig. (2-tailed) & 0.000 & \\
\hline & $\mathrm{N}$ & 75 & 75 \\
\hline \multicolumn{4}{|c|}{ Model Summary ${ }^{b}$} \\
\hline Model & Adjusted R Square & Std. & e Estimate \\
\hline $.858^{\mathrm{a}}$ & 0.733 & & \\
\hline
\end{tabular}

*. Correlation is significant at the 0.01 level (2-tailed).

a. Predictors: (Constant), VPSM2

${ }^{\mathrm{b}}$. Dependent Variable: ICV

Fuente: Elaboración propia

sentido directo, donde a valores altos del precio de suelo de uso habitacional corresponde una calidad de vida alta; de igual forma pasa con los valores bajos: a menor precio del suelo, calidad de vida menor (gráfica 9-1).

La mayoría de los datos se concentra en valores bajos, siendo municipios o delegaciones con un ICVO más reducido de 0.60 y con precios del suelo menores de 1000 pesos por metro cuadrado. Lo anterior no sólo refleja una metrópoli desequilibrada, también deja ver un crecimiento urbano con funcionalidad débil; se han incorporado municipios que abandonan su carácter rural por el urbano, tal vez sin tener los atributos para considerarles metropolitanos, o bien, otros que se adhieren por ser receptores de las inversiones inmobiliarias en cuanto a la producción masiva de vivienda, como es el caso de municipios del norte de la zona metropolitana, donde ha crecido su población, pero que mantienen el reto de mejorar las condiciones de vida de sus residentes.

\section{EL CASO DE LOS MUNICIPIOS DEL NORTE DE LA METRÓPOLI}

El proceso de ocupación de los municipios conurbados se ha intensificado desde la década de 1970 debido al encarecimiento del suelo en áreas centrales, lo cual 


\section{Gráfica 9-1}

Relación entre índice de calidad de vida objetivo (ICVO) y el valor promedio del suelo por metro cuadrado (VPSM²) de uso habitacional, por delegación y municipio

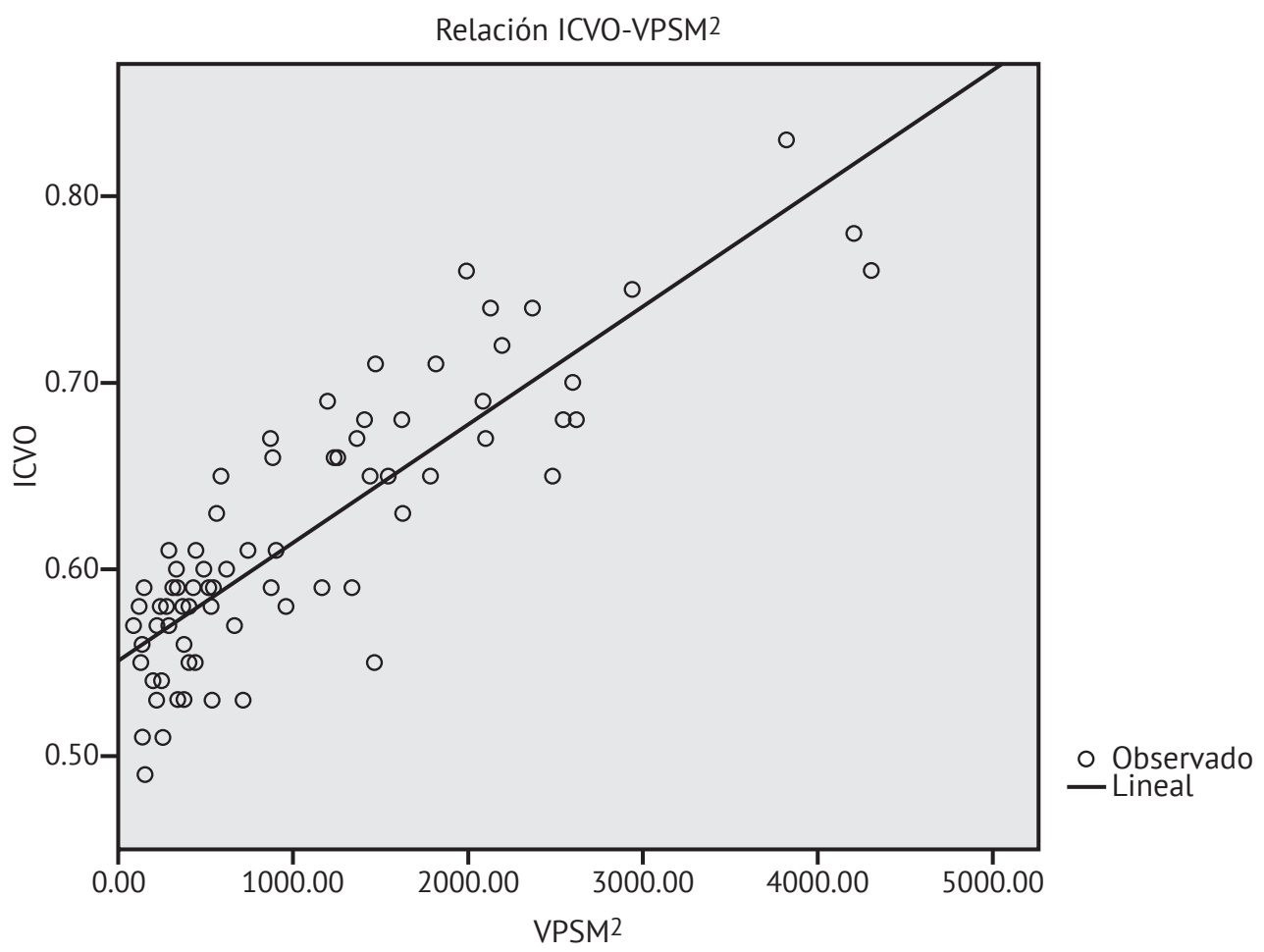

Fuente: Elaboración propia con datos del anexo 9-1.

ha desplazado a pobladores de escasos recursos a la periferia inmediata del núcleo metropolitano, al incorporar municipios como Naucalpan, Tlalnepantla, Ecatepec, Chimalhuacán, Nezahualcóyotl, Cuautitlán, La Paz, Huixquilucan, Coacalco, Atizapán de Zaragoza y Tultitlán ${ }^{6}$ (Cruz, 2001, p. 108).

Esta incorporación de municipios acentuó el carácter metropolitano y con ello la irregularidad de la ocupación del suelo, sobre todo al oriente de la ZMVM. En los

${ }^{6}$ Para los años setenta, el Estado de México dejó de ser una entidad expulsora de población al convertirse en una zona de atracción, principalmente, para los migrantes procedentes de Guanajuato, Puebla, Tlaxcala, Querétaro, Guerrero, Veracruz, Michoacán e Hidalgo (Consejo Estatal de Población [Coespo], 1993). Este proceso migratorio aceleró la urbanización de la metrópoli, al adherir los municipios de Atizapán de Zaragoza, Coacalco, Cuautitlán de Romero Rubio, La Paz y Tultitlán; para el decenio de 1980, se incorporaron Cuautitlán Izcalli, Chalco, Chicoloapan, Ixtapaluca, Nicolás Romero y Tecámac. Ante la constante llegada de población, el Estado de México tuvo un incremento demográfico importante en relación con el Distrito Federal. 
municipios de "Nezahualcóyotl", "Ecatepec", "Chimalhuacán" y, más recientemente, "Valle de Chalco Solidaridad", la solución habitacional que prevalecía consistía en el acceso al suelo a través de los procesos de urbanización por medio de la invasión y de la autoproducción de vivienda (POZMVM, 1998: 12).

En lo que respecta a la década subsecuente de 1990, la reforma constitucional del artículo 27 da apertura a un mercado libre de la tierra, y los cambios en las dos principales instituciones promotoras de vivienda para los trabajadores, el Instituto del Fondo Nacional de la Vivienda para los Trabajadores (Infonavit) y el Fondo de Vivienda del Instituto de Seguridad y Servicios Sociales de los Trabajadores del Estado (Fovissste), respecto de un sistema de puntuaciones individual con base en el ingreso y el tiempo de aportación del trabajador, así como la disminución del papel regulador del Estado en la actividad productora de vivienda hacen que la urbanización habitacional de la periferia se acelere (Duhau, 2004).

Para la década de 1990, el crecimiento poblacional era mayor en los municipios conurbados del Estado de México que en el Distrito Federal. La tasa de crecimiento promedio anual de la población de los municipios conurbados de 1970 a 1990 fue de 5.7\% y la del Distrito Federal de 0.6\% (Consejo Estatal de Población [Coespo], 1993) (gráfica 9-2).

Gráfica 9-2

Crecimiento poblacional del Distrito Federal y los municipios conurbados del Estado de México de 1970 a 2010

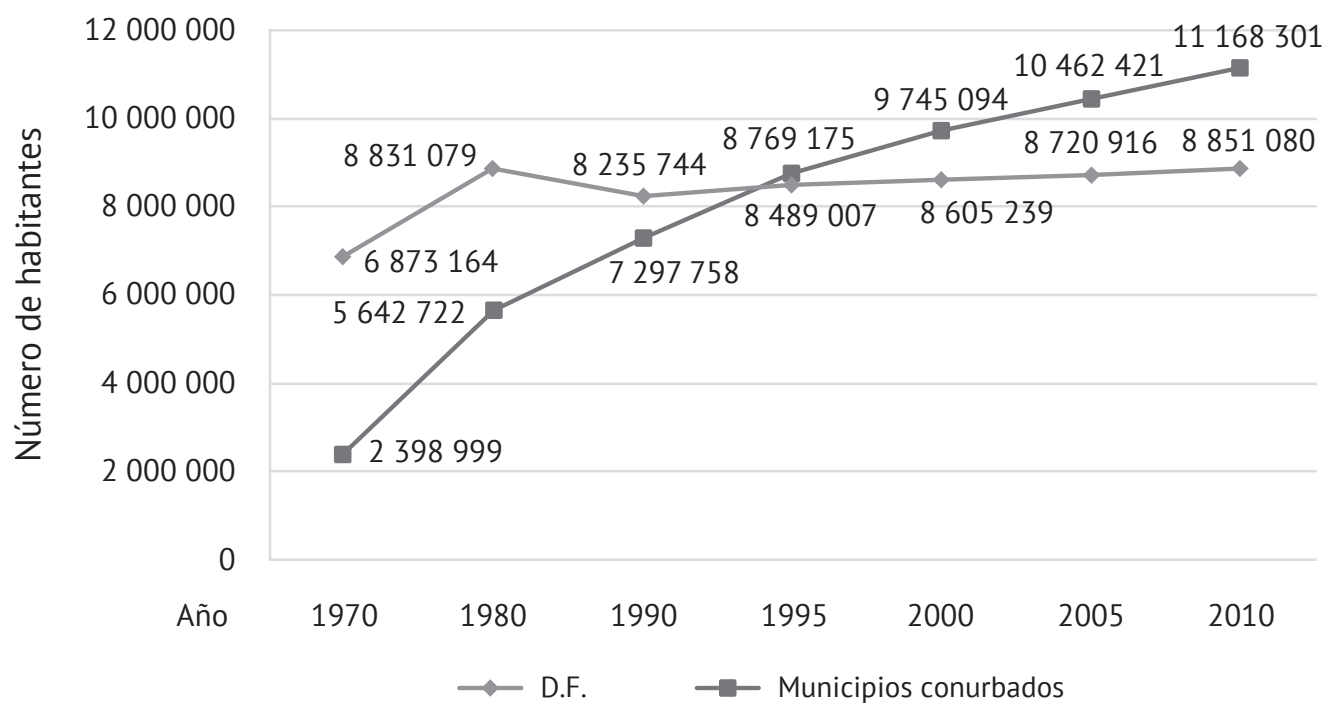

Fuente: Elaboración propia con datos de los censos y los conteos de población de 1970, 1980,1990, 2000, 2005 y 2010 del Instituto Nacional de Estadística y Geografía (INEGI). 
De igual forma, el crecimiento del suelo urbano se ha dado de manera mucho más importante en los municipios conurbados que en la Ciudad de México; entre 1970 y 1990, para los primeros, el incremento de suelo urbano fue de $166 \%$, mientras que para el segundo apenas registró 42\% (Cruz, 2001: 122).

El periodo 2000 a 2010 se caracterizó por la intensa producción de conjuntos habitacionales, en su mayoría de interés social, los cuales eran soluciones del financiamiento privado y del gobierno por medio de las instituciones de vivienda. Se planteaba que los conjuntos urbanos habitacionales fueran espacios planificados con diversos prototipos de vivienda y servicios urbanos, pero no todos cumplían con las normas; esto hizo que la expansión metropolitana se realizara de forma fragmentada en la periferia, en condiciones de ordenamiento débil.

La producción masiva de vivienda en municipios metropolitanos impulsó el desplazamiento de la población de zonas centrales a periféricas; asimismo, el crecimiento del área urbana no se produjo de manera continua y no se ha respetado la línea límite marcada en zonas previamente urbanizadas. Una parte importante de la mancha urbana sigue esta tendencia, y también hay pueblos con la dinámica de facilitar tierras a bajo costo, las cuales son suelos en zonas rurales cada vez más alejadas, donde se construyen conjuntos habitacionales de interés social que demandan los servicios que rebasan la capacidad de gobiernos locales para satisfacerlas.

Casi todos los municipios que acrecentaron su población y fueron atractivos para las inversiones inmobiliarias se ubican hacia el norte de la metrópoli, por tener suelo más barato y porque el gobierno del Estado de México también influyó al programar la orientación del poblamiento al norte de la Sierra de Guadalupe. En la figura 9-1, se observa el área (gris oscuro y con circulos) donde, según el gobierno, es más fácil y más económico introducir infraestructura para estructurar un crecimiento más autónomo y favorable. Con esa planeación, es posible interpretar que, más allá de integrar una zona metropolitana continua, se busca una independencia de los municipios del norte de la entidad respecto de la zona central (Prduc-T, 2005).

En la zona señalada, se promovió estructurar el crecimiento por medio de cuatro ejes y consolidar cuatro subcentros urbanos, dado que tal área era apta y susceptible de incorporar infraestructura y servicios a menor costo, y se podía establecer un sistema de transporte masivo eficaz, de amplia cobertura, así como una red vial articulada. Asimismo, se consideraba impulsar la productividad y la competitividad de la zona mediante una mezcla de actividades, con preservación de un gran espacio abierto al centro de dichos ejes, que permitiera equilibrar los usos del suelo, con resguardo el medio ambiente y mejoría de la calidad de vida. 
Figura 9-1

Área programada para orientar el poblamiento en municipios de la Zona Metropolitana del Valle de México (ZMVM)

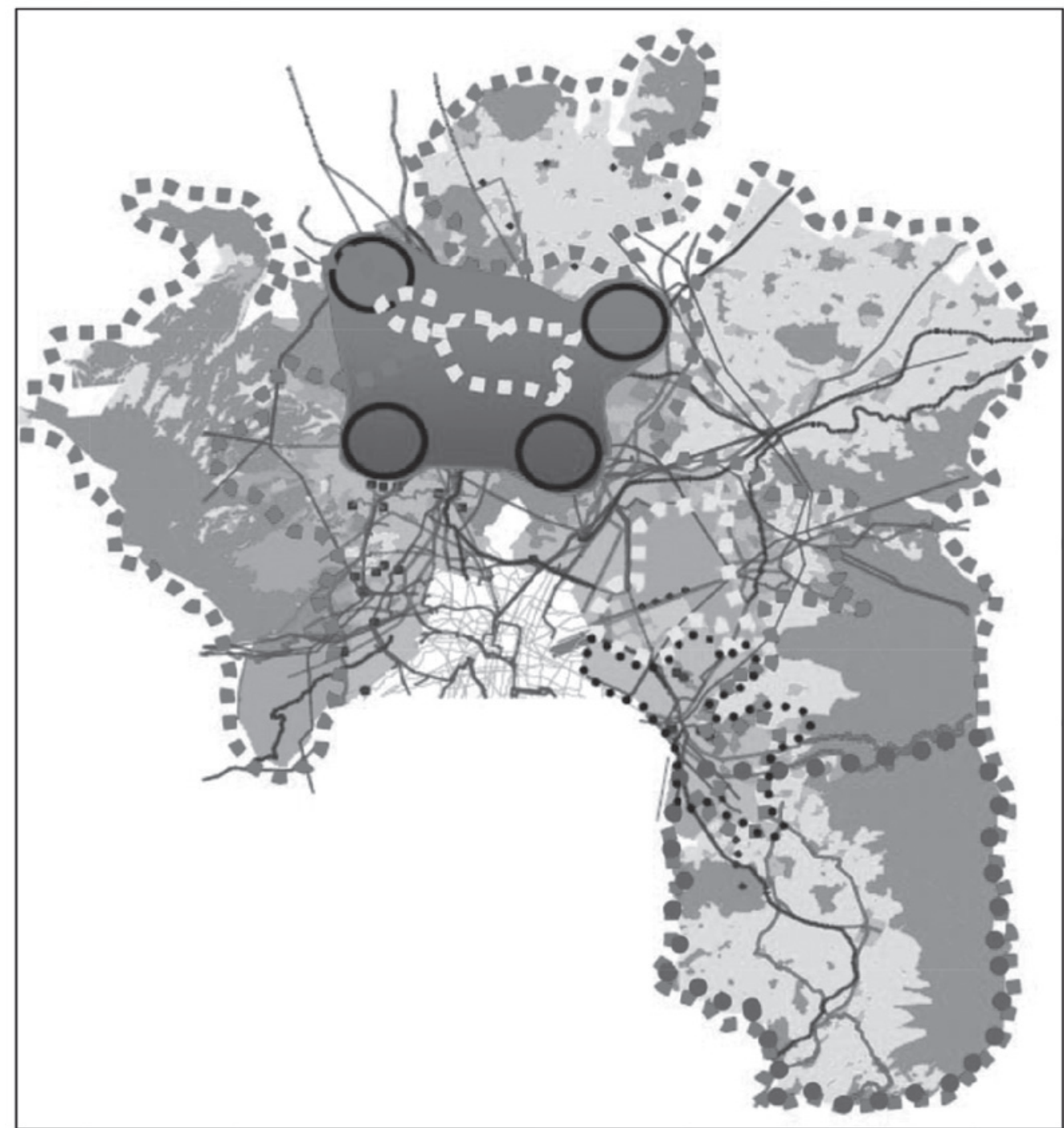

Fuente: Plan Regional de Desarrollo Urbano del Valle Cuautitlán-Texcoco. 2005.

La zona propuesta se estructura con cuatro centros urbanos formados por las localidades de Huehuetoca, Los Reyes Acozac, Cuautitlán Izcall y Ecatepec, donde se concentra el mayor número de conjuntos urbanos autorizados por el gobierno estatal y con mayor cantidad de viviendas, los cuales se ubican en Tecámac, Huehuetoca, Zumpango, Tepotzotlán y Cuautitlán; también Chalco, en el sureste de la entidad, tiene grandes desarrollos de vivienda (Prduc-T, 2005:11) (mapa 9-2). 
Mapa 9-2

Conjuntos urbanos autorizados por el gobierno del Estado de México de 2000 a 2013 en los municipios conurbados de la Zona Metropolitana del Valle de México (ZMVM)

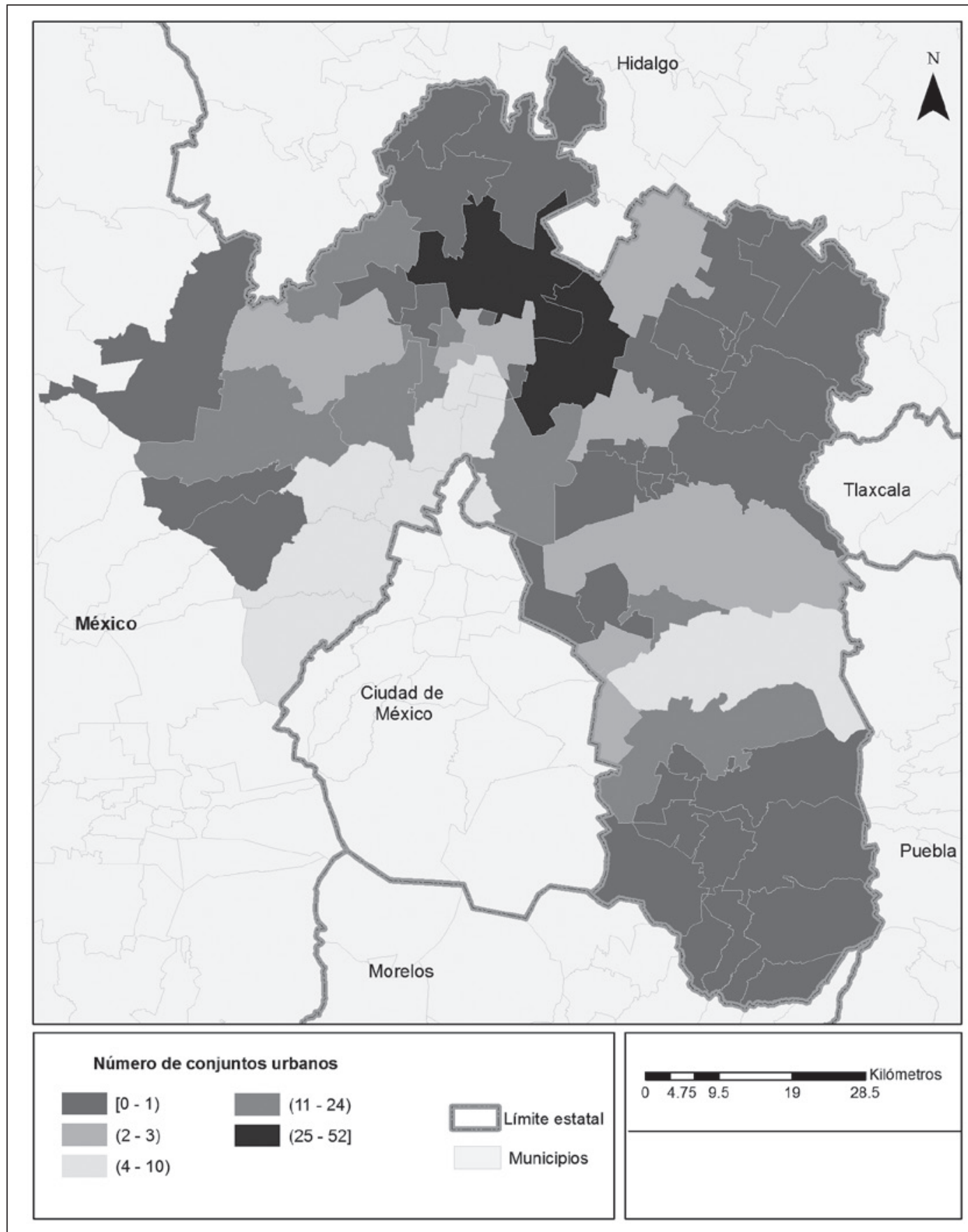

Fuente: Elaboración propia con base en estadísticas de conjuntos urbanos autorizados por el gobierno del Estado de México, Secretaría de Desarrollo Urbano. 


\begin{tabular}{|c|c|c|}
\hline \multicolumn{3}{|c|}{ Conjuntos urbanos autorizados de 2000 a 2013} \\
\hline \multirow[b]{2}{*}{ Municipio } & \multicolumn{2}{|c|}{ Total } \\
\hline & $\begin{array}{l}\text { Núm. de conjuntos } \\
\text { habitacionales }\end{array}$ & Núm. de viviendas \\
\hline Tecámac & 52 & 134841 \\
\hline Zumpango & 32 & 89369 \\
\hline Huehuetoca & 24 & 68878 \\
\hline Chalco & 14 & 43818 \\
\hline Chicoloapan & 14 & 38883 \\
\hline Cuautitlán & 14 & 25436 \\
\hline Escatepec de Morelos & 12 & 22066 \\
\hline Cuautitlán Izcalli & 13 & 21095 \\
\hline Nicolás Romero & 13 & 16831 \\
\hline Coacalco de Berriozábal & 10 & 16494 \\
\hline Acolman & 3 & 15982 \\
\hline Nextlalpan & 2 & 12241 \\
\hline Tultepec & 9 & 11729 \\
\hline Ixtapaluca & 6 & 9570 \\
\hline Atizapán de Zaragoza & 7 & 6377 \\
\hline Tultitlán & 10 & 6374 \\
\hline Tepotzotlán & 3 & 5464 \\
\hline Tlalneplantla de Baz & 7 & 4926 \\
\hline Temascalpa & 2 & 4502 \\
\hline Huixquilucan & 9 & 4445 \\
\hline Valle de Chalco Solidaridad & 3 & 4336 \\
\hline Naucalpan de Juárez & 7 & 3777 \\
\hline Melchor Ocampo & 2 & 2986 \\
\hline La Paz & 2 & 1150 \\
\hline Tonanitla & 1 & 957 \\
\hline Atenco & 1 & 850 \\
\hline Texcoco & 2 & 678 \\
\hline
\end{tabular}


Con el desarrollo dirigido hacia el norte de la entidad, quedan espacios urbanos vacíos y zonas habitacionales dispersas, vinculadas con la presión por adquirir suelo barato, ya no realizada por los grupos sociales de escasos recursos como en antaño, sino ahora por los capitales inmobiliarios que demandan el suelo cada vez más alejado de los centros urbanos. Dejar que los agentes privados y los mecanismos del mercado solucionen el problema de la vivienda ha sido inadecuado. Los fines lucrativos de las empresas constructoras e inmobiliarias provocan la ineficiencia en el uso del suelo urbano, así como altos costos por la dispersión y la fragmentación de las zonas habitacionales para introducir el equipamiento urbano requerido (Maya y Cervantes, 2005).

La oferta y la cobertura de vivienda a los beneficiarios se ha ampliado, existe mayor accesibilidad a créditos y la política de vivienda se considera como un sector para el crecimiento de la economía. Esto incluye los mercados de la construcción y el financiamiento con efectos multiplicadores, además de mejorar los ingresos y el empleo. Para la mayoría de las familias, asegurar una vivienda implica el acceso a un entorno urbano organizado, con sistemas de transporte público, obras de equipamiento e infraestructura, y actividades productivas que acompañen los cambios de residencia de la población.

De acuerdo con lo anterior, la política de vivienda estaría enfocada en dos aspectos: el primero, mejorar las condiciones de vida al facilitar la obtención de una vivienda digna, a través de instituciones, programas y creación de leyes que protejan el derecho a una morada decorosa; el segundo, considerar la política de vivienda como un instrumento del ordenamiento territorial, mediante esquemas de planeación que permitan un crecimiento urbano estructurado, al orientar la producción habitacional hacia zonas aptas, equipadas y accesibles, donde las relaciones espaciales metropolitanas sean equilibradas e integrales, que reduzcan costos de movilidad y estén orientadas no solo a contribuir al crecimiento económico, sino también al desarrollo de la metrópoli y de quienes habitan en ella.

\section{CONCLUSIONES}

Las ciudades se consideran espacios de oportunidades donde las familias alcanzan el bienestar, la seguridad y el acceso a bienes y servicios, donde se satisfacen las necesidades y se mejora la calidad de vida; sin embargo, esa imagen de ciudad bondadosa se ha perdido y quienes buscan algo mejor, como un espacio digno donde vivir, se encuentran con una marcada segregación y en condiciones de insa- 
tisfacción habitacional, inmersos en un mercado de vivienda que inhibe el derecho a la vivienda, dotado de servicios y equipamiento urbano, cerca de los lugares de trabajo.

El Comité de Derechos Económicos, Sociales y Culturales de la Organización de las Naciones Unidas (ONU) señala que el derecho a la vivienda no es el simple hecho de tener "un tejado encima de la cabeza", más bien es un derecho a vivir con seguridad, en paz y con dignidad, y la garantía de aspectos y contenidos mínimos como: a) seguridad legal de la ocupación; b) proximidad a servicios, materiales, equipamientos e infraestructura necesaria; c) costo asequible, incluso para los más pobres; d) habitabilidad, y e) acceso para los grupos vulnerables (Organización de las Naciones Unidas, 2011).

La mercantilización del suelo y la vivienda en la metrópoli ha prevalecido en décadas recientes con el apoyo de las políticas públicas. Las inversiones inmobiliarias buscan los suelos más baratos donde construyen, lo cual ha generado diversos conflictos y, a pesar de los buenos propósitos institucionales, las acciones de vivienda se quedan lejos de satisfacer las necesidades habitacionales. Subsisten problemas como:

- Casas-habitación construidas en una superficie de suelo minúscula, que cumplen un mínimo de habitabilidad, lo cual provoca hacinamiento con afectación a la relación familiar y el bienestar personal.

- Dispersión de los desarrollos habitacionales mal ubicados.

- Segregación con asentamientos diferenciados de acuerdo con estatus social y la condición cultural.

- Esquemas de financiamiento insuficientes, dirigidos tanto a la adquisición de una vivienda nueva como para la autoconstrucción, la vivienda en renta, la ampliación de la casa o la adquisición de suelo urbanizado.

- Poca disponibilidad de suelo y oferta para los sectores que buscan un espacio urbanizado.

- Una fuerte demanda de servicios e infraestructura urbana que resuelven los gobiernos municipales.

- Costos altos de desplazamiento "origen-destino" con internalización de costos por parte de las familias.

En este sentido, la metrópoli ha sido botín de los capitales inmobiliarios que han construido el espacio urbano, lo cual ha generado paisajes clonados de viviendas de 
interés social, que son grandes fraccionamientos cerrados y privados que fomentan la exclusión social y rompen con la continuidad de la metrópoli. Se ha fomentado un negocio urbano que ha cambiado las relaciones sociales y fractura el espacio urbano, donde los individuos no se identifican con el territorio e inducen a que una considerable cantidad de viviendas esté abandonada por los altos costos de transporte del lugar de residencia a zonas de empleo, situación que deja ver un panorama de movilidad intensiva y un uso extensivo del territorio, pero sin reconocimiento y sintiéndose ajenos de lo que pasa en la ciudad. Estas condiciones casi impuestas por los capitales inmobiliarios aumentan el acceso a la vivienda, pero alejan a la población de tener una buena calidad de vida.

En general, la aseveración inicial se comprobó con los valores de suelo de uso habitacional que en la periferia son más baratos, con viviendas precarias, económicas o de interés social y éstas, a su vez, se correlacionan con un ICVO bajo; asimismo, la lógica del patrón centro-periferia se complementa con un centro urbano que tiene mejores condiciones, costos del suelo altos con viviendas muy buenas o de lujo. En este modelo, se desarrolla una metrópoli desequilibrada que requiere niveles iguales de accesibilidad a bienes y servicios urbanos.

Ante ello, falta mayor responsabilidad de instituciones públicas, empresas inmobiliarias y sociedad civil para crear y asumir que la construcción de vivienda implica también "construir ciudad", ya que no solo se trata de producir fraccionamientos aislados que erigen un territorio heterogéneo, desigual y fragmentado. Prevalece el reto de mejorar la calidad de vida de los habitantes, con un Estado e instituciones fuertes, que tengan una participación activa en la regulación del mercado de vivienda para asegurar no solo una casa con requerimientos mínimos; se requiere reivindicar la vivienda digna como un derecho de la sociedad civil, con ampliación de las alternativas habitacionales sin supeditación a la oferta del mercado inmobiliario, donde la población pueda decidir la utilización de sus recursos en la localización y el diseño de su casa. En la medida que se den mayores opciones, se torna más efectivo el derecho a la vivienda, incluida su localización, diseño y entorno. El gran objetivo es lograr una metrópoli estructurada, funcional, accesible y equipada con la participación de todos los sectores. 


\section{Anexo 9-1}

Zona Metropolitana del Valle de México (ZMVM): número de "manzanas" y valor promedio por metro cuadrado del suelo habitacional por municipio y delegación

\begin{tabular}{|c|c|c|c|c|c|c|c|}
\hline \multirow{2}{*}{$\begin{array}{l}\text { Delegación/municipio ("man- } \\
\text { zanas"y valor promedio por } \\
\text { metro cuadrado }\left[\mathrm{m}^{2}\right] \text { ) }\end{array}$} & \multicolumn{6}{|c|}{ Dígito de uso de suelo habitacional por "manzana" } & \multirow{2}{*}{$\begin{array}{c}\text { Total } \\
\text { Suma y } \\
\text { promedio }\end{array}$} \\
\hline & $0=H 1$ & $1=H 2$ & $2=H 3$ & $3=H 4$ & $4=H 5$ & 5 y $6=H 6$ & \\
\hline \multicolumn{8}{|l|}{ ÁLVARO OBREGÓN } \\
\hline “Manzanas” & 99 & 1267 & 2200 & 632 & 79 & 397 & 4674 \\
\hline Valor promedio por $\mathrm{m}^{2}$ & 1241 & 1090 & 1670 & 2388 & 3476 & 5740 & 2601 \\
\hline \multicolumn{8}{|l|}{ AZCAPOTZALCO" } \\
\hline “Manzanas” & & & 1200 & 533 & & & 1733 \\
\hline Valor promedio por $\mathrm{m}^{2}$ & & & 1861 & 2124 & & & 1993 \\
\hline \multicolumn{8}{|l|}{ BENITO JUÁREZ } \\
\hline “Manzanas" & & & & 241 & 725 & 1211 & 2177 \\
\hline Valor promedio por $\mathrm{m}^{2}$ & & & & 2959 & 3053 & 5455 & 3822 \\
\hline \multicolumn{8}{|l|}{ COYOACÁN } \\
\hline “Manzanas” & & & 643 & 1111 & 681 & 273 & 2708 \\
\hline Valor promedio por $\mathrm{m}^{2}$ & & & 2157 & 2540 & 2785 & 4274 & 2939 \\
\hline \multicolumn{8}{|l|}{ CUAJIMALPA } \\
\hline “Manzanas” & 181 & 70 & 481 & 63 & 44 & 113 & 952 \\
\hline Valor promedio por $\mathrm{m}^{2}$ & 934 & 870 & 1628 & 2218 & 3297 & 6341 & 2548 \\
\hline \multicolumn{8}{|l|}{ CUAUHTÉMOC } \\
\hline “Manzanas” & & & & 349 & 675 & 807 & 1831 \\
\hline Valor promedio por $\mathrm{m}^{2}$ & & & & 3670 & 3373 & 5868 & 4304 \\
\hline \multicolumn{8}{|l|}{ GUSTAVO A. MADERO } \\
\hline “Manzanas" & & 2682 & 3073 & 1358 & 679 & 23 & 7815 \\
\hline Valor promedio por $\mathrm{m}^{2}$ & & 802 & 1713 & 2063 & 2710 & 3694 & 2196 \\
\hline \multicolumn{8}{|l|}{ IZTACALCO } \\
\hline “Manzanas" & & & 1217 & 637 & 186 & & 2040 \\
\hline Valor promedio por $\mathrm{m}^{2}$ & & & 1989 & 2041 & 2351 & & 2127 \\
\hline \multicolumn{8}{|l|}{ IZTAPALAPA } \\
\hline “Manzanas” & 158 & 2,434 & 5,575 & 1,817 & 217 & & 10,201 \\
\hline Valor promedio por $\mathrm{m}^{2}$ & 500 & 937 & 1,432 & 1,813 & 2,362 & & 1,409 \\
\hline \multicolumn{8}{|l|}{ MAGDALENA CONTRERAS } \\
\hline “Manzanas” & 7 & 421 & 718 & 155 & 34 & 88 & 1423 \\
\hline Valor promedio por $\mathrm{m}^{2}$ & 739 & 799 & 1,312 & 2,346 & 3,322 & 4,067 & 2098 \\
\hline \multicolumn{8}{|l|}{ MIGUEL HIDALGO } \\
\hline “Manzanas" & & & 325 & 579 & 316 & 806 & 2026 \\
\hline Valor promedio por $\mathrm{m}^{2}$ & & & 2326 & 2859 & 4628 & 7017 & 4208 \\
\hline
\end{tabular}


Continuación Anexo 9-1

\begin{tabular}{|c|c|c|c|c|c|c|c|}
\hline \multirow{2}{*}{$\begin{array}{l}\text { Delegación/municipio ("man- } \\
\text { zanas"y valor promedio por } \\
\text { metro cuadrado }\left[\mathrm{M}^{2}\right] \text { ) }\end{array}$} & \multicolumn{6}{|c|}{ Dígito de uso de suelo habitacional por "manzana" } & \multirow{2}{*}{$\begin{array}{c}\text { Total } \\
\text { Suma y } \\
\text { promedio }\end{array}$} \\
\hline & $0=H 1$ & $1=H 2$ & $2=H 3$ & $3=H 4$ & $4=H 5$ & 5 y $6=H 6$ & \\
\hline \multicolumn{8}{|l|}{ MILPA ALTA } \\
\hline “Manzanas” & 796 & & & & & & 796 \\
\hline Valor promedio por $\mathrm{m}^{2}$ & 530 & & & & & & 530 \\
\hline \multicolumn{8}{|l|}{ TLÁHUAC } \\
\hline “Manzanas" & 443 & 2344 & & & & & 2787 \\
\hline Valor promedio por $\mathrm{m}^{2}$ & 670 & 1076 & & & & & 873 \\
\hline \multicolumn{8}{|l|}{ TLALPAN } \\
\hline “Manzanas" & 408 & 1012 & 1296 & 425 & 630 & 79 & 3850 \\
\hline Valor promedio por $\mathrm{m}^{2}$ & 488 & 1278 & 1556 & 2179 & 2901 & 7311 & 2619 \\
\hline \multicolumn{8}{|l|}{ VENUSTIANO CARRANZA } \\
\hline “Manzanas" & & & 265 & 1749 & 449 & & 2463 \\
\hline Valor promedio por $\mathrm{m}^{2}$ & & & 1803 & 2290 & 3015 & & 2369 \\
\hline \multicolumn{8}{|l|}{ XOCHIMILCO } \\
\hline “Manzanas” & 125 & 989 & 990 & 105 & 49 & & 2258 \\
\hline Valor promedio por $\mathrm{m}^{2}$ & 570 & 969 & 1688 & 2282 & 2629 & & 1628 \\
\hline \multicolumn{8}{|l|}{ ACOLMAN } \\
\hline “Manzanas" & 278 & 855 & 242 & 33 & & & 1408 \\
\hline Valor promedio por $\mathrm{m}^{2}$ & 145 & 298 & 431 & 400 & & & 319 \\
\hline \multicolumn{8}{|l|}{ AMECAMECA } \\
\hline “Manzanas" & 249 & 356 & 2 & 19 & & & 626 \\
\hline Valor promedio por $\mathrm{m}^{2}$ & 102 & 277 & 490 & 260 & & & 282 \\
\hline \multicolumn{8}{|l|}{ APAXCO } \\
\hline “Manzanas” & 332 & 175 & & 1 & & & 508 \\
\hline Valor promedio por $\mathrm{m}^{2}$ & 140 & 382 & & 504 & & & 342 \\
\hline \multicolumn{8}{|l|}{ ATENCO } \\
\hline “Manzanas" & 457 & 397 & & & & & 854 \\
\hline Valor promedio por $\mathrm{m}^{2}$ & 290 & 393 & & & & & 342 \\
\hline \multicolumn{8}{|l|}{ ATIZAPÁN DE ZARAGOZA } \\
\hline “Manzanas" & 2 & 1760 & 591 & 971 & 342 & 320 & 3986 \\
\hline Valor promedio por $\mathrm{m}^{2}$ & 517 & 808 & 1024 & 1490 & 2175 & 2195 & 1368 \\
\hline \multicolumn{8}{|l|}{ ATLAUTLA } \\
\hline “Manzanas” & 96 & 279 & & 65 & & & 440 \\
\hline Valor promedio por $\mathrm{m}^{2}$ & 148 & 243 & & 367 & & & 253 \\
\hline
\end{tabular}




\begin{tabular}{|c|c|c|c|c|c|c|c|}
\hline \multirow{2}{*}{$\begin{array}{l}\text { Delegación/municipio ("manza- } \\
\text { nas"y valor promedio por metro } \\
\text { cuadrado }\left[\mathrm{m}^{2}\right] \text { ) }\end{array}$} & \multicolumn{6}{|c|}{ Dígito de uso de suelo habitacional por "manzana" } & \multirow{2}{*}{$\begin{array}{c}\text { Total } \\
\text { Sumay } \\
\text { promedio }\end{array}$} \\
\hline & $0=H 1$ & $1=H 2$ & $2=H 3$ & $3=H 4$ & $4=H 5$ & 5 y $6=H 6$ & \\
\hline \multicolumn{8}{|l|}{ AXAPUSCO } \\
\hline “Manzanas" & 867 & 231 & & & & & 1098 \\
\hline Valor promedio por $\mathrm{m}^{2}$ & 145 & 344 & & & & & 245 \\
\hline \multicolumn{8}{|l|}{ AYAPANGO } \\
\hline “Manzanas" & 78 & 86 & & & & & 164 \\
\hline Valor promedio por $\mathrm{m}^{2}$ & 145 & 344 & & & & & 245 \\
\hline \multicolumn{8}{|l|}{ COACALCO DE BERRIOZABAL } \\
\hline “Manzanas” & 16 & 274 & 510 & 547 & & & 1347 \\
\hline Valor promedio por $\mathrm{m}^{2}$ & 1000 & 1700 & 1993 & 2570 & & & 1816 \\
\hline \multicolumn{8}{|l|}{ COCOTITLÁN } \\
\hline “Manzanas” & 54 & 144 & & & & & 198 \\
\hline Valor promedio por $\mathrm{m}^{2}$ & 300 & 366 & & & & & 333 \\
\hline \multicolumn{8}{|l|}{ COYOTEPEC } \\
\hline “Manzanas" & 122 & 152 & & & & & 274 \\
\hline Valor promedio por $\mathrm{m}^{2}$ & 150 & 437 & & & & & 294 \\
\hline \multicolumn{8}{|l|}{ CUAUTITLÁN } \\
\hline “Manzanas” & 196 & 277 & 492 & 104 & & & 1069 \\
\hline Valor promedio por $\mathrm{m}^{2}$ & 517 & 1401 & 1965 & 2000 & & & 1471 \\
\hline \multicolumn{8}{|l|}{ CUAUTITLÁN IZCALLI } \\
\hline “Manzanas" & 10 & 1994 & 969 & 860 & 140 & & 3973 \\
\hline Valor promedio por $\mathrm{m}^{2}$ & 533 & 793 & 1268 & 1506 & 1890 & & 1198 \\
\hline \multicolumn{8}{|l|}{ CHALCO } \\
\hline “Manzanas” & 681 & 2204 & 538 & 8 & & & 3431 \\
\hline Valor promedio por $\mathrm{m}^{2}$ & 277 & 633 & 1191 & 1734 & & & 959 \\
\hline \multicolumn{8}{|l|}{ CHIAUTLA } \\
\hline “Manzanas" & 104 & 268 & 19 & & & & 391 \\
\hline Valor promedio por $\mathrm{m}^{2}$ & 157 & 266 & 687 & & & & 370 \\
\hline \multicolumn{8}{|l|}{ CHICOLOAPAN } \\
\hline “Manzanas” & 62 & 560 & 408 & & & & 1030 \\
\hline Valor promedio por $\mathrm{m}^{2}$ & 189 & 838 & 1624 & & & & 884 \\
\hline \multicolumn{8}{|l|}{ CHICONCUAC } \\
\hline “Manzanas" & 101 & 202 & & & & & 303 \\
\hline Valor promedio por $\mathrm{m}^{2}$ & 240 & 514 & & & & & 377 \\
\hline
\end{tabular}


Continuación Anexo 9-1

\begin{tabular}{|c|c|c|c|c|c|c|c|}
\hline \multirow{2}{*}{$\begin{array}{l}\text { Delegación/municipio (“man- } \\
\text { zanas” y valor promedio por } \\
\text { metro cuadrado }\left[\mathrm{m}^{2}\right] \text { ) }\end{array}$} & \multicolumn{6}{|c|}{ Dígito de uso de suelo habitacional por "manzana" } & \multirow{2}{*}{$\begin{array}{c}\text { Total } \\
\text { Sumay } \\
\text { promedio }\end{array}$} \\
\hline & $0=H 1$ & $1=H 2$ & $2=H 3$ & $3=H 4$ & $4=H 5$ & 5 y $6=H 6$ & \\
\hline \multicolumn{8}{|l|}{ CHIMALHUACÁN } \\
\hline “Manzanas” & 2155 & 2753 & 5 & & & & 4913 \\
\hline Valor promedio por $\mathrm{m}^{2}$ & 903 & 1861 & 1633 & & & & 1466 \\
\hline \multicolumn{8}{|l|}{ ECATEPEC DE MORELOS } \\
\hline “Manzanas" & & 8806 & 1597 & 1683 & & & 12086 \\
\hline Valor promedio por $\mathrm{m}^{2}$ & & 1272 & 1304 & 1754 & & & 1,443 \\
\hline \multicolumn{8}{|l|}{ ECATZINGO } \\
\hline “Manzanas" & 85 & 64 & & & & & 149 \\
\hline Valor promedio por $\mathrm{m}^{2}$ & 140 & 170 & & & & & 155 \\
\hline \multicolumn{8}{|l|}{ HUEHUETOCA } \\
\hline “Manzanas” & 159 & 541 & 830 & & & & 1530 \\
\hline Valor promedio por $\mathrm{m}^{2}$ & 129 & 618 & 940 & & & & 562 \\
\hline \multicolumn{8}{|l|}{ HUEYPOXTLA } \\
\hline “Manzanas" & 712 & 226 & & & & & 938 \\
\hline Valor promedio por $\mathrm{m}^{2}$ & 92 & 189 & & & & & 141 \\
\hline \multicolumn{8}{|l|}{ HUIXQUILUCAN } \\
\hline “Manzanas” & 253 & 1126 & 16 & 4 & 5 & 493 & 1897 \\
\hline Valor promedio por $\mathrm{m}^{2}$ & 245 & 531 & 1540 & 2045 & 6576 & 3964 & 2484 \\
\hline \multicolumn{8}{|l|}{ ISIDRO FABELA } \\
\hline “Manzanas" & 190 & & & 1 & & & 191 \\
\hline Valor promedio por $\mathrm{m}^{2}$ & 64 & & & 196 & & & 130 \\
\hline \multicolumn{8}{|l|}{ IXTAPALUCA } \\
\hline “Manzanas” & 1168 & 1679 & 620 & 113 & 115 & & 3695 \\
\hline Valor promedio por $\mathrm{m}^{2}$ & 208 & 458 & 471 & 662 & 445 & & 449 \\
\hline \multicolumn{8}{|l|}{ JALTENCO } \\
\hline “Manzanas” & & 139 & 12 & & & & 151 \\
\hline Valor promedio por $\mathrm{m}^{2}$ & & 299 & 880 & & & & 590 \\
\hline \multicolumn{8}{|l|}{ JILOTZINGO } \\
\hline “Manzanas” & 246 & & & & & & 246 \\
\hline Valor promedio por $\mathrm{m}^{2}$ & 88 & & & & & & 88 \\
\hline \multicolumn{8}{|l|}{ JUCHITEPEC } \\
\hline “Manzanas” & 50 & 219 & & & & & 269 \\
\hline Valor promedio por $\mathrm{m}^{2}$ & 255 & 500 & & & & & 378 \\
\hline
\end{tabular}




\begin{tabular}{|c|c|c|c|c|c|c|c|}
\hline \multirow{2}{*}{$\begin{array}{l}\text { Delegación/municipio ("manza- } \\
\text { nas"y valor promedio por metro } \\
\text { cuadrado }\left[\mathrm{m}^{2}\right] \text { ) }\end{array}$} & \multicolumn{6}{|c|}{ Dígito de uso de suelo habitacional por "manzana" } & \multirow{2}{*}{$\begin{array}{c}\text { Total } \\
\text { Sumay } \\
\text { promedio }\end{array}$} \\
\hline & $0=H 1$ & $1=H 2$ & $2=H 3$ & $3=H 4$ & $4=H 5$ & 5 y $6=H 6$ & \\
\hline \multicolumn{8}{|l|}{ MELCHOR OCAMPO } \\
\hline “Manzanas” & 188 & 443 & 62 & & & & 693 \\
\hline Valor promedio por $\mathrm{m}^{2}$ & 453 & 722 & 678 & & & & 618 \\
\hline \multicolumn{8}{|l|}{ NAUCALPAN DE JUÁREZ } \\
\hline “Manzanas” & 47 & 3850 & 6 & 1080 & 845 & 47 & 5875 \\
\hline Valor promedio por $\mathrm{m}^{2}$ & 464 & 976 & 1190 & 1971 & 2690 & 3415 & 1784 \\
\hline \multicolumn{8}{|l|}{ NEZAHUALCÓYOTL } \\
\hline “Manzanas” & 75 & 4544 & 574 & 91 & & & 5284 \\
\hline Valor promedio por $\mathrm{m}^{2}$ & 1137 & 1564 & 1742 & 2058 & & & 1625 \\
\hline \multicolumn{8}{|l|}{ NEXTLALPAN } \\
\hline “Manzanas” & 155 & 378 & 180 & & & & 713 \\
\hline Valor promedio por $\mathrm{m}^{2}$ & 97 & 216 & 900 & & & & 404 \\
\hline \multicolumn{8}{|l|}{ NICOLÁS ROMERO } \\
\hline “Manzanas” & 802 & 2185 & 228 & 18 & & & 3233 \\
\hline Valor promedio por $\mathrm{m}^{2}$ & 584 & 1305 & 1183 & 1600 & & & 1168 \\
\hline \multicolumn{8}{|l|}{ NOPALTEPEC } \\
\hline “Manzanas” & 29 & 439 & & & & & 468 \\
\hline Valor promedio por $\mathrm{m}^{2}$ & 209 & 239 & & & & & 224 \\
\hline \multicolumn{8}{|l|}{ OTUMBA } \\
\hline “Manzanas” & 434 & 256 & 2 & & & & 692 \\
\hline Valor promedio por $\mathrm{m}^{2}$ & 232 & 337 & 659 & & & & 409 \\
\hline \multicolumn{8}{|l|}{ OZUMBA } \\
\hline “Manzanas” & 159 & 234 & 1 & & & & 394 \\
\hline Valor promedio por $\mathrm{m}^{2}$ & 222 & 551 & 531 & & & & 435 \\
\hline \multicolumn{8}{|l|}{ PAPALOTLA } \\
\hline “Manzanas" & 16 & 40 & & & & & 56 \\
\hline Valor promedio por $\mathrm{m}^{2}$ & 190 & 397 & & & & & 294 \\
\hline \multicolumn{8}{|l|}{ LA PAZ } \\
\hline “Manzanas" & 1167 & 1344 & 38 & & & & 2549 \\
\hline Valor promedio por $\mathrm{m}^{2}$ & 893 & 1485 & 1627 & & & & 1335 \\
\hline \multicolumn{8}{|l|}{ SAN MARTÍN DE LAS PIRÁMIDES } \\
\hline “Manzanas” & 124 & 378 & 72 & & & & 574 \\
\hline Valor promedio por $\mathrm{m}^{2}$ & 64 & 119 & 178 & & & & 120 \\
\hline
\end{tabular}


Continuación Anexo 9-1

\begin{tabular}{|c|c|c|c|c|c|c|c|}
\hline \multirow{2}{*}{$\begin{array}{l}\text { Delegación/municipio ("man- } \\
\text { zanas" y valor promedio por } \\
\text { metro cuadrado }\left[\mathrm{m}^{2}\right] \text { ) }\end{array}$} & \multicolumn{6}{|c|}{ Dígito de uso de suelo habitacional por "manzana" } & \multirow{2}{*}{$\begin{array}{c}\text { Total } \\
\text { Suma y } \\
\text { promedio }\end{array}$} \\
\hline & $0=H 1$ & $1=H 2$ & $2=H 3$ & $3=H 4$ & $4=H 5$ & 5 y $6=H 6$ & \\
\hline \multicolumn{8}{|l|}{ TECÁMAC } \\
\hline “Manzanas" & 381 & 1539 & 1138 & 221 & 13 & & 3292 \\
\hline Valor promedio por $\mathrm{m}^{2}$ & 509 & 883 & 2244 & 2372 & 300 & & 1262 \\
\hline \multicolumn{8}{|l|}{ TEMAMATLA } \\
\hline “Manzanas” & 54 & 55 & 89 & 2 & & & 200 \\
\hline Valor promedio por $\mathrm{m}^{2}$ & 177 & 330 & 550 & 900 & & & 489 \\
\hline \multicolumn{8}{|l|}{ TEMASCALAPA } \\
\hline “Manzanas” & 346 & 435 & 65 & & & & 846 \\
\hline Valor promedio por $\mathrm{m}^{2}$ & 172 & 306 & 1676 & & & & 718 \\
\hline \multicolumn{8}{|l|}{ TENANGO DEL AIRE } \\
\hline “Manzanas” & 46 & 103 & & & & & 149 \\
\hline Valor promedio por $\mathrm{m}^{2}$ & 245 & 309 & & & & & 277 \\
\hline \multicolumn{8}{|l|}{ TEOLOYUCAN } \\
\hline “Manzanas" & 262 & 130 & 1 & & & & 393 \\
\hline Valor promedio por $\mathrm{m}^{2}$ & 416 & 709 & 879 & & & & 668 \\
\hline \multicolumn{8}{|l|}{ TEOTIHUACÁN } \\
\hline “Manzanas” & 393 & 394 & & & & & 787 \\
\hline Valor promedio por $\mathrm{m}^{2}$ & 109 & 184 & & & & & 147 \\
\hline \multicolumn{8}{|l|}{ TEPETLAOXTOC } \\
\hline “Manzanas" & 169 & 186 & & & & & 355 \\
\hline Valor promedio por $\mathrm{m}^{2}$ & 93 & 184 & & & & & 139 \\
\hline \multicolumn{8}{|l|}{ TEPETLIXPA } \\
\hline “Manzanas” & 68 & 148 & & 18 & 19 & & 253 \\
\hline Valor promedio por $\mathrm{m}^{2}$ & 311 & 379 & & 388 & 322 & & 350 \\
\hline \multicolumn{8}{|l|}{ TEPOTZOTLÁN } \\
\hline “Manzanas" & 489 & 647 & 20 & 25 & 74 & & 1255 \\
\hline Valor promedio por $\mathrm{m}^{2}$ & 399 & 509 & 1151 & 314 & 376 & & 550 \\
\hline \multicolumn{8}{|l|}{ TEQUIXQUIAC } \\
\hline “Manzanas" & 390 & 115 & & & & & 505 \\
\hline Valor promedio por $\mathrm{m}^{2}$ & 123 & 270 & & & & & 197 \\
\hline \multicolumn{8}{|l|}{ TEXCOCO } \\
\hline “Manzanas" & 457 & 1403 & 253 & 100 & 15 & & 2228 \\
\hline Valor promedio por $\mathrm{m}^{2}$ & 355 & 966 & 933 & 1244 & 1028 & & 905 \\
\hline
\end{tabular}




\begin{tabular}{|c|c|c|c|c|c|c|c|}
\hline \multirow{2}{*}{$\begin{array}{l}\text { Delegación/municipio ("manzanas" } \\
\text { y valor promedio por metro cuadra- } \\
\text { do }\left[\mathrm{m}^{2}\right] \text { ) }\end{array}$} & \multicolumn{6}{|c|}{ Dígito de uso de suelo habitacional por "manzana" } & \multirow{2}{*}{$\begin{array}{c}\text { Total } \\
\text { Suma y } \\
\text { promedio }\end{array}$} \\
\hline & $0=H 1$ & $1=H 2$ & $2=H 3$ & $3=H 4$ & $4=H 5$ & 5 y $6=H 6$ & \\
\hline \multicolumn{8}{|l|}{ TEZOYUCA } \\
\hline “Manzanas" & 31 & 274 & & & & & 305 \\
\hline Valor promedio por $\mathrm{m}^{2}$ & 427 & 642 & & & & & 535 \\
\hline \multicolumn{8}{|l|}{ TLALMANALCO } \\
\hline “Manzanas” & 157 & 404 & 80 & 27 & & & 668 \\
\hline Valor promedio por $\mathrm{m}^{2}$ & 313 & 377 & 471 & 565 & & & 432 \\
\hline \multicolumn{8}{|l|}{ TLALNEPANTLA DE BAZ } \\
\hline “Manzanas" & 267 & 1949 & 494 & 628 & 18 & & 3356 \\
\hline Valor promedio por $\mathrm{m}^{2}$ & 750 & 1621 & 2084 & 2638 & 3334 & & 2085 \\
\hline \multicolumn{8}{|l|}{ TONANITLA } \\
\hline “Manzanas” & 84 & 50 & 17 & & & & 151 \\
\hline Valor promedio por $\mathrm{m}^{2}$ & 253 & 296 & 1018 & & & & 522 \\
\hline \multicolumn{8}{|l|}{ TULTEPEC } \\
\hline “Manzanas" & 330 & 822 & 94 & 17 & & & 1263 \\
\hline Valor promedio por $\mathrm{m}^{2}$ & 798 & 1326 & 1967 & 2091 & & & 1546 \\
\hline \multicolumn{8}{|l|}{ TULTITLÁN } \\
\hline “Manzanas" & 612 & 2008 & 940 & 28 & & & 3588 \\
\hline Valor promedio por $\mathrm{m}^{2}$ & 951 & 1168 & 1296 & 1545 & & & 1240 \\
\hline \multicolumn{8}{|l|}{ VALLE DE CHALCO SOLIDARIDAD } \\
\hline “Manzanas" & 188 & 3440 & 79 & & & & 3707 \\
\hline Valor promedio por $\mathrm{m}^{2}$ & 527 & 1005 & 1080 & & & & 871 \\
\hline \multicolumn{8}{|l|}{ VILLA DEL CARBÓN } \\
\hline “Manzanas" & 420 & 101 & 30 & 3 & 2 & & 556 \\
\hline Valor promedio por $\mathrm{m}^{2}$ & 50 & 123 & 157 & 191 & 576 & & 219 \\
\hline \multicolumn{8}{|l|}{ ZUMPANGO } \\
\hline “Manzanas" & 771 & 634 & 1155 & & & & 2560 \\
\hline Valor promedio por $\mathrm{m}^{2}$ & 127 & 445 & 1649 & & & & 740 \\
\hline \multicolumn{8}{|l|}{ Total delegaciones } \\
\hline Total de “manzanas" & 2217 & 11219 & 17983 & 9754 & 4764 & 3797 & 49734 \\
\hline Promedio total del valor por $\mathrm{m}^{2}$ & 709 & 978 & 1761 & 2412 & 3069 & 5530 & 2410 \\
\hline \multicolumn{8}{|l|}{ Total municipios } \\
\hline Total de "manzanas" & 17834 & 54695 & 12469 & 6667 & 1588 & 860 & 94113 \\
\hline Promedio total del valor por $\mathrm{m}^{2}$ & 329 & 629 & 1139 & 1283 & 1792 & 3191 & 1394 \\
\hline \multicolumn{8}{|l|}{ Total general } \\
\hline Total de "manzanas" & 20051 & 65914 & 30452 & 16421 & 6352 & 4657 & 143847 \\
\hline Promedio total del valor por $\mathrm{m}^{2}$ & 376 & 672 & 1288 & 1678 & 2484 & 4945 & 1907 \\
\hline
\end{tabular}

Fuente: Elaboración propia. 


\section{BIBLIOGRAFÍA}

Alonso, William (1964), Location and land use: Toward a general theory of land rent, Cambridge Massachusetts, Harvard University Press, 216 pp.

Buzai, G. Daniel (2003), Mapas sociales urbanos, Buenos Aires, 1ª. ed., Lugar Editorial, 384 pp. Cámara Nacional de la Industria de Desarrollo y Promoción de la Vivienda (Canadevi), Valle de México (2012), "La industria de la vivienda nueva terminada en el Valle de México: palanca del desarrollo económico", septiembre de 2012, <http://docplayer.es/9743643-La-industria-de-la-vivienda-nueva-terminada-en-el-valle-de-mexico-palanca-del-desarroIlo-economico-septiembre-de-2012.html>.

Comisión Metropolitana de Asentamientos Humanos (1998), "Programa de ordenación de la Zona Metropolitana del Valle de México", México, Gobierno de la Ciudad de México, Gobierno del Estado de México, Secretaría de Desarrollo Social.

Consejo Estatal de Población del Estado de México (1993), Estado actual de la migración interna e internacional de los acuerdos del Estado de México, Toluca.

Cruz Rodríguez, María Soledad (2001), Propiedad, poblamiento y periferia rural en la Zona Metropolitana de la Ciudad de México, México, UAM-A, Red Nacional de Investigación Urbana, 356 pp.

Duhau, Emilio (1998), Hábitat popular y política urbana, México, UAM Azcapotzalco, Miguel Ángel Porrúa, 304 pp.

(2004). "Políticas habitacionales e integración en México. Del estado promotor a la promoción inmobiliaria", Revista Mundo Urbano, núm. 23, junio-julio-agosto, <http://www. mundourbano.unq.edu.ar/index.php/ano-2004/49-numero-23/53-4-politicas-habitacionales-e-integracion-en-mexico-del-estado-promotor-a-la-promocion-inmobiliaria $>$.

Gobierno del Distrito Federal (2014), "Decreto por el que se reforman, adicionan y derogan diversas disposiciones del Código Fiscal del Distrito Federal", Gaceta Oficial del Distrito Federal, tomo I, núm. 2012, diciembre.

Gobierno del Estado de México (2005), "Plan Regional de Desarrollo Urbano del Valle Cuautitlán-Texcoco", junio .

(2009), "Acuerdo del ejecutivo del Estado, por el que se expide el Reglamento del Título Quinto del Código Financiero del Estado de México y Municipios, denominado Catastro", Gaceta de Gobierno, tomo CLXXXVII, núm. 1, enero, Toluca, México. 2012), "Decreto número 28, por el que se actualizan las tablas de valor para la determinación de valores unitarios de suelo y de construcción para el año 2013", Gaceta de Gobierno, tomo CXCIV, núm. 107, diciembre, Toluca, México.

(2014), "Decreto número 341, por el que se aprueban las tablas de valores unitarios de 
suelo y construcciones actualizadas para la determinación de valores catastrales durante el año 2015", Gaceta de Gobierno, tomo CXCVIII, núm. 107, noviembre, Toluca, México. Infonavit (2013), "Comparación entre niveles de oferta y demanda de vivienda a nivel industria", http://www.cmic.org/comisiones/sectoriales/vivienda/2013/infonavit/minutas_y_presentaciones/comision_mixta/sesion_119/03_OFERTA_DEMANDA_VIVIENDA.pdf $>$.

Maya Pérez, Esther y Cervantes Borja, Jorge F. (coords.) (2005), La producción de vivienda del sector privado y su problemática en el municipio de Ixtapaluca, México, Editorial Plaza y Valdés, 208 pp.

Mills, Edwin (1975), Economía urbana, México, Editorial Diana, 328 pp.

Organización de las Naciones Unidas (2011), "Urban population, development and the environment 2011", Department of Economic and Social Affairs, <http://www.un.org/esa/population/publications/2011UrbanPopDevEnv_Chart/urban_wallchart_2011-web-smaller. pdf $>$.

Porter, Michael (1991), La ventaja competitiva de las naciones, Buenos Aires, Vergara Ediciones, 1025 pp.

Sociedad Hipotecaria Federal (2014), "Demanda de vivienda 2014", Dirección de Estudios Econó micos de la Vivienda, enero, <http://www.shf.gob.mx/estadisticas/EstudiosVivienda/Docu ments/demanda\%202014.pdf>. 



\section{Grandes centros comerciales, estructura sociorresidencial y calidad de vida en la Zona Metropolitana del Valle de México}

José Gasca Zamora

\section{INTRODUCCIÓN}

Los centros comerciales (Cc) constituyen grandes equipamientos diseñados para centralizar la distribución y maximizar el consumo de bienes y servicios; poseen formas y dimensiones variables, pero casi siempre se distinguen por sus edificaciones construidas sobre extensas superficies donde se instalan empresas minoristas dedicadas a la oferta de mercancías y servicios básicos y especializados, incluidos el entretenimiento y el ocio. Ello posibilita el desarrollo de conjuntos multifuncionales, donde se lleva a cabo un flujo diversificado, integrado y continuo de consumo.

El advenimiento de los CC ha tenido lugar principalmente en metrópolis y grandes ciudades. En América Latina, México atestiguó su aparición durante la década de 1960, aunque en otros países su apertura se reporta hasta el decenio de 1980. En la Ciudad de México, su emergencia representó al inicio un modelo de negocio empresarial orientado sobre todo hacia el consumo de sectores de ingresos altos y medios de áreas suburbanas y periféricas. Durante sus primeras dos décadas de existencia, los cc tuvieron un moderado crecimiento, lo cual configuró enclaves inéditos en los paisajes del comercio de la ciudad. Sin embargo, desde mediados de la década de 1990 registraron un acelerado crecimiento y amplia dispersión que configuraron un fenómeno de dimensiones metropolitanas.

En este capítulo se analiza la forma en que este modelo de consumo y comercio se relaciona con el enorme mercado de consumidores de la Zona Metropolitana del Valle de México (ZMVM), y cómo su difusión espacial y patrones actuales de localización mantienen una estrecha relación con las áreas que presentan mejores condi- 
ciones de calidad de vida. Esto significa que las modalidades diferenciadas de equipamientos de distribución y consumo de la ciudad van siguiendo la progresión de la propia estructura sociorresidencial desigual y fragmentada de la metrópoli.

El soporte metodológico incluye el tratamiento de información cualitativa y cuantitativa a partir de la revisión de documentos especializados del sector inmobiliario y comercial; el procesamiento de datos estadísticos sobre indicadores y la localización de las unidades de análisis. Asimismo, se integraron indicadores espaciales de los niveles de calidad de vida por "manzana". La información se procesó mediante un sistema de información geográfica para obtener la cartografía correspondiente.

El trabajo se organiza en tres apartados. En el primero, se revisan los antecedentes en la investigación de los cc y se explican las causas del surgimiento y la expansión; en el segundo, se ofrece un panorama de los CC en México y la participación que éstos tienen en el contexto latinoamericano, incluidos los grupos de capital financiero e inmobiliario que participan en su edificación; en el tercero, se destaca el proceso de difusión espacial y se identifican tendencias relevantes que promueven su localización en términos de la estructura espacial sociorresidencial y la calidad de vida metropolitana.

\section{ANTECEDENTES Y PERSPECTIVAS DE ANÁLISIS EN EL ESTUDIO DE LOS CENTROS COMERCIALES}

Los cc han sido motivo de análisis desde distintos enfoques. Uno de ellos ha centrado su interés en explicar su papel como parte de los procesos de consumo en contextos urbanos, al partir del estudio de los sistemas de significados y representaciones sociales. Desde esta perspectiva, estos se reconocen como hitos del consumo de la sociedad contemporánea que han favorecido la creación de ámbitos donde se reconstituyen lazos de sociabilidad, así como lugares que inducen percepciones e imaginarios para dotar de nuevos sentidos a los usos del espacio y el tiempo. En México, se encuentra una profusa literatura desde esta vertiente, la cual abarca distintas disciplinas sociales a partir de trabajos como los de Ramírez (1993), Monnet (1996), López (1999), Cornejo (2007), entre otros.

Otra perspectiva explica el auge reciente de los Cc en su relación con las dinámicas que ha seguido la movilización del capital inmobiliario en el contexto neoliberal. Así, por ejemplo, Dávila (2016) centra su interés en los CC como parte de los procesos de revaloración del suelo urbano y de los motores del crecimiento de las ciudades a partir de la conjugación de un nuevo régimen financiero y las políticas 
empresarialistas urbanas. Una veta de análisis ha hecho más énfasis en su efecto en las transformaciones de la estructura y funcionalidad urbanas. Así, el trabajo de Pradilla et al. (2008), al analizar las etapas del proceso de expansión de los CC en la Ciudad de México, destacan su contribución a la consolidación de corredores de actividad terciaria. Conclusiones similares aporta la investigación de Paquette (2007), quien enfatiza que los Cc en la Ciudad de México han favorecido la emergencia y la consolidación de subcentros urbanos, al resaltar su papel estructurador y regenerador del tejido urbano. Una perspectiva parecida a las dos anteriores, en el contexto argentino, es la de Vecslir y Ciccolella (2011), quienes analizan los CC como parte del proceso de crecimiento y difusión territorial de las actividades terciarias en las dos últimas décadas y su relación con las diferentes modalidades de reestructuración de las centralidades y subcentralidades en la región metropolitana de Buenos Aires, al identificar su integración en las tendencias de consolidación de dinámicas, morfologías y localizaciones tradicionales y la red emergente de distritos de terciarios.

La mirada que interesa destacar en este trabajo está más próxima a trabajos como el de Pintaudi (1992), que indaga sobre las condicionantes socioeconómicas del surgimiento de cc y sus estrategias de localización en distintas ciudades brasileñas, en especial a partir de su auge registrado desde la década de 1980 asociado con el crecimiento a las estrategias del capital financiero-inmobiliario, la dinámica de grandes mercados de consumidores y segmentos de alto poder adquisitivo concentrados en las principales metrópolis. En un sentido similar, se encuentra la propuesta de Amaya (2009) sobre el papel de los cc en las principales aglomeraciones urbanas deVenezuela, donde destaca su patrón hacia su concentración en las ciudades de mayor jerarquía y, en el tejido urbano, su tendencia a localizarse en las áreas de sectores socioeconómicos de ingresos medios y altos, al seguir el proceso de fragmentación social.

En este capítulo se considera que las fuerzas impulsoras de los cc en distintos contextos urbanos en México se vinculan con al menos dos procesos: por un lado, la transformación funcional de la ciudad que ha ocurrido como consecuencia de la emergencia de nuevas formas y escalas de consumo urbano y, por otra parte, la creciente movilización del capital inmobiliario en megaproyectos comerciales, ambos procesos direccionados de forma predominante hacia segmentos de clases medias y de altos ingresos tanto en áreas consolidadas como de reciente urbanización.

En este sentido, los cc forman parte de las actividades comerciales emergentes que se distribuyeron de manera progresiva hacia áreas suburbanas y periféricas de la ciudad, lo cual refleja parte del proceso de disociación que diferentes segmentos de la economía comenzaron a tener respecto del centro tradicional de negocios donde, de 
forma histórica se ubicó el núcleo más importante de la oferta comercial. La progresión de la mancha urbana hacia las áreas de más reciente incorporación en la ciudad demandó nuevos equipamientos para la distribución de bienes y servicios, sobre todo aquellos de corte empresarial donde además de los CC, se incluyen supermercados, almacenes especializados, tiendas departamentales y franquicias; es decir, esquemas de mayor capacidad de distribución de bienes y servicios con formatos de negocio adaptados a modalidades y estilos de consumo de estratos sociales y nuevos entornos residenciales.

Lo anterior marca una ruptura con respecto a los segmentos precedentes del comercio tradicional, como mercados públicos y concentraciones en espacios públicos distribuidos sobre calles y avenidas que presentan mayor atomización y, hasta hace pocos años, se ubicaban como los canales más representativos de la distribución de bienes en la Ciudad de México. La transición progresiva de sistemas de comercio tradicionales a formatos empresariales modernos de mayor escala ha sido parte de un fenómeno que, en México, tiene por lo menos dos decenios; dicho fenómeno se relaciona con el retiro del respaldo del Estado a los sistemas de comercio y abasto popular, la limitada regulación institucional que ha generado la apertura indiscriminada a empresas comerciales de distintos tamaños y modalidades, así como con el carácter disfuncional de los negocios tradicionales que no han resistido el embate global de grandes consorcios que cuentan con mejores sistemas organizacionales, tecnológicos y logísticos.

Por otro lado, la edificación de cc constituye una de las modalidades más importantes del financiamiento destinado a la producción del espacio urbano a partir de su inserción en el mercado inmobiliario. México registra desde los años noventa un auge sin precedentes en la captación de inversiones inmobiliarias que se canalizan en desarrollos residenciales, enormes edificaciones del segmento corporativo y de oficinas, complejos de hoteles, segundas residencias en zonas turísticas y, obviamente, los destinados a grandes proyectos orientados al comercio y consumo de bienes y servicios.

Estos segmentos han sido motivo de cuantiosas inversiones privadas nacionales y globales en la ciudad, puesto que conforman distintas modalidades de revaloración del mercado de suelo urbano a partir de las altas rentas que generan; por ello, constituyen una de las expresiones del régimen urbano neoliberal actual que ha favorecido sobre todo las intervenciones privadas. Estos procesos han contribuido a la recalificación de nuevos usos del suelo; la regeneración urbana, así como a la formación y la consolidación de corredores de comercio y servicios, nodos terciarios, distritos 
corporativos y complejos de usos mixtos. En este contexto, numerosos proyectos de CC van siguiendo la lógica de la demanda, es decir, no emergen de manera aleatoria, sino se ajustan a las condiciones socioeconómicas de la población y la calidad de los entornos urbanos para garantizar su éxito.

\section{CARACTERÍSTICAS DE LOS CENTROS COMERCIALES Y ACTORES PROMOTORES}

De acuerdo con el International Council of Shopping Center (ICSC), para el año 2014, México ocupa el primer lugar en América Latina con 584 unidades de CC; le sigue Brasil con 511, y después Colombia y Argentina (cuadro 10-1). México también cuenta con más metros cuadrados de superficie rentable (16.2 millones) y, luego de Chile, tiene la tasa comercial urbana más alta en este segmento, equivalente a 16.9 metros cuadrados por cada 100 habitantes (ICSC, 2015).

El crecimiento y los escenarios diferenciados de cc en algunos países representativos de América Latina sugieren una relación estrecha con la mayor cantidad absoluta y relativa de población urbana de cada país; sin embargo, el hecho que México supere a Brasil en número de cc y Chile a México en términos de tasa comercial indica que se trata de un fenómeno más complejo. Hay indicios para pensar que la difusión del modelo de cc se relaciona más con la estructura del sistema urbano y, al interior de las ciudades, con la expansión y la consolidación de segmentos sociorresidenciales medios y altos, lo cual prefigura un fenómeno más adaptado a las grandes urbes.

Las metrópolis y las ciudades grandes albergan el mayor número de cc y superficie rentable, fenómeno atribuible a la presencia de mercados más densos, mayor

Cuadro 10-1

Centros comerciales de países seleccionados en América Latina (2014 y estimados al 2025)

\begin{tabular}{|c|c|c|c|c|c|c|}
\hline \multirow[b]{3}{*}{ País } & \multirow{2}{*}{\multicolumn{2}{|c|}{$\begin{array}{l}\text { Número de centros } \\
\text { comerciales }\end{array}$}} & \multirow{2}{*}{\multicolumn{2}{|c|}{$\begin{array}{c}\text { Superficie de venta } \\
\text { (millones de metros } \\
\text { cuadrados) }\end{array}$}} & \multirow{2}{*}{\multicolumn{2}{|c|}{$\begin{array}{l}\text { Tasa comercial urbana } \\
\text { (metros cuadrados por } \\
\text { cada } 100 \text { habitantes) }\end{array}$}} \\
\hline & & & & & & \\
\hline & 2014 & 2025 & 2014 & 2025 & 2014 & 2025 \\
\hline México & 584 & 760 & 16.9 & 23.3 & 16.9 & 22 \\
\hline Brasil & 511 & 700 & 13.5 & 22.8 & 7.8 & 12 \\
\hline Colombia & 196 & 339 & 4.2 & 8.3 & 10.8 & 18 \\
\hline Argentina & 114 & 178 & 2.1 & 4.3 & 5.4 & 10 \\
\hline Chile & 79 & 320 & 3.5 & 6.5 & 22.2 & 22 \\
\hline Perú & 71 & 90 & 9.2 & 3.8 & 9.2 & 25 \\
\hline
\end{tabular}

Fuente: ICSC, 2015. 
concentración del ingreso y una estructura sociorresidencial con una cifra importante de segmentos medios. Esto aplica a países como Brasil, Argentina, Chile, Venezuela y Perú, donde metrópolis, como Sao Paulo, Buenos Aires, Santiago, Caracas y Lima han registrado un mayor auge de CC en los últimos años, en comparación con otras ciudades en estos mismos países (cuadro 10-1).

Esta idea también se corrobora para el caso mexicano, donde a pesar de tener 59 zonas metropolitanas que conforman 56\% de la población nacional, sólo las tres metrópolis más grandes (México, Guadalajara y Monterrey) concentran alrededor de $70 \%$ de los Cc y de superficie rentable. La Ciudad de México constituye un fenómeno sin precedentes en este caso, pues con poco más de 20 millones de habitantes aloja a 221 CC, casi una tercera parte del total nacional.

El origen del cc en México se remonta a finales del decenio de 1960 y principios de la década de 1970, como resultado de alianzas entre tiendas departamentales y desarrolladores inmobiliarios. Medio siglo después, existe una gran diversidad de esquemas que favorecen la edificación de CC, los cuales incluyen empresas inversionistas internacionales y nacionales, desarrolladores inmobiliarios mexicanos, alianzas entre grupos financieros y desarrolladores; sistemas de inversión a través del mercado bursátil (como los "fideicomisos en bienes raíces" mejor conocidos como Fibras), entre otros. Por ello, es posible encontrar diversidad de empresas y grupos de desarrolladores dentro del ámbito de construcción y operación de CC. En México y, en particular en la ZMVM, la participación de éstos en el mercado inmobiliario es diversificada, si se considera la cantidad y el tamaño de los proyectos donde han venido participando (cuadro 10-2).

\section{DIFUSIÓN ESPACIAL DE LOS CENTROS COMERCIALES Y SU ARTICULACIÓN CON LA ESTRUCTURA SOCIORRESIDENCIAL Y LA CALIDAD DE VIDA DE LA METRÓPOLI}

El proceso de difusión en el tejido urbano de cc responde al inicio a una lógica de emergencia de establecimientos fuera de los centros tradicionales de la ciudad y la aparición de nuevas formas y escalas de concentración del consumo. La relativa pérdida de importancia del centro de la ciudad, otrora locus principal del comercio y el consumo, se sumó a las estrategias descentralizadas de las empresas para instalar equipamientos de oferta de bienes y servicios que van siguiendo algunos de los patrones espaciales de expansión de la metrópoli. Alrededor de 60\% de la apertura de cc entre 1969 y 2016 tuvo lugar en áreas suburbanas y periurbanas. De acuerdo con los años de registro de apertura, las escalas, las morfologías y las tendencias de 


\section{Cuadro 10-2}

Zona Metropolitana del Valle de México: principales desarrolladores inmobiliarios y empresas que financian centros comerciales

\begin{tabular}{|c|c|c|}
\hline $\begin{array}{l}\text { Empresa } \\
\text { desarrolladora } \\
\text { o financiera }\end{array}$ & \multicolumn{2}{|c|}{ Centros comerciales y año de apertura } \\
\hline \multirow{7}{*}{ Grupo Frisa } & Multiplaza “Valle Dorado” (1974) & Multiplaza “La Hacienda” (1991) \\
\hline & Multiplaza “Alamedas" (1976) & “Mundo E” (1998) \\
\hline & Multiplaza “Bosques” (1977) & Multiplaza “Vergel” (2000) \\
\hline & Multiplaza “San Juan” (1980) & "Magnocentro 26" (2001) \\
\hline & Multiplaza “Aragón” (1979) & “Multimart Baz" (2001) \\
\hline & Multiplaza “Izcalli” (1989) & Multiplaza “Arboledas" (2006) \\
\hline & Centro Comercial “Plaza Jardines” (1990) & Multiplaza “Ojo de Agua” (2009) \\
\hline PLANI Grupo & Super Plaza “Las Haciendas” (2009) & $\begin{array}{l}\text { Macroplaza "Héroes de Tecámac" } \\
\text { (2009) }\end{array}$ \\
\hline \multirow{3}{*}{ ICON Comercial } & “Gran Sur” (1999) & “Espacio Interlomas” (2007) \\
\hline & "San Marcos Power Center" (2005) & “Tecámac Power Center” (2008) \\
\hline & “Coacalco Power Center” (2007) & “Espacio Esmeralda” (2008) \\
\hline \multirow{5}{*}{$\begin{array}{l}\text { Mexico Retail } \\
\text { Properties }\end{array}$} & "El Cortijo Ixtapaluca" (2006) & “Gran Patio" (2011) \\
\hline & Patio “Ayotla” (2006) & Patio “Santa Fe” (2013) \\
\hline & Patio “El Cortijo” (2006) & Patio “Universidad” (2013) \\
\hline & “Parques Polanco” (2008) & Patio “Clavería” (2013) \\
\hline & Patio “Chimalhuacán” (2011) & \\
\hline \multirow{5}{*}{$\begin{array}{l}\text { Grupo/Fibra } \\
\text { Danhos }\end{array}$} & Parque “Duraznos" (2000) & Parque “Lindavista” (2006) \\
\hline & Parque "Alameda" (2003) & Reforma 222 (2007) \\
\hline & “Plaza Magna” (2002) & Parque “Tezontle” (2007) \\
\hline & Parque "Alameda" (2003) & Parque “Toreo Central” (2015) \\
\hline & Parque “Delta” (2005) & \\
\hline \multirow{6}{*}{$\begin{array}{l}\text { E-Group/Fibra } \\
\text { UNO }\end{array}$} & Centro Comercial “Interlomas” (1991) & $\begin{array}{l}\text { Centro Comercial "Lago de Guadalupe" } \\
\text { (2008) }\end{array}$ \\
\hline & “Vallejo 2000” (1994) & “Plaza Central” (2010) \\
\hline & “Vía Morelos” (1997) & “Terraza Pedregal” (2010) \\
\hline & Plaza “Legaria” (1997) & "Samara Santa Fe" (2011) \\
\hline & “Las Palomas” (1998) & “Pabellón Cuemanco" (2013) \\
\hline & Multiplaza “Tultitlán” (2005) & “Pabellón Iztapalapa” (2014) \\
\hline Grupo ACCION & Centro Comercial “Insurgentes” (1996) & "Pabellón Altavista” (1996) \\
\hline \multirow{3}{*}{ GICSA } & “Paseo Arcos Bosques” (2008) & "Forum Buenavista” (2008) \\
\hline & “Center Plazas” (2006) & “Paseo Interlomas” (2009) \\
\hline & “City Walk” (2008) & \\
\hline
\end{tabular}


Continuación Cuadro 10-2

\begin{tabular}{|c|c|c|}
\hline $\begin{array}{l}\text { Empresa } \\
\text { desarrolladora } \\
\text { o financiera }\end{array}$ & \multicolumn{2}{|c|}{ Centros comerciales y año de apertura } \\
\hline Grupo ACBC & Plaza “Las Flores” (2004) & \\
\hline \multirow{2}{*}{$\begin{array}{l}\text { Grupo Acosta } \\
\text { Verde }\end{array}$} & Plaza “Sendero Ixtapaluca” (2005) & “Gran Patio Valle de Chalco" (2011) \\
\hline & Plaza “Sendero Ecatepec” (2008) & \\
\hline \multirow{3}{*}{ ZKC } & Plaza “Cafetales” (2015) & Plaza “Copilco” (2016) \\
\hline & Plaza “Picacho Ajusco” (2015) & Plaza “Huipulco” (2016) \\
\hline & Plaza “Eduardo Molina” (2015) & Plaza “Tenorios” (2016) \\
\hline \multirow{4}{*}{ Inmuebles Carso } & “Pabellón Polanco” (1990) & Plaza “Telmex Ciudad Jardín” (2008) \\
\hline & Plaza “Loreto” (1994) & “Mexipuerto Ciudad Azteca” (2009) \\
\hline & Plaza “Insurgentes” (1996) & “Cetram El Rosario” (2012) \\
\hline & Plaza “Inbursa Cuicuilco” (1997) & Plaza “Carso” (2014) \\
\hline \multirow{3}{*}{ Sordo Madaleno } & Plaza “Universidad”/1 (1969) & Centro Comercial “Lilas” (1992) \\
\hline & Plaza “Satélite” /1 (1971) & “Moliere Dos22”/2 (1997) \\
\hline & “Centro Coyoacán” /2 (1982) & “Antara Polanco” (2006) \\
\hline \multirow{4}{*}{ Grupo GDI } & “Coacalco Power Center” (2007) & “Town Center Zumpango” (2010) \\
\hline & “Espacio Interlomas” (2007) & “Town Center Nicolás Romero” (2013) \\
\hline & “Town Center El Rosario” (2012) & “Cosmopol” (2015) \\
\hline & “Espacio Esmeralda” (2009) & \\
\hline \multirow{2}{*}{ Grupo CAABSA } & Centro Comercial “Santa Fe” (1986) & “Pabellón Bosques” (1999) \\
\hline & Plaza “Lindavista” (1990) & \\
\hline \multirow{3}{*}{$\begin{array}{l}\text { Grupo Galerías/ } \\
\text { El Puerto de } \\
\text { Liverpool }\end{array}$} & Centro Comercial “Perisur” (1979) & “Perinorte” (1992) \\
\hline & “Galerías Coapa” (1992) & “Galerías Atizapán” (2009) \\
\hline & “Galerías Insurgentes” (1992) & \\
\hline \multirow{2}{*}{ Fibra Shop } & “Puerta Texcoco”/3 (2010) & “Urban Center Condesa”/5 (2011) \\
\hline & “City Center Esmeralda" /4 (2010) & \\
\hline
\end{tabular}

11 En coparticipación con "Sears Roebuck".

$/ 2$ En coparticipación con el "Palacio de Hierro".

13 Desarrollador original Grupo ACBC.

14 Desarrollador original Hinest Interest.

15 Desarrollador original Central de Arquitectura.

Fuente: elaboración propia con datos de "Centros Comerciales Passion for Shopping" (2015) y páginas de internet de las empresas desarrolladoras.

localización, se identifican tres momentos en el proceso de crecimiento y difusión espacial de los CC en la ZMVM (cuadro 10-3).

La primera fase corresponde al proceso de introducción que va de 1969, con el inicio de actividades del primer CC, hasta mediados de los años ochenta. El creci- 
miento de los Cc en la Ciudad de México en esta fase fue incipiente pues por casi tres lustros su número llegó sólo a 10 unidades, lo cual refleja un esquema muy selectivo y de penetración leve en las preferencias de los consumidores. Los primeros cc representaron fenómenos excepcionales en el paisaje urbano, ya que formaban un cierto tipo de enclaves en áreas relativamente consolidadas; tal fue en caso de algunos de ellos, como Plaza "Universidad" (1969), Plaza "Satélite" (1971), "Valle Dorado" (1979), Multiplaza "Aragón" (1979), "Perisur" (1981) y "Centro Coyoacán" (1982).

En la fase inicial, estos primeros cc representaron grandes equipamientos horizontales articulados por tiendas departamentales, ubicados en la mayoría de los casos sobre avenidas primarias que facilitaban la conectividad con distintas áreas de la ciudad; contaban con una amplia superficie de estacionamiento que permitía el ingreso principalmente de segmentos de altos ingresos que disponían de automóvil. Su aparición corresponde a áreas suburbanas y periféricas de ingresos medios y altos, en colonias de las delegaciones "Benito Juárez" y "Coyoacán" en el Distrito Federal, así como zonas residenciales más recientes en municipios del Estado de México, como Naucalpan y Tlalnepantla.

Una segunda etapa, entre la década de 1980 y finales de los años noventa, se

\section{Cuadro 10-3}

Zona Metropolitana del Valle de México: centros comerciales (CC) edificados por periodos de acuerdo con su localización (1969 a 2016)

\begin{tabular}{|c|c|c|c|c|c|c|}
\hline Ubicación & $\begin{array}{c}1969 \\
a \\
1984\end{array}$ & $\begin{array}{c}1985 \\
a \\
1999\end{array}$ & $\begin{array}{c}2000 \\
a \\
2016\end{array}$ & $\begin{array}{l}\text { Número } \\
\text { de uni- } \\
\text { dades }\end{array}$ & $\begin{array}{c}\text { Por- } \\
\text { centaje }\end{array}$ & Ejemplos \\
\hline Centro histórico & 0 & 0 & 1 & 1 & 0.5 & Parque "Alameda" \\
\hline Zona pericentral & 1 & 2 & 17 & 20 & 9 & $\begin{array}{l}\text { Parque "Delta“, Plaza "Aeropuerto“, } \\
\text { "Urban Center Condesa“,"Torre } \\
\text { Diana“ }\end{array}$ \\
\hline Zona suburbana & 4 & 19 & 35 & 58 & 26.2 & $\begin{array}{l}\text { Parque “Tezontle“,"Oasis Coyoa- } \\
\text { cán“,"Cetram Rosario“,"Antara } \\
\text { Polanco“ }\end{array}$ \\
\hline Periferia urbana & 5 & 13 & 64 & 82 & 37.1 & $\begin{array}{l}\text { "Espacio Interlomas“, Plaza "Bella } \\
\text { Mexiquense“" "Zentralia Coacalco“, } \\
\text { Patio "Chimalhuacán" }\end{array}$ \\
\hline Periferia metropolitana & 0 & 0 & 6 & 6 & 2.7 & $\begin{array}{l}\text { “Town Center Zumpango“, Plaza } \\
\text { “Los Volcanes“, Plaza “Sendero } \\
\text { Ixtapaluca“ }\end{array}$ \\
\hline CC, año no especificado & 0 & 0 & 0 & 54 & 24.4 & \\
\hline Total & 10 & 34 & 123 & 221 & 100 & \\
\hline
\end{tabular}

Fuente: elaboración propia con datos de "Passion for Shopping" (2015b). 
puede caracterizar por una relativa expansión y diversificación de cc, cuando crecieron en número con 34 nuevos CC, si se considera sólo aquéllos donde se cuenta con el registro del año de apertura. El rasgo más notable en esta fase fue que comenzaron un proceso de diversificación mediante esquemas que complementaron la oferta de productos y servicios básicos, con servicios especializados, de ocio y entrenamiento. La mayoría de ellos también siguió la lógica de incrustarse en contextos residenciales de clase media y alta, entre los cuales destaca el Centro "Santa Fe" (1986) ubicado en el poniente en la delegación Cuajimalpa en el poniente de la ciudad, un lugar que terminó por expandirse hasta formar un gran distrito de corporativos y áreas residenciales de altos ingresos. En el norponiente de la metrópoli, los Cc también se multiplicaron en áreas consolidadas en la delegación Gustavo A. Madero y el municipio de Ecatepec, donde se erigieron las plazas Lindavista (1990) y Vallejo 2000 (1994), así como Vía Morelos (1997), aunque continuaron apareciendo en áreas de reciente urbanización, como en Cuautitlán Izcalli, Naucalpan y Tlalnepantla, donde se edificaron: Multiplaza Izcalli (1989), Perinorte (1990), Centro Comercial "Interlomas" (1991); Multiplaza "La Hacienda" (1991) y "Mundo E" (1998). En el caso del sur de la ciudad, los CC registraron una relativa expansión en casos como "Galerías Coapa" (1992), "Loreto" (1994), "Pabellón Altavista" (1996), "Gran Sur" (1999) y "Cuicuilco" (1997) en las delegaciones de Coyoacán y Tlalpan. Asimismo, otros se instalaron en zonas de negocios y corredores comerciales y financieros suburbanos y pericentrales de la ciudad, como en el caso de "Pabellón Polanco" (1990), "Galerías Insurgentes" (1992) y "Plaza Insurgentes" (1996).

La tercera fase corresponde al momento más reciente que registra el proceso de mayor colonización, innovación funcional y mutación morfológica que se observa desde finales de la década de 1990, pero sobre todo en los primeros tres lustros del siglo XXI. El número de los CC en la ZMVM crecieron de manera importante, pero además de haberse duplicado entre los años 2000 y 2016, introdujeron esquemas atomizados y tematizados de consumo, es decir, adaptados a preferencias específicas de consumidores, o bien a contextos urbanos de reciente urbanización hacia la periferia, así como en áreas suburbanas y pericentrales que han registrado una trasformación sociorresidencial a partir de proyectos de regeneración urbana, donde se han instalado nuevos asentamientos.

En este sentido se observan tres procesos en sus patrones de localización. Primero, una ubicación acentuada hacia áreas periurbanas, sobre todo en municipios como Coacalco y Atizapán, donde ha tenido lugar un importante auge inmobiliario de grandes unidades habitaciones y residenciales para segmentos medios. Segundo, una 
Figura 10-1

Zona Metropolitana del Valle de México (ZMVM): centros comerciales (CC) edificados de 1969 a 1984

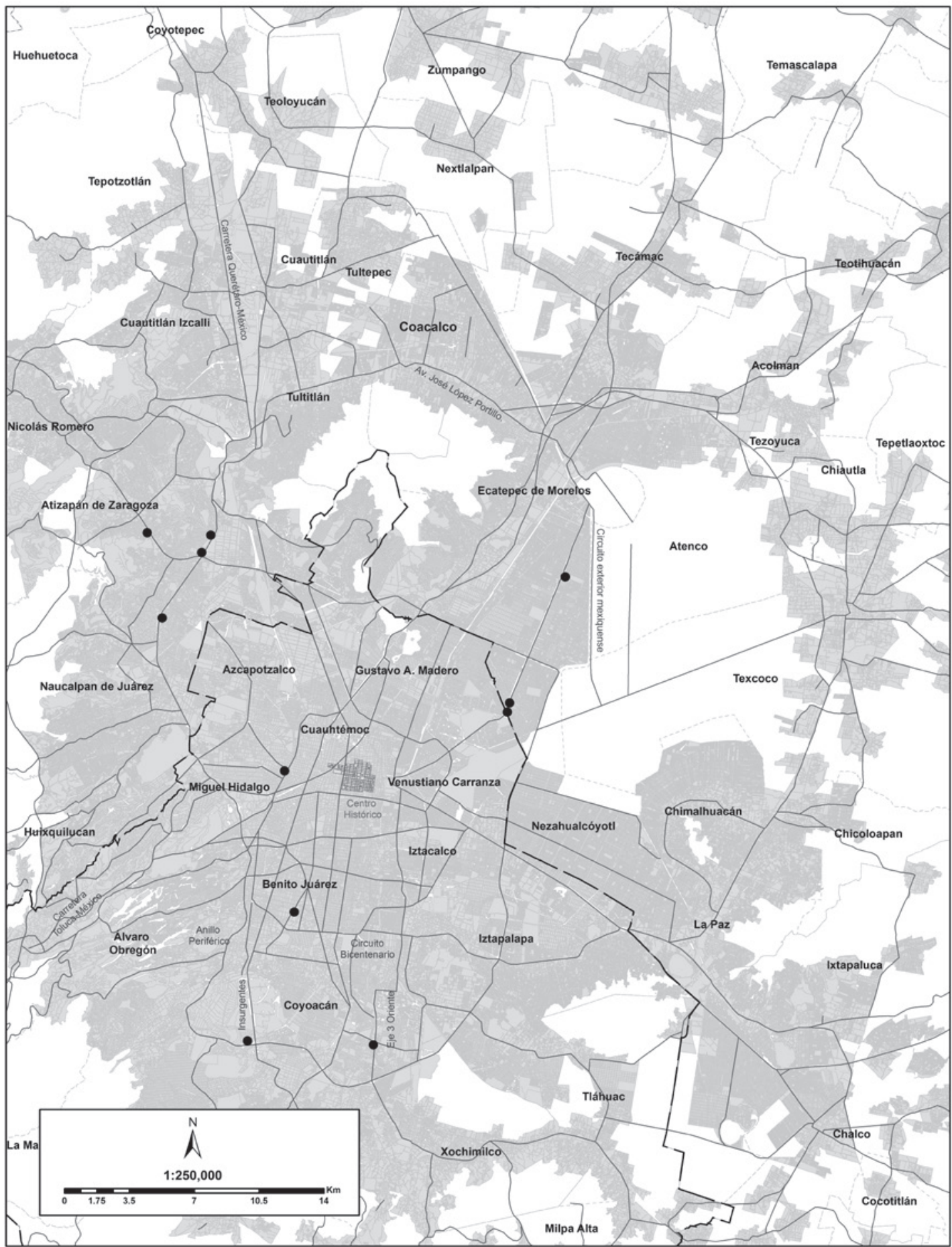


Figura 10-2

Zona Metropolitana del Valle de México (ZMVM): centros comerciales (CC) edificados de 1985 a 2000

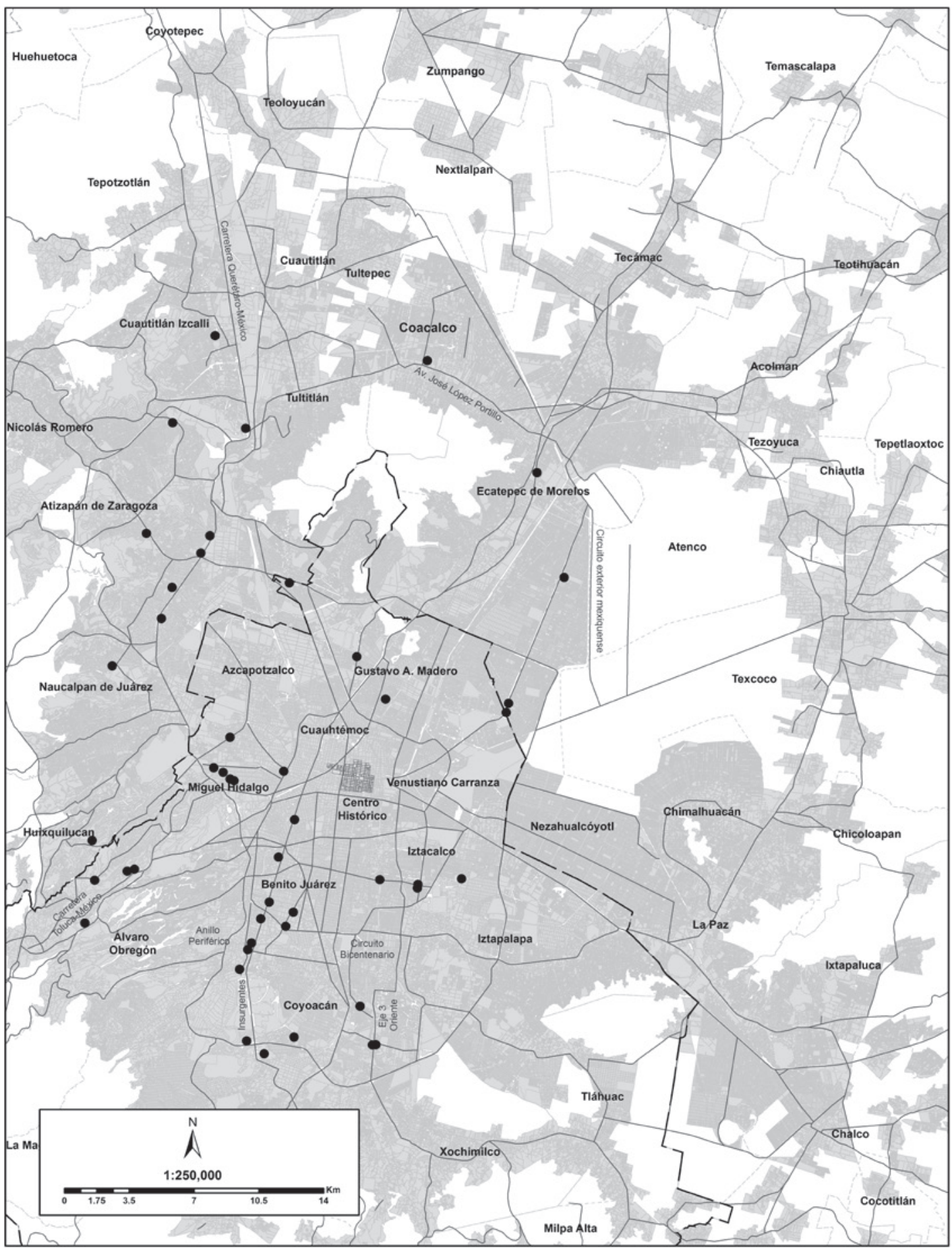


Figura 10-3

Zona Metropolitana del Valle de México (ZMVM): centros comerciales (CC) edificados de 2001 a 2016

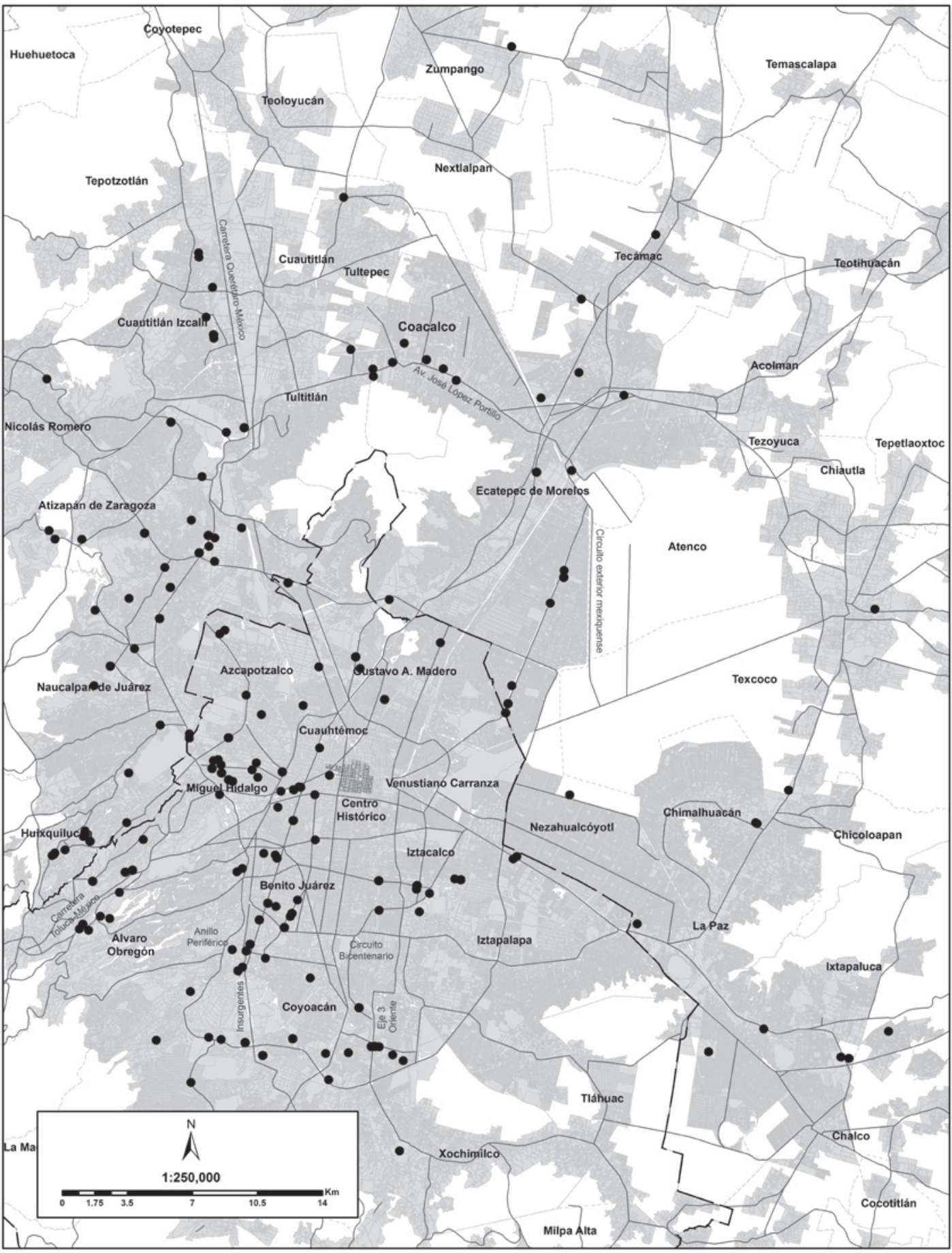


producción notable de equipamientos en áreas pericentrales y suburbanas sujetas a procesos de regeneración urbana, como "Parque Delta" (2005) que ocupó el predio del antiguo parque de béisbol perteneciente al Seguro Social; "Moliere Dos22" (2003) se levantó donde se ubicaba un colegio de Jesuitas; "Fórum Buenavista" (2008) que se desarrolló sobre la desaparecida estación central de ferrocarriles; "Paseo Acoxpa" (2010) realizado sobre los terrenos donde había una antigua fábrica de hilados sintéticos; "Plaza Carso" (2014) cuya instalación se hizo en la vieja zona industrial de la "Ampliación Granada" y, de forma más reciente, "Oasis Coyoacán" (2015) que se levantó sobre un predio que en el pasado ocupó la fábrica de cosméticos "Avón"; mientras, Parques Toreo Central (2015) ocupó el antiguo centro de tauromaquia y espectáculos del "Toreo de Cuatro Caminos" y, por último, "Pabellón Cuemanco" (2015), el cual se edificó sobre un extenso predio que dejó una empresa dedicada a la venta de muebles y electrodomésticos. En tercer lugar, se encuentran los CC de reciente aparición ubicados en los confines de la metrópoli, su número es reducido y aislado y ocupan lugares de municipios mexiquenses, como Ojo de Agua, Texcoco, Ixtapaluca, Nicolás Romero y Chimalhuacán, asociados con algunos contextos residenciales de nivel medio y vinculados con áreas habitacionales que en el interior carecen de diversos equipamientos (figuras 10-1 a 10-4).

Las tendencias de difusión espacial que registran los CC expresan con claridad cómo se fueron conjugando con una mayor segmentación y fragmentación sociorresidencial de la ciudad, lo cual permite deducir que sus estrategias de localización se encuentran fuertemente asociadas con las condiciones de calidad de vida de la población, el nivel del ingreso y el entorno urbano (figuras 10-5 y 10-6).

Sin embargo, la localización de los cc se expresa tanto en un sentido de agrupamientos o conglomerados sobre importantes áreas residenciales medias con una mayor presencia en la parte poniente de la ZMVM, en algunos casos, sobre ejes urbanos primarios comerciales y, en otros, en núcleos terciarios. De esta manera, destaca su presencia en las inmediaciones de las colonias Del Valle y Narvarte; las avenidas Universidad e Insurgentes en su segmento centro y sur; la avenida Miramontes en la zona de Coapa y a lo largo del periférico de norte a sur. En el caso de áreas terciarias, sobresale Polanco y la zona de Santa Fe, donde los CC tienden a integrarse en regiones y complejos terciarios y corporativos de mayor escala; en el norte la zona de Satélite, en Naucalpan y el corredor de Periférico Norte, su prolongación autopista México-Querétaro (Tlalnepantla y Cuautitlán), así como la vía José López Portillo en Coacalco (cuadro 10-4).

A su vez, hay una menor presencia de cc en la zona oriente de la Ciudad de 
Figura 10-4

Zona Metropolitana del Valle de México (ZMVM): centros comerciales (CC) en 2016, de acuerdo con su localización por sectores

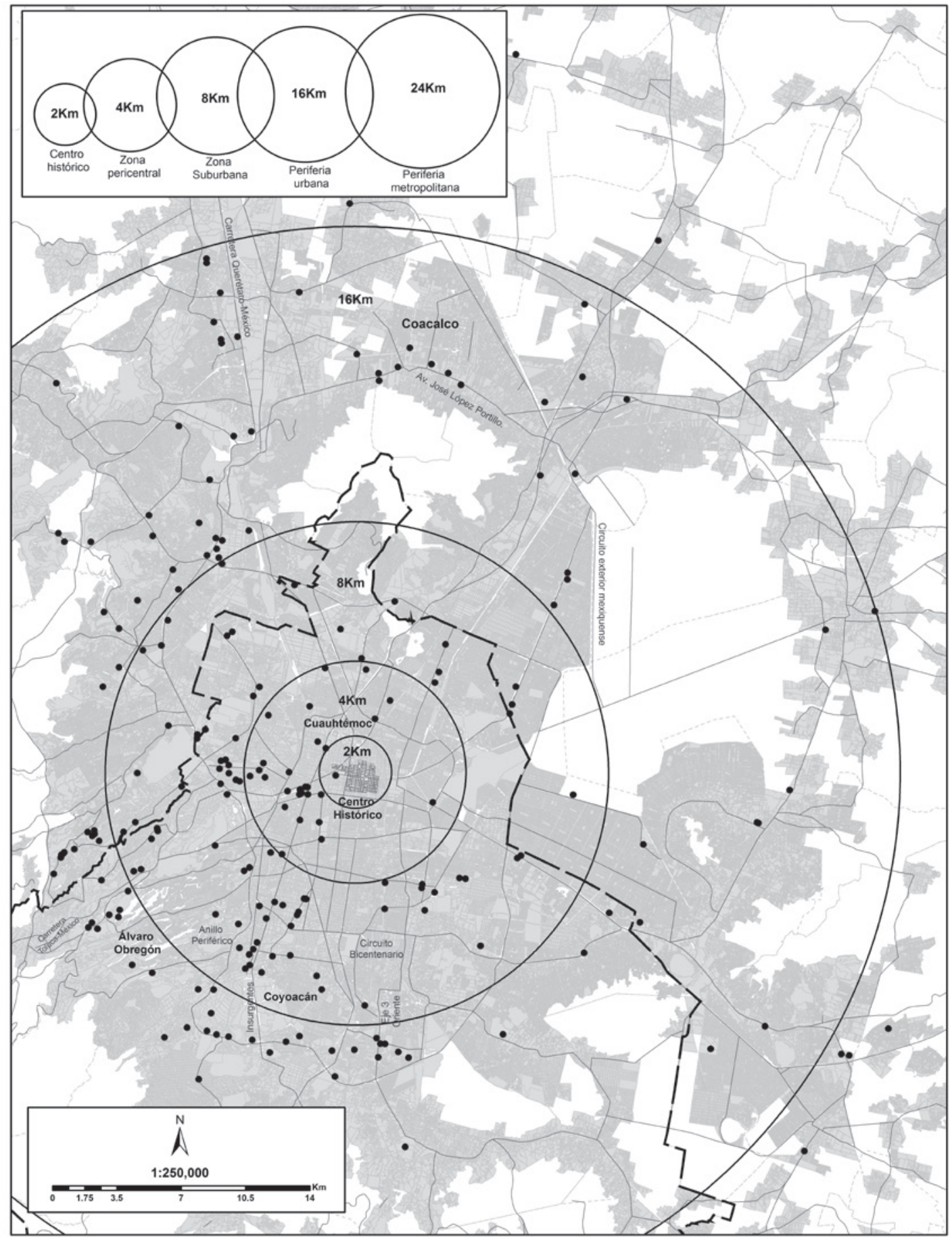


Figura 10-5

Zona Metropolitana del Valle de México (ZMVM): localización de centros comerciales según niveles de calidad de vida objetivo por "manzana"
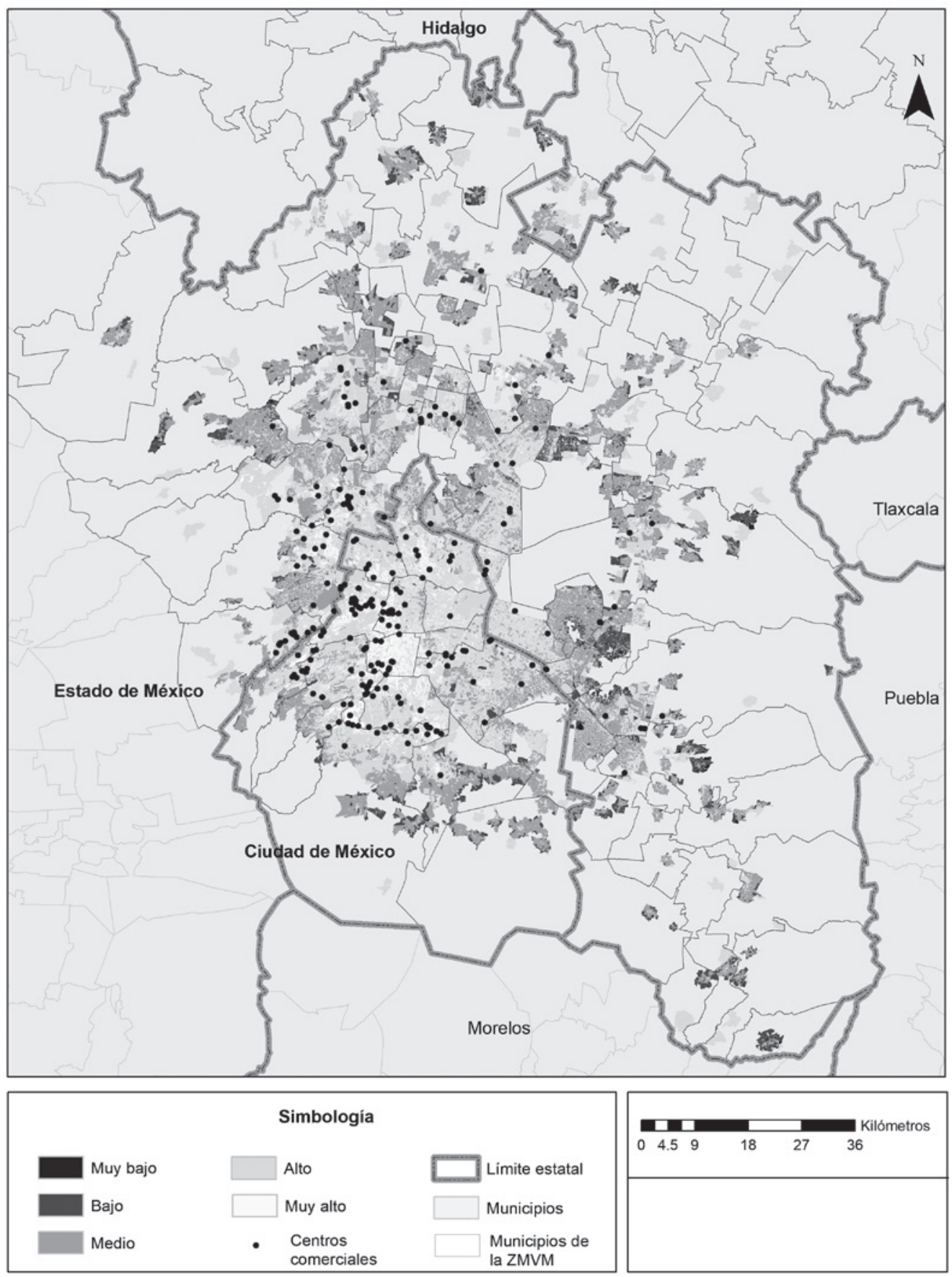

Fuente: Elaboración propia con datos del Instituto Nacional de Estadística y Geografía (INEGI) (2010); M.S.E., medios de comunicación (2015) y páginas de internet de empresas desarrolladoras. 
Figura 10-6

Zona Metropolitana del Valle de México (ZMVM): centros comerciales por área geoestadística básica (AGEB) de acuerdo con las áreas de ingreso (2015). NSE.

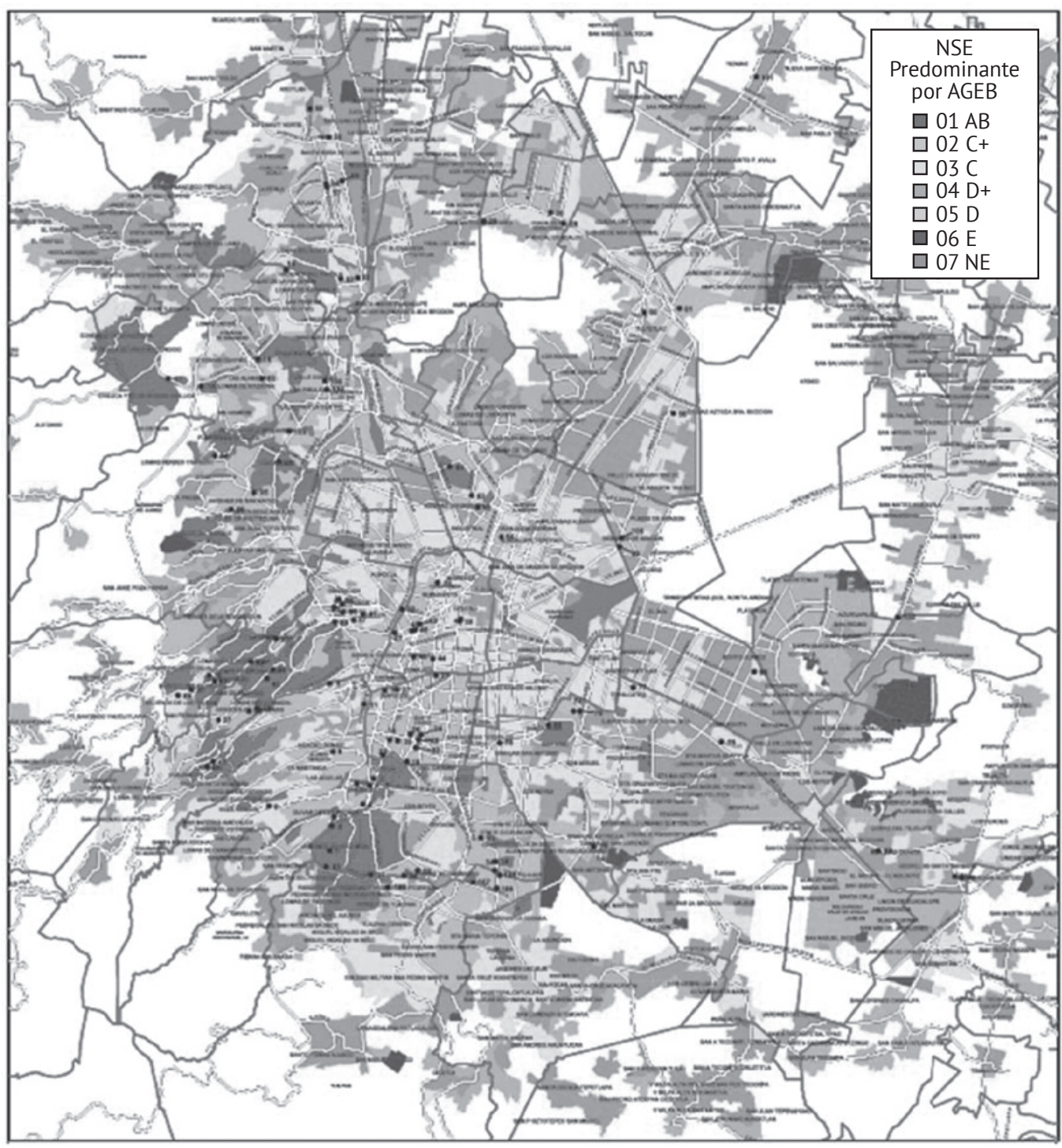

Fuente: "Passion for Shopping" (2015).

México, donde a pesar de ser la de mayor población en la metrópoli, los centros comerciales parecen ser excepcionales. Algunos se ubican, por ejemplo, en la avenida central en Ecatepec, en la zona circundante a la Central de Abasto en Iztapalapa y a lo largo de la avenida Ignacio Zaragoza, algunos favorecidos por la accesibilidad y otros por su proximidad a zonas de ingresos medios. Lo anterior refleja que los CC 
Cuadro 10-4

Zona Metropolitana del Valle de México: centros comerciales (CC) ubicados en distintos corredores comerciales y complejos terciarios

\begin{tabular}{|c|c|c|c|}
\hline Tipo & $\begin{array}{l}\text { Corredores comer- } \\
\text { ciales o complejos } \\
\text { terciarios }\end{array}$ & Ejemplos & $\begin{array}{l}\text { Nú- } \\
\text { mero }\end{array}$ \\
\hline \multirow{3}{*}{$\begin{array}{l}\text { Centros comer- } \\
\text { ciales en grandes } \\
\text { complejos o dis- } \\
\text { tritos terciarios }\end{array}$} & Santa Fe & $\begin{array}{l}\text { Centro comercial “Santa Fe" "Zentrika” "City Walk”, } \\
\text { "Garden Santa Fe" “Park Plaza" "Samara“,"Patio } \\
\text { Santa Fe” }\end{array}$ & 7 \\
\hline & Norte de Polanco & $\begin{array}{l}\text { Plaza “Carso” Centro comercial “Polanco” “Antara } \\
\text { Polanco” }\end{array}$ & 3 \\
\hline & Tlalnepantla & $\begin{array}{l}\text { “Fashion Mall Plaza Tlalne”, Centro “Olimpus”, Mul- } \\
\text { tiplaza “Pirules”, Multiplaza “Arboledas”,“Multimart } \\
\text { Baz”, Multiplaza “Valle Dorado” }\end{array}$ & 6 \\
\hline \multirow{8}{*}{$\begin{array}{l}\text { Ejes terciarios con } \\
\text { presencia de cen- } \\
\text { tros comerciales }\end{array}$} & $\begin{array}{l}\text { Avenida Univer- } \\
\text { sidad y su pro- } \\
\text { longación sobre } \\
\text { Cuauhtémoc }\end{array}$ & $\begin{array}{l}\text { Plaza “Las Manzanas”, “Oasis Coyoacán”, Centro } \\
\text { “Coyoacán”, “Patio Universidad”, Plaza “Universidad”, } \\
\text { “Pabellon Del Valle”,“Universidad 767”,"Parque } \\
\text { Delta”“Pabellón Cuauhtémoc” }\end{array}$ & 9 \\
\hline & $\begin{array}{l}\text { Avenida Miramon- } \\
\text { tes }\end{array}$ & $\begin{array}{l}\text { “Coaplaza”,"Galerías Coapa”, Plaza “Fiesta Coapa”, } \\
\text { Plaza “Soriana Miramontes” }\end{array}$ & 4 \\
\hline & $\begin{array}{l}\text { Insurgentes cen- } \\
\text { tro-sur }\end{array}$ & $\begin{array}{l}\text { Plaza “Niza66”, Plaza “Insurgentes”, “Galerías Insur- } \\
\text { gentes”, Centro “Insurgentes”, Plaza “Inn” }\end{array}$ & 5 \\
\hline & $\begin{array}{l}\text { Avenida Revolu- } \\
\text { ción }\end{array}$ & $\begin{array}{l}\text { "Pabellón Altavista”,"Grand San Ángel”,"Patio Revo- } \\
\text { lución” }\end{array}$ & 3 \\
\hline & $\begin{array}{l}\text { Anillo periférico } \\
\text { segmento ponien- } \\
\text { te sur }\end{array}$ & $\begin{array}{l}\text { “Patio Pedregal”, “Perisur”, “Acora Pedregal”, “Terraza } \\
\text { Pedregal”, Plaza "Santa Teresa”, Centro comercial } \\
\text { "San Jerónimo", “Lomas Plaza”, “Diamante Toreo”, } \\
\text { “Parque Toreo” }\end{array}$ & 9 \\
\hline & $\begin{array}{l}\text { Anillo periférico } \\
\text { segmento poniente } \\
\text { norte y su prolon- } \\
\text { gación Carretera } \\
\text { México-Querétaro }\end{array}$ & $\begin{array}{l}\text { “Pabellón Las Torres”, Plaza “Satélite”,“Mundo E”, } \\
\text { Multiplaza “Pirules”, Multiplaza “Arboledas”, Multi- } \\
\text { plaza “Valle Dorado”,“Perinorte”, Centro comercial } \\
\text { "Cuautitlán-Periférico” }\end{array}$ & 8 \\
\hline & $\begin{array}{l}\text { Vía José López } \\
\text { Portillo }\end{array}$ & $\begin{array}{l}\text { “Cosmopol”, “Coacalco Power Center”, “Paseo Coa- } \\
\text { calco”, Plaza “Las Flores”,"Zentralia Coacalco”, Plaza } \\
\text { “Coacalco” }\end{array}$ & 6 \\
\hline & $\begin{array}{l}\text { Avenida Central } \\
\text { (Carlos Hank Gon- } \\
\text { zález) }\end{array}$ & $\begin{array}{l}\text { Multiplaza “Bosques”, Multiplaza “San Juan”, Multi- } \\
\text { plaza “Vergel”,"Center Plazas Ecatepec”, Multiplaza } \\
\text { "Aragón”, “Mexipuerto Ciudad Azteca” }\end{array}$ & 6 \\
\hline \multirow{2}{*}{$\begin{array}{l}\text { Centros comercia- } \\
\text { les en desarrollos } \\
\text { de usos mixtos } \\
\text { verticales }\end{array}$} & Insurgentes & "Plaza Inn”, Centro “Insurgentes”,"Forum Buenavista” & 3 \\
\hline & $\begin{array}{l}\text { Paseo de la Re- } \\
\text { forma }\end{array}$ & $\begin{array}{l}\text { “Torre Virreyes”, “Torre Diana”, “Reforma 180”, “Torre } \\
\text { Reforma Latino”, “Capital Reforma”, “'Reforma 222” }\end{array}$ & 6 \\
\hline
\end{tabular}

Fuente: Elaboración propia. 
son más escasos en áreas con segmentos de población de menores ingresos, cuyas preferencias y demandas de consumo se llevan a cabo a través de sistemas tradicionales, lo cual refuerza la idea central de este trabajo sobre la estrecha relación entre modalidades de formas y lugares de consumo con los patrones espaciales de la estructura sociorresidencial y la calidad de vida.

\section{CONCLUSIONES}

Los CC son lugares que muestran una de las formas emergentes de organización del consumo y el comercio en las grandes ciudades y metrópolis. Como negocios comerciales, su lógica económica se debe a la tendencia de centralizar la distribución y maximizar el consumo de bienes y servicios. Como proyectos inmobiliarios, la fuerza que los impulsa es la captación de rentas urbanas por grandes inversionistas y firmas de desarrolladores globales y nacionales.

Los CC han tendido hacia una transformación de sus características morfológicas, tamaños y funciones que obedece a una readaptación permanente a nuevos segmentos de población, estratos sociales, entornos urbanos y estilos de vida que se gestan en la ciudad, lo cual hace posible configurar espacios donde se fragmentan, diversifican y tematizan las prácticas de consumo.

Por otra parte, si bien los cc surgieron como fenómenos excepcionales en la Ciudad de México, su difusión hacia zonas consolidadas y periféricas de la metrópoli en los últimos años muestra un proceso de diseminación y patrones espaciales que se van articulando de modo predominante con los segmentos de ingresos medios y altos ingresos, según la estructura sociorresidencial y las condiciones de calidad de vida y del entorno urbano de la metrópoli.

Los Cc forman parte de una reestructuración funcional y de la consolidación urbana pues su expansión suburbana y periférica permite estructurar nuevas áreas, mediante equipamientos para determinados segmentos de población con dificultades para vincularse con las áreas tradicionales de comercio. Por otra parte, la edificación de cc en áreas y corredores pericentrales y suburbanos, impulsados por procesos de regeneración urbana, también ha permitido complementar el equipamiento y la oferta para nacientes desarrollos inmobiliarios de clases medias, y consolidar complejos y áreas terciarias donde se suman a la dinámica integrada de espacios de servicios, hoteles, oficinas y corporativos. En este sentido, el patrón de expansión y localización de los CC en la ZMVM se vincula de forma directa con el índice de calidad de vida estimado por "manzana" o por colonia (capítulo 4). 


\section{BIBLIOGRAFÍA}

Amaya H., Carlos A. (2000), "El rol de los centros comerciales en la organización espacial de las principales aglomeraciones urbanas de Venezuela", Revista Geográfica Venezolana, vol. 50, núm. 2, pp. 263-286.

Guénola Capron y Bruno Sabatier (2007), "Identidades urbanas y culturas públicas en la globalización. Centros comerciales paisajísticos en Río de Janeiro y México", Alteridades, vol. 17, núm. 33.

Cornejo, P. Inés (2007), El lugar de los encuentros: comunicación y cultura en un centro comercial, México, Universidad Iberoamericana.

ICSC (2015), Shopping Centers America's first and foremost marketplace, International Council of Shopping Centers, Inc.

Ramírez Kuri, Patricia (1993), "Centro comercial 'Coyoacán", en Transformaciones espaciales y modernización urbana: la Ciudad de México y los macroproyectos comerciales (19891993), octubre, Tesis de Maestría en Estudios Regionales, México, Instituto de Investigaciones “Dr. José María Luis Mora", 168 pp.

López, L. Liliana (1999), Centros comerciales: espacios que navegan entre la realidad y la ficción, México, Nuestro Tiempo.

Medina C., Federico (1997), "Centro comercial: una burbuja de cristal", Estudios sobre las Culturas Contemporáneas, vol. 4, núm. 8, pp. 61-91.

Paquette, Catherine (2007), "Comercio y planificación urbana: las nuevas grandes centralidades comerciales en los planes de desarrollo urbano de la Ciudad de México, Revista Trace, núm. 51.

Passion for Shopping (2015), "Bases de datos sobre centros comerciales en el Distrito Federal y el Estado de México", ms.

Pintaudi, M. Silvana y Heitor Frúgol (1992), Shopping centers. Espaço, cultura e modernidade nas cidades brasileiras, San Paulo, Editora Universidad Estadual Paulista.

Vecslir, Lorena y Pablo Ciccolella (2011), "Relocalización de las actividades terciarias y cambios en la centralidad en la Región Metropolitana de Buenos Aires", Revista de Geografía Norte Grande, núm. 49, pp. 63-78. 


\section{El comercio informal y sus efectos en la calidad de vida de los habitantes de la Ciudad de México`}

Carlos Bustamante Lemus

\section{INTRODUCCIÓN}

El objetivo de este trabajo es mostrar que la insuficiente o casi inexistente regulación de las actividades económicas informales en la vía pública de la Ciudad de México, durante los últimos 40 años, ha repercutido en el deterioro de la calidad de vida de los habitantes de esta ciudad. En el caso de ciudades de gran tamaño y consolidadas, como la ZMVM, la demostración incluye la hipótesis de que las actividades informales, en particular las comerciales, tienden a destruir el espacio público, se convierten en focos de conflicto social y político, deterioran la calidad de vida de los habitantes y, por último, destruyen ciudadanía.

\section{EL ESPACIO PÚBLICO Y LA CALIDAD DE VIDA URBANA}

Con el desarrollo del capitalismo, los centros industriales y comerciales urbanos (como espacios concentradores del capital, la producción, el intercambio y el consumo de bienes y servicios diversos) demandaron la construcción de elementos de infraestructura y equipamiento que fueron transformando a gran velocidad el territorio. El rápido proceso de urbanización en el mundo, en particular, el concepto de espacio público, se ha estudiado con diferentes enfoques. Por ejemplo, en la perspectiva neomarxista de Lojkine (1981), se considera el espacio público como parte de

* El autor agradece la valiosa colaboración de la Urbanista Natalia Romero Piedrabuena en la realización de este capítulo, en particular, en la investigación teórica y en el trabajo de campo en los CETRAMS de Tacuba y Tacubaya. 
los bienes comunes o medios de consumo colectivo, es decir, aquellos espacios que el modo de producción capitalista a través de las inversiones en su infraestructura va creando, pero como una forma de trasladar el costo de reproducción de la fuerza de trabajo a la propia clase trabajadora; es decir, calles, transporte, alumbrado, drenaje y otros son bienes necesarios para el funcionamiento del aparato productivo-distributivo que el sistema capitalista requiere para su reproducción; sin embargo, los costos utilizados para su construcción y mantenimiento se trasladan de manera individual a la población.

Subirats (2016), explora el espacio público como bien común; con apoyo en varias concepciones teóricas, cita a Hardin (1968) diciendo:

[...] un bien común es algo de todos, no es de nadie, y cada quien puede decidir aprovecharse de ello utilizándolo o consumiendo lo más que pueda en el menor tiempo posible" (p. 75). Sin embargo, la explicación que el autor da a esta aseveración es que apunta a que los bienes comunes no pueden dejarse solo en manos de quienes los usaban, ya que ello conllevaría su ruina, al prevalecer siempre el interés individual por encima de una perspectiva más amplia de beneficio colectivo [...] (ibid.).

De ahí que el autor infiere la necesidad de una intervención por parte de una autoridad, con objeto de regular su uso, de manera que no se apropie un solo individuo o unos cuantos de dicho bien común, privando de su disfrute a la colectividad, lo cual derivaría de modo irremisible a conflictos sociales. También advierte sobre el debate que el concepto de "propiedad" tiene con el espacio público, pues señala con sustento en Rodotá (2011), que un bien común puede suponer una lógica de "no propiedad y un enfrentamiento con las visiones hegemónicas de propiedad privada o propiedad estatal bien consolidadas en la contemporaneidad que, de hecho, han sido presentadas como si se tratara de un juego de suma cero en el que la mayor o menor proporción de propiedad privada en relación con un determinado bien lleva aparejado, en sentido complementario, una mayor o menor proporción de propiedad estatal (Subirats, op. cit.: 80). A su vez, un planteamiento más amplio es el de Borja y Muxí: "[...] el espacio público es la ciudad [...] puede ser un elemento fundamental para lograr la nueva urbanización de las implantaciones desurbanizadas" (Bohígas, 2000).

En el mundo subdesarrollado, algunos especialistas defienden la tesis de que el comercio informal en espacios abiertos construye espacio público. En ciudades de 
África, Medio Oriente, sur de Asia y América Latina, donde existe infraestructura y equipamiento urbanos precarios, los comerciantes al menudeo ofrecen sus mercancías en espacios abiertos, los cuales, con el tiempo y la costumbre, adquieren el reconocimiento entre las autoridades y la población, como áreas de mercado público y creación de espacio urbano, sin importar que los comerciantes sigan operando en la calle, o que las autoridades emprendan o no alguna acción para ofrecer espacios más apropiados y puedan liberarse las calles para el tránsito sin obstáculos de vehículos y peatones.

Otros estudiosos en grandes ciudades de América Latina, como Ramírez (2016), definen el espacio público urbano como:

[...] espacio de encuentro, comunicación y de relación entre diferentes miembros de la sociedad urbana: grupos etarios, etnias, géneros y clases sociales, quienes en la experiencia cotidiana usan y se apropian de los lugares asignándoles significados distintos. En la ciudad contemporánea, las calles y plazas, son escenarios donde se construye el espacio de lo público como lugar común donde actores sociales con posiciones e intereses diferentes, contrapuestos y a veces irreconciliables, viven la ciudad y se disputan el acceso a bienes públicos (Ramírez, 2016: 99).

En este proceso aparecen diferentes formas de socialización, relaciones de poder, de confrontación, cooperación y solidaridad, entrelazados con fenómenos de inseguridad, temor y violencia, que alteran el sentido de lo público como bien común, espacio de todos y lugar donde se construye la ciudadanía.

Estas formas de apropiación del espacio público urbano se tratan de explicar como un supuesto fenómeno de "reinvención del espacio público". Lo anterior podría justificarse en lugares donde se carece de usos de suelo definidos o construidos con infraestructura o equipamiento o ambos, o como algunas áreas periféricas en proceso de ocupación por pobladores, vivienda u otros asentamientos, pero que no poseen todavía una definición en cuanto a usos de suelo. Este fenómeno, sin embargo, no es el caso donde existen ya usos de suelo (vialidades, parques, jardines, lotes públicos baldíos, pero residenciales o industriales) y que se invaden y ocupan de manera permanente o semipermanente a través de actividades informales en la calle, llámense comerciantes, vendedores, taxistas, transportistas concesionados de carga y pasajeros, talleres mecánicos en la calle, mueblerías, etcetera.

Hay que advertir que algunos planteamientos y reflexiones teóricas podrían ser peligrosas, en el sentido que describen formas de ciudad o de ocupación laboral a 
favor del neoliberalismo, que justifican las acciones del capital, el libre mercado y algunas actividades de gobierno, las cuales a su vez causarían los guetos, el caos por la ocupación de los espacios y la administración política de los conflictos sociales.

También hay otro frente [...] más sutil y, por tanto, más peligroso, corresponde a los que dicen que, si bien la forma urbana $-y$, como consecuencia, la ordenación del espacio público- es un factor de aglutinamiento social y de creación de identidades, esta aglutinación puede convertirse en un elemento negativo -e incluso subversivo- para la buena convivencia en libertad. El mantenimiento del espíritu de vecindad, el refuerzo de las identidades a través de la forma, la aceptación de la imagen representativa de lo que es público, puede acabar enmascarando la realidad de los problemas insalvables de la vida colectiva e, incluso, puede ser un germen de clasificación social agresiva y, finalmente, un punto de partida para solidificar los guetos. Por tanto, la ciudad radicalmente libre sería la ciudad sin forma, sin barrios, sin calles ni plazas. Una ciudad en la cual el espacio público no sea urbano (Bohígas, Prólogo, en Borja y Muxí, 2000: 4-5).

Estos autores enfatizan que el espacio público define la ciudad, porque indica la "calidad de vida" de la gente, de su ciudadanía y de sus habitantes. En este sentido, se sostiene la idea que la calidad de vida se relaciona con la calidad del espacio proporcionada por la ciudad.

La historia de la ciudad es la de su espacio público. Las relaciones entre los habitantes y entre el poder y la ciudadanía se materializan, se expresan en la conformación de las calles, las plazas, los parques, los lugares de encuentro ciudadano, en los monumentos. La ciudad entendida como sistema, de redes o de conjunto de elementos -tanto si son calles y plazas como si son infraestructuras de comunicación (estaciones de trenes y autobuses), áreas comerciales, equipamientos culturales, es decir, espacios de uso colectivo debido a la apropiación progresiva de la gente- que permiten el paseo y el encuentro, que ordenan cada zona de la ciudad y le dan sentido, que son el ámbito físico de la expresión colectiva y de la diversidad social y cultural. Es decir, que el espacio público es a un tiempo el espacio principal del urbanismo, de la cultura urbana y de la ciudadanía. Es un espacio físico, simbólico y político (Borja y Muxí, 2000). 
Por todo ello, es posible definir como espacio público al lugar donde toda persona tiene derecho al tránsito, el descanso y el libre esparcimiento o la recreación, donde no hay restricciones para ninguna persona. Para el caso del espacio público urbano, es el lugar, área espacial, terrestre, acuática o ambiental en general, donde todos los ciudadanos pueden transitar, descansar, conversar y divertirse, manifestarse de forma pública, o simplemente disfrutar del esparcimiento en completa libertad. Sin embargo, en este espacio existen reglas y normas jurídicas y sociales que sirven para vigilar y controlar el cumplimiento de dichas normas, muchas de las cuales han estado ausentes en el caso del Gobierno de la Ciudad de México, en particular, ante las actividades económicas informales realizadas en los espacios públicos.

\section{LAS ACTIVIDADES INFORMALES EN LOS ESPACIOS PÚBLICOS DE LA CIUDAD DE MÉXICO}

En la Ciudad de México, los espacios urbanos (como calles y avenidas, mercados, parques y jardines) y las estaciones de servicio de transporte público (como los centros de transferencia multimodal [Cetram], incluidos "Metro", trenes, trolebuses y autobuses urbanos) se consideran parte de la infraestructura y los servicios urbanos, es decir, son fundamentales para el funcionamiento de la vida urbana en su dinámica de desarrollo y son responsabilidad del Gobierno de la Ciudad de México y de las delegaciones políticas del gobierno de la ciudad, tanto su construcción como su mantenimiento, como parte del aprovisionamiento de los servicios públicos urbanos.

Por lo general, las autoridades del gobierno capitalino argumentan no contar con los recursos presupuestarios suficientes para el cuidado y el mantenimiento de estos espacios públicos de utilidad primaria, los cuales son el soporte para el funcionamiento de las actividades económicas y sociales de la ciudad y la movilidad de sus habitantes que requieren Ilegar a su empleo, escuela u hogar, lo cual significa una necesidad básica.

La falta de atención prioritaria al aprovisionamiento y el mantenimiento de este tipo de servicios en los espacios públicos ha favorecido su ocupación por actividades económicas informales, por ejemplo las desarrolladas de manera individual o colectiva por las agrupaciones de comerciantes y transportistas informales liderados por personajes beligerantes respaldados por políticos, jefes policiacos o funcionarios influyentes, que se apropian de los espacios públicos urbanos.

La informalidad ha penetrado casi todas las esferas de la actividad económica (industrial, comercial, servicios), social, política y cultural. Precisamente por la 
escasa o insuficiente regulación oficial, en algunas de estas actividades se mezclan y fusionan acciones legítimas, aunque sin registro oficial, con una importante cantidad de prácticas delictivas, como contrabando, piratería, venta de artículos robados y tráfico de enervantes, entre otros.

\section{EL COMERCIO Y LA CALIDAD DE VIDA EN LA CIUDAD DE MÉXICO}

Las actividades económicas se han expandido en varios territorios urbanos o están en proceso de que el crecimiento de las ciudades las absorba; entre ellas, destacan los concesionarios particulares del transporte público (autobuses, microbuses y taxistas), quienes amplían sus rutas de servicio y deciden de modo unilateral la ubicación de sus bases terminales para sus unidades de transporte en las calles, en lugar del uso de estacionamientos particulares cerrados; o los "sitios de taxis" logran permisos de las autoridades locales sin consultar a la población o a los residentes locales. Lo mismo sucede con los comerciantes en espacios públicos abiertos, como lotes baldíos, parques y jardines, calles y avenidas.

Los grupos organizados realizan estas prácticas y deciden sobre los espacios a ocupar, con mínima regulación y gran tolerancia por parte de diversas autoridades locales, (funcionarios delegacionales, agentes de policía judicial o preventiva, políticos de diversas filiaciones y otros), pero sin control de los espacios, usos de suelo o sin considerar posibles afectaciones a terceros, como ciudadanos residentes locales, empresarios y comerciantes del lugar establecidos de manera formal o legal, así como a la ciudadanía en general, aparte de los bloqueos al tránsito peatonal o vehicular, la ocupación de espacios públicos urbanos, y la generación de ruido, suciedad o deterioro ambiental.

Entre estos sectores, se analizan los comerciantes informales en espacios públicos de la Ciudad de México. Al respecto, existen antecedentes sobre el comercio desde la época prehispánica, en la Gran Tenochtitlán, se desarrollaba en los espacios públicos abiertos, donde tanto los comerciantes como los compradores acudían desde grandes distancias a efectuar sus operaciones de intercambio de bienes y servicios; autoridades de gobierno asignaban, distribuían, supervisaban y controlaban esos espacios de forma racional. Con la "Conquista" y la colonización del imperio español, esas actividades comerciales continuaron operando y expandiéndose hacia otros espacios abiertos donde la concentración de población y demás factores de localización (como el acceso a las principales vías de comunicación, terrestre y lacustre) les fueron favorables. La administración y la regulación del comercio continuaron 
bajo la autoridad colonial española y crecieron durante la época independiente, en el "porfirismo" y en la Revolución Mexicana, con creación de nuevos espacios mercantiles públicos con cierto grado de regulación.

\section{Etapa de modernización urbana con mercados bajo techo (1920 a 1970)}

A partir de los gobiernos postrevolucionarios, la Ciudad de México comenzó a adquirir una nueva imagen urbana; se fueron creando nuevos instrumentos legales y normativos, así como modernos espacios públicos con calles y avenidas, medios de transporte eléctrico y terrestre, y mejoramiento de parques y jardines.

En relación con los mercados en la vía pública se emprendió su modernización, y casi todos se relocalizaron en áreas de venta al menudeo, construidos bajo techo para los mismos locatarios que ocupaban las calles y con un reglamento general. Hacia mediados de la década de 1970, se construyeron 314 mercados públicos techados en colonias populares y residenciales de clase media, sin que los locatarios perdieran su clientela y prestigio, con la total aceptación de consumidores, residentes locales y ciudadanía en general. La población capitalina ganó nuevos espacios públicos por la liberación de las calles donde solían asentarse los mercados-tianguis a cielo abierto, por más vialidades y áreas peatonales libres de basura orgánica e inorgánica y por mercados nuevos, organizados y regulados que ofrecían un servicio a la población con mayor higiene y a los mismos precios al menudeo como solía ser en las calles.

La más reciente información indica que se tiene el mismo número de 314 mercados públicos techados con 63807 locales (Sedeco, 2014). El número de oferentes o locatarios no está completo pues varias delegaciones no registran información, pero con un promedio de dos vendedores por local y entre 2 y 4.5 metros cuadrados, se estiman cerca de 128000 vendedores. La mayor concentración de ellos se localiza en las delegaciones Cuauhtémoc (22.3\%), Gustavo A. Madero (15.5\%), Venustiano Carranza (14.1\%) y Miguel Hidalgo (10.5\%). En la fecha en que se cerró el programa de construcción de mercados públicos populares, la ciudad aún no se había extendido tanto, como luego fue el caso de las delegaciones Azcapotzalco, Iztapalapa y Benito Juárez.

\section{Etapa de involución del comercio popular (1970 a 1990)}

Desde finales de los años sesenta, la economía mexicana comenzó a sentir los efectos de la recesión económica mundial. Esta situación se reflejó principalmente en menor crecimiento económico, aumento del desempleo manufacturero, rápidos 
incrementos de los precios de los productos de consumo no duradero, salarios depreciados, desmesurados endeudamientos externo e interno y adelgazamiento del gasto público. En el ámbito de la Ciudad de México, el gobierno federal y el Departamento del Distrito Federal emprendieron en 1970, como una de las respuestas a las demandas de productores agrícolas explotados por el intermediarismo y a las de consumidores con bajo poder adquisitivo, lanzaron el programa de los "mercados sobre ruedas", por conducto de la entonces Secretaría de Industria y Comercio, ${ }^{1}$ hoy día Secretaría de Economía.

Este programa consistió en organizar tianguis itinerantes a lo largo de las semanas en zonas populares definidas por las propias autoridades, en los cuales estas permitían la participación de productores del campo, para ofrecer sus productos a menor precio, sin la intermediación de los bodegueros ni intermediarios mayoristas, todo bajo control de oficiales de gobierno en el propio mercado que supervisaban pesos y medidas, así como precios más o menos uniformes al consumidor urbano. Dicho programa, al paso de los años, comenzó a deformarse al permitirse el ingreso a los propios introductores, bodegueros y mayoristas de productos de consumo básico, quienes, a final de cuentas y hasta la fecha, influyen en los precios de los productos perecederos en los tianguis capitalinos.

En los años ochenta, como resultado del decremento de los precios mundiales del petróleo, el Estado mexicano impuso un "Programa de ajuste estructural", instrumentado con una política macroeconómica de austeridad dirigida a disminuir la deuda pública mediante reducciones sistemáticas del gasto público, restricciones al crédito, aumentos en las tarifas de los bienes y servicios públicos, devaluaciones, incrementos a los precios de los artículos de consumo, contención de los salarios y renegociaciones de la deuda externa, incluida la reconversión industrial.

El costo social de estas medidas fue y sigue siendo muy grave para la población y sus niveles de vida. Sólo en los dos primeros años del "ajuste estructural" (1983 a 1984), la tasa de desempleo aumentó de alrededor de 5 a casi $15 \%$ de la fuerza de trabajo (más de 3.5 millones de personas); en 1985, el poder adquisitivo de un trabajador asalariado se había deteriorado $35 \%$ en relación con 1982. Con la crisis de ese año, 300000 trabajadores en todo el país perdieron su empleo y el sector servicios funcionó como válvula de escape, al generar en el mismo año 120000 empleos. En 1983, la pérdida de puestos de trabajo fue todavía mayor al reducirse el producto in-

${ }^{1}$ En este programa "[...] se rescataba la tradición de los tianguis prehispánicos y se favorecía la venta directa en las calles capitalinas de productos perecederos de consumo básico a los mismos precios de la Central de Abasto de 'La Merced'"' (SIC, 1970). 
terno bruto del país menos 5.3\%. El sector más afectado fue el industrial, pues su producción bajó de -1.6\% en 1982 a -8.1\% en 1983, lo cual se reflejó de inmediato en las tasas de ocupación que disminuyeron a poco más de 500000 trabajadores. La cifra de desempleados y "ocupados no remunerados" rebasó en ese año el millón de personas, con aumento de la cifra nacional a casi 5 millones de personas (Naufal, 1987).

El gobierno del Departamento del Distrito Federal suspendió desde la segunda mitad de la década de 1970 su programa de construcción de mercados públicos al menudeo bajo techo y conservó solo su atención en el mantenimiento de los existentes. Incluso la idea original de suprimir el mercado de abasto (establecido y ambulante) del barrio de "La Merced" y calles aledañas del centro de la ciudad, con la gran fuente de trabajo que constituye para abarroteros, vendedores de bisutería, de ropa y alimentos preparados, cargadores, diableros, etc., no pudo ni ha podido lograrse a pesar de la construcción de la nueva "Central de Abasto" en Iztapalapa, el sureste de la ciudad en el decenio de 1980.

\section{Etapa reciente (1990 a 2010)}

En un entorno de crisis económica, política y de confianza, agudizada con los fuertes terremotos que azotaron principalmente la Ciudad de México, la sociedad civil y los pequeños empresarios manufactureros y comerciantes tuvieron que sacar fuerzas para sobreponerse de manera autosuficiente, al margen del apoyo y de respuestas de un aparato estatal con legitimación decadente y que, a falta de recursos y opciones para ofrecer a sus gobernados una forma de vida y empleo decorosos, únicamente le quedó publicitar en los medios masivos de comunicación slogans, como: “iEmpléate a fondo... empléate a ti mismo!", “Tenemos ingenio, tenemos talento para progresar!"; “¡Mexicano: tú puedes!”, y otros. Para el año 1990, la Cámara de Comercio de la Ciudad de México estimaba que existían ya en 1989 más de 112000 negocios informales en la vía pública (Canaco, 1990).

\section{EL COMERCIO INFORMAL EN LA VÍA PÚBLICA DE LA CIUDAD DE MÉXICO}

El rápido crecimiento y la expansión territorial de los comerciantes en los últimos 30 años se han instalado en múltiples calles de la capital, parques, estaciones de trenes, autobuses y minibuses de pasajeros; se les encuentra en casi todos los espacios públicos abiertos para tránsito o recreación, donde ofrecen al peatón o al automovilista servicios diversos e infinidad de productos de consumo. De la misma forma, en calles y avenidas principales se advierten por doquier puestos fijos y semifijos de 
comerciantes, vendedores (tianguistas), con sus vehículos estacionados casi todo el día, con los cuales transportan, cargan y descargan su mercancía, lo cual ocasiona de manera continua bloqueos al tránsito vehicular, peatonal y residencial. Con lo anterior, se ha creado una imagen urbana con graves conflictos por ocupaciones "callejeras" que está ocasionando deterioro general, en términos de seguridad, higiene y contaminación del ambiente (basura, ruido y desechos orgánicos e inorgánicos al aire libre y en el drenaje, etcetera).

La más reciente información que el Instituto Nacional de Estadística y Geografía (INEGI) ha recopilado y procesado sobre el sector informal en el Distrito Federal (2014) registra una ocupación informal total de 1117000 personas en el Distrito Federal, mismas que conforman más de $50 \%$ de la ocupación total en esta ciudad (ENOE, 2014). De ellos, 820000 se encuentran en el sector terciario de la economía, donde 35\% (287 000) desempeña actividades comerciales y 19\% (157 000) en el transporte. Dentro de esta estimación, 287000 comerciantes informales se encuentran en alrededor de 200000 establecimientos en la calle. Este trabajo describe cuatro formas de comercio llamado "ambulante", sin considerar a miles de vendedores itinerantes (en realidad ambulantes) que se distribuyen por calles, avenidas y colonias populares, ofreciendo sus mercancías o servicios o ambos: a) concentraciones de ambulantes; b) "mercados sobre ruedas"; c) tianguis-bazar, y d) puestos fijos en la vía pública (mapa 11-1).

\section{Las concentraciones de ambulantes}

Estas se caracterizan por el alto número de vendedores que establecen sus puestos (provisionales o desmontables con facilidad) en zonas con gran afluencia de consumidores, como el centro de la ciudad, La Merced, Tepito, La Lagunilla, las calles de Correo Mayor, y las avenidas México-Tacuba, Jalisco, San Cosme, Ignacio Zaragoza, y otras. Cada una de estas concentraciones tiene su organización surgida por el liderazgo de una persona o un pequeño grupo, con cierta habilidad para establecer los contactos indispensables entre los funcionarios representantes de la autoridad local que expiden los "permisos" correspondientes para que lleven a cabo tal actividad comercial.

Las redes de liderazgo forman parte de un sistema de control orientado a asegurar que los agremiados brinden su apoyo incondicional y obligatorio a las autoridades, los procesos electorales o su respaldo político para algún partido, en especial al oficial (antes el Partido Revolucionario Institucional (PRI) y ahora también divididos entre Partido de la Revolución Democrática (PRD), PRI, Partido del Trabajo (PT) y, de 


\section{Mapa 11-1}

Ciudad de México: localización de comercio en vía pública

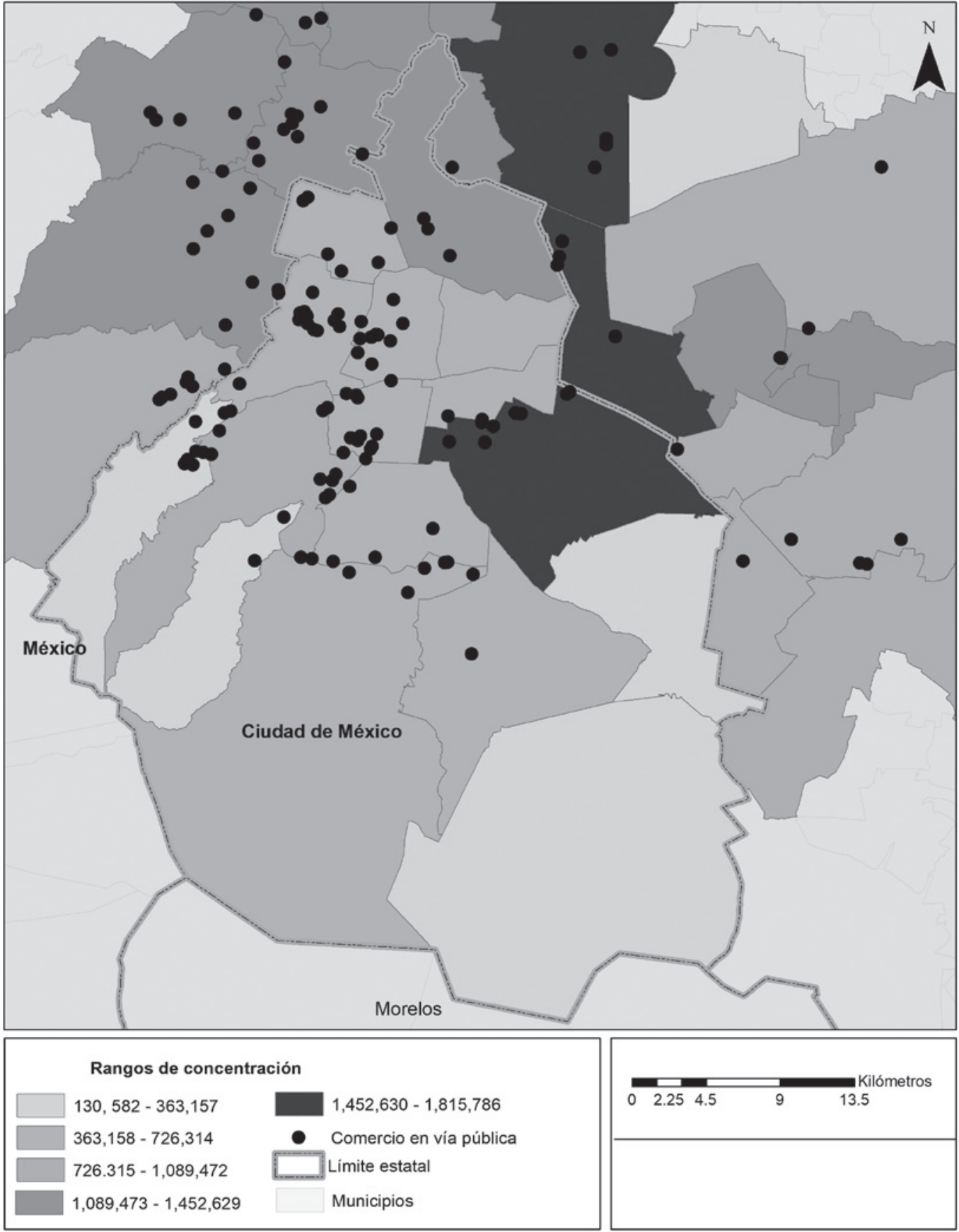

Fuente: Elaborado por Pamela Gutiérrez con datos del Gobierno del Distrito Federal (GDF), Secretaría de Desarrollo Económico. 
modo marginal, el Partido Acción Nacional (PAN). Así, el líder de la organización casi siempre está ligado de manera directa o indirecta con algún alto funcionario representante de la autoridad gubernamental, política, administrativa, judicial, policiaca y hasta militar. Este tipo de ambulantes opera a determinadas horas del día; por ello, mediante un equipo móvil, traslada su puesto y mercancía. En muchos casos, casas, vecindades, edificios y oficinas aledañas sirven para guardar durante la noche todo el puesto.

Las concentraciones de ambulantes en la vía pública han proliferado de forma veloz en la Ciudad de México y los centros tradicionales de los municipios conurbados del Estado de México. Los casos más agudos se encuentran en las delegaciones Cuauhtémoc, Venustiano Carranza, Iztapalapa, Gustavo A. Madero y Miguel Hidalgo; así como Ecatepec, Nezahualcóyotl, Los Reyes y Valle de Chalco, en el estado de México.

\section{Los "mercados sobre ruedas"}

En este tipo de comercio, se expendían sólo artículos de consumo básico y ahora es posible encontrar también bisutería y artículos para el hogar, electrónicos y no electrónicos, de producción nacional y extranjera. En el año 1991, el gobierno de la capital tenía registradas 70 ubicaciones de "mercados sobre ruedas"; 53 de ellos estaban en el Distrito Federal y 17 en los municipios conurbados del Estado de México y ocupaban a 4335 comerciantes, con quienes se permitía abarcar lugares de mercadeo toda la semana por medio de 10 rutas. En el 2003, ya se tenían registrados 8073 puestos instalados en estos mercados y su administración se ha transferido en años recientes al gobierno de la Ciudad de México (cuadro 11-1).

\section{Los tianguis-bazar}

Al inicio, se ubicaban sobre todo en terrenos baldíos privados o públicos, levantados con material portátil para funcionar sábados y domingos y, en ocasiones, un día entre semana. Hoy, ya se establecen también en la vía pública. La autoridad responsable de otorgar los permisos y registros a los tianguistas es el Gobierno del Distrito Federal (GDF) (o gobierno de la Ciudad de México), por medio de la Secretaría de Desarrollo Económico y de la Comisión de Abasto (Coabasto); en algunos casos, estas instituciones se apoyan en las delegaciones políticas para efectos de seguridad, tránsito, vialidad y limpieza. Para el año 2010, se registraban 152665 oferentes, lo cual refleja un incremento medio anual de 4940 trabajadores en este tipo de mercados (datos de Sedeco y del GDF). Algunos de los tianguis más destacados en el Dis- 
Cuadro 11-1

Distrito Federal: "mercados sobre ruedas", puestos fijos y semifijos (2009)

\begin{tabular}{|c|c|c|c|}
\hline \multicolumn{4}{|c|}{ Distribución de "mercados sobre ruedas" y puestos fijos y semifijos en el Distrito Federal } \\
\hline & 2003 & 2009 & 2009 \\
\hline Delegación & $\begin{array}{c}\text { Puestos en "mercados } \\
\text { sobre ruedas" }\end{array}$ & Puestos fijos & $\begin{array}{c}\text { Puestos fijos } \\
\text { y semifijos }\end{array}$ \\
\hline Azcapotzalco & 516 & 640 & 6155 \\
\hline Álvaro Obregón & 646 & 280 & 2687 \\
\hline Benito Juárez & 389 & 413 & 2040 \\
\hline Cuajimalpa de Morelos & 109 & 66 & 889 \\
\hline Cuauhtémoc & 705 & 13 & 24046 \\
\hline Coyoacán & 841 & 71 & 3707 \\
\hline Miguel Hidalgo & 623 & 852 & 9177 \\
\hline Iztacalco & 473 & 234 & 7784 \\
\hline Milpa Alta & -- & 2 & 838 \\
\hline Magdalena Contreras & 340 & 9 & 2776 \\
\hline Gustavo A. Madero & 2013 & 200 & 13238 \\
\hline Tlalpan & 280 & 602 & 5044 \\
\hline Tláhuac & 128 & 27 & 3428 \\
\hline Venustiano Carranza & 88 & 475 & 9573 \\
\hline Xochimilco & -- & 128 & 5906 \\
\hline Iztapalapa & 922 & 27 & 16784 \\
\hline Total & 8073 & 4039 & 114072 \\
\hline
\end{tabular}

Fuente: Gobierno del Distrito Federal (GDF), Secretaría de Desarrollo Económico.

trito Federal, por el tamaño de su concentración, son los de: "San Felipe", "Cárcel de Mujeres", "Lagunilla", "Pericoapa", "Balbuena", "Zaragoza", "Aerotianguis", "Perisur", "Chopo", "Lindavista", "Bazar Universitario", "Águilas", "Chapultepec", "San Ángel" y "Súllivan" (cuadro 11-2).

\section{Los puestos fijos y semifijos en la vía pública}

Expenden en la calle, en especial alimentos preparados, prendas de vestir y bisutería; en los últimos años, han constituido un problema grave para los comerciantes establecidos, la población residente donde se asientan y los consumidores, debido a las condiciones de insalubridad e inseguridad con que operan. A finales de 1988, la Cámara Nacional de Comercio (Canaco) detectó la existencia de más de 14000 puestos metálicos en el Distrito Federal y, para el 2009, el GDF tenía registrados 4039 puestos fijos y más de 134072 puestos semifijos. 
Cuadro 11-2

Distrito Federal: distribución y evolución de los tianguis (1988 a 2010)

\begin{tabular}{|c|c|c|c|c|}
\hline \multicolumn{5}{|c|}{ Distribución de tianguis (mercados móviles) en el Distrito Federal (1988 a 2010) } \\
\hline \multirow[b]{2}{*}{ Delegación } & \multicolumn{2}{|c|}{ Número de oferentes } & \multirow[b]{2}{*}{ Incremento } & \multirow{2}{*}{$\begin{array}{c}\text { Tasa de } \\
\text { crecimiento \% }\end{array}$} \\
\hline & Año 1988 & Año 2010 & & \\
\hline Azcapotzalco & 2800 & 7010 & 4210 & 4.3 \\
\hline Álvaro Obregón & 3400 & 6859 & 3459 & 3.2 \\
\hline Benito Juárez & 3300 & 6558 & 3258 & 3.2 \\
\hline Cuajimalpa de Morelos & 857 & 1477 & 620 & 2.5 \\
\hline Cuauhtémoc & 3200 & 6133 & 2933 & 3.0 \\
\hline Coyoacán & 4000 & 17194 & 13194 & 6.9 \\
\hline Miguel Hidalgo & 2300 & 2027 & -273 & -0.6 \\
\hline Iztacalco & 3100 & 6578 & 3478 & 3.5 \\
\hline Milpa Alta & 230 & 288 & 58 & 1.0 \\
\hline Magdalena Contreras & 950 & 2100 & 1150 & 3.7 \\
\hline Gustavo A. Madero & 12100 & 27933 & 15833 & 3.9 \\
\hline Tlalpan & 3400 & 6711 & 3311 & 3.1 \\
\hline Tláhuac & 650 & 1092 & 442 & 2.4 \\
\hline Venustiano Carranza & 3100 & 4924 & 1824 & 2.1 \\
\hline Xochimilco & 600 & 546 & -54 & -0.4 \\
\hline Iztapalapa & -- & 55235 & -- & -- \\
\hline Totales & 43987 & 152665 & 53443 & 42 \\
\hline
\end{tabular}

Fuente: Secretaría de Desarrollo Económico.

Los datos de la investigación de la Canaco eran indicadores muy importantes para cuantificar el comercio en vía pública en el Distrito Federal; sin embargo, algunos datos deberían tomarse sólo como referencia, ya que no hay una normatividad para establecer un determinado número de puestos en la vía pública (excepto en vialidades primarias, como Eje Norte 1, San Cosme, calzada México-Tacuba, San Antonio Abad, avenida Parque Lira/avenida Jalisco [Tacubaya], avenida Revolución y calzada Acoxpa, y otras laterales de algunas vías rápidas): es más, en varios casos inclusive se viola el Acuerdo publicado el 11 de octubre de 1967 que declara la prohibición de ejercer el comercio ambulante o el que se practica por medio de puestos fijos o semifijos en las vías públicas siguientes: a) primer cuadro de la ciudad; b) zonas comprendidas dentro de un perímetro radial de 200 metros de los mercados públicos, y c) avenidas y calzadas de primer orden. Hoy día, todo ello no se cumple ni se respeta.

Estos negocios se establecen en un lugar fijo, ya sea con puestos metálicos sol- 
dados al piso o puestos semifijos que se desmantelan por la tarde-noche y vuelven a instalarse a la mañana siguiente, pero no cuentan con agua corriente, ni lavabos o sanitarios, ni con sistemas de refrigeración para mantener frescos los alimentos que expenden; la mayor parte de ellos que usan corriente eléctrica, no la paga, ya que se conectan de manera ilegal a los postes de electricidad situados en la vía pública. Los vendedores de comida preparada utilizan tanques de gas para sus estufas, los cuales colocan dentro o fuera del puesto sin la menor precaución para los propios vendedores y mucho menos para el público que transita o los residentes de la zona.

El procedimiento que se sigue para instalar un puesto fijo en la vía pública es similar al de los puestos móviles, es decir, los comerciantes convienen con un líder afiliado a alguna organización política, que sirve de gestor ante las autoridades locales y mediante una inversión inicial millonaria y cuotas semanales que varían entre 10000 y 20000 pesos; de este modo, dichos comerciantes se mantienen casi "libres de molestias", pues de otra manera hay "problemas" esporádicos con los cuerpos policiacos o los inspectores delegacionales y de salubridad.

\section{Acciones de gobierno para la regulación del comercio ambulante}

Una de las respuestas que el Gobierno del Distrito Federal emprendió en 1993 fue el "Programa de mejoramiento del comercio popular" (1993). El principal objetivo de este último fue remover y controlar el comercio informal de los espacios públicos de la capital del país. No obstante, al revisar el contenido de este programa, puede observarse que los objetivos subyacentes sólo buscaban eliminar de las calles del Ilamado "Centro Histórico" de esta ciudad a los aproximadamente 10000 vendedores informales y reubicarlos en lugares cercanos en plazas de comercio popular, acondicionadas en pasajes bajo techo por las propias autoridades, entre los cuales estaban "Meave", "Pino Suárez", "Tacuba”, "Vizcaínas", "Pensador Mexicano", "San Antonio 1 y 2", y "Mesones". Se exceptuó de la reubicación a los vendedores en los puestos de periódicos y revistas, libros, billetes de lotería y lustradores de calzado dado que se les consideraba de interés público cotidiano (Asamblea Legislativa del DDF, III Legislatura, 1993).

Los lugares y las plazas citados son algunos de los más exitosos y conocidos. Hubo algunos otros sitios que fracasaron por su mala ubicación comercial o falta de planeación, aunque la mayoría de los que no funcionaron como puestos de venta, los comerciantes los utilizaron como bodegas para sus productos e instalaciones móviles y volvieron a la venta en las calles.

En respuesta al cúmulo de demandas ciudadanas y la presión de parte de las or- 
ganizaciones de comerciantes del centro de la ciudad, tanto formal como informal, el nuevo gobierno del Distrito Federal elegido en un proceso democrático (1997 a 2003) convocó a un congreso sobre mercados al menudeo en la Ciudad de México, con el propósito de coordinar y organizar las ventas al menudeo. Derivado de este congreso, que duró tres días, surgió el nuevo "Programa de reordenamiento del comercio popular en la vía pública 1998". Este programa establecía tres objetivos principales: 1) contención del comercio en espacios públicos; 2) preservación y rescate de los espacios públicos y el bienestar social en la ciudad, y 3) contribuir al proceso de formalización de los vendedores informales de las calles.

Con el propósito de llevar a cabo esos objetivos, dicho gobierno ordenó la creación de un registro de vendedores callejeros y de puestos en cada delegación, con el propósito de integrar un Sistema de Información para Controlar el Comercio en la Vía Pública (Siscovip) (GDF, 1998). A primera vista, este programa pareciera enfocarse de manera genuina a enfrentar el explosivo crecimiento del comercio en las calles del Distrito Federal; sin embargo, en la práctica, el principal objetivo para reordenar a los vendedores de las calles estuvo limitado solo al Ilamado "Centro Histórico". El resto fue dejado a la buena voluntad de las autoridades locales, las cuales han hecho realmente muy poco para controlar el rápido crecimiento de estos mercados y mejorar la situación urbana y social relacionada con esta problemática.

Con respecto al esperado registro de comerciantes en la vía pública dentro de cada demarcación y de los responsables de cada una de ellas (los delegados políticos), hasta la fecha no se presenta, al menos de forma pública, ninguna información estadística que dé seguimiento al fenómeno creciente de ocupación de los espacios públicos por el comercio informal. Incluso, cuando se trata de obtener las estadísticas o cualquier información sobre mercados y vendedores callejeros tanto por delegación como por el total de ellos en el Distrito Federal, su página de internet muestra sólo una página en la cual se menciona la fecha de la inscripción oficial de dicho sistema, pero nada más.

En el 2003, se creó el "Acuerdo" mediante el cual se crea la Comisión de Reordenamiento y Regulación del Comercio en Vía Pública del Centro Histórico de la Ciudad de México, 2003 (Gaceta Oficial, 2003), enfocada al reordenamiento y la regulación de dicha actividad, pero limitada al "Centro Histórico".

Entre los principales poderes de la Comisión estaban:

- Coordinar todos los poderes de cada organización o entidad en materia de espacios públicos, en particular aquellos relacionados con el comercio en las calles. 
- Permitir o retirar todas las autorizaciones otorgadas para el uso de los espacios públicos en el "Centro Histórico" del Distrito Federal.

- Lanzar el calendario de festividades tradicionales en las cuales los comerciantes pueden instalar puestos semifijos en el centro histórico.

- Diseñar y publicar normas específicas para la instalación de puestos semifijos en el "Centro Histórico" del Distrito Federal (resulta interesante observar que este tipo de poder contradice por completo la disposición oficial de 1993, la cual establece el "Bando" por el cual el comercio en vía pública en puestos fijos y semifijos y de cualquier otra índole están estrictamente prohibidos dentro del perímetro determinado del "Centro Histórico" del Distrito Federal, o sea, el perímetro " $\mathrm{A}$ ", con casi 3.3 kilómetros cuadrados), de acuerdo con la primera fase de desarrollo del "Programa de mejoramiento del comercio popular".

- Establecer el tipo de bienes permitidos para comerciar en esta área;

- Definir zonas especiales en las cuales los comerciantes existentes deban de reubicarse.

- Diseñar y proponer varios tipos de instrumentos jurídicos relativos al comercio en vía pública en el Distrito Federal.

Todos estos poderes dados a la comisión, aunque parecieran orientarse a ordenar y gobernar el comercio en vía pública, quedaron sujetos a cuestionamiento cuando se confrontaron con la realidad, porque muy poco se ha hecho hasta ahora para controlar y formalizar el comercio en la vía pública de la Ciudad de México. La mínima acción de las autoridades locales ha sido remover a los comerciantes de las principales calles que circundan la plaza central o "Zócalo".

El tema relativo a otorgar permiso a los vendedores para instalarse en puestos semifijos durante las festividades tradicionales se ha ampliado al lanzar en el 2002, el Decreto especial sobre el comercio en vía pública durante las "romerías", Ilamado: "Normas para la realización de romerías en los mercados públicos" (Gaceta Oficial del Distrito Federal, 28 de noviembre de 2002).

Mediante este decreto, la Secretaría de Desarrollo Económico del Gobierno del Distrito Federal establece las normas para la autorización y la operación de las ferias temporales locales, Ilamadas "romerías", donde se permite establecerse temporalmente a los comerciantes en espacios públicos, casi siempre alrededor de iglesias o plazas locales, para que puedan vender diversos productos de consumo básico y artesanías durante cierto número de días para las festividades populares y eventos patrióticos históricos. Con base en este decreto, el Gobierno del Distrito Federal au- 
toriza a los comerciantes de las calles a colocar sus puestos en espacios abiertos, como calles, pavimento, aceras, plazas, áreas de estacionamiento y jardines alrededor de las principales iglesias o plazas locales; todo ello, con toda la discrecionalidad respecto de los límites espaciales y usos de suelo.

Hay tres problemas importantes que subyacen en este decreto: el primero es que ese tipo de eventos no están sujetos a los reglamentos que deben regular a los mercados callejeros (en particular, los programas de reordenamiento del comercio en espacios públicos, según lo refiere el Código Financiero del Distrito Federal, artículo 267-A); el segundo, que el calendario establecido para la operación de esas romerías es demasiado extenso y permite a mercados y vendedores en vía pública operar como ellos deseen en muchas áreas de la ciudad por casi una tercera parte del año (93 días entre tres principales periodos), y el tercero, que se otorga al delegado correspondiente la prerrogativa de extender dichos permisos de acuerdo con su propio criterio, mismo que casi siempre sobrepasa las normas en cuanto a tiempos y áreas de mercado.

En el 2007, se publicó también el "Programa de apoyo para la reubicación del comercio popular de la Ciudad de México", el cual se considera en la práctica lo mismo, en cuanto a objetivos y contenidos, al publicado en 1993, pues se apoya con el "Programa de reubicación del comercio popular de la Ciudad de México" (GDF, 16 de octubre de 2007), en cuanto a que se propone eliminar a casi 16000 vendedores de las calles del llamado "Primer Cuadro" del centro de la ciudad (un área muy similar al referido "Bando" o perímetro "A" del "Centro Histórico") y ubicarlos en plazas especiales o corredores comerciales construidos o adaptados en especial para ellos, cerca de esa zona. Una de las novedades de este programa es que, en su justificación, se reconoce de modo oficial la existencia del comercio informal en las calles, como una forma para que las numerosas familias (sobre todo de bajos ingresos) obtengan una fuente económica para sobrevivir. Sin embargo, es bien sabido, pero siempre se soslaya, que la mayoría de los vendedores de las calles tiene ingresos más altos que los trabajadores y los empleados formales.

Como puede observarse, en la práctica, todos los programas y las normas publicadas por los gobiernos de la Ciudad de México se han limitado a tratar de ordenar el llamado "Centro Histórico", el cual por cierto es un área más amplia en comparación con la que las autoridades intentan "limpiar" de comerciantes ambulantes. Mientras tanto, el comercio en las calles continúa incrementándose de manera notable, sobre todo por la tolerancia y la permisibilidad que se les ha dado a los jefes delegacionales para otorgar permisos discrecionales a las diversas agrupaciones de comerciantes informales, en casi todas las principales vialidades de la ciudad con gran afluencia 
de personas o tránsito de vehículos. Tampoco deben omitirse los miles de vendedores que en las esquinas de las principales calles y avenidas ofrecen sus artículos a los automovilistas ni los que abordan los vehículos de transporte colectivo, como autobuses, "Metro", trolebús y tren ligero (tranvía). De igual manera, están los llamados "toreros", quienes portan prendidos a sus vestiduras (sacos, chamarras y gabardinas) los artículos de venta y deambulan donde se concentran los comerciantes semifijos; de esta manera, eluden la vigilancia de autoridades y líderes por su imposibilidad para cubrir las "cuotas" respectivas.

\section{LA INFORMALIDAD EN DOS CENTROS DE TRANSFERENCIA MODAL DE LA CIUDAD DE MÉXICO}

El deterioro de los espacios públicos de la Ciudad de México se encuentra, entre otros lugares, en el perímetro de los Cetram. 45. Se presentaron al inicio de la administración de Marcelo Ebrard como Jefe de Gobierno de la Ciudad de México (2006 a 2012), como parte de la infraestructura ubicada en diversos puntos de gran afluencia de pasajeros urbanos, suburbanos y foráneos, como estaciones del "Metro", centrales de autobuses de servicio nacional y subnacional, y de servicios de taxis, con el propósito fundamental de agilizar el transporte público y facilitar la conectividad hacia diversos puntos de la ciudad.

De acuerdo con estimaciones del Institute for Transportation and Development Policy (ITDP) (ITDP, 2014), se reciben a diario en estos Cetram a casi seis millones de personas, tanto capitalinos como población flotante. Sin embargo, gran parte de los espacios públicos dispuestos para la libre circulación de residentes vecinos de dichos centros, pasajeros y medios de transporte, se ve afectada por la falta de organización, regulación y control sobre la ubicación, la operación y el servicio proporcionado por los transportistas, conductores de taxis y vendedores en espacios públicos abiertos (calles, parques y jardines, accesos a las estaciones del Metro, Cetram, y otros), ya que restringen con dichas operaciones no reguladas, el acceso, la circulación y hasta el derecho al libre tránsito de la población que habita o circula por esas áreas. El ITDP concluía que todos esos centros son inseguros y se subutilizan.

En este análisis, se presentan dos estudios de campo en las áreas colindantes con el estado en que se encuentran dos de los principales Cetram de la Ciudad de México: Tacuba y Tacubaya. Se eligieron éstos, tanto por su antigua tradición, el primero, porque es un espacio territorial del antiguo señorío prehispánico de Tlacopan y, el segundo, porque también durante la época colonial fue uno de los principales cen- 
tros de asentamiento de importantes encomenderos españoles y, siglos después, durante el "México Independiente" y la dictadura porfirista, también fueron asiento de importantes personajes de la vida política, económica y social, como el conde de la Cortina, los señores Bardet y Jamison y las familias de Teresa Mier y Pesado y Manuel Escandón (Molina, 2012).

Una vez en el México contemporáneo, estos centros de barrio se han poblado y popularizado cuando la expansión urbana y el acelerado crecimiento poblacional los absorbió; se han convertido en importantes centros en el corazón de esta gran urbe, para el tránsito constante y la distribución de usuarios de todos los niveles socioeconómicos a muchos otros puntos de esta ciudad capital. De ahí que se convirtieron en dos de los 45 Cetram más poblados y son focos para el creciente asentamiento y la expansión territorial de comerciantes y transportistas formales e informales.

\section{El centro de transferencia modal de Tacuba}

El Cetram de Tacuba contaba originalmente con una superficie de 11400 metros cuadrados y se localiza sobre las avenidas México-Tacuba y Marina Nacional, abajo del puente vehicular. Para el 2014, se registró una afluencia diaria de 130000 pasajeros y tenía una estación para dos líneas del "Metro" y 708 unidades de transporte colectivo terrestre. Sin embargo, está rebasado en su extensión ya que un número importante de unidades ocupan el espacio vial de las avenidas México-Tacuba, Azcapotzalco y Cuitláhuac, para estacionarse y cargar pasaje. Esto ha generado que el comercio informal de igual modo se coloque en dichas avenidas y en algunas calles aledañas. En el mapa, se destaca un área sombreada que corresponde a las arterias viales donde se encuentran asentados los comerciantes informales y transportistas (mapa 11-2).

En trabajo de campo in situ se recopilaron datos de levantamiento. Los recorridos abarcaron 2012 metros lineales, donde el promedio de tamaño de banqueta es de 2.2 metros de ancho; se consideraron 3845 metros cuadrados, más el área de la explanada del Templo de "San Miguel Arcángel", que comparte con un jardín colindante con el mercado. Esto constituye un área de 27000 metros cuadrados. En total se cuantificaron 30450 metros cuadrados de banqueta, de los cuales, 46\% (1788 metros cuadrados) estaban ocupados por los comerciantes informales. En la explanada de la iglesia y el jardín, casi la mitad del área total estaba ocupada por el comercio en puestos semifijos, los cuales miden en su mayoría dos metros de largo por 1.5 metros de ancho. En todo el espacio público registrado y cuantificado en este Cetram, 
Mapa 11-2

Centros de transferencia modal de Tacuba

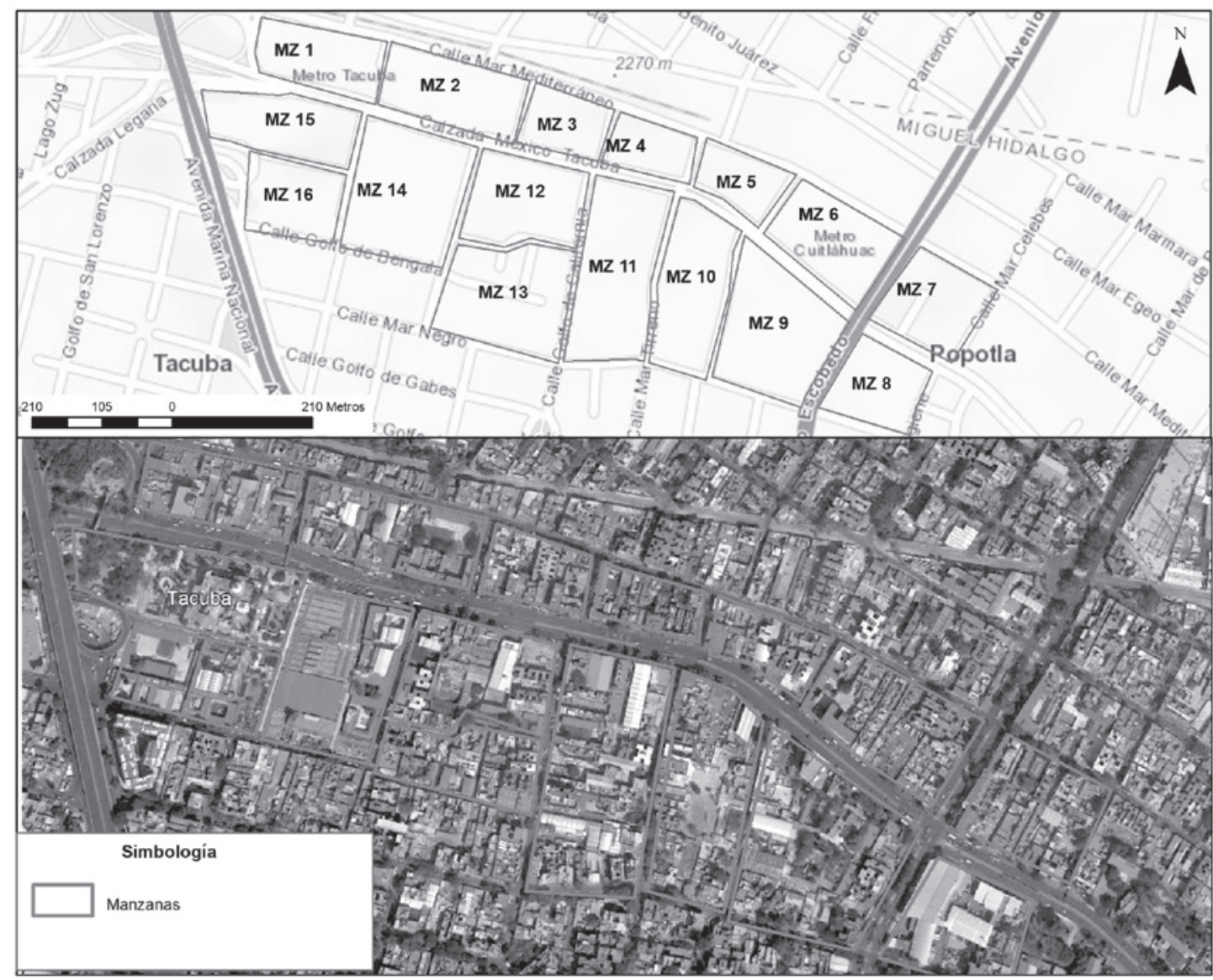

Fuente: Elaboración de Natalia Romero con datos de Google Earth 2016.

se contaron 2922 puestos semifijos y se calculó que 52\% tenía comercio informal y transporte concesionado (plano 11-1).

El espacio de banqueta es ocupado por los puestos y la vialidad se ve afectada por los transportistas de microbuses y los propietarios de los camiones de carga de los comerciantes, quienes abarcan el primer carril como estacionamiento semipermanente. Por tanto, se ocupan 14611 metros cuadrados de banqueta y espacio público con puestos fijos y semifijos, así como 7119 metros cuadrados de vialidades; esto al considerar que camiones y autobuses sólo estarán en un carril, aunque en muchos casos Ilegan a invadir hasta dos carriles de la avenida México-Tacuba, dejando dos carriles libres para el tránsito vehicular por cada sentido de circulación (cuadros 11-3 y 11-4). 
Plano 11-1

Centros de transferencia modal de Tacuba: densidad de ambulantes por acera

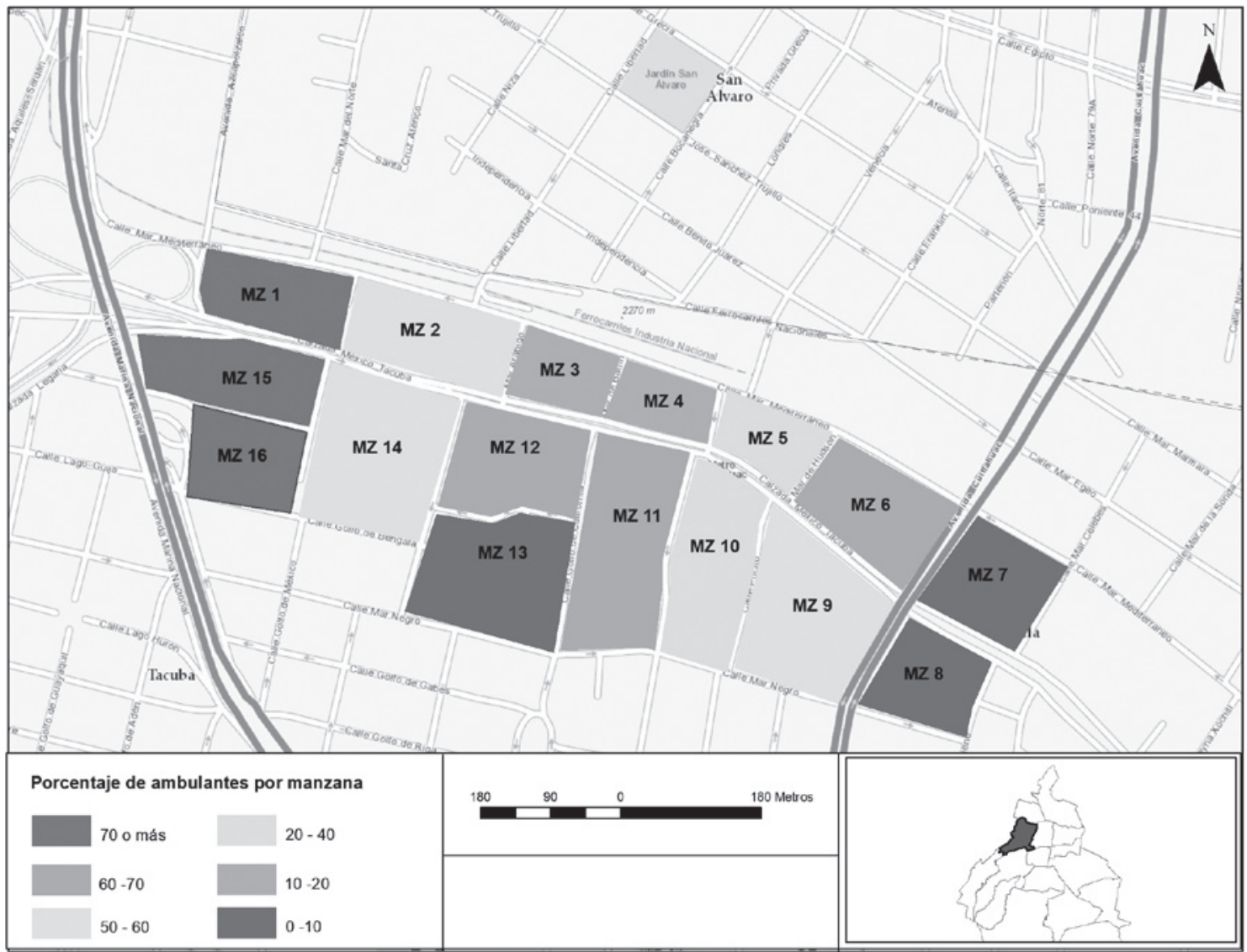

Fuente: Elaboración de Natalia Romero con datos de Google Earth.

\section{Cuadro 11-3}

Centros de transferencia modal "Tacuba": superficie ocupada

\begin{tabular}{l|c|c|c|c}
\hline Puestos fijos y semifijos & $\begin{array}{c}\text { Metros cuadrados } \\
\text { totales de ban- } \\
\text { queta y espacio } \\
\text { público }\end{array}$ & $\begin{array}{c}\text { Metros } \\
\text { cuadrados } \\
\text { ocupados }\end{array}$ & $\begin{array}{c}\text { Porcentaje de metros } \\
\text { cuadrados ocupados }\end{array}$ & $\begin{array}{c}\text { Total de } \\
\text { puestos } \\
\text { semifijos }\end{array}$ \\
\cline { 2 - 5 } Camiones microbuses & 28106.04 & 14611 & $52 \%$ & 2574 \\
\hline & $\begin{array}{c}\text { Metros cuadrados } \\
\text { totales de vialidad }\end{array}$ & $\begin{array}{c}\text { Metros cuadra- } \\
\text { dos ocupados }\end{array}$ & $\begin{array}{c}\text { Porcentaje de metros } \\
\text { cuadrados ocupados }\end{array}$ & \\
\cline { 2 - 4 } & 66552.34 & 7119 & $12 \%$ & \\
\hline
\end{tabular}

Fuente: Elaboración propia. 


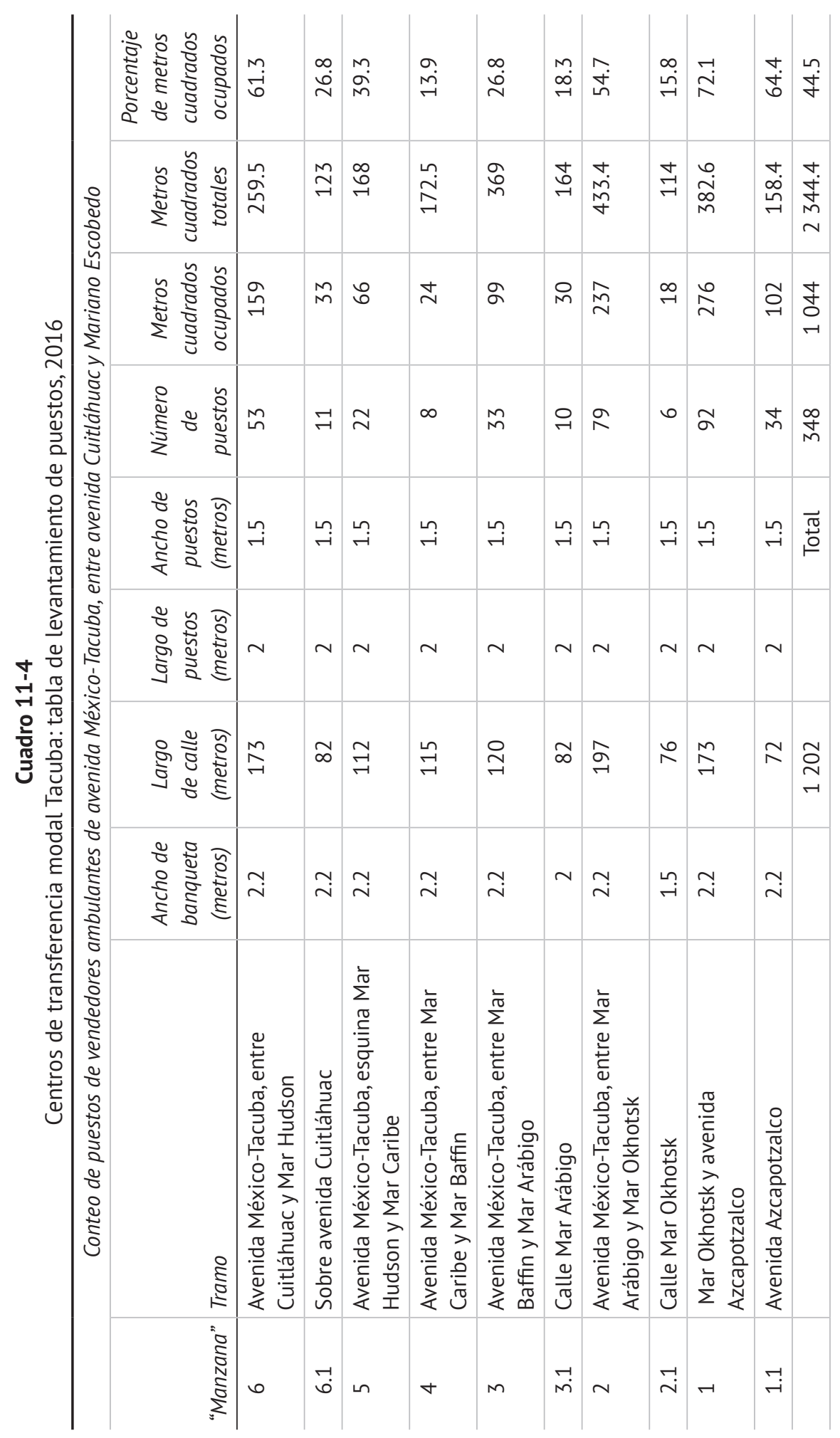




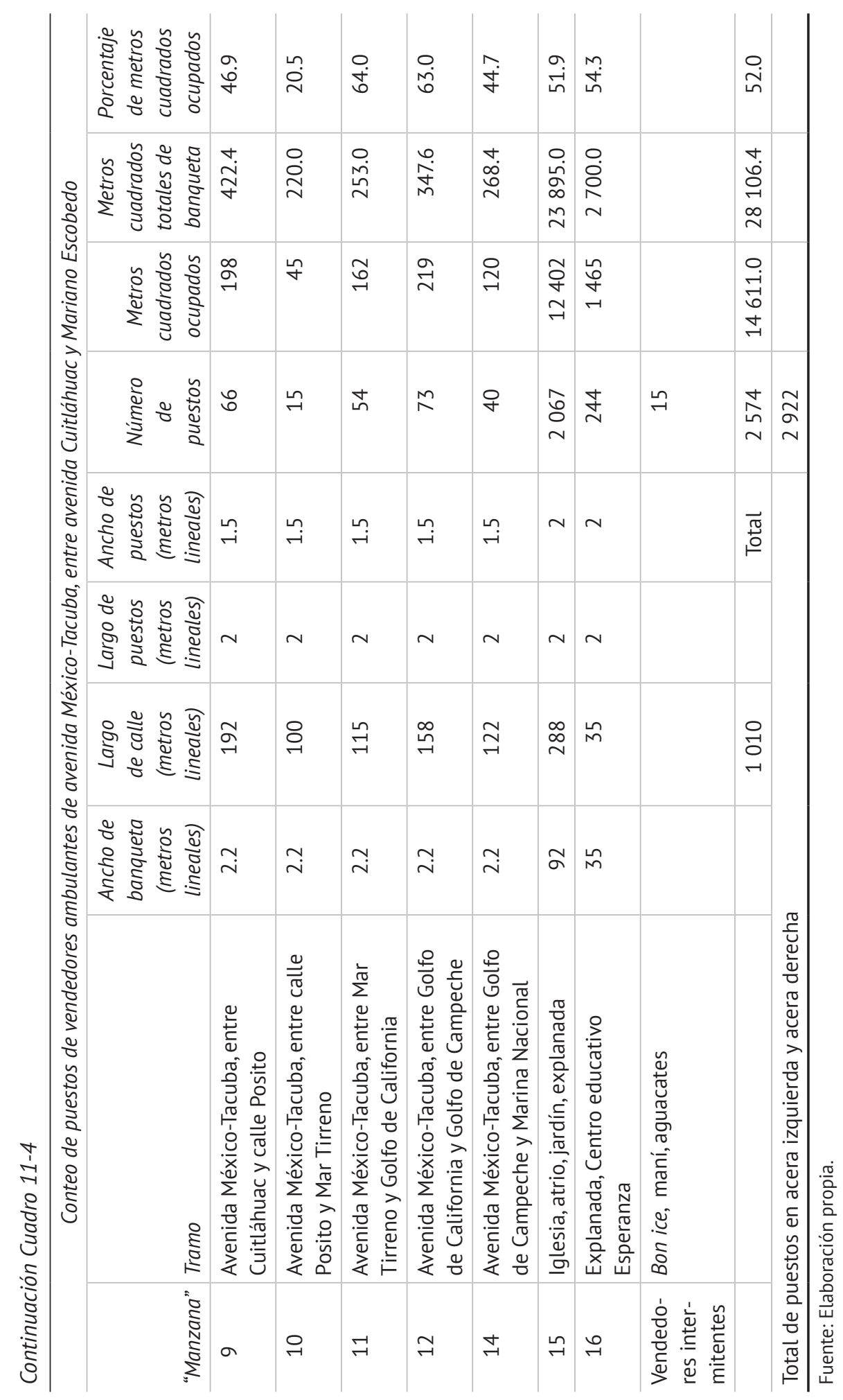




\section{El centro de transferencia modal de Tacubaya}

Este centro se inauguró en 1990 y cuenta con una superficie de 4702 metros cuadrados, los cuales se dividen en seis andenes y cuatro bahías. En él funcionan la estación del "Metro Tacubaya" y ocho rutas de transporte colectivo terrestre con 1292 unidades de transporte, cuya afluencia diaria es de 115000 pasajeros. En el trabajo de campo, se contabilizaron 24 "manzanas" que conforman un total de 7059 metros cuadrados (mapa 11-3).

El comercio informal y los microbuses se han extendido sobre un área aproximada de 7059 metros cuadrados, de los cuales 3582 (50.7\%) están ocupados por los vendedores Ilamados ambulantes en 1234 puestos semifijos y fijos (plano 11-2 y cuadro 11-5).

En los dos casos estudiados, se muestra el creciente fenómeno del comercio informal en vía pública y los espacios públicos invadidos por dicha actividad; esto, a su

\section{Mapa 11-3}

Centros de transferencia modal (Cetram) Tacubaya y alrededores, "manzana” (MZN).

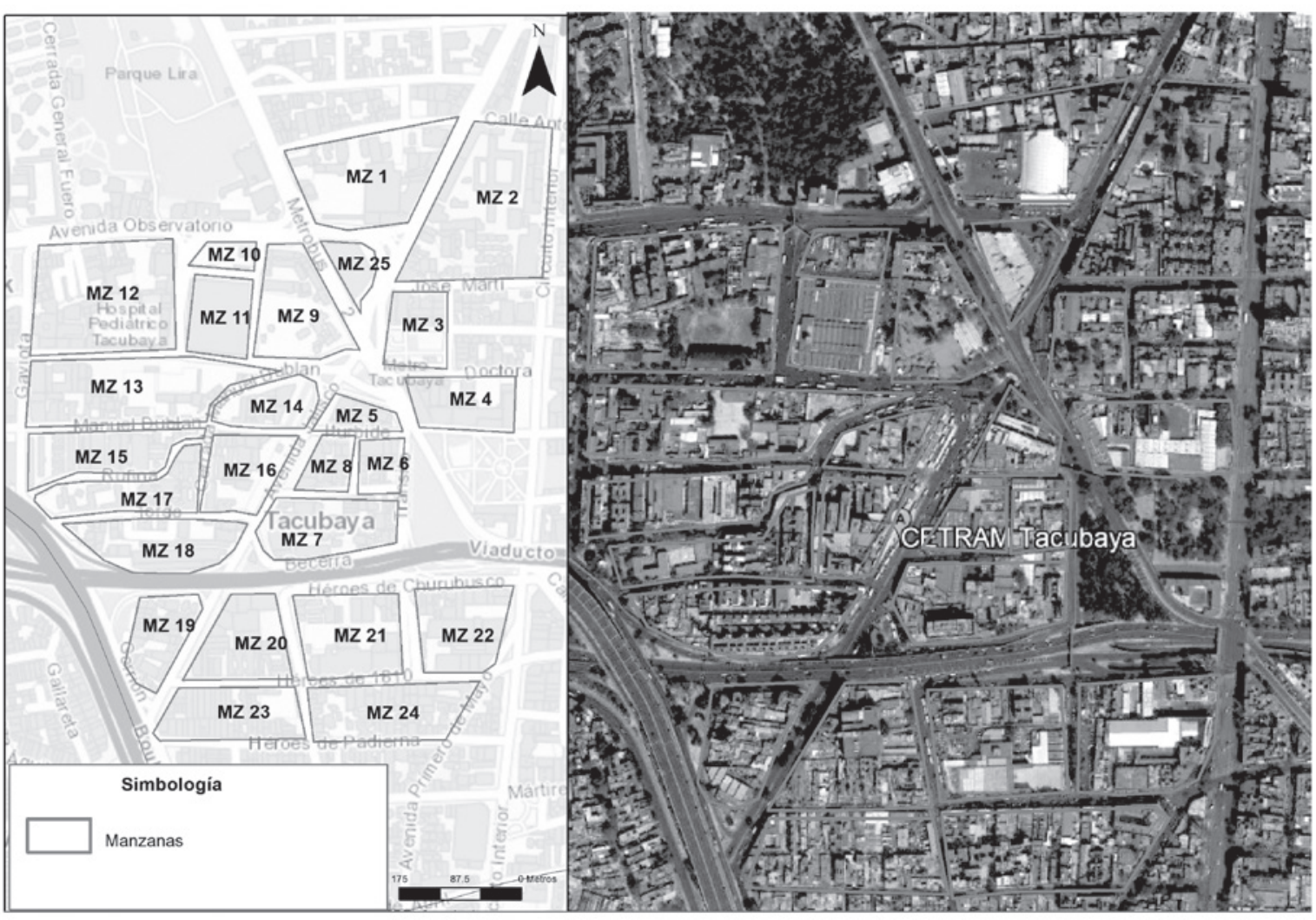

Fuente: Elaborada por Natalia Romero con imagen tomada de Google Earth. 
Plano 11-2

Centros de transferencia modal (Cetram) Tacubaya: densidad de ambulantes "manzana" (MZN)

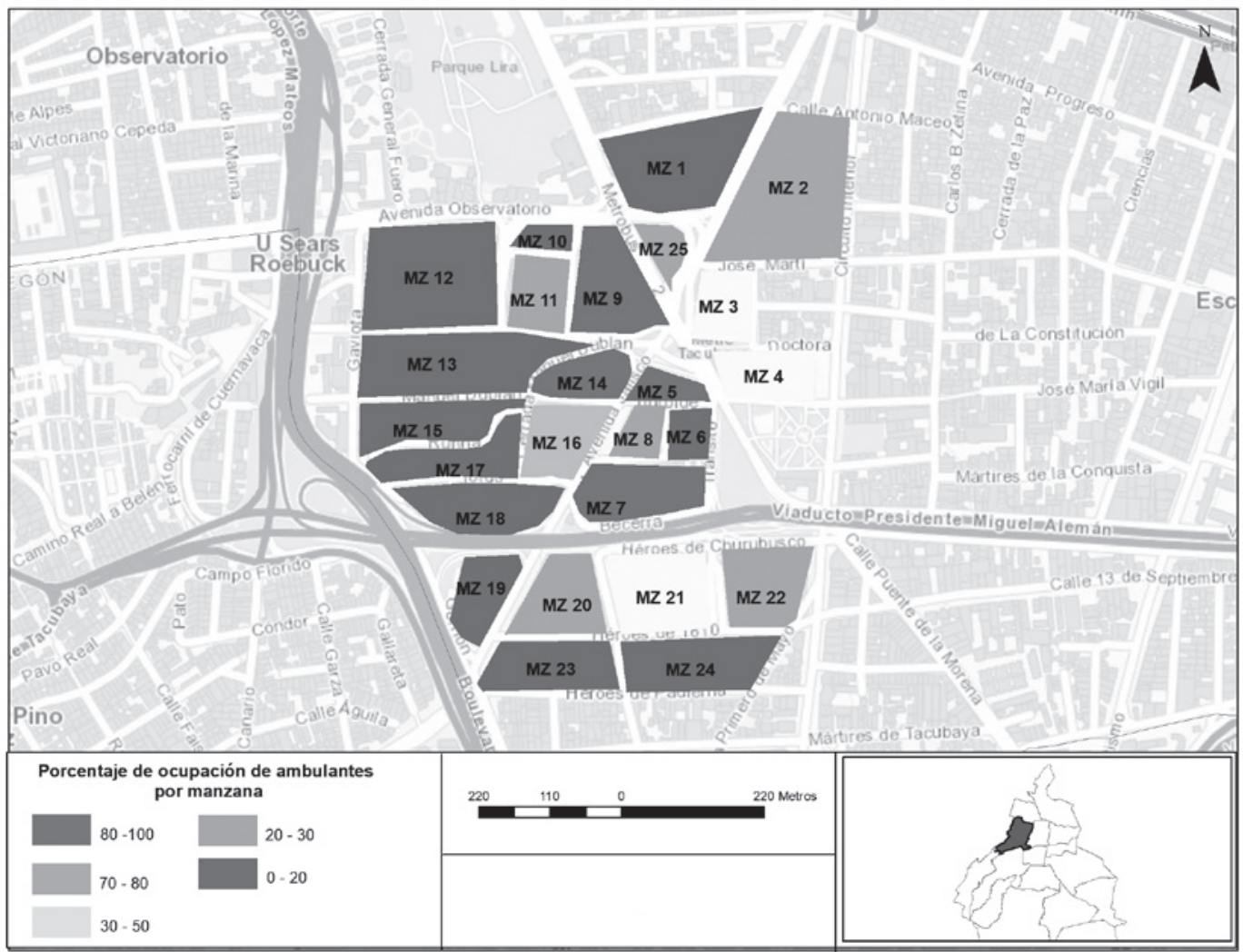

Fuente: elaboración de Natalia Romero con datos de Google Earth.

vez, restringe espacios a la ciudadanía en general (residentes, transeúntes, pasajeros y automovilistas) para el libre tránsito y recreación, pues también se han ocupado parques y jardines que de manera muy difícil sirven para el esparcimiento, con excepción de su uso por los vendedores, sus familiares y, en ocasiones, consumidores transitorios.

\section{AFECTACIONES DEL COMERCIO EN VÍA PÚBLICA A LA CALIDAD DE VIDA URBANA}

Muchos espacios públicos urbanos de la Ciudad de México se convierten en espacios ocupados, de tránsito restringido, sin regulación de autoridades públicas, excepto la de los propios comerciantes y de sus líderes; aumenta la inseguridad para los transeúntes en esos espacios sucios, ruidosos y donde se producen delitos en sus diversas manifestaciones (robo, violencia, tráfico de enervantes, piratería, y más), lo cual resta su función de bien común o de consumo colectivo. 


\begin{tabular}{|c|c|c|c|c|c|c|c|c|c|c|c|}
\hline & 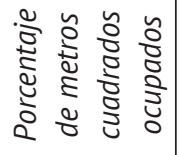 & $\stackrel{+}{\stackrel{N}{N}}$ & $\stackrel{\stackrel{n}{-}}{\underset{\forall}{+}}$ & $\underset{\infty}{\infty}$ & $\stackrel{\overbrace{}}{\stackrel{f}{f}}$ & $\begin{array}{l}\text { นn } \\
\infty\end{array}$ & $\begin{array}{l}m \\
m \\
m\end{array}$ & 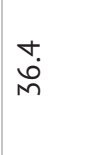 & Mo. & $\stackrel{\vec{\Im}}{\widehat{N}}$ & $\hat{\sigma}$ \\
\hline & 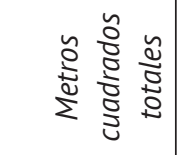 & $\begin{array}{l}\infty \\
\text { ஸ் } \\
\text { ஸे }\end{array}$ & $\begin{array}{l}\circ \\
\text { న }\end{array}$ & 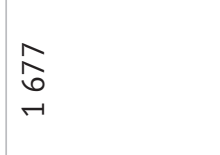 & $\stackrel{\circ}{M}$ & $\stackrel{\text { I }}{\underset{H}{H}}$ & 움 & 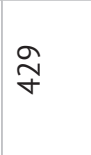 & $\stackrel{\stackrel{+}{\sim}}{ }$ & 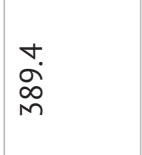 & $\stackrel{\infty}{\infty}$ \\
\hline 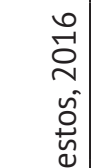 & 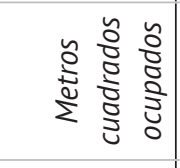 & 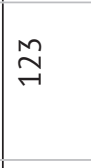 & $\begin{array}{l}\stackrel{L}{\sim} \\
\stackrel{+}{+} \\
\stackrel{+}{-1}\end{array}$ & $\begin{array}{l}\stackrel{2}{\infty} \\
\stackrel{M}{\sim} \\
\rightarrow\end{array}$ & $\underset{\sim}{\stackrel{J}{*}}$ & 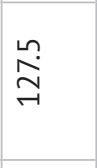 & $\stackrel{\circ}{\leftrightarrow}$ & $\stackrel{\circ}{\stackrel{\leftrightarrow}{\sim}}$ & \begin{tabular}{l}
$n$ \\
\multirow{1}{0}{} \\
$\infty$ \\
0 \\
$\sim-1$
\end{tabular} & $\frac{\infty}{m}$ & 음 \\
\hline $\begin{array}{l}\overline{2} \\
0 \\
0 \\
0 \\
0 \\
\stackrel{0}{0}\end{array}$ & 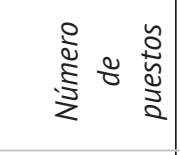 & $\overrightarrow{+}$ & $\stackrel{M}{\wedge}$ & $\begin{array}{l}M \\
b\end{array}$ & ఫ̛ & $\stackrel{\llcorner}{\infty}$ & 유 & กี & $\stackrel{\text { Ln }}{\wedge}$ & $\underset{\sim}{\stackrel{\sim}{\sim}}$ & ㅇ \\
\hline 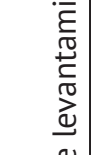 & 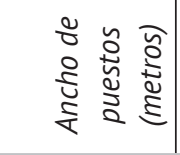 & $\stackrel{n}{\rightarrow}$ & $\stackrel{\text { ㄴ }}{\sim}$ & $\stackrel{\text { ำ }}{\sim}$ & $\stackrel{n}{\rightarrow}$ & $\stackrel{n}{\sim}$ & $\sim$ & $\sim$ & $\stackrel{n}{\sim}$ & $\sim$ & $\neg$ \\
\hline 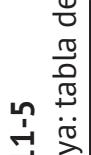 & 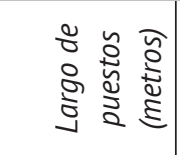 & v & $\stackrel{n}{\sim}$ & $\sim$ & $\stackrel{n}{\sim}$ & $-r$ & 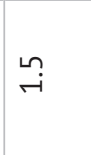 & $\stackrel{\text { Ln }}{\rightarrow}$ & $\stackrel{\text { นn }}{\rightarrow}$ & $\stackrel{n}{\sim}$ & $\stackrel{n}{\sim}$ \\
\hline 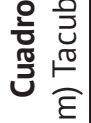 & 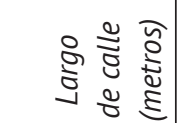 & 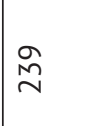 & $\underset{\sim}{\stackrel{\infty}{\sim}}$ & ํㅗํ & ষ & 느 & 옴 & $\stackrel{\text { ڤn }}{\sim}$ & $\underset{\sim}{\stackrel{\overbrace{}}{ન}}$ & $\stackrel{\hat{\lambda}}{\neg}$ & $\underset{\text { 구 }}{ }$ \\
\hline 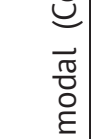 & 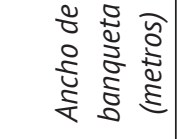 & $\stackrel{\sim}{i}$ & $\stackrel{\sim}{\sim}$ & $m$ & $\forall$ & $\stackrel{n}{\sim}$ & $M$ & $\underset{\sim}{\sim}$ & $\sim$ & $\stackrel{\sim}{\sim}$ & $\stackrel{n}{\sim}$ \\
\hline 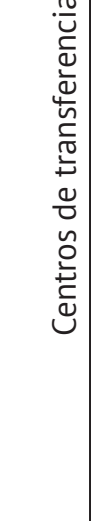 & $\stackrel{?}{\vdots}$ & 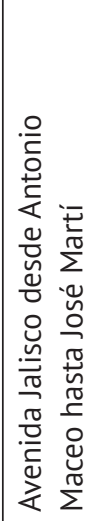 & 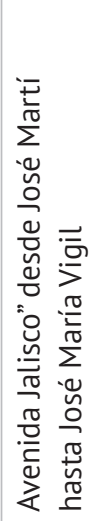 & 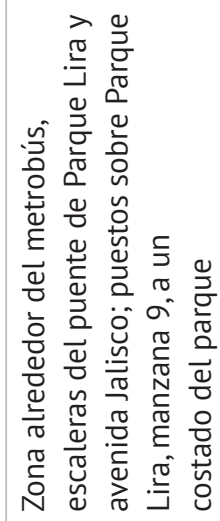 & 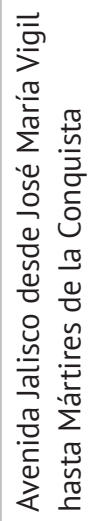 & 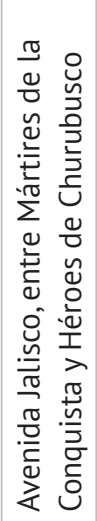 & 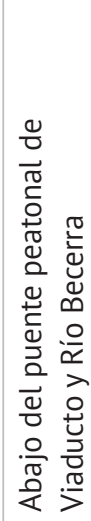 & 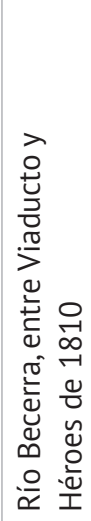 & 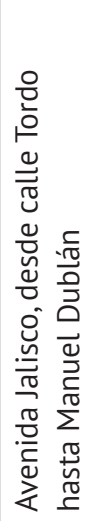 & 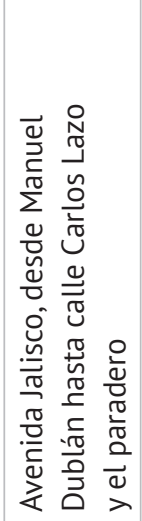 & 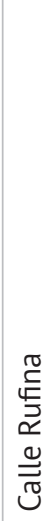 \\
\hline & 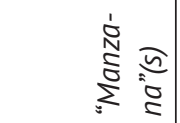 & $\sim$ & $\underset{M}{\stackrel{+}{\lambda}}$ & $\stackrel{a}{>}$ & $\infty$ & $\wedge$ & 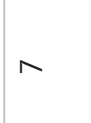 & $\vec{\sim}$ & $\stackrel{\bullet}{\sim}$ & $\stackrel{ \pm}{\sim}$ & $\stackrel{Ð}{\sim}$ \\
\hline
\end{tabular}




\begin{tabular}{|c|c|c|c|c|c|}
\hline 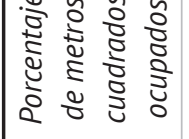 & & 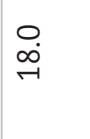 & $\stackrel{M}{\infty}$ & & î \\
\hline 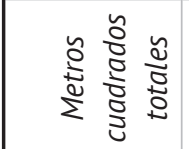 & & $\begin{array}{l}\infty \\
\stackrel{+}{+} \\
-1\end{array}$ & 壳 & & 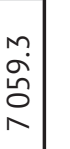 \\
\hline 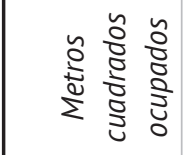 & $\overrightarrow{7}$ & 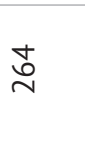 & \& & & $\begin{array}{c}\infty \\
\stackrel{\alpha}{2} \\
m\end{array}$ \\
\hline 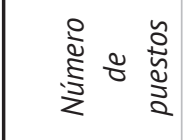 & in & $\begin{array}{l}\infty \\
\infty\end{array}$ & $\stackrel{i}{ }$ & q & 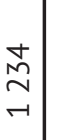 \\
\hline 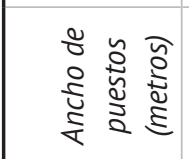 & $\sim$ & N & $\stackrel{\text { n }}{\rightarrow}$ & & \\
\hline 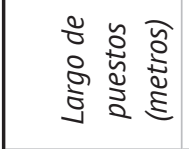 & $\stackrel{n}{\rightarrow}$ & $\stackrel{n}{\rightarrow}$ & $\stackrel{n}{\rightarrow}$ & & \\
\hline 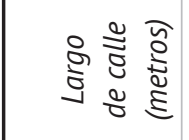 & $\stackrel{\infty}{\exists}$ & î & $\stackrel{N}{N}$ & & \\
\hline 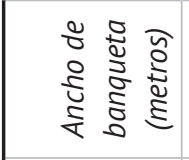 & i & + & $\sim$ & & \\
\hline 气̊ & & 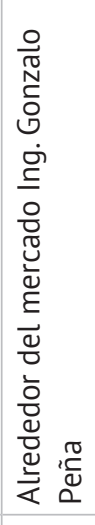 & 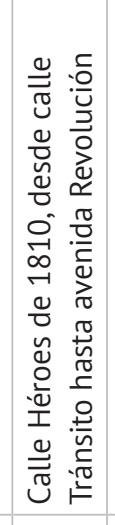 & 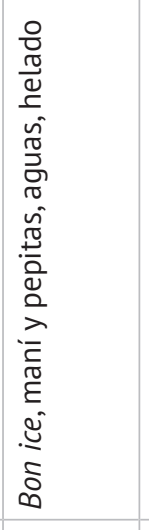 & $\mid$ \\
\hline 率 & & $\exists$ & $\approx$ & 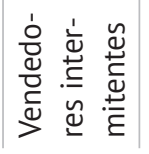 & 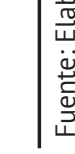 \\
\hline
\end{tabular}


Los límites del espacio público son los intereses políticos y de grupos de comerciantes informales que aprovechan la demanda que pueden tener en esos sitios. Por su parte, los representantes de las autoridades del gobierno de la Ciudad de México continúan otorgando de forma discrecional permisos a representantes de diversas agrupaciones de comerciantes y transportistas urbanos, a cambio de cuotas monetarias y de apoyo político-electoral cada vez que se requiere. Todo ello, sin importar las afectaciones a terceros y sin tomar en cuenta las obligaciones con el resto de la ciudadanía al corriente con sus obligaciones fiscales o cualquier otra contribución por el uso o consumo de servicios públicos.

¿En qué lugar queda el usuario, los residentes o los transeúntes? ¿Hasta qué punto estos son corresponsables de tal situación?, ya que a su vez consumen la mercancía informal sobre todo por un precio más bajo que el obtenido en establecimientos formales (comercios establecidos, tiendas de autoservicio o plazas comerciales) y porque los encuentran con frecuencia a su paso cotidiano, con lo cual se promueve que existan más vendedores, quienes consideran este tipo de comercio como una actividad exitosa (con ahorros considerables por las externalidades positivas con las que cuentan). Cuando el público consumidor utiliza esta modalidad de comercio, sin quererlo, la promueven y se convierten al mismo tiempo en cómplices y víctimas de las situaciones adversas que genera este tipo de apropiación del espacio público por unos cuantos individuos. Asimismo, todo ello genera deterioro físico, basura, inseguridad e imposibilidad de transitar por las áreas de uso común

Además, estas actividades, al ser informales, también propician prácticas ilegales, como contrabando, piratería, comercio de artículos robados, narcomenudeo, y otras. Todo ello hace que los espacios se conviertan en un gueto urbano, pues cuando las autoridades de gobierno permiten estos tipos de actividades informales, también dan lugar a la delincuencia, la violencia, el descontrol de bandas, y los robos y asaltos; de este modo, ceden de forma gradual, aunque a gran velocidad, su control a cambio de obtener un clientelismo político, y dejan a un lado su responsabilidad de combatir las externalidades negativas que eso causa, tanto a la economía en su conjunto, como a la sociedad en general.

\section{CONSIDERACIONES FINALES Y PROPUESTAS}

Hay varios factores en la dimensión política y social que envuelve la problemática del comercio informal. Uno de ellos ha inducido su proliferación y tiene carácter macroeconómico por las reducciones en el gasto público, la contención salarial, el desempleo 
manufacturero o la disminución del crédito a programas de desarrollo. Otro factor es el abandono de las autoridades del gobierno capitalino y de muchos de los municipios periféricos del Estado de México, de su responsabilidad para construir nuevos mercados públicos y considerar sólo de manera marginal la reparación y el mantenimiento de los inmuebles ya construidos con anterioridad a las dos grandes recesiones de la economía mexicana en los años de 1976 y 1982. Desde mediados de la década de 1970, el número de mercados públicos en el Distrito Federal no ha crecido y estos continúan siendo los mismos 314 distribuidos en las 16 delegaciones políticas, con un total de 63807 locales (Sedeco, GDF), en los cuales laboran poco más de 70000 locatarios.

El crecimiento demográfico desde 1980 a la fecha y su asentamiento en espacios periurbanos metropolitanos ha traído como consecuencia una gran brecha entre oferta de una infraestructura en servicios de abasto al menudeo de la población y la creciente demanda, tanto de la población local como de la residente, en barrios periféricos pero que laboran y permanecen casi todos los días en la Ciudad de México y sus municipios conurbados. Esta brecha ha tenido que Ilenarse con las grandes cadenas de autoservicio y el comercio informal. A partir de las políticas de ajuste estructural y de la apertura al capital trasnacional comercial, industrial y financiero, las cadenas comerciales que de modo incipiente se habían desarrollado en México, como "Sumesa", "Aurrerá", "La Comercial Mexicana" y otras, fueron creciendo y casi todas ellas se han transformado o fusionado con otras cadenas de autoservicio que han ingresado al país con todas las ventajas y los permisos light tanto del gobierno federal, como de los gobiernos estatales y locales. En el 2015, la Asociación Nacional de Tiendas de Autoservicio y Departamentales (ANTAD) registró, sólo en el Distrito Federal, 1082 tiendas de autoservicio (19\% del total nacional), las cuales incluyen las grandes corporaciones y tiendas que ocupan 2.6 millones de metros cuadrados y que generaron ventas por 181000 millones de pesos; asimismo, éstas registraron un crecimiento nominal de $6 \%$ en los últimos cinco años (ANTAD, 2015).

Lo anterior es un reflejo de la permisibilidad del Estado mexicano a la inversión privada en medios de consumo para sus habitantes, mientras que, de manera cómoda, ha dejado a la deriva los crecientes niveles de desocupación formal y la creación de fuentes de empleo con ingresos salariales oficiales cada vez más devaluados. Se calcula que entre 40 y $65 \%$ del total de la población capitalina no cuenta con los mínimos de ingreso para alcanzar una canasta básica de consumo en alimentos, bienes y servicios indispensables para su supervivencia con bienestar.

La mayor parte de los comerciantes informales, liderados por sus representantes, argumenta a su favor el derecho constitucional al trabajo. Similar argumento es en 
cierto modo respaldado por sociólogos, antropólogos y geógrafos, al caracterizar las dificultades que ofrece el mercado laboral globalizado con despidos masivos, contrataciones temporales, bajos salarios y ninguna prestación social. Los gobernantes y las autoridades locales, por su parte, están conscientes de su escasa legitimidad ante la población capitalina y, por tanto, de la relativa desventaja ante la creciente presión social por tener acceso a mejores niveles de bienestar y de justicia social en general, por lo que su posición es ceder ante las constantes demandas de los grupos organizados por espacios para desarrollar actividades que les proporcionen ingresos.

Las autoridades locales no cuestionan las políticas macroeconómicas adoptadas por el Estado mexicano desde hace ya más de 30 años, que han impuesto un modelo de crecimiento económico basado en la supresión de los salarios mínimos oficiales, la reducción gradual de la inversión pública en infraestructura urbana, mientras ofrecen las mejores ventajas al gran inversionista para realizar sus operaciones comerciales, financieras y crediticias, en demérito de la clase trabajadora. Ante lo anterior, tales autoridades prefieren beneficiarse de dichas condiciones, al atribuirse el derecho de usufructuar los espacios públicos existentes cuando otorgan permisos "no oficiales" a diversas organizaciones de comerciantes, taxistas y transportistas, en los lugares donde éstos lo demanden o en los sitios ocupados ya por ellos previamente. Es decir, permisos de facto, a condición de cuotas monetarias o de apoyo político-electoral.

El permiso extraformal de parte de las autoridades locales afecta intereses de otros actores sociales con reconocimiento formal de la Constitución Política de los Estados Unidos Mexicanos. Por ejemplo, mientras un comerciante establecido debe realizar entre 15 y 28 trámites diferentes ante las autoridades para poder funcionar, los comerciantes informales de vía pública o puesteros realizan uno solo ante las autoridades locales por intermedio de sus líderes que los representan en cualquier gestión o trámite. Estos ganan, sólo por concepto de cuotas de sus agremiados, entre 40 y 140 millones de pesos diarios, sumas de las que no declaran un solo peso a la Tesorería de la Ciudad de México, ni tampoco a las autoridades hacendarias, mucho menos los captados por los representantes de las autoridades de gobierno que otorgan los permisos o que deben regular su funcionamiento. ¿ En dónde queda tal cantidad de dinero que podría añadirse a los limitados recursos dedicados a la atención de los espacios públicos urbanos?

Toda esta situación y las prácticas adoptadas de mutua responsabilidad (por parte de autoridades de gobierno y trabajadores informales en vía pública) conllevan un gran riesgo para la gobernabilidad de la ciudad, dado que a los gobiernos nacional 
y locales les ha resultado más cómodo y redituable dar permisos casi en cualquier lugar de la ciudad, de manera irresponsable, pues son los primeros en no respetar los usos del suelo de los programas de desarrollo urbano previamente autorizados; esto afecta espacios públicos y a la ciudadanía en zonas residenciales, escolares, parques y jardines, y otras áreas; inclusive en zonas comerciales en las cuales tanto los comerciantes como los residentes han invertido su escaso capital en cuanto a compra, renta o alquiler de espacios y además han cumplido con todos los requisitos de ley, en cuanto a licencias, permisos y contribuciones fiscales.

Entre las propuestas para el rescate de espacios públicos urbanos se mencionan las siguientes. Hay crecientes voces en el mundo que reconocen la insuficiencia de demostrar que las ciudades cumplan con las necesidades y las expectativas individuales o colectivas del bienestar, además, deben ofrecer otros factores. Muestra de ello es el reporte de la Organización de las Naciones Unidas (ONU) (ONU-Hábitat, 2012), en el cual se presenta el concepto de "Ciudades prósperas", donde se proponen nuevas líneas para reforzar la idea de prosperidad de una ciudad, a partir de la revisión del modelo actual de desarrollo urbano para introducir cambios importantes en su forma y función, para crear una urbe en escala humana, donde la diversidad, la conectividad y la integración física estén fusionadas en el entretejido urbano y que la prosperidad se comparta de manera colectiva.

El diagnóstico sobre la Ciudad de México indica espacios públicos cada vez más deteriorados e invadidos por las actividades de grupos de personas que operan de manera informal; con una infraestructura urbana cada vez más dañada por falta de un mantenimiento suficiente e ineficaz, y equipamientos modernos para solamente un sector de la población, cada vez más amplios sectores sufren a diario la reducción de su calidad de vida por disminución de sus espacios públicos, inseguridad y la exclusión o marginación de las prioridades de atención pública, por lo cual la ciudad no resulta competitiva ante otras de primer orden y de algunos países en desarrollo.

Es urgente que los gobiernos nacional y de la Ciudad de México emprendan diversas acciones para atender aspectos jurídicos, fiscales, económicos y sociales del fenómeno de la "informalidad" en general, y para regular la localización y la operación de las actividades comerciales y de servicios (comercio, transporte masivo, taxis, y otros) en la vía pública, que conserven en buenas condiciones de seguridad y limpieza los espacios ocupados, con respeto del derecho a la movilidad de la ciudadanía, la libre circulación peatonal y vehicular en los espacios públicos y a los comerciantes establecidos de modo formal. 
Al mismo tiempo, debe retomarse el programa de construcción de nuevos mercados públicos o la regeneración de los mismos, pero con un sentido moderno; por ejemplo, no construir los tradicionales galerones de una sola planta, sino hacerlos de dos niveles y más, con objeto de albergar locales en dos plantas, más áreas de estacionamiento público y de servicios, tanto de carga y descarga, como de recolección de desechos orgánicos e inorgánicos.

Debe prohibirse y regular de manera estricta la ocupación de las calles como estacionamientos a manera de bases o garajes permanentes para los vehículos destinados al transporte público de carga-descarga y de pasajeros, así como de las bases de taxis de sitio, ya que obstruyen considerables espacios de vialidad en toda la ciudad. Ha de existir la obligación de utilizar depósitos o garajes propios o alquilados. La utilización de las calles puede ser sólo transitoria en horarios no laborables o nocturnos (de 22:00 a 5:00 horas).

La atención de esta problemática no es fácil, pues intervienen diversidad de intereses de orden económico, político, laboral, social y cultural que, con la permisibilidad de más de cuatro décadas, resultan difíciles de modificar. No obstante, es indispensable ante la vida moderna y la pretensión de lograr una mayor competitividad en el mundo globalizado. Si las autoridades y los comerciantes y prestadores de servicios en vía pública no logran modernizarse y adaptarse a la nueva competencia, se seguirá degradando la calidad de vida en la urbe y los tianguis y puesteros en las calles no serán más que elementos del llamado "folclore urbano" y ejemplo de un país pobre, con su ciudad capital degradada.

La calidad de vida urbana constituye la síntesis de valores universales y éticos; asimismo, se vincula con la legitimación de las demandas locales y la formulación de derechos que permiten desarrollar un combate democrático por la justicia en la ciudad. Como consecuencia, es responsabilidad de toda la sociedad reclamar sus derechos ciudadanos y demandar mayores acciones de parte de legisladores y servidores públicos del orden federal y local, para lograr una mejoría del bienestar en cualquier punto del espacio metropolitano.

\section{BIBLIOGRAFÍA}

Acemoglu, Daron y James Robinson, (2013), "Why nations fail: the origins of power", Prosperity and Poverty, September, núm. 17.

Ardila, Rubén, "Calidad de vida: una definición integradora", http://www.redalyc.org/ pdf/805/80535203.pdf 
Barre, Raymond (1968), El desarrollo económico, 4a ed., México, Fondo de Cultura Económica. Blackmar, Elizabeth (2006), "Appropriating 'the commons': The tragedy of property rights discourse", en S. Low y N. Smith (eds.), The politics of public space, Nueva York-Londres, Routledge.

Borja, Jordi y Zaida Muxí (2000), El espacio público, ciudad y ciudadanía, Barcelona, Electa-Diputación Barcelona.

Brown, A. (2015), "Claim and contest in street trading. Dynamics of legal \& spatial empowerment", International Seminar on Street Trading in the Global South, 15 March, The Bartlett Development Planning Unit, UCL, University of London.

Castells, Manuel (1977), La cuestión urbana, 4ª ed., en español, México, Siglo XXI. (1999), "La era de la información" en El poder de la identidad, vol. II, México, Siglo XXI.

Cross, John (2005), "Las organizaciones", en J. Monnet y J. Bonnafé (coords.), El ambulantaje en la Ciudad de México: investigaciones recientes, México, UNAM-CEMCA.

Crossa, Verónica (2014), "Las políticas de reordenamiento del comercio ambulante en la Ciudad de México. Una perspectiva crítica", en Silvia Giorguli y Vicente Ugalde, Gobierno, territorio y población: las políticas públicas en la mira, México, El Colegio de México, CEDUA, pp. 315-341.

De la Peña (2000): "Corrupción e informalidad", en C. Lomnitz, Vicios públicos, virtudes privadas. La corrupción en México, México, CIESAS/Porrúa, pp. 113-128.

Duhau, E. y A. Giglia (2008), "El espacio negociado: la ciudad autoconstruida" en Las reglas del desorden. Habitar la metrópoli, México, UAM-Azcapotzalco/ Siglo XXI.

Furtado, Celso (1969), Desarrollo y subdesarrollo, serie Lectores 53, 4ª ed., Buenos Aires, Eudeba.

Gasca, José y Felipe Torres (2014), "El control corporativo de la distribución de alimentos en México", Problemas del Desarrollo, vol. 45, núm. 176, enero-marzo, pp. 133-155.

Germani, Gino (1969), Sociología de la modernización. Estudios teóricos y metodológicos aplicados a América Latina, Buenos Aires, Paidós.

Giglia, A. (2004), "Conflictos por el espacio y orden urbano", Estudios Demográficos y Urbanos, vol. 19, núm. 2 (56), pp. 257-288.

González, Roberto (2006), “El comercio ambulante en México y las políticas públicas para su regulación y control", 13 de octubre, La Jornada, México, 2006.

Harms, E. (2009), "Vietnam's civilizing process and retreat from the street. A turtle's eye view from Ho Chi Minh City", City \& Society, núm. 21, pp. 182-206.

Harvey, David (2006), "The political economy of public space", en S. Low y N. Smith (eds.), The politics of public space, Nueva York/Londres, Routledge, pp. 17-33.

International Monetary Fund (2006), "Mexico: selected issues", IMF Country Report No. 06/351, octubre. 
ITDP (2014), "Megacentralidades: propuesta de integración de los Cetram al desarrollo urbano de la Ciudad de México", citado por Jennifer Alcocer, Más por más, paraderos hostiles, México y Embajada Británica en México, www.ciudadanos en red. 01/03/2016.

Jusidman, Clara (1993), "Tendencias en la estructura económica y el sector Informal en México", Cuadernos del Trabajo, núm. 10, STPS.

Ramírez Kuri, Patricia (coord.) (2003), Espacio público y reconstrucción de la ciudadanía, México, Editorial Porrúa-Flacso, pp. 31-58.

Lojkine, Jean (1981), El marxismo, el estado y la cuestión urbana, 2ª ed., México, Siglo XXI.

Myrdal, Gunnard (1953), The political element in the development of economic theory, Londres.

Nussbaum, Martha C., y Sen Kumar Amartya (1996), La calidad de vida, México, Fondo de Cultura Económica, 588 pp., https://es.scribd.com/doc/132034788/Libro-La-Calidad-deVida-SEN-NUSSBAUM

Oriard, L. (2015), "Comercio callejero y creación de espacio urbano. Casos de Ahmedabad, India y Tepito, México", Seminario interno en el Instituto de Investigaciones Económicas, febrero, México, UNAM.

OIT (1982), XIII Conferencia Internacional de Estadígrafos del Trabajo (CIET) 1997), Grupo de Delhi, sobre estadísticas del sector informal (2001), XVII Conferencia de Estadísticas del Trabajo, (CIET)

OIT, ILO (1991), The dilemma of the informal sector.

(1992), Statistics on employment in the informal sector. (1985), XV Conferencia Internacional Estadísticas del Trabajo (CIET)

Portes, Alejandro (1994), "When more can be less labour standard, the development and the informal economy", .

Ramírez Kuri (2016), "La reinvención del espacio público en el lugar central. Desigualdades urbanas en el barrio de La Merced, Centro Histórico de la Ciudad de México", en Ramírez, P. (coord.), La reinvención del espacio público en la ciudad fragmentada, México, Instituto de Investigaciones Sociales, UNAM, pp. 99-133.

Subirats, Joan (2016), "Explorar el espacio público como bien común. Debates conceptuales y de gobierno en la ciudad fragmentada", en Patricia Ramírez Kuri (coord.), La reinvención del espacio público en la ciudad fragmentada, México, Instituto de Investigaciones Sociales, UNAM, pp. 73-98.

Urzúa M., Alfonso y Alejandra Caqueo-Urízar (2012), Calidad de vida: una revisión teórica del concepto, México, Proyecto del Conacyt, pp. 61-71. 



\section{Calidad de vida y desastres naturales en la Zona Metropolitana del Valle de México}

Abraham Granados Martínez

\section{INTRODUCCIÓN}

Los desastres se presentan por precondiciones socioambientales, las cuales se potencializan como consecuencia de los riesgos antrópicos, como deforestación, erosión, contaminación (PNUD, 1999: 40). Los efectos de los desastres naturales son producto de entornos sociales, políticos y económicos (Wisner et al., 2003: 4).

Las repercusiones de los desastres en la población reciben influencia de la calidad de vida y la seguridad social. Los riesgos suelen ser más peligrosos para ciertas poblaciones y regiones con peores condiciones de calidad de vida. El riesgo se agrava ante la ausencia de condiciones socioeconómicas y de infraestructura adecuadas.

Los riesgos de desastres se distribuyen entre las personas de forma semejante como ya está dividida socialmente una colectividad. Los efectos de los fenómenos ambientales extremos en la población reflejan estructuras sociales en las que se producen (Enarson, 2000: 2). Así, los desastres no son naturales de manera estricta, son producto de interacciones ambientales y antrópicas con repercusiones diferentes por regiones y para poblaciones, según su capacidad de adaptación y resiliencia. ${ }^{1}$

\footnotetext{
${ }^{1}$ La resiliencia se entiende como la capacidad de adaptación a la combinación de las fortalezas, atributos y recursos disponibles para un individuo, comunidad, sociedad u organización que pueden utilizarse para reducir los efectos adversos, moderar daños o para favorecer oportunidades benéficas. La resiliencia se refiere a la capacidad de un sistema y sus componentes para anticipar, absorber, adaptarse o recuperarse de los efectos de un peligro, de forma oportuna y eficiente, incluso con garantía de preservación, restauración o mejora de sus estructuras y funciones básicas (IPCC, 2012: 556 y 563).
} 


\section{RELACIÓN ENTRE EL GRADO DE CALIDAD DE VIDA Y LOS DESASTRES}

La calidad de vida de la población se fundamenta en logros y opciones que una persona tuvo la oportunidad de elegir, es decir, se relaciona con ampliar la dotación de bienes iniciales con que cuentan las personas y además favorecer sus condiciones para convertir ese conjunto de bienes en capacidades de realización; también, implica asegurar que las instituciones generen situaciones para mayor bienestar de la sociedad, con base en la garantía de libertades individuales fundamentales que favorezcan el desarrollo humano.

En lo referente al riesgo de padecer desastres extremos, se establece una correlación con los problemas estructurales y coyunturales de una sociedad. Las carencias sociales, económicas y políticas de una región influyen para determinar la capacidad para enfrentar riesgos climáticos. Por ejemplo, se reconoce que existe mayor probabilidad de que una región sea afectada por desastres cuando la población tiene bajos niveles de ingresos (Larrañaga y Herrera, 2010: 7).

La satisfacción de la población con la vivienda y la ciudad donde habitan depende de los servicios básicos y la infraestructura física, pero del mismo modo de diversos factores donde se incluye la seguridad, la cercanía a lugares de esparcimiento o culturales, así como por los riesgos que devengan de desastres naturales (Lora et al., 2008: 229). Así, la calidad de vida se relaciona con la satisfacción de los hogares sobre su entorno físico y humano (Royuela et al., 2006).

En la figura 12-1, se presenta la causalidad entre los procesos sociales y los desastres climáticos. Se parte de un ambiente determinado, donde se distribuyen los recursos naturales de forma desigual en el territorio. Esto determina la capacidad de recursos y la posibilidad de riesgo para la población en una región. Estos fenómenos reciben influencia de procesos sociales y mediados por la calidad de vida de cada región.

Los riesgos son un producto de las condiciones territoriales y sociales de una región. Por ello, los desastres generados por fenómenos climáticos extremos tienen repercusiones diferenciadas en zonas relativamente cercanas. Al presentarse un fenómeno climático extremo, sus repercusiones no son homogéneas en el territorio. El riesgo es producto de interacciones, en un determinado tiempo y espacio, de las poblaciones humanas expuestas y vulnerables (ICSU-LAC, 2009: 1).

Se reconoce que algunos grupos de población absorben en cierta medida las consecuencias de los desastres, como inundaciones, Iluvias atípicas y otros, pero otros sectores sin privilegios y con alta vulnerabilidad social tienden a enfrentar el colapso del orden social y, en algunos casos, hasta incremento de violencia (Beck, 
Figura 12-1

Relación entre procesos sociales y desastres climáticos

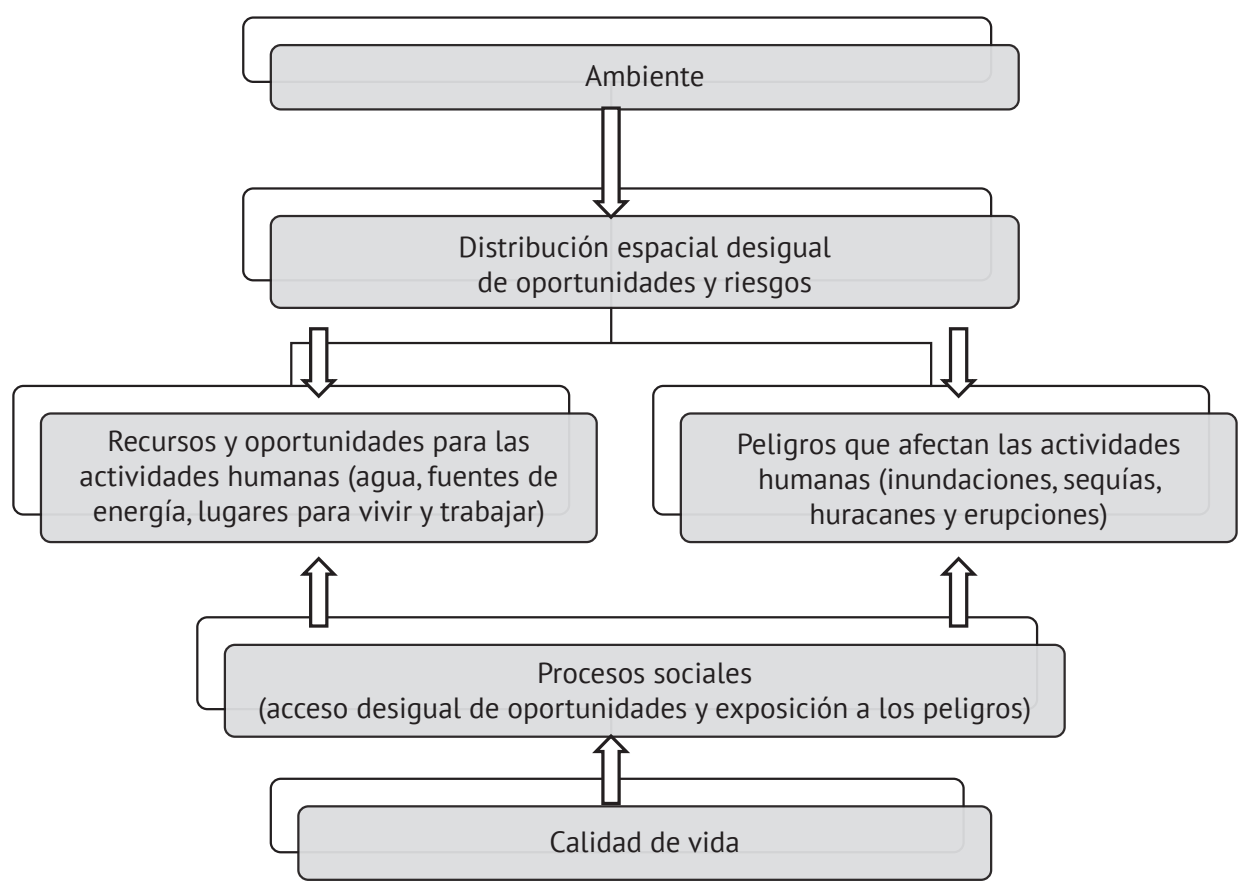

Fuente: Elaboración propia con datos de Wisner et al. (2003: 8).

2010: 258). A su vez, las acciones de un peligro natural dependen del contexto social en que ocurren, como consecuencia de la vulnerabilidad social y relaciones de poder contextuales (Enarson, 2000; Nelson et al., 2002).

Las estructuras económicas y políticas tienden a relegar a la población más pobre, la cual tiene limitadas opciones para decidir dónde vivir y trabajar. Esta población suele localizarse en zonas más vulnerables a riesgos, como en laderas o zonas bajas que pueden verse afectadas por desastres, como deslizamientos o inundaciones (Chafe, 2007: 86). Por ello, la población con mayores carencias suele padecer más los riesgos climáticos debido a las condiciones de sus asentamientos y sus medios de vida.

Los desastres constituyen un freno al desarrollo económico y humano. El nivel de calidad de vida de la población se vincula con su grado de vulnerabilidad ante el riesgo a desastres. Así, estos afectan la calidad de vida en diversos aspectos. El Programa de las Naciones Unidas para el Desarrollo (PNUD) y el Ministerio de Planificación de Chile llevó a cabo una encuesta para conocer los efectos en la calidad de vida de la población afectada por el terremoto en Chile y el posterior tsunami del 27 
de febrero de 2010; tal encuesta identificó que el efecto fue mayor en las viviendas de la población de bajos ingresos, ya que en seis regiones que sufrieron afectaciones, $12 \%$ de la población en el quintil más pobre padeció mayor daño o destrucción de la vivienda, en relación con $4.6 \%$ de la población en el quintil de mayores ingresos. Además, se encontró mayor incidencia de estrés postraumático en los sectores de bajos ingresos, como consecuencia de la afectación material mayor que sufrieron y por la limitante de recursos para recibir el tratamiento necesario (Larrañaga y Herrera, 2010: 2-3). Asimismo, se reconoció que la pobreza se incrementó de 2009 a 2010 como efecto del terremoto/tsunami, al pasar de una tasa de pobreza a nivel nacional de 16.4 a 19.4\% (Larrañaga y Herrera, 2010: 19). ${ }^{2}$

Por su parte, el crecimiento poblacional es un factor que influye en el nivel de vulnerabilidad ante desastres. Al respecto, la localización espacial de la población es determinante en la magnitud de las consecuencias de los desastres (UNFPA et al., 2012: 11). Ante una densidad de población alta en regiones muy vulnerables desde el punto de vista social, aunada a la degradación y la contaminación ambiental, se agravan los efectos de los desastres climáticos. Así, los cambios demográficos que modifican el espacio físico y construido derivarán en variaciones en los perfiles de riesgos en el mediano y largo plazos.

\section{RIESGOS DE DESASTRES DESIGUALES PARA LA POBLACIÓN}

Los riesgos tienen mayor alcance en las personas que viven en sistemas sociales endebles, con limitado o nulo acceso a protección de salud, así como con menor capacidad de adaptación y resiliencia

Las personas pobres y los grupos marginados cargan con mayor parte del riesgo. En especial, las niñas y los niños pobres son más propensos a enfermedades relacionadas con el clima, como el paludismo, la desnutrición y la diarrea. La población con mayores ingresos no se excluye de los efectos negativos derivados de eventos extremos, riesgos emergentes y propagación de efectos adversos en las poblaciones más vulnerables (IPCC, 2014). Sin embargo, aquélla cuenta con mayor capacidad de adaptación y resiliencia, respecto de la población con menores recursos.

En síntesis, los factores sociodemográficos y económicos de la población influyen en el nivel de riesgo al exponerse a fenómenos climáticos riesgosos. Las personas más pobres son vulnerables a desastres y diversas catástrofes por laxitud política,

${ }^{2}$ Los resultados de la encuesta consideran ser cautos al interpretar este incremento de la pobreza, por la naturaleza longitudinal de la encuesta y el efecto de estacionalidad, dada la comparación en meses distintos entre años. 
racismo y pobreza arraigada, y no sólo por su localización geográfica (Scheper-Hughes, 2014: 220).

\section{FONDO DE DESASTRES NATURALES}

\section{EN LA ZONA METROPOLITANA DEL VALLE DE MÉXICO}

El Fondo de Desastres Naturales (Fonden) es un instrumento financiero del gobierno federal para apoyar a municipios y delegaciones de la República Mexicana, y a las dependencias y entidades de la Administración Pública Federal, en atención y recuperación de los efectos que produzca un fenómeno natural.

El objetivo del Fonden es atender los efectos de desastres naturales imprevisibles, cuya magnitud supere la capacidad financiera de respuesta de municipios y delegaciones, dependencias y entidades paraestatales. El Fonden atiende fenómenos de: salud, químicos, geológicos e hidrometeorológicos. Con esta información, se obtiene una variable "proxy" que permite tener una aproximación sobre la magnitud de los eventos extremos relacionados con el ambiente, para delegaciones y municipios de la Zona Metropolitana del Valle de México (ZMVM).

El financiamiento del Fonden para atender fenómenos de salud, químicos y geológicos fueron mínimos de 2001 a $2008 .{ }^{3}$ Casi la totalidad de eventos financiados por el Fonden de 2001 a 2008 correspondieron a fenómenos hidrometeorológicos. Por ello, en esta investigación se utiliza sólo la información del número de eventos hidrometeorológicos de 2001 a 2008 financiados por el Fonden en la ZMVM. La distribución espacial de tales eventos se presenta en el mapa 12-1.

En dicho mapa, los tonos grises muestran delegaciones o municipios de la ZMVM con mayores participaciones del Fonden de 2001 a 2008 y el color blanco representa los sitios donde no se utilizó este tipo de financiamiento. Esto no implica que estos últimos estuvieran exentos de padecer fenómenos hidrometeorológicos extremos, pero que a pesar de tenerlos, los riesgos no rebasaron su capacidad financiera para contrarrestar los daños en la zona afectada.

Con información del Fonden en los ámbitos delegacional y municipal, es posible dar cuenta de los eventos que sobrepasaron la capacidad de respuesta gubernamental; dicha información es una evidencia del riesgo que enfrentan las regiones ante eventos climáticos extremos y permite vincular estos datos de desastres con el índice de calidad de vida objetivo (ICVO) para la ZMVM.

\footnotetext{
${ }^{3}$ Se utiliza este periodo porque fue la información disponible de Protección Civil, de la Secretaría de Gobernación (Fonden, 2012).
} 
Mapa 12-1

Eventos del Fondo de Desastres Naturales (Fonden) en la Zona Metropolitana del Valle de México (ZMVM) (2001 a 2008)

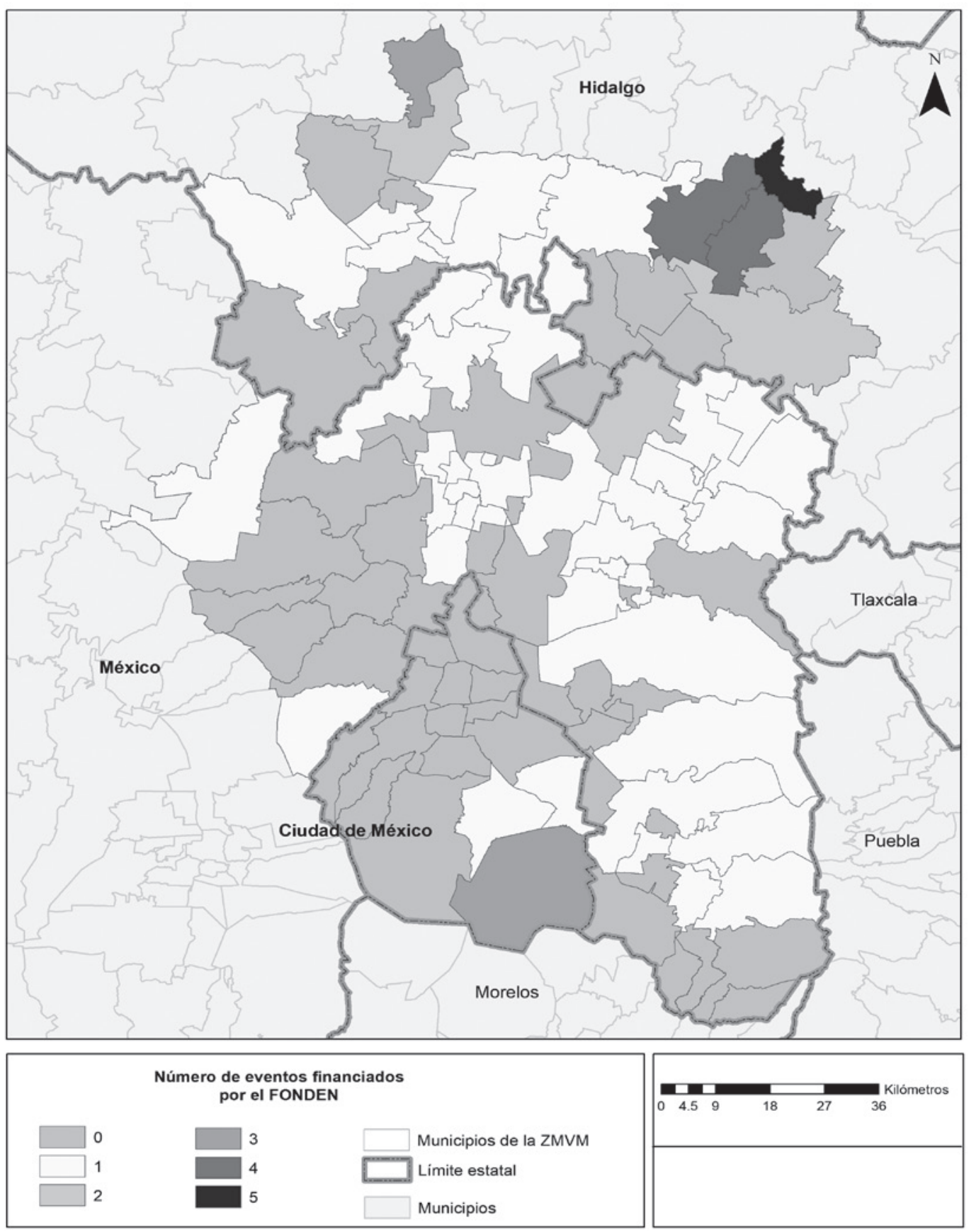

Fuente: Fonden, 2001 a 2008. 


\section{CORRELACIÓN ENTRE CALIDAD DE VIDA Y DESASTRES EN LA ZONA METROPOLITANA DEL VALLE DE MÉXICO}

A continuación, se analiza una correlación que hay entre el ıcvo y los desastres climáticos presentados en la ZMVM, mediante el uso de datos del Fonden como variable "proxy". Con esta finalidad, se utiliza la autocorrelación espacial del índice I de Moran, con base en el software GeoDa. ${ }^{4}$ Este índice presenta el nivel de autocorrelación espacial de una distribución de datos, es decir, proporciona un dato estadístico para determinar el grado de asociación espacial entre los valores vecinos de una variable (" $y$ ") en relación con los valores de otra variable (" $x$ ") (Arizona State University, 2016). En este caso, la asociación se lleva a cabo para las variables del ICVO (índice de calidad de vida objetivo) y el Fonden (gráfica 12-1).

Existe una correlación espacial negativa entre el ICVO y los eventos financiados por el Fonden para la ZMVM de 17.3\%, ya que se estima un índice I de Moran de -0.173466 (gráfica 12-1). Es decir, las delegaciones o los municipios de la ZMVM con mayor ICvo tienden a presentar menos desastres hidrometeorológicos que superen su capacidad financiera para solventar este riesgo.

Al revisar dicha gráfica, se identifica que la mayoría de delegaciones y municipios de la zмvм tiene una relación negativa entre variables del ICvo y el Fonden; destacan el cuadrante inferior derecho, porque agrupa valores altos del ICVO rodeado por vecinos con valores bajos para la variable del Fonden. En tanto, el cuadrante superior izquierdo, corresponde a una asociación de variables negativas (Anselin, 1996: 117), donde los valores bajos del ICvO están rodeados por valores altos de la variable Fonden. Esta correlación espacial de variables muestra que a mayor ICVO, tiene lugar menor proporción de eventos del Fonden; contrario a ello, con menor ICVO, hay mayor asociación de eventos hidrometeorológicos financiados por el Fonden para la ZMVM.

La distribución espacial del ICVO y los eventos financiados por el Fonden se presentan en el mapa 12-2, donde se evidencia lo identificado mediante la correlación espacial con el índice I de Moran. Es posible verificar las regiones con mayor categoría del ICVO con menores eventos que el Fonden financia. Como es el caso de casi todas las delegaciones en el Distrito Federal, con excepción de tres que tuvieron financiamiento de dicho fondo, como es el caso de Milpa Alta que padeció tres desastres y

\footnotetext{
${ }^{4}$ GeoDa es un paquete para el análisis de datos espaciales, que Luc Anselin creó en el Centro GeoDa de la Universidad Estatal de Arizona (Arizona State University, 2016).
} 


\section{Gráfica 12-1}

Autocorrelación espacial del índice I de Moran, para el índice de calidad de vida objetivo (ICVO) y el Fondo de Desastres Naturales (Fonden)

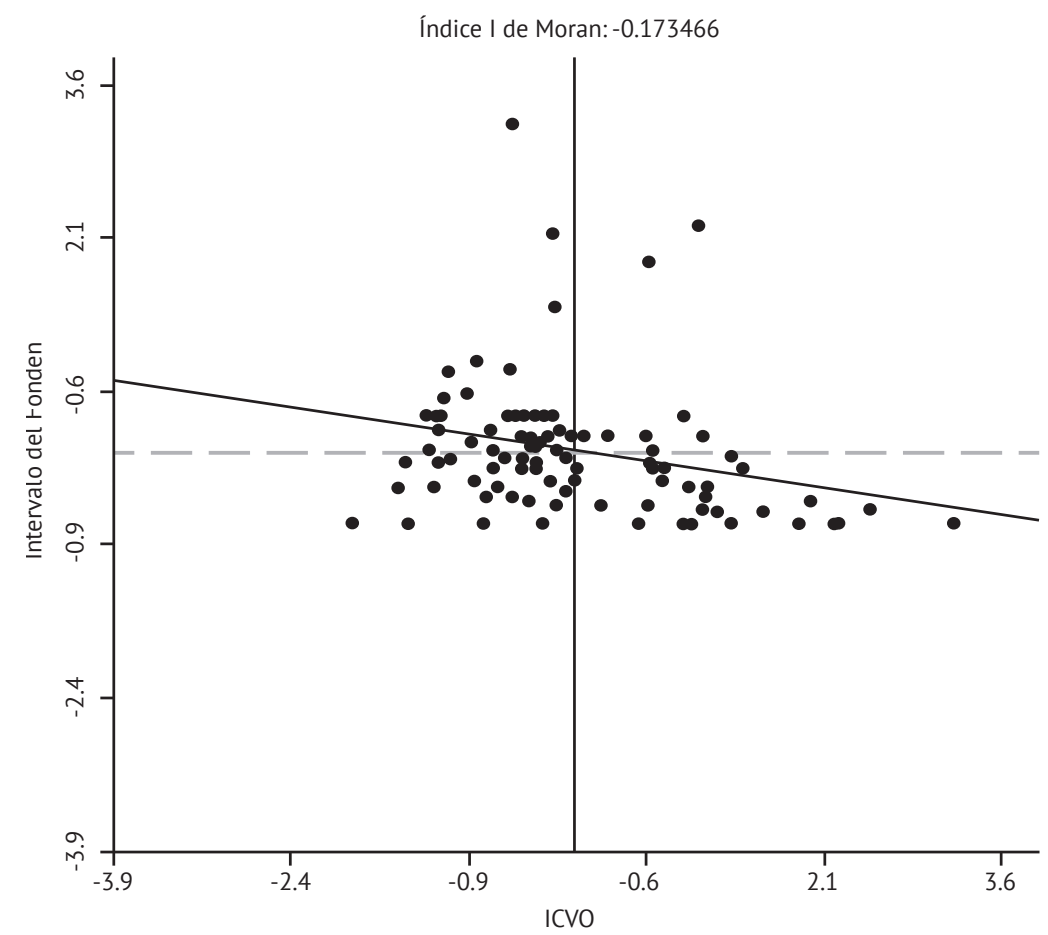

Fuente: Elaboración propia con datos de GeoDa.

tiene un grado de ICVO "bajo", así como Tláhuac y Xochimilco, ambas con grado de ICVO "medio" y un desastre financiado en el periodo de 2001 a $2008 .^{5}$

Para la revisión más detallada, los municipios y las delegaciones que han enfrentado desastres climáticos se agrupan en aquellos que padecieron por lo menos un evento financiado por el Fonden de 2001 a 2008 en la ZMVM y en los que no tuvieron desastres.

Con esta clasificación, se identifican 46 delegaciones y municipios (47.9\%) de 96 que se consideran en la ZMVM donde se hubo financiamiento del Fonden. ${ }^{6}$ Es de-

${ }^{5}$ El ICVO se clasifica en cinco grados, con base en los siguientes rangos: 1) muy alto, de 0.80 a $1.00 ; 2$ ) alto, de 0.60 a 0.79 ; 3) medio, de 0.40 a 0.59 ; 4) bajo, de 0.20 a 0.39 , y 5) muy bajo, de 0.01 a 0.19 .

${ }^{6}$ En adelante, las delegaciones y los municipios que recibieron financiamiento del Fonden de 2001 a 2008 serán considerados como "delegaciones y municipios con desastres". Por su parte, las delegaciones y los municipios que tuvieron este apoyo serán referidos como "delegaciones y municipios sin desastres". 


\section{Mapa 12-2}

Índice de calidad de vida objetivo (ICVO) y Fondo de Desastres Naturales (Fonden) en la Zona Metropolitana del Valle de México (ZMVM) (2001 a 2008)

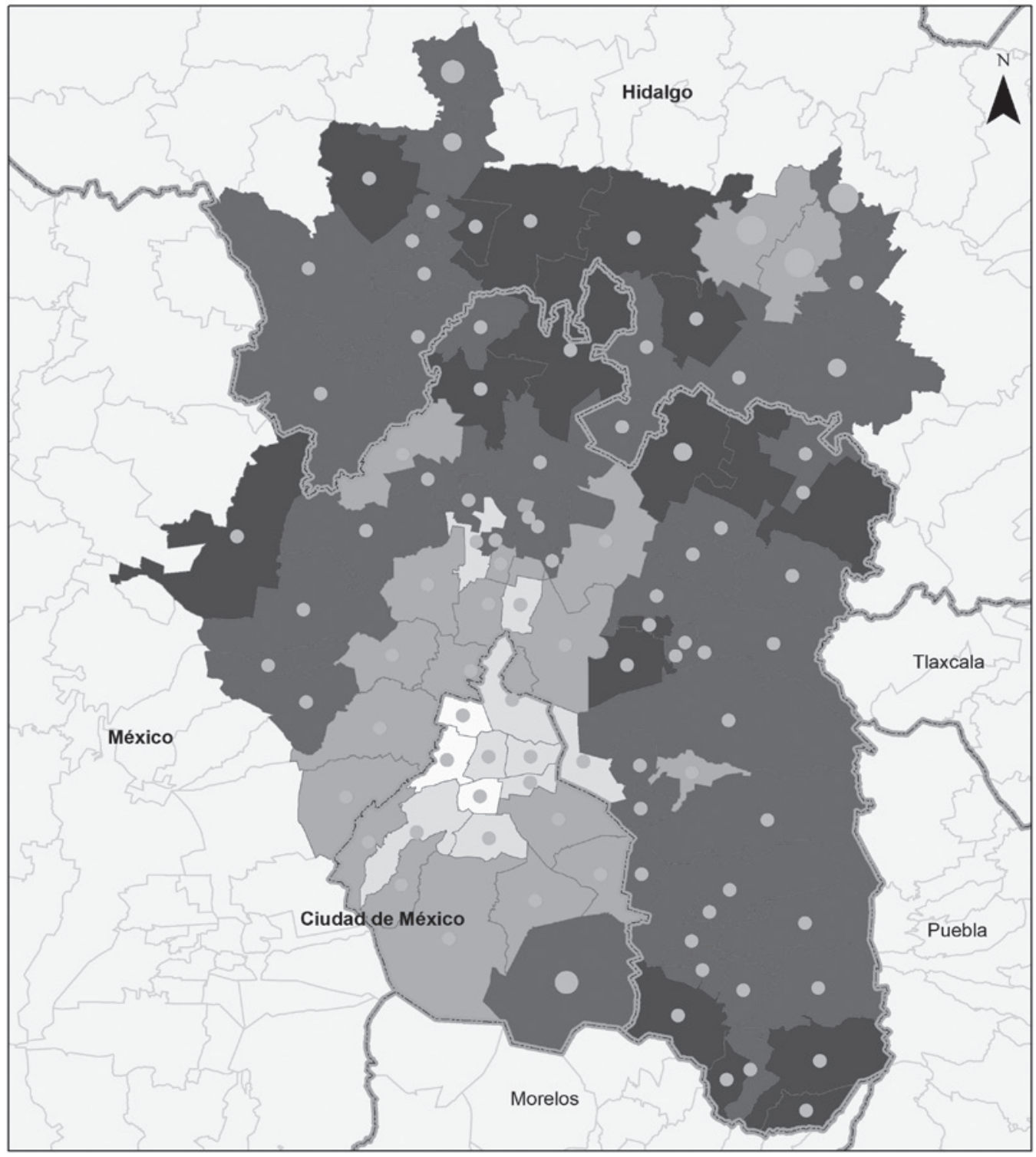

\begin{tabular}{|c|c|c|c|c|c|c|}
\hline \multicolumn{2}{|c|}{ Grado de calidad de vida } & $\begin{array}{l}\text { Número de eventos financiados } \\
\text { por el FONDEN }\end{array}$ & \multirow{2}{*}{ 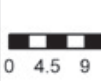 } & \multirow[b]{2}{*}{18} & & \multirow{2}{*}{$\begin{array}{l}\text { Kilómetros } \\
36\end{array}$} \\
\hline Muy bajo & Muy alto & {$[0-1)$} & & & 27 & \\
\hline Bajo & Municipios de la ZMVM & $(1-2)$ & & & & \\
\hline Medio & Limite estatal & $(2-3)$ & & & & \\
\hline Alto & Municipios & $(3-5]$ & & & & \\
\hline
\end{tabular}

Fuente: Fonden, 2001 a 2008. 
cir, cerca de 50\% de delegaciones y municipios que conforman la metrópoli tuvieron algún desastre en el periodo revisado. No obstante, de las 16 delegaciones del Distrito Federal solo tres obtuvieron financiamiento de parte del fondo. También, destaca que ninguna delegación o municipio con grado "muy alto" de ICVO tuviera desastres financiados por el Fonden y únicamente un municipio, Cuautitlán, con grado "alto" de ICVO presentara un desastre. En cambio, más de la mitad de las (25 de 46) delegaciones y los municipios con apoyo del Fonden muestra un grado "bajo" de ICVO y una quinta parte (9 de 46) tiene un grado "muy bajo".

Por su parte, menos de la mitad (23 de 50) de las delegaciones y los municipios que no utilizaron un financiamiento del Fonden tiene ICVO "bajo" y sólo seis municipios presentan un grado "muy bajo". En cambio, tres delegaciones cuentan con ICVO "muy alto". Al analizar los promedios de este último en delegaciones y municipios que tuvieron desastres, respecto de las delegaciones y los municipios sin recursos del Fonden, destaca que el promedio del ICVO es menor para los municipios con financiamiento del Fonden por algún desastre. Esto permite corroborar la correlación entre calidad de vida y desastres en una región, ya que sus condiciones no son lo suficientemente adecuadas para solventar riesgos climáticos extremos (gráfica 12-2).

Al revisar la composición por dimensiones del ICVO para delegaciones y municipios que tuvieron o no desastres financiados por el Fonden, se encuentra que la "dimensión de entorno urbano" es donde se presenta mayor diferencia en el promedio por delegaciones y municipios, donde aquellos con desastres poseen un indicador promedio menor por 0.06234 , en relación con los lugares donde no hubo desastres.

Gráfica 12-2

Índice de calidad de vida objetivo en la Zona Metropolitana del Valle de México

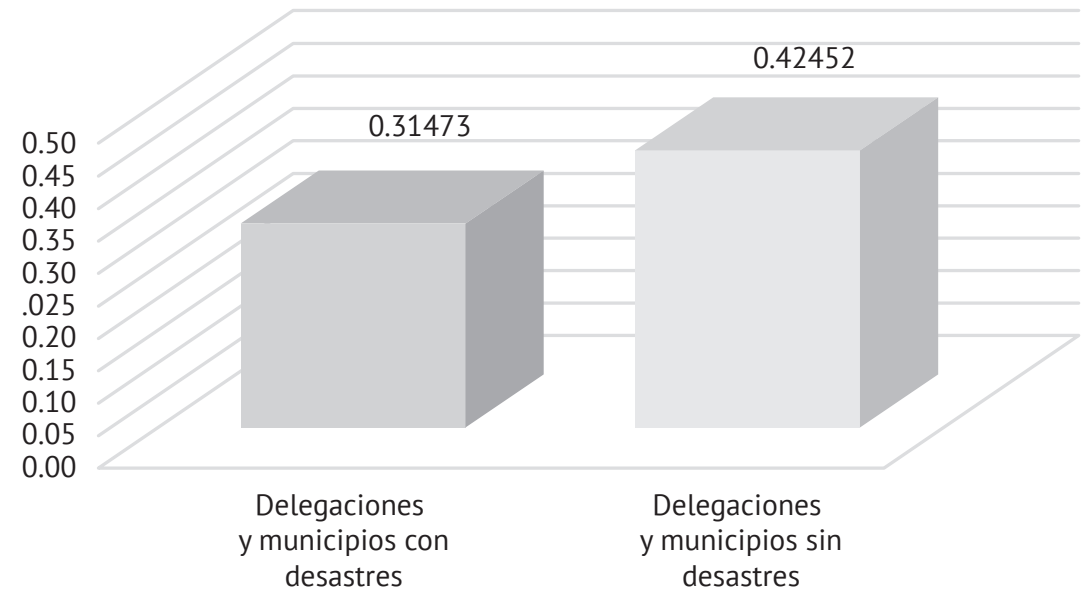


Gráfica 12-3

Dimensiones del índice de calidad de vida objetivo en la Zona Metropolitana del Valle de México

Vivienaas

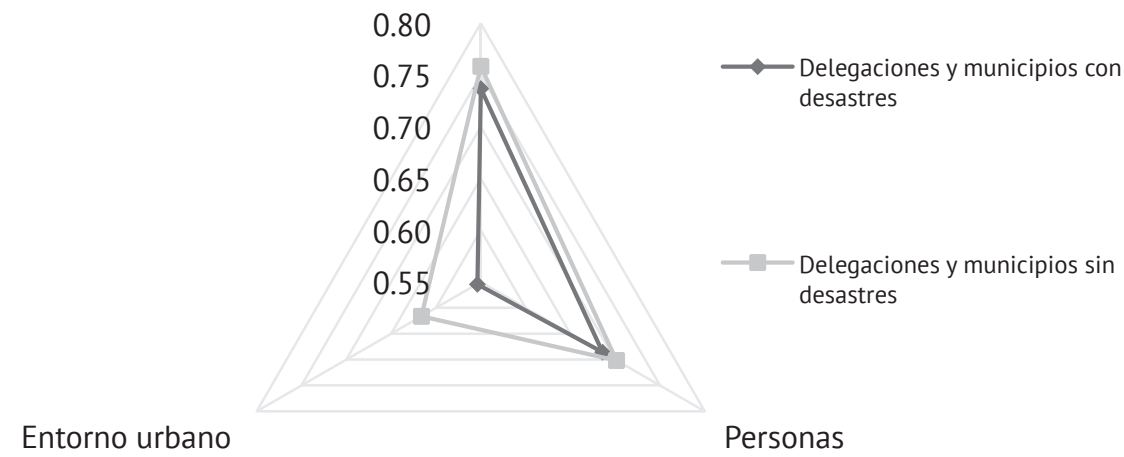

En tanto, las "dimensiones de viviendas y personas" presentan una relativa similitud para los dos grupos estudiados, con una diferencia de 0.02171 y 0.01570 por dimensión, respectivamente (gráfica 12-3).

En la dimensión de entorno urbano, la cual tiene la mayor diferencia en promedio del indicador por delegaciones y municipios, las subdimensiones de "mobiliario y servicios públicos" e "infraestructura vial" son las más precarias para los casos con desastres, con diferencias de 0.10322 y 0.09949 , respectivamente, en comparación con las delegaciones y los municipios sin desastres. Por su parte, la subdimensión de "acceso vial y comercio en vía pública" es prácticamente igual para los dos grupos, con y sin desastres (gráfica 12-4).

La mayor disparidad en la subdimensión de "mobiliario y servicios públicos" se presenta en la "disponibilidad de drenaje pluvial", donde las delegaciones y los municipios con desastres son las que presentan más carencias. En la subdimensión de "infraestructura vial", la "disponibilidad de pavimento y banqueta" es donde se presentan mayores diferencias negativas para delegaciones y municipios con desastres.

El mobiliario, los servicios y la infraestructura pública son fundamentales para explicar las disparidades entre grupos de delegaciones y municipios, con y sin desastres, dado que son elementos que contribuyen a contar con más o menos capacidad de adaptación y resiliencia en una región ante desastres climáticos. Cuando se presentan inundaciones o lluvias atípicas es importante contar con servicios públicos e infraestructura adecuada para reducir el riesgo frente a desastres extremos.

Por último, existen diferencias en la calidad de vida entre los grupos de delegaciones y municipios de la ZMVM que tuvieron financiamiento del Fonden de 2001 a 
Gráfica 12-4

Dimensiones del índice de calidad de vida objetivo en la Zona Metropolitana del Valle de México

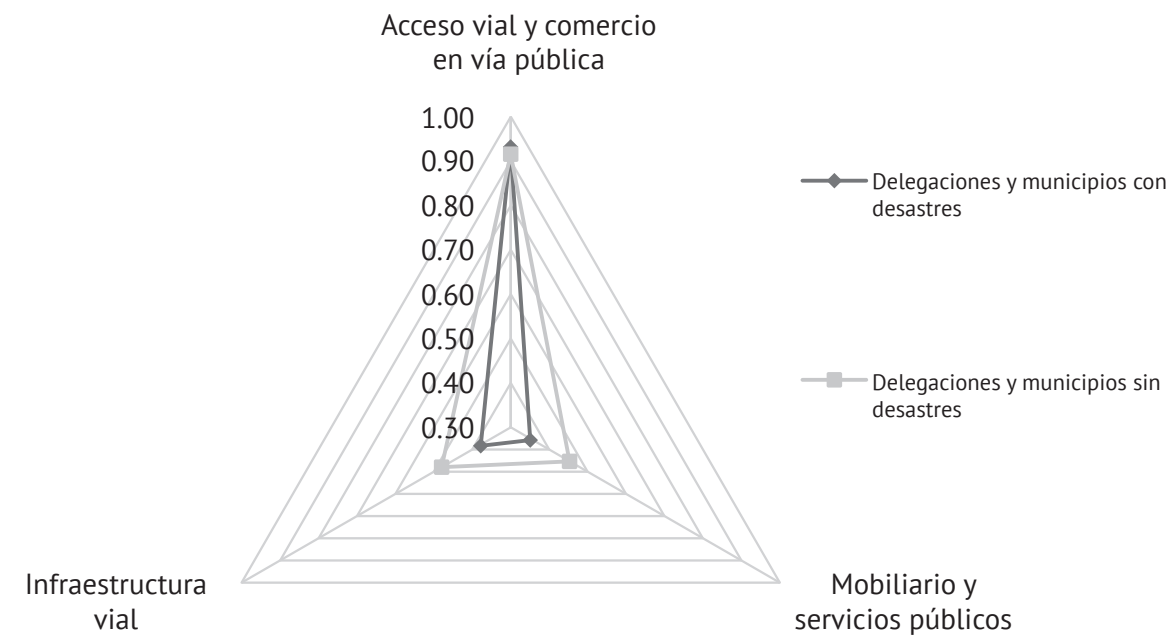

2008, lo cual deriva en distintos elementos y medios para afrontar los riesgos ante desastres. Asimismo, se corrobora la relación entre las condiciones de vida y la probabilidad de padecer desastres, en este caso, de eventos hidrometeorológicos en la ZMVM.

\section{BIBLIOGRAFÍA}

Anselin, Luc (1996), "The Moran scatterplot as an ESDA tool to assess local instability in spatial association", en Fischer, et al. (eds.), Spatial analytical perspectives on GIs in environmental and socio-economic sciences, Londres, Taylor and Francis, pp. 111-125.

Arizona State University (2016), “GeoDa Center", <http://geodacenter.asu.edu>.

Beck, Ulrich (2010), "Climate for change, or how to create a green modernity?", Theory, Culture \& Society, vol. 27, núms. 2-3, pp. 254-266.

Chafe, Zoë (2007), "Las crecientes amenazas de desastre y su potencial riesgo de desplazamientos de población", Ecología Política, núm. 33, pp. 84-87.

Delgado, Pedro y Tulia Salcedo (2008), "Aspectos conceptuales sobre los indicadores de calidad de vida", La Sociología en sus Escenarios, Universidad de Antioquia, núm. 17, pp 1-33.

Enarson, Elaine (2000), "Gender and natural disasters", Recovery and Reconstruction Department, Ginebra, septiembre, Working Paper 1.

Fonden (Fondo de Desastres Naturales) (2012), “Dirección General para la Gestión de Riesgos (del Fonden)", <http://www.proteccioncivil.gob.mx>.

ICSU-LAC (2009), Understanding and managing risk associated with natural hazards: an inte- 
grated scientific approach in Latin America and the Caribbean, Río de Janeiro y México, ICSU-LAC.

IPCC (Intergovernmental Panel on Climate Change), 2012, "Glossary of terms. In: Managing the risks of extreme events and disasters to advance climate change adaptation", en C. B. Field et al. (eds.), A special report of working groups I and II of the IPCC, Cambridge, Reino Unido y Nueva York, Cambridge University Press, pp. 555-564.

Larrañaga, Osvaldo y Rodrigo Herrera (2010), Encuesta post terremoto: principales resultados. Efectos en la calidad de vida de la población afectada por el terremoto/tsunami, Santiago de Chile, Programa de las Naciones Unidas para el Desarrollo (PNUD)-Ministerio de Planificación de Chile.

Lavell, Allan et al. (2012), "Climate change: new dimensions in disaster risk, exposure, vulnerability, and resilience", en C. B. Field et al. (eds.), "Managing the risks of extreme events and disasters to advance climate change adaptation", Un reporte especial de los grupos de trabajo I y II del Intergovernmental Panel on Climate Change (IPCC), Cambridge, Reino Unido, y Nueva York, Editorial de la Universidad de Cambridge, pp. 25-64.

Lora, Eduardo et al (2008), Calidad de vida más allá de los hechos, México, Banco Interamericano de Desarrollo-Fondo de Cultura Económica, 304 pp.

Mertz, Ole et al. (2009), "Adaptation to climate change in developing countries", Environmental Management, vol. 43, núm. 5, pp. 743-752.

PNUD (Programa de Naciones Unidas para el Desarrollo) (1999), Informe Nacional sobre Desarrollo Humano Honduras. El impacto de un huracán, PNUD, pp. 37-52.

Royuela, Vicente et al (2008), “Economía urbana y calidad de vida. Una revisión del estado del conocimiento en España", Revista Bibliográfica de Geografía y Ciencias Sociales, vol. 13, núm. 794, pp. 1-16.

Scheper-Hughes, Nancy (2014), "Katrina. The disaster and its doubles", en Michael R. Dove (ed.), The anthropology of climate change: an historical reader, Sussex, Reino Unido, Wiley-Blackwell, pp. 217-222.

UNFPA (Fondo de Población de las Naciones Unidas México) et al. (2012), Vínculos entre las dinámicas demográficas, los procesos de urbanización y los riesgos de desastres: una visión regional de América Latina, UNFPA, UNISDR y ONU-Hábitat.

Wisner, Ben et al. (2003), At risk: natural hazards, people's vulnerability and disasters, 2a ed., Londres, Routledge. 



\section{Las finanzas públicas y la calidad de vida en la Zona Metropolitana del Valle de México}

Marcela Astudillo Moya

\section{INTRODUCCIÓN}

Las zonas metropolitanas de México se caracterizan por profundas desigualdades sociales. Los problemas más comunes desde el punto de vista de la infraestructura son: equipamiento urbano insuficiente, carencia de vivienda, transporte público deficiente y problemas de contaminación ambiental.

El objetivo de este capítulo es analizar, desde una perspectiva fiscal, los diversos mecanismos de financiamiento con que cuentan el Distrito Federal y los municipios del Estado de México y de Hidalgo, que conforman la Zona Metropolitana del Valle de México (ZMVM), para satisfacer la demanda de bienes públicos de sus habitantes. Esta zona está integrada por entidades con límites políticos administrativos definidos, cada una con régimen fiscal propio, por lo que el financiamiento de los servicios públicos necesarios para mejorar la calidad de vida de sus habitantes está fragmentado y carece de un objetivo común. Ante ello, por una parte, es necesario otorgar mayores facultades de gasto e ingreso a los gobiernos estatales y municipales y, por la otra, instituir mecanismos de coordinación para mejorar el aprovechamiento de los escasos recursos fiscales.

\section{EL PAPEL DE LAS METRÓPOLIS}

En general, las metrópolis se consideran las catalizadoras del crecimiento económico (Cabrero et al., 2009). La innovación es la llave de la prosperidad y la mayor parte de la innovación tiene lugar en las metrópolis que atraen trabajadores especializados, 
empresas, instituciones y medios de comunicación, ya que por lo regular son las áreas que cuentan con suficiente infraestructura (Bird y Slack, 2007). Sin embargo, también atraen migrantes que requieren empleo, vivienda $y$, en general, servicios sociales (Bahl, Linn, y Wetzel, 2013a). En el caso de la ZMVM, se considera que el incremento en el empleo puede deberse, entre otras razones, a la adopción de nuevas tecnologías, la inmigración de mano de obra calificada y la presencia de centros de investigación y desarrollo (Valdivia et al., 2010).

Los desafíos son diversos. La migración rural-urbana presiona el nivel de servicios; por lo regular, los países en desarrollo cuentan con una infraestructura deficiente $y$, por otra parte, se requiere expandir los servicios para reducir las desigualdades entre los asentamientos de ingresos altos y bajos (Bahl y Linn, 2015). Las desigualdades socioeconómicas suelen determinar la exclusión de grandes sectores de la población del acceso a servicios indispensables, como agua y saneamiento (Castro, 2004). En el caso de la ZMVM, hay grandes diferencias entre las jurisdicciones que la integran: por ejemplo, el gasto per cápita en el Distrito Federal es 75\% más alto que en el Estado de Hidalgo y 42\% mayor que en el Estado de México (Bahl y Linn, 2015). Asimismo, en países atrasados las metrópolis enfrentan "deseconomías" de escala con efectos muy diversos. Otro desafío es el daño ambiental en grandes zonas del territorio, pues la presión de los estratos pobres ha dado lugar a la ocupación de reservas ecológicas y, en muchos casos, también de tierras con valor agrícola (Rodríguez, 2002).

\section{GOBERNANZA Y CARACTERÍSTICAS DE LAS ZONAS METROPOLITANAS}

Dependiendo de cómo se organice la gobernanza, el tamaño de las zonas metropolitanas puede significar prosperidad o desgracia; no obstante, de manera indudable, éstas tienen grandes retos. El mayor papel de los gobiernos locales es proveer bienes y servicios a los residentes de un área geográfica particular (Bird y Slack, 2007). De forma característica, la responsabilidad de la gobernanza y el suministro de bienes en un área metropolitana están fragmentados de modo vertical entre los gobiernos federal, estatal y municipal; tal es el caso de México. En la mayoría de los países subdesarrollados, no hay un gobierno metropolitano, pues no está definida con claridad una distribución de competencias y responsabilidades asociada con una asignación de recursos entre los gobiernos federal, estatal y municipal (Trivelli, 2000). Esta responsabilidad se fragmenta de manera horizontal entre las municipalidades, una amplia área de gobiernos locales que persiguen un propósito general, localida- 
des que buscan propósitos especiales y empresas públicas. Rara vez hay coordinación entre los actores y las instituciones de los ámbitos locales, estatales y federales (Brenner, 2002).

Por lo general, la estructura de gobierno en las zonas metropolitanas es una mezcla de dos estrategias básicas: fragmentación jurisdiccional (municipios autónomos y estados soberanos dentro del área metropolitana) y fragmentación funcional (empresas públicas de propósito único). La manera en la cual los países adoptan estas estrategias depende de la política y cómo valúan la autonomía local y de la eficiencia técnica (Bahl et al., 2013a).

Es muy probable que, en alguna medida, la autonomía por debajo del nivel metropolitano se perderá. La única manera de evitarlo es instituir mecanismos de coordinación vertical. En el caso de la autonomía de los municipios mexicanos, esta se encuentra garantizada por la Constitución Política de los Estados Unidos Mexicanos. En el artículo 115, se señala que ellos constituyen la base de la división territorial y de la organización política y administrativa de los estados. También se establece que los municipios de un mismo estado podrán coordinarse y asociarse para la provisión de los servicios públicos que les corresponda.

La gobernanza debe ser capaz de enfrentar el crecimiento metropolitano y de aprovechar las oportunidades sobre las cuales prospera. El planteamiento escalar de la gobernanza se atiene a la lógica de la descentralización, la delegación de atribuciones y la subsidiariedad, y se ha propuesto un tratamiento multiescalar para los casos metropolitanos (Neuman, 2006).

La "zona metropolitana" también es un concepto económico con fronteras que se modifican conforme cambia la economía; en la práctica, se usa más para propósitos de planeación. Los planes casi nunca se implementan por completo, pero incluso si se aplican, tienden a ser limitados en la cobertura del área y en las funciones consideradas. Los gobiernos estatales y municipales, en contraste, son electos y con límites políticos definidos, lo cual fragmenta el espacio metropolitano, por lo que no existe un gobierno unificado.

La elección de la descentralización puede aplicarse también en las áreas metropolitanas (Bahl et al., 2013a). El teorema de la descentralización fiscal de Oates señala que una gran cantidad de servicios públicos debería gestionarse a través del ámbito de gobierno local, a menos que por cuestiones de eficiencia fuera preferible que los hiciera el gobierno federal. El federalismo permite que la provisión de bienes públicos se adecúe a las diversas demandas de los consumidores (quienes viven en diferentes jurisdicciones) y al incrementarse el incentivo del ahorro, se propicia ma- 
yor inversión en capital humano que da lugar a un rápido crecimiento económico (Brueckner, 2006).

De acuerdo con lo anterior, si solo se considerara la eficiencia, el mejor gobierno para las áreas metropolitanas sería un gran número de pequeñas municipalidades con población relativamente homogénea; pero es necesario tomar en cuenta las economías de escala en la provisión de servicios, las externalidades y los factores políticos. De esta manera, la estructuración del gobierno metropolitano dependerá de la demanda por autonomía en contraposición con la demanda por más eficiencia en la entrega de servicios.

\section{EL RETO DE LAS FINANZAS PÚBLICAS}

El reto de las finanzas públicas en los países subdesarrollados al igual que en las metrópolis es orientar una parte adecuada del crecimiento económico al financiamiento de los gastos y lograr que los servicios públicos se proporcionen de manera eficiente. Como señala Lefèvre (2005), en el análisis de las finanzas públicas, es fundamental identificar quiénes tienen el dinero y preguntar cuál es su origen; asimismo, cuáles son las condiciones para que pueda gastarse y por quién. Por otra parte, es conveniente tener en cuenta la necesidad de los ingresos y los gastos que se relacionen con la optimación de la eficiencia, ya que, en caso contrario, se dificulta la rendición de cuentas y con ello se reduce la transparencia en el manejo de las finanzas públicas.

Cuando la estructura de gobierno está fragmentada, algunas cuestiones a resolver son: ¿cómo dividir las responsabilidades administrativas?, ¿cómo configurar un sistema en una amplia área para vigilar los resultados? (Bahl et al., 2013a). Con respecto a la responsabilidad de la provisión de servicios públicos en las áreas metropolitanas, su asignación dependerá de las economías de escala, las externalidades en la entrega de servicios y las preferencias por el control local (Bahl y Linn, 2015). A su vez, una dificultad para las zonas metropolitanas es coordinar la entrega de servicios y la fiscalidad que puede ser horizontal (intrametropolitana) o vertical (federal, estatal y municipal).

\section{LA POBLACIÓN Y LOS INGRESOS PÚBLICOS EN LA ZONA METROPOLITANA DEL VALLE DE MÉXICO}

En la ZMVM, se produce $28.5 \%$ del producto interno bruto (PIB), lo cual tiene beneficios y desafíos. Este hecho favorece el crecimiento de empresas que abastecen a la 
industria metropolitana y la generación de impuestos; además, fomenta la captación de cerebros provenientes de otras regiones, pues los trabajadores más talentosos migran a ciudades en búsqueda de mejores oportunidades. En contraste, el porcentaje de la población con ocupación informal es muy alta, ya que en escala nacional es de $52.7 \%$. Entre las entidades que conforman la ZMVM, en el Estado de Hidalgo se encuentra en esta situación $63.4 \%$ de la población trabajadora; en el Estado de México, 56.4\% y, en el Distrito Federal, 49.7\%, lo cual repercute en la recaudación impositiva (cuadro 13-1).

\section{Cuadro 13-1}

Porcentaje de la población con ocupación informal (2014)

\begin{tabular}{lc}
\hline Entidad & Porcentaje \\
\hline Distrito Federal & 49.7 \\
Estado de México & 56.4 \\
Estado de Hidalgo & 63.4 \\
Promedio nacional & 52.7 \\
\hline
\end{tabular}

Fuente: México ¿cómo vamos? Con datos de la Encuesta Nacional de Ocupación y Empleo del Instituto Nacional de Estadística y Geografía (INEGI).

Desde el punto de vista de los ingresos públicos, en la Zmvм destacan tres características: fragmentación, centralización y desigualdad del ingreso. El gobierno de la ZMVM está conformado de jurisdicciones político-administrativas (Distrito Federal, entidades federativas y municipios), las cuales son partes de la metrópoli y reducen las posibilidades de políticas integradas, que deja fragmentadas las finanzas públicas (Iracheta e Iracheta, 2014).

En México, el marco normativo que regula la distribución de potestades tributarias entre los tres ámbitos de gobierno (federal, estatal y municipal) es la "Constitución Política". En ella se establecen como fuentes exclusivas del gobierno federal a la energía eléctrica; la producción y el consumo de tabacos labrados; la gasolina y otros productos derivados del petróleo; los cerillos y fósforos; el aguamiel y los productos de su fermentación; la explotación forestal, y la producción y el consumo de cerveza. La federación tiene poderes fiscales implícitos en materia de hidrocarburos, minería, industria cinematográfica, comercio, juegos con apuestas y sorteos, intermediación y servicios financieros, y energía nuclear. Por otra parte, prohíbe a los estados imponer gravámenes al tránsito de personas o cosas que atraviesen su 
territorio, a la entrada y salida de su territorio de mercancía nacional y extranjera, así como emitir estampillas y papel sellado.

Además, hay concurrencia tributaria entre el gobierno federal y los estatales al señalar que el Congreso tiene facultad para "imponer las contribuciones que sean necesarias para cubrir el presupuesto" (artículo 73, fracción VII). En el Artículo 124, se señala: "las facultades que no están expresamente concedidas por esta Constitución a los funcionarios federales, se entienden reservadas a los estados".

Asimismo, de acuerdo con el artículo 115 constitucional, los ingresos tributarios de la hacienda pública municipal dependen de lo establecido por las legislaturas estatales. De forma explícita se señala que percibirán las contribuciones que establezcan los estados sobre la propiedad inmobiliaria, de su fraccionamiento, división, consolidación, traslación, mejora y las que tengan por base el cambio de valor de los inmuebles.

A principios del siglo xx, esta distribución constitucional de facultades tributarias derivó en una multiplicidad de sistemas hacendarios en toda la República, ya que cada estado tenía su propia política fiscal (Astudillo, 2001). Con el tiempo, esto fue un obstáculo para el crecimiento económico del país, por lo cual fue necesario iniciar un ordenamiento de los diversos sistemas fiscales existentes. Para ello, ha desempeñado un papel muy importante el método de distribución de ingresos adoptado desde 1922, el cual se denomina "sistema de participaciones" y consiste en que el gobierno federal recaude el impuesto y el Estado reciba una parte de lo recaudado siempre que este suspenda o derogue dicho impuesto en su territorio.

El uso de las participaciones para distribuir los ingresos se fortaleció con el paso del tiempo, al institucionalizarse por medio de leyes especiales para regular su pago, las cuales normaron de manera jurídica el uso de este sistema durante la segunda mitad del siglo xx. En 1980, entró en vigor la "Ley de Coordinación Fiscal" que rige las relaciones fiscales entre los gobiernos federal, estatal y municipal.

En la exposición de motivos de dicha ley, se señala que es la respuesta al problema del reparto desigual de las participaciones, ya que se uniforma la integración y la distribución de estas. Así, se toman como participables todos los impuestos federales y tal mecanismo se uniforma al crearse el "Sistema nacional de coordinación fiscal", con lo cual se consumó la apropiación por parte del gobierno federal de los impuestos con mayor capacidad recaudatoria, como el impuesto sobre la renta (ISR) y el impuesto al valor agregado (IVA), dejando a los otros ámbitos gubernamentales la posibilidad de manejar muy pocos impuestos con capacidad recaudatoria importante. Como puede verse en el cuadro 13-2, los impuestos con mayor potencial recauda- 


\section{Cuadro 13-2}

Ingresos tributarios por ámbito gubernamental

\begin{tabular}{|c|c|c|}
\hline Federal & Estatal & Municipal \\
\hline Impuesto sobre la renta (ISR) & Sobre diversiones y espectáculos públicos & Impuesto predial \\
\hline impuesto al valor agregado (IVA) & $\begin{array}{l}\text { Sobre loterías, rifas, concursos, sorteos y } \\
\text { juegos permitidos }\end{array}$ & $\begin{array}{l}\text { Impuesto sobre } \\
\text { adquisición de } \\
\text { inmuebles }\end{array}$ \\
\hline $\begin{array}{l}\text { Impuesto especial sobre } \\
\text { producción y servicios (IEPS) }\end{array}$ & \multirow[t]{11}{*}{$\begin{array}{l}\text { Erogaciones por remuneraciones al trabajo } \\
\text { personal. }\end{array}$} & \multirow[t]{11}{*}{ Derechos (agua) } \\
\hline $\begin{array}{l}\text {-Gasolinas, diésel para combustión } \\
\text { automotriz }\end{array}$ & & \\
\hline $\begin{array}{l}\text {-Bebidas con contenido alcohólico } \\
\text { y cerveza }\end{array}$ & & \\
\hline -Tabacos labrados & & \\
\hline -Juegos con apuestas y sorteos & & \\
\hline $\begin{array}{l}\text {-Redes públicas de } \\
\text { telecomunicaciones }\end{array}$ & & \\
\hline -Bebidas energetizantes & & \\
\hline -Bebidas saborizadas & & \\
\hline $\begin{array}{l}\text {-Alimentos no básicos con alta } \\
\text { densidad calórica }\end{array}$ & & \\
\hline -Plaguicidas & & \\
\hline -Combustibles fósiles & & \\
\hline $\begin{array}{l}\text { Impuesto sobre automóviles } \\
\text { nuevos (ISAN) }\end{array}$ & Sobre nóminas & \\
\hline Impuestos al comercio exterior & $\begin{array}{l}\text { Sobre ejercicio de profesiones u honorarios } \\
\text { o ambos }\end{array}$ & \\
\hline Accesorios & $\begin{array}{l}\text { Compra-venta de vehículos de motor } \\
\text { usados }\end{array}$ & \\
\hline Otros impuestos: & Sobre adquisición de bienes muebles & \\
\hline \multirow[t]{6}{*}{$\begin{array}{l}\text {-Impuestos por la actividad de } \\
\text { exploración y extracción de } \\
\text { hidrocarburos }\end{array}$} & & \\
\hline & Local sobre tenencia o uso de vehículos & \\
\hline & $\begin{array}{l}\text { Sobre actividades mercantiles e industria- } \\
\text { les. }\end{array}$ & \\
\hline & $\begin{array}{l}\text { Sobre instrumentos públicos y operaciones } \\
\text { contractuales }\end{array}$ & \\
\hline & Sobre hospedaje & \\
\hline & Adicionales & \\
\hline
\end{tabular}

Fuente: Secretaría de Hacienda y Crédito Público (SHCP), Cuenta de la Hacienda Pública Federal y Finanzas Públicas Estatales y Municipales. 
torio los reúne el gobierno federal y, en el otro extremo, los municipios básicamente cobran el impuesto predial y los derechos de agua.

En cuanto a los ingresos tributarios de las entidades federativas hay una gran diversidad de gravámenes, de los cuales los más importantes por su potencial recaudatorio son: nóminas, prestación de servicios de hospedaje, enajenación de vehículos de motor usados y bienes muebles, y tenencia.

Esta asignación de potestades tributarias entre los tres ámbitos de gobierno ha dado lugar a un desequilibrio vertical, al centralizar los ingresos tributarios en el gobierno federal, que es otra de las características señaladas antes, de la manera en que se obtienen los ingresos públicos en México y desde luego en la ZMVM. En 2013, el gobierno federal recaudó en promedio 90.8\% del total de los ingresos fiscales, los estados 6.1\% y los municipios 3.1\% (Chávez y Hernández, 2013). Así, hoy día la característica definitoria de las finanzas públicas en México, al igual que en la mayoría de los países en desarrollo, es la centralización. El gobierno federal mexicano cobra los impuestos de mayor importancia recaudatoria (ISR e IVA); gasta una gran parte del presupuesto público y determina la manera en que operan los gobiernos estatales y municipales, por ejemplo, las facultades tributarias, la asignación de gastos y la política de deuda.

Otra característica de las metrópolis mexicanas es la desigualdad, aunque tienden a lograr mayor desarrollo que las regiones rurales. Incluso dentro de una misma metrópoli, se observan profundos contrastes entre las entidades que la conforman, lo cual da lugar a una gran polarización del ingreso. Hay considerables diferencias en cuanto a los montos de recursos tributarios recaudados en las entidades que conforman la ZMVM, por ejemplo, el Distrito Federal obtiene por concepto de impuestos locales $22.4 \%$ y el Estado de Hidalgo 19.8\%, mientras que el Estado de México sólo 6.7\% (cuadro 13-3).

Respecto de las transferencias condicionadas (aportaciones), el artículo 25 de la "Ley de Coordinación Fiscal" contempla ocho fondos, de los cuales dos tienen especial relevancia en los ingresos municipales, que son: el Fondo de Aportaciones para el Fortalecimiento de los Municipios y de las Demarcaciones Territoriales del Distrito Federal (Fortamundf) y el Fondo de Aportaciones para la Infraestructura Social (FAIS).

\section{Cuadro 13-3}

Ingresos 2015: porcentajes con respecto al total

\begin{tabular}{lccc}
\hline Concepto & Distrito Federal & Hidalgo & Estado de México \\
\hline Impuestos locales & 22.4 & 19.8 & 6.7 \\
Transferencias provenientes de la federación & 46.1 & 58.9 & 75.1 \\
\hline
\end{tabular}

Fuente: Elaboración propia con base en las leyes de ingresos correspondientes. 
Dado que la ZMVM está conformada sólo por algunos municipios del Estado de México y del Estado de Hidalgo, es necesario analizar las relaciones fiscales entre la entidad federativa y sus municipios.

\section{Ingresos municipales del Estado de México}

De acuerdo con el artículo 219 del Código Financiero del Estado de México y sus Municipios, los ingresos municipales por concepto de participaciones, derivados del Sistema Nacional de Coordinación Fiscal e incentivos federales derivados de convenios, y el Sistema de Coordinación Hacendaria del Estado de México serán equivalentes a:

a) Cien por ciento del fondo de fomento municipal.

b) Veinte por ciento del fondo general de participaciones.

c) Cincuenta por ciento del fondo de fiscalización y recaudación.

d) Veinte por ciento del impuesto especial sobre producción y servicios.

e) Cincuenta por ciento del impuesto sobre automóviles nuevos.

f) Veinte por ciento del impuesto sobre tenencia o uso de vehículos.

g) Cien por ciento del impuesto sobre la renta correspondiente al salario del personal que preste un servicio en los municipios, así como en sus organismos públicos descentralizados.

Los ingresos ministrados por el gobierno estatal equivalen a:

a) Treinta por ciento del impuesto local sobre tenencia o uso de vehículos automotores.

b) Treinta y cinco por ciento del impuesto sobre la adquisición de vehículos automotores usados.

c) Cincuenta por ciento del impuesto sobre loterías, rifas, sorteos, concursos y juegos permitidos con cruce de apuestas.

La distribución entre los municipios de los recursos mencionados se efectúa con base en la recaudación del impuesto predial, los derechos de agua potable y drenaje, y el número de habitantes.

En cuanto a las transferencias provenientes del gobierno federal por concepto de aportaciones, con base en el artículo 25, fracción IV, y los artículos 36, 37 y 38 de la "Ley de Coordinación Fiscal", se establecen variables, fórmulas, metodologías, 
distribución y calendario de las asignaciones por municipio que corresponden al Fortamundf. La distribución de este último entre los municipios se lleva a cabo en proporción directa al número de habitantes de cada municipio.

En cuanto al Fondo para la Infraestructura Social Municipal y de las Demarcaciones Territoriales del Distrito Federal (Fismdf) la asignación por municipio se basa en los artículos 25 (fracción III), 32, 33, 34 y 35 de la "Ley de Coordinación Fiscal". El cálculo se realiza en función de la proporción que corresponda a cada municipio de la pobreza extrema a nivel estatal.

\section{Ingresos municipales del Estado de Hidalgo}

La otra entidad federativa que forma parte de la ZMVM es el Estado de Hidalgo. La "Ley de Coordinación Fiscal para el Estado de Hidalgo" regula las relaciones en materia de coordinación fiscal entre dicho estado y sus municipios. En ella, se establecen los mecanismos y los porcentajes para la distribución de las participaciones entre los municipios del estado.

En el artículo 4 de la mencionada ley, se establece que los municipios tienen derecho a percibir:

a) Veinte por ciento del fondo general de participaciones.

b) Cien por ciento del fondo de fomento municipal.

c) Veinte por ciento del impuesto especial sobre producción y servicios.

d) Veinte por ciento del impuesto sobre automóviles nuevos.

e) Veinte por ciento del fondo de fiscalización y recaudación.

f) Veinte por ciento del fondo de compensación.

g) Veinte por ciento del fondo de estabilización de ingresos de las entidades federativas.

h) Veinte por ciento del impuesto a la venta final de gasolina y diésel.

i) Veinte por ciento del fondo de compensación del impuesto sobre automóviles nuevos.

En la distribución de los recursos participables a los municipios, provenientes del fondo general de participaciones, del impuesto especial de producción y servicios y del impuesto sobre automóviles nuevos, los criterios que se toman en cuenta son: población, índice de marginación, número de comunidades existentes en cada municipio e incremento en la recaudación de predial y agua medido a través de los dos últimos ejercicios. 
En lo que corresponde al faIs, en el artículo 20 de la mencionada ley se establece que estos recursos se destinarán a los siguientes rubros: agua potable; alcantarillado; drenaje y letrinas; urbanización municipal; electrificación rural y de colonias o barrios pobres; infraestructura básica de salud; infraestructura básica educativa; mejoramiento de vivienda; caminos rurales, e infraestructura productiva rural. El criterio de distribución de estos recursos se basa en la pobreza extrema.

En cuanto al Fondo de Aportaciones para el Fortalecimiento de los Municipios, de acuerdo con el artículo 21 de la citada ley, se debe destinar a: cumplimiento de sus obligaciones financieras; pago de derechos y aprovechamientos por concepto de agua; descargas de aguas residuales; modernización de los sistemas de recaudación locales; mantenimiento de infraestructura, y atención de las necesidades directamente vinculadas con la seguridad pública de sus habitantes. Estos recursos se distribuyen en proporción directa al número de habitantes con que cuente cada municipio.

\section{Ingresos delegacionales del Distrito Federal}

En el caso del Distrito Federal, se tienen delegaciones en lugar de municipios, donde el Jefe de Gobierno es el encargado de administrar la hacienda pública con apego a la Ley de Ingresos y el Presupuesto de Egresos aprobados por la Asamblea Legislativa del Distrito Federal. El gobierno central es el responsable de transferir a las delegaciones los recursos federales provenientes de los diferentes fondos que se establecen en la "Ley de Coordinación Fiscal". Las delegaciones no pueden coordinarse de modo fiscal con municipios, gobiernos estatales o la federación.

En cuanto a la coordinación fiscal entre las delegaciones y el gobierno central no hay una ley como tal; sólo existe un ordenamiento jurídico relativo a los aprovechamientos ${ }^{1}$ y productos, ${ }^{2}$ el cual se denomina "Reglas para el control y manejo de los ingresos que se recauden por concepto de aprovechamientos y productos que se asignen a las dependencias, delegaciones y órganos desconcentrados que los generan, mediante el mecanismo de aplicación automática de recursos". De acuerdo con este ordenamiento, las delegaciones pueden recaudar de forma directa los apro-

\footnotetext{
${ }^{1}$ En el Código Fiscal, se definen los "aprovechamientos" como los ingresos que percibe el Estado por funciones de derecho público distintos de las contribuciones; por ejemplo, uso de instalaciones deportivas, actividades desarrolladas en bosques, zoológicos y áreas naturales protegidas, y uso de locales comerciales en centros recreativos.

${ }^{2}$ Se definen los productos como las contraprestaciones por los servicios que presta el Estado en sus funciones de derecho privado, así como por uso, aprovechamiento o enajenación de bienes de dominio privado; por ejemplo, servicios prestados en centros culturales, centros deportivos, estacionamientos y alquiler de máquinas de fotocopiado.
} 
vechamientos y sus accesorios, los productos y los ingresos que deriven de la aplicación de los artículos 267-B, 321 y 322 del Código Financiero del Distrito Federal y sus accesorios, entre los cuales se encuentran casetas telefónicas, comerciantes en vías públicas y acomodadores de vehículos (Gaytán, 2013). Esta disposición legal también transfiere la facultad de gasto de lo recaudado por los conceptos anteriores a las delegaciones.

En la literatura (Almagro Martín, 2013; Bahl et al., 2013b), se considera que los gobiernos de las zonas metropolitanas deberían contar con los suficientes recursos impositivos para satisfacer sus responsabilidades asignadas de gastos para que no dependan de las transferencias. Algunos autores (Lefèvre, 2005) señalan la necesidad de que las metrópolis tengan autonomía fiscal, entendiéndose como tal la responsabilidad tanto en el suministro de los servicios locales como para cobrar sus propios impuestos. Cabe aclarar que las ciudades grandes (Slack, 2009) tienen mayor capacidad fiscal respecto de los municipios pequeños.

En México los gobiernos estatales y municipales tienen escasa recaudación debido en gran parte a que sus poderes impositivos son limitados, carecen de un diseño adecuado de los instrumentos de cobranza y, en muchos casos, éstos no se utilizan como deberían, además porque el sistema de transferencias intergubernamentales no proporciona incentivos para aumentar la recaudación de estos ámbitos de gobierno. Ingresos locales, como los derechos y el impuesto predial, no pueden cobrarse a tasas suficientemente altas para cubrir los gastos de los grandes gobiernos urbanos.

La principal fuente de ingresos para los municipios de la ZMVM es el impuesto a la propiedad. En este caso, las cuestiones fundamentales a resolver son: ¿cómo coordinar la administración de los diversos impuestos relacionados con la propiedad?, ¿Cómo captar mejor las economías de escala en la valoración y el cobro del impuesto predial? y ¿cómo involucrar al gobierno federal en la administración del impuesto a la propiedad?

Los gobiernos de las entidades federativas son responsables de determinar la tasa y la base gravable del impuesto, pero no participan del ingreso, por tanto, no tienen incentivos para incrementar la productividad del impuesto (Bahl y Linn, 2015). El Distrito Federal tiene bajo su responsabilidad determinar la tasa y la base gravable del impuesto. La productividad de este impuesto varía enormemente respecto de los municipios, pero por lo regular es más baja que el promedio internacional, si se toman en cuenta los países con menor desarrollo.

La reducida recaudación del predial se explica entre otras razones por cuestiones políticas ya que es impopular y su incremento suele tener un costo para los 
líderes políticos locales. Además, en la medida en que las instituciones locales son débiles, las exenciones y los tratamientos preferenciales serán mayores, con lo que disminuye la recaudación. Es muy importante la dirección política para una adecuada actuación fiscal, de tal manera que los gobiernos subnacionales y locales tengan la suficiente fortaleza para oponerse a la presión de grupos de interés que, por una parte, buscan una mínima carga impositiva y, por otra, abogan por el aumento del gasto (Benito y Bastida, 2008).

El diseño de las transferencias intergubernamentales ha desincentivado el cobro de impuestos a la propiedad. Otra explicación de la baja recaudación del predial es que se trata de un impuesto costoso de administrar (Bartle et al., 2003), pues es necesaria la actualización frecuente del catastro y, en muchos casos, los asentamientos irregulares son muy grandes y el cobro de este impuesto es limitado por la ausencia de títulos de propiedad. Debido a la baja recaudación del predial las opciones que tienen los gobiernos locales son reducir sus responsabilidades de gasto o depender de las transferencias del gobierno nacional (Lefèvre, 2005).

Hoy día, hay una tendencia creciente a utilizar otras fuentes de recursos para financiar los presupuestos de los gobiernos subnacionales (Bartle et al, 2003). En general, son pocas las opciones con que cuentan estos órdenes de gobierno ya que la competencia en factores móviles daría lugar a niveles bajos de impuestos por ineficacia (Borck et al, 2007). En México, el gravamen de mayor importancia para los gobiernos estatales y del Distrito Federal es el impuesto a las nóminas, el cual se retiene en el lugar de trabajo (Bahl y Linn, 2015). La mayor ventaja de este impuesto es que se administra con facilidad; la desventaja es que se constituye como una barrera impositiva al empleo e introduce distorsiones en la elección de la técnica de producción (Bird y Slack, 2007). En este caso, los estados y el Distrito Federal determinan libremente la tasa, la base gravable y la administración del impuesto. El Distrito Federal obtiene $49 \%$ del impuesto recaudado en la zona metropolitana, lo cual se explica porque la mayor parte del empleo y el ingreso se localiza allí.

En México, la recaudación impositiva de los gobiernos subnacionales representa menos de 1\% del PIB (Bahl y Linn, 2015). El Distrito Federal es el que depende menos de las transferencias. Sobre todo las transferencias condicionadas y no condicionadas financian los servicios metropolitanos. Las transferencias son indispensables para eliminar los desequilibrios verticales y horizontales (Almagro Martín, 2013); sin embargo, resultan perniciosas cuando se usan como la fuente de mayor importancia de ingresos.

En la República Mexicana no hay una estructura diferencial de transferencias para gobiernos metropolitanos y no metropolitanos. Un sistema de fórmula uniforme 
discrimina a las metrópolis sin considerar la igualdad. En principio, se podría pensar que la mayor capacidad de las metrópolis para movilizar los ingresos locales daría lugar a una menor necesidad de transferencias que otras jurisdicciones; sin embargo, los ingresos necesitan ser mayores por el rápido y sostenido crecimiento metropolitano que también genera necesidades y expectativas de mejores servicios de infraestructura física y social. En general, las metrópolis tienen más responsabilidades de los servicios locales y, a su vez, mayor habilidad de cobrar sus propios impuestos (Slack, 2009).

En la ZMVM existe una desigual distribución de las transferencias per cápita de recursos a entidades federativas y municipios. En el 2011, de las tres entidades, Hidalgo recibió mayores recursos por habitante, con 24232 pesos y el Estado de México fue el que obtuvo menos con 2983 pesos (cuadro 13-4).

\section{Cuadro 13-4}

Transferencias per cápita de recursos a entidades federativas y municipios de la Zona Metropolitana del Valle de México (2011)

\begin{tabular}{l|c|c|c}
\hline \multirow{2}{*}{ Entidad Federativa } & Transferencias & Población & Transferencias per cápita \\
\cline { 2 - 4 } & Millones de pesos & Personas & \multicolumn{1}{c}{ Pesos } \\
\hline Estado de Hidalgo & 64580.3 & 2665018 & 24232.6 \\
Distrito Federal & 106388.6 & 8851080 & 12019.8 \\
Estado de México & 45283.7 & 15175862 & 2983.9 \\
Promedio nacional & 36078.9 & 3510516.81 & 10277.4 \\
\hline
\end{tabular}

Fuente: Secretaría de Hacienda y Crédito Público (SHCP), Cuenta de la Hacienda Pública Federal (2011) e Instituto Nacional de Estadística y Geografía (INEGI), "México en cifras" en Auditoría Superior de la Federación, Perfil de México a través de indicadores clave (2013).

\section{EL GASTO PÚBLICO Y LA CALIDAD DE VIDA EN LA ZONA METROPOLITANA DEL VALLE DE MÉXICO}

Por lo general, en el análisis de los gastos, resulta difícil su comparación porque hay diferencias en la manera de registrarlos. Por otra parte, las diferencias de gasto pueden deberse a causas diversas, como niveles de servicios, costos, eficiencia en el suministro de servicios o necesidad de reemplazar la infraestructura usada. En resumen, el nivel de gasto no refleja por necesidad la calidad de los servicios públicos ni el estado de la infraestructura subyacente. En México, las áreas metropolitanas comprenden numerosos gobiernos locales, cuyos límites no cambian con facilidad. Casi 
siempre la asignación de responsabilidades de gasto y su financiamiento se ajusta a estos límites. De ahí que para el estudio del gasto público en la ZMVM, es indispensable usar los datos de cada una de las entidades que la conforman.

\section{Gastos del Estado de México}

De acuerdo con el artículo 290 del Código Financiero del Estado de México y sus Municipios, el proyecto de presupuesto de egresos municipal lo integra la Tesorería del Estado y lo somete a la consideración del presidente municipal.

En el presupuesto de egresos del Estado de México, sólo hay un programa destinado a la coordinación metropolitana y constituye $0.05 \%$ del total de los gastos presupuestados. Esta entidad tiene dos zonas metropolitanas. Respecto de las transferencias, las participaciones y las aportaciones federales a municipios abarcan $14.42 \%$ del presupuesto y, las participaciones municipales, 9.01\%. En esta entidad federativa, también se cuenta con un Fondo Estatal de Fortalecimiento Municipal (Fefom) para obras y proyectos de infraestructura, equipamiento y desarrollo social, y se establece que en caso de ser necesario, 50\% de dicho fondo podrá destinarse a saneamiento financiero. Este fondo se distribuye en función de: a) población (40\%); b) marginalidad (45\%), y c) el inverso de la densidad poblacional por municipio (15\%).

\section{Gastos del Estado de Hidalgo}

Según el artículo 5 de la "Ley de hacienda municipal", los ayuntamientos del Estado tienen a su cargo la elaboración de sus respectivos proyectos de ley de ingresos y presupuesto de egresos para cada ejercicio fiscal. Dichos proyectos debe aprobarlos el Congreso del Estado. El artículo 7 de la mencionada ley establece que la recaudación y, en general, el manejo de la hacienda pública municipal corresponden a la tesorería municipal. Al igual que en el caso anterior, en el presupuesto de egresos de 2015 hay un fondo para desarrollo metropolitano que equivale a $0.03 \%$ del total de gastos. Las participaciones y las aportaciones que el gobierno estatal reparte entre sus municipios conforman $18.57 \%$ del presupuesto.

\section{Gastos del Distrito Federal}

De acuerdo con el artículo 39 de la Ley Orgánica de la Administración Pública del Distrito Federal, las funciones fiscales que ejecutan los jefes delegacionales son dos: a) formulación de los programas que servirán de base para la elaboración del anteproyecto de presupuesto y $b$ ) plantear al jefe de gobierno los proyectos de programas operativos anuales y de presupuesto de la delegación. 
En cuanto a las relaciones fiscales entre delegaciones, el artículo 380 del Código Financiero otorga a las unidades administrativas consolidadoras la facultad de establecer compromisos con cargo a los presupuestos aprobados de las delegaciones, previa aprobación del jefe delegacional correspondiente. En el artículo 465-A, se señala que las delegaciones pueden celebrar convenios de coordinación entre sí en materia de gasto público, siempre que permitan un mejor cumplimiento de los objetivos de sus programas (Gaytán, 2013).

En el Distrito Federal, el gasto corriente constituye en promedio $71.0 \%$, del cual $37.8 \%$ se ejerció en servicios personales. En el gasto de capital, la principal partida a la que se destinan recursos es la de obras públicas con 15.6 por ciento.

La mayoría de estos gobiernos subnacionales depende mucho de las transferencias intergubernamentales o del programa de gasto del gobierno federal. Para algunos autores (Pradilla, 2004), hay una crisis de las finanzas públicas estatales, lo cual afecta las restricciones del gasto público destinado a la atención de las necesidades de promoción del crecimiento y del mejoramiento de las condiciones de vida de la población de menores ingresos.

\section{Fondo de aportaciones para la infraestructura social municipal}

La infraestructura se considera el elemento más influyente de configuración del crecimiento de las zonas metropolitanas; en su planeación y financiación, intervienen todos los ámbitos gubernamentales (Neuman, 2006). Por su efecto en la calidad de vida, es importante el destino que se le dé a los recursos provenientes del FAIs. Las áreas a las que suelen destinarse estos recursos son: vivienda, urbanización, transporte y vialidades, seguridad, salud, educación, deporte, cultura y turismo, comunicaciones, asistencia social, agua y saneamiento. En el 2014, en el Distrito Federal y en el Estado de Hidalgo, el mayor número de proyectos con cargo a este fondo se destinó a agua y saneamiento; mientras que en el Estado de México fue a educación (gráfica 13-1). En los recursos, el Distrito Federal e Hidalgo destinaron mayor cantidad a agua y saneamiento (149 y 787 millones de pesos, respectivamente); en el Estado de México, la mayor cuantía se destinó a proyectos de asistencia social (gráfica 13-2).

En el 2015, el Distrito Federal registró el mayor número de proyectos en "agua y saneamiento" (gráfica 13-3). En el Estado de Hidalgo, "agua y saneamiento" pasó al segundo lugar con 307 proyectos y el primer lugar lo obtuvo "otros proyectos" con 675. En el Estado de México, "educación” pasó al segundo lugar con 960 proyectos y el primer lugar lo obtuvo "otros proyectos" con 1 501. En cuanto al monto de recursos 


\section{Gráfica 13-1}

Zona Metropolitana del Valle de México: número de proyectos por tipo de obra (2014)

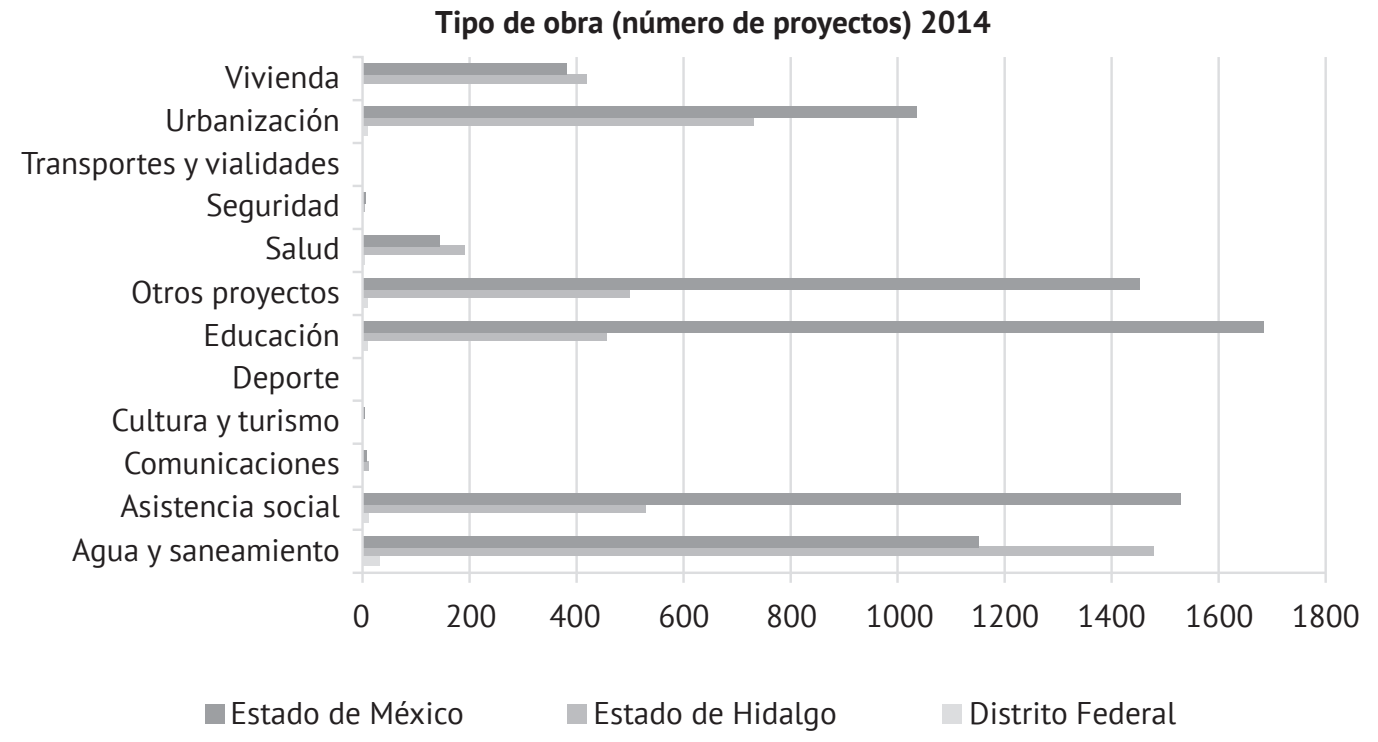

Fuente: Secretaría de Desarrollo Social (Sedesol), Reportes municipales, http://www.sedesol.gob.mx/es/SEDESOL/ Reportes_Municipales_FISM.

Gráfica 13-2

Zona Metropolitana del Valle de México: presupuesto comprometido por tipo de obra (2014)

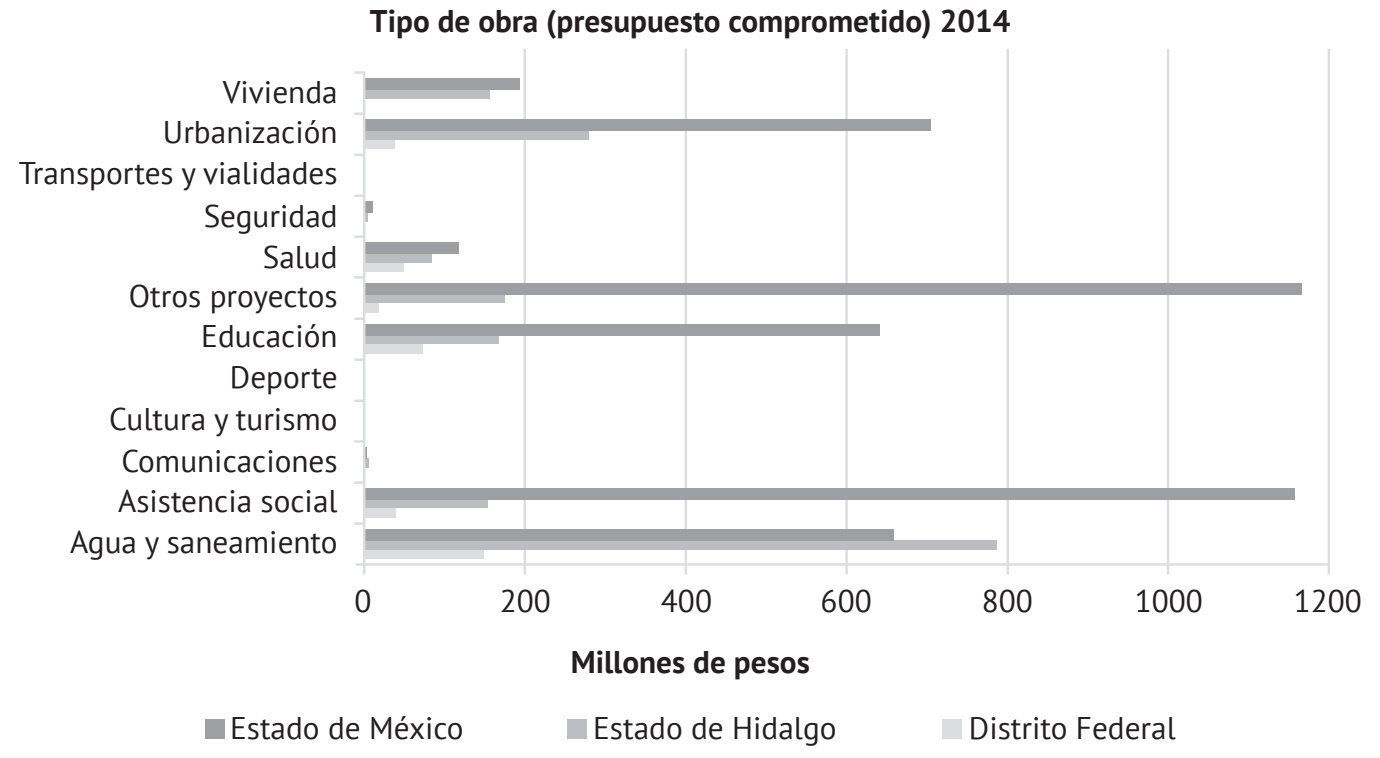

Fuente: Secretaría de Desarrollo Social (Sedesol), Reportes municipales, http://www.sedesol.gob.mx/es/SEDESOL/ Reportes_Municipales_FISM. 


\section{Gráfica 13-3}

Zona Metropolitana del Valle de México: número de proyectos por tipo de obra (2015)

Tipo de obra (número de proyectos) 2015

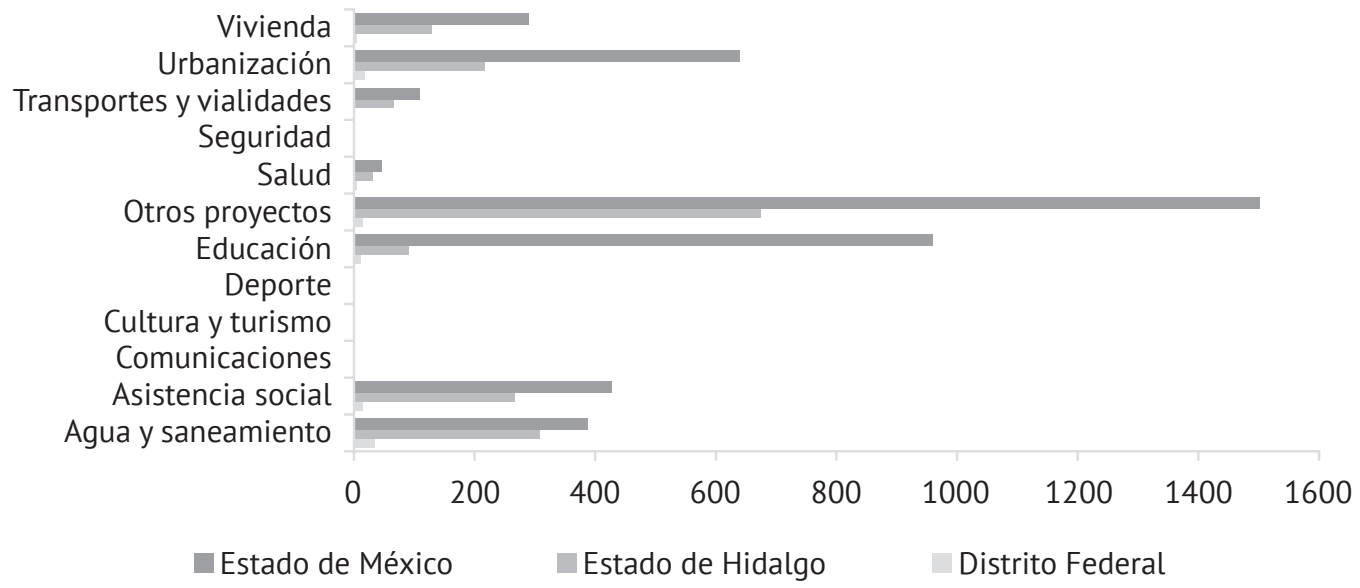

Fuente: Secretaría de Desarrollo Social (Sedesol), Reportes municipales, http://www.sedesol.gob.mx/es/SEDESOL/ Reportes_Municipales_FISM.

\section{Gráfica 13-4}

Zona Metropolitana del Valle de México: presupuesto comprometido por tipo de obra (2015)

Tipo de obra (presupuesto comprometido) 2015

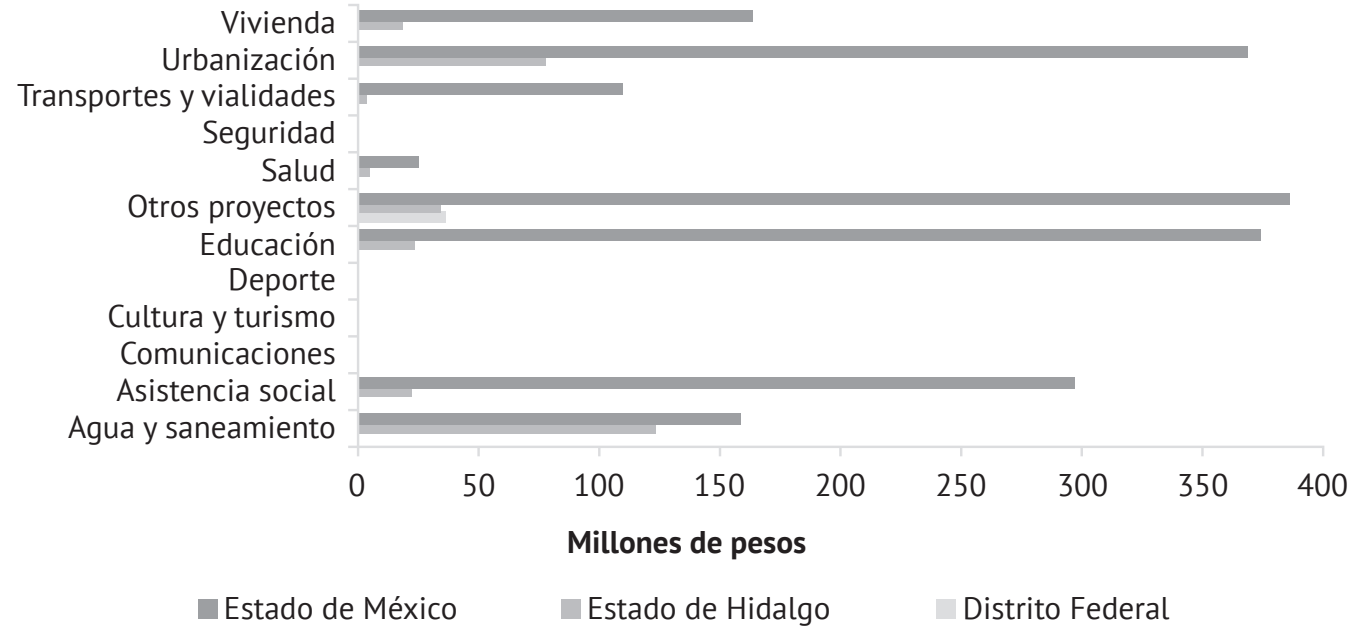

Fuente: Secretaría de Desarrollo Social (Sedesol), Reportes municipales, http://www.sedesol.gob.mx/es/SEDESOL/ Reportes_Municipales_FISM. 
en el Distrito Federal, la mayor cantidad se destinó a "otros proyectos". El Estado de Hidalgo destinó mayores recursos a "agua y saneamiento" (787.3 millones de pesos). El Estado de México dedicó la mayor cantidad de recursos a "otros proyectos" (386 millones de pesos), "educación" ocupó el segundo sitio con 374 millones de pesos (gráfica 13-4).

En el artículo 115 de la Constitución Política, se señala que los servicios públicos a cargo de los municipios son: agua potable y alcantarillado, alumbrado público, limpia, mercados y centrales de abasto, panteones, rastro, calles, parques y jardines, seguridad pública y tránsito. En cuanto a las entidades federativas, no hay una delimitación constitucional de los servicios públicos que deben proveer. Sin embargo, en función de la importancia y la trascendencia que tiene en la calidad de vida la educación y la salud, se incluyen en este apartado algunos aspectos del gasto público en dichas áreas. Los bajos porcentajes destinados a educación básica en el Distrito Federal se explican porque la mayor parte del gasto corre a cargo del gobierno federal. En el caso del Estado de México, el rubro de salud incluye seguridad y asistencia social (cuadro 13-5).

\section{Cuadro 13-5}

Porcentaje del total del presupuesto de 2015

\begin{tabular}{lcc}
\hline Entidades & Educación & Salud \\
\hline Distrito Federal & 3.6 & 7.2 \\
Estado de Hidalgo & 38.5 & 8.7 \\
Estado de México & 34.3 & 19.9 \\
\hline Fuente: Presupuesto de egresos del Estado de México, \\
del Estado de Hidalgo y del Distrito Federal (2015)
\end{tabular}

El Instituto Tecnológico y de Estudios Superiores de Monterrey elaboró un índice de infraestructura de las entidades federativas que evalúa infraestructura física y de capital humano, el cual se compone de cinco subfactores: infraestructura básica, infraestructura tecnológica, infraestructura científica, salud y ecología, y educación. En esta clasificación, el Distrito Federal ocupó la posición 1, el Estado de México la posición 16 y el Estado de Hidalgo la 21 (cuadro 13-6).

\section{Fondo metropolitano}

Con el objetivo de paliar la problemática que ha dado lugar el marco institucional actual del sistema federal, el gobierno central provee recursos económicos, los cua- 


\section{Cuadro 13-6}

Índice de infraestructura de los estados de la Zona Metropolitana del Valle de México (2012)

\begin{tabular}{clc}
\hline Posición & Entidad federativa & Indice \\
\hline 1 & Distrito Federal & 0.774 \\
16 & Estado de México & 0.48 \\
21 & Estado de Hidalgo & 0.441 \\
\hline
\end{tabular}

Fuente: ITESM, La competitividad de los Estados Mexicanos, 2012 en Auditoría Superior de la Federación, Perfil de México a través de indicadores clave (2013).

les tienen el carácter de subsidio federal, a través de fondos. Uno de ellos es el "Fondo metropolitano", el cual se creó en el 2006 con un monto de 1000 millones de pesos. En sus primeros dos años de operación, todos los recursos se destinaron a la ZMVM; hoy día, se benefician 47 zonas metropolitanas del país. Este fondo está vinculado con el "Ramo 23" del Presupuesto de Egresos de la Federación (PEF). Para 2015, dicho fondo asciende a 10382 millones de pesos, de los cuales 4052 millones se destinan a la ZMVM, lo cual equivale a 39.03\%.

En el artículo 38, párrafo segundo, del decreto del PEF para el "Ejercicio fiscal $2015^{\prime \prime}$, se señala que estos recursos se deben destinar, entre otros, a proyectos y obras de infraestructura y su equipamiento. Se pretende impulsar la competitividad económica, la sustentabilidad y las capacidades productivas, la consolidación urbana, así como el aprovechamiento óptimo de las ventajas competitivas de funcionamiento regional, urbano y económico de las zonas metropolitanas.

El Instituto Mexicano para la Competitividad (Imco) publicó el "Índice de competitividad estatal, 2012". ¿Dónde quedó la bolita?, del federalismo de la recriminación al federalismo de la eficacia. Se mide la competitividad como la "capacidad

\section{Cuadro 13-7}

Índice de competitividad estatal de las entidades de la Zona Metropolitana del Valle de México (2012)

\begin{tabular}{lcc}
\hline Entidad Federativa & Índice & Posición \\
\hline Distrito Federal & 58.64 & 1 \\
Estado de México & 34.88 & 23 \\
Estado de Hidalgo & 34.73 & 24 \\
\hline
\end{tabular}

Fuente: IMCO, "Índice de competitividad estatal, 2012", enAuditoría Superior de la Federación, Perfil de México a través de indicadores clave, 2013. 
para atraer y retener inversiones y talento". La entidad federativa con mayor competitividad toma el valor de 100 y la de menor el valor de 0. Entre las entidades de la ZMVM, también hay grandes desigualdades en este rubro: el Distrito Federal ocupa la posición 1; mientras que el Estado de México e Hidalgo se encuentran en las posiciones 23 y 24, respectivamente (cuadro 13-7).

En las "Reglas de operación del fondo metropolitano", se señala que los recursos se deben asignar de manera exclusiva a programas basados en un plan de orden metropolitano, pero de acuerdo con una evaluación, las decisiones no responden a políticas integradas, la coordinación metropolitana es muy débil y, a pesar de la existencia de organismos encargados de dicha coordinación, en la práctica no se observan resultados concretos (Iracheta e Iracheta, 2014).

Si bien los recursos deben destinarse a los objetivos que se señalan en las citadas "Reglas", su interpretación es muy diversa y ambigua, con lo cual casi cualquier acción o proyecto puede justificarse. Por otra parte, la ZMVM recibe el mismo tratamiento que las otras metrópolis, no obstante que aquella tiene características muy particulares.

En cuanto al destino de los recursos de este fondo, la mayor parte se ha asignado a proyectos viales y, en segundo lugar, a la infraestructura hidráulica. La gestión del fondo y la planeación están a cargo de los gobiernos de las entidades federativas con una exigua intervención de los gobiernos municipales (op cit).

Es previsible que la presión sobre el presupuesto de egresos para apoyar los servicios metropolitanos aumente en el futuro porque cada vez hay mayor demanda por servicios públicos, los costos se están incrementando y hay graves atrasos. Los factores que presionan el incremento de los gastos públicos de las metrópolis incluyen:

1) Crecimiento de la población.

2) Necesidad de modernizar la infraestructura y los servicios públicos para atraer y retener la inversión (muchas veces la disyuntiva está entre invertir en nueva infraestructura física y social o mantener y mejorar los bienes existentes, pero una infraestructura mejor puede atraer inversiones que originen nuevas corrientes de ingresos.

3) Las externalidades negativas que acompañan la urbanización, como la contaminación atmosférica, la congestión del transporte y otras.

4) Las necesidades especiales de una alta concentración de pobres y de familias que viven en cinturones de miseria y que requieren mayor inversión pública por parte de los gobiernos metropolitanos (Bahl et al., 2013a). 
El crecimiento económico metropolitano requiere de gran inversión en transporte público, autopistas o aeropuertos. Las deseconomías también incrementan los costos unitarios de la provisión de servicios en las zonas metropolitanas, la mayoría relacionada con la calidad de vida; por ejemplo, en recolección de basura y el reciclaje de los desechos sólidos, el manejo del tráfico, el tratamiento de la contaminación y el abastecimiento de recursos como el agua potable, además, de que el trabajo y el costo de la tierra son más altos en las metrópolis que en las pequeñas ciudades.

\section{CONSIDERACIONES FINALES}

Es factible que en los países en desarrollo los gobiernos metropolitanos tiendan a la descentralización; sin embargo, los obstáculos abarcan el rápido crecimiento de la población, la escasez de recursos y las dificultades para limitar la centralización fiscal. Con objeto de lograr un mejor gobierno metropolitano, el proceso deben iniciarlo los gobiernos nacionales. El éxito en las finanzas públicas de las áreas metropolitanas depende de cómo están estructuradas las relaciones verticales intergubernamentales. En especial, hay tres cuestiones importantes: la primera es si las metrópolis se tratarán igual que otros gobiernos subnacionales y locales en el país o tendrán una gestión fiscal diferente; la segunda cuestión es cómo los gobiernos estatales y municipales y el gobierno federal coordinarán la prestación de servicios; y el tercer asunto es hasta qué grado las secretarías del gobierno federal regularán las acciones de los gobiernos subnacionales y locales del área metropolitana. Por ejemplo, las regulaciones en educación y salud pueden limitar de modo importante el gasto de los gobiernos estatales y municipales. La rápida urbanización ha superado las estructuras actuales de los gobiernos metropolitanos, en términos de la habilidad para coordinar servicios, proveer infraestructura y usar las herramientas de financiamiento regional. Por lo regular, la responsabilidad de proveer servicios de infraestructura en las áreas metropolitanas se comparte entre varios gobiernos locales y casi siempre hay problemas de coordinación entre ellos. Una alternativa es que la responsabilidad sea de una empresa pública metropolitana o del gobierno federal.

Desde el punto de vista de los ingresos públicos, los métodos para financiar la infraestructura de las áreas metropolitanas son: a) aumentar los ingresos propios; b) endeudamiento, porque en este caso se requiere que los gobiernos estatales y municipales controlen su nivel de recursos presupuestarios, y que el destino de la deuda se limite a proyectos de inversión de larga vida y con restricciones a los prestatarios sin posibilidad de rescate por parte del gobierno federal; $c$ ) transferencias, y $d$ ) fi- 
nanciamiento del sector privado, el cual suele darse por medio de las asociaciones públicas y privadas (APP), tema importantísimo de las finanzas metropolitanas. Estas asociaciones se han enfocado más en energía, sector de transportes y telecomunicaciones. En este caso, el riesgo es la débil capacidad institucional de los gobiernos estatales y municipales en las naciones en desarrollo (Bahl et al, 2013a).

Una posibilidad de financiamiento de las áreas metropolitanas es el impuesto a la propiedad por su facilidad de utilización de manera progresiva para evitar una pesada carga fiscal a las familias de menores ingresos y, además, puede coincidir con los beneficios de los gastos, siempre que las responsabilidades de erogaciones de los gobiernos locales estén limitadas a los servicios relacionados con la propiedad, como policía, bomberos, parques, mercados, drenaje, alumbrado público, recolección de basura, calles y escuela primaria. Otros impuestos que los gobiernos estatales utilizan de forma más fácil incluyen los de nómina y la tenencia vehicular.

En relación con los gastos, los gobiernos estatales y municipales tienen en general una limitada asignación de responsabilidades de gasto, lo cual da lugar a que su manejo se mantenga centralizado. Esto se justifica porque en dichos ámbitos de gobierno con frecuencia falta personal calificado por los bajos salarios y las pocas oportunidades de desarrollo; además, en muchos casos, no se cuenta con sistemas adecuados de gestión, hay incapacidad para aprovechar las economías de escala, las responsabilidades de gastos los establece el gobierno federal y también se carece de una base adecuada de ingresos. Sin embargo, es necesario romper con estas inercias para fortalecer la gestión pública de las zonas metropolitanas y, con ello, tener la capacidad necesaria para cubrir los requerimientos de servicios públicos que permitan una adecuada calidad de vida de la población.

\section{BIBLIOGRAFÍA}

Almagro Martín, Carmen (2013), "El gravamen patrimonial de los vehículos e inmuebles por las haciendas locales" en Una reforma en términos de sostenibilidad, Granada, Editorial Universidad de Granada, pp. 385-397.

Astudillo Moya, Marcela (2001), La distribución de los impuestos entre la federación, estados y municipios en el siglo XX, México, Miguel Ángel Porrúa.

Bahl, Roy W. et al., (2013a), "Financing metropolitan governments in developing countries" en Roy W. Bahl et al. (eds.), Financing metropolitan governments in developing countries, Lincoln Institute of Land Policy.

(2013b), Financing metropolitan governments in developing countries, Lincoln Institute of Land Policy. 
Bahl, Roy W., y F. Linn Johannes (2015), "Delivering and financing public services in metropolitan areas", en Ehtisham Ahmad y Giorgio Brosio (eds.), Handbook of multilevel finance, Edward Elgar.

Bartle, John R. et al. (2003), "Beyond the property tax: Local government revenue diversification", Journal of Public Budgeting, Accounting, and Financial Management, vol. 15, núm. 4, p. 622.

Benito, Bernardino, y Francisco Bastida (2008), "Política y gestión financiera municipal", Spanish Accounting Review, vol. 11, núm. 2, pp. 43-66.

Bird, Richard M, y Enid Slack (2007), "An approach to metropolitan governance and finance", Environment and Planning C, vol. 25, núm. 5, p. 729.

Borck, Rainald et al. (2007), "Fiscal competition and the composition of public spending: Theory and evidence", FinanzArchiv/Public Finance Analysis, pp. 264-277.

Brenner, Neil. (2002), “Decoding the newest 'metropolitan regionalism' in the USA: A critical overview", Cities, vol. 19, núm. 1, pp. 3-21.

Brueckner, Jan K. (2006), "Fiscal federalism and economic growth", Journal of Public Economics, vol. 90, núm. 10, pp. 2107-2120.

Cabrero, Mendoza Enrique et al. (2009), "Competitividad urbana en México: una propuesta de medición", Eure (Santiago), vol. 35, núm. 106, pp. 79-99.

Castro, José Esteban (2004), "Urban water and the politics of citizenship: the case of the Mexico City Metropolitan Area during the 1980s and 1990s", Environment and Planning A, vol. 36, núm. 2, pp. 327-346.

Chávez Presa, Jorge, y Fausto Hernández Trillo (2013), El México del 2013. Hacia una reforma del federalismo fiscal, México, Centro de Estudios Espinosa Yglesias.

Cruz Rodríguez, María Soledad (2002), "Procesos urbanos y 'ruralidad' en la periferia de la Zona Metropolitana de la Ciudad de México", Estudios demográficos y urbanos, pp. 39-76.

Gaytán, Eric (2013), "El Sistema Nacional de Coordinación Fiscal y las finanzas del Distrito Federal: implicaciones y efectos en el periodo 2000-2011", tesis para Maestría en economía, México, Universidad Nacional Autónoma de México.

Iracheta Cenecorta, Alfonso y José A. Iracheta Carroll (2014), Evaluación de los fondos metropolitano y regional del Gobierno Federal Mexicano, México, Centro de Investigación y Docencia Económicas, A. C.

Lefèvre, Christian (2005), "Gobernabilidad democrática de las áreas metropolitanas. Experiencias y lecciones internacionales para las ciudades latinoamericanas", Gobernar las Metrópolis, pp. 195-261.

Neuman, Michael (2006), "La gobernanza regional metropolitana. Grandes redes institucionales y fenómenos de multiescala", Urban, vol. 11, núm. 2, pp. 6-23. 
Pradilla Cobos, Emilio (2004), "Lo conocido, lo ignorado y lo que necesitamos investigar. Distrito Federal, Zona Metropolitana del Valle de México, Ciudad Región del Centro", Andamios, núm. 1, pp. 161-174.

Slack, Enid (2009), Transferencias a ciudades grandes y áreas metropolitanas, en Robin, Boadway y Amnar Shah (eds.), Transferencias fiscales intergubernamentales, Washington, Banco Mundial, pp. 465.492.

Trivelli, Pablo (2000), "Gestión urbana para el desarrollo sustentable de las grandes ciudades latinoamericanas", Mercado del suelo urbano en el Área Metropolitana de Santiago.

Valdivia López, Marcos et al. (2010), "Nuevos patrones espaciales en las derramas de empleo en la zona metropolitana de la Ciudad de México", Problemas del desarrollo, vol. 41, núm. 163, pp. 99-117. 



\section{CONCLUSIONES GENERALES*}

Adolfo Sánchez Almanza

La calidad de vida constituye un objetivo del desarrollo inscrito en el marco de los derechos sociales, económicos, culturales y ambientales, los cuales son necesarios para alcanzar mejores condiciones de vida tanto objetivas como subjetivas, con equidad e inclusión social; asimismo, aquella se alinea con los principios del derecho a la ciudad y la justicia socioespacial. En este sentido, los enfoques teóricos e institucionales sobre la calidad de vida consideran estructuras historicosociales determinadas con manifestaciones territoriales que pueden ser justas o injustas. En los marcos jurídicos, se establecen normas igualitarias en la escala nacional, aunque diferenciadas entre los órdenes de gobierno estatales y municipales, los cuales son fuente de desigualdad en el bienestar de la población, de acuerdo con su localización en las distintas unidades político-administrativas.

El Estado es responsable de cumplir esos derechos ante la sociedad civil y por ello está sujeto a demandas de la población, pero no se encuentra exento de contradicciones en su gestión, en particular, sobre los criterios de asignación de los recursos públicos. La forma que asumen las políticas públicas instrumentadas, en general, ilustra el sesgo de clase que en realidad adopta el Estado nacional o los gobiernos subnacionales y establece los retos para conseguir una urbanización justa y sostenible.

La calidad de vida en su sentido amplio y multidimensional se expresa en un acceso diferenciado a satisfactores, bienes y servicios en el tiempo y el espacio don-

* Aquí se recuperan algunas de las principales aportaciones de los capítulos del libro, a las cuales hay que recurrir con el propósito de una lectura detallada. 
de se producen diferentes procesos simultáneos. A partir de estos planteamientos generales, el universo de análisis de este libro ha sido la población que reside en el territorio ampliado de la ZMVM, la cual se delimita aquí con 96 unidades político-administrativas pertenecientes a la Ciudad de México, Hidalgo y Estado de México. La metrópoli así definida concentraba una población de 21.1 millones de habitantes (18.8\% del total nacional) en el 2010. Este territorio alcanza casi 11000 kilómetros cuadrados ( $0.6 \%$ de la superficie nacional), y una densidad promedio alta de 2028 habitantes por kilómetro cuadrado frente a 61 en el país en el año 2015. En un escenario tendencial, con el método de autómatas celulares, las proyecciones indican que llegue a 21.4 millones de habitantes en el 2020, a casi 22.6 millones en el 2030 y a más de 24.3 millones para el año 2040, con una expansión física y funcional hacia los municipios localizados en el norte de la mancha urbana.

La ZMVM es un fenómeno complejo que presenta una discordancia entre la producción social de espacio y su apropiación privada, con varias contradicciones que tienen un comportamiento dinámico. La metrópoli se ubica en un entorno nacional y regional que sufre los efectos de un modelo económico ampliado hacia la globalización, con un sistema social marcado por una estructura sociopolítica que genera consecuencias diferenciadas en su territorio.

La calidad de vida de los habitantes en la ZMVM, como en otras metrópolis, expresa una estructura morfológica de clases sociales, niveles de ingreso, fuerza política y gestión administrativa desiguales en su superficie, así como marcos jurídicos de obligatoriedad e intervenciones diferenciadas entre los órdenes de gobierno responsables del cumplimiento de derechos.

La justicia espacial, a su vez, implica desde un punto de vista estadístico una calidad de vida próxima entre unidades territoriales a los promedios de los indicadores con que se mide en el universo considerado. Para la medición de la calidad de vida objetiva, se estima un índice con los microdatos del "Censo de población y vivienda del año 2010" (con tres dimensiones, ocho subdimensiones y 33 indicadores censales para 186124 "manzanas", 4641 colonias o barrios y 96 delegaciones o municipios), el cual ofrece evidencia empírica sobre las formas de segregación social en la metrópoli con su localización georreferenciada. Esta forma de medición de la calidad de vida objetiva es parcial debido a la disponibilidad de información estadística desde la escala de "manzana" que es la menor; por ello, no se incluyen otras variables que también expresan bienestar, el cual es multidimensional. No obstante, se elaboró una gran base de datos mediante toda la información censal del 2010 existente desde la escala de "manzana" (base disponible en: http://ru.iiec.unam.mx/4122/). 
Los resultados de las mediciones ofrecen evidencia para verificar hipótesis sobre un modelo centro-periferia ampliado por contornos, donde el núcleo conformado por las delegaciones centrales o ciudad interior reportan la más alta calidad de vida objetiva (0.823 en relación a 1), mientras que a mayor distancia del mismo, las condiciones de vida de la población empeoran de modo gradual hacia el cuarto contorno (0.661); en tanto que al acercarse a algunos subcentros de la metrópoli o a la zona metropolitana de Pachuca, vuelve a aumentar el bienestar (0.697). Este patrón general indica también que las condiciones de bienestar más bajas se localizan en los municipios periurbanos del norte, el nororiente, oriente y sureste de la metrópoli próximos a zonas rurales o de regiones de difícil acceso.

El índice de calidad de vida objetivo (ICVO) más alto corresponde a la dimensión de vivienda (0.793), y la disponibilidad de electricidad o contar con televisión resultan los índices mayores, mientras que los más bajos corresponden a viviendas sin computadora e internet. La segunda dimensión es la de "personas" (0.723), en la cual los indicadores de población de cinco años y más que sabe leer y escribir un recado y la población sin discapacidad generan los valores más altos de bienestar en el territorio, pero los de población con derechohabiencia a servicios de salud y la escolaridad de la población de 25 años y más son los más bajos. A su vez, la dimensión de entorno urbano es la más reducida (0.644), con acceso a peatones y comercio semifijo con los datos más altos, mientras que en el otro extremo la disponibilidad de rampas para silla de ruedas y de transporte público ofrecen las peores condiciones. Estas situaciones se observan en la medición de las escalas de "manzana", delegación y municipio, pero también en colonias o barrios, la cual constituye una contribución de este libro, al considerar que es una unidad territorial indispensable para la planeación urbana y la instrumentación de políticas públicas, en particular, por su importancia en términos de identidad ciudadana.

En relación con los aspectos subjetivos de la calidad de vida, los resultados con representatividad estadística para la Ciudad de México revelan que la población acepta los programas sociales, aunque en las unidades territoriales con menor calidad de vida objetiva todavía no los consideran derechos sino mecanismos de cooptación. A su vez, las entrevistas a profundidad confirman la falta de correspondencia entre la percepción y las condiciones objetivas de la calidad de vida según la tipología territorial. Una conclusión es que la opinión y la participación de las personas para lograr su propio desarrollo resultan fundamentales para armonizar las políticas públicas con las necesidades de la sociedad civil.

En el caso de los adultos mayores de 60 años que residen en las "manzanas" de 
la metrópoli, predomina un grado alto de calidad de vida; no obstante, hay "manzanas" con grados bajo y muy bajo que registran una alta relación con un nivel de escolaridad bajo de este grupo de edad. La subdimensión que presenta mejores resultados es la de servicios e instalaciones de la vivienda para este grupo, mientras que en el otro extremo aparece la educación con los valores promedio más bajos. Las características educativas se asocian con el acceso a recursos económicos en la vejez, por lo cual habría que garantizar los medios de subsistencia a las personas con niveles bajos de escolaridad. A su vez, las "manzanas" con muy alta calidad de vida tienden a concentrarse en la Ciudad de México, mientras que los grados medios aparecen en la periferia, por tanto, son estos espacios los que requieren mayor atención. Estos hallazgos territoriales definen las acciones de política pública a seguir dirigidas a las personas en edades avanzadas para asegurar su calidad de vida en un contexto de envejecimiento demográfico.

El cambio del uso del suelo subyacente al objetivo de la maximización de la ganancia expresa un patrón centro-periferia con gradientes en la calidad de vida que se reducen en función de la distancia. Los valores altos del ıcvo coinciden con precios más costosos de suelo y vivienda que conforman áreas residenciales homogéneas en un espacio urbano heterogéneo. La metrópoli presenta asentamientos habitacionales homogéneos de escasos recursos que se mezclan con otros de altos ingresos y de desarrollo. La periferia reúne las viviendas con características de menor calidad, con el valor de suelo más barato y donde recurre la población con menor poder adquisitivo para establecerse. Asimismo, se han incorporado municipios que modifican su carácter rural por uno urbano, aun sin contar con los atributos para considerarlos plenamente metropolitanos; ejemplos de ello son los casos que reciben las grandes inversiones en desarrollos inmobiliarios para la producción masiva de vivienda, sobre todo, en lugares lejanos del norte de la zona metropolitana donde ha crecido su población pero sin "hacer ciudad" y que mantienen el reto de mejorar la calidad de vida de sus residentes, en particular, con vivienda popular que requiere de accesibilidad a esquemas de financiamiento, empleos, infraestructura y servicios públicos. Esta dinámica de ocupación del suelo genera segregación con un crecimiento urbano disperso y fragmentado, aunque a mayor lejanía de la vivienda popular respecto de los centros o subcentros intrametropolitanos, se reduce el bienestar y aumentan los costos sociales que internalizan las familias.

Los centros comerciales forman parte de la funcionalidad metropolitana y, como negocios, su lógica económica responde a la tendencia de centralizar la distribución y maximizar el consumo de bienes y servicios. En su evolución hacia proyectos in- 
mobiliarios, la fuerza que los impulsa es la captación de rentas urbanas por grandes inversionistas y firmas de desarrolladores globales y nacionales; por ello, manifiestan una reestructuración funcional en la consolidación de la metrópoli, pues su expansión suburbana y periférica permite estructurar nuevas áreas mediante equipamientos para algunos segmentos de población que presentan dificultades para vincularse con las áreas tradicionales de comercio. Esta tendencia se asocia con la "gentrificación" con sustitución de usos de suelo residenciales a comerciales o aun de usos mixtos, pero para familias de altos ingresos, en espacios mejor comunicados. En general, el patrón de expansión y localización de los centros comerciales se asocia de forma directa con el índice de calidad de vida estimado por "manzana" o por colonia para la metrópoli.

Por otra parte, la menor calidad de vida en la ZMVM se relaciona y expresa en el crecimiento de las actividades informales, en particular, las comerciales, las cuales tienden a destruir el espacio público, se convierten en focos de conflicto social y político y destruyen a la ciudadanía. La falta de atención al aprovisionamiento y el mantenimiento de servicios en los espacios públicos ha favorecido su ocupación con actividades económicas informales, ya sea individuales o colectivas, que llevan a cabo las agrupaciones de comerciantes y transportistas liderados por personajes que se apropian de los espacios urbanos, al sustentarse en su beligerancia respaldada por funcionarios públicos. La informalidad ha penetrado en casi todas las esferas de la vida por la escasa o insuficiente regulación oficial y, en algunas actividades, las acciones legítimas, aunque no registradas de modo oficial, se mezclan y fusionan con otras delictivas, lo cual afecta la seguridad de la población. Una expresión de lo anterior se observa en el fenómeno del comercio informal en vía pública y los espacios invadidos como los "Centros de transferencia de transporte multimodal" de Tacuba y Tacubaya, aquí estudiados, lo cual restringe las áreas para la movilidad de la ciudadanía y el libre tránsito o la recreación, aumenta la inseguridad para los transeúntes en esos espacios sucios, ruidosos y susceptibles a la delincuencia, restando con ello su función de bien común o de consumo colectivo.

Los desastres naturales se presentan por precondiciones socioambientales, las cuales se potencializan como consecuencia de los riesgos antrópicos, como deforestación, erosión, contaminación y sus efectos. En general, dichos desastres resultan de sus entornos sociales, políticos y económicos, es decir, de las estructuras sociales en las que se producen. Las repercusiones más graves de los desastres en la población están influidas por la calidad de vida y la seguridad social menores, y los riesgos aumentan ante la ausencia de condiciones socioeconómicas y de infraestructura 
adecuadas. En la ZMVM se observa esta situación, en particular, en la localización de asentamientos irregulares en zonas de alto riesgo ante desastres naturales, como laderas, barrancas, riberas de ríos en zonas de difícil acceso expuestas a varios fenómenos meteorológicos.

Asimismo, se confirma una correlación espacial negativa entre el ıcvo y los eventos financiados por el Fondo de Desastres Naturales (Fonden) para la metrópoli de $17.3 \%$, es decir, un índice de Moran de -0.173466. Las delegaciones o los municipios de la ZMVM con mayor calidad de vida tienden a presentar menos desastres hidrometeorológicos que superen su capacidad financiera para solventar este riesgo. Es de destacar que el promedio del ICVO es más bajo para los municipios o las delegaciones que sí tuvieron financiamiento del Fonden por algún desastre, y la asociación es mayor respecto de los rezagos del entorno urbano en mobiliario, servicios e infraestructura pública, como la vial o el drenaje pluvial, lo cual indica una asignación adecuada de dichos recursos, pero confirma la desigualdad espacial en el bienestar de la población.

Las fuertes diferencias en la calidad de vida de los habitantes de una unidad funcional como lo es la ZMVM, obligan a estudiar, desde una perspectiva fiscal, los diversos mecanismos y montos de financiamiento con que cuentan la Ciudad de México y los municipios del Estado de México y de Hidalgo que la conforman, para satisfacer la demanda de bienes públicos de sus habitantes. El análisis indica que los límites político-administrativos de tres órdenes de gobierno reducen las posibilidades de políticas integradas y explican la fragmentación de las finanzas públicas y la carencia de un objetivo metropolitano común. Esto se combina con una fuerte centralización fiscal que inhibe la captación local de recursos propios: la Ciudad de México obtiene por concepto de impuestos locales $22.4 \%$; el Estado de Hidalgo 19.8\%; mientras que el Estado de México sólo 6.7\%. Los servicios metropolitanos reciben financiamiento principalmente de las transferencias condicionadas y no condicionadas, pero esta dependencia ha desincentivado el cobro de impuestos, en particular, a la propiedad, que sería redistributivo, ya que la recaudación del predial es baja porque constituye un impuesto costoso por la administración del catastro y, donde los asentamientos irregulares son muy grandes, el cobro de este impuesto es limitado por la ausencia de títulos de propiedad, además de tener costos políticos. Debido a la baja recaudación propia, las opciones de los gobiernos locales son reducir sus responsabilidades de gasto social para mejorar la calidad de vida de sus ciudadanos, o bien, depender de las transferencias del gobierno nacional, el endeudamiento o las asociaciones públicas y privadas. Ante ello, por una parte es necesario otorgar mayores fortalezas 
y facultades de gasto e ingreso a los gobiernos estatales y municipales y, por la otra, instituir mecanismos de coordinación para mejorar el aprovechamiento de los escasos recursos fiscales.

El territorio metropolitano, en general, muestra un polo con una tendencia hacia una mejor habitabilidad con espacios para la sociabilidad y, otro, dominado por la desregulación mercantil para la reproducción ampliada del capital en múltiples lugares centrales y periféricos, donde los extremos son la exclusión y el derecho a la ciudad. Este último entendido como un principio programático que avanza de forma jurídica hacia una norma garantizada por el Estado, como se observa sobre todo en la "Constitución de la Ciudad de México", y que obliga al diseño de políticas públicas interestatales más homogéneas al aplicar principios de justicia distributiva, con preferencia hacia los grupos más pobres y marginados.

Las disparidades territoriales en la calidad de vida objetiva constituyen un área de atención por parte del Estado y los órdenes de gobierno respectivos que están obligados a cumplir con los derechos establecidos en los marcos jurídicos correspondientes, aun sin que éstos sean homogéneos. En este sentido, las leyes estatales definen el camino para el diseño de una política socioespacial susceptible de una gran precisión en la localización territorial, es decir, para que en una primera etapa se focalicen las acciones y los recursos en función de una estrategia espacio-temporal, pero sin olvidar que se debe aplicar un enfoque de bienestar de cobertura universal de acuerdo con la obligatoriedad de su cumplimiento. En este sentido, la medición de la calidad de vida en diferentes escalas territoriales ofrece elementos para afinar el diseño de las políticas públicas orientadas a su mejoría y a lograr la justicia social en todo el territorio.

El derecho a la ciudad y la justicia socioespacial incluyen varios procesos entre los cuales se pueden mencionar tres. El primero se refiere a la apropiación y la participación de la sociedad en el territorio donde se expresan formas de desigualdad o de injusticia que generan demandas ciudadanas, sobre todo, en relación con la vivienda, servicios de salud, educación, infraestructura y equipamientos urbanos, los cuales constituyen componentes básicos de la calidad de vida objetiva. Desde una visión neoclásica, hay una inadecuación entre oferta y demanda solvente en el mercado, pero bajo un enfoque de desmercantilización hay derechos que cumplir. En este contexto, el "derecho a la ciudad" surge como una necesidad ante la imposibilidad de los habitantes de usar y apropiarse los espacios urbanos, sobre todo, en los lugares menos aventajados.

El segundo proceso corresponde a la planificación del desarrollo urbano por medio de políticas públicas que tienen como objetivo central mejorar la calidad de 
vida de la población y, con ello, confirmar también la legitimidad del Estado. En sociedades democráticas, se espera la colaboración entre los actores gubernamentales y la sociedad civil para tomar decisiones al considerar la localización y el acceso óptimo a recursos, a la estructura y dinámica económicas, a los bienes y servicios en las múltiples escalas, pero con atención preferente a las comunidades más atrasadas con criterios justos en la asignación de los recursos fiscales. En general, el incumplimiento de derechos cuestiona la instrumentación y los resultados de las políticas públicas.

Y el tercer proceso consiste en desarrollar el saber científico y tecnológico para analizar y evaluar los procesos de metropolización; sus resultados pueden utilizarse para apoyar la intervención y la gestión del Estado de acuerdo con lineamientos claros de igualdad. Por último, el derecho a la ciudad implica que la propiedad cumpla con su función social, con respecto a las exigencias generales y las regulaciones en la producción del hábitat que garanticen la calidad de vida, el uso del territorio sostenible desde un punto de vista ambiental y la justicia socioespacial. 


\section{SOBRE LOS AUTORES}

\section{Adolfo Sánchez Almanza}

Doctor en Ciencias Políticas y Sociales por la Facultad de Ciencias Políticas y Sociales (UNAM). Realizó cursos de posgrado en Planeación del Desarrollo Regional Integrado en Rehovot, Israel, y dos diplomados en el Instituto de Administración Pública. Investigador titular en la Unidad de Investigación en Economía Urbana y Regional del Instituto de Investigaciones Económicas de la UNAM. Profesor y tutor de Urbanismo en la Facultad de Arquitectura y en el posgrado de Economía. Autor de 10 libros, 56 capítulos de libro y 30 artículos. Entre los libros más recientes destacan: Estrategia territorial nacional, IIEc-UNAMSedesol y El desarrollo económico de las regiones medias de México, IIEc-UNAM, y el artículo: "Sistema de ciudades y redes urbanas en los modelos económicos de México", en la Revista Problemas del Desarrollo. Miembro fundador de la Red Temática sobre Pobreza y Desarrollo Urbano del Conacyt. Exconsejero Ciudadano en el Consejo de Evaluación del Desarrollo Social del Distrito Federal; expresidente de la Asociación Mexicana de Ciencias para el Desarrollo Regional, A.C.

\section{Abraham Granados Martínez}

Economista por la Universidad Autónoma Metropolitana, cuenta con la maestría en Estudios Urbanos por El Colegio de México. Es doctor en Economía por la Universidad Nacional Autónoma de México (UNAM). Investigador en el Área de Desarrollo y Políticas Públicas del Instituto de Investigaciones Económicas de la UNAM. Ha impartido clases en la Facultad de Economía, el posgrado de Economía y la Facultad de Ciencias Políticas y Sociales de la misma universidad. Ha realizado presentaciones académicas de sus investigaciones en diversos congresos, seminarios, conferencias y reuniones nacionales e internacionales. 
Sus líneas de investigación son: género y políticas públicas; vulnerabilidad social y salud, y desarrollo sustentable.

\section{Andrea Colores Ramos}

En su trayectoria en el mundo del desarrollo urbano ha desarrollado proyectos en Tabasco, Nayarit, Ciudad de México, Veracruz y Sinaloa, en el ámbito regional y municipal de la planeación urbana, económica y turística. También en la actualización de la legislación urbana y ambiental, en sus contrapartes internacionales, en la creación de una nueva agenda urbana para las ciudades mexicanas y el urbanismo con perspectiva de género, conformando tres ejes temáticos que han tenido importante injerencia en sus trabajos recientes. Colabora con la Secretaría de Desarrollo Urbano y Vivienda de la Ciudad de México en la determinación de criterios y lineamientos para el futuro desarrollo del Aeropuerto Internacional Benito Juárez de la Ciudad de México.

\section{Carlos Bustamante Lemus}

Es investigador titular "C" adscrito al Instituto de Investigaciones Económicas de la UNAM. Egresado de la ahora Facultad de Economía (UNAM); diplomado en Planificación Regional y Urbana, por la Universidad Técnica de Szczecin, Polonia; diplomado en Economía y Administración, por el Economics Institute de la University of Colorado, EU; maestría en Planeación Económica Urbana, por la Faculty of Economics, University of London, Inglaterra; PhD en Estudios de Planeación, también por el University College London, de la University of London, Inglaterra. Ha publicado numerosos libros y artículos en revistas científicas, tanto como autor, como en coautoría desde las líneas disciplinarias del desarrollo regional y urbano de México y sus zonas metropolitanas, así como al estudio de la economía informal en grandes metrópolis o los mercados públicos en vía pública en la Ciudad de México y en Londres. Ha sido responsable de diversos grupos de trabajo académico y tutorías a alumnos de licenciatura y posgrado. Destaca su trabajo como Presidente de la Asociación Mexicana de Ciencias para el Desarrollo Regional, A.C., coordinador de la sede IIEc del Programa de Posgrado en Economía donde es tutor y docente, así como en la licenciatura de Urbanismo de la UNAM.

\section{Domingo Flores Miranda}

Licenciado en Ciencias Políticas y Administración Pública de la Facultad de Estudios Superiores Acatlán (UNAM), con estudios de posgrado en la Universidad Autónoma Metropolitana, Unidad Xochimilco en la maestría de Políticas Públicas; maestro en Ciencias Sociales por el Instituto de Ciencias Sociales y Administración de la Universidad Autónoma de 
Ciudad Juárez. Doctorante en Economía con especialidad en Economía Urbano Regional en la Facultad de Estudios Superiores Acatlán (UNAM). Es profesor en las licenciaturas de Sociología, Ciencias Políticas y Relaciones Internacionales en la Facultad de Estudios Superiores Acatlán; ha sido ponente en diversos congresos, conferencias, pláticas académicas y sociales en institutos públicos y privados, en organizaciones rurales para evaluar proyectos, así como asistente a cursos de actualización, seminarios, diplomados y congresos, además de visitas de investigación en instituciones relacionadas con la cuestión urbana. Entre sus temas de investigación destacan: el desarrollo urbano municipal, las políticas de vivienda y suelo, y su impacto urbano, económico y ambiental.

\section{Edgar Rodrigo Buenrostro Salazar}

Licenciado en Urbanismo, con estudios de maestría en Economía (UNAM). En el ámbito profesional ha colaborado en la elaboración y desarrollo de proyectos de investigación vinculados al desarrollo económico regional del país, entre los que destacan: "Criterios para el diseño y operación de la política nacional regional" y el proyecto "Análisis de indicadores para la fundamentación de políticas urbanas" realizados en el Instituto de Investigaciones Económicas (UNAM) en convenio con la Secretaría de Desarrollo Social. Asimismo, ha aplicado diversas técnicas de análisis regional en la elaboración de estudios en el área territorial de alcance nacional como son el "Índice de marginación 2010" para el Consejo Nacional de Población y la "Estrategia Territorial Nacional" para la Secretaría de Desarrollo Social.

\section{Erica Alejandra Hernández Montes de Oca}

Tras haber estudiado la licenciatura en Urbanismo se ha dedicado a la planeación municipal del desarrollo urbano, contribuyendo a consolidar estrategias territoriales de carácter social y económico. Entre sus principales líneas de trabajo se encuentra el análisis de la importancia de las zonas metropolitanas y su papel en el desarrollo nacional, los instrumentos innovadores para el financiamiento y operación del desarrollo urbano y la planeación bottom-up de las ciudades como espacio público y político. Actualmente, colabora en proyectos de planeación municipal, en la rama turística y en la escala regional del desarrollo territorial, así como en la gestión de diversos proyectos inmobiliarios en la Ciudad de México.

\section{Flor Araceli Ruiz Peña}

Licenciada en Geografía (UNAM), con estudios de maestría en el área de Sociedad y Territorio por la misma universidad. Su actividad laboral la ha desarrollado en diversas áreas de la geografía y cartografía, en instituciones como el Consejo de Evaluación de la Política 
de Desarrollo Social, Instituto de Geografía (UNAM), el Instituto Nacional Electoral, el Consejo de Evaluación del Desarrollo Social del Distrito Federal y la Universidad Autónoma Metropolitana, Unidad Xochimilco. Ha participado en proyectos sobre pobreza, desigualdad, calidad de vida y política pública en el Instituto de Investigaciones Económicas (UNAM), el Consejo Nacional de Población, la Facultad Latinoamericana de Ciencias Sociales y con la Secretaría de Desarrollo Social. Ha participado en la autoría y coautoría de libros de texto de geografía y estructura socioeconómica en los niveles secundaria y bachillerato.

\section{Isalia Nava Bolaños}

Investigadora titular del Instituto de Investigaciones Económicas (UNAM). Licenciada en Economía, egresada de la maestría en Demografía y el doctorado en Estudios de Población de El Colegio de México. En 2012 obtuvo el primer lugar del Premio Gustavo Cabrera Acevedo otorgado por dicho colegio, en la modalidad de investigación en población. Obtuvo el reconocimiento Distinción Universidad Nacional para Jóvenes Académicos 2017, en el área de investigación en Ciencias Económicas-administrativas. Sus líneas de investigación y publicaciones abordan las relaciones entre demografía y economía, en especial, sobre el efecto económico del cambio poblacional, del envejecimiento de la población y de las condiciones de género.

\section{José Gasca Zamora}

Doctor en Geografía (UNAM) con especialización en territorio y sociedad. Se desempeña como investigador titular en el Instituto de Investigaciones Económicas de la misma universidad. Sus líneas de investigación se llevan a cabo en temas de economía urbana y regional y políticas territoriales; ha incursionado en temas sobre consumo y comercio en contextos urbanos y efectos socio-espaciales del mercado inmobiliario. Ha publicado dos libros individuales, es coautor de tres libros de texto, 10 libros colectivos, coordinador de 10 libros, autor de 30 capítulos de libros y alrededor de 20 artículos en revistas especializadas. Actualmente es Presidente de la Asociación Mexicana de Ciencias para el Desarrollo Regional UNAM y es miembro de la Association of American Geographers y la Regional Science International Association.

\section{Manuel Canto Chac}

Doctor en Sociología (UNAM) y profesor-investigador en el Departamento de Política y Cultura de la Universidad Autónoma Metropolitana Xochimilco. Jefe del Departamento de Política y Cultura UAM-X (1986-1990). Exconsejero Ciudadano del Consejo de Evaluación del Desarrollo Social del Distrito Federal de junio de 2008 a 30 de abril de 2014. Ha publicado diversos textos sobre política social y participación ciudadana en las políticas 
públicas. Ha realizado evaluaciones de programas sociales en México y en varios países de América Latina.

\section{Marcela Astudillo Moya}

Licenciada en Economía, maestra y doctora en Administración Pública por la Facultad de Ciencias Políticas y Sociales (UNAM). Se desempeña como investigadora titular "C", en el Instituto de Investigaciones Económicas (UNAM). En la Facultad de Ingeniería ha impartido cátedra desde 1990. También ha sido profesora en la División de Posgrado de la Facultad de Economía. Es tutora en los posgrados de Ciencias Políticas y Sociales y de Contaduría y Administración. Sus líneas de investigación las ha enfocado al estudio de las finanzas públicas y la metodología de investigación documental. Es autora de numerosos trabajos, entre los actuales destacan: Conceptos básicos de federalismo fiscal. El caso de México, Fundamentos de economía y La investigación documental en la era de la información; así como artículos en revistas especializadas y coautora de trabajos publicados por el Centre for Tax Policy and Administration de la OECD.

\section{Roberto Ramírez Hernández}

Doctor y maestro en Economía, especialista en estadística aplicada y licenciado en Matemáticas Aplicadas y Computación (UNAM). Es investigador de tiempo completo en el Instituto de Investigaciones Económicas de la misma universidad. Especialista en análisis económico de ciudades y regiones, modelos matemáticos y econométricos espacio-temporales para el análisis económico regional y urbano, también es especialista en estudios de prospectiva territorial, económica y social. Profesor titular y tutor en posgrado y licenciatura en Economía, Facultad de Economía (UNAM). Ganador del Premio Anual de Investigación Económica "Maestro Jesús Silva Herzog" 2009. Recibió la beca del Lincoln Institute of Land Policy (2006). Autor de trabajos sobre desarrollo económico urbano. Consultor en proyectos de investigación económica, desarrollo regional y urbana para el BID, Sedatu, Nafin, Comisión Reguladora de Energía, PNUD-ONU, SCJN, Seduvi, Evalúa-DF, PUEC-UNAM, CPAM, Sedesol, Diconsa, gobiernos de Tamaulipas y Michoacán, IMSS, Conaculta y Conade.

\section{Sergio de la Vega Estrada}

Doctor en Ciencias Sociales, maestro en Estadística e Investigación de Operaciones y licenciado en Actuaría. Ha sido director de área en el Programa de Educación Salud y Alimentación (1997-2000). Profesor investigador de la Universidad Autónoma Metropolitana, Unidad Xochimilco desde 1978. Miembro del Comité Técnico Académico de la Red Temática Conacyt de Pobreza y Desarrollo Urbano. Diseñador del Índice de marginación del Consejo 
Nacional de Población para municipios en 1992, para localidades en 1996, para municipios y localidades en 2011, con sistemas de información geográfica para la puesta en mapa de las localidades del país consideradas para la selección de localidades marginadas beneficiarias del Progresa. Autor del Índice de desarrollo social de los pueblos indígenas, para el Instituto Nacional Indigenista 2001, 2008 y 2019; de varios libros y artículos en temas de marginación y pobreza, entre los cuales destaca Para contender con la pobreza, 2014. Tiene a su cargo el Laboratorio Geoestadístico en la UAM-Xochimilco. Ha dirigido tesis de licenciatura, maestría y doctorado, los temas de interés son: pobreza, marginación y Estado. 




\section{CALIDAD DE VIDA}

EN LAZONA METROPOLITANA DEL VALLE DE MÉXICO. HACIA LA JUSTICIA SOCIOESPACIAL

es una obra del Instituto de Investigaciones Económicas de la Universidad Nacional Autónoma de México.

Se terminó de imprimir en agosto de 2018. Se tiraron 500 ejemplares en los talleres de Offset Rebosán S.A. de C.V.

Acueducto 115, Col. Huipulco, Tlalpan, Ciudad de México, C.P. 14370.

Formación de Juan Carlos Burgoa.

El cuidado de la edición estuvo a cargo de Marisol Simón. 
